\title{
Reduction in Tribological Energy Losses in the Transportation and Electric Utilities Sectors
}

September 1985

Prepared for the U.S. Department of Energy under Contract DE-AC06-76RLO 1830

Pacific Northwest Laboratory Operated for the U.S. Department of Energy by Battelle Memorial Institute 


\title{
DISCLAIMER
}

This report was prepared as an account of work sponsored by an agency of the United States Government. Neither the United States Government nor any agency thereof, nor any of their employees, makes any warranty, express or implied, or assumes any legal liability or responsibility for the accuracy, completeness, or usefulness of any information, apparatus, product, or process disclosed, or represents that its use would not infringe privately owned rights. Reference herein to any specific commercial product, process, or service by trade name, trademark, manufacturer, or otherwise, does not necessarily constitute or imply its endorsement. recommendation, or favoring by the United States Government or any agency thereof. The views and opinions of authors expressed herein do not necessarily state or reflect those of the United States Government or any agency thereof.

\author{
PACIFIC NORTHWEST LABORATORY \\ operated by \\ BATTELLE \\ for the \\ UNITED STATES DEPARTMENT OF ENERGY \\ under Contract DE-AC06-76RLO 1830
}

\begin{tabular}{|c|c|}
\hline \multicolumn{2}{|c|}{ Printed in the United States of America } \\
\hline \multicolumn{2}{|c|}{ Available from } \\
\hline \multirow{3}{*}{\multicolumn{2}{|c|}{$\begin{array}{c}\text { National Technical Information Service } \\
\text { United Stares Department of Commerce } \\
5285 \text { Port Royal Road } \\
\text { Springfield, Virginia } 22161\end{array}$}} \\
\hline & \\
\hline & \\
\hline \multicolumn{2}{|c|}{ NTIS Price Codes } \\
\hline \multicolumn{2}{|c|}{ Microfiche $A 01$} \\
\hline \multicolumn{2}{|c|}{ Printed Copy } \\
\hline & Price \\
\hline Pages & Codes \\
\hline 001.025 & $A 02$ \\
\hline $026-050$ & $\mathrm{AO3}$ \\
\hline 057.075 & $A 04$ \\
\hline a) $6-100$ & Aas \\
\hline $101-125$ & $A 06$ \\
\hline $126-150$ & 107 \\
\hline $151-175$ & $A 06$ \\
\hline $176-200$ & $A 09$ \\
\hline $201-225$ & A010 \\
\hline $226 \cdot 250$ & A011 \\
\hline 251.275 & $\wedge 012$ \\
\hline $276-500$ & A013 \\
\hline
\end{tabular}


REOUCTION IN TREOLOGICAL ENERGY LOSSES

IN THE TRANSPORTATION AHD ELECTRIC

UTHLTTES SECTORS

0. Pinkus

Mechantcal Technology Inc.

O,F。制 1 cock

Tribolock Inc. and Consultant to Mechanical wecmology unc.

T. M. Levinson

DOE/ECUT Progran Manager

September 1985

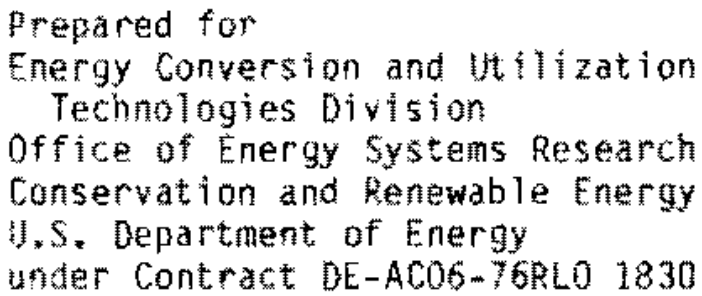

Pacific Northwest Laboratory

Richland, Washington 99352 

Experts estimate that in 1978 over four quadrillion Btu of energy were lost in the United States because of simple friction and wear--enough energy to supply New York City for an entire year. This translates to a $\$ 20$ billion loss, based on oil prices of about $\$ 30$ per barrel. (a) Because of the enormity of this energy loss, the Energy Conversion and Utilization Technologies (ECUT) Program in the U.S. Department of Energy (DOE) initiated a program in 1983 to study tribology--the science of friction and wear--to learn more about the causes of these energy losses (or tribological "sinks") and how to reduce them.

The ECUT Program itself was started in 1980 to encourage research to improve energy conversion and utilization efficiency. The enormous energy loss in tribological sinks has been targeted by the ECUT program as having significant potential for energy conservation. One goal of the ECUT Tribology Program is to reduce these energy losses by developing improved lubricants and more durable materials.

To support initial Tribology Program planning. ECUT conducted six surveys to gather three types of information about the current tribology problem in the U.S.:

1. The identification of typical industrial sinks

2. A survey of current U.S. Government tribology projects

3. The identification of tribology R\&D needs based on industry perceptions.

The six ECUT-sponsored surveys are listed in Table ES.1. Each survey is being published as a separate volume with its own summary. This executive summary, which also appears in each of the six volumes, presents an overview of results from the six surveys and their implications for energy conservation. The results of these six surveys and their implications for energy conservation are presented in this summary. These results will be used to support further research planning for the ECUT Tribology Program.
TABLE ES.1. ECUT Surveys Reviewed in this Summary

1. A Review of Tribological Sinks in Six Major Industries. Imhoff, et al. PNL -5535, Pacific Northwest Laboratory, Richland, Washington.

2. Reduction in Tribological Energy Losses in the Transportation and Electric Utilities Sectors. Pinkus and Wilcock, Mechanical Technology Incorporated. PNL-5536, Pacific Northwest Laboratory, Richland, Washington.

3. Identification of Tribological Research and Development Needs for Lubrication of Advanced heat Engines. Fehrenbacher, Technology Assessment and Transfer, Incorporated. PNL-5537, Pacific Northwest Laboratory, Richland, Washington.

4. Energy Conservation Potential of Surface Modification Technologies. Le Khac, DHR, Inc. PNL-5538, Pactfic Northwest Laboratory, Richland, Washington.

5. Assessment of Government Tribology Programs. Peterson, Wear Sciences Corporation. PNL-5539, Pacific Northwest Laboratory, Richland, Washington.

6. Assessment of Industrial Attitudes Toward Generic Research Needs in Tribology. Sibley and Zlotnick, Tribology Consultants Incorporated. PNL-5540, Pacific Northwest Laboratory, Richland, Mashington.

IDENTIFYING TYPICAL TRIBOLOGICAL SINKS AND MECHAINISMS

ECUT's first step in collecting information about tribology was to identify significant tribological sinks and mechanisms. This information was needed to focus research on key technological problems. Because the industry, transportation, and utilities sectors account for most of the

(a) Calculations in this surmary are based on a $\$ 30$ figure. 
energy consumed in the U.S., ECUT concentrated first on the tribological energy sinks and mechanisms found in these three sectors. The report by Imhoff, et al.s describes the most important tribological sinks typically found in industry, and the report by Pinkus and Wilcock describes tribological energy losses in the transportation and utilities sectors. Two specific studies assessed tribological problems in the metalworking industry and in the advanced diesel engine.

To identify areas in which tribology has a significant impact, the authors examined the energy consumed, the fuels used, and the primary products and processes found in the transportation, industrial, and utilities sectors. Once energy losses were identified, their magnitude was estimated. The estimates include both friction losses (di rect losses) and material wear losses (indirect losses). The authors also estimated the energy savings potential in each sector and recomended some specific R\&D programs to help achieve these energy savings.

\section{The Industrial Sector}

Tribological energy losses are pervasive throughout industry. Because reviewing all industries and industrial processes in detail would be impossible, the Imhoff, et al. survey, instead chose six representative industries (Mining, Agriculture, Primary Metals, Chemicals/Refining. Pulp and Paper, and Food Processing) that appeared to have the most significant tribological sinks and energy losses. These industries were selected because of their 1) major, nonthermal energy streams (such as machine drives); 2) high material wear rates and friction; 3) significant material transportation/aiteration processes; and 4) total energy use.

The study identified important tribological sinks in each selected industry, based on both friction and material wear energy losses and on the tribological mechanisms and materials involved. Figure ES.1 and Table ES.2 show the key results for each of the six industries.

The first conclusion from this study confirmed earlier claims that losses from material wear are greater than energy losses from friction; the wear losses in five of the industries were found to be more than twice as large as the friction losses. (a) The study also concluded that reducing material wear rates to improve equipment life

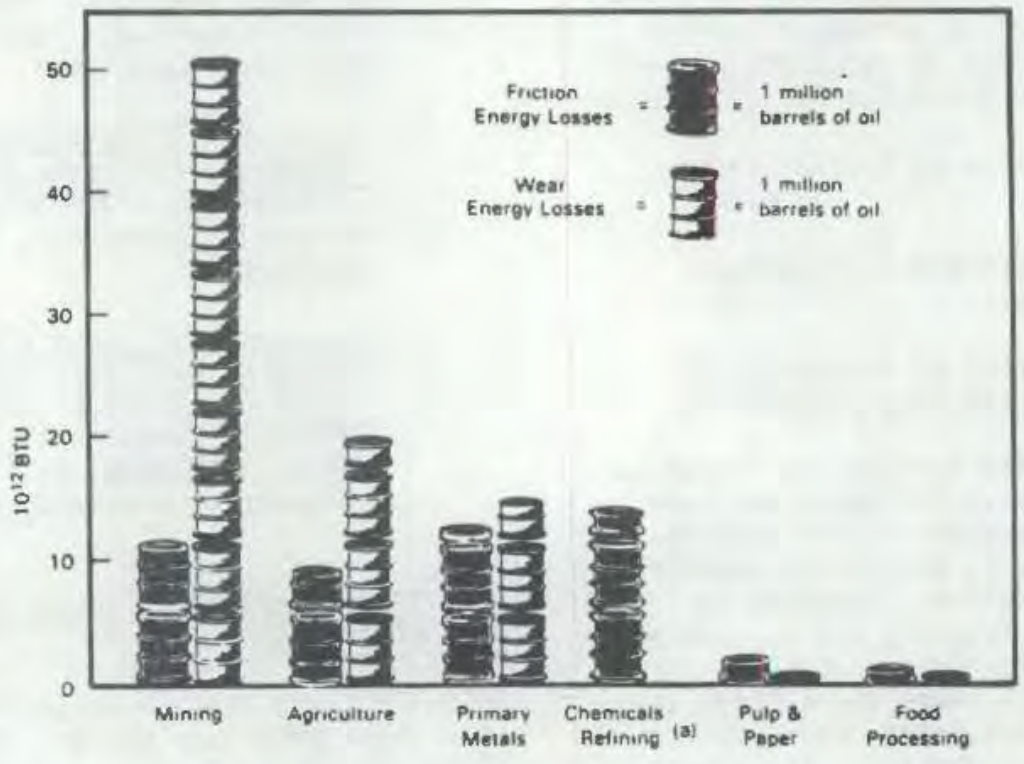

FIGURE ES.1. Annual Friction and Hear Losses in Surveyed Industries

(a) These five industries had estimates of both friction and material wear losses; the sixth, Chemicals/Refining, did not have estimates of wear losses. 
TABLE ES.2. Primary Mechanisms in Friction Energy Losses and Principal Materials Involved in Wear Energy Losses

$\begin{array}{lc}\frac{1}{\text { Mndustry }} & \frac{\text { Mechanisms }}{\text { A-body Abrasion }} \\ \text { Agriculture } & \begin{array}{c}\text { 3-body Abrasion } \\ \text { Friction }\end{array} \\ \text { Primary Metals } & \begin{array}{c}\text { Hot Rolling } \\ \text { Inefficiencies }\end{array} \\ \text { Chemicals/Refining } & \text { Friction, Erosion } \\ & \text { Abrasion }\end{array}$

Pulp \& Paper Friction

Food Processing

Friction

Erosion, Abrastion

\author{
Materials \\ Iron, Steel \& alloys, \\ Alumi num, Rubber \\ Steel, Rubber, Lubricants \\ Steel \& alloys \\ Not studied \\ Steel alloys, Chromium- \\ Molybdenum alloys \\ Grinding stones
}

Steel \& alloys and reliability would also significantly. improve industrial productivity. The industry representatives interviewed strongly emphasized the positive impacts that tribological research could have on operational productivity.

\section{Tribology in the Metalworking Industry}

In addition to the general review of tribological sinks in industry, ECUT sponsored a more specific study of tribolagy in the metalworking industry by Le Khac at DHR, Inc. The study estimated the energy conservation potential of using advanced surface modification technologies in this industry. These surface modification technologies are thermal, chemical, or mechanical treatments that reduce friction and wear at a material's surface without changing its bulk properties. The advanced surface modification technologies considered were ion implantation, laser surface hardening, electron beam surface hardening, and wearresistant coating deposition. The author studied 70 percent of the metal-forming and metal-cutting machines used in the United States (except those associated with primary metals processing), identified tribological mechanisms, and estimated friction and wear energy losses. Potential energy savings from using surface-modified tools were also estimated.

The metal-forming machines studied were punches, presses and forges, and the metalcutting machines studied were turning, drilling, milling, broaching, and sawing machines. Models were developed to estimate friction and wear energy losses and potential sayings. The friction losses were estimated by adding friction losses at the motor drive system and at the tool-workpiece interface. Estimates of energy consumption mere based on standard operating conditions (known friction coefficients, total working time, etc.) The indirect losses from wear were estimated based on the replacement costs of all metalworking tools used and discarded in one year.

Based on actual experimental or production data, the author estimated that the friction losses in all U.S. metalworking machines amount to $20.2 \times 1012$ Btu per year, or $\$ 104.5 \mathrm{milli}$ on. Of this energy loss, $1.8 \times$ $10^{12}$ Btu per year, or $9 \%$, could be saved using surface modification technologies to reduce friction. The wear loss was estimated to be $7.7 \times 10^{12}$ Btu per year. (a) Possible energy savings using surface modification technologies to reduce wear could conserve $5.5 \times 10^{12}$ Btu per year, or $71 \%$.

Finally, the author estimated that tribological energy losses in all U, $U_{\text {. metal- }}$ working machines total $27.9 \times 10^{12} \mathrm{Btu}$, equivalent to $4.8 \mathrm{million}$ barrels of oil or $\$ 144 \mathrm{milli}$ on annually. More than a quarter of this loss could be saved using surface modification technologies to reduce friction and wear. These results are shown in Figure ES.2.

(a) Using 19.2 million Btu per ton as the embodied energy in steels. 


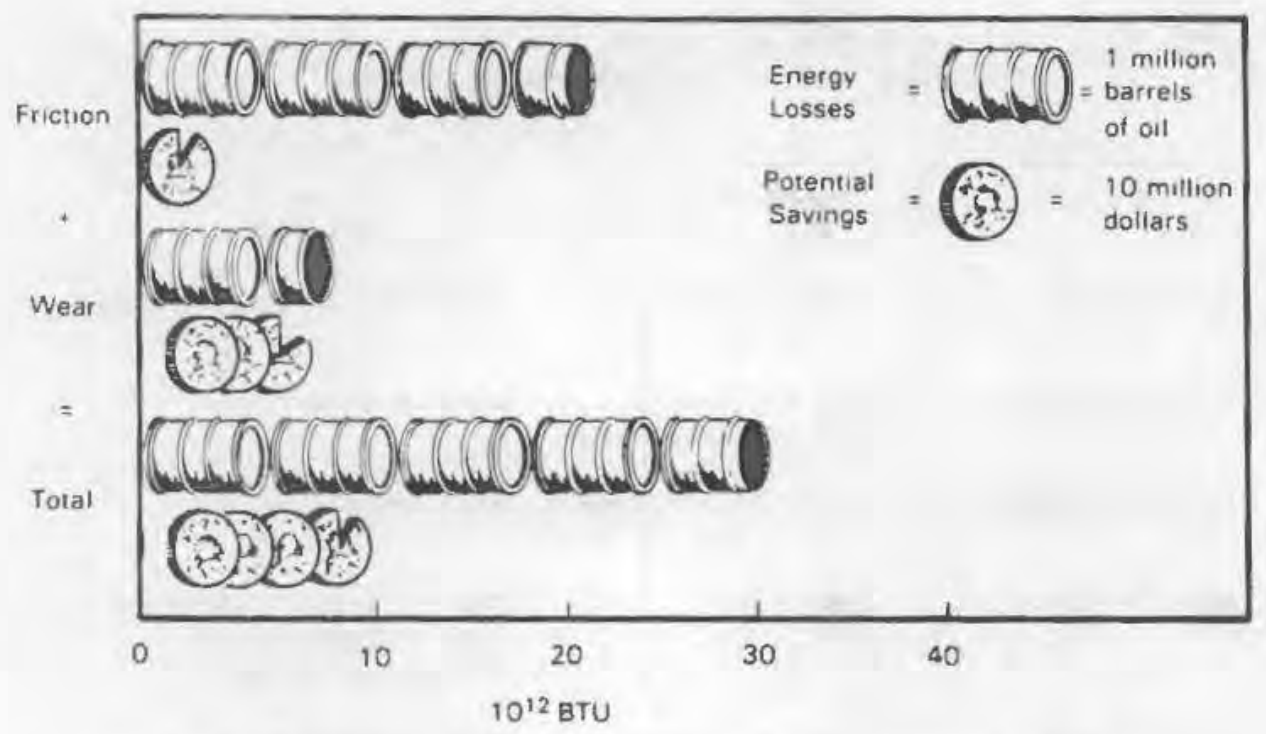

FIGURE ES.2. Annual Friction and Wear Energy Losses in the Metalworking Industry, and Potential Savings from Surface Modification Technologies

\section{The Transportation Sector}

The transportation sector is impartant both in terms of its energy consumption (26\% of tota] U.S. annual energy consumption, or $19 \times 10^{15} \mathrm{Btu}$, equivalent to $\$ 98$ billion), and because of the high level of tribological losses. The Pinkus and Wilcock study primarily focused on the highway fleets (passenger cars, buses and trucks), which consume $77 \%$ of the total energy used in the transportation sector. The survey primarily addressed the conventional otto cycle engine. However, other concepts were also considered, such as the adiabatic diesel, the gas turbine, and the Stirling engine; in addition, the Fehrenbacher report evaluated tribological activity in advanced diesel engines.

Figure ES, 3 shows the principal automotive tribological sinks and the estimated energy savings. The principal automotive energy sinks are caused by the mechanical inefficiency of the engines and drive trains; most of the energy losses are due to friction.

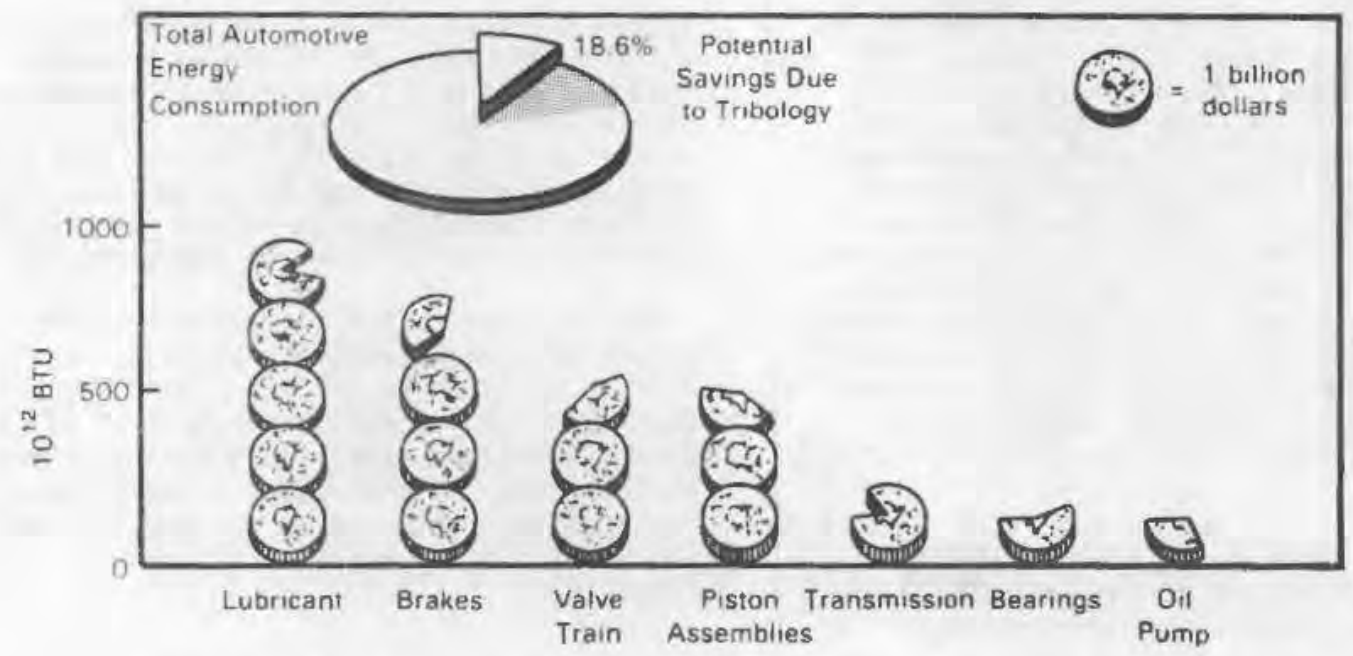

FIGURE ES,3. Potential Energy Savings Per Year for the Conventional Engine (Based on highway fleet size in 1976) 
The survey by Pinkus and Wilcock revealed several tribological areas of particular concern for conventional engines, such as the piston ring assembly and the long-range effect of low-viscosity oil on engine wear. As shown in Figure ES.3, tribological improvements could save $18.6 \%$ of the total annual energy consumed by automobiles, or $\$ 14.3$ billion.

Research on conventional engines of ten applies to unconventional engines as well. Except for the adiabatic diesel, the energy savings possible from tribological improvements to unconventional engines are less significant than those of the conventional Deto cycle engine. The major problems in unconventional engi nes are related to hightemperature tribological problems. Introducing adiabatic and mi nimum friction engines into the bus and truck fleets of the U.S. could save up to $2.9 \%$ of total U.S. energy consumption.

This survey also revealed the difficulties with devising adequate performance tests to quantify energy losses and evaluate new designs and products. Laboratory tests that accurately reflect real-world conditions are badly needed. The ability to test entire systems is vital, since tribological energy losses are often caused by complex interactions between all the components of a system.

\section{Advanced Diesel Engines}

Because of the great potential for energy savings, the ECUT study by Fehrenbacher examined the lubrication of advanced diesel engines in detail. The efficiency of these engines could be improved by about 10 ; however, higher operating temperatures $\left(1000^{\circ} \mathrm{F}\right.$ and higher in the upper cylinder area) are required to reach this greater efficiency. As a result, the primary development challenge for these engines concerns friction, wear, and lubrication of the upper cylinder region. In fact, tribological advancements in these areas are essential if diesel engine performance and durability goals are to be reached. This study assessed these vital tribological concerns in both current and future technologies and recommended tribology R\&D topics for further advanced engíne development.

Both the mechantcal design of the upper cylinder and the chemical effects of lubricants and fuel determine the friction and wear characteristics of the upper cylinder region. These two factors interact in a complex and sometimes synergistic manner. The geometry of the piston, piston ring, and cylinder directly affect the rate and nature of deposit formation, of 1 consumption, and friction. Efforts have been made to optimize the upper cylinder geometry in current diesel engine technology; this will also be a critical area in future developments. However, problems with upper cylinder deposits, bare polishing, and oil consumption still exist. This study indicates that these problems are caused by the chemical interactions between upper cylinder materials, oil degradation products, and fuel combustion by-products. Therefore, lubricants, oil degradation rates, and mechanisms will continue to be important research areas.

Although a great deal of research has been conducted on liquid lubricants, in most cases the lubricants have been tested without constdering the tribological factors specific to the upper cylinder. Since the lubricants interact with the materials and environment of the upper cylinder, they must be developed and tested under $51 \mathrm{mil}$ lar conditions.

The ECUT study also pointed out that future advanced engine concepts will require ceramic upper cylinder materials able to withstand the higher operating temperatures. New lubricants will have to be developed, and solid lubricants are likely to play a major role. A major research effort will be needed in this area; again, the research must be conducted on a total system basis to be most effective.

The study concluded that many problems with current diesel engines will continue to exist in advanced diesel engines. Tribological problems in the upper cylinder region will be most critical in terms of engine performance and wear. Lubricant R\&D is still a major research area in current technology, but total system materials and design considerations should be emphasized. Advanced diesel concepts will requil re new design approaches, but the tribology of the upper cylinder region will still be critical and may even be the 11 miting factor in achieving higher engine efficiencies. Extensive materials R\&D w11 be required for advanced designs as well, especially in ceramics, ceramic composites and solid lubricants.

\section{The Utilities Sector}

The utilities sector was also reviewed for significant tribology sinks. This sector accounts for roughly $28 \%$ of total U.S. energy consumption. ECUT's review revealed that tribological improvements in efficiency and rellability could save 2.3\% of the total energy annually consumed by utilities, or about $\$ 2.5$ billion. As in the transportation sector, efficiency is a major factor. 
However, reliability (especially in generating units) is just as important for energy conservation.

The data used in these studies were primarily for the utilities' power plants. The average power plant operates at an efficiency (output energy/input energy) between 30 and $40 \%$. Mechanical losses account for 17-26\% of the total energy used. Reliability problems that lead to generator shutdown require using standby equipment, which generally has less efficient fuel consumption. This causes losses both in terms of fuel economy, and revenue and labor costs. Tribological problems are estimated to cause as much as $5 \%$ of the reliability problems that require shutdown. Furthermore, tribology-caused shutdowns increase with the size of the power generating unit.

The ECUT survey found several tribological areas with significant energy savings potential, including gas path leakage, seals, and bearings on both the main turbine generator and on the various accessories. Different forms of bearing and lubricant problems (contaminated oils, pump problems, etc.) and vibrations are the leading causes of the plant shutdowns.

Figure ES.4 summarizes potential savings from improving tribological problems in the electric utilities. For accessories, the major concern is sealing problems with feedwater pumps. Friction and wear are implicated in much of the seal and bearing 1osses. The major problems identified in this study will require research on lubrication theory and advanced materials and coatings developments.

\section{CURRENT U.S. GOVERNMENT PROGRAMS}

The second part of ECUT's information collecting efforts involved identifying tribology R\&D currently being sponsored or conducted by the U.S. Government. This information was needed to avoid duplicating existing research and to locate those areas that need more research support. The Peterson study identified 215 current projects sponsored by 21 different government organi$z$ ations. The study classified these projects by subject, objective, energy conservation relevance, type of research, phenomena and variables being investigated, materials, and applications. The principal government sponsors include the Department of Defense (DOD), the National Aeronautics and Space Administration (NASA), National Science Foundation (NSF), National Bureau of Standards (NBS), and DOE.

The study located these tribology projects initially by using infomation from ifterature searches. Data bases used included the Smithsonian Science Information Exchange, the Defense Technical Information Center's Research and Technology Work Unit Information System, and the Materials Science Abstracts of the National Technical information Service (NTIS). The study located a

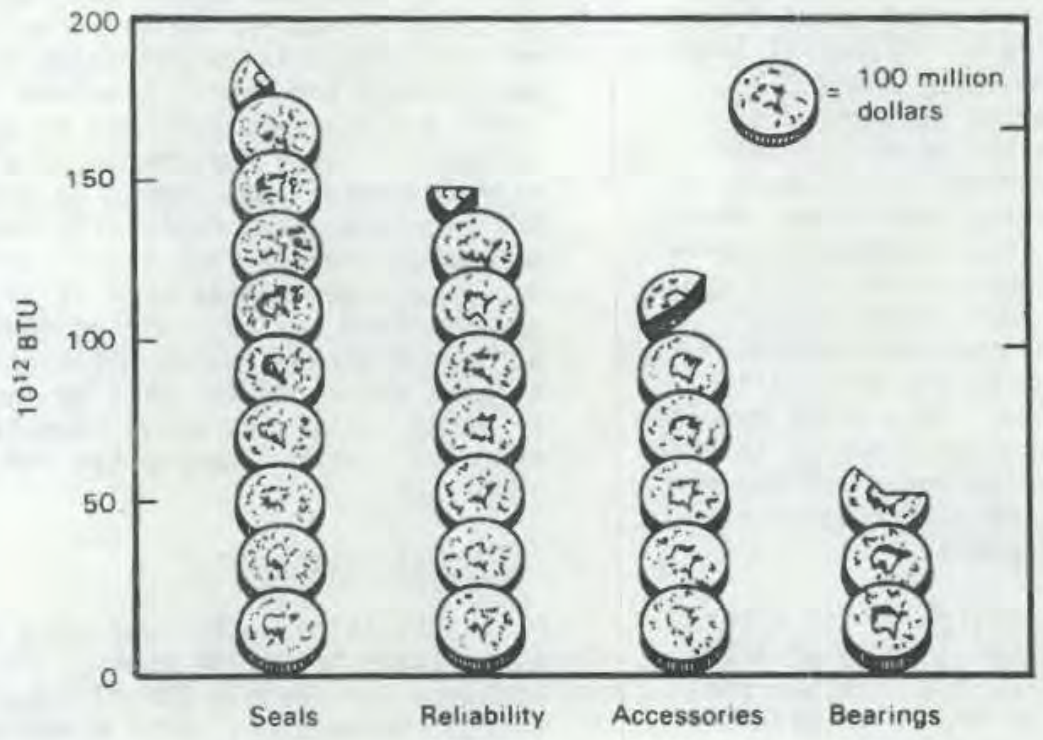

FIGURE ES.4. Potential Energy Savings for the Utilities (Based on estimates of installed capacity in 1983 and on an energy cost of $\$ 30$ per barrel.) 
total of 640 government-sponsored projects covering the fiscal years 1978-1983. These organizations were then contacted by mail, followed by visits and/or phone discussion. Of the original 640 projects, 215 were found to be current. A detailed description of each project is included in the report.

According to this study, until several years ago tribology research emphasized component development, fluid film and elastohydrodynamic lubrication, and concentrated contacts. Since then the emphasis has shifted dramatically, and research efforts now concentrate on lubricants, materials and coatings, and friction and wear mechanisms. There is still considerable interest in rolling contact bearings and seals, as well as in early failure detection in maintenance technology.

The study also concluded that most current tribology research is related to DOD objectives of longer life, low maintenance/ failure-free machinery, and the basic understanding of friction, wear, materials, and coatings. High-temperature lubrication also continues to be a major objective in tribology research; the effects of new materials and solid lubricants on current temperature limitations are also being studied. Castings are receiving the most attention in general materials development. Figure ES. 5 shows a breakdown of the materials considered in the 215 projects.

The author also concluded that current programs generally do not emphasize energy or materials conservation. Design predictability and composite materials are other areas that are receiving little attention. Finally, the study concluded that current
U.S. Government high-temperature lubrication work is the most applicable to energy conservation goals.

\section{INDUSTRY PERCEPTIONS OF GENERIC RESEARCH NEEDS IN TRIBOLOGY}

Because transferring information to industries is a major part of the ECUT program, ECUT conducted a survey of industry perspectives on tribology R\&D needs. This survey, conducted by S1bley and Zlotnick, involved interviewing industry contacts to discover what research results are needed.

The authors held in-depth discussions with engineers and managers from 27 companies. These companies were chosen by definting different tribological categories (such as transportation, power plants, seals, gears, aerospace, etc.). At least one company was then selected for each category, and two or three were chosen for categorles that are particularly important to the ECUT program. The purpose of this study was not to produce statistically significant findings, but rather to represent many different viewpoints and a variety of interests.

The authors' main emphasis was on determining the engineering limitations imposed by tribology considerations. They also tried to determine the type and funding level of current generic tribology R\&D in each company, although only pon-proprietary information was available. (a)

Based on the levels of generic tribology R $8 D$ in the 27 individual companies, the authors then estimated total tribology R\&D in each industrial segment. Although this approach is obviously limited, reasonably

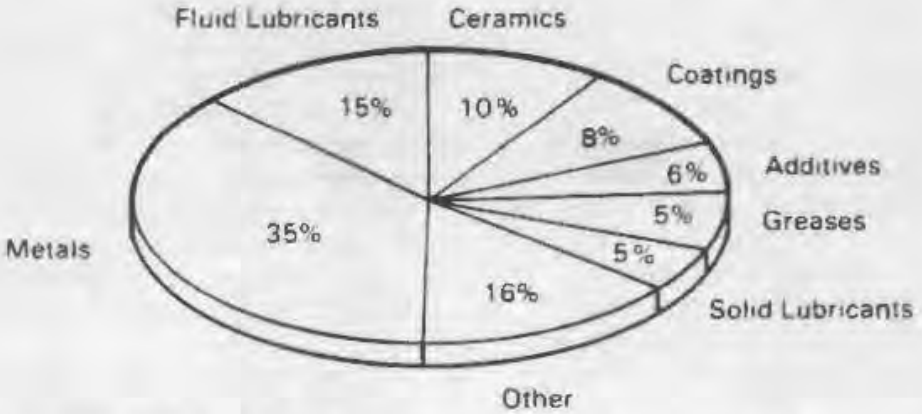

FIGURE ES,5. Materials Under Consideration in the 215 Current Government-Sponsored Tribology Projects

(a) "Generic" R\&D in this case is basic research that is not directed toward a specific end use or product. 
TABLE ES.3. Estimate of Generic Tribology R\&D and Total R\&D Budget for Representative Industries (In SM)

\begin{tabular}{|c|c|c|c|}
\hline Classification & Company & $\begin{array}{l}\text { Total } \\
\text { R\&D(a) } \\
\end{array}$ & $\begin{array}{c}\text { Generic } \\
\text { Iribology R\&O (b) } \\
\end{array}$ \\
\hline Liquid Lubricants & Mobil & 188 & 1 \\
\hline Transportation & Ford & 1764 & 1 \\
\hline Aerospace & Pratt \& Whitney & 835 & 0 \\
\hline Powerplants & Caterpillar & 234 & 0 \\
\hline Seals & Crane & 10 & $<1$ \\
\hline Rolling Elements & TRW & 109 & $>0$ \\
\hline Gears & Eaton & 100 & $>0$ \\
\hline Sliding Bearings & Tribon & 0 & $>0$ \\
\hline Filters & Pall & 7 & 0 \\
\hline Small Mechanical & Xerox & 565 & $>0$ \\
\hline Ceramics & Norton & 26 & $<1$ \\
\hline Coatings & Union Carbide & 240 & $<1$ \\
\hline \multirow[t]{2}{*}{ Forming } & Bethlehem & 46 & $\leq 1$ \\
\hline & & 4124 & 6 \\
\hline
\end{tabular}

(a) From the report to the Securities and Exchange Commlssion for 1982. (Source: "Business Week," June 20, 1983.)

(b) Based on discussions with research staff and referring to only company-funded generic tribology R\&D.

accurate estimates were developed of the amounts of generic tribology R\&D being conducted in each of the industrial segments. The results for the individual companies are sumarized in Table ES.3.

These authors concluded that industry funds only a very limited amount of generic tribology research. Some 'hidden' generic $R \& D$ is incorporated into the companies' design manuals, but much of this information is proprietary. As illustrated in Table ES.3, some industry segments have little or no generic tribology R\&D. Tribology research efforts are often too small to be likely to improve the state-of-theart; ceramics is an example of an area in which the funding levels are too small to promote significant advances, although industry has expressed considerable interest in this area. However, the liquid lubricant research budget in the transportation industries is substantial.

The industry representatives expressed interest in the ECUT Tribology Program, and also in obtaining a fundamental physical understanding of tribological mechanisms. The industry contacts also requested more effective presentations of research results, especially results in a form that design and development engi neers could readily use.
Another industry concern involved developing more realistic laboratory tests and more rational performance standards.

\section{CONCLUSIONS}

The six ECUT surveys summarized here were conducted to provide an overview of the major tribological sinks and the current state of U.S. tribology research. Although much of this preliminary ECUT work involved general surveys and samplings, the overall picture is consistent and reveals areas of major concern. The findings in the general surveys have been largely substantiated by the two focused studies on metalworking industries and the advanced diesel engine. These results are being used to support ECUT Tribology Program planning.

These surveys describe the current status of U.S. tribology R\&D in 1984; the findings will be updated as necessary. Much of the infornation is necessarily somewhat speculative and theoretical, and many of the general findings have not yet been fully corroborated. This is due in part to the lack of previous research; improving this initial information should be an important goal of current research. In particular, identifying tribological mechanisms should 
be emphasized in order to define specific research projects. Further discussion with industry representatives is also needed.

The five key resuits from these ECUT studies are listed below:

1. Advanced tribo-materials, coatings, and lubricants must be developed to further improve energy efficiency. Although tritiological improvements can be made with the current technology, new and inncivative materials and designs (such as the advanced diesel engine) are neeced to significantly increase energy efficiency.

2. Tritological mechanisms that shorten equipment life and cause excessive dowrtime and repair should be identified and studied. Initial research shows that these indirect energy losses from material wear are often greater than the direct energy losses from friction. In addition to the energy conservation impacts, reducing these losses could also significantly improve industrial productivity.

3. Generic tribologicai research will affect all three major sectors, since similar tribological mechanisms are found in many different processes. Although the transportation sector has the largest tribological energy loss and the greatest potential for energy savings, there is significant energy savings potential in all sectors. Thus research results must be effectively transferred to all sectors.

4. Meaningful performance tests and standards must be developed so that new designs and products can be accurately evaluated. Laboratory tests that accurately reflect real-world conditions are badly needed. Total system testing is vital, since tribological energy losses are often caused by complex interactions between a 11 the components of a system.
5. Continuing communication with industry is critical to ensure that industry research needs are addressed and that the results are adequately transferred.

These results supported the development of the ECUT Tribology Program plan for 1985. The research program is divtded into two parts. The Mechanisms component includes such areas as advanced tribo-materials R\&D, identifying and characterizing tribological mechanisms, and developing performance test requirements. Projects in this area include developing new tribological materials, and modeling and experimental efforts to determine physical and chemical interactions and processes in tribologtcal systems. Liquid and solid lubricants, tribological coatings and surface modifications, and ceramic and cermet materials are specific topics to be considered. The Mechanisms area also includes efforts to develop novel characterization and testing procedures and diagnostic tools and equipment to assess the performance of tribological systems.

The second part of the research program, Design, includes such topics as design and reliability modeling of components, systens, and system assemblies. Industry is di rectly involved in these projects. The Design area will also establish a data center to gather and disseminate information on tribology. These projects concentrate on generic tribology R\&D, including energy losses from material wear.

Clearly, tribology research can have a major impact on energy use and conservation in the U.S. Much of the needed research identified in these studies is innovative and high-risk, which makes tribology a vital and appropriate area for ECUT support. Thus the ECUT Tribology Program, wh th 1 ndustry participation and cooperation, will continue its efforts to reduce the enormous energy losses caused by friction and wear. 
. 
SUMHARY

This report is part of a study of ways and means of advancing the national energy conservation effort, particularly with regard to oil, via progress in the technology of tribology. The report is confined to two economic sectors: transportation, where the scope embraces primarlly the highway flects, and electric uthlties. Together these two sectors account for half of the U.S. energy consumption. The goal of the study is co ascertain the energy sinks attributible to tribological components and processes and to recomend longrange research and development (R\&D) programs aimed at reducing these losses. In addition to the obvious tribological machine components such as bearings, piston rings, transmissions and so on, the study also extends to processes which are linked to tribology indirectly such as wear of machine parts. coatings of blades, high temperature naterials leading to higher cycle efflctencies, attenuation of vibration, and ather cycle inprovenents.

Much of the methodology used in arriving at the required information consisted of proper literature searches and the wtilization of MTI's records in the fiel is of energy and conservation. However, to make the study as comprehenstve and practical as passible, visits and interviews were arranged with designer: manufacturers and trsers of relevant equipment and their evaluations and oplintons were obtained on how best to further progress and energy savings in the yrious areas under consideration. These views were subsequently integrated with the results of the literature search, and together they constitute the substance of the material presented herein.

\section{AUTONOTIVE UEHICLES}

Since the conventional otto cycle engine has been and is likely to remain the predominant prine nover for automoblies, the bulk of this report is concerned with the conventional engine. However, due attention is also given to novel concepts such as the adiabatic diesel, the autonotive gas turbine, and the stirling engine. In addition to specific engine components, the study revealed a need for progress in some generic areas such as defining atatisthally valid driving cycle tin place of the eph cycle), detemining the 
validity of motoring tests, and others. Of the specific automotive components that need particular attention, the piston ring assembly and the long-range effect of low-viscosity ofl on engine wear are the most consplouous itens.

A detailed analysis of automotive vehicle performance yielded a mapping of the portions of energy required for the functioning of various subparts of the encine and drive srain. These energy shares in terms of percentages of the fuel energy input are given in figure $S .1$. The savings achievable in these energy sinks va tribological progress are listed in Table 5.1 . Table 5.1 shows a potential gath of $17.5 \%$ in fuel economy, which at $\$ 30$ per barrel of crude oil is equivalent to a savings of $\$ 14$ billion per year. Should the ongoing projects on novel types of engines be successful and the expected $30 \%$ improvement in fuel economy be achieved (over that of an equivalent st engine), then the expected gains would anount to some $\$ 23$ billion per year.

The Ro programs reguired to achieve these inprovenents in engine performance are given in Table 5.2. There are 17 of these projects, some of a bas c nature best to be sponsored by government agencies and some of a desin and development nature better suited for a pooled industrial effort. They range from programs which may require five years or more to establish the meeded basic information to prograns of component development in which particular concepts or approaches can be demonstrated in one to two years. Reyond these achiatenents must come time for product development. and findlly the time reauired for the lower loss approach to enter the automotive fleet fperhaps five years to achieve a $50 \%$ presence in the fleet). The probability of success on each individual project is intuitively $50 \%$ or better, but a realistic estimate would have to be based on more detailed and more definitive project descriptions:

\section{ELECTRIC UTHITIES}

In autorlotive vehicles, it is sufficient to discuss component periormance to obtain a picture of energy lost in various forms of mechanical inefficiency. While efficiency remains a vital concept also with electric utilities yet 


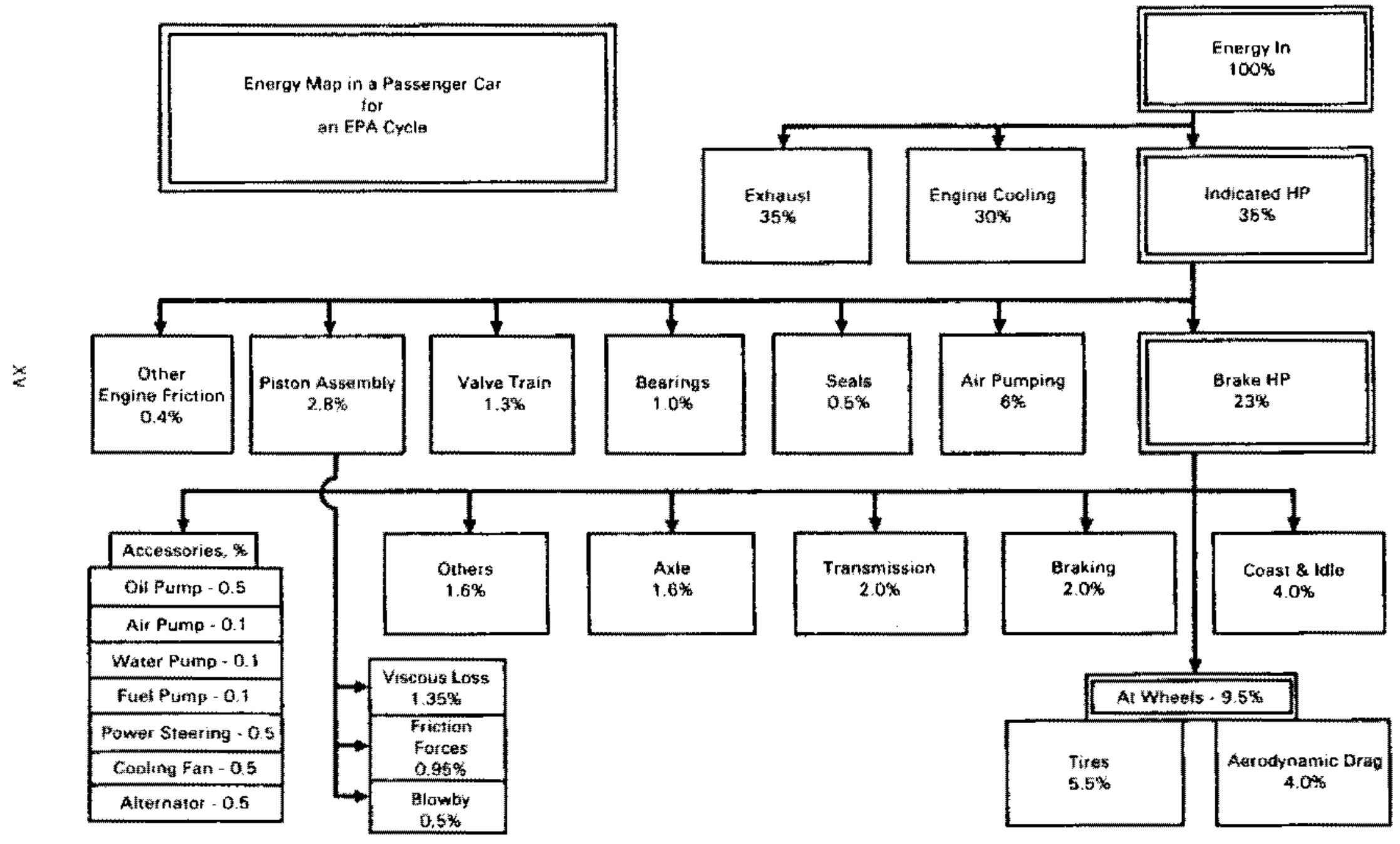

FIGURE 5.1. Energy Required by Passenger Car Components in EPA Cycle 
TABLE 5.1. Sumary of Potential Savings in Automotive Tribological Losses

\begin{tabular}{|c|c|c|c|c|c|c|c|c|c|}
\hline \multirow[b]{2}{*}{ 基 } & \multirow[b]{2}{*}{ Component } & \multirow{2}{*}{$\begin{array}{l}\text { Energy cont } \\
\text { suned: tof } \\
\text { Total fout } \\
\text { Consumpt lon }\end{array}$} & \multicolumn{3}{|c|}{ Potental Sarings in fercent } & \multicolumn{3}{|c|}{ Potentlal Savings lem Year } & \multirow[b]{2}{*}{ femarts } \\
\hline & & & Component & $\begin{array}{l}\text { Highay } \\
\text { Fleet: }\end{array}$ & $\begin{array}{l}\text { 11.5. Totat } \\
\text { Energy Demonde }\end{array}$ & $8 t y_{2} \times 10^{-1+1}$ & 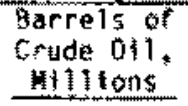 & $\begin{array}{r}1984 \\
\text { a.S.\$ } \\
\text { Bitilons }\end{array}$ & \\
\hline s & Plston Assensty & 8,0 & 39.2 & 3.1 & 0.61 & 460 & 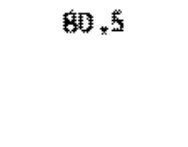 & 2,41 & 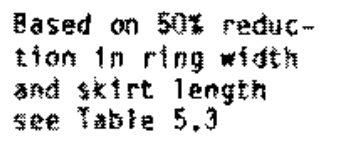 \\
\hline 2 & transmisston & 8.7 & 7.3 & 1.1 & 0,22 & 161 & 27,8 & 0.83 & $\begin{array}{l}\text { Refers to conventional } \\
\text { system }\end{array}$ \\
\hline 3 & Walye Toln & 3.7 & 83 & 3,1 & 0.62 & 465 & gito & 2.44 & \\
\hline a & 011 on & 2.2 & 20 & 0.44 & 0.0 & 86 & 11.0 & b. 35 & Shaft monted putip \\
\hline$\$$ & Butaks & 8.7 & 5 & 4.5 & $0 . B 7$ & 652 & $10 \pm .0$ & 3.35 & $\begin{array}{l}\text { Wse of regenerat tye } \\
\text { brakling }\end{array}$ \\
\hline 6 & Dearngs & 2.9 & 30 & 0.85 & 0.17 & 128 & 21.4 & 0.66 & \\
\hline 7 & Lubricant & $m *$ & $\ldots$ & 5.6 & $1 * 12$ & 930 & 142.0 & 4.30 & $\begin{array}{l}\text { Inclutes anti-friction } \\
\text { ddtutues }\end{array}$ \\
\hline & tatal & & $\ldots$ & 17.5 & 3.5 & 2760 & 474 & 14.3 & \\
\hline
\end{tabular}

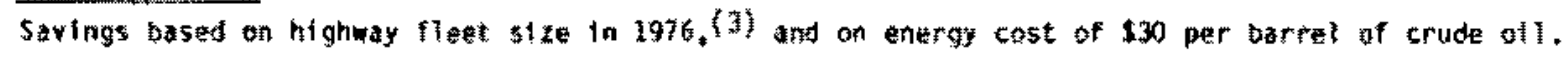


TABLE S.2. Summary of Recommended Research and Development Programs - Transportation Sector

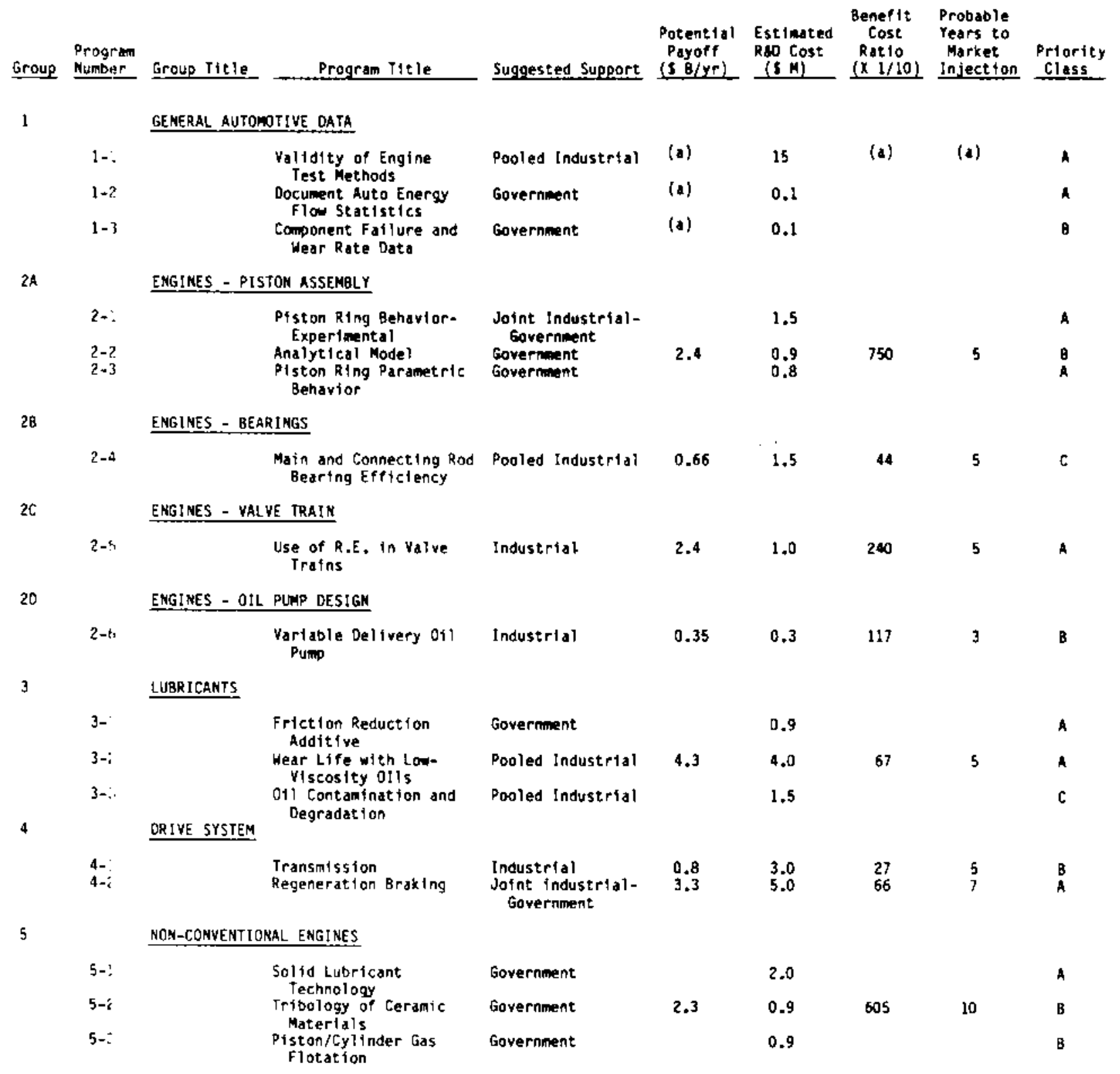

(a) Input cata support for other program. 
another concept looms here as perhaps the more important aspect of efficient utility operation. That concept is reliability which pertains to avoidance of all those forms of equipment malfunctions which very often cause the shutdown of turbogenerator sets and the cessation of operation of the power plant. Thus, the tribological improvements which lead to raising plant reliability figure here alongside the potential gains in efficiency. A scrutiny of the causes of plant shutdown revealed that various forms of bearing and lubricant induced problems like vibrations, contarninated oil, pump problems and others, account for up to one-quarter of the outages; furthermore, the percentage of tribologically induced shutdowns rises with size of the unit so that in an 800-Mw unit it is nearly twice as high as in a 400-MW unit. In the accessories the main area of difficulty is the feedwater pumps, particularly its sealing problem.

Figure S.2 shows the energy demanded by the various components of a turbogenerator set and its accessories as a fraction of the fuel energy delivered to the boiler. As seen, the largest loss is due to gaspath leakage, followed by the hearings and labyrinth seals. The levels of savings possible in these various areas are given in Table S.3, where the total possible savings due to both improved efficiency and enhanced reliability amount to $2.3 \%$ of the consumed energy, which translates into savings of some $\$ 2.3$ billion per year. Table 5.4 gives a listing of the R\&D projects required to accomplish these savings. There are, as seen, 10 of these projects, each given a priority ranking similar to that used in the automotive R\&n plan.

EUROPEAN ACTIVITIES IN ENERGY CONSERVATION

Judging by the activity of three of the countries of EEC, France, Germany, (FRG) and Great Britain, it appears that centralized planning efforts focused on the "cutting edge" type of R\&n activity in tribology that can catalyze breakthroughs in basic machine efficiency are still in their infancy. There is, however, a sizable body of work going on in the traditional areas of tribology. This may be the reflection of a broddly sensed feeling that 


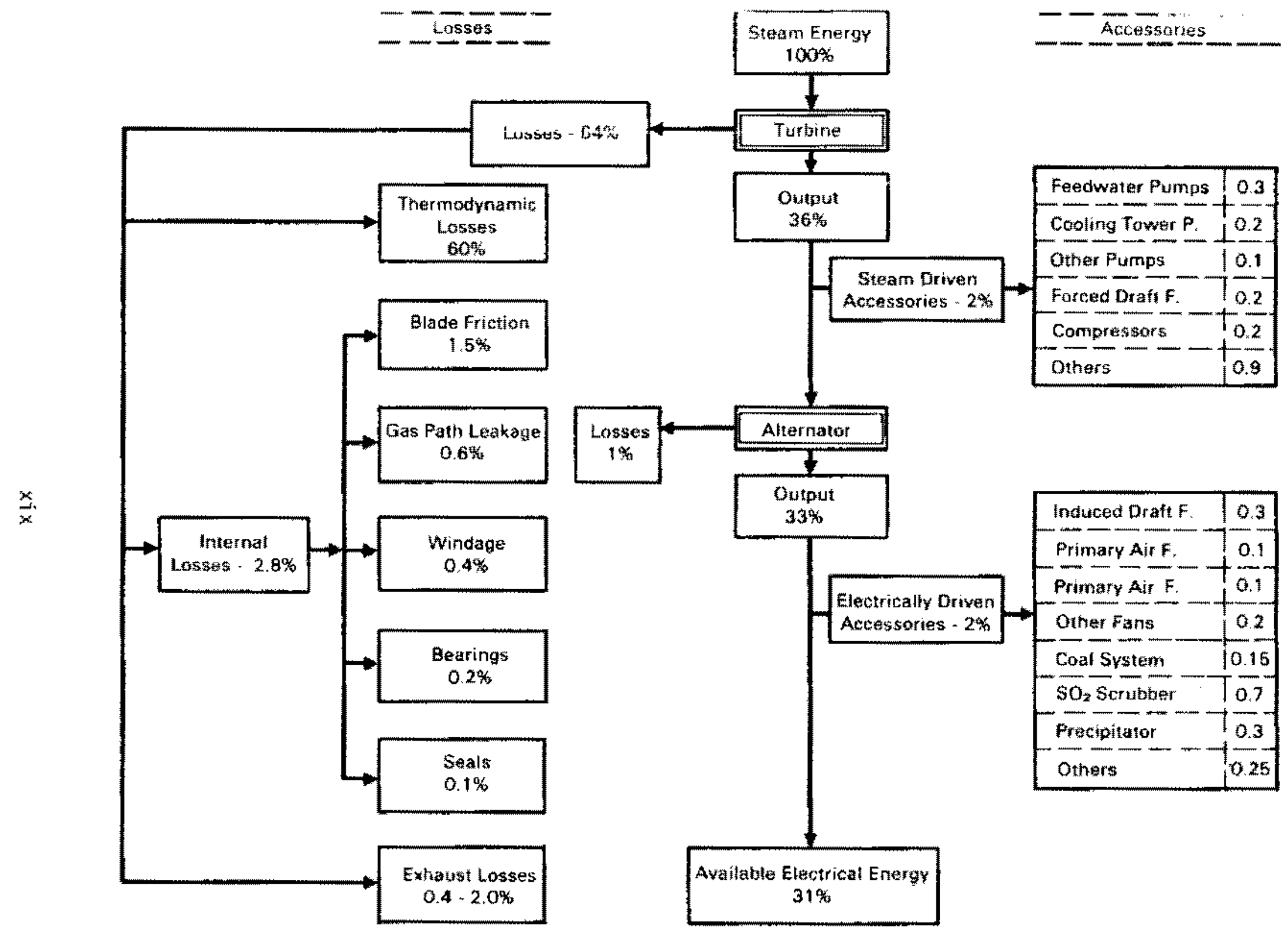

FIGUEE 5.2. Energy Demanded by Trlbologically Related Components of a TurboGenerator Set and its Accessories 
TABLE S.3. Summary of Potential Savings in the Electric Utillitities and on energy cost of $\$ 30$ per barrel of crude oil)

\begin{tabular}{|c|c|c|c|c|c|c|c|}
\hline \multirow[b]{2}{*}{10} & \multirow[b]{2}{*}{ Comonoent or Aren } & \multicolumn{3}{|c|}{ Percent Savinas } & \multicolumn{3}{|c|}{ Yearly Savinas } \\
\hline & & $\begin{array}{l}\text { Component } \\
\text { or Area }\end{array}$ & $\begin{array}{l}\text { Utilitias } \\
\text { Sector }\end{array}$ & $\begin{array}{l}\text { To.s. } \\
\text { Totai } \\
\text { nemand }\end{array}$ & $8+u \times 10^{-12}$ & $\begin{array}{l}\text { Rarrels of } \\
\text { Crute Oil } \\
\text { Millilons }\end{array}$ & $\begin{array}{l}\text { Uag4 } \\
\text { Militions }\end{array}$ \\
\hline 1 & $\begin{array}{l}\text { Seals (Gaspath } \\
\text { and Lahyrinth) }\end{array}$ & 50 & 0.88 & 0.25 & 180 & $3 \uparrow$ & 910 \\
\hline 2 & Rearinas & 50 & 0.25 & 0.07 & 52 & 9 & 270 \\
\hline 3 & Accessories & 5 & 0.50 & 0.14 & 104 & 18 & 530 \\
\hline 4 & RAliahility & 25 & 0.68 & 0.19 & $14 \Pi$ & 24 & 720 \\
\hline
\end{tabular}

significant improvements in energy utilization efficiency can be made by better application of present knowledge in the field, and by the results of R\&D in the usual areas of interest. In these latter areas, industry appears to be assisted by substantial government participation, particularly in Germany and freat Britain.

France established in 1981 an Agency for Mastery of Energy under the Ministry of Industry and Research. However, there has been as yet no specific identification of tribology as a significant field for energy research. The French National Center for Scientific Research has initiated some action in tribology, but there has been little actual funding.

In Germany, there has been a highly focused effort for almost ten years. Funding at the level of several million dollars per year has been devoted to development of tribology. This has largely been in conventional areas, however. Much of the effort bas been used to support the solution of specific industrial problems, and to collect, codify, and analyze the world-wide results of tribological work.

In Great Britain, the Institute of Tribology at Leeds has emerged as the dominant center for tribology, both in research and in the training of new professionals. By whatever means, the British are continuing to contribute significantly in many of the traditional areas of tribological research. However, their planning of breakthrough work in key areas significant to energy conservation is at a moderate level only, intermediate between the activity in France and Germany. 
TABLE S.4. Summary of Recomnended hesearch and Development Prograns - Ut lity Sector

\begin{tabular}{|c|c|c|c|c|c|c|c|c|c|}
\hline Grope & $\begin{array}{l}\text { Program } \\
\text { Number }\end{array}$ & Grost $T 1+10$ & Program ritie & Suggested Sugport & $\begin{array}{c}\text { Potential } \\
\text { Payott } \\
\text { is B/yri }\end{array}$ & $\begin{array}{l}\text { Est I mated } \\
\text { Rat cost } \\
(5 \%)\end{array}$ & 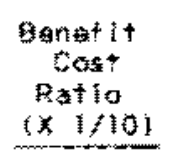 & $\begin{array}{l}\text { Probabla } \\
\text { Years to } \\
\text { Markat } \\
\text { Mnjection }\end{array}$ & $\begin{array}{l}\text { Prtority } \\
\text { Class } \\
\end{array}$ \\
\hline \multirow[t]{3}{*}{6} & & SEALS & & & & & & & \\
\hline & $6-1$ & & $\begin{array}{l}\text { Active cilearance } \\
\text { control }\end{array}$ & Pooled Industriat & 0.91 & 2.5 & 22 & 10 & s \\
\hline & $6-2$ & & $\begin{array}{l}\text { Abradiable seat } \\
\text { Materials }\end{array}$ & Government & & 1.5 & & 10 & A. \\
\hline \multirow[t]{6}{*}{ z } & & BEARINGS & & & & & & & \\
\hline & $7-1$ & & $\begin{array}{l}\text { Turning foar was } \\
\text { Etfocts }\end{array}$ & Govetnment & & 6.2 & & 5 & a \\
\hline & $y-2$ & & $\begin{array}{l}\text { High Teneerature } \\
\text { "gabbitt" }\end{array}$ & Govarnment" & & 0.5 & & 7 & $\mathrm{~g}$ \\
\hline & $7-3$ & & $\begin{array}{l}\text { oft Groove Mixing } \\
\text { Temperature }\end{array}$ & Government & 0.76 & 0.5 & 7.4 & 3 & A \\
\hline & $7-4$ & & $\begin{array}{l}\text { Proot Tests on Low } \\
\text { Pow Less Bearlings }\end{array}$ & Poolad Indastrla! & & 0.8 & & 7 & B \\
\hline & $7-5$ & & $\begin{array}{l}\text { Larga Wotor Lubri- } \\
\text { eated Benrings }\end{array}$ & Eovarnment & & 1.5 & & 10 & a \\
\hline \multirow[t]{2}{*}{8} & & ACCESSORIES & & & & & & & \\
\hline & $x_{i=1}$ & & $\begin{array}{l}\text { Fagdwater Pumo fortor } \\
\text { Systems }\end{array}$ & Poolad Indystrlal & 0.53 & 1.0 & 53 & 4 & A \\
\hline \multirow[t]{3}{*}{$\$$} & & PELIABILITY & & & & & & & \\
\hline & $9-1$ & & $\begin{array}{l}\text { Contanlingnt/faiture } \\
\text { Study }\end{array}$ & Government & 0.72 & 0.3 & 10 & 3 & A \\
\hline & $9-2$ & & Eearling/Seal Whitoring & Poolad Industria! & & 0.4 & & 4 & $B$ \\
\hline
\end{tabular}


In summary, one can say that focused efforts towards energy conservation via tribology are only now beginning to take root in the EEC countries of Europe. Continued progress in the field in this country, with continued attention to catalytic support in key breakthrough areas, may give the U.S. a technological lead in the intensely competitive areas of the automotive and power plant industries. 


\begin{tabular}{|c|c|}
\hline$A C_{1}^{\top}$ & Advanced Gas Turbine \\
\hline API & American Petroleum Institute \\
\hline $\mathrm{BHP}$ & Brake hp \\
\hline $\mathrm{BOC}$ & Bottom lead Center \\
\hline BHEP & Brake Mean Effective Pressure \\
\hline C & Pearing Radial Clearance \\
\hline$c s$ & Centistokes \\
\hline CuT & Continuously Yariable Transmission \\
\hline$\eta$ & Garing nameter \\
\hline ECE & European Standart Driving Cycle \\
\hline ENO & Elastonydrodynamic \\
\hline Fo & Forced Draft \\
\hline FEO & Friction Efficient Dil \\
\hline FHP & Friction hp \\
\hline F 100 & Ford Integral Overdrive \\
\hline FMED & Friction Hean Effective Pressure \\
\hline Gị & Gas Turbine \\
\hline$H$ & Power Loss \\
\hline $\mathrm{HP}$ & Horsepower, also high Pressure \\
\hline$h_{\min }$ & 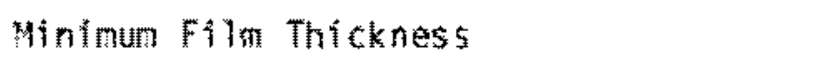 \\
\hline IC & Internal Combustion Engine \\
\hline ID & Induced oraft \\
\hline IGT & Impreved has Turbine \\
\hline IHP & Indicated hp \\
\hline IMEP & Indicated Mean Efective Pressure \\
\hline IP & Intermediate Pressure \\
\hline k & Rotor stiffness \\
\hline$X W$ & kilowats \\
\hline$k_{x}$ & Steam Induced Lateral Spring Constant \\
\hline$k_{y}$ & Steam Induced Colinear Spring Constant \\
\hline L & Bearing width (or Length) \\
\hline$[1]$ & Megajoules, $10^{6}$ joules \\
\hline
\end{tabular}




\begin{tabular}{|c|c|}
\hline 铸 & Megawatts, in watts \\
\hline mpg & Nives per Gallon \\
\hline$m p$ & Mlles per Hour \\
\hline N & Revolutions per unit Time \\
\hline$p$ & Pressure \\
\hline$p$ & Unit Loading, $(h / L D)$ \\
\hline 0 & Lubricant Flow; also Heat \\
\hline R & Pearing or Journal Radius \\
\hline $\mathrm{Re}$ & Reynolds number \\
\hline$s !$ & Spark Ignition \\
\hline SSH & Saybolt Seconds \\
\hline$T$ & Temperature \\
\hline ToC & Top Dead Center \\
\hline TIT & Turbine Inlet Tenperature \\
\hline U & Linear Velocity \\
\hline v & Vol ume \\
\hline VMT & Vehicle Miles Travelled \\
\hline VSTC & Variable Stator Torque Converter \\
\hline URTO & Variable Ratio Traction Drive \\
\hline W & Load \\
\hline WOT & $\begin{array}{l}\text { Wide Open Throttle } \\
\rho^{2}\end{array}$ \\
\hline$\overline{\mathrm{W}}$ & $\overline{\mathrm{HN}}\left(\overline{\mathrm{R}^{2}}\right.$ \\
\hline$w_{x}$ & Lateral Force \\
\hline$H_{y}$ & Vertical Force \\
\hline$\varepsilon$ & Eccentricity Ratio \\
\hline 实 & Motational Speed \\
\hline$n$ & Plrst Natural Frequancy \\
\hline 进 & Absolute viscosity \\
\hline
\end{tabular}




\section{INTRODUCTION}

The stranglehold of the OPEC cartel on the production and pricing of oil has kept the energy market in turmoil now for over a decade. Although, at the present moment, the shortage of oil and the spiral of crude oil prices have abated, this is probably only a temporary lull, with the basic problem of sufficient and moderately priced oil supplies remaining unresolved. Most telling is the fact that the present improvement has come about largely because of the effectiveness of conservation measures. According to published data, (1) the following gains were achieved by the U.S. in 1982 vis-a-vis 1973:

1. Automobiles traveled $90 \%$ further for the same quantity of fuel.

2. Total consumption of automobile gasoline was reduced $4 \%$.

3. Consumption of fuel oil was reduced $12 \%$.

4. Total energy consumption was reduced $4.9 \%$.

5. Energy required per gross national product was reduced $19 \%$.

It seems then that it is the pursuit of conservation policies that can best guarantee for the U.S. economy the continuation of the present relatively favorable state of affairs. With a further improvement in the conservation field, the U.S. can linit the consequences of any potential political or economic crises with regard to energy shortages.

The present project is a study of ways and means of advancing and furthering the energy conservation effort, particularly with regard to oil. The project is, in a way, a continuation of the DOE/ASME sponsored workshop and study conducted in 1977, the product of which was the publication of Strategy for Energy Conservation via Tribology. (2) The 1977 study embraced all four sectors of the U.S. economy: transportation, electric utilities, industry, and the commercial/residential sectors. The present effort deepens the 1977 work by concentrating on two sectors: transportation, where the scope is confined primarily to the highway fleets (excluding railroads and aircraft), and electric utilities. The goal of the study is to ascertain the energy sinks attributable to tribological components and processes and to recommend long-range basic R\&D programs aimed at reducing the level of these energy losses. In 
order to appreciate fully the range of tribological involvement in the machinery under discussion, it should be noted that our attention is not confined to the obvious tribological machine components such as bearings, piston rings, transmissions, etc., but extends to parts and processes which are linked to tribology indirectly such as wear of machine parts, coatings of blades, high-temperature materials leading to higher cycle efficiencies, attenuation of vibration and the consequent reduction of downtime of a utility's power plant, and other improvements that can be achieved by progress in tribological technology.

Much of the methodology used in arriving at the required information consisted of proper literature searches and the utilization of MTI's own records in the fields of energy and conservation. However, to make the study as comprehensive and practical as possible, visits and interviews were arranged with designers, manufacturers, and users of relevant equipment and their evaluations and opinions were obtained on how best to further progress and energy savings in the various areas under consideration. A list of the plants and organizations visited is given in Appendix $B$, and a record of the discussions is available from transcripts of the tape recordings made during the sessions (with the permission of the participants). These views were subsequently integrated with the results of the literature search, and together they constitute the substance of the material presented herein. 


\section{CONTENTS}

EXECUTIVE SUMMARY OF TRIBOLOGY SERIES $\ldots \ldots \ldots \ldots \ldots \ldots \ldots \ldots \ldots \ldots \ldots \ldots \ldots$

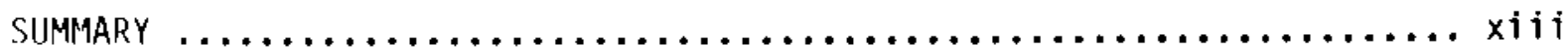

L.IST OF SYMBOLS AND ABBREVIATIONS $\ldots \ldots \ldots \ldots \ldots \ldots \ldots \ldots \ldots \ldots \ldots \ldots \ldots \ldots \ldots \ldots \ldots$

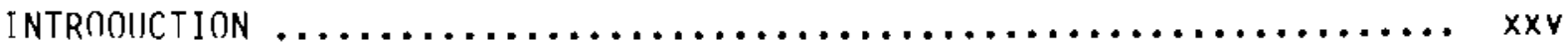

PART I - AUTOMOTIVE VEHICLES

1.0 AlutOM0tive Statistics $\ldots \ldots \ldots \ldots \ldots \ldots \ldots \ldots \ldots \ldots \ldots \ldots \ldots \ldots \ldots \ldots \ldots .1$

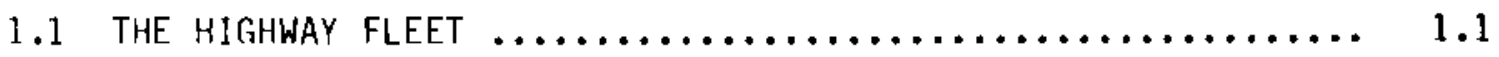

1.2 THE EPA CYCLE $\ldots \ldots \ldots \ldots \ldots \ldots \ldots \ldots \ldots \ldots \ldots \ldots \ldots \ldots \ldots \ldots \ldots$

2.0 CONVENTIONAL OTTO CYCLE ENGINES $\ldots \ldots \ldots \ldots \ldots \ldots \ldots \ldots \ldots \ldots \ldots \ldots . \ldots \ldots$

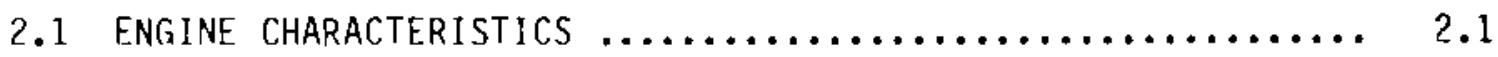

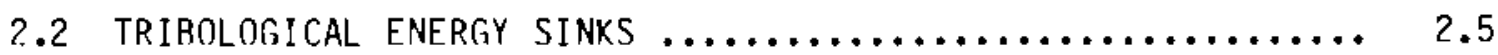

2.2 .1 Spectrum of Engines $\ldots \ldots \ldots \ldots \ldots \ldots \ldots \ldots \ldots \ldots \ldots \ldots \ldots$

2.2.2 Five Small 4- and 6-Cylinder Engines .......... 2.9

2.2.3 Correlation of Various Sources $\ldots \ldots \ldots \ldots \ldots \ldots \ldots . . . . .2 .9$

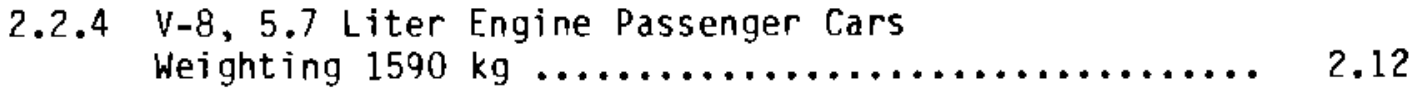

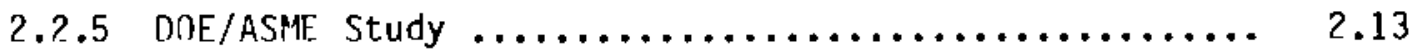

2.2.6 Supplementary Data from Interviews ........... 2.14

2.2 .7 Integration of Results $\ldots \ldots \ldots \ldots \ldots \ldots \ldots \ldots \ldots \ldots \ldots$

3.0 UnCONVENTIONAL ENGines $\ldots \ldots \ldots \ldots \ldots \ldots \ldots \ldots \ldots \ldots \ldots \ldots \ldots \ldots \ldots \ldots$

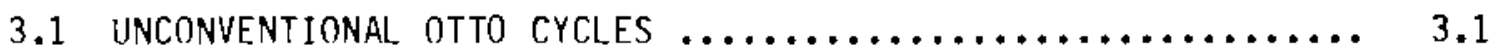

3.2 DIESEL CYCLE EngINES $\ldots \ldots \ldots \ldots \ldots \ldots \ldots \ldots \ldots \ldots \ldots \ldots \ldots \ldots \ldots \ldots \ldots \ldots$

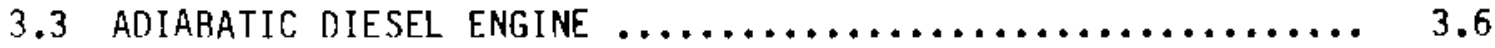

3.3.1 General Features $\ldots \ldots \ldots \ldots \ldots \ldots \ldots \ldots \ldots \ldots \ldots \ldots \ldots .3 .6$

3.3.2 Development Data $\ldots \ldots \ldots \ldots \ldots \ldots \ldots \ldots \ldots \ldots \ldots \ldots \ldots$ 
3.3.3 Levels of Possible Savings $\ldots \ldots \ldots \ldots \ldots \ldots \ldots \ldots \ldots . . .15$

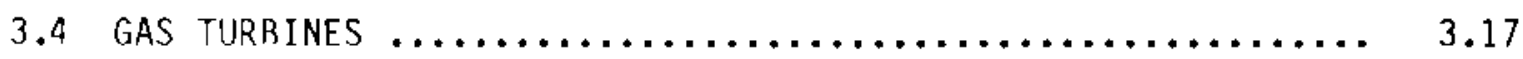

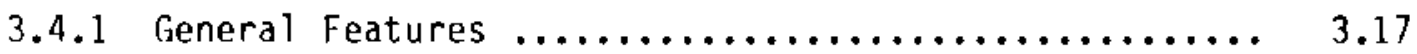

3.4 .2 Development Data $. . \ldots \ldots \ldots \ldots \ldots \ldots \ldots \ldots \ldots \ldots, 3.24$

3.4.3 Tribological Elements ......................... 3.24

3.4 .4 Reduction Gears $\ldots \ldots \ldots \ldots \ldots \ldots \ldots \ldots \ldots, \ldots \ldots \ldots, 3.31$

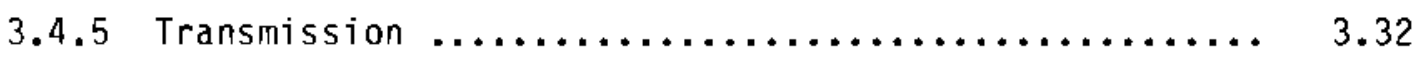

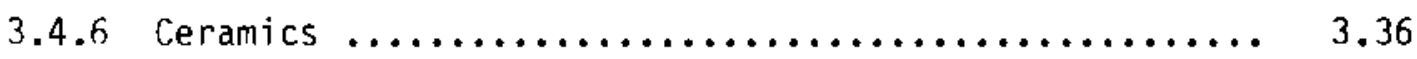

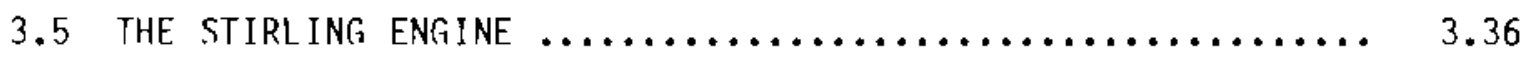

3.5 .1 General Features $\ldots \ldots \ldots \ldots \ldots \ldots \ldots \ldots \ldots \ldots \ldots \ldots .3 .36$

3.5.2 Development Data $\ldots \ldots \ldots \ldots \ldots \ldots \ldots \ldots \ldots \ldots \ldots \ldots, 3.42$

3.5.3 Tribological Losses $. . \ldots \ldots \ldots \ldots \ldots \ldots \ldots \ldots \ldots \ldots . . .4 .44$

4.0 ANALYSIS OF TRIBOLOGICAL ENERGY LOSSES $\ldots \ldots \ldots \ldots \ldots \ldots \ldots \ldots . \ldots . . \ldots \ldots$

4.1 PISTON ASSEMRLY $\ldots \ldots \ldots \ldots \ldots \ldots \ldots \ldots \ldots \ldots \ldots \ldots \ldots \ldots \ldots \ldots \ldots \ldots .2$

4.1.1 Piston Cylinder Interaction $\ldots \ldots \ldots \ldots \ldots \ldots \ldots \ldots, 4.2$

4.1.2 Effect of Parameters on Performance ............. 4.13

4.2 TRANSMISSIONS $\ldots \ldots \ldots \ldots \ldots \ldots \ldots \ldots \ldots \ldots \ldots \ldots \ldots \ldots \ldots \ldots \ldots \ldots \ldots \ldots \ldots \ldots, 23$

4.2.1 Conventional Transmissions $\ldots \ldots \ldots \ldots \ldots \ldots \ldots \ldots, 4.24$

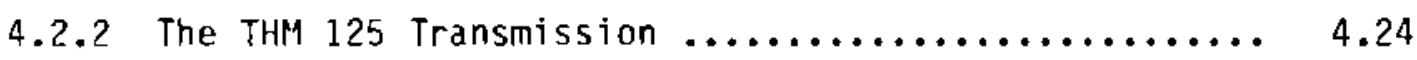

4.2.3 Effect of Fluid Friction Modifiers .............. 4.28

4.2.4 Continuously Variable Transmissions $\ldots \ldots \ldots \ldots \ldots \ldots .4 .30$

4.3 valve trains $\ldots \ldots \ldots \ldots \ldots \ldots \ldots \ldots \ldots \ldots \ldots \ldots \ldots \ldots \ldots, 4.31$

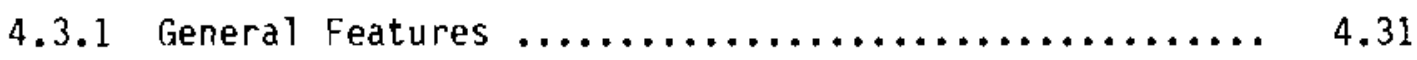

4.3.2 Losses Bue to Individual Components ............. 4.34

4.4 OIL PUMPS $\ldots \ldots \ldots \ldots \ldots \ldots \ldots \ldots \ldots \ldots \ldots \ldots \ldots \ldots \ldots \ldots \ldots \ldots, 4.45$

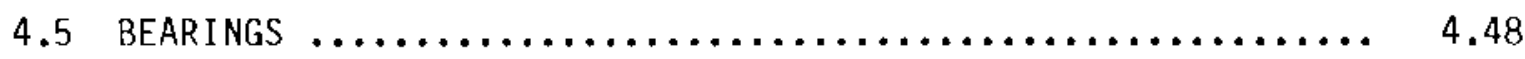


4.6 BRAKING $\ldots \ldots \ldots \ldots \ldots \ldots \ldots \ldots \ldots \ldots \ldots \ldots \ldots \ldots \ldots \ldots \ldots \ldots \ldots, 4.52$

4.7 LUBRICANT FORMULATION $\ldots \ldots \ldots \ldots \ldots \ldots \ldots \ldots \ldots \ldots \ldots \ldots, 4.53$

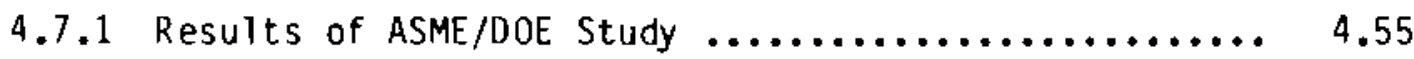

4.7.2 Results of European Study ................... 4.56

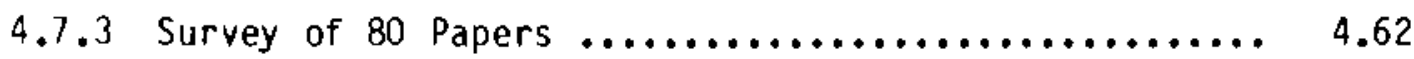

4.7.4 EPA and FTP Standards Tests $\ldots \ldots \ldots \ldots \ldots \ldots \ldots \ldots . .6 .65$

4.7.5 Cold Start Fuel Efficiency $\ldots \ldots \ldots \ldots \ldots \ldots \ldots \ldots . . .6 .66$

4.7.6 Negative Effects of Low Viscosity $0 i 1 s \ldots \ldots \ldots \ldots .4 .68$

4.8 Materials AND COATINGS $\ldots \ldots \ldots \ldots \ldots \ldots \ldots \ldots \ldots \ldots \ldots \ldots, 4.71$

4.9 Tthers $\ldots \ldots \ldots \ldots \ldots \ldots \ldots \ldots \ldots \ldots \ldots \ldots \ldots \ldots \ldots \ldots \ldots \ldots \ldots \ldots \ldots \ldots, 4.73$

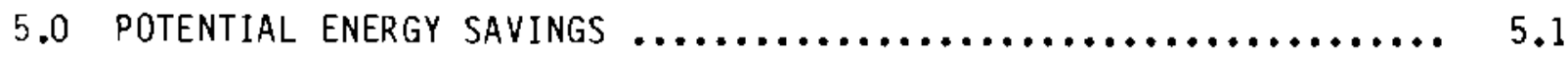

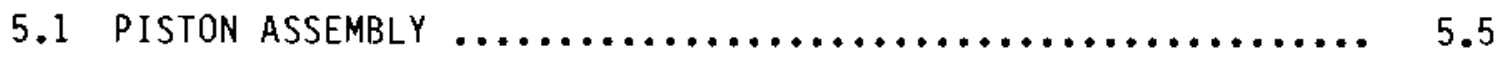

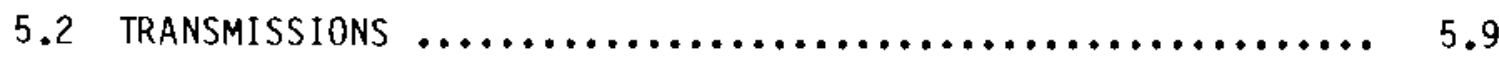

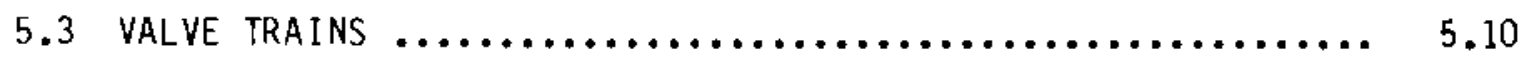

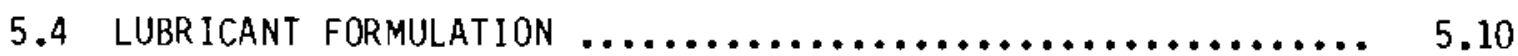

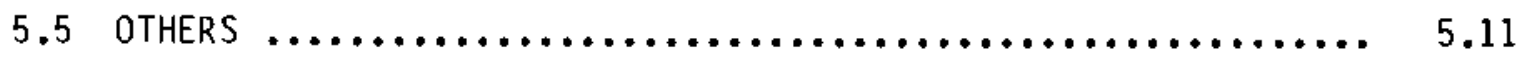

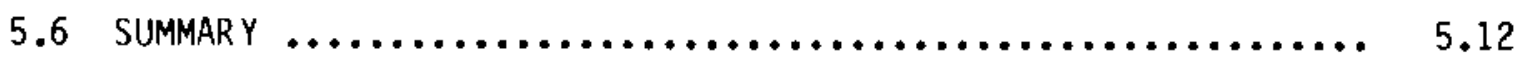

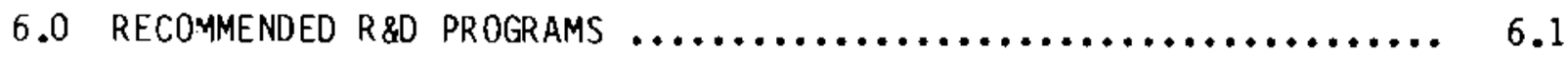

PART II - ELECTRIC UTILITIES

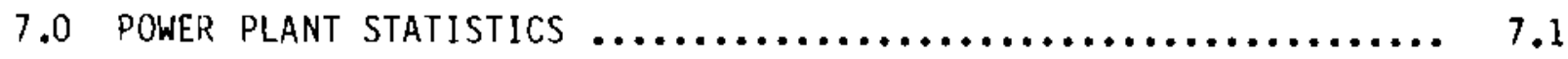

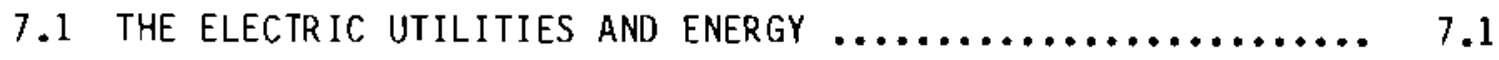

7.2 EQUIPMENT USED BY UTILITIES $\ldots \ldots \ldots \ldots \ldots \ldots \ldots \ldots \ldots \ldots \ldots \ldots \ldots \ldots \ldots \ldots$

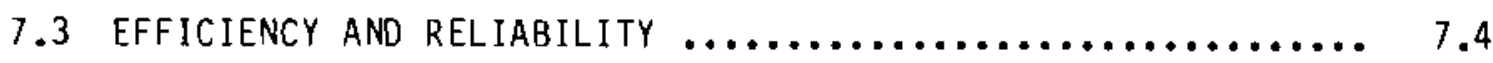

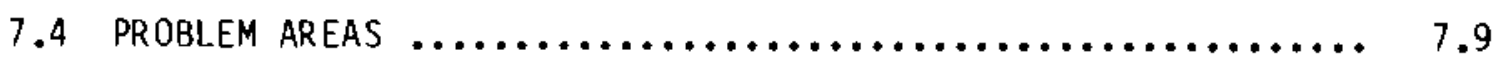

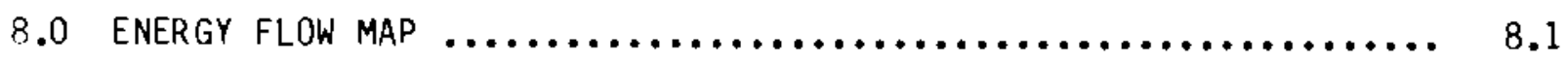




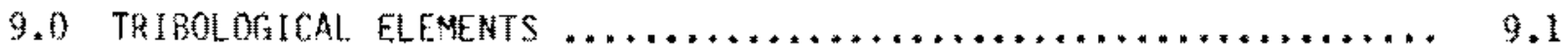

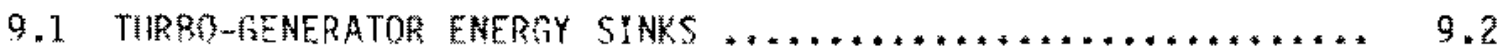

9.1 .1 Plate and Nozzle Losses ....................... 9.4

9.1 .2 Seals $\ldots \ldots \ldots \ldots \ldots \ldots \ldots \ldots \ldots \ldots \ldots \ldots \ldots \ldots, 9.10$

9.1 .3 Bearings $\ldots \ldots \ldots \ldots \ldots \ldots \ldots \ldots \ldots \ldots \ldots \ldots \ldots, 9.11$

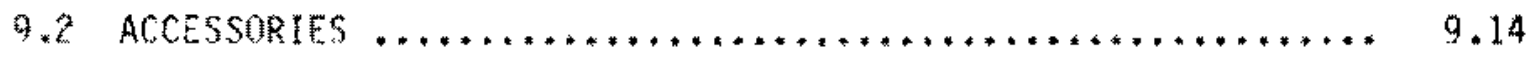

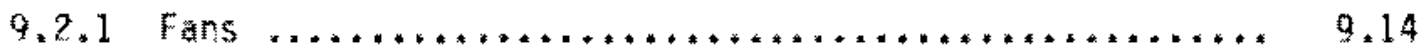

9.2 .2 Feedwater Pumps ............................ 9.17

9.2 .3 Coal Handling Equipment ...................... 9.19

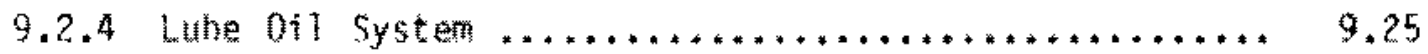

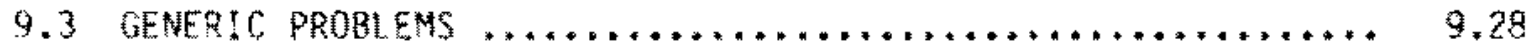

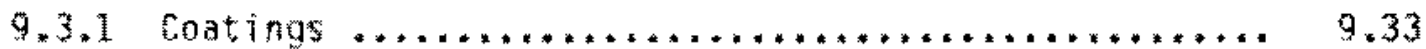

9.3 .2 Monitoring and Diagnostics ,................... 9,35

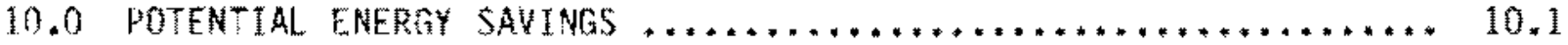

11.0 RECOMMENDED RRD PQOGRAMS - IITILITY SECTOR $\ldots \ldots \ldots \ldots \ldots \ldots \ldots \ldots, 11.1$

PART III - BRIEF EUROPEAN STUDY

12.0 ENERGY CONSERVATION AND ITTILIZATION TECHNOLOGY IN EUROPE ........ 12.1

12.1 FRANCE--PROF. M. GODET $\ldots \ldots \ldots \ldots \ldots \ldots \ldots \ldots \ldots \ldots \ldots \ldots \ldots, 12.1$

12.1.1 Professor Godet's Personal Thoughts and Recommendations .............................. 12.2

12.2 GERMANY-APROF. H. CZYCHOS ....................... 12.3

12.3 GREAT BRYTAIN $\ldots$ PROF. 0. DOWSON $\ldots \ldots \ldots \ldots \ldots \ldots \ldots \ldots \ldots \ldots, 12.6$

12.3.1 General Coments ........................... 12.9

12.4 SIMMARY $\ldots \ldots \ldots \ldots \ldots \ldots \ldots \ldots \ldots \ldots \ldots \ldots \ldots \ldots \ldots \ldots \ldots, 12.9$

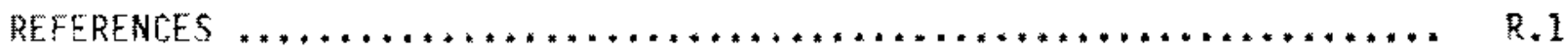

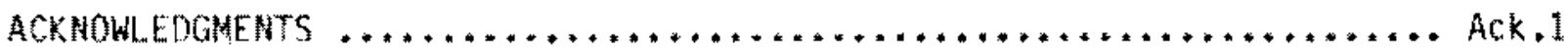


APPENDIX A - STATEMENT OF WOKK $\ldots \ldots \ldots \ldots \ldots \ldots \ldots \ldots \ldots \ldots \ldots \ldots \ldots \ldots \ldots \ldots+$ A.1

APPENDIX $B$ - LISTIAO OF CONDUCTED INTERVIEWS ................. B.

APPENDIX $C \ldots$ CONVERSLON TABLES $\ldots \ldots \ldots \ldots \ldots \ldots \ldots \ldots \ldots \ldots \ldots \ldots \ldots \ldots$ 


\section{FIGIRES}

ES. Annual Friction and hear Losses in Surveyed Industries $\ldots \ldots \ldots \ldots$ iv

ES.2 Annual Friction and Wear Energy Losses in the Metalwarking Industry, and Potential Sayings from Surface Modification

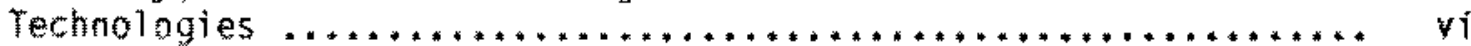

ES. 3 Potential Eneray Savings per Year for the

Conventional Engine $\ldots \ldots \ldots \ldots \ldots \ldots \ldots \ldots \ldots \ldots \ldots \ldots \ldots \ldots \ldots \ldots \ldots \ldots \ldots$ w

ES.4 potential Energy sayings for the Utilities $\ldots \ldots \ldots \ldots \ldots \ldots \ldots \ldots \ldots$ vill

ES.5 Material linder Consideration in the 215 Current

Government - Sponsored Tribology Projects .................. ix

S.l Energy Required by Passenger Car Components in EPA Cycle **.... Xy

5.2 Energy Demanded by Yribologically Related Components of a

Turbo-generator Set and Its Accessories $\ldots \ldots \ldots \ldots \ldots \ldots \ldots \ldots \ldots \ldots \ldots$. Ix

1.1 Total Annual Fuel Consumption by Type of Vehicle $\ldots \ldots \ldots \ldots \ldots \ldots \ldots \ldots$ 1.4

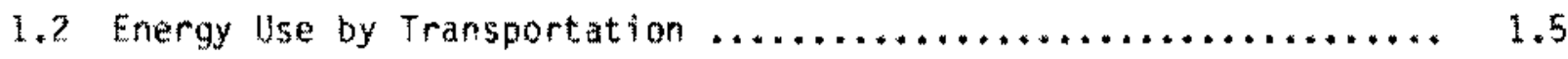

1.3 Cost of operating Suburban-Based Autonobite $\ldots \ldots \ldots \ldots \ldots \ldots \ldots \ldots$

1.4 Average Automobile Irip Length by Purpose of Trip and Season ..* 1,7

1.5 Federal Oriving Cycle power Requirenent for a $3400-10$

Automobile $\ldots \ldots \ldots \ldots \ldots \ldots \ldots \ldots \ldots \ldots \ldots \ldots \ldots \ldots \ldots \ldots \ldots \ldots \ldots \ldots \ldots \ldots, 1.9$

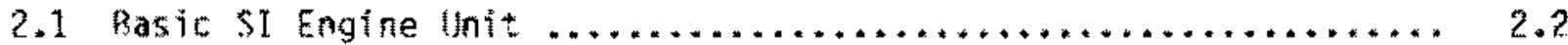

2.2 Brake Horsepower Thermal Efficiency as Function of Speed
and Load $\ldots \ldots \ldots \ldots \ldots \ldots \ldots \ldots \ldots \ldots \ldots \ldots \ldots \ldots \ldots \ldots \ldots \ldots \ldots \ldots \ldots \ldots$

2.3 Events Ouring 3-5peed Transmission Upshift Sequence ......... 2.5

2.4 Brake and Frictional Mep in Passenger Vehicle $\ldots \ldots \ldots \ldots \ldots \ldots \ldots$.6.6

2.5 Distribution of "Frictional" Losses at Road Conditions .........2.8

2.6 Levels of Frictional Losses in "Small" Automobiles ........... 2.10

2.7 Major Energy Components in Automotive Cycle ................ 2,11

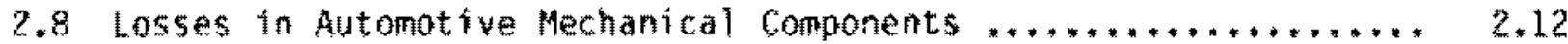

2.9 Frlation Coefficient for Autonotive Components ...........** 2.14 
2.10 Energy Distribution in a $V-8$ Engine Vehicle $\ldots \ldots \ldots \ldots \ldots \ldots . . . . . .25$

2.11 Energy Map in a Passenger Car During EPA Cycle .............. 2.16

2.12. Frictional Losses in a $348 \mathrm{in}^{3}$ Passenger Car at $50 \mathrm{mph} . \ldots . \ldots .2 .17$

2.13 Passenger Car Accessory Power Consumption .................. 2.18

?.14 Fnergy Map in a Passenger Car for an EPA Cycle $\ldots . . . . . . . . . .2 .21$

3.1 Characteristics of Various Automotive Engines $\ldots \ldots \ldots \ldots \ldots \ldots . . .2$

3.? Typical Energy Balance of a Diesel Engine $\ldots \ldots \ldots \ldots \ldots \ldots \ldots . . . . . .3$

3.3 Frictional Energy Losses in a Diesel Engine $\ldots \ldots \ldots \ldots \ldots \ldots \ldots .3 .4$

3.4 IIrban Fuel Economy of 1978 Diesel and SI Engine Vehicles ....... 3.5

3.5 Turbocompound Diesel $\ldots \ldots \ldots \ldots \ldots \ldots \ldots \ldots \ldots \ldots \ldots \ldots \ldots \ldots, 3.8$

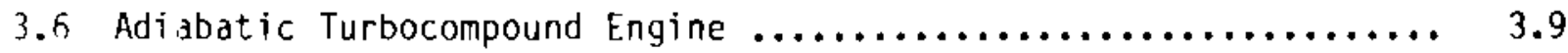

3.7 Expected Cylinder Liner Temperatures in Advanced and
Adiabatic Diesels $\ldots \ldots \ldots \ldots \ldots \ldots \ldots \ldots \ldots \ldots \ldots \ldots \ldots \ldots \ldots \ldots \ldots \ldots \ldots \ldots \ldots \ldots \ldots \ldots$

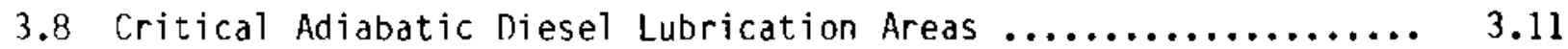

3.9 Efficiency of Advanced and Adiabatic Diesel Engines ........... 3.12

3.10 Effects of Diesel Engine Insulation and Turbocompounding ....... 3.13

3.11 Effect of Insulation on Engine Friction and Temperature ........ 3.14

3.12 Calsulated 0il Film Thickness of Top Ring and Cylinder Linær Wear Pattern ......................................... 3.15

3.13 Temperatures of Cylinder Liners $\ldots \ldots \ldots \ldots \ldots \ldots \ldots \ldots \ldots \ldots . . . \ldots \ldots$

3.14 Effect of Ceramic Coating on Heat Insulation

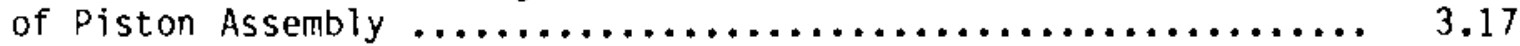

3.15 Single Shaft Automotive Gas Turbine $\ldots \ldots \ldots \ldots \ldots \ldots \ldots \ldots \ldots . .6 .20$

3.16 Two-Shaft Automotive Gas Turbine $\ldots \ldots \ldots \ldots \ldots \ldots \ldots \ldots \ldots \ldots \ldots, \quad 3.21$

3.17 Speed Ranges in Gas Turbine Drive Automobile ................ 3.22

3.18 AGT 101 Gearbox and Transmission Layout $\ldots \ldots \ldots \ldots \ldots \ldots \ldots \ldots . . .23$

3.19 Projected Fuel Economy for AGT 101 Versus Diesel and SI Vehicles ....................................... 3.27 
3.20 ar Vehicle Performance as Function of speed ................. 3.27

3.21 Energy flow in an AaT-1ne Driven Vehicle $\ldots \ldots \ldots \ldots \ldots \ldots \ldots \ldots . . .28$

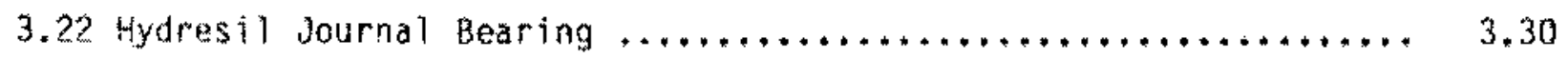

3.23 Hydromechanical Transmission Efficiency .................... 3.33

3.24 Efficiency of ChT Versus Automatic Transmission .............. 3.34

3.25 Input power at Road-Load for Various Transmissions ............ 3.35

3.26 Properties of Various Ceramic Materials ..................... 3.38

3.27 Basic Podel of Stirling Cycle ............................. 3.39

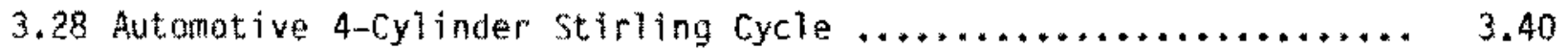

3.29 Automotive Stirling Engine $\ldots \ldots \ldots \ldots \ldots \ldots \ldots \ldots \ldots \ldots \ldots \ldots \ldots, 3.41$

3.30 Dependence of Stirling Engine Performance on Source and
Ambient Temperatures ...................................... 3.42

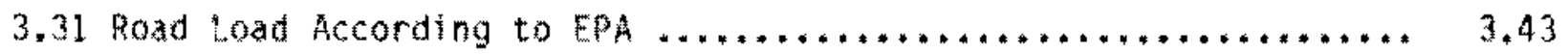

3.32 Scheduled Performance Map for Stirling Veticle .............. 3,45

3.33 Energy Map in a Stirling Engine Vehicle ................... 3.46

3.34 Mechanical Losses in Simulated Stirling Engine .............. 3.47

3.35 Typtcal Rod Surface Temperature Profile .................... 3.49

3.36 The "poll-sock" seal ................................. 3.50

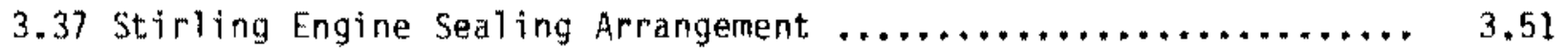

3.38 poeing Foot Seal ................................... 3.52

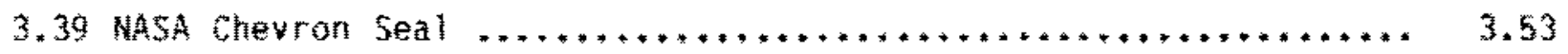

4.2 Piston-Cylinder Assembly of IC Engines ..................... 4.3

4.2 Cylinder Bore Shape for Perkins AT6-354 Engine During Exhaust

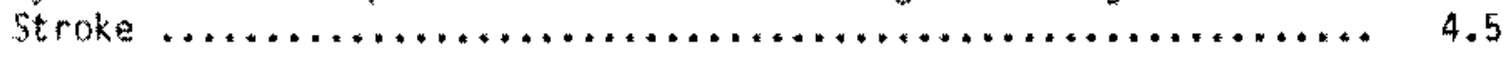

4.3 Typical Automotive Engine Ring Pack ...................... 4.6

4.4 Friction in the Individual Components of Piston Assembly ....... 4.7

4.5 Viscous and Nonviscous Frictional Losses in Piston Assembly ..... 4.8 
4.6 Blowby FMEP, Percent of Total FMEP $\ldots \ldots \ldots \ldots \ldots \ldots \ldots \ldots \ldots \ldots \ldots . . \ldots$

4.7 Inter-Ring Gas pressures $\ldots \ldots \ldots \ldots \ldots \ldots \ldots \ldots \ldots \ldots \ldots \ldots \ldots \ldots \ldots \ldots . . \ldots$

4.8 Calculated Ring-Liner 0il Film Thickness of Turbocharged Diesel

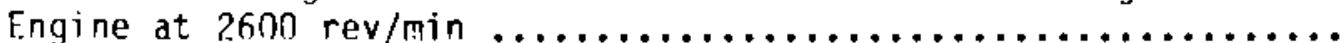

4.9 Calculated Dil Ring Film Thickness Distributions With and Without $0 i 1$ Starvation

4.10 Pressure Distributions in a Piston Ring with a Shallow Profile. Largest Negative Pressure was $-0.78 \mathrm{NM} / \mathrm{m}^{2}$

4.11 Effects of Narrow Face and Reduced Tension in Piston Rings ......

4.12 Effect of Reduced Face Width and Ring Tension in

Piston Rings

4.13 The Effect of Ring Face Profile on Film Thickness

4.14 Effect of Ring Barreling and Plating

L.15 Mearis of Reducing Friction in Piston Skirts

4.16 Influence of Piston Skirt Length on Engine Friction and Economy

4.17 Effect of Stroke Length on Piston Friction

4.18 Effect of Transmission Overall Ratio Spread on Performance and Economy

L.19 Comprarison of Drive Train Efficiencies at Road Load

C.20 Variable Capacity 0il Pump

4.21 The Effect of Friction Modifiers on Three-Speed Transmission Shift Quality

4.22 The Effect of Fluid Degradation on Shifting Quality in ThreeSpeed Transmissions at $275^{\circ} \mathrm{F}$ Bulk Fluid Temperature ............

4.23 Idec̀l Engine Line for CVT

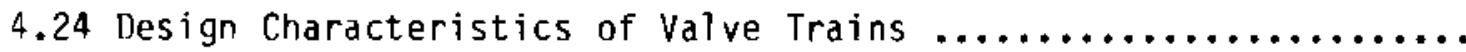

4.25 Valve Pumping FMEP, Percent of Total FMEP ................ 4.34

4.26 Rolling Element Bearing Application to Valve Train ........... 4.35 
4.27 Type IV Valve Train Friction Reduction with Various

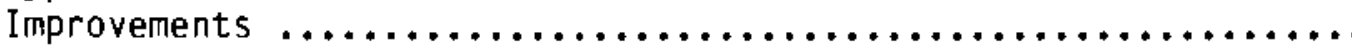

4.28 Effect of Improved Cam-Tappet Interface Lubrication on Type IV

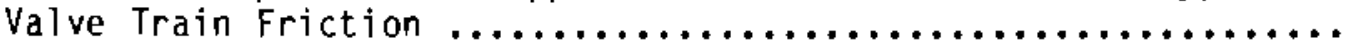

4.29 Effect of Valve Size on Friction, Economy, and Power ......... 4.38

4.30 Torques for Valve Train Contacts, Using a Modified SAE $300 i 1$ at $100^{\circ} \mathrm{C}$

4.31 The Effect of Roller Tappets and Rocker Arm/Fulcrum Needle Bearings on Friction

4.32 Design Features of Conventional and

Low Friction Valve Trains

4.33 The Effect of Needle Rearing Cam Journals and Roller Followers on Friction in the Ford 2.3L Engine

4.34 The Effect of Spring Load on Friction

4.35 The Effect of $0 i 1$ Viscosity and of a Friction Modifier on Friction

4.36 Types of Engine 0i1 Pumps

$4.370 i 1$ Pump Drive Requirements at 310 Pa Pressure, $99^{\circ} \mathrm{C}$

4.38 011 Pump Torque Reduction with Redesign

4.39 Bearings in a 6-Cylinder IC Engine

4.40 Engine Journal Rearing Load Diagran and Resulting

Eccentricity Locus

4.41 Distored Bearing Clearance Boundaries at $3000 \mathrm{rpm}$

4.42 Viscosity-Volatility Relationship

4.43 Average Fuel Economies During EPA City Tests with High and Low Viscosity Engine 0ils and Rear Axle Lubricants

4.44 Effects of Different VI Improvers and Viscosity Grades on Fuel

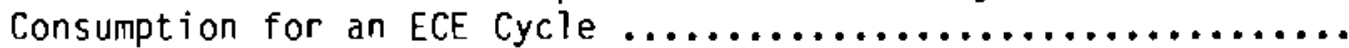

4.45 Cold Start Chassis Dynamometer Data $\ldots \ldots \ldots \ldots \ldots \ldots \ldots \ldots \ldots \ldots \ldots . \ldots \ldots 2$

4.46 Average Fuel Consumption Versus 0il Viscosity at $300^{\circ} \mathrm{F} \ldots \ldots \ldots .64$

4.47 Effect of Lubricating $0 i 1$ Viscosity on Gasoline Engines ....... 4.64 
4.48 Friction Versus 0il Temperature During Warm-up CFR-F4 Engine ... 4.64

4.49 Fuel Efftciency Details for EPA-FTP Tests .................4.67

4.50 Test Cycle for cold 5 tarts $\ldots \ldots \ldots \ldots \ldots \ldots \ldots \ldots \ldots \ldots \ldots \ldots \ldots \ldots \ldots .4 .68$

4.51 Effect of Engine 011 Viscostzy on Fuel Economy $\ldots \ldots \ldots \ldots \ldots \ldots \ldots .4 .69$

4.52 Relationship of Viscosity to 0 li Consumption Rate $\ldots \ldots \ldots \ldots \ldots \ldots$. 4.7

4.53 oiamler Benz nM 616 Cylinder Wear as Detected by Ratiotracer

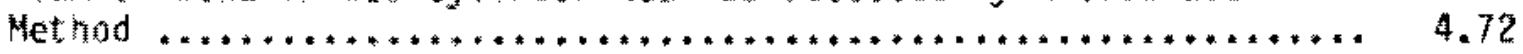

5.1 Energy Required by Passenger Car Components in EPA Cycle ...... 5.3

5.2. Allocation of Brake He Energy in a Passenger Cars for

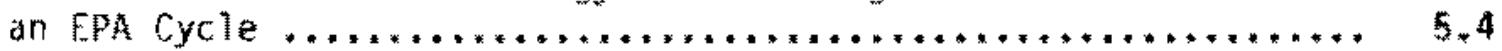

7.1 Installed USA Generating capability by principal Fuel Types *... 7.2

7.2 Categories of Plant Auxiliaries $\ldots \ldots \ldots \ldots \ldots \ldots \ldots \ldots \ldots \ldots \ldots \ldots \ldots \ldots, 7.4$

7.3 leat Rates for Large Coal-Fired plants .................. 7.7

.4 Equ valent Avallability of Fossil Units Over 400 Mis .......... 7.9

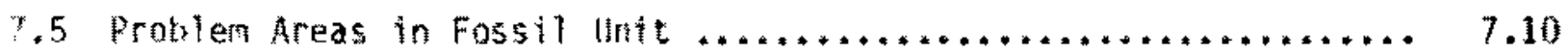

7.6 Yearly Outage Hours in Fossil Intts .................... 7.12

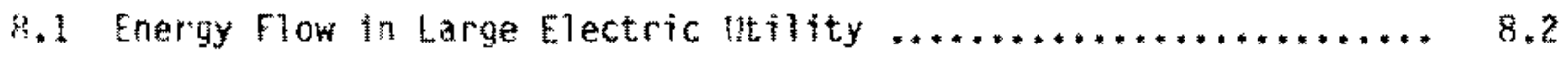

8.2 Energy Flow in Large Power Plant Excluding the

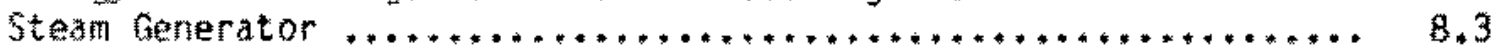

9.1 Tritologically Related Areas Affecting plant feliability ...... 9.1

9.2 Tribological Energy sinks in Turbomenerator Sets $\ldots \ldots \ldots \ldots \ldots \ldots .9 .3$

9.3 Approxinate l.oss in Stage Efficjency as a Function of

9.4 Gaspath Leakage in a Turbine Stage $\ldots \ldots \ldots \ldots \ldots \ldots \ldots \ldots \ldots \ldots \ldots \ldots \ldots .9 .7$

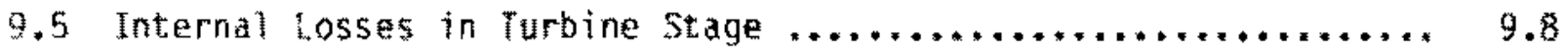

9.5 Internal 5tage Los ses in Large Turbogenerator Set ............ 9.9

9.7 Model of Labyrinth Seal .............................. 9.10

9.8 Bearing Arrangement on Large-Size Turbine $\ldots \ldots \ldots \ldots \ldots \ldots \ldots . . .9 .12$ 
9.9 Power Loss in Turbulent Bearings $\ldots \ldots \ldots \ldots \ldots \ldots \ldots \ldots \ldots . . \ldots .13$

9.10 Furnace Boiler Draft system ......................... 9.15

9.11 Mrect-Firing System for Pulverized Coal .................. 9.21

9.12 Lube 0il system schematic ............................. 9.26

9.13 Lift Pump System Schematic ............................. 9.27

9.14 Cumulative Forced Outage Megawatt-Hours due to
Contaminated 011 ...................................... 9.27

9,15 unbalance Response of a 350-4h Steam-Turbine and Generator linit ..................................... 9.28

9.16 oil Whirl Stability Characteristics of Three Rearing Designs .... 9.30

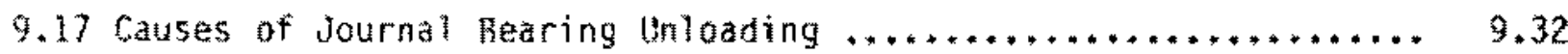

9.18 Effect of Steam Exciting Forces on Rotor Stability ............. 9.34

9.19 Schenatic Diagram of Signal Analysis Hethod ,................. 9.36

10.1 Energy Required by Turboset Components and Auxiliaries ......... 10.2

10.2 Low Powe Loss Journal Bearings .......................... 10.4

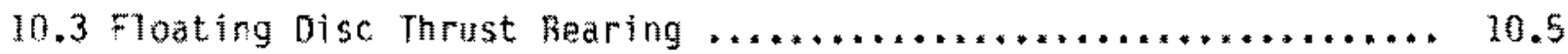




\section{TABLES}

E5.1 ECUT Surveys Revi ewed in this Sumary ...................... ii

ES.2. Primary Mechanisms in Friction Energy Losses and

Principal Materials Involved in Wear Energy Losses .............. v

E5.3 Estimate of Generic Tribology R\&D and Total Ro Budget for Representative Industrtes $\ldots \ldots \ldots \ldots \ldots \ldots \ldots \ldots \ldots \ldots \ldots \ldots \ldots \ldots \ldots \ldots \times \times$

S.1 Sumrary of Potential Savings in Automotive Tribological

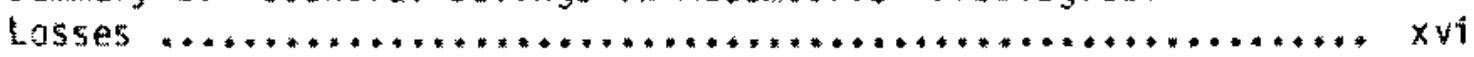

5.2 Sumary of Recommended Research and Development Programs Transportation Sector $\ldots . \ldots \ldots \ldots \ldots \ldots \ldots \ldots \ldots \ldots \ldots \ldots \ldots \ldots \ldots$ xwi

S.3 Summary of Potential Savings in the Electric Utflities .......... $x x$

S.4 Summary of Recomnended Research and Development Programs -

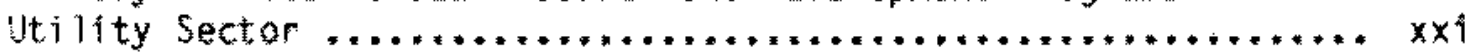

1.1 Autonotive statistics $\ldots \ldots \ldots \ldots \ldots \ldots \ldots \ldots \ldots \ldots \ldots \ldots \ldots \ldots \ldots, 1.2$

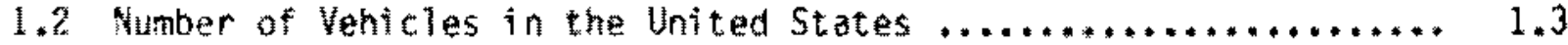

1.3 Mi les Traveled by Automotive Vehicles $\ldots \ldots \ldots \ldots \ldots \ldots \ldots \ldots \ldots, 1.8$

2.1 Energy Losses in Various Frictional Components $\ldots \ldots \ldots \ldots \ldots \ldots . .7$

2.2 Energy Losses in Various Mechanical Components at an EPA Cycle .........................................

2.3 Energy Losses in Various Mechanical Components ................ 2.13

2.4 Automotive Friction Components Small Front wheel Drive on EPA Cycle ............................................. 2.19

2.5 Pribological Energy Losses in EPA Cycle - Percent of Energy Input ....................................... 2.20

3.1 Comparison of Frictional Losses in Adiabatic and Míninum Friction Engi nes .................................... 3,18

3.2 Frictional Losses as Percentage of BHP for Adíabatic and Minimum Friction Engines

3.3 Advanced Diesel Engines and Energy Savings on Trucks and Buses 
3.4 Development Work on Gas Turbine Driven Automobile Vehicle

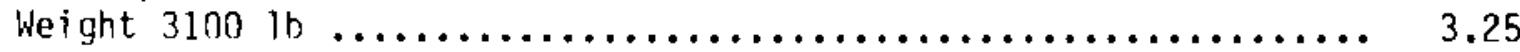

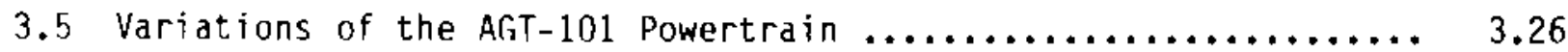

3.6 EPA Performance for GT and SI Automobiles ................ 3.26

3.7 Tribological Losses in AGT-101 Vehicle at $20 \%$ Power .......... 3.28

3.8 Energy Consumption in AGT Vehicles $\ldots \ldots \ldots \ldots \ldots \ldots \ldots \ldots \ldots \ldots . \ldots \ldots$

3.9 Friction Hp Power Savings with an

All Air Foil Bearing System .............................. 3.3

3.10 $2070^{\circ} \mathrm{F}$ Engine Configuration Ceramic Part Development Test

Results $1900^{\circ} \mathrm{F}$ Operating Conditions ........................ 37

3.11 DOE/NASA Specifications for Stirling Vehicles ............... 3.44

3.12 Performance of Stirling Engine Vehicle Engine Mod IA ......... 3.45

3.13 Performance and Mechanical Losses in Simulated Stirling Engine .. 3.48

3.14 Test Results for Two Stirling Engine Seals $\ldots \ldots \ldots \ldots \ldots \ldots \ldots \ldots . \ldots \ldots$

4.1 Energy Losses in Piston Assembiy ..................... 4.9

4.2 0il Film Temperatures Between Ring and Liner Estimated from Ring Temperatures and Local and Average Cylinder Liner

Temperatures .....................................

4.3 Maximum Temperature of Bil Film at Top Ring Travel Exposed to Combustion Gases ................................ 4.12

4.4 Parameters Affecting Piston Assembly Friction ............. 4.15

4.5 Effects of $0 i l$ Viscosity and Speed on Friction Loss .......... 4.39

4.6 Effect of Substituting Rolling for Sliding Contacts ......... 4.42

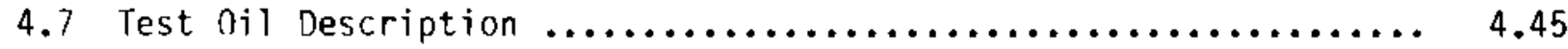

4.8 Energy Consumed by Braking $\ldots \ldots \ldots \ldots \ldots \ldots \ldots \ldots \ldots \ldots \ldots \ldots \ldots . . \ldots \ldots$

4.9 Fuel Economy Improvements with Low Viscosity Lubricants ....... 4.56

4.10 EPA Fuel Economy Improvements with Low Viscosity Lubricants .... 4.56

4.11 Automotive Efficiency as Function of Lubricant Properties for an EPA Cycle ............................... 4.58 
2.12 Viscosity Influence on Relative Fuel Econony -

Individual Vehicles ....................................... 4.60

4.13 Viscosity Influence on Relative Fuel Economy -

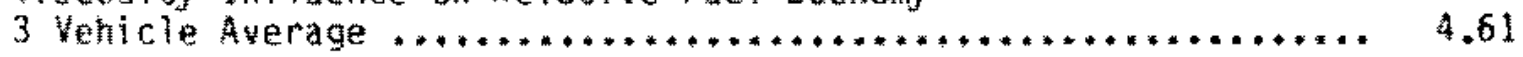

4.14 Viscosity Infivence on Relative Fuel Economy -

Identical vehicies . $\ldots \ldots \ldots \ldots \ldots \ldots \ldots \ldots \ldots \ldots \ldots \ldots \ldots \ldots \ldots \ldots \ldots \ldots \ldots \ldots \ldots \ldots .4 . \ldots 1$

4.15 Typical Fuel-Consumption Ratios as Related to 011

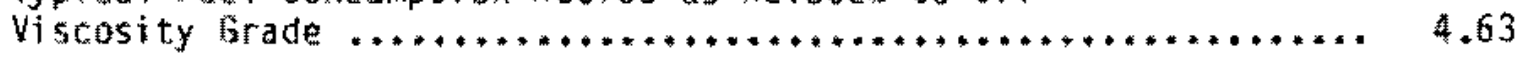

4.15 Efficiency Gains as Function of oll Properties ............. 4.65

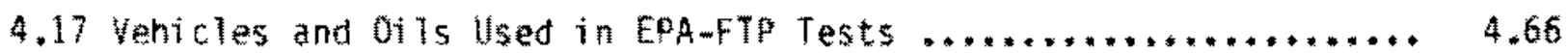

4.18 Improvement in Constant Speed Fuel Economy ................ 4.68

4.19 Effect of Friction Modifier an Fuel Economy Obtained with Two

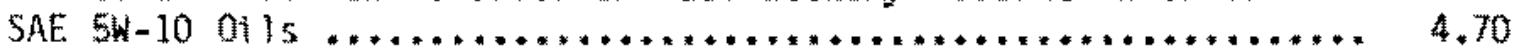

4.20 Eneray Consumed by Tires for an EPA Cycle $\ldots \ldots \ldots \ldots \ldots \ldots \ldots \ldots \ldots, 4.73$

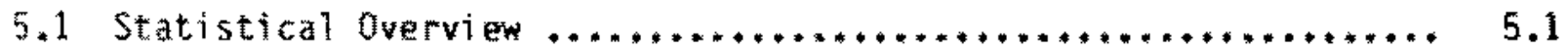

5.2 Reduction of Tribological Losses in Piston Assembly .......... 5.6

5.3 Potential Savings in Automotive Piston Assembly ............. 5,8

5.4 Potential Savings from Lowering 0il Viscosity and Adding

5.5 Summary of Potential savings in Automotive Tribological

Lossts. ................................................ 5.13

5.5 Sumnary of Potential Savings with Non-Conventional Engines ...... 5.14

6.1 Summary of Recommended Research and Development. Programs -

7.1 Enercy Consumed by Electric Jthlities, $1 n^{15}$ Btu $\ldots \ldots \ldots \ldots \ldots \ldots .7 .2$

7.2 Kind of Fuel Used by the Utilities, of Total $\ldots \ldots \ldots \ldots \ldots \ldots \ldots \ldots 7.3$

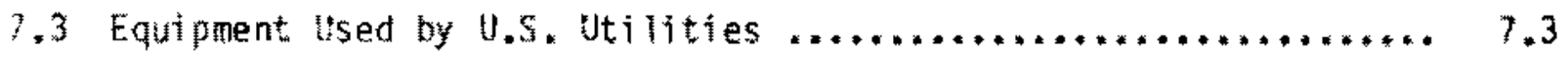

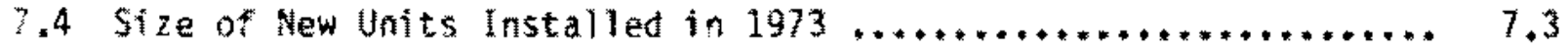

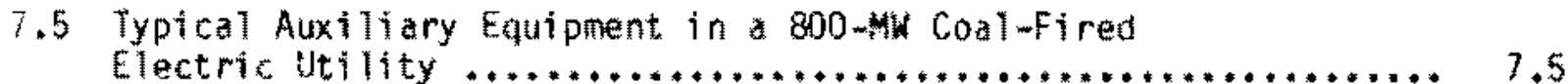


7.6 Coal-Burning Steam Power Plants for 1973-1978 ...*............ 7.8

7.7 Tritologically Related Causes of Outages $\ldots \ldots \ldots \ldots \ldots \ldots \ldots, 7.13$

8.1 Power Required by Accessortes in an 800-Mh Coal-Fired

Utility plant $\ldots \ldots \ldots \ldots \ldots \ldots \ldots \ldots \ldots \ldots \ldots \ldots \ldots \ldots \ldots \ldots \ldots \ldots, 8.4$

9.1 Fluid Film Rearing Losses in Utilities .................... 9.13

9.2 Summary of Centrifugal Fan Problem Areas According to Apptications ............................................ 9.16

9.3 Lost Generation in Fans Due to Different Pearing and

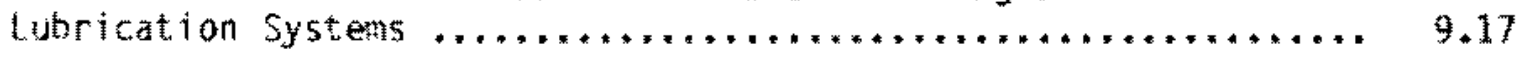

9.4 Lost Generation Attributed to Bearings and Lubrication System for All Fans in Survey ................................... 9.18

9.5 Functional and Design Parameters of Main Boiler Feed Pumps ..... 9.19

9.5 Cost of Lost Reneration Due to Feedwater Pump Problems at Nuclear and fossil lienerating Stations ........................ 9.20

9.7 Punp Faiture Rankings $\ldots \ldots \ldots \ldots \ldots \ldots \ldots \ldots \ldots \ldots \ldots \ldots \ldots \ldots, 9.20$

9.8 Causes of Pulverizer System Breakdowns $\ldots \ldots \ldots \ldots \ldots \ldots \ldots \ldots \ldots, 9.22$

9.9 Pulverizer Problem Areas on a Station Basis ................ 9.24

9.10 Dynantes of Low-Pressure Steam Turbine with Loss of a LastStage Blade ......................................... 9.29

10.1 Savings with the New Journal Bearings $\ldots \ldots \ldots \ldots \ldots \ldots \ldots \ldots \ldots . . . \ldots 10.5$

10.2 Savings with the New Thrust Bearings $\ldots \ldots \ldots \ldots \ldots \ldots \ldots \ldots \ldots . \ldots .6$

10.3 Sumary of Potential Savings in the Electric Utflities ......... 10.7

11.1 Sumary of Recommended RBD Programs--lltility Sector ............ 11.2

12.1 Tribology programs Pursued by gAM in West Germany ............ 12.5

13.2 Percentages of Papers Published in Various irtbological Areas During 1977/78; horldwi de Sample of 9000 Papers ............. 12.6 
PART :

AUTOMOTIVE VEHICLFS 


\subsection{AUTOMOTIVE STATISTICS}

Although the econonic sector under consideration here is that of transpottablon, the scope of the study is actualy restricted to highway vehicles.m passenger cars, buses and trucks tsee Work Statement in Appentix A). This leaves out alroraft, trains and seagoing vesse 15 , but as Table 1.1 shows, in terms of energy consumption, automotive vehicles consume $77 \%$ of the total and thiss an impravenent in this domain would have decisive effect. Furthermore,

- Afrplane fuel consumption per passenger-ride ts decreasing under competitive pressure and also because it constitutes one-third of the cotal cost of operation.

- The of mroad englnes and vericles will automatically benafit from the highway vehicle advances.

\section{I TH: NITHWAY FLEET}

The ulthate goal of realizing energy savings in the automotive vehicle has muty to with the statistatcal pattern characteristic of the distribution, usage, and practices prevalling in the field. The typical average length of a wehicle's journey, the amount of traveling done in cold and hot periods of the year, and even the driving habits of driversmall have a say as to the direction ant the prospects of achieving the desifed energy savings. Thus, this hrief staction contains some of the bastic data on automotive statistics in the 1. .8 ,

Tables 1.1 and 1.2 and Figures 1.1 through 1.4 provide some relevant data on the pattarn of fuel consumption by the automotive vehicle in the U.S. On the bas"s of the infomation contained in these sources, one can state the foll thit:

- In 1976, the relative distribution of the nunber of passenger cars, trucks, and buses was as follows: 
TABLE 1.1. Autonot ive Statistics $(1976)(3)$

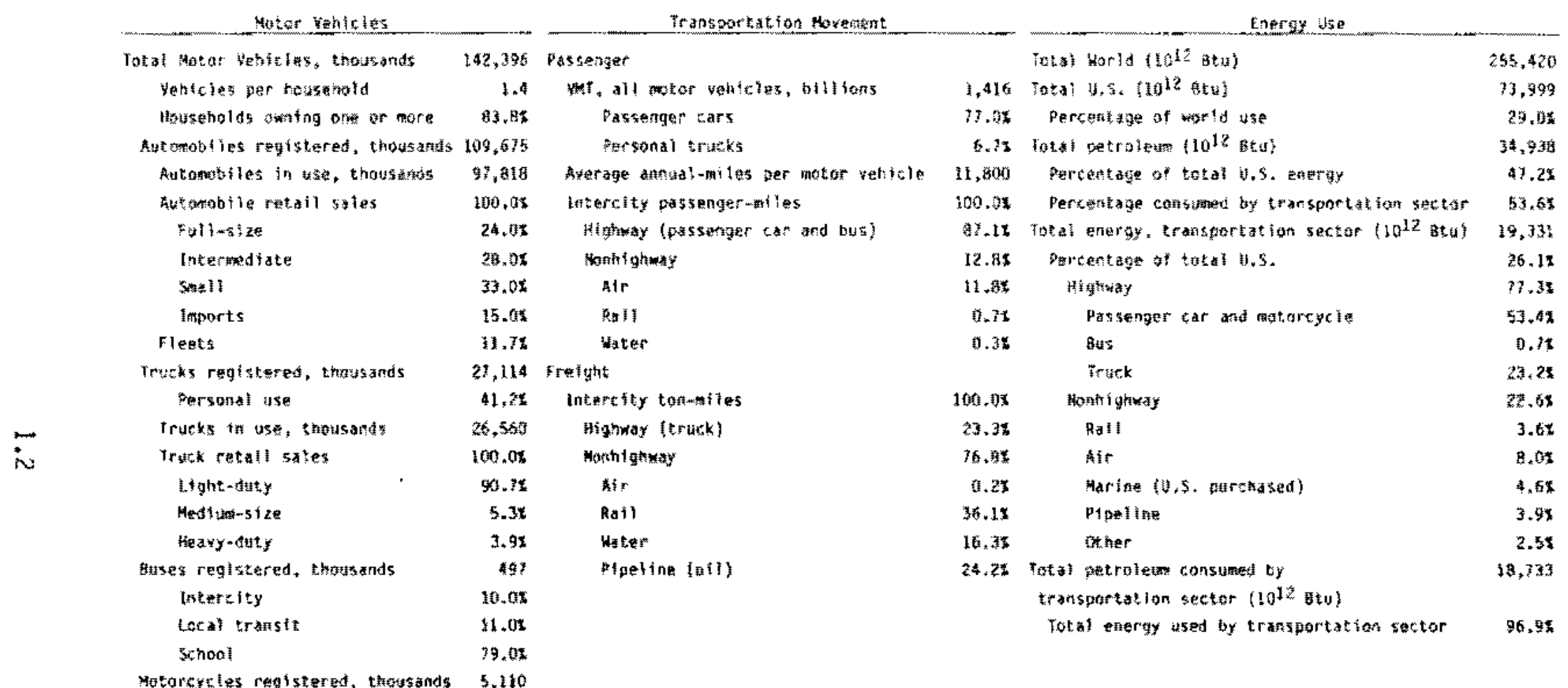





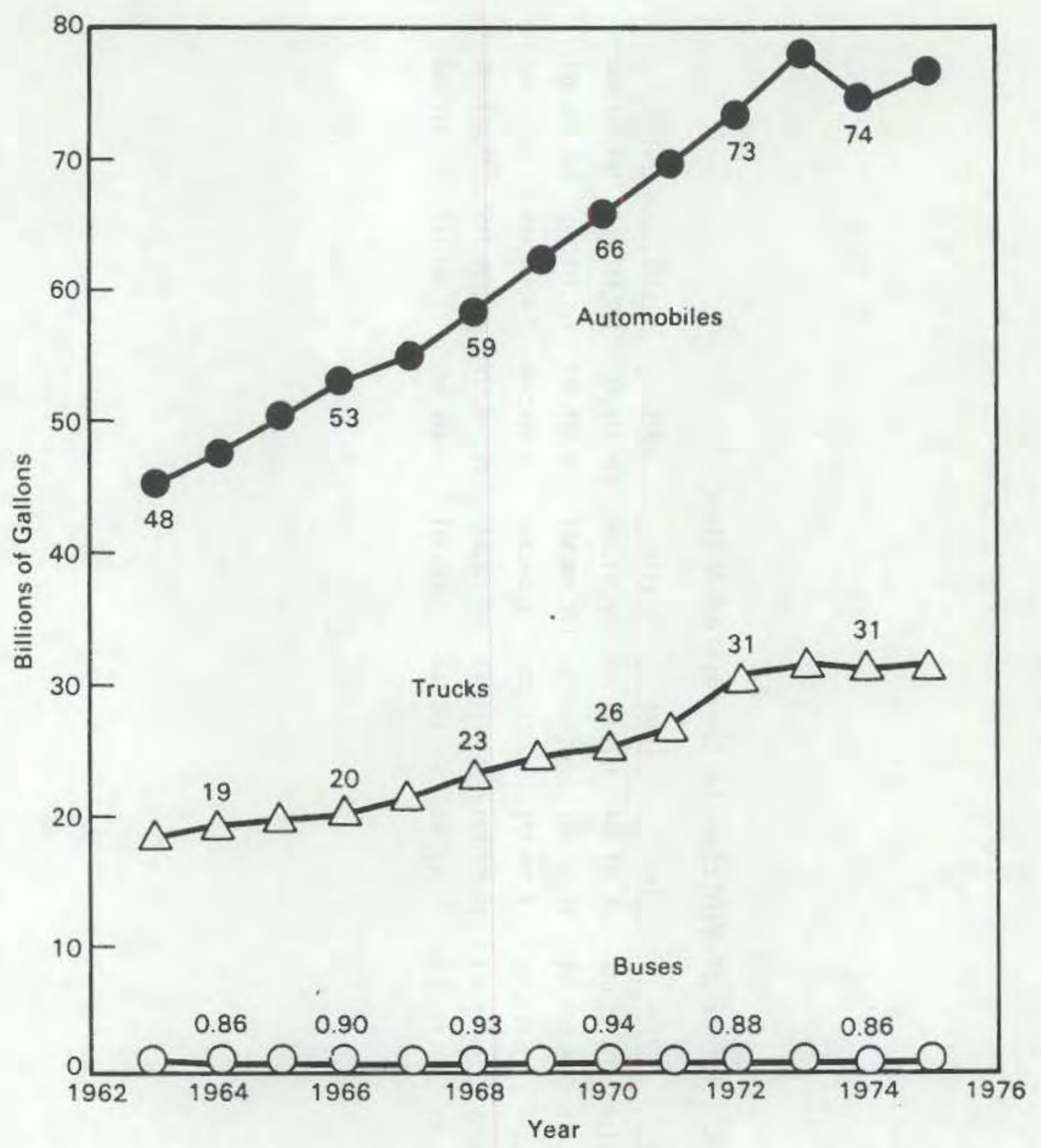

FIGURE 1.1. Total Annual Fuel Consumption by Type of Vehicle ${ }^{(3)}$

$\begin{array}{ll}\text { Passenaer cars } & -77 \% \\ \text { Trucks } & -19.5 \% \\ \text { Buses } & -3.5 \%\end{array}$

- Over the decade preceding 1976, the total consumption of fuel by the automotive vehicle rose by $50 \%$. The increase was roughly the same for passenger cars and trucks, while the consumption by buses remained minimal and constant. 


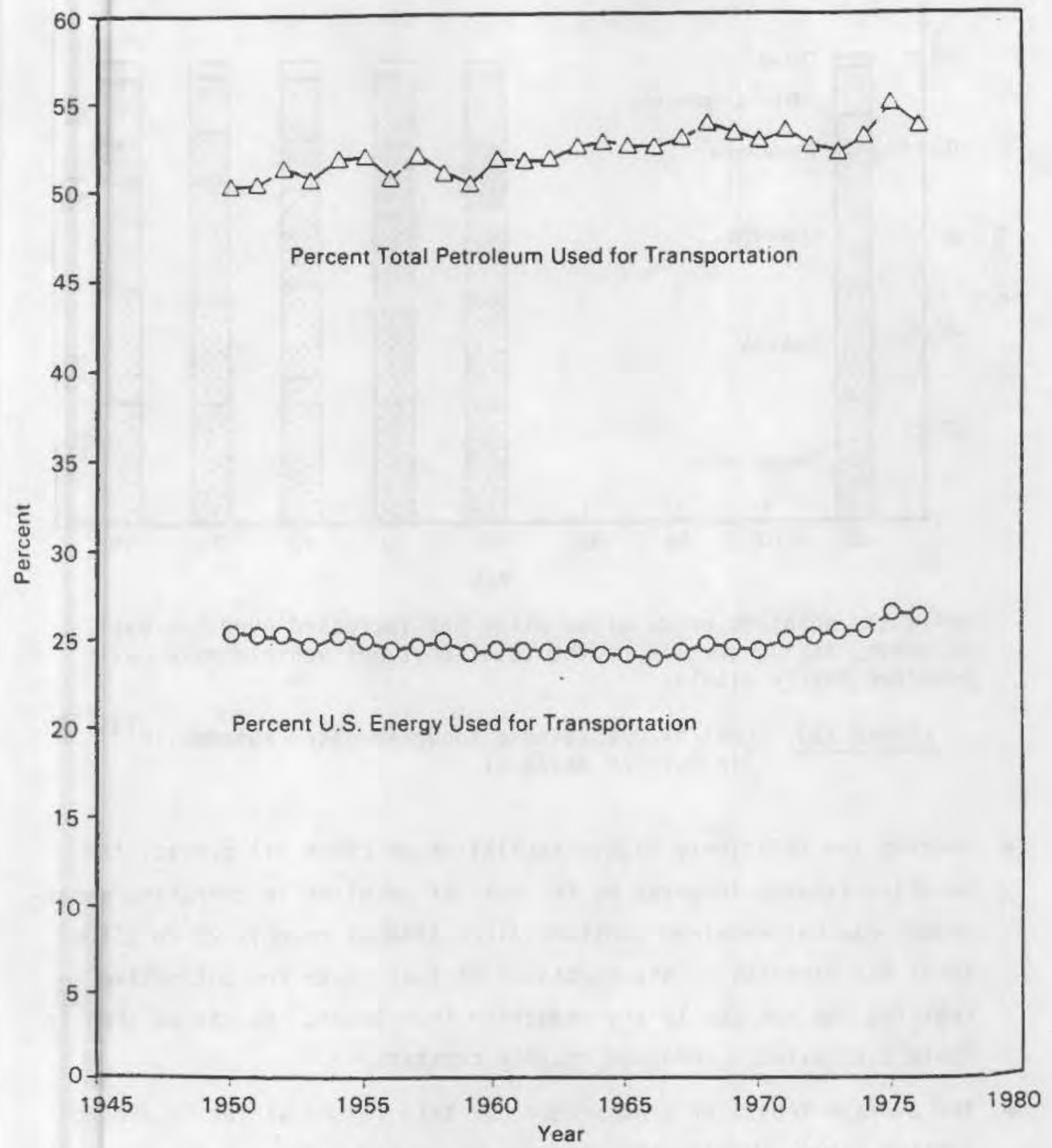

FIGURE 1.2. Energy Use by Transportation (3)

- In terms of the percentage of either the total energy or the total oil quantity used by the U.S. economy, the renuirements of transportation remained constant for the last 30 years; total energy share amounted to 25 to $26 \%$, oil consumption stayed at 52 to $54 \%$. 


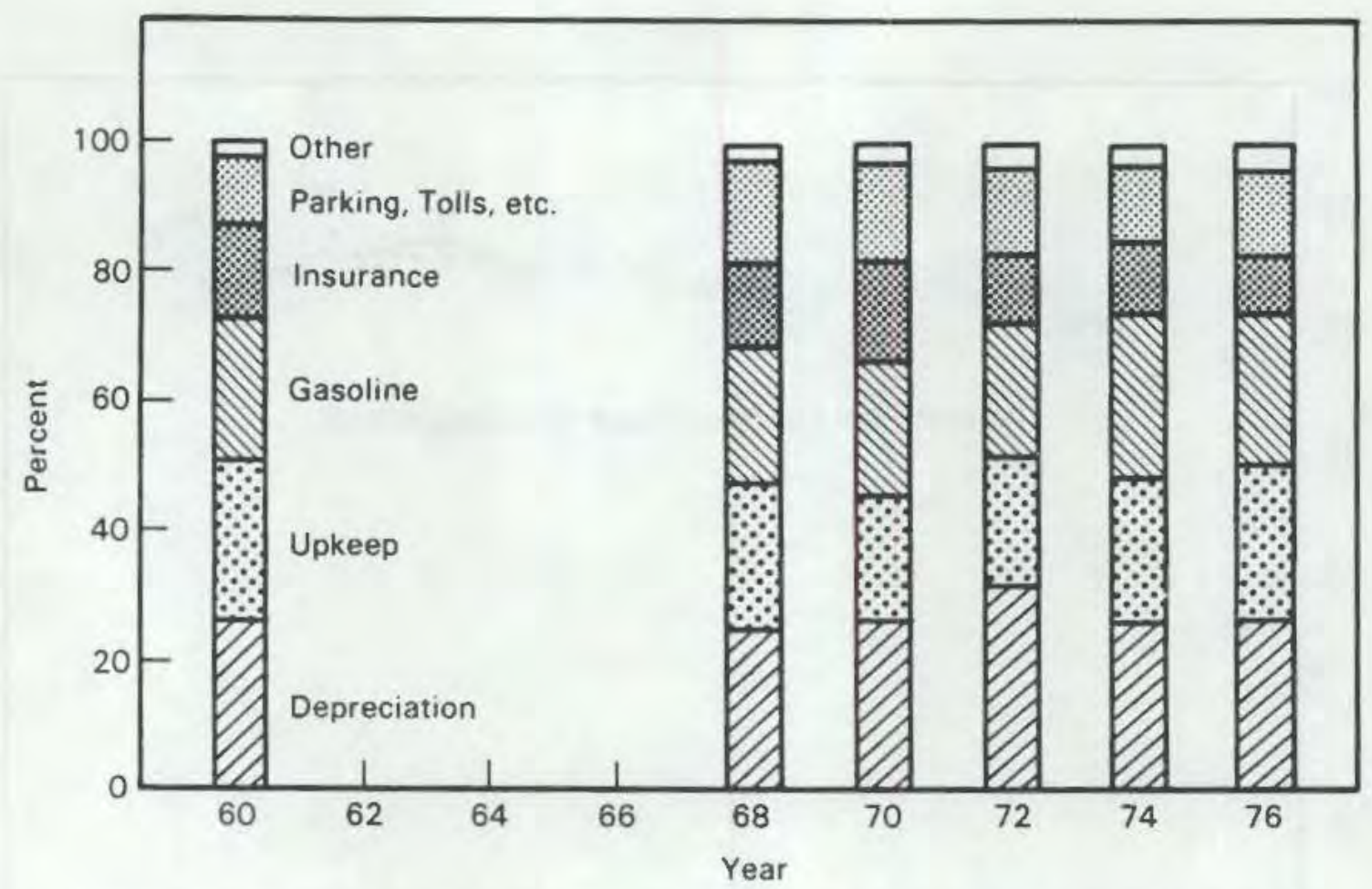

While the absolute price of gasoline has increased over the past 15 years, its proportion of the total cost per vehicle mile has remained fairly stable.

FIGURE 1.3. Cost of Operating a Suburhan-Based Automobile ${ }^{(3)}$ (in current dollars)

- Despite the relatively higher escalation of crude oil prices, the relative expense incurred by the cost of gasoline in operating a passenaer car has remained constant since 1960 at roughly 20 to $25 \%$ of total car expenses. This constancy of fuel costs for automotive vehicles was not due to any reduction in mileage. As can be seen in Table 1.3 , mileage remained roughly constant.

- The average length of a passenger car trip in the winter is around 8 miles versus 10 miles for the summer period. The amount of traveling mileage done during the three winter months is about $22 \%$ of the total yearly mileage.

\subsection{THE EPA CYCLE}

Much of the discussion about the efficiency and performance of automotive vehicles refers to a standard designated as the EPA cycle. The specifications 


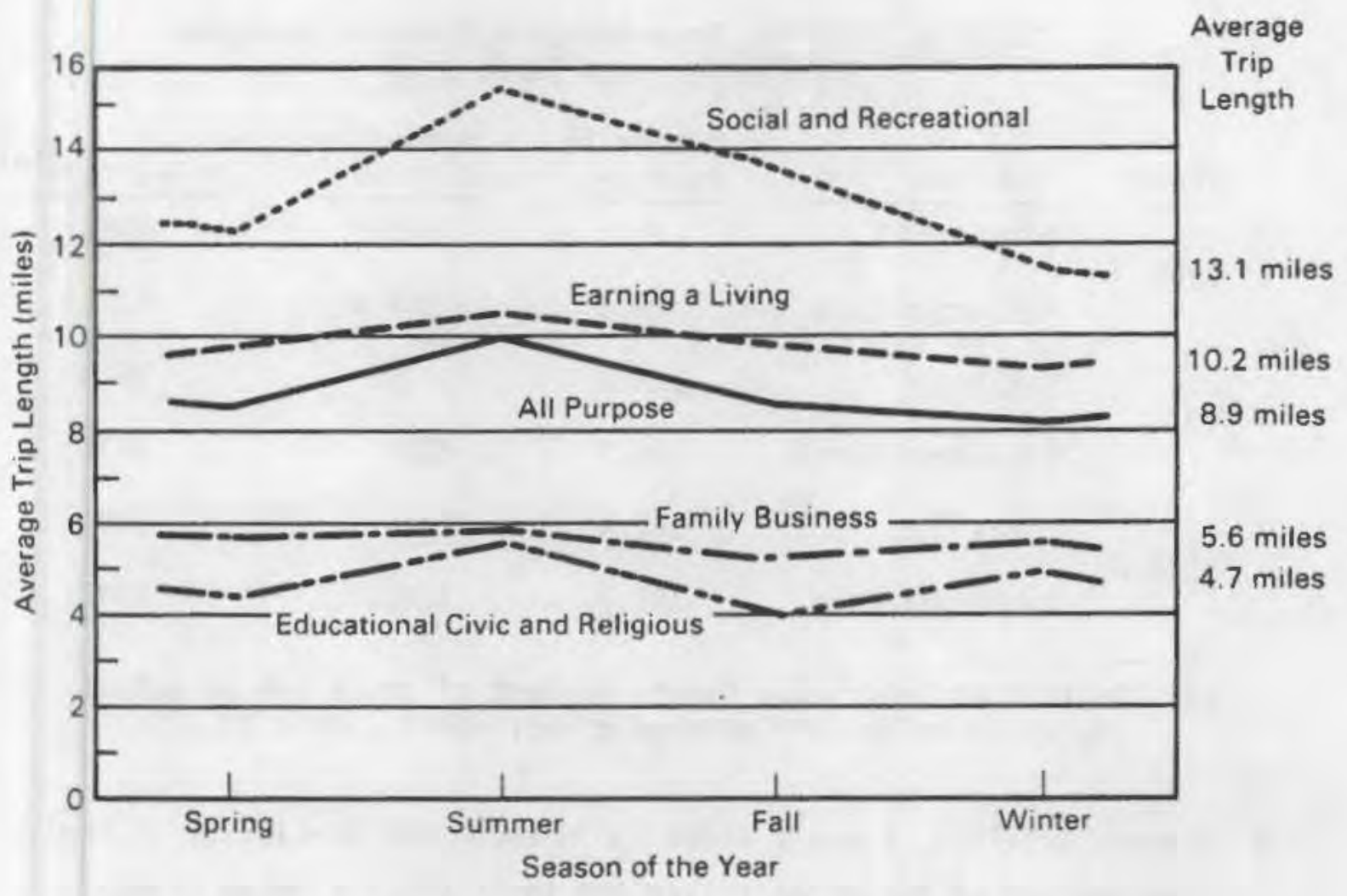

\begin{tabular}{|l|r|c|r|r|}
\hline & Spring & Summer & Fall & Winter \\
\hline Average trip length (miles) & $8.5 \%$ & 10.1 & 8.7 & 8.3 \\
$\begin{array}{l}\text { Distribution of total trips } \\
\text { (percent) }\end{array}$ & $26.9 \%$ & 24.8 & 25.0 & 23.3 \\
$\begin{array}{c}\text { Distribution of VMTs } \\
\text { (percent) }\end{array}$ & $25.6 \%$ & 28.2 & 24.4 & 21.8 \\
\hline
\end{tabular}

FIGURE 1.4. Average Automobile Trip Length by Purpose of Trip and Season $(3)$

of this driving cycle, which are supposed to reflect an "average" mode of traveling under both urban and highway conditions, are as follows:

- Urban Driving: Average speed $31 \mathrm{~km} / \mathrm{hr}(19.2 \mathrm{miles} / \mathrm{hr}$ ) with maximum speed of $93 \mathrm{~km} / \mathrm{hr}(57.7 \mathrm{miles} / \mathrm{hr})$. Thirty-eight percent of the urban driving cycle is spent on idling or under closed-throttle deceleration. Of the total miles driven, $55 \%$ are spent in the urban mode. 
TABLE 1.3. Miles Traveled by Automotive Vehicles

(reworked from Table 1.1)

\begin{tabular}{|c|c|c|c|c|}
\hline Year & Vehicles (a) & $\begin{array}{l}\text { Number in } \\
\text { Millions } \\
\end{array}$ & $\begin{array}{l}\text { Number in } \\
\text { Billions }\end{array}$ & Miles/Year (a) \\
\hline \multirow{2}{*}{1965} & Total & 91.7 & 888 & 9684 \\
\hline & Passenger Cars & 75.3 & 706.4 & 9381 \\
\hline \multirow{2}{*}{1975} & Total & 138.0 & 1330 & 9640 \\
\hline & Passenger Cars & 106.7 & 1028 & 9634 \\
\hline \multirow{2}{*}{1976} & Total & 142.4 & 1416 & 9940 \\
\hline & Passenger Cars & 109.7 & 1090 & 9940 \\
\hline
\end{tabular}

(a) Registered Vehicles. Ninety percent of these are in actual use which raises the average miles/year to about 11,000 .

- Highway Driving: Average speed is $78 \mathrm{~km} / \mathrm{hr}(48.4 \mathrm{miles} / \mathrm{hr})$. Fortyfive percent of the miles driven are spent under highway conditions. Inling extends only over $8 \%$ of the highway driving cycle.

The specific time-speed relationships over the two driving cycles are given in Figure 1.5. While this seems a reasonable pattern of driving, it leaves out a number of very important elements which enter the notion of a representative driving pattern. As will be seen in later discussions, the EPA cycle is not considered by the automotive industry to be a valid model for measuring and judging automobile performance. Moreover, it does not provide a valid base for quantifying the levels of energy loss and possible economics in the operation of automobiles. The problem of cold starts can be mentioned as one such important factor. The energy expended on the frequent starts of an engine during cold periods is a substantial portion(a) of the total frictional energy consumption, yet the EPA cycle does not reflect this element of car operation. Similarly, there are other features of car operation which escape

(a) This has not yet been quantified, but automotive engineers agree that it is substantial. 


\subsection{CONVENTIONAL OTTO CYCLE ENGINES}

A cross-section of a typical four-stroke 0tto cycle engine is shown in Figure 2.1. The 0tto engine is now over 100 years old, and up to the present date it remains the dominant prime mover for automotive vehicles. Most passenger cars operate on this conventional engine and al though many attempts have been made over the last 40 years to replace it with a gas turbine or electric batteries--the conventional engine remains in the forefront in the automotive industry. And today, too, alternate candidates do not have enough of an edge, either in cost, efficiency, or structural simplicity, to offer serious competition to present-day ntto cycle engines. It seems likely that this will remain the situation in the foreseeable future. For this reason, the bulk of this study has concentrated on the characteristics and possible energy-saving techniques for this basic engine and its associated power-train.

The only other type of power plant in major use primarily in trucks and buses is the diesel engine. In passenger cars, the place occupied by the diesel engine is, according to Wards Engine Update, ${ }^{(6)}$ given by the following statistics:

\begin{tabular}{cc} 
Year & $\begin{array}{c}\text { Diesels Sold as Percent } \\
\text { of Total Car Sales }\end{array}$ \\
\cline { 2 - 2 } 1981 & 6.0 \\
1982 & 4.6 \\
1983 & 2.5
\end{tabular}

Thus, as seen, the percentage is small. Moreover, it is declining at a fairly steep rate. The diesel engine is discussed in Section 3.0 along with several other novel concepts of automotive engines.

\subsection{ENGINE CHARACTERISTICS}

The first step in evaluating the potential for eneray savings is to have an inventory of the energy consumption pattern in an automotive vehicle. Since our interest here is in the tribological components of the engine and drive 


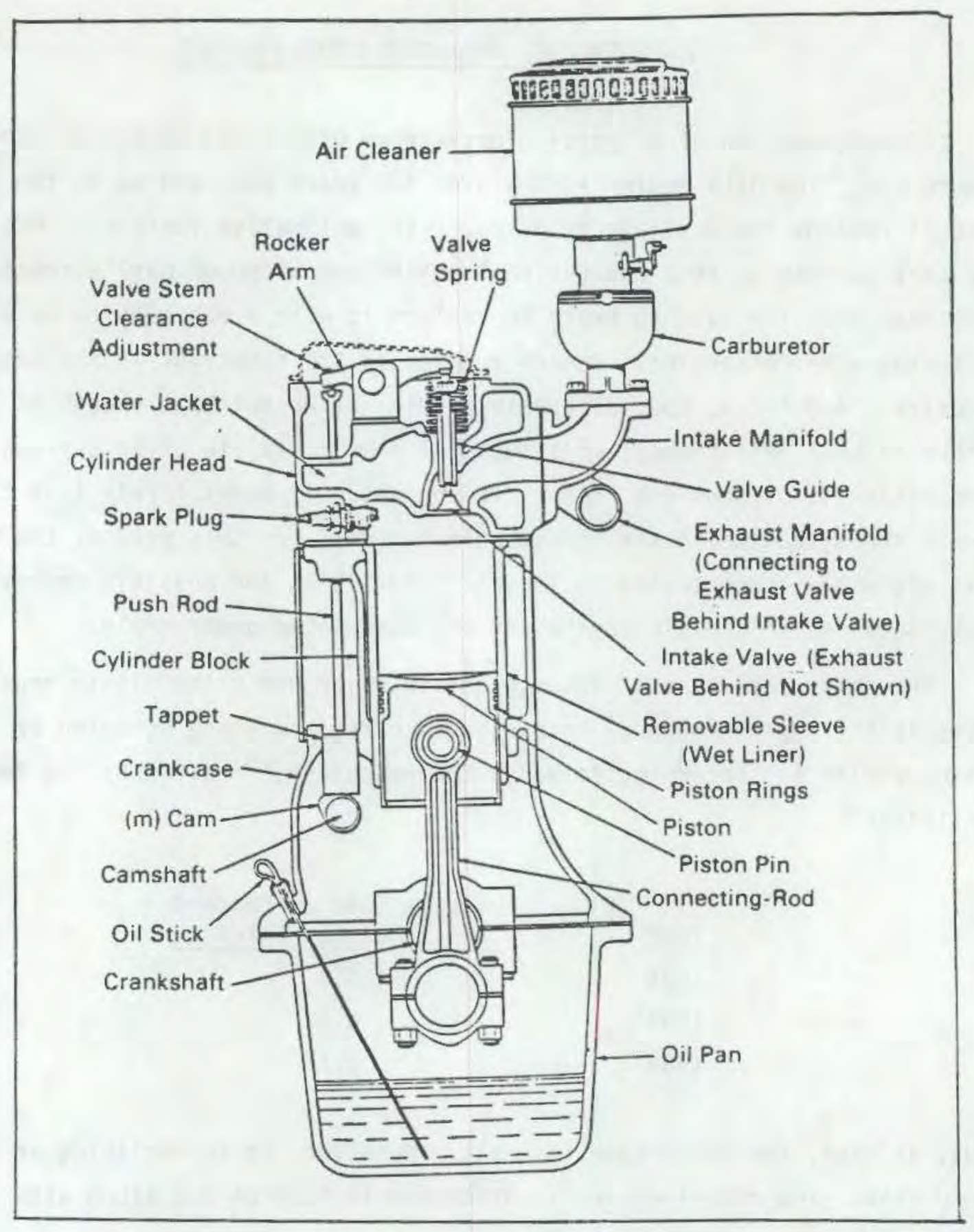

FIGURE 2.1. Basic SI Engine Unit ${ }^{(5)}$

train, and since these most of ten are themselves but parts of engine and chassis components, it is clear that it is mandatory to have as detailed a flow tree as possible. A major difficulty here lies in the fact that such detailed data are not always available or known. Another is that it is not always 
possible to talk about a single set of numbers. As Figure 2.2 shows, the efficiency of an engine is a function of both speed of the engine and of its road load, and of course, also of the size and make of the engine. The figure is a plot of brake thermal efficiency contours of the engine as a function of load and speed over its entire operating range. Constant thermal efficiency lines roughly parallel the full throttle power line. The engine power and speed renuired for constant speed operation on a level road is shown for reference. of course in normal driving, the engine operating point varies widely. The variatinn of engine speed as related to a three-speed transmission is shown in Figure 2.3. Acceleration or grades cause it to be above the engine load line and deceleration below. It is thus clear that at light loads the engine operates in a relatively inefficient regime. While the efficiency, that is, the useful hp, varies with speed and load, the frictional losses are much less affected by a variation in load. Thus, as seen in Figure 2.4, while at part load and $1500 \mathrm{rpm}$, the frictional $\mathrm{hp}$ is some $15 \%$ of the bhp, at $5500 \mathrm{rpm}$ the two items are nearly equal.

Because of the complexity of engine operating regimes, the general approach here will be to relate the analysis either to what is called "road conditions" or to the EPA driving cycle. No attempt is made to map the detailed energy flow for various driving cycles since, as discussed in Section 2.2, there does not as yet exist a statistically valid or representative driving cycle. Until a statistically valid study is made to determine automotive usage in the U.S. in terms of speed, load, climate, number of starts and stops and other pertinent parameters, the EPA cycle or a reasonable road load will be used as a basis for discussion.

Data on the energy losses in different components of an engine are usually obtained not from functioning engines under "firing" conditions, but from socalled "motoring" tests. In motoring tests the contribution of each component is determined by its selective removal. This test procedure does not duplicate the actual combustion forces, the temperatures, nor certain inertia forces, that are present during normal engine operation. However, these tests are useful on a relative basis in determining component friction and the effects of engine friction on overall engine performance. 


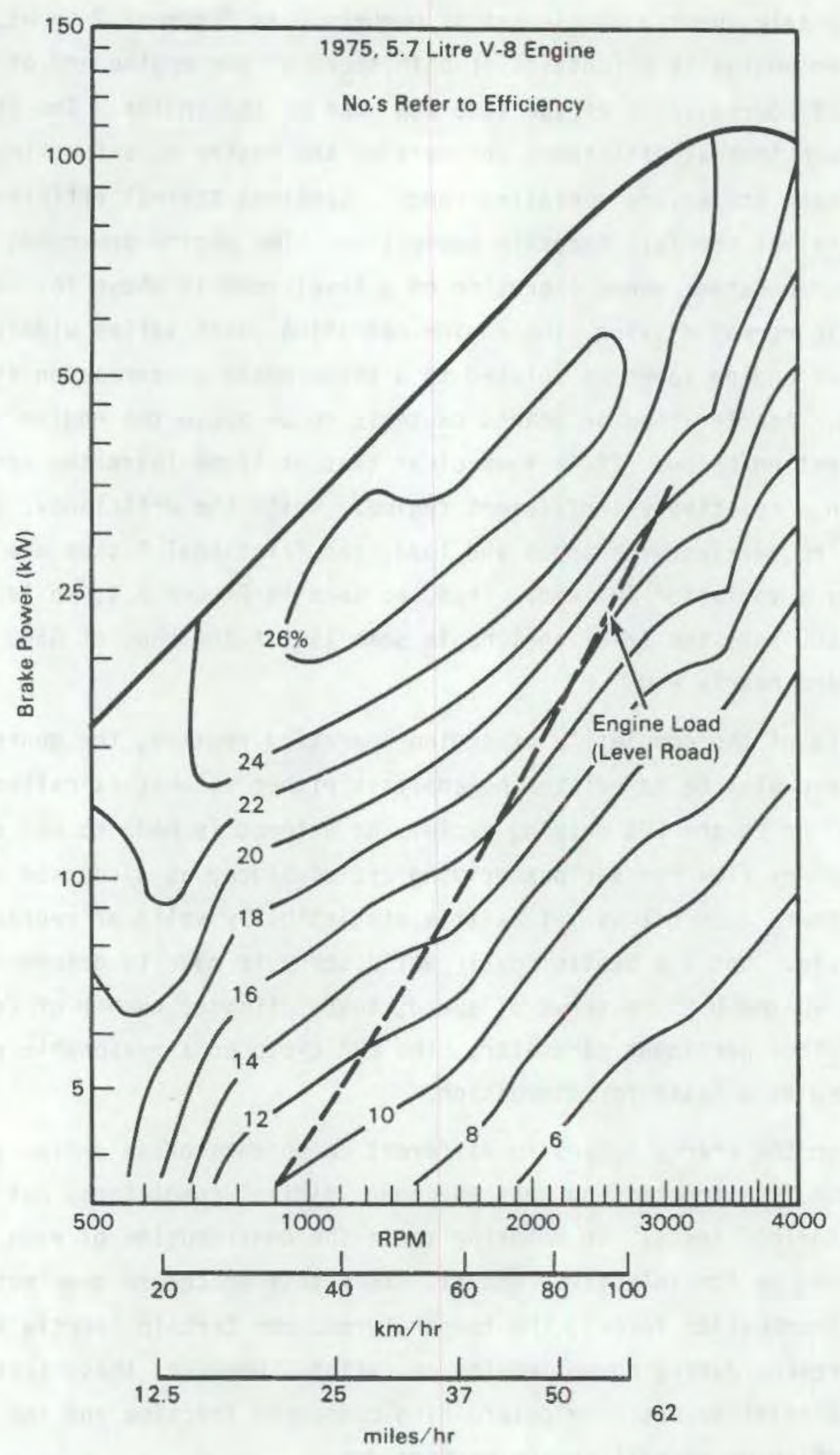

FIGURE 2.2. Brake Horsepower Thermal Efficiency as Function of Speed and Load $(7)$ 


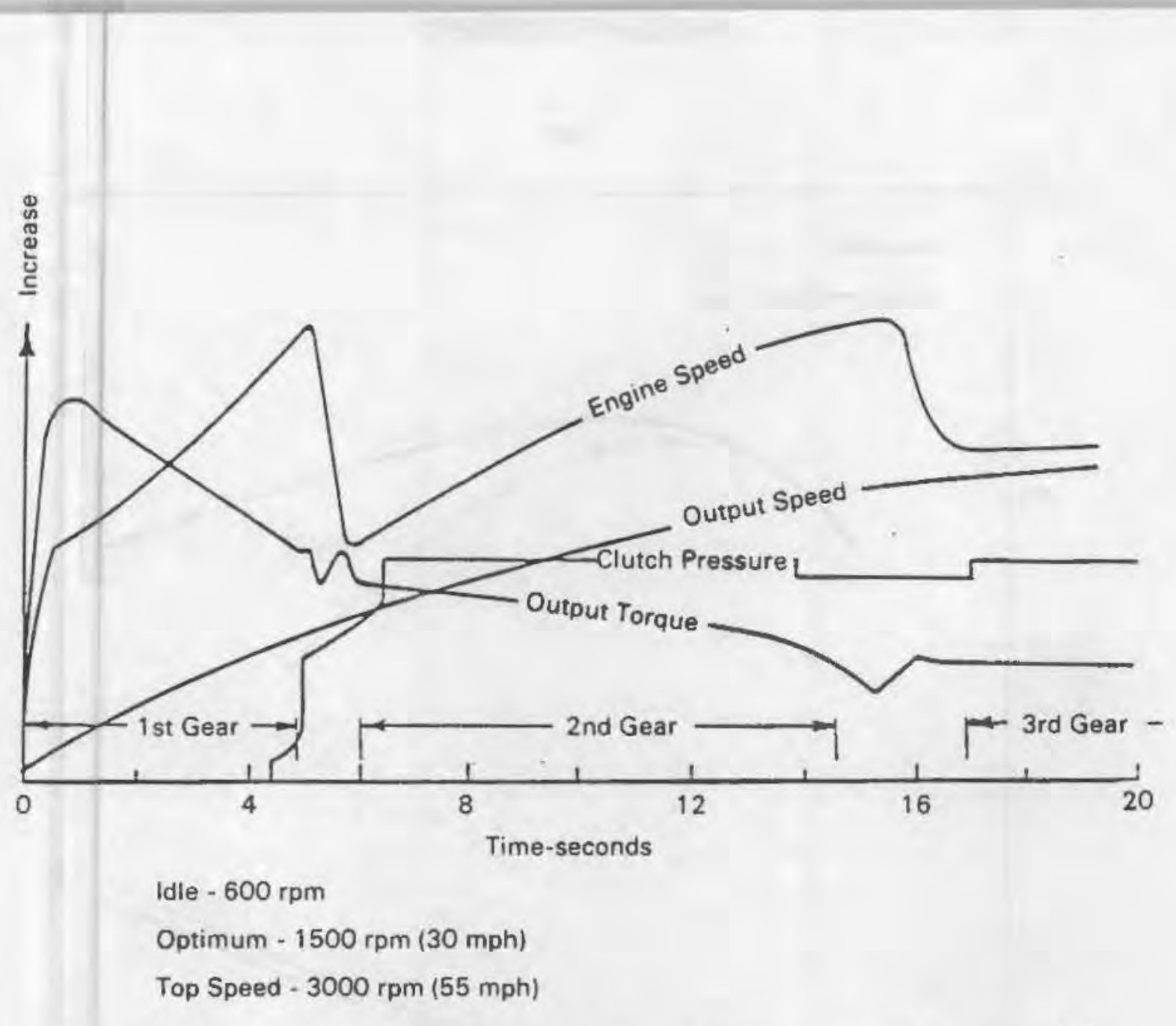

FIGURE 2.3. Events During 3-Speed Transmission Upshift Sequence ${ }^{(8)}$

\subsection{TRIBOLOGICAL ENERGY SINKS}

In addition to the range of engine speeds and load conditions, one of the difficulties in setting down specific numbers is, the variety of sizes and makes of automobiles. References 7 through 14 all provide an accounting of the energy distribution. However, they are all for different vehicles and none of them are complete, or uniform. Since much of the data contained in these references are reworked to provide input for an energy flow chart, brief mention will be made here of the vehicle and operating conditions on which these references have based their data.

\subsubsection{Spectrum of Engines}

Fairly extensive data on components losses were obtained by Bishop of Ford Motor Company. (9) The data were taken from dynamometer tests run on 4-, 6-, 


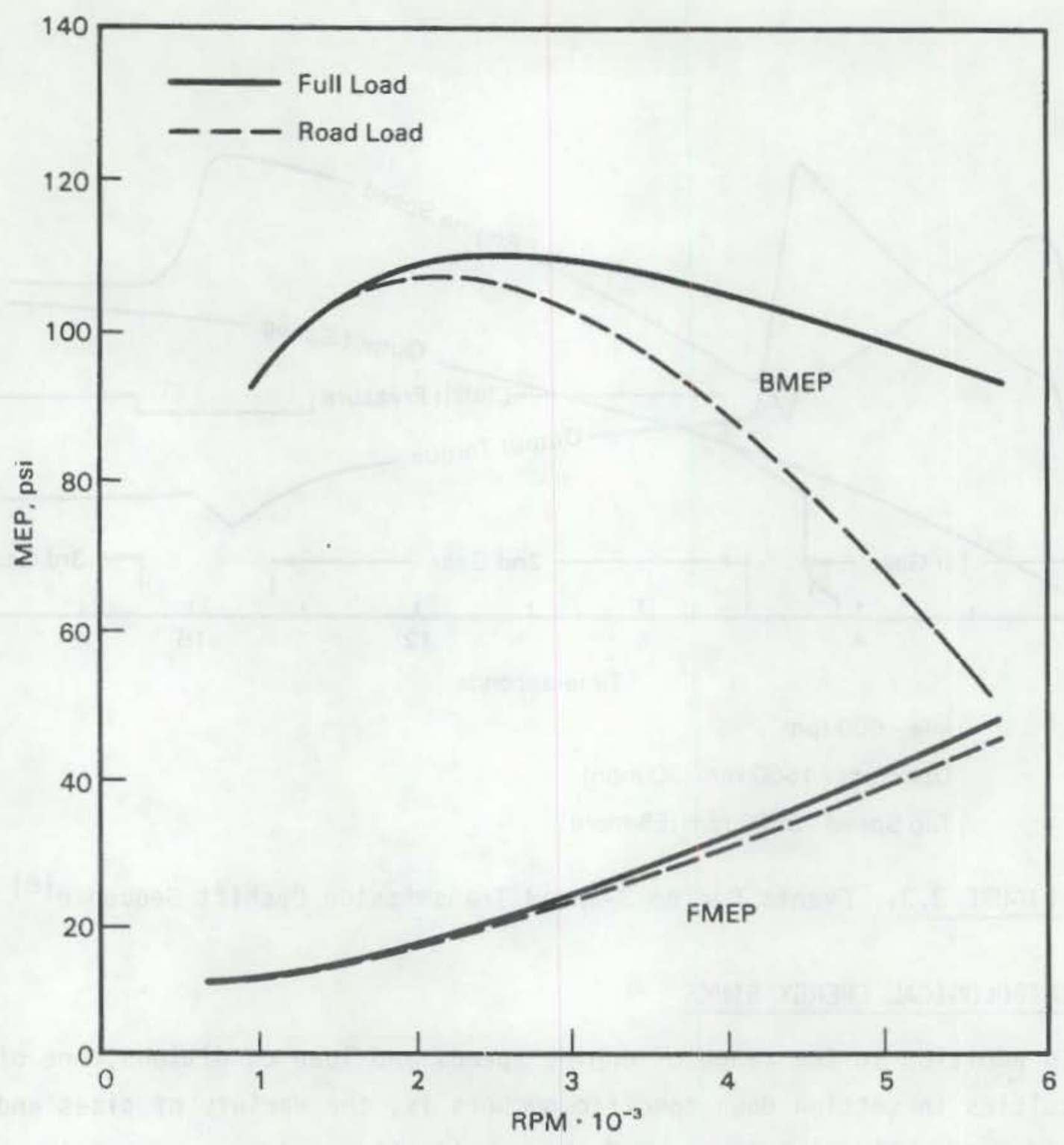

FIGURE 2.4. Brake and Frictional MEP in a Passenger Vehicle ${ }^{(9)}$

and 8-cylinder engine configurations ranging from $4: 1$ to $17: 1$ compression ratios and 0.75 to 2.5 bore/stroke ratio. Displacements ranged from 24 in. $^{3}$ to 125 in. ${ }^{3}$ per cylinder. The previously given Figure 2.4 from this work shows the following:

\begin{tabular}{|c|c|c|c|}
\hline Engine rpm & FMEP & BMEP & (FMEP/BMEP) \\
\hline 1500 & 16 & 107 & $15 \%$ \\
\hline 3000 & 26 & 103 & $25 \%$ \\
\hline
\end{tabular}


The items included here under friction are:

- Pumping - loss due to pumping of gases past the valves and combustion chamber

- Throttling - intake and exhaust losses

- Blowby - leakaqe past piston

- Crankcase - losses in bearings and seals, valve gear friction, and pump losses

- Viscous Piston Friction - friction caused by viscous forces between skirt and piston rings and the cylinder walls

- Non-Viscous Piston Friction - friction caused by the gas pressure and ring tension forces.

With these definitions, Table 2.1 is a reworking of the data given in Reference 9 showing the percentages of energy consumed by the six friction components. The range of these losses for an automobile operating under normal road conditions is given in Figure 2.5.

\section{TABLE 2.1. Energy Losses in Various Frictional Components}

$$
\text { (Wide Spectrum of Engines) }
$$

\begin{tabular}{|c|c|c|c|c|c|}
\hline \multicolumn{2}{|r|}{ Component } & \multicolumn{2}{|c|}{$\frac{\text { Percent of Total Friction }}{1500 \mathrm{rpm}}$} & \multicolumn{2}{|c|}{$\begin{array}{l}\text { Percent of BHP at } \\
1500 \mathrm{rpm} \quad 3000 \mathrm{rpm}\end{array}$} \\
\hline 1 & Valve pumping & 6.0 & 18.0 & 0.90 & 4.50 \\
\hline 2 & Throttling & 39.5 & 22.5 & 5.92 & 5.62 \\
\hline 3 & Blowby & 9.5 & 5.0 & 1.42 & 1.25 \\
\hline 4 & Crankcase & 16.5 & 20.5 & 2.47 & 5.10 \\
\hline 5 & Viscous piston & 15.5 & 22.5 & 2.32 & 5.62 \\
\hline 6 & Nonviscous piston & 13.5 & 11.0 & 2.02 & 2.75 \\
\hline & & $100 \%$ & $100 \%$ & $15 \%$ & $25 \%$ \\
\hline
\end{tabular}




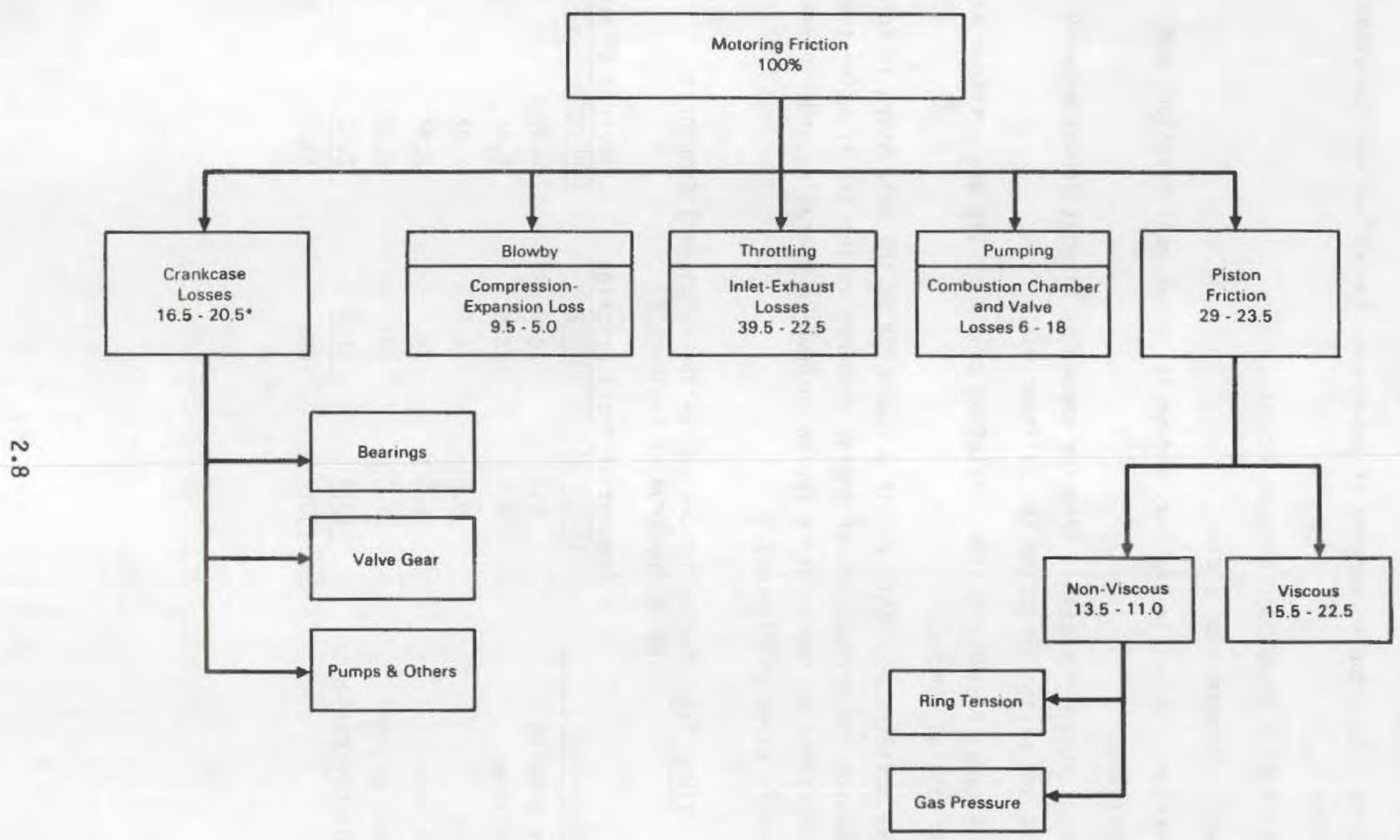

"First number is for $1500 \mathrm{rpm}$; second for $3000 \mathrm{rpm}$

FIGURE 2.5. Distribution of "Frictional" Losses at Road Conditions(9) 


\subsubsection{Five Smal1 4- and 6-Cylinder Engines (10)}

Figure 2.6a gives the total mean effective pressures consumed by reasonably small automobiles, while $2.6 \mathrm{~b}$ gives the component losses that make up the bulk of the total friction. According to the data given in Reference 10, we have for an EPA cycle the following:

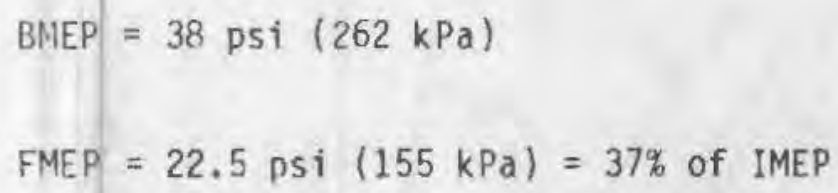

Thus, while FMEP is $37 \%$ of IMEP, it is $59 \%$ of the BMEP. With this data on hand, one can relate the individual component losses to both the brake hp output and to the indicated $h p$ as given in Table 2.2.

\subsubsection{Correlation of Various Sources $(11,13)$}

Based on some 25 sources dealing with automotive friction, Rosenberg of General Motors Corporation, (11) constructed the curves in Figure 2.7 for the pumping and mechanical losses as functions of speed. At low load factors these are high percentages of the hp output. At $50 \% 10 \mathrm{ad}$, the pumping 105s would amount to about $15 \%$ and the frictional losses to $20 \%$ of the bhp. The individual elements of the mechanical friction are given in Figure 2.8. If one takes an average speed of $50 \mathrm{~km} / \mathrm{hr}(30+\mathrm{miles} / \mathrm{hr})$ then in terms of brake hp the losses in these components are as given in Table 2.3. A partial insight as to the origins of the various levels of friction in the engine components can be gleaned from Figure 2.9 which shows the regimes of lubrication that various components operate in. Thus, while the engine bearings have adequate hydrodynamic films, the valve train components operate mostly in the boundary lubrication regions due to the high loadings and low sliding speeds, and may even experience direct rubbing contact. Piston rings, while maintaining a full film over most of the stroke, lose this film near the piston's top or bottom dead center. The coefficient of friction thus may range anywhere from a low of 0.001 for hydrodynamic operation to 0.2 for the valve seats. 


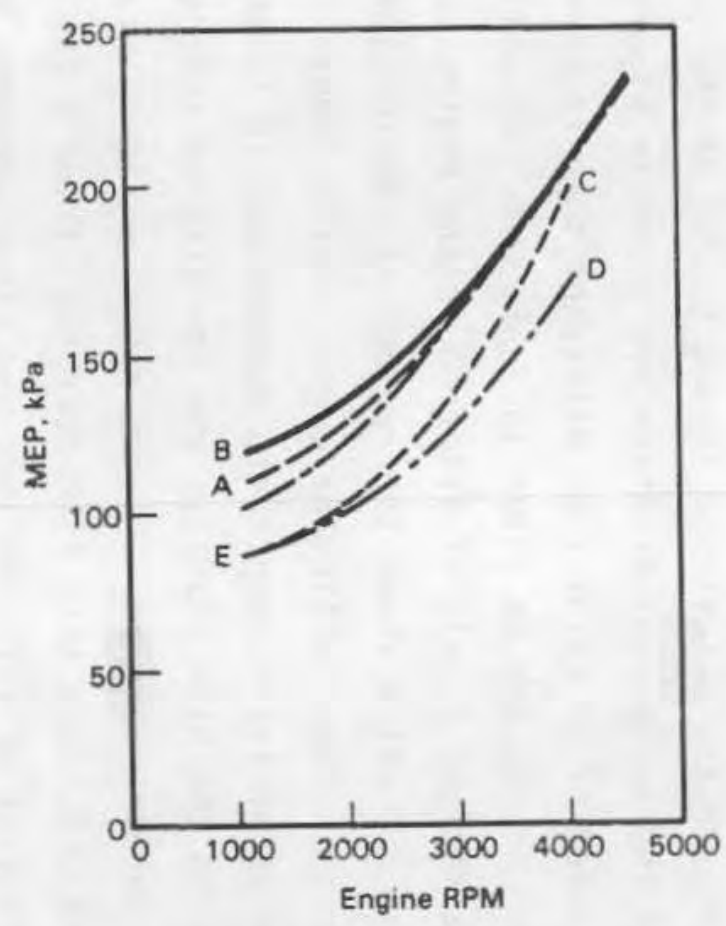

a) Motoring Friction of 5 Engines: $A, B$ and D 4-Cyl., C \& E 6-Cyl. Measured at WOT

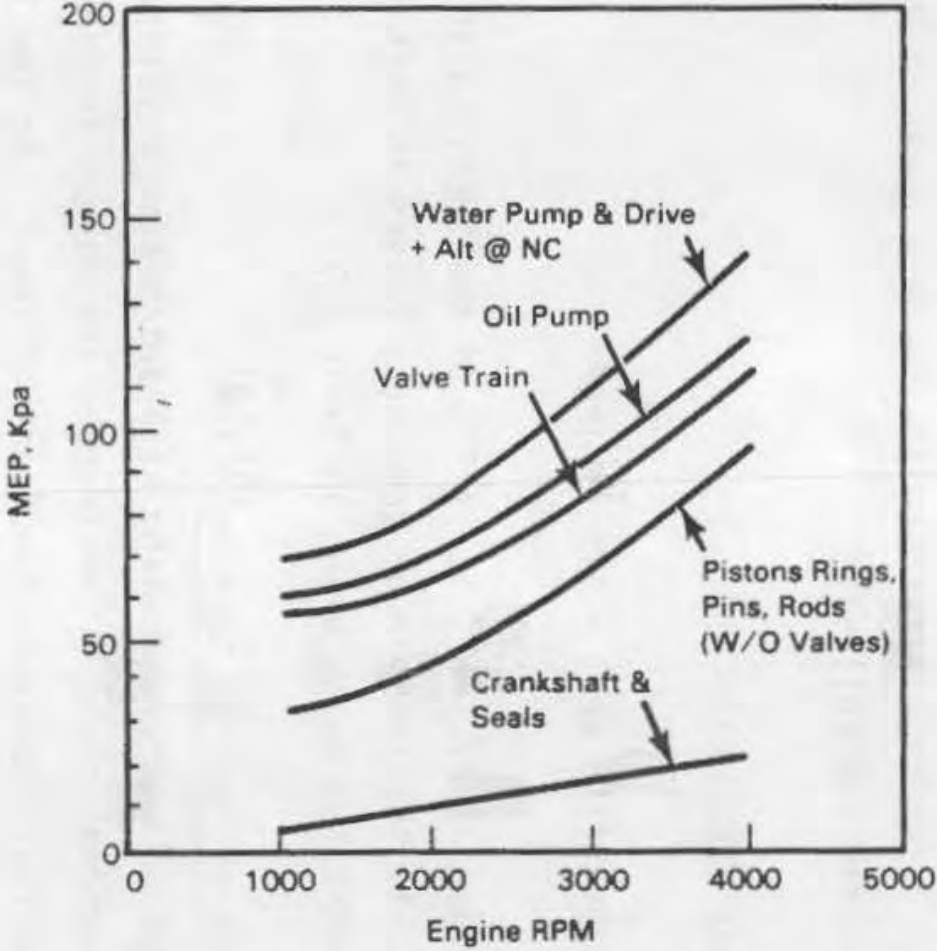

b) Motoring Friction Breakdown, 4-Cylinder Engine

FIGURE 2.6. Levels of Frictional Losses in "Small" Automobiles(10) 
TABLE 2.2. Energy Losses in Various Mechanical Compgpents (Small 4- and 6-Cylinder (ars) at an EPA Cycle

\begin{tabular}{|c|c|c|c|}
\hline \multicolumn{2}{|r|}{ Component } & $\begin{array}{l}\text { Percent } \\
\text { of } \mathrm{BHP} \\
\end{array}$ & $\begin{array}{l}\text { Percent } \\
\text { of IHP }\end{array}$ \\
\hline 1 & Water Pump and Drive & 4.0 & 2.3 \\
\hline 2 & $0 i 1$ Pump & 2.0 & 1.2 \\
\hline 3 & Valve Train & 9.5 & 5.8 \\
\hline 4 & Piston Rings & 10.7 & 6.5 \\
\hline 5 & Crankshaft and Seals & 2.7 & 1.6 \\
\hline \multirow[t]{2}{*}{6} & others $(a)$ & 30.5 & 20.0 \\
\hline & & 59 & 37 \\
\hline
\end{tabular}

(a) Pumping, throttling, etc.

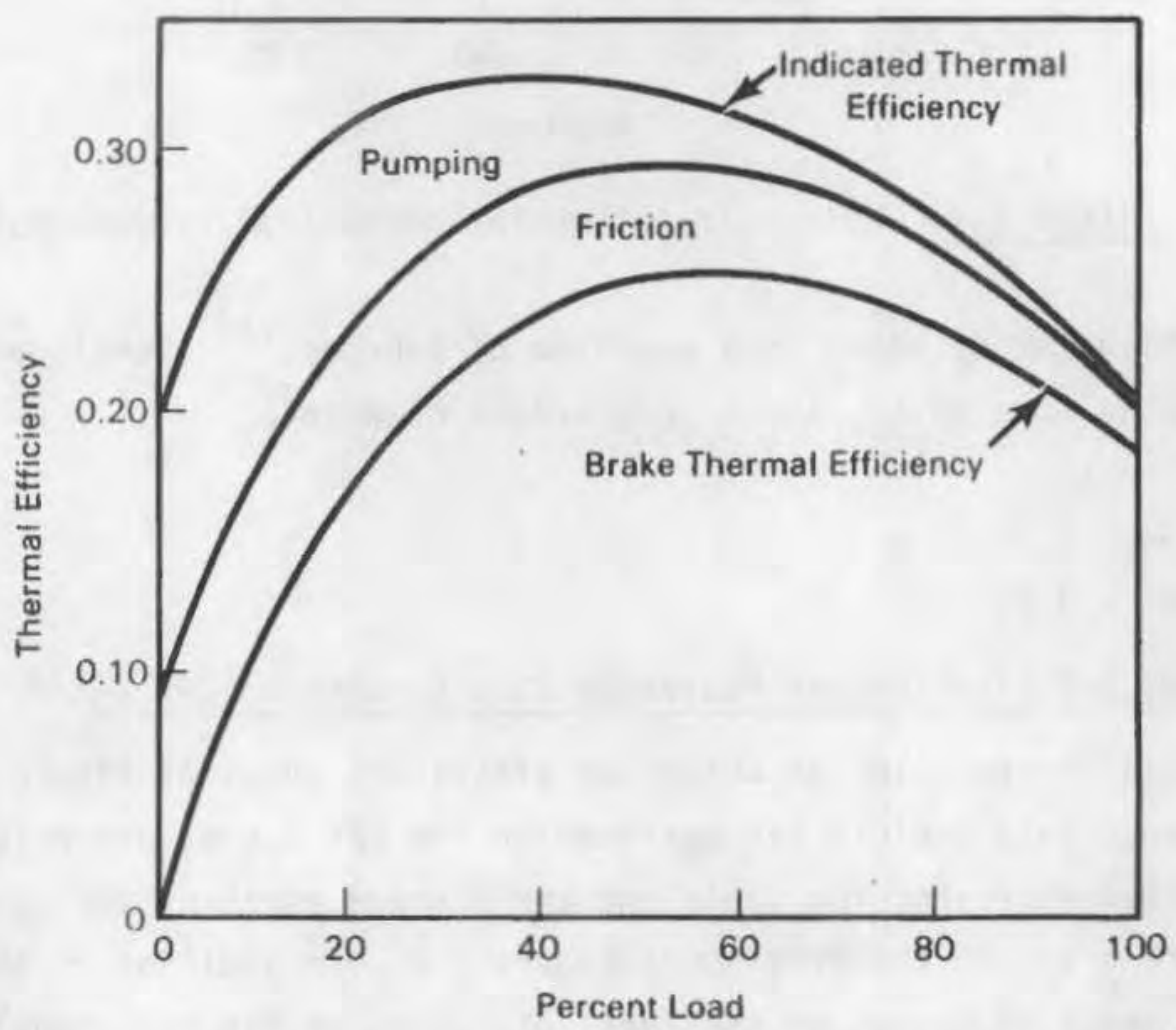

FIGURE 2.7. Major Energy Components in Automotive Cycle $\mathrm{e}^{(11)}$ 


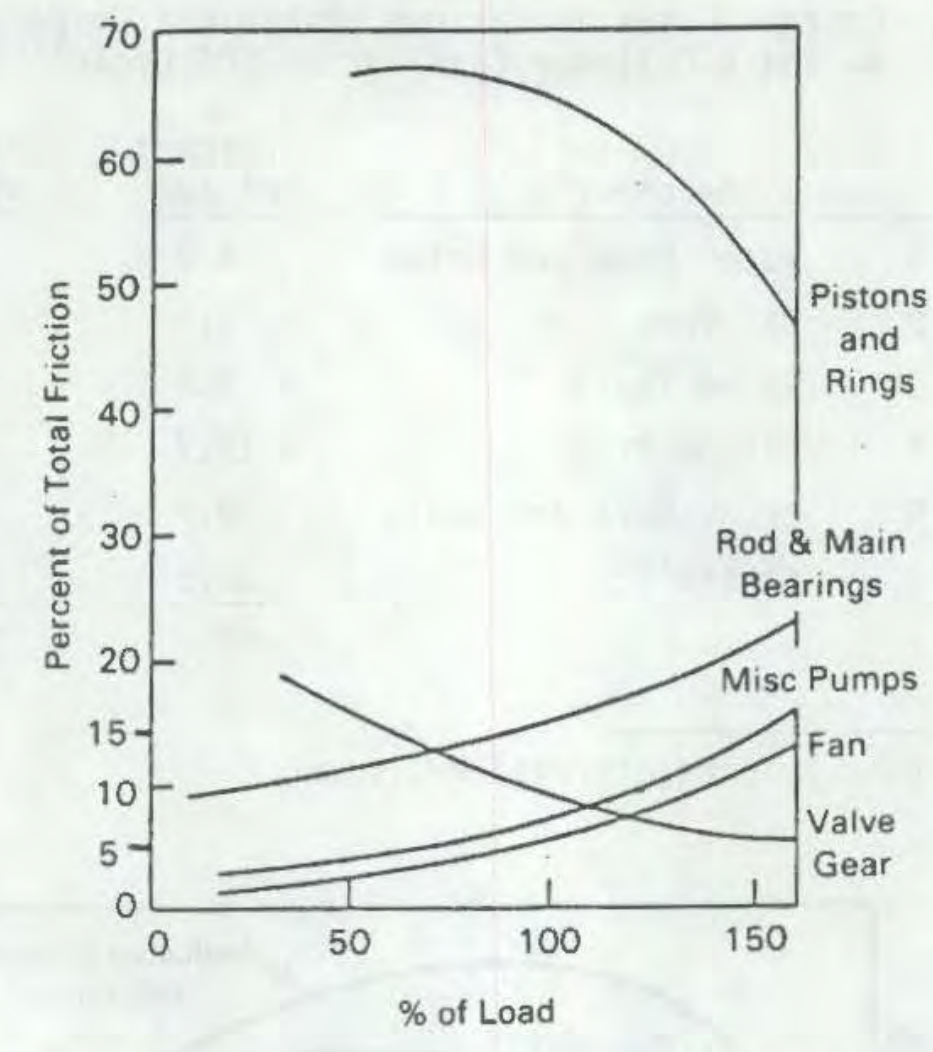

FIGURE 2.8. Losses in Automotive Mechanical Components (11)

A similar study based on a spectrum of sources, ${ }^{(13)}$ concluded that the IHP efficiency is some $28.5 \%$, which then breaks down into:

- BHP - $18 \%$

- FHP - $7.2 \%$

- Others - $3.3 \%$

2.2.4 $\mathrm{V}-8,5.7$ Liter Engine Passenger Cars Weighting $1590 \mathrm{~kg}^{(7)}$

This is the vehicle for which the efficiency chart of Figure 2.1 has been constructed. This vehicle was operated on the EPA cycle, and results were obtained separately for the urban and the highway parts of the cycle. The results are given in the diagram of Figure 2.8. In addition to the effects of these two modes of travel on the level of losses of the individual components, the following overall results may be of interest: 


\begin{tabular}{|c|c|c|}
\hline Cycle & Average Speed & Energy Input \\
\hline Urban & $31 \mathrm{~km} / \mathrm{hr}$ (19.2 miles $/ \mathrm{hr}$ ) & $5.70 \mathrm{MJ} / \mathrm{km}$ \\
\hline Highway & $78 \mathrm{~km} / \mathrm{hr}$ (48.4 miles $/ \mathrm{hr}$ ) & $4.67 \mathrm{MJ} / \mathrm{km}$ \\
\hline
\end{tabular}

Thus, even though the average highway speed was two-and-a-half times that of urban drivina, it required $18 \%$ less energy to cover the same distance.

\subsubsection{DOE/ASME Study}

Fiqures 2.10, 2.11 and 2.12 are charts taken directly from Reference 2, which was a result of the 1977 DOE/ASME Workshop Study on energy losses for the U.S. economy as a whole. The automotive accessory losses are given in Figure 2.13, where it can be seen that aside from the optional air-conditioning

TABLE 2.3. Energy Losses in Various Mechanical Components (Summary of Various Sources)

\begin{tabular}{|c|c|c|c|}
\hline & omponent ${ }^{(a)}$ & $\begin{array}{l}\text { Percent of Total } \\
\text { Mechanical Friction }\end{array}$ & $\begin{array}{l}\text { Percent } \\
\text { of BHP } \\
\end{array}$ \\
\hline 1 & Piston Assembly & 50 & 10.0 \\
\hline 2 & Valve Gear & 5 & 1.0 \\
\hline 3 & Bearings & 7 & 1.4 \\
\hline 4 & Pumps & 2.5 & 0.5 \\
\hline 5 & Fan & 2.5 & 0.5 \\
\hline 6 & Others & 33 & 6.6 \\
\hline & & 100.0 & 20.0 \\
\hline & omponent (b) & & \\
\hline 1 & Piston Rings & 12.0 & 4.8 \\
\hline 2 & Remainder of Piston & 20.0 & 8.0 \\
\hline 3 & Crankshaft & 12.6 & 5.0 \\
\hline 4 & Others & 55.4 & 22.2 \\
\hline & & 100.0 & 40.0 \\
\hline
\end{tabular}

(a) Reference 7 .

(b) Reference 13. 


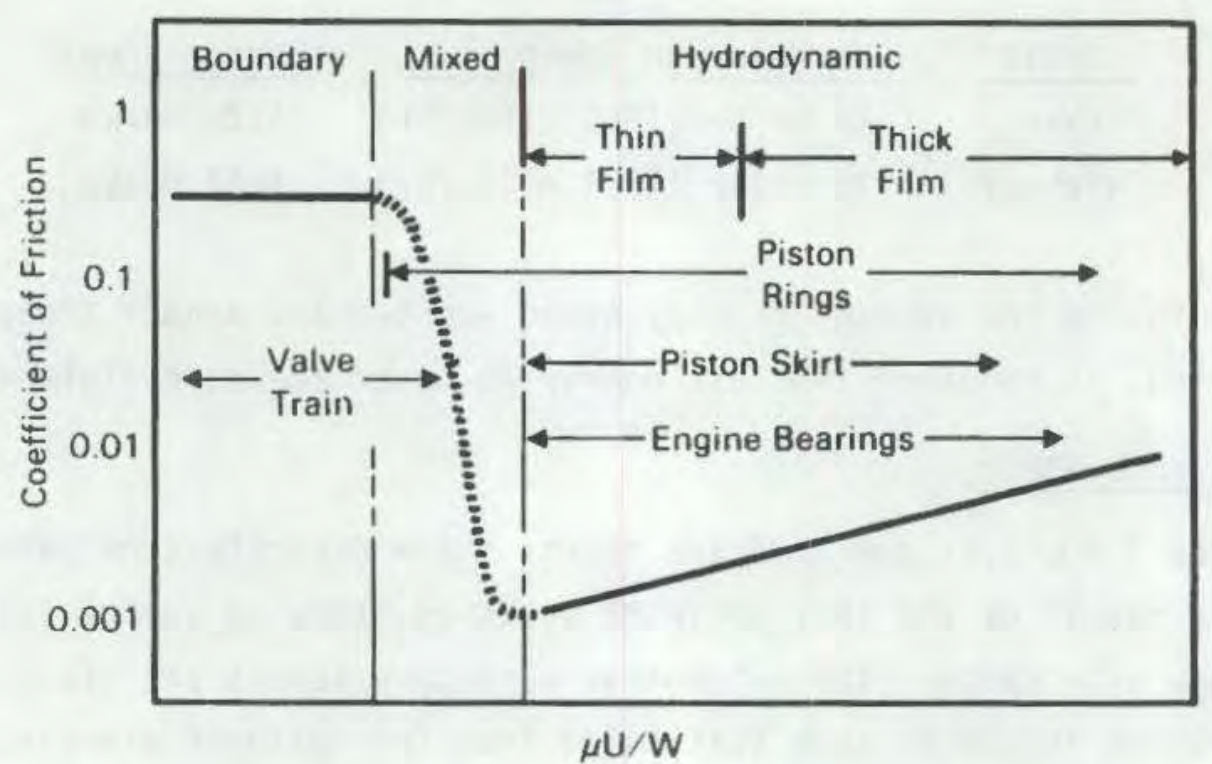

FIGURE 2.9. Friction Coefficient for Automotive Components (7)

compressor, the direct drive fan consumes the largest share of energy. What is missing in this chart is the oil pump, which likewise is a relatively large consumer of energy.

\subsubsection{Suoplementary Data from Interviews}

In the course of the interviews conducted on the present program, input was obtained for the distribution of energy within the automotive vehicle. What is labeled in Figure 2.11 "0ther engine friction - 4.5\%" was further broken down as follows:

- Valve train - $1.3 \%$

- Bearings - $1.0 \%$

- Seals $-0.5 \%$

- 0 thers $-\frac{1.7 \%}{4.5 \%}$

For a small front-wheel drive car, integrated over a complete EPA cycle, Table 2.4 gives some of the major combonents of frictional energy sinks in terms of total energy input. The total is $11 \%$ which, for a bhp efficiency of $25 \%$, amounts to $44 \%$ of the bhp. 


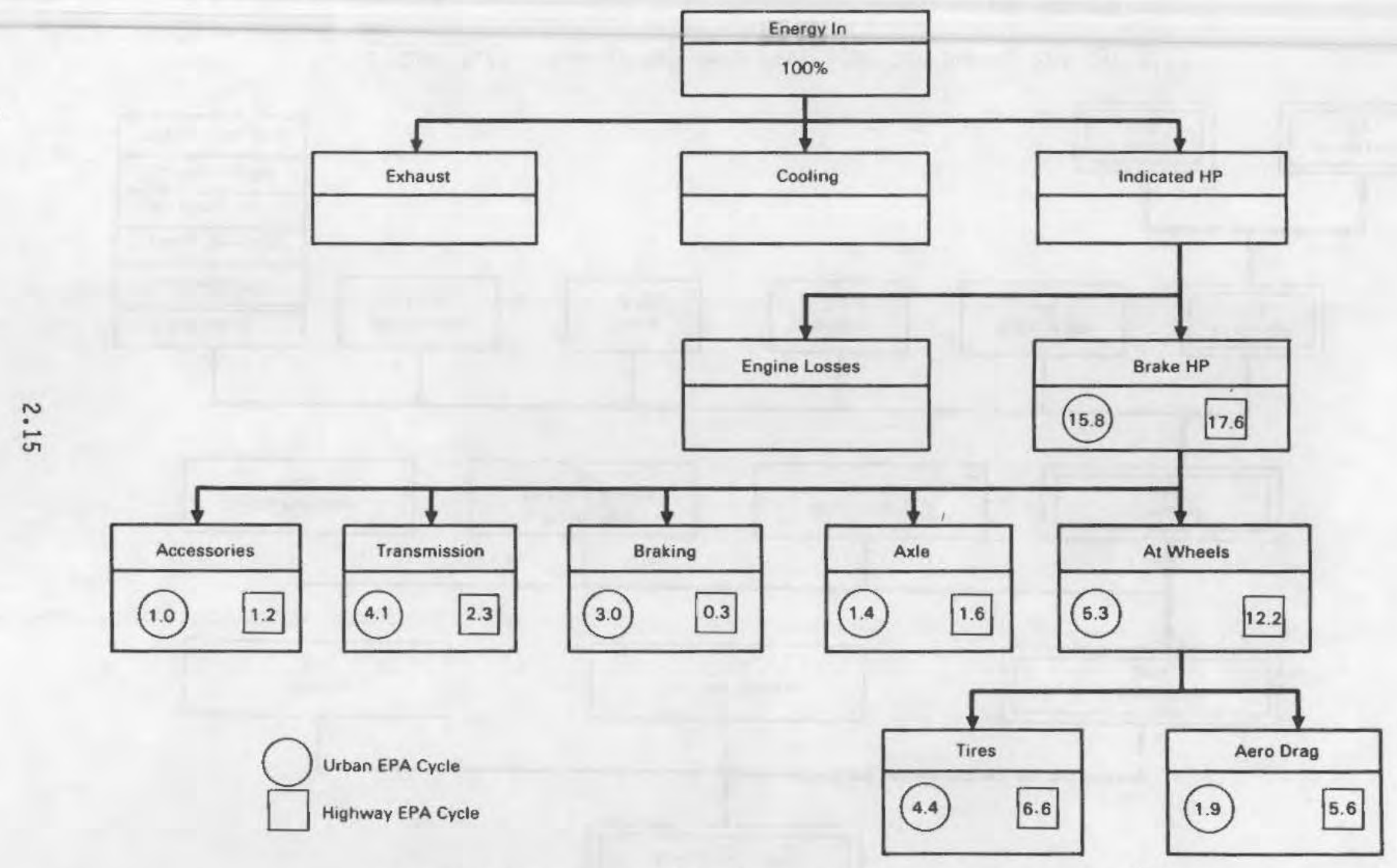

FIGURE 2.10. Energy Distribution in a V-8 Engine Vehicle ${ }^{(7)}$ 


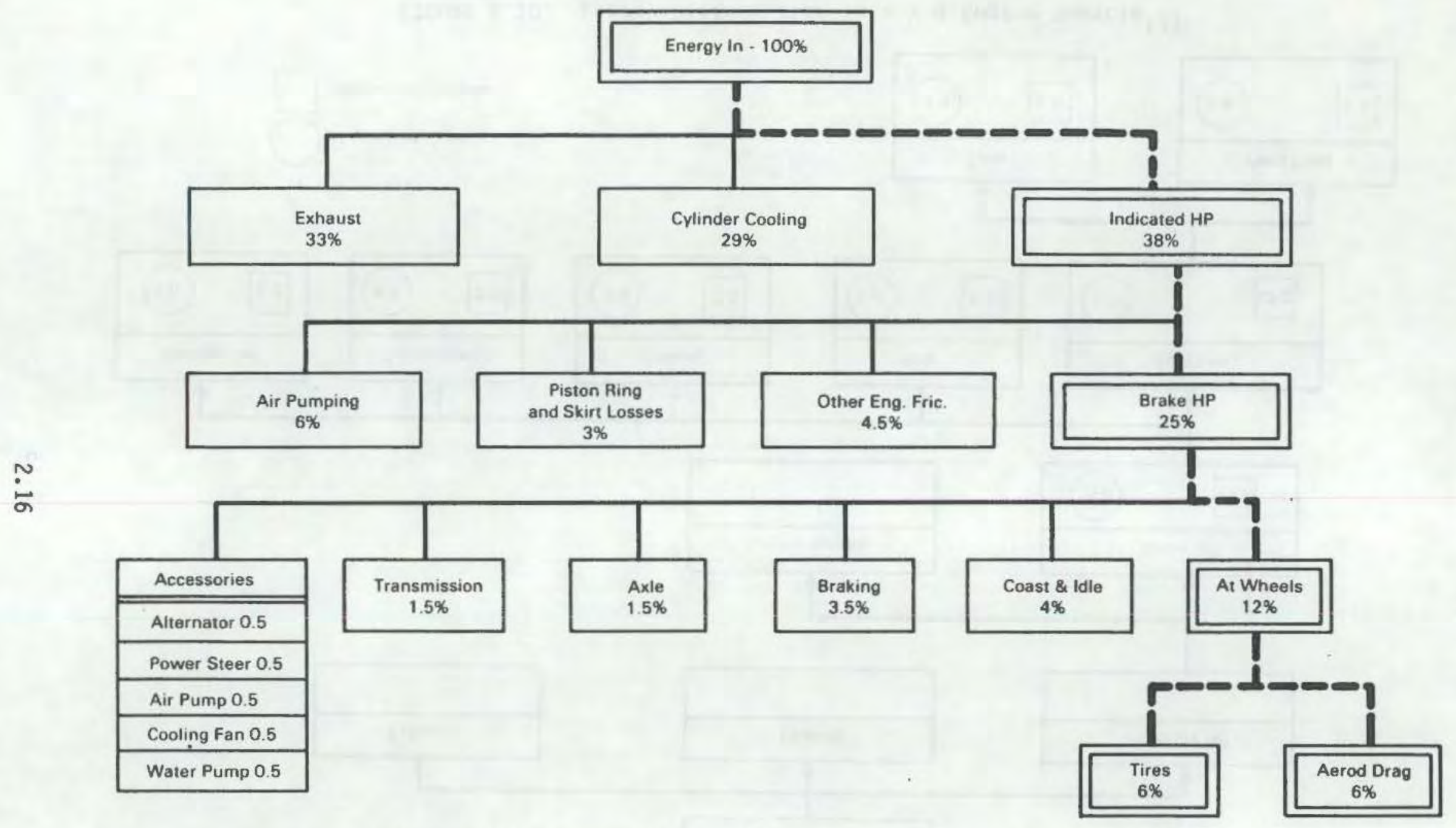

FIGURE 2.11. Energy Map in a Passenger Car During EPA Cycle $\mathrm{e}^{(2)}$ 


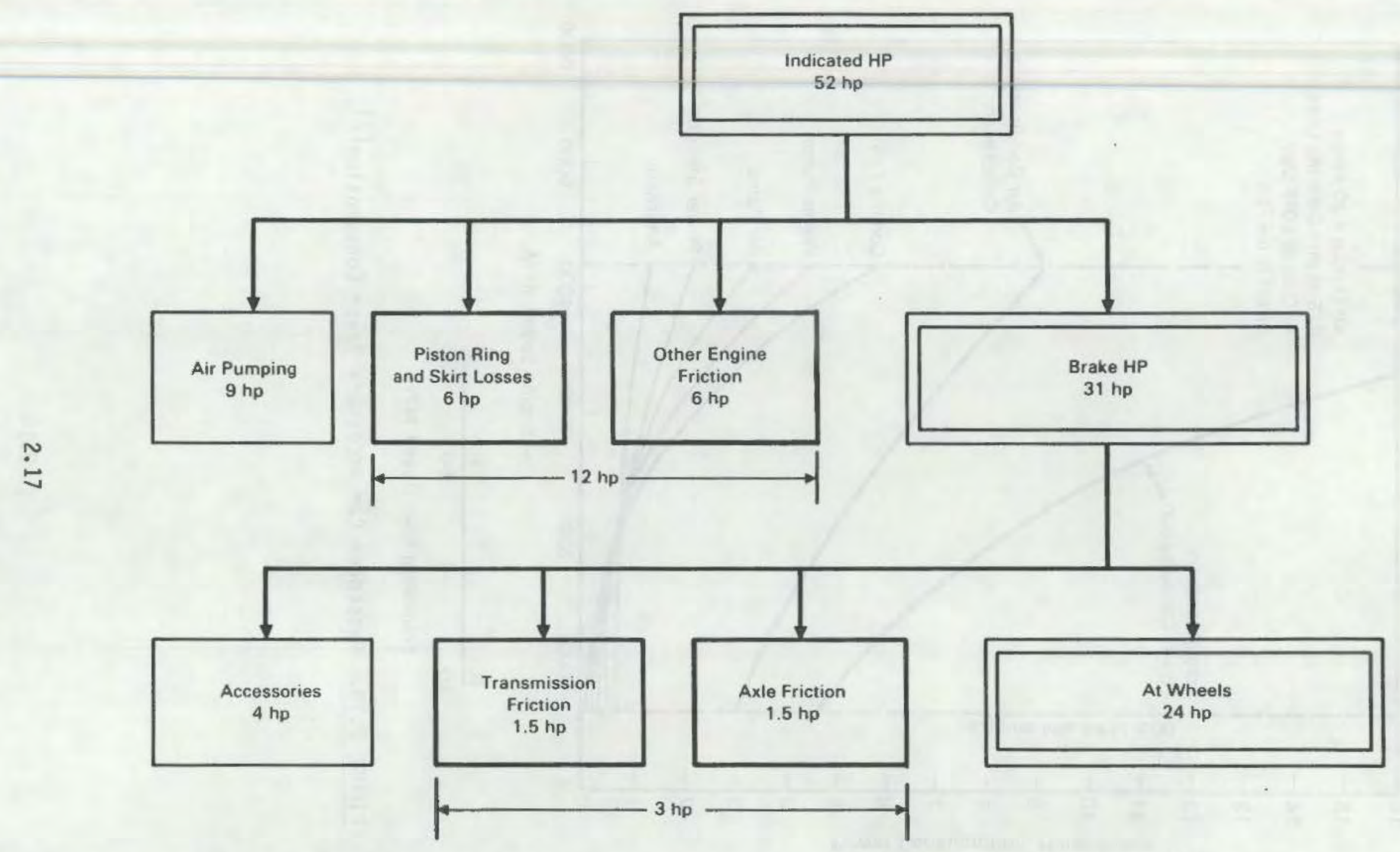

FIGURE 2.12. Frictional Losses in a 348 in. $^{3}$ Passenger Car at $50 \mathrm{mph}^{(2)}$ 


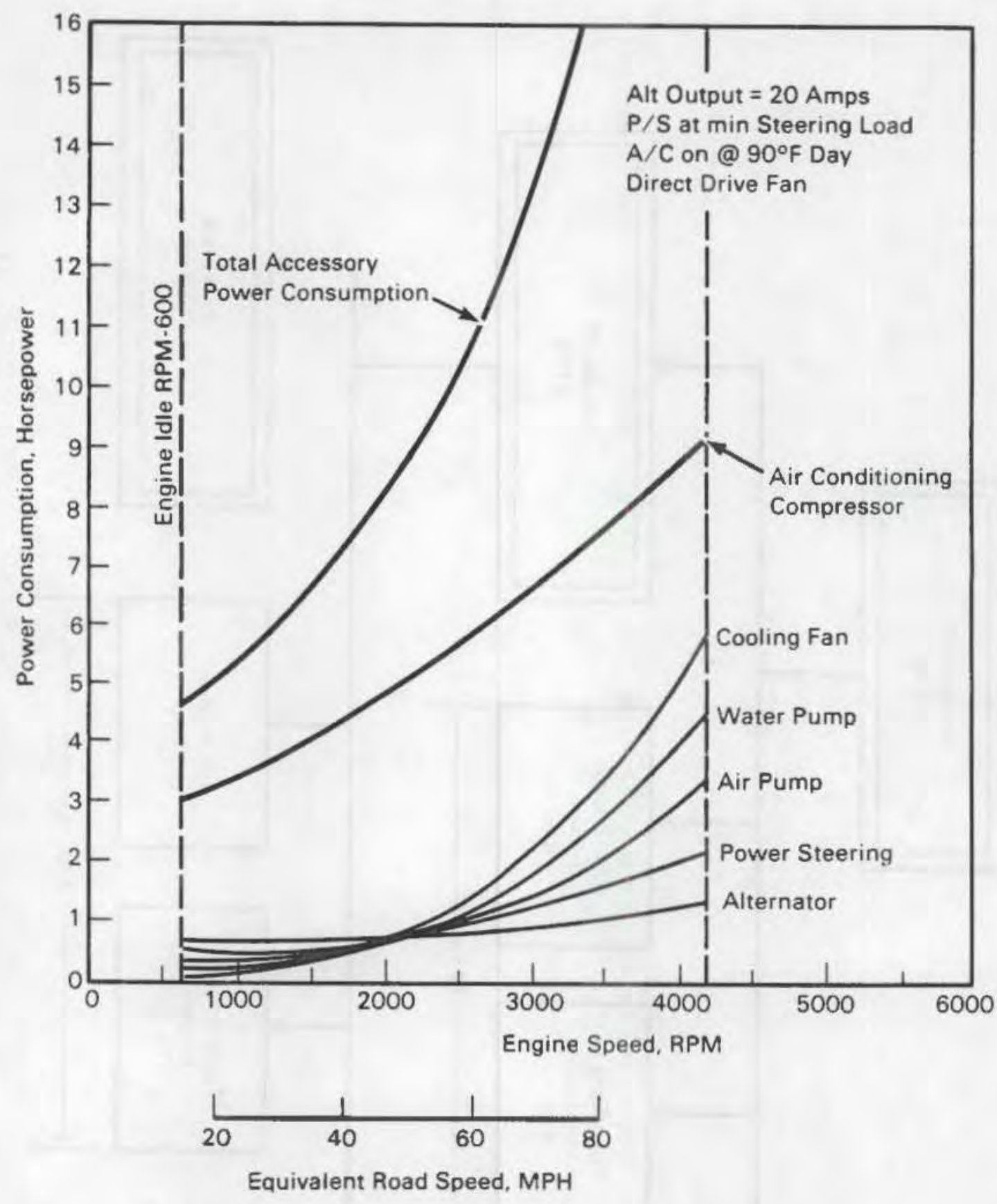

FIGURE 2.13. Passenger Car Accessory Power Consumption(2) 
TABLE 2.4. Automotive Friction Components (14) Small Front Wheel Drive on EPA Cycle

\begin{tabular}{|c|c|c|c|}
\hline & Component & $\begin{array}{c}\text { Percent of } \\
\text { Mechanical } \\
\text { Friction } \\
\end{array}$ & $\begin{array}{l}\text { Percent of } \\
\text { Input Energy }\end{array}$ \\
\hline 1 & Piston Assembly and Rods & 40 & 4.4 \\
\hline 2 & Valve Train & 26 & 2.9 \\
\hline 3 & Crankshaft with Seals & 11 & 1.2 \\
\hline 4 & 0il Pump & 12 & 1.3 \\
\hline \multirow[t]{2}{*}{5} & Water Pump & 11 & 1.2 \\
\hline & & $100 \%$ & $11.0 \%$ \\
\hline
\end{tabular}

\subsubsection{Integration of Results}

In pulling together the various inputs discussed in the previous pages, the following is assumed:

$$
\begin{aligned}
& \text { IHP efficiency }=35 \% \\
& \text { BHP efficiency }=65 \% \text { of IHP }=23 \%
\end{aligned}
$$

Table 2.5 then tabulates the inputs from the various references with the bottom line giving an average of the numbers listed. These data together with the more detailed information worked out in the previous paragraphs were then utilized in constructing the detailed energy chart of Figure 2.14. 
TABLE 2.5. Tribological Energy Losses in EPA Cycle - Percent of Energy Input

\begin{tabular}{|c|c|c|c|c|c|c|c|c|c|c|}
\hline Source & $\begin{array}{c}\text { Piston } \\
\text { Assembly } \\
\end{array}$ & $\begin{array}{l}\text { Trans- } \\
\text { mission }\end{array}$ & $\begin{array}{l}\text { Valve } \\
\text { Train } \\
\end{array}$ & $\begin{array}{l}0 i 1 \\
\text { Pump } \\
\end{array}$ & Axle & Bearings & Fan & $\begin{array}{c}\text { Crankshaft } \\
\text { Assembly } \\
\end{array}$ & Others & \\
\hline DOE/ASME (2) & 3.0 & 1.5 & & & 1.5 & & 0.5 & & & \\
\hline Bishop $(9)$ & 1.2 & & 2.2 & 0.5 & & & & 0.9 & & \\
\hline $\operatorname{Kovach}^{(10)}$ & 2.5 & & & & & & & & Water Pump & $=0.1$ \\
\hline Rosenberg (11) & 2.8 & & 1.3 & 0.9 & & 0.4 & 0.5 & & Water and Fuel Pumps & $=0.1$ \\
\hline Bidwel1 ${ }^{(7)}$ & & 3.1 & & & 1.9 & & & & $\begin{array}{l}\text { Accessories } \\
\text { Brakes } \\
\text { Aero } \\
\text { Tires }\end{array}$ & $\begin{array}{l}=1.0 \\
=2.0 \\
=4.0 \\
=5.5\end{array}$ \\
\hline Parker (13) & 2.9 & & 1.1 & & & & & 1.15 & & \\
\hline Baker $(14)$ & 4.4 & & 2.9 & 1.3 & & & & 1.20 & & \\
\hline $\mathrm{GM}(16)$ & & 1.3 & & & & 1.0 & & & Seals & $=0.5$ \\
\hline Average & 2.8 & 2.0 & 1.9 & 0.9 & 1.65 & 0.7 & 0.5 & 1.10 & Water Pump & $=0.1$ \\
\hline & & & & & & & & & Seals & $=0.5$ \\
\hline
\end{tabular}




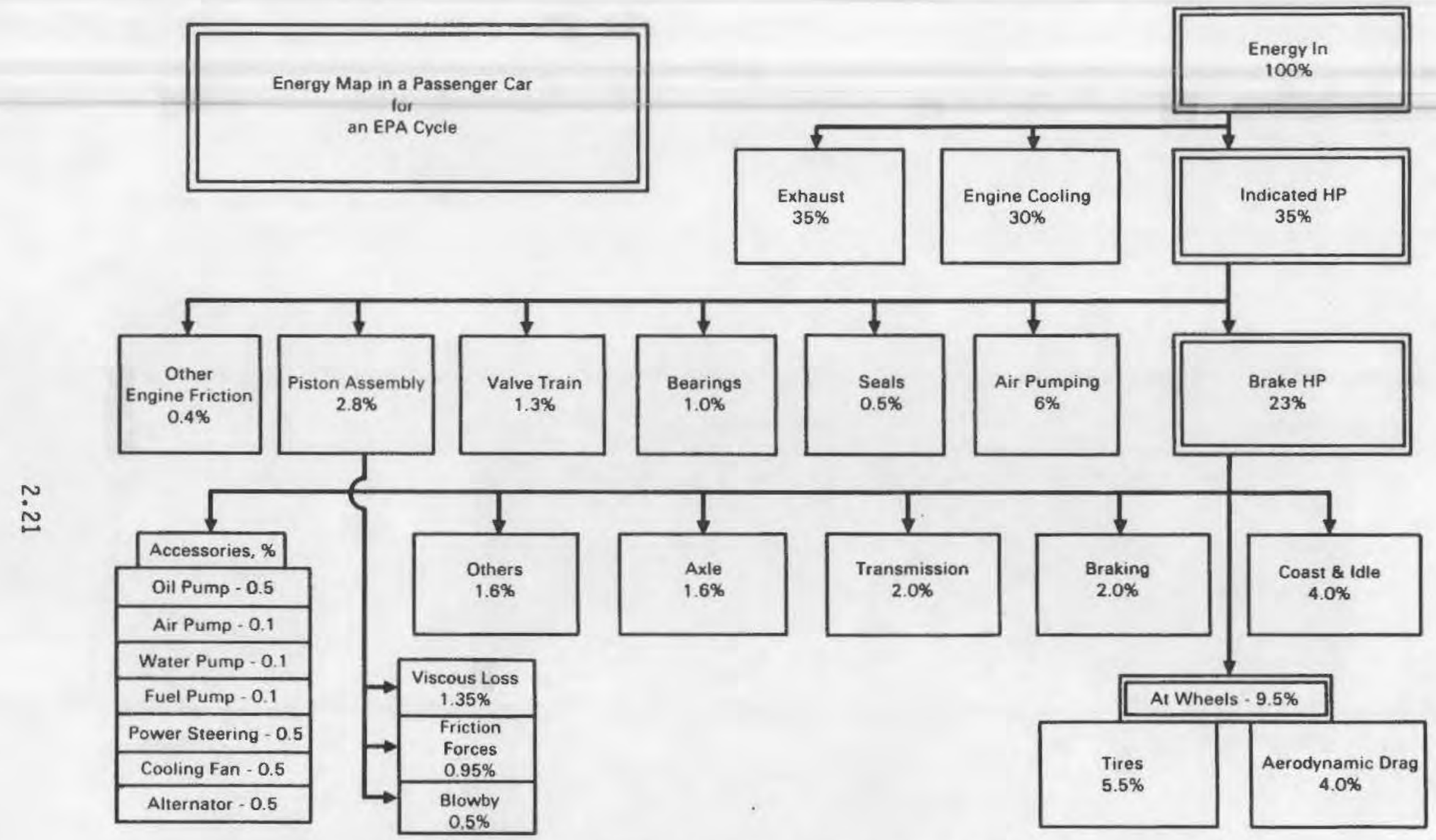

FIGURE 2.14. Energy Map in a Passenger Car for an EPA Cycle 


\subsection{UNCONVENTIONAL ENGINES}

This section is concerned with the energy flow patterns of engines not operating on the conventional otto cycle. Treated here are the diesel, the gas turbine, and the Stirling engines. As pointed out at the beginning of this report, the number of vehicles using nonconventional engines is small and even the most popular design, the diesel engine, is decreasing in its share of the U.S. market. Except for the adiabatic diesel, the tribological aspects of these engines and the opportunities they offer for energy savings are of less significance than in the conventional otto cycle engine. As shown in Figure 3.1 , the conventional engine has occasional advantages in terms of part load efficiency or power density and has the lowest manufacturing cost. However, it ranks lowest in the efficiency of its components, the very area we are concerned with in the present study. Thus, given the fact of the small market share of these engines and of the relatively high efficiency of their components, an extensive study of their tribological elements would be out of proportion to the possible results. The only engine with major component problems and potentialities is the adiabatic diesel engine.

\subsection{UNCONVENTIONAL OTTO CYCLES}

The most common modification of the spark-ignition engine is the stratified charge engine. This relies essentially on injection of pressurized gasoline fuel to obtain a more controlled pattern of combustion and thus, better utilization of the fuel. There is otherwise no major change in the engine and drive train arrangements and thus no major implications for the tribological processes involved in such an engine. Everything, then, that will be said about the conventional 0tto cycle in Section 4.0 is applicable also to the modified otto cycles.

\subsection{DIESEL CYCLE ENGINES}

The diesel cycle engine is also fundamentally not much different from the otto engine except that fuel combustion is initiated not by an electric spark, 


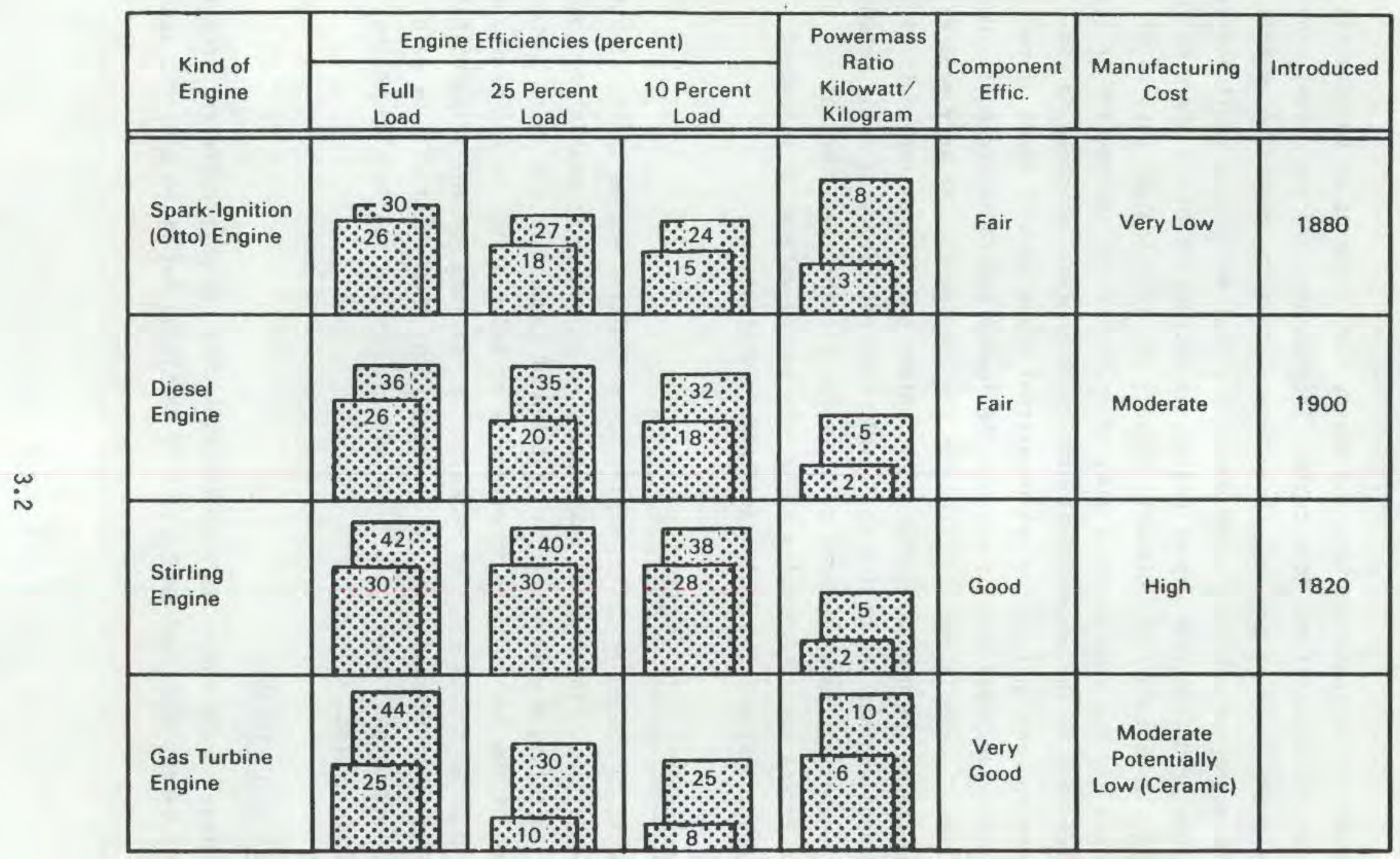

Lower Figure for Year 1975

Upper Figures for Year 1985

FIGURE 3.1. Characteristics of Various Automotive Engines (15) 
but by compressing the mixture. Consequently, both the peak pressures and temperatures in the combustion chamber are higher than for the SI engine. Some of the relevant features of the diesel cycle are:

- Because of the higher initial thermodynamic state of the mixture, diesel cycles are more efficient than the 0tto cycle. A typical thermodynamic balance is shown in Figure 3.2. Overall, a conventional diesel cycle yields fuel economies that are $10 \%$ to $15 \%$ better than the Otto cycle.

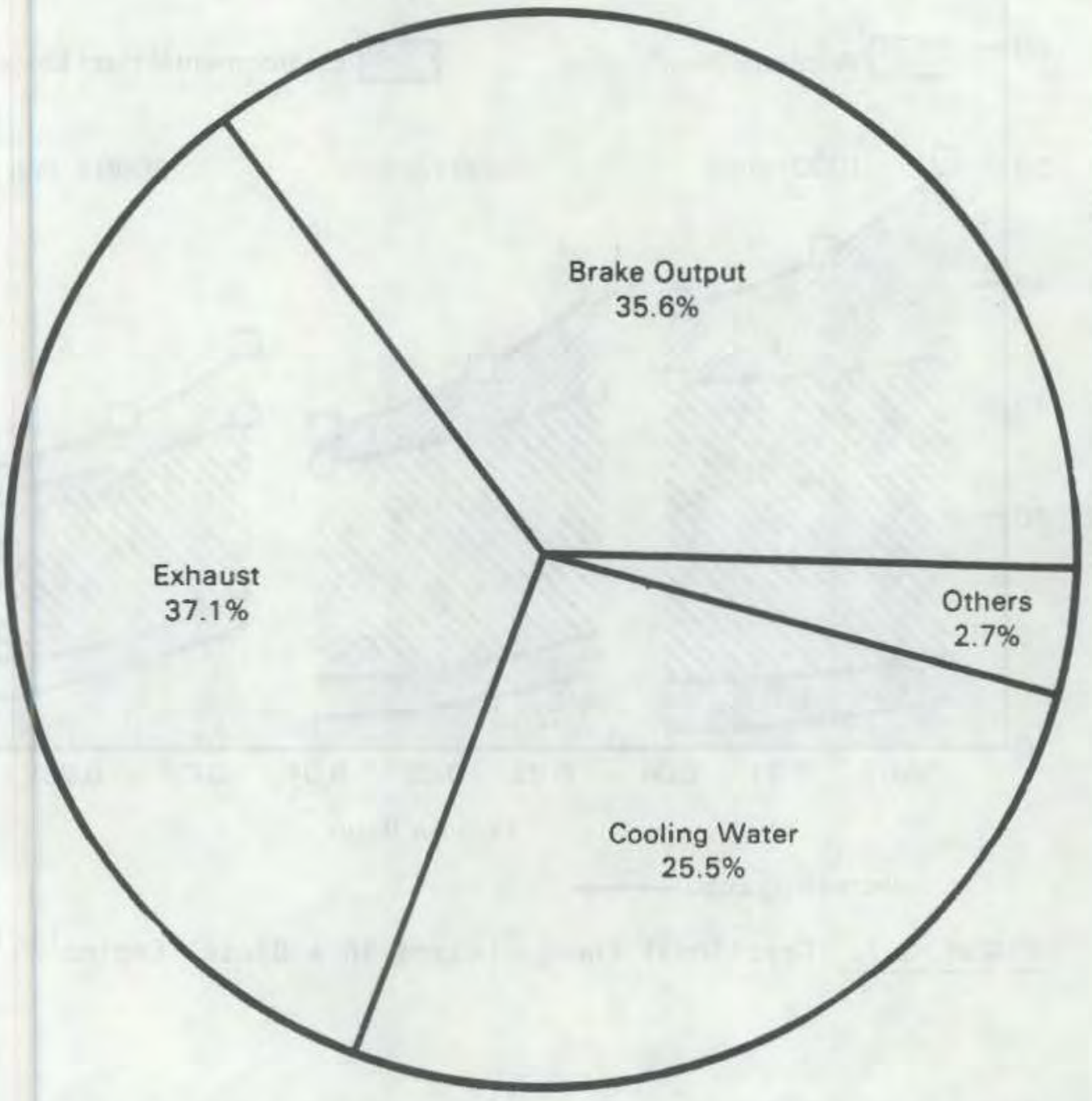

FIGURE 3.2. Typical Energy Balance of a Diesel Engine(2) 
- Frictional losses are higher than for the 0tto cycle. Figure 3.3 shows some representative values as a function of speed and load. Using an average fuel/air ratio of 0.03 (and interpolating for the $1500 \mathrm{rpm}$ ) we obtain from this figure a $4 \%$ frictional loss at $1500 \mathrm{rpm}$, and an $8 \%$ 10ss at $3000 \mathrm{rpm}$, both in terms of total energy input. In Section 2.2, the frictional losses in terms of BHP were $15 \%$ at $1500 \mathrm{rpm}$ and $25 \%$ at $3000 \mathrm{rpm}$. Since the hp in an otto cycle

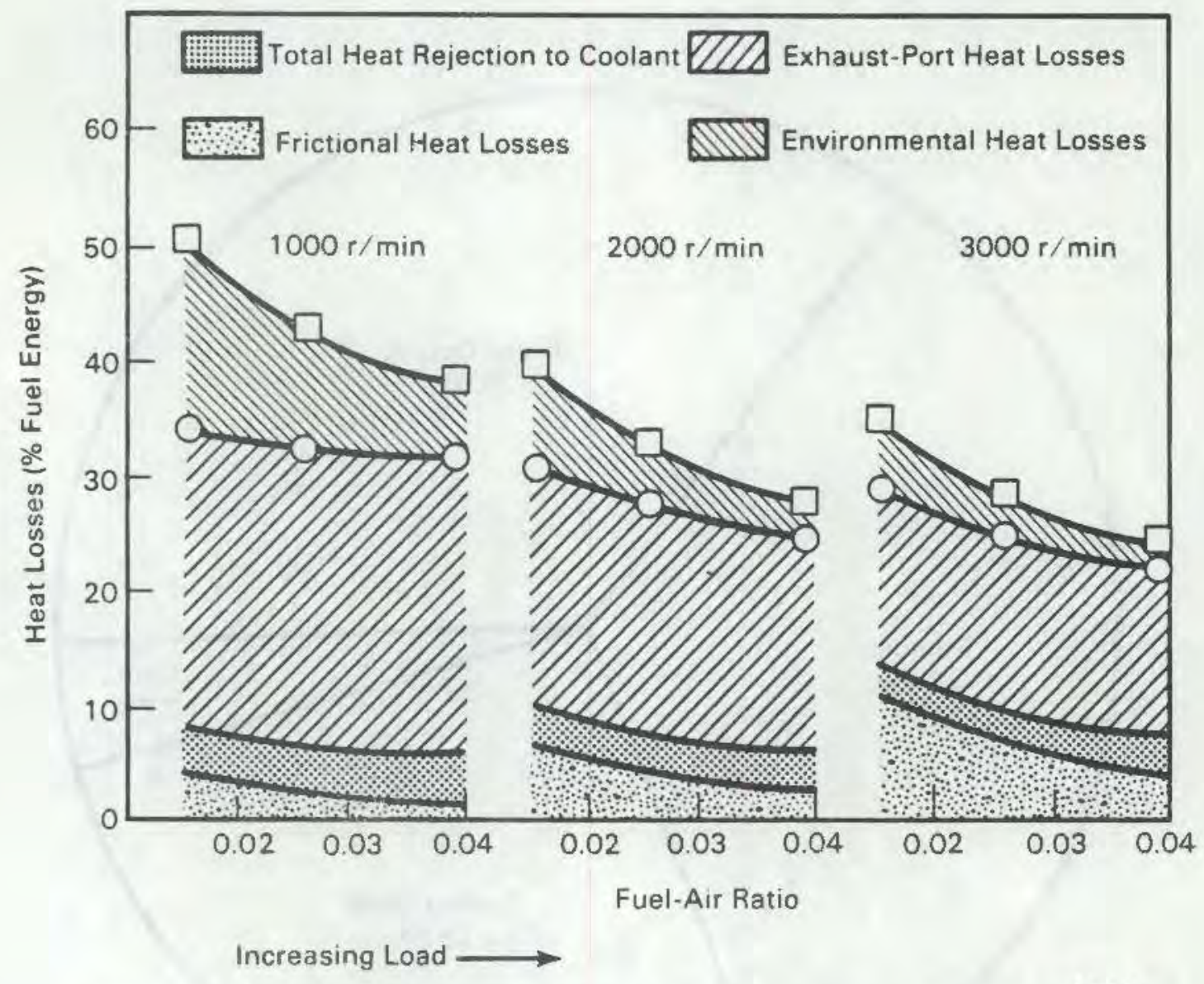

FIGURE 3.3. Frictional Energy Losses in a Diesel Engine (12) 
was estimated to be about $23 \%$ (see Figure 2.12) of the input energy, the two numbers correspond to $3.5 \%$ and $5.7 \%$. Thus, a comparison of the losses in the two cycles would yield the following:

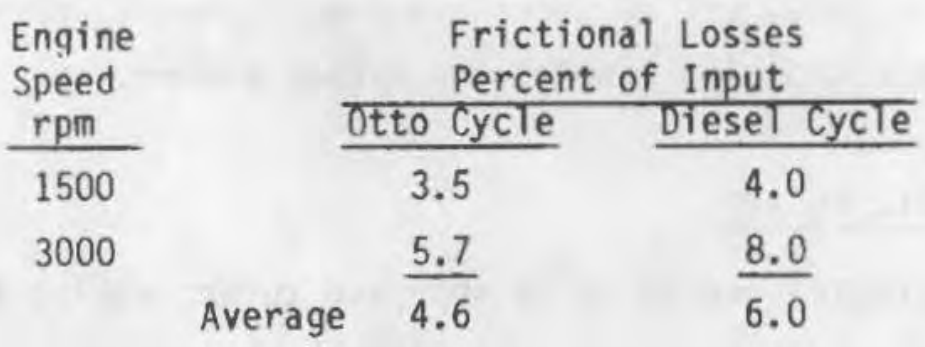

- Diesel cycles are particularly efficient in part-load operation. Thus, in Figure 3.4 where we have a comparison for the urban cycle, which is a part-load operation, the diesel mpg exceeds that of a SI engine by something of the order of $30 \%$ (for a $3000-1 b$ vehicle).

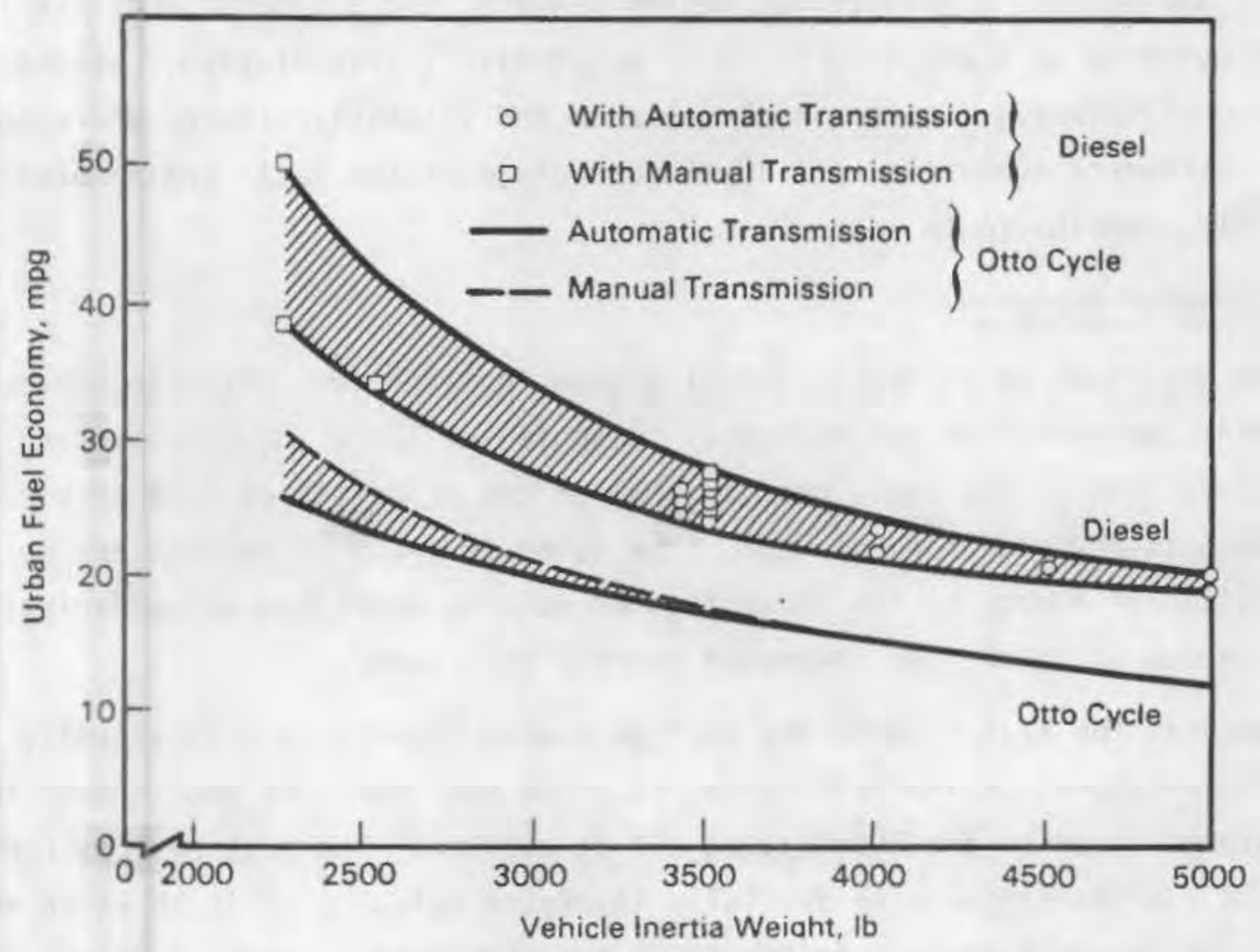

FIGURE 3.4. Urban Fuel Economy of 1978 Diesel and SI Engine Vehicles 
- Some negative features of diesel cycle engines are noise, higher MOX emission levels, higher cost, and greater vehicle weight.

Since, in general, the engine and drive train are similar to the conventional otto cycle engines, any advances and breakthroughs achieved with the conventional engine would also benefit the diesel engine.

\subsection{ADIABATIC DIESEL ENGINE}

The adiabatic diesel engine is an approach to increasing the efficiency of diesel engines by blocking the heat loss path to the cooling water and radiator. The adiabatic approach has aroused a considerable degree of interest for truck, bus, and off-road vehicle engines. The potential increase in fuel economy of $30 \%$ or more makes it attractive for both civilian and military applications. Attaining these economies appears to require the solution to a number of difficult high-temnerature tribological problems. Because their solution might be applicable to smaller automotive engines, the adiabatic approach is being considered as a possible field of automotive transportation. Whether the projected efficiency qains are achievable in the automotive field, where engine load requirements average a much lower percentage of the total engine power capability, remains to be seen.

\subsubsection{General Features}

The notion of an adiabatic diesel engine involves two critical changes in the engine concept which are essential to achieving large increases in engine efficiency. One is the basic change in which the rejection of heat to a cooling system is reduced or eliminated. The other is required because the resultant additional energy in the exhaust gases must be extracted as mechanical work in order to obtain the increased overall efficiency.

Blocking the heat flow to the cooling system results in significantly higher temperatures on the cylinder walls. The net result is much higher local temperatures to which the lubricating oil is exposed. The best available oils have been run in engines with partially insulated cylinder walls in which the maximum nil temperatures are in the $600^{\circ} \mathrm{F}$ to $700^{\circ} \mathrm{F}$ range. Maximum results will be achieved when near complete insulation is attained with ceramic walls and 
the local wall temperatures reach the range of $1000^{\circ} \mathrm{F}$ to $1200^{\circ} \mathrm{F}$. This is beyond the range of liquid lubrication, and will require the development of gas-lubricated piston/cylinder interfaces, the use of solid lubricants, and

probably the use of some form of cross-head mechanism to reduce the piston side loads. Boundary lubrication via solid lubricant transfer to the walls, or vapor-phase boundary lubrication seem to be areas that require exploratory research.

The additional heat energy in the working gas resulting from the elimination of heat flow through the cylinder walls cannot all be removed in a piston expansion engine of reasonable height and size. As a result, the exhaust gas from an adiabatic diesel contains a large portion of the additional power representing the increase in efficiency. The exhaust gases must therefore be passed through an additional expansion engine that is coupled to the main engine shaft or to the transmission. The commonly considered approach is to use a high speed turbine coupled to the drive transmission, a technique commonly called "turbo-compounding." The turbocharger is retained in the cycle, and a possible turbocharger-turbocompound engine arrangement is shown in Figure 3.5. (ther forms of expansion engines are being considered also; and a study of adding two Stirling cylinders to the main engine block for the additional energy extraction is under way.

A schematic diagram of an adiabatic engine is shown in cross section in Figure 3.6, where the exhaust gas temperature (inlet to turbine) is seen to be some $1500^{\circ} \mathrm{F}$. The major problems that arise in the design and operation of an adiabatic diesel nearly all follow from the fact that the temperatures will be substantially higher than in a conventional engine, and from the additional work extraction mechanism that replaces the cooling system. Thus:

- Coatings are required to protect engine parts.

- Volatility and chemical decomposition of oil calls for special lubricants. 


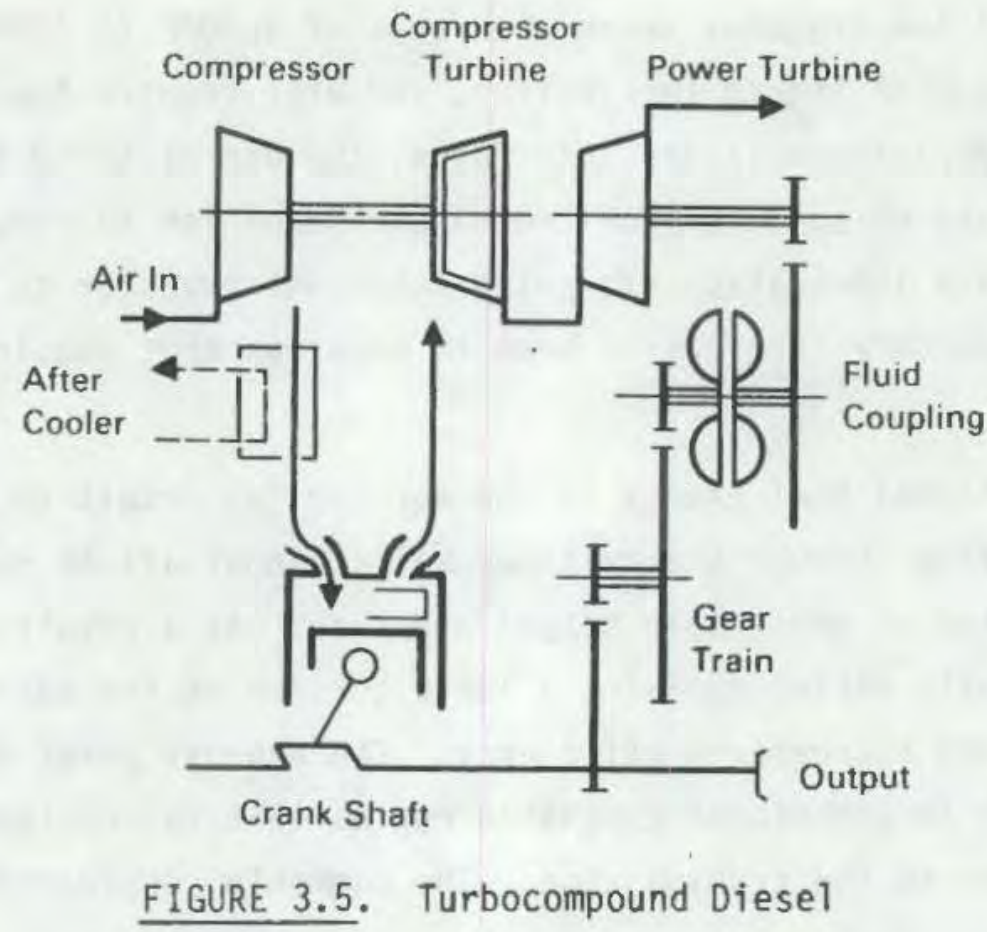

- Critical areas result at top piston ring interface and valve seating.

- Best efficiencies are obtained at full load and thus, application to passenger cars is limited with best results applicable to buses and trucks.

The relation between degree of engine insulation and associated cylinder temperatures is shown in Figure 3.7 and some of the temperatures expected in the critical areas for a full adiabatic engine are given in Figure 3.8. Finally, a typical efficiency gain of a fully insulated adiabatic diesel vis-a-vis the other versions is shown in Figure 3.9 where the gain in SFC is seen to be $35 \%$ over the conventional diesel cycle engine.

\subsubsection{Development Data}

The adiabatic engine is still in its developmental stages. Some testing conducted in Japan and reported in Reference 8 will be briefly summarized here to show the kind of technical problems and the complexity to be expected from this revolutionary engine. A six-cylinder, $125 \mathrm{~mm}$ bore, turbocharged diesel engine was chosen. The power turbine ran at 55,000 rpm for an engine speed of $1800 \mathrm{rpm}$. This required two sets of reduction gears with an overall ratio 


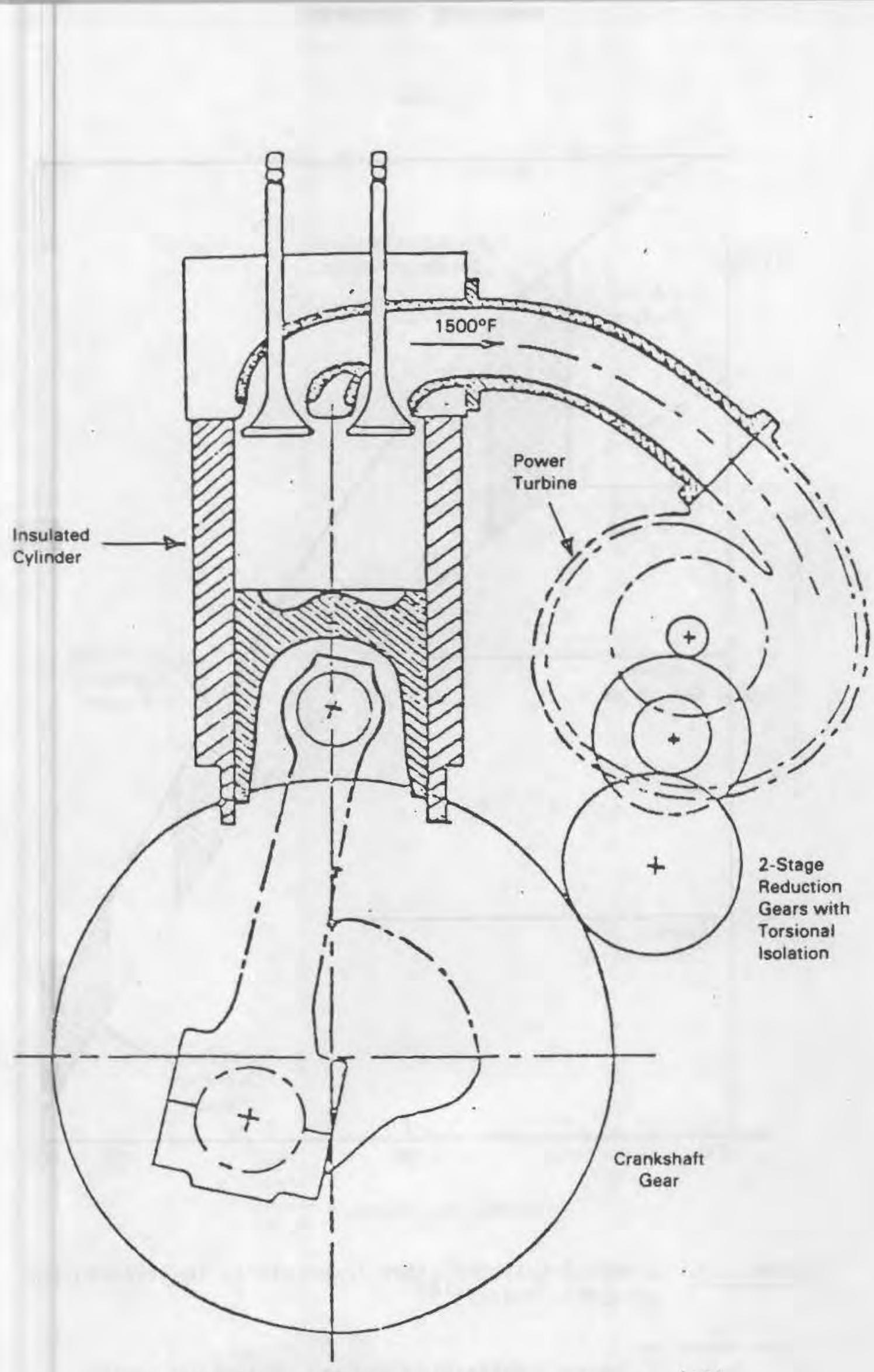

FIGURE 3.6. Adiabatic Turbocompound Engine (12) 


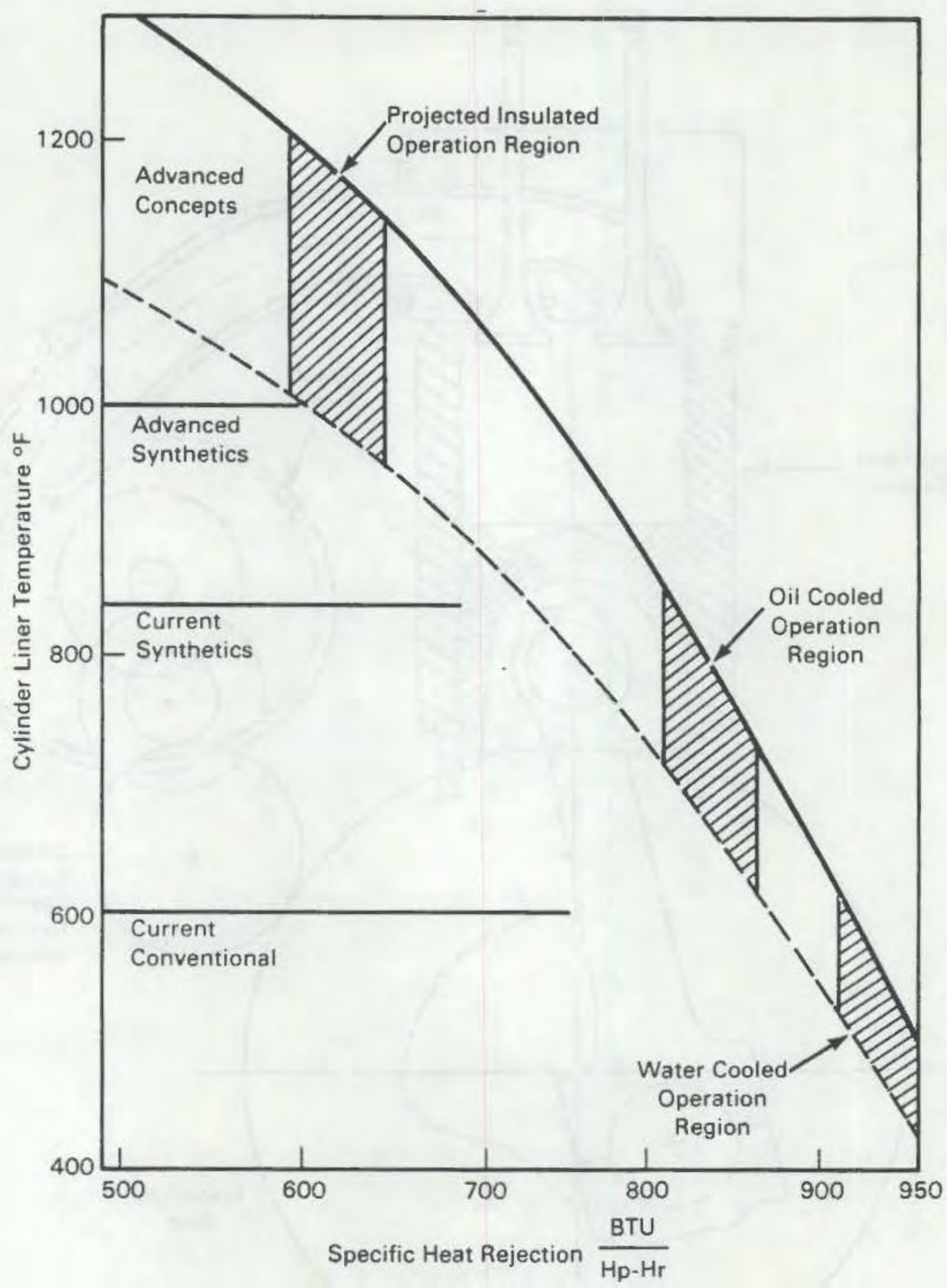

FIGURE 3.7. Expected Cylinder
Adiabatic Diesels $s(a)$ ner Temperatures in Advanced and

(a) Source: Curmins Engineering Company, Columbus, Indiana 


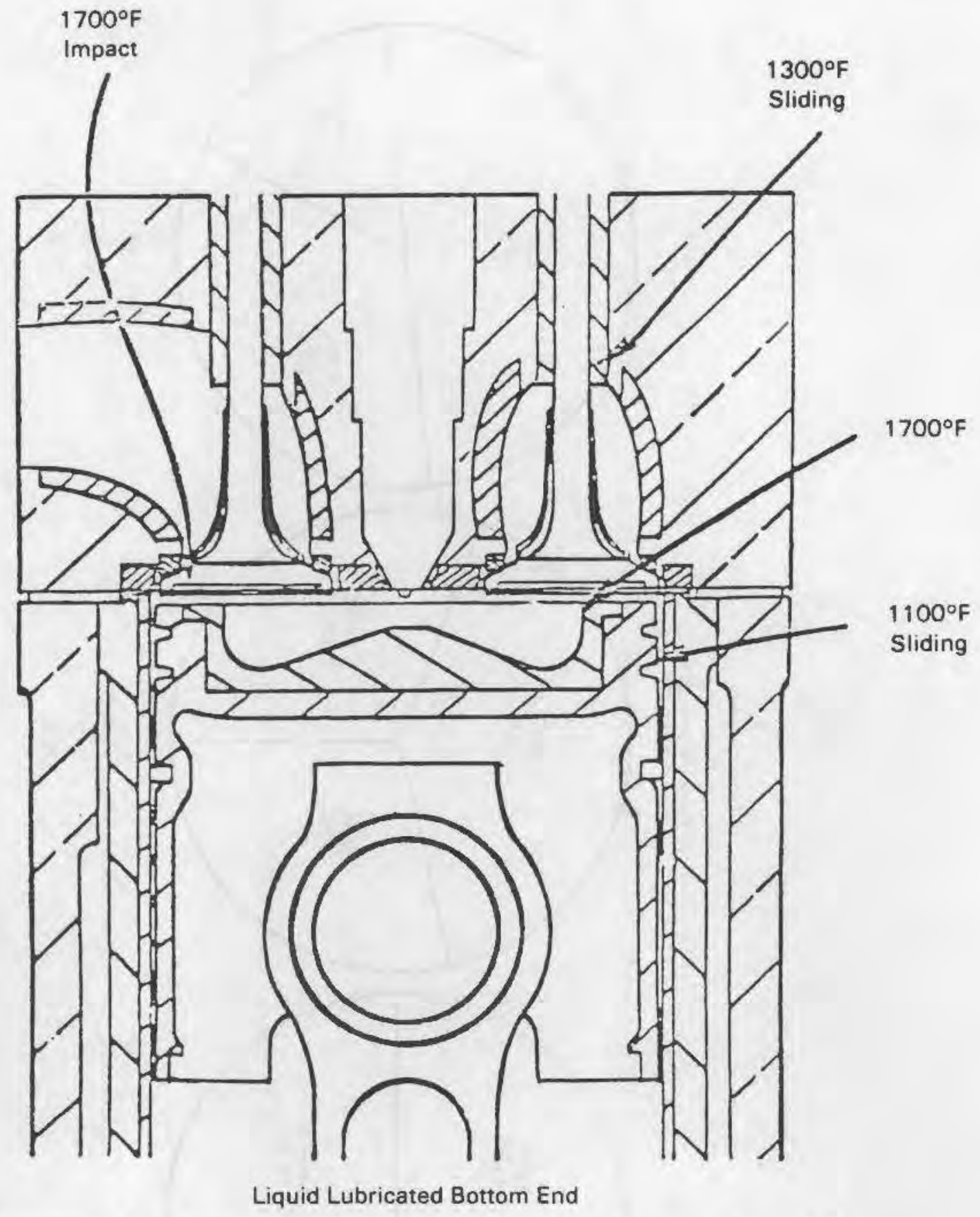

FIGURE 3.8. Critical Adiabatic Diesel Lubrication Areas(a)

(a) Source: Cummins Engineering Company, Columbus, Indiana 


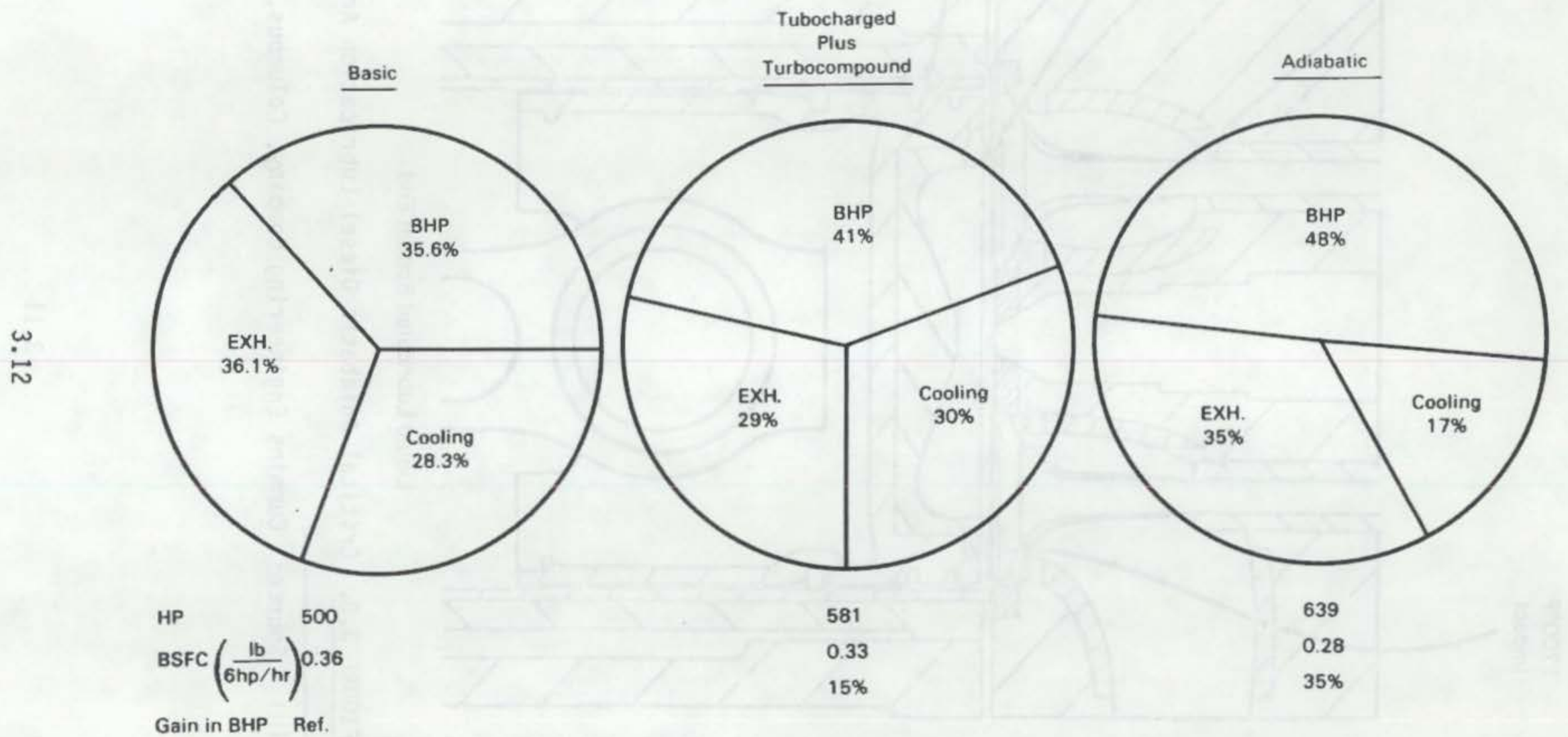

FIGURE 3.9. Efficiency of Advanced and Adiabatic Diesel Engines(11) 
of 30.6. A fluid coupling was used to isolate the turbine from the torsional oscillations of the crankshaft. Ceramic coatings were employed as a means of insulating and protecting engine parts. A ductile case-iron piston coated with $\mathrm{ZrO}_{2}$ was used and the cooling water was entirely eliminated. The amount of insulation was varied so as to obtain a range from free heat transfer to almost complete engine insulation. Figure 3.10 shows efficiency as a function of degree of insulation; at a $55 \%$ level of insulation, a BHP efficiency of $48 \%$ was obtained. The figure also emphasizes the point that turbocompounding adds as much to the rise in efficiency as does the insulation (at 55\%). Oue to the higher temperature, the frictional losses go down as shown in figure 3.11 .

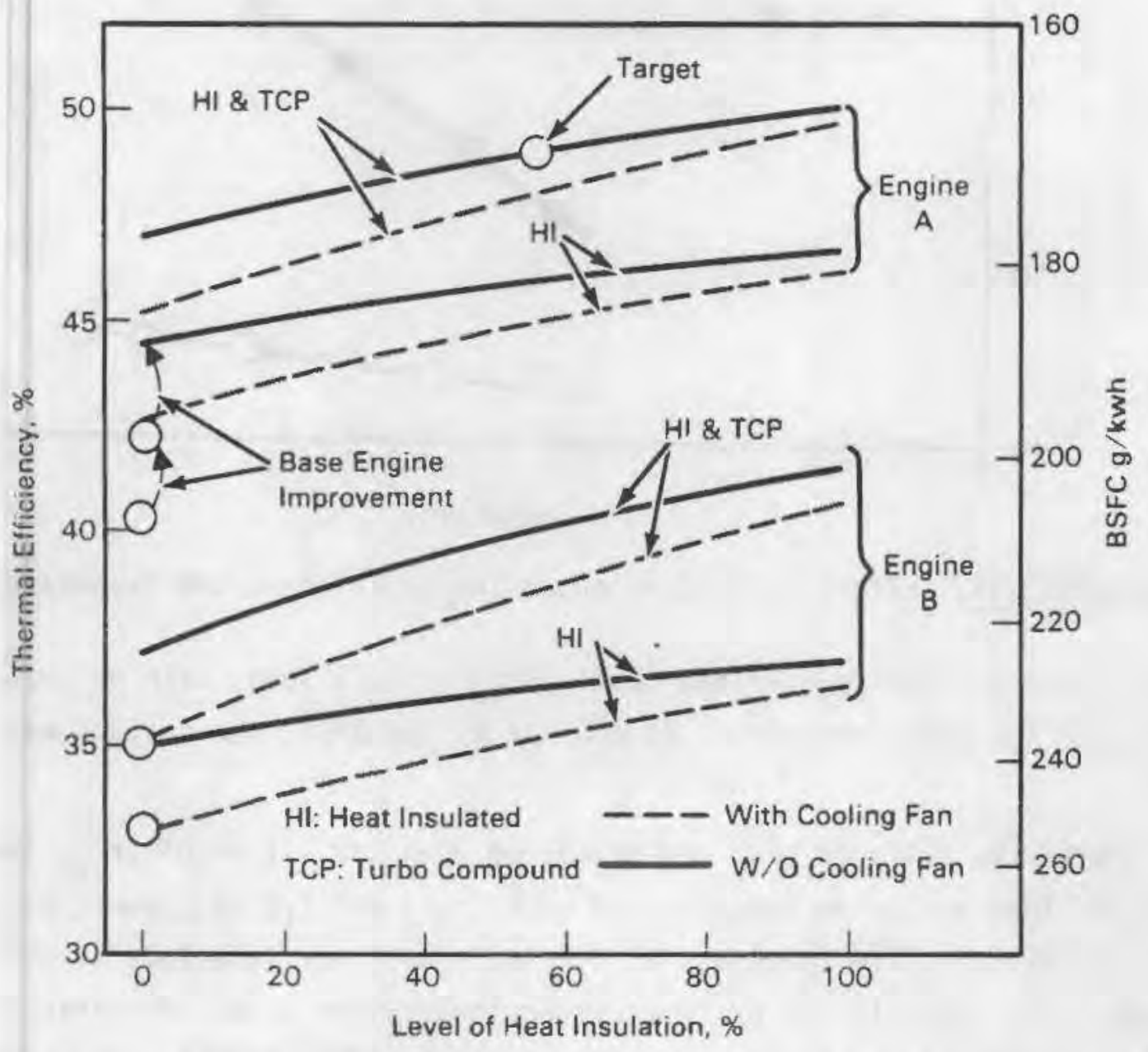

FIGURE 3.10. Effects of Diesel Engine Insulation and Turbocompounding(18) 

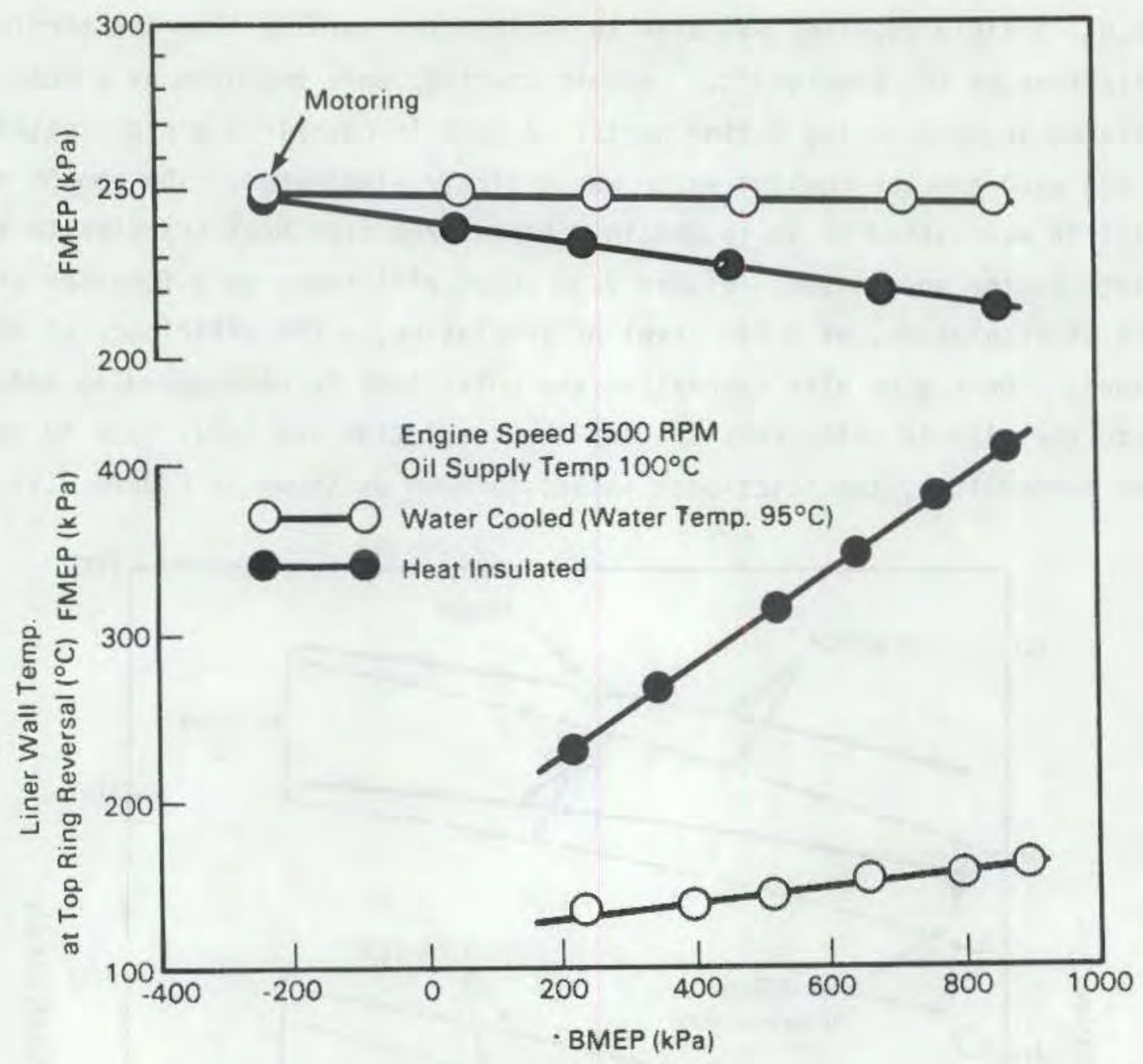

FIGURE. 3.11. Effect of Insulation on Engine Friction and Temperature (18)

These, however, are reduced noticeably only at full load, with no change at idling or low load condition. At $600 \mathrm{Kpa}$ of the BMEP, the savings was about $10 \%$.

While the cylinder head was insulated with $1 / 2-1 \mathrm{~mm}$ of $\mathrm{ZrO}_{2}$, the 1 iner and top rings had to be spray coated with $\mathrm{Cr}_{2} \mathrm{C}_{3}$ and $\mathrm{T}_{i} \mathrm{C}$ to prevent wear due to the reduction in film thickness at the top ring-liner interface as shown in Figure 3.12. The rise in cylinder liner temperature in an adiabatic engine is shown in Figure 3.13 where top temperatures of $350^{\circ} \mathrm{C}\left(660^{\circ} \mathrm{F}\right)$ were reached. These are still reasonable levels and in the tests performed, no damage to any 


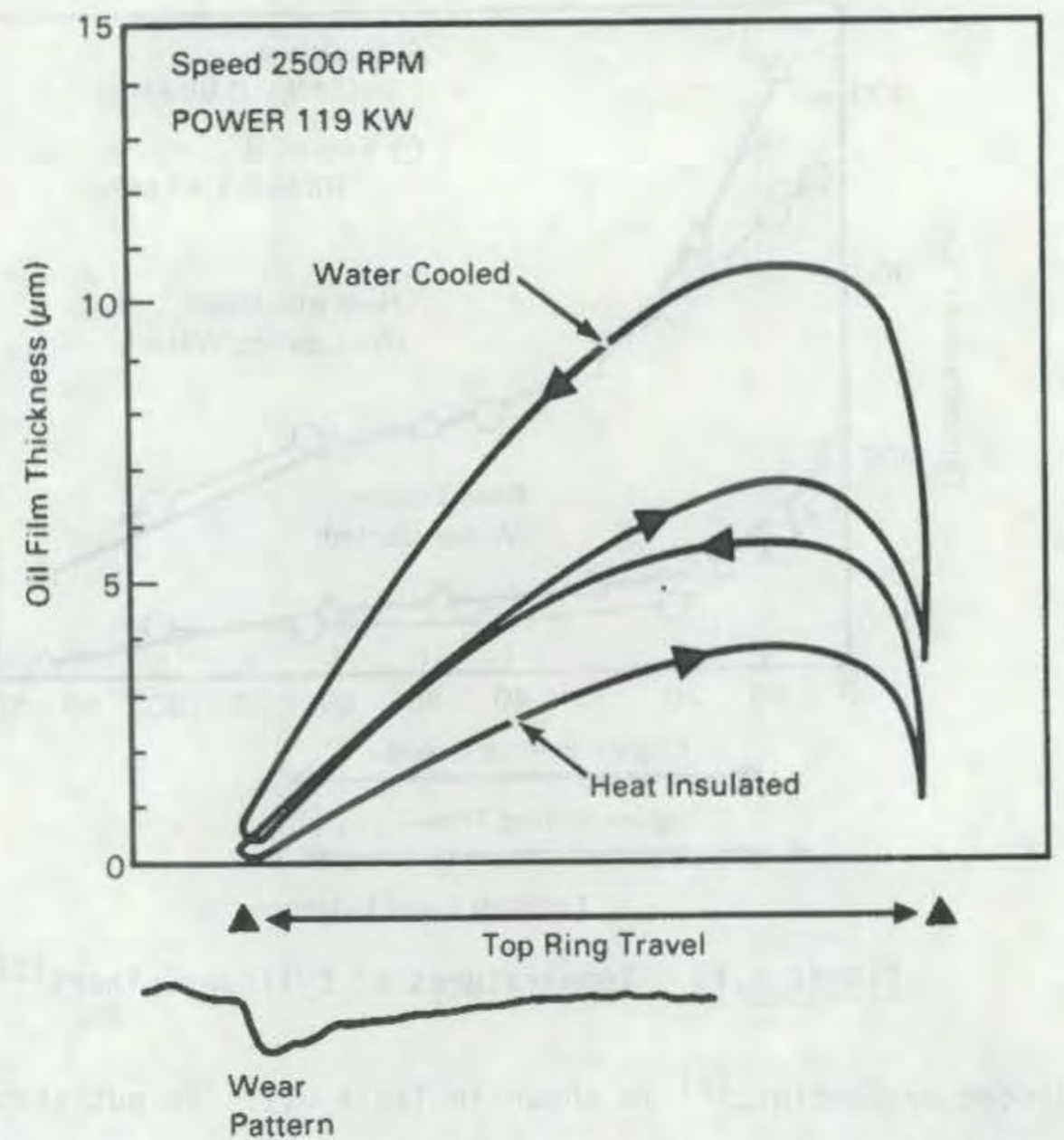

FIGURE 3.12. Calculated 0il Film Thickness 9 f Top Ring and
Cylinder Liner Wear Pattern

of the components was incurred. Both mineral and synthetic oils were used, without undue complications.

The effectiveness of the ceramic coating insulation is shown in Figure 3.14. While the cylinder head could be kept to some $400^{\circ} \mathrm{C}$ and the top piston ring below $300^{\circ} \mathrm{F}$--the exposed surface of the ceramic reached temperatures of $700^{\circ} \mathrm{C}$ and more.

\subsubsection{Levels of Possible Savings}

When the concept of the adiabatic engine is carried to its ultimate conclusion and one dispenses with the liquid lubricant, then the gains occurring in the frictional losses are substantial. A sample gain for three such items 


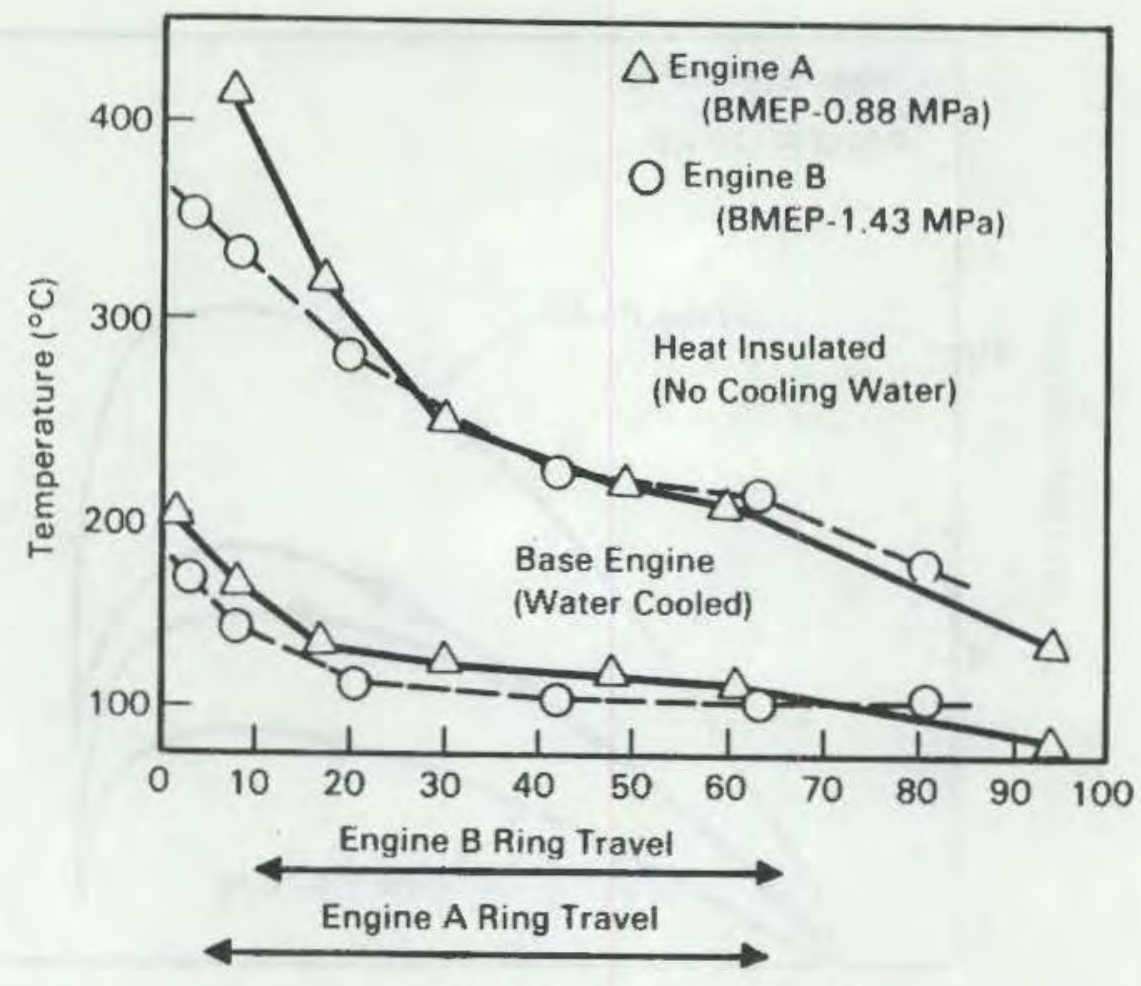

Cylinder Liner Distance (\%)

FIGURE 3.13. Temperatures of Cylinder Liners(18)

as projected by Cummins, $(a)$ is shown in Table 3.1 . To put these numbers in more amenable form, it has been reworked into the form given in Table 3.2. As seen, the frictional losses can be reduced to less than a third of those prevailing in the turbocompound adiabatic diesel engine.

Finally, Table 3.3 shows the potential savings that would result from the introduction of the adiabatic and minimum friction engines into the bus and truck fleets of the U.S. While in terms of total U.S. energy consumption the figures are $1.2 \%$ and $1.7 \%$, in terms of automotive fuel savings these would amount to $6 \%$ and $8.5 \%$, respectively.

(a) Interview at Cummins Engineering Company, Columbus, Indiana. 


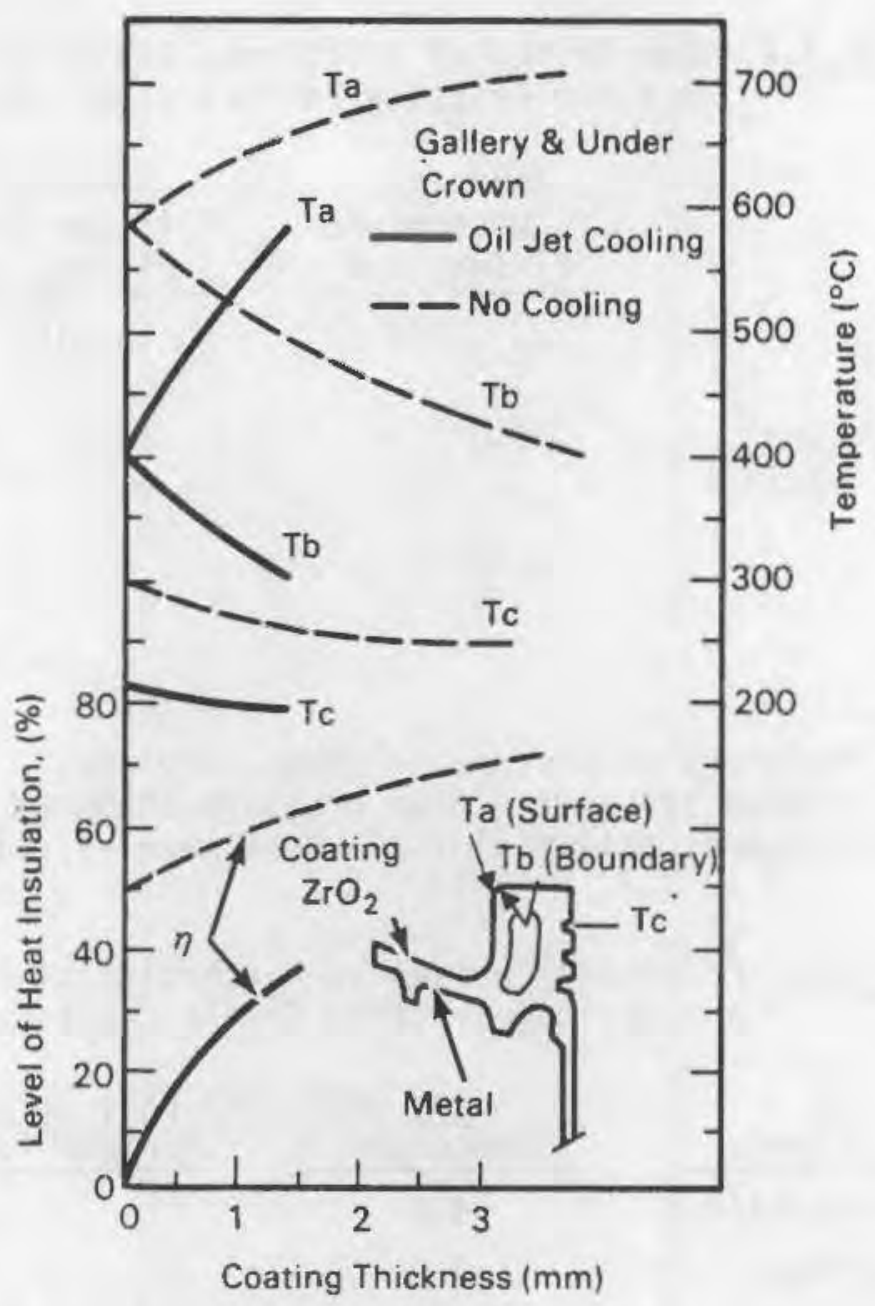

FIGURE 3.14. Effect of Ceramic Coating on Heat
Insulation of Piston Assembly

\subsection{GAS TURBINES}

\subsubsection{General Features}

The power train of a gas turbine-driven automobile contains essentially four major assemblies. One is the power source consisting of the compressorturbine assembly; second are the reduction gears to reduce the high turbine speed to the range of vehicle speeds; third is the transmission; and finally the fourth, a regenerator to recover some of the high temperature exhaust. The power source comes in two basic varieties; the single shaft type shown in Figure 3.15 and the two-shaft shown in Figure 3.16. The essential difference is that in the latter version the compressor is driven by a separate turbine. The 

TABLE 3.1. Comparison of Frictional Losses in Adjabatic and
Minimum Friction Engines $(1900 \mathrm{rpm})$ (a)

\begin{tabular}{|c|c|c|c|}
\hline & $\begin{array}{c}\text { Adiabatic } \\
\text { Turbocompound } \\
\text { Firing, psi } \\
\end{array}$ & $\begin{array}{c}\text { Minimum } \\
\text { Friction Engine } \\
\text { Firing, psi } \\
\end{array}$ & $\begin{array}{c}\text { BSFC } \\
\text { Improvement, } \\
\text { Percent } \\
\end{array}$ \\
\hline Piston/Rings & $10-12^{(b)}$ & $2-3^{(b)}$ & $3-4^{(c)}$ \\
\hline $\begin{array}{l}\text { Connecting Rod and } \\
\text { Crankshaft Bearings }\end{array}$ & $6-8$ & $1-2$ & $2-3$ \\
\hline 0 i1 Pumn & 1.50 & 0 & $<1$ \\
\hline & & & $5-8$ \\
\hline
\end{tabular}

(a) Cummins Engineering Company, Columbus, Indiana.

(b) Portion of mean brake effective pressure consumed by given item.

(c) Working backwards this yields a BHP of mean effective pressure of 243 psi.

TABLE 3.2. Frictional Losses as Percentage of BHP for Adiabatic and Minimum Friction Engines (Based on Table 3.3)

\begin{tabular}{|c|c|c|}
\hline Item & $\begin{array}{l}\text { For BMEP } \\
\text { Turbocompound }\end{array}$ & $\begin{array}{l}3 \text { psi, Percent Loss } \\
\text { Minimum Friction Engine }\end{array}$ \\
\hline Piston/Rings & 4.5 & 1.5 \\
\hline Bearings & 3.0 & 1.0 \\
\hline 0il Pump & 0.6 & 0 \\
\hline
\end{tabular}
8.1
2.5

complexity of the speed map in the prime mover can be gleaned from Figure 3.17 where the speeds are seen to range from $55,000 \mathrm{rpm}$ to $100,000 \mathrm{rpm}$ for the turbine, all the way down to zero forward speed for the axle, as well as a reverse speed.

There are, of course, advantages and disadvantages to a gas turbine driven automobile. Here we will concern ourselves only with those features of such a vehicle which impact the tribological elements. From this standpoint, the advantages are as follows:

- fewer frictional or sliding elements (no piston rings or valve trains) 
TABLE 3.3. Advanced Diesel Engines and Energy Savings on Trucks and Buses (2)

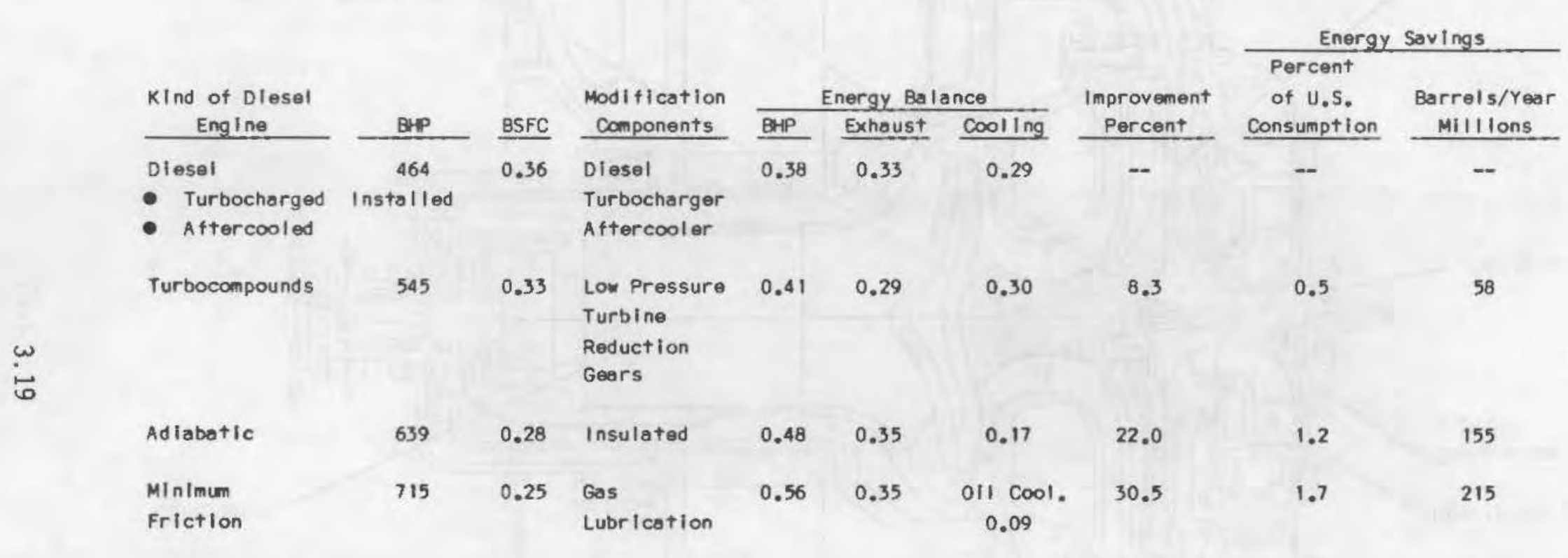




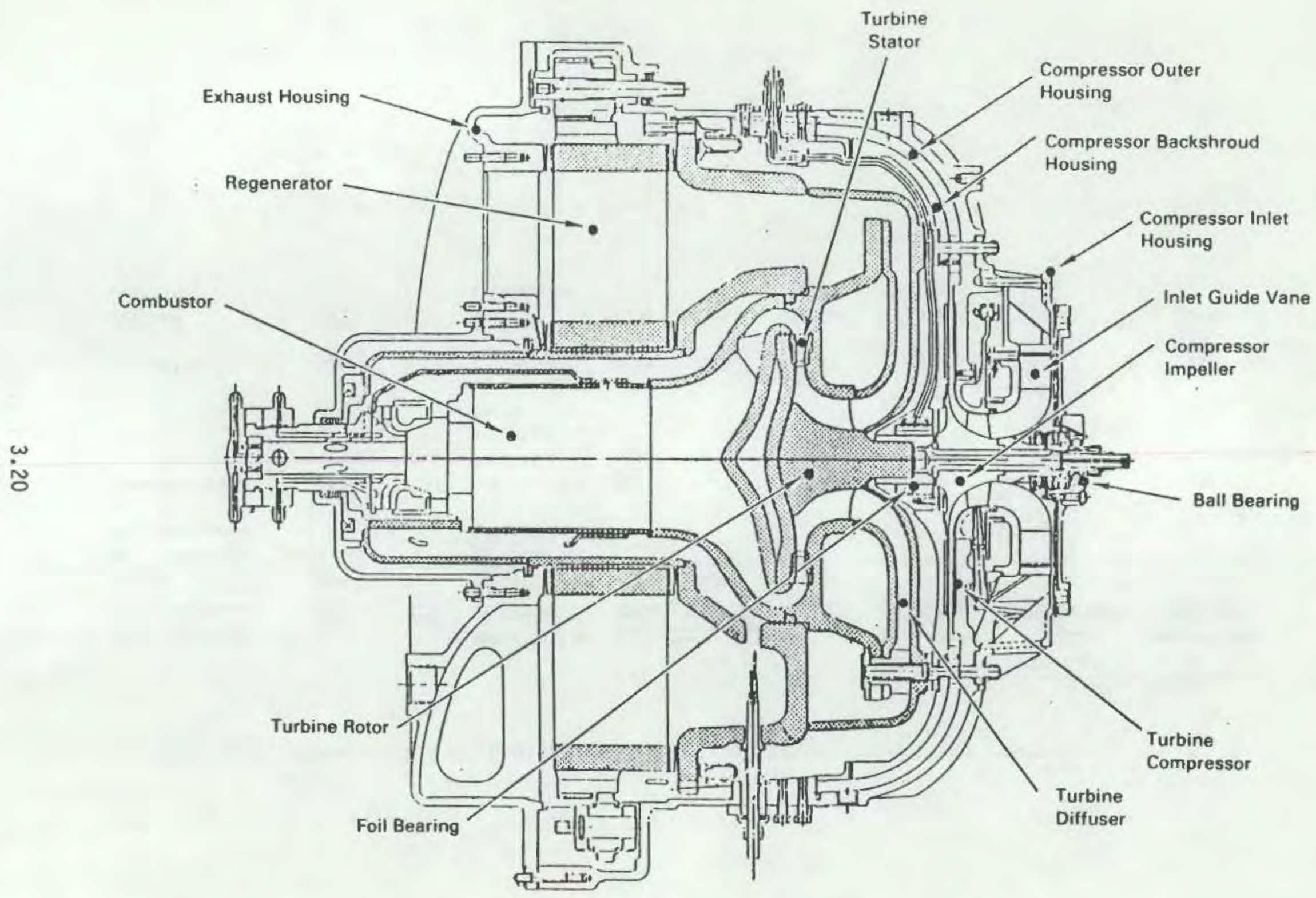

FIGURE 3.15. Single Shaft Automotive Gas Turbine(19) 


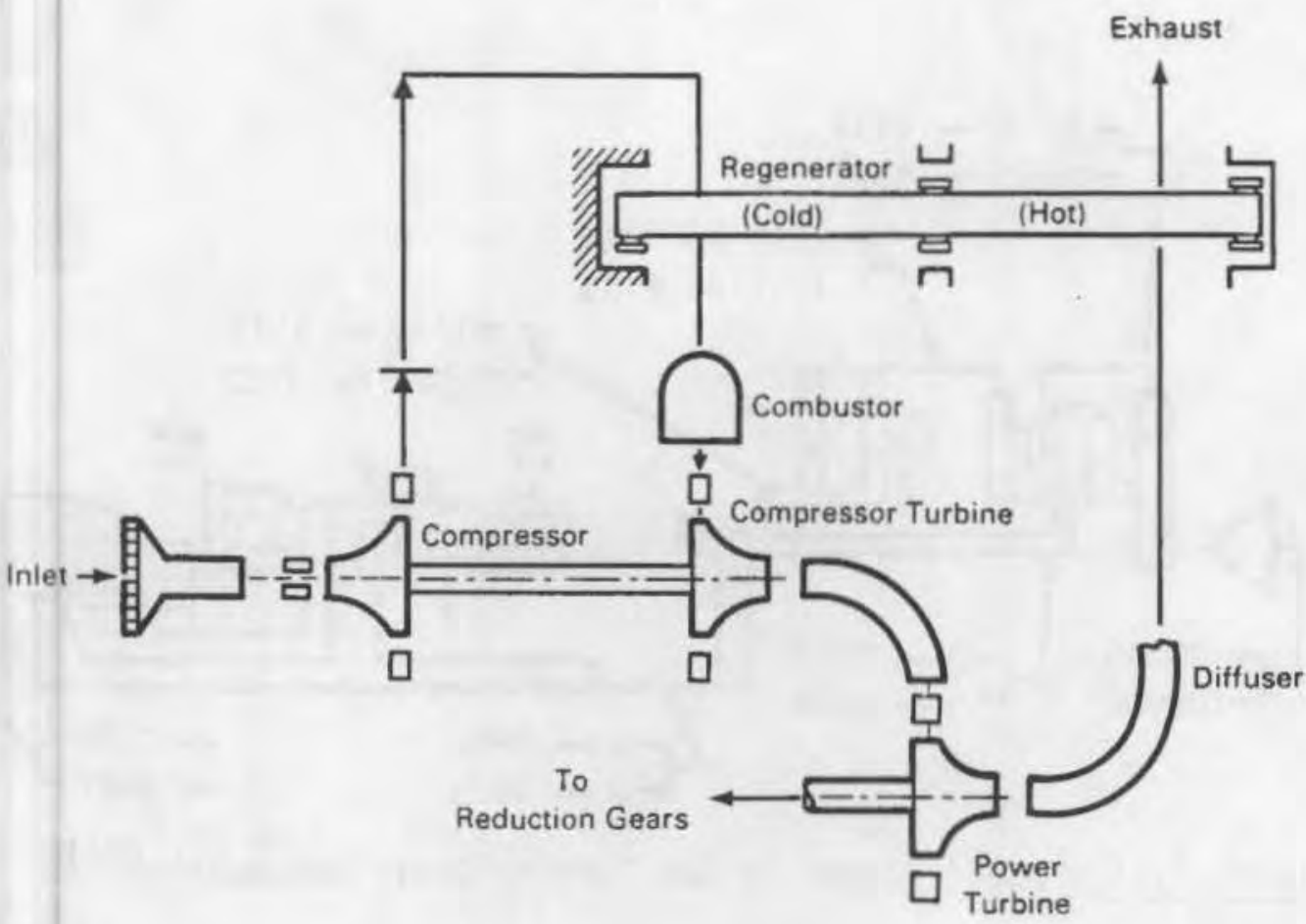

a) Power Train

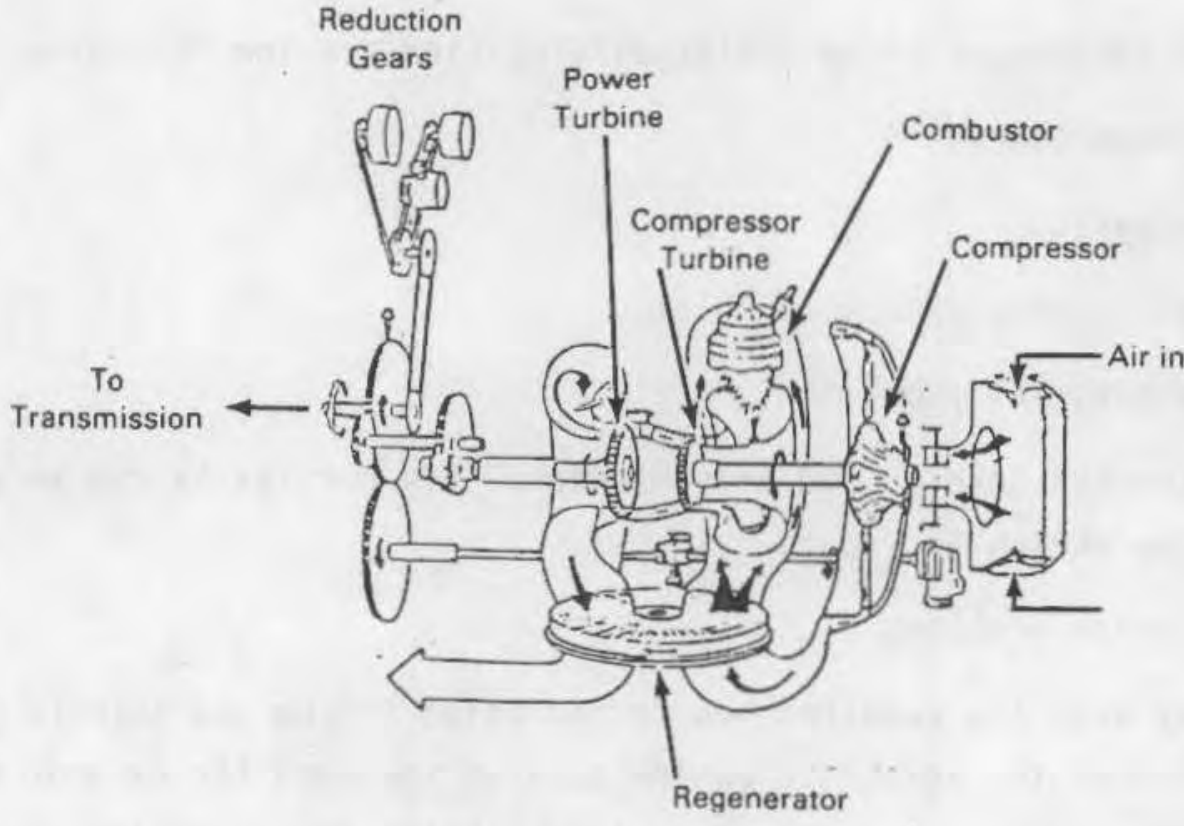

b) Power Train and Reduction Gearings

FIGURE 3.16. Two-Shaft Automotive Gas Turbine(20) 


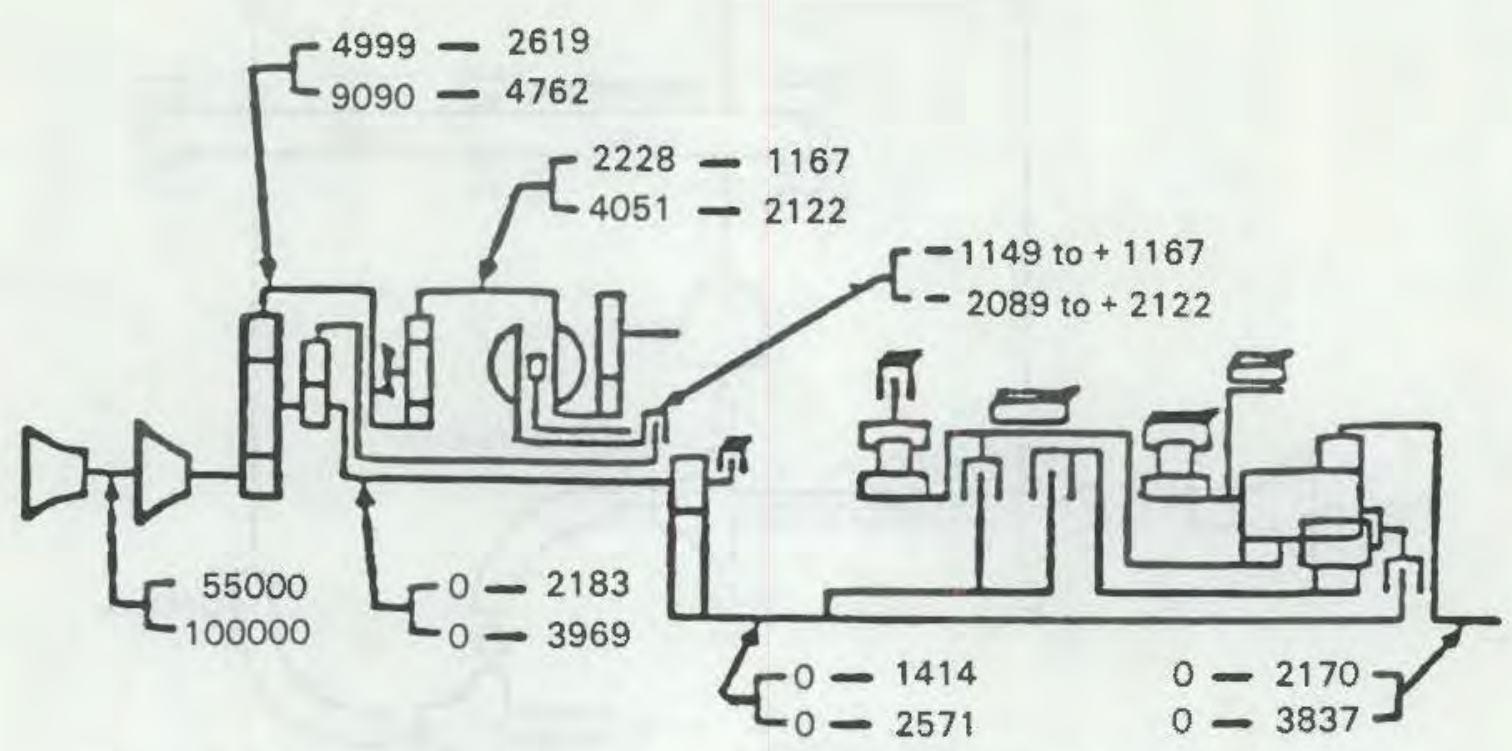

FIGURE 3.17. Speed Ranges in Gas Turbine Drive Automobile (21) $^{(21)}$

- more room for unconventional lubricants

- easier cold starting.

The disadvantages or potential difficulties are the following:

- high temperatures

- high speeds

- potential rotor-dynamic problems

- severe material problems

- more complex gearing and transmission. Its complexity can be gleaned from the sketch in Figure 3.18.

- fabrication problems.

In many ways the required new technologies in the gas turbine vehicle overlap those of the adiabatic engine such as the need for ceramic materials for high temperatures; reduction gearing to bring down the high turbine speeds; requirement for supercharging main prime mover; and a more complex transmission. This is in a way fortuitous for it leaves open the application of any new materials and components to either of the two vehicles. Another common 


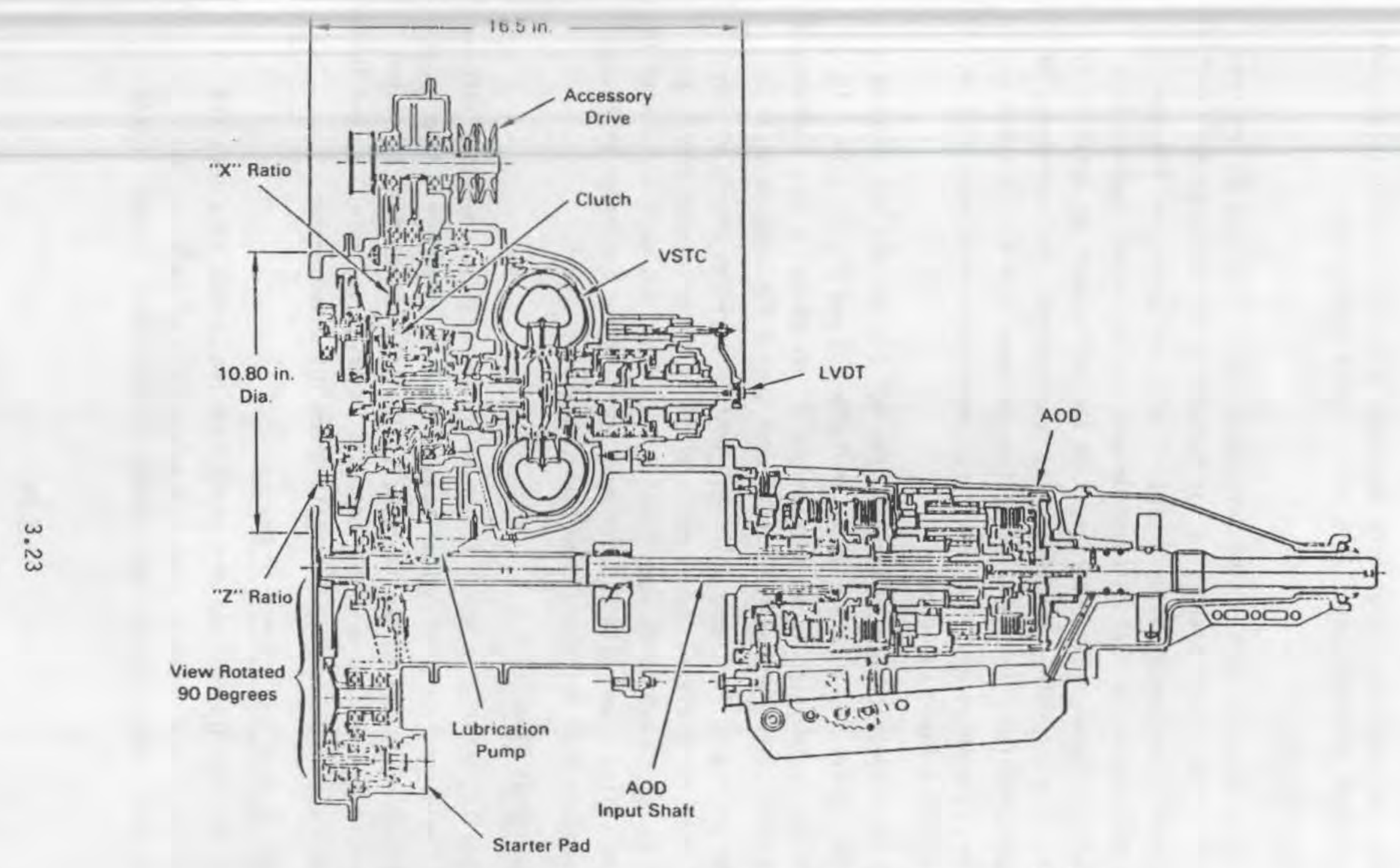

FIGURE 3.18. AGT 101 Gearbox and Transmission Layout (19) 
feature of the two engines is that both are most efficient at full load conditions and have poor performance at idle and low-load operation.

3.4.2 Development Data

Table 3.4 summarizes some of the development work conducted during the last ten years or so in the field of a gas turbine-driven automobiles. Most of the ongoing work is concentrated on a single shaft configuration, the goal being a $30 \%$ improvement in fuel consumption over an equivalent compact SI vehicle. Much of the work is concentrated on the replacement of metallic by ceramic parts in the turbine, combustor, and regenerator. The dependence of power and fuel efficiency on the level of temperatures possible is shown in Table 3.5, the rise in permissible levels of temperature being dependent on the ever wider use of ceramic materials.

The gains in fuel economy achieved by the AGT 101 and AGT 102 version of the gas turbine-driven vehicle are shown in Table 3.6 and Figure 3.19. As seen, on the EPA cycle there is an improvement of one-third in fuel consumption vis-a-vis the SI engine, $10 \%$ against the diesel engine (at 3100-1b vehicle weight). But as Figure 3.20 shows, the AGT vehicle performs poorly at low speed (part load) conditions. Thus, while at 40 to $50 \mathrm{mph}$ steady speed, the $\mathrm{mpg}$ is over 50, at $10 \mathrm{mph}$ it is more like $15 \mathrm{mpg}$. That has much to do with the fact that the idling speed of a 100,000 rpm turbine is on the order of 50,000 rpm with attendant high frictional and other parasitic losses.

\subsubsection{Tribological Elements}

Since the AGT vehicle is still in the development stage, detailed information on the losses of its tribological components is unavailable. Some general data are given in Figure 3.21 and Table 3.7. The information from these two sources has been reworked to a common base and is given in Table 3.8 , and these data will be given in some of the specific items discussed below:

- Internal Turbine and Compressor Losses

In Section 8.0 dealing with steam turbines, there is a detailed description of the internal loss characteristics of turbines and compressors. These include such things as interstage leakage, blade 
TABLE 3.4. Development Work on Gas Turbine Driven Automobile Vehicle Weight $31001 \mathrm{~b}(19,20)$

\begin{tabular}{|c|c|c|c|c|c|c|c|c|c|}
\hline Eng Ine & $\begin{array}{l}\mathbb{H P}_{(\max )} \\
\end{array}$ & $\begin{array}{l}\text { Projected } \\
\text { Gain } \\
\text { Percent } \\
\end{array}$ & $\begin{array}{l}\text { Mpg } \\
\text { on } \\
\text { EPA } \\
\text { Cycle } \\
\end{array}$ & $\begin{array}{c}\text { Number } \\
\text { of } \\
\text { Shafts } \\
\end{array}$ & $\begin{array}{c}\text { Turblne } \\
\text { Inlet } \\
\text { Temperature } \\
\text { F }\end{array}$ & Transmission & $\begin{array}{c}\text { Turbline } \\
\text { Speed } \\
\text { rpm } \\
\end{array}$ & Company & Remarks \\
\hline Base S1 & 90 & Ref. & 19.6 & - & - & $\begin{array}{l}\text { 3-speed } \\
\text { automatic }\end{array}$ & & & 1976 \\
\hline IGT & & 20 & 23.5 & 2 & 2350 & $\begin{array}{l}\text { 3-speed } \\
\text { automatic }\end{array}$ & & $\begin{array}{l}\text { NIII lams } \\
\text { DDA-PontIac }\end{array}$ & $\begin{array}{l}\text { With ref. to } 1976 \\
\text { Si engine }\end{array}$ \\
\hline AGT-101 & 100 & 30 & 36 & 1 & 2500 & VSTC & 100,000 & Garrett/Ford & \\
\hline AGT-102 & 90 & 30 & 36 & 1 & 2300 & CUT & 100,000 & $\begin{array}{l}\text { Chrysler/ } \\
\text { williams }\end{array}$ & $\begin{array}{l}\text { As compared to } 26 \mathrm{mpg} \\
\text { for Si engine }\end{array}$ \\
\hline
\end{tabular}


TABLE 3.5. Variations of the AGT-101 Powertrain(19)

\begin{tabular}{|c|c|c|c|c|}
\hline & $\begin{array}{l}\text { Mod I } \\
\text { Build } 1\end{array}$ & Mod I & Mod II & RPD \\
\hline Reference Fuel & Gasoline & Gasoline & $\mathrm{DR}-2$ & Gasoline \\
\hline CFDC (mpg) (3163 ib Vehicle) & $\mathrm{N} / \mathrm{Aq}$ & 30 & 41.4 & 36 \\
\hline Cruise sfc & 0.503 & 0.309 & 0.329 & 0.329 \\
\hline Maximum rpm & 100,000 & 100,000 & 100,000 & 100,000 \\
\hline Maximum Power (hp net) & 50 & 93.6 & 100 & 130 \\
\hline Turbine Inlet Temperature $\left({ }^{\circ} \mathrm{F}\right)$ & 1,600 & 2,100 & 2,500 & 2,500 \\
\hline Regenerator Maximum Temperature $\left({ }^{\circ} \mathrm{F}\right)$ & 1,441 & 1,936 & 2,000 & 2,000 \\
\hline \multicolumn{5}{|l|}{ Materials } \\
\hline - Compressor & 2219 T6 & PM Alum & PM Alum & PM Alum \\
\hline - Turbine & Metal & Metal & Ceramic & Ceramic \\
\hline - Structures & Metal & Ceramic & Ceramic & Ceramic \\
\hline
\end{tabular}

TABLE 3.6. EPA Performance for GT and SI Automobiles (mpg) (22)

\begin{tabular}{|c|c|c|}
\hline Cycle & AGT-102 & Baseline SI \\
\hline City, Hot & 34 & 23 \\
\hline City, Cold & 29 & 22 \\
\hline Highway & 49 & 32 \\
\hline Combined & 35 & 28 \\
\hline
\end{tabular}

friction, windage, and others. According to Table 3.8, then, these losses, most of which are tribological in nature amount to about $12 \%$ of the input energy.

- Seal and Flow Paths

The outright mass leakage which aets past the shaft sealing ranges from $2.3 \%$ to $1.5 \%$. To this can be added a portion of the $3.0 \%$ ascribed to pressure drops since with better flow paths this energy loss, too, could be reduced. Assigning half of these losses to tribological causes, we obtain $3.4 \%$ as the combined loss due to imperfect piping and sealing. 


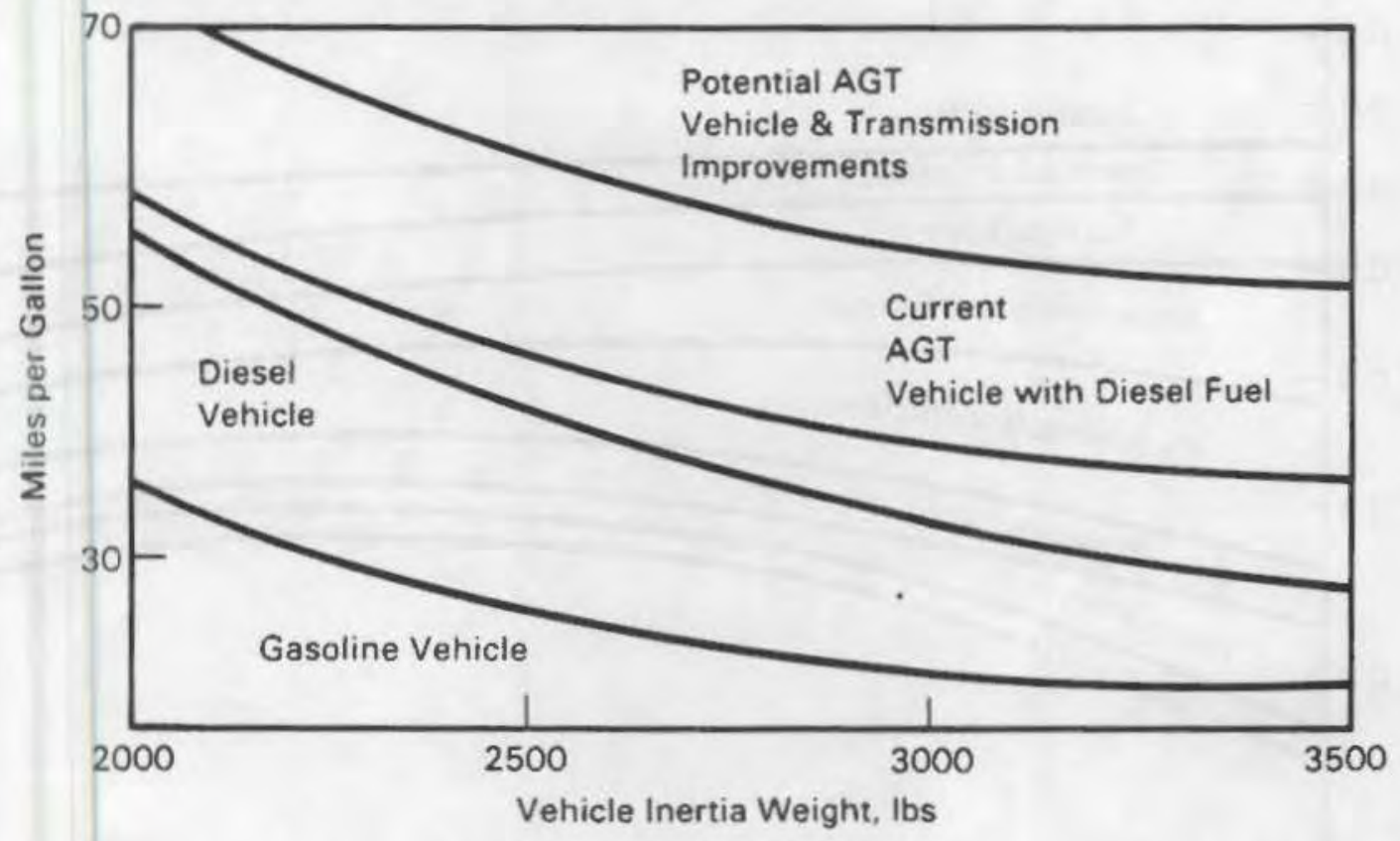

FIGURE 3.19. Projected Fyel Economy for AGT 101 Versus Diesel and SI Vehicles 23$)$

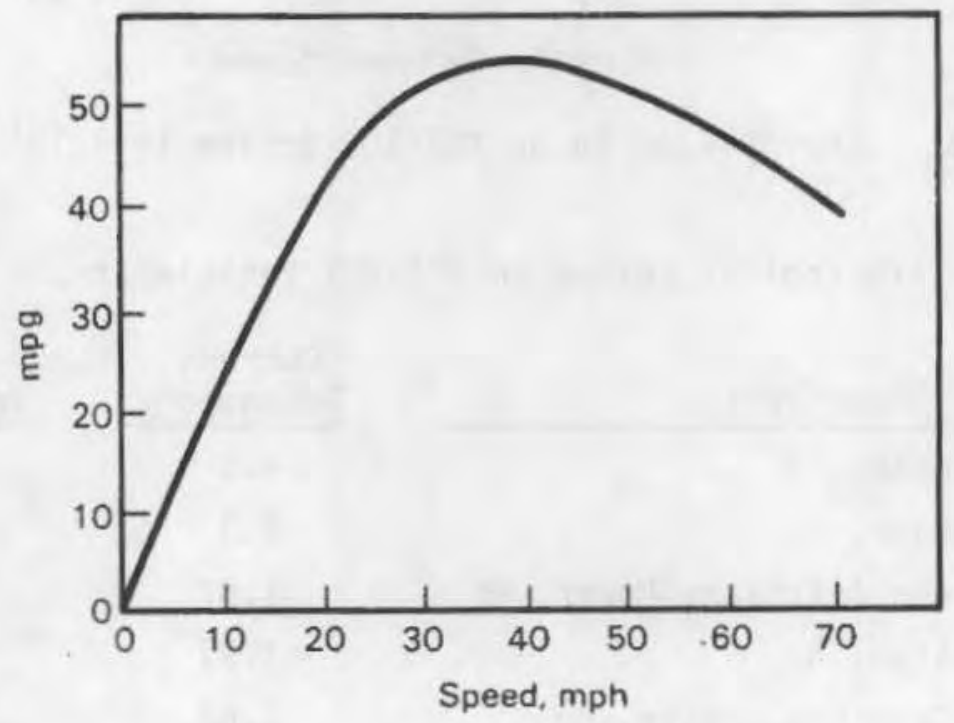

FIGURE 3.20. GT Vehicle Performance as Function of Speed (9) 


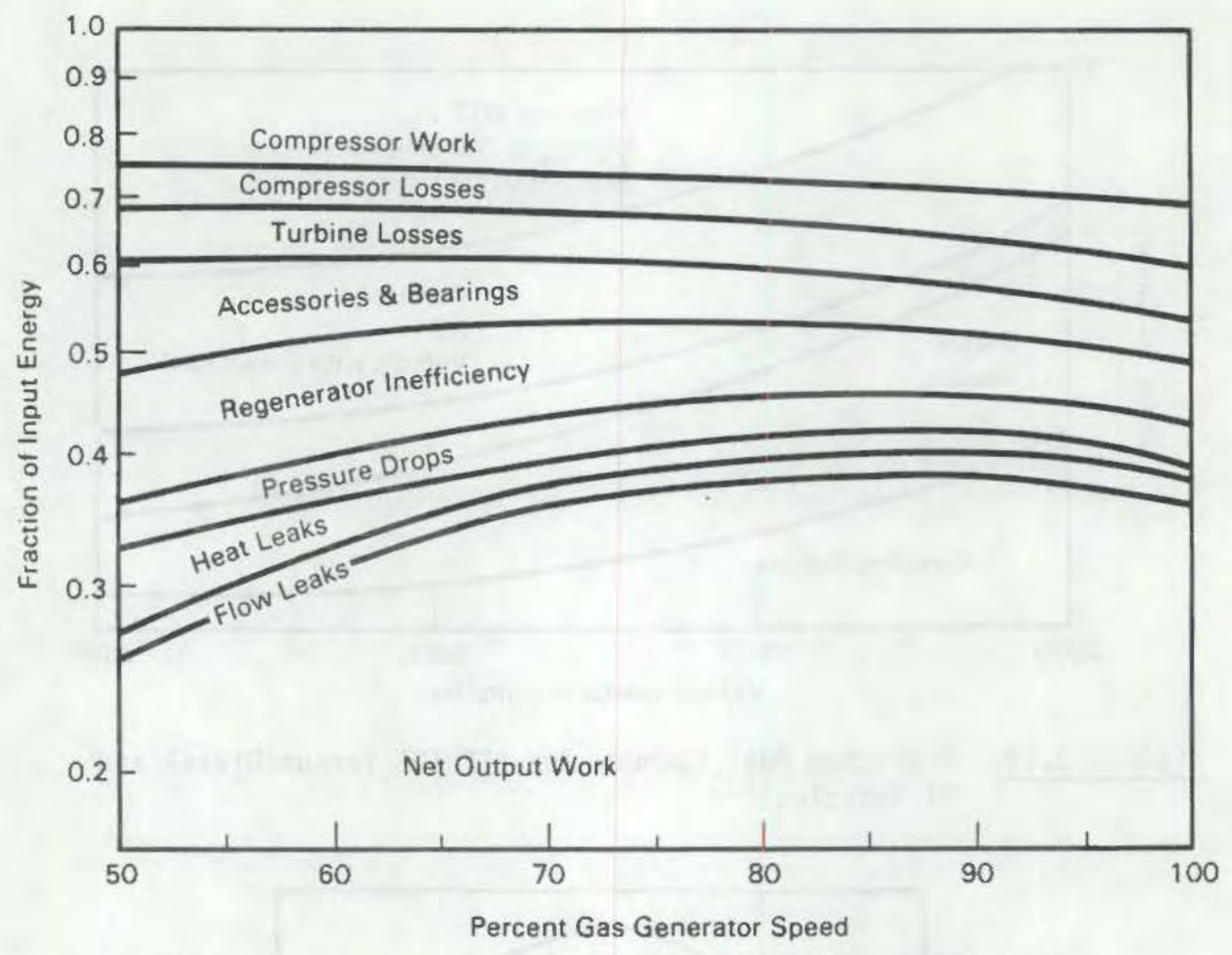

FIGURE 3.21. Energy Flow in an AGT-102 Driven Vehicle ${ }^{(16)}$

TABLE 3.7. Tribological Losses in AGT-101 Vehicle at $20 \%$ Power (16)

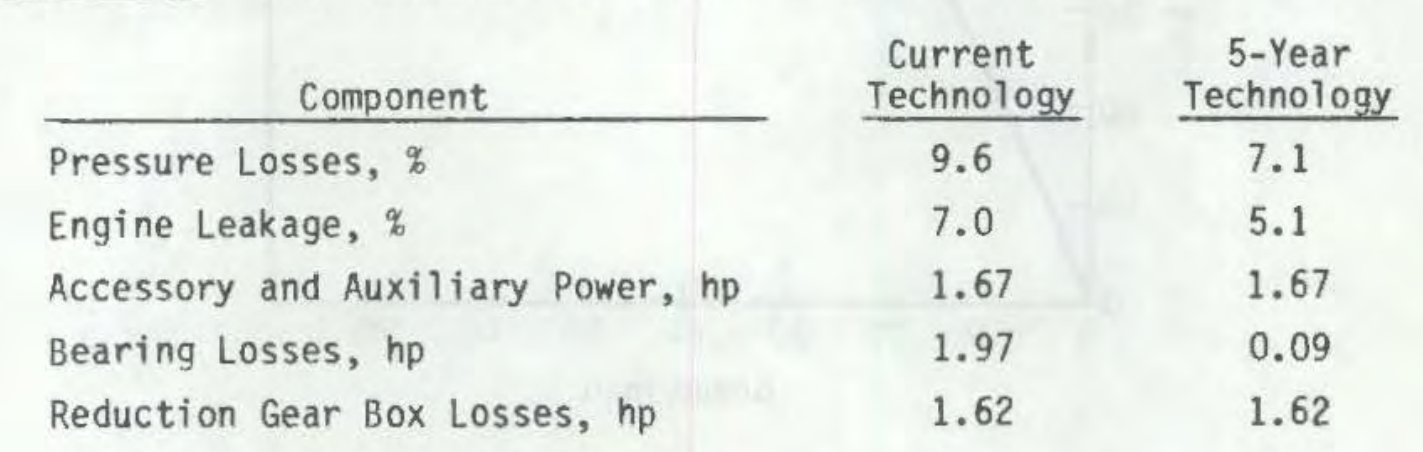


TABLE 3.8. Energy Consumption in AGT Vehicles

\begin{tabular}{|c|c|c|c|c|c|c|c|c|}
\hline & & Con & dition & & & Item & & $\begin{array}{l}\text { Percent of } \\
\text { Input Energy }\end{array}$ \\
\hline $75 \%$ & Tur & rbine $\mathrm{S}$ & speed, 1 & Figure & 3.21 & Flow Leaks & & 1.5 \\
\hline & & & & & & Turbine Losses & & 6.0 \\
\hline & & & & & & Compressor Loss & & 6.0 \\
\hline & & & & & & Accessories and & earings & 8.0 \\
\hline & & & & & & Pressure Drops & & 3.0 \\
\hline & & & & & & Heat Leaks & & 2.5 \\
\hline & & & & & & Regenerator Los & & 9.0 \\
\hline & & & & & & Compressor Work & & 28.0 \\
\hline & & & & & & Output Work & & 36.0 \\
\hline & & & & & & & & $(100.0)$ \\
\hline & & & & & & & Present & Projected \\
\hline At & $20 \%$ & Power, & , Table & 3.7 & & Pressure Drops & 3.2 & 2.4 \\
\hline & & & & & & Engine Leakage & 2.3 & 1.7 \\
\hline & & & & & & Bearing Losses & 0.7 & 0.039 \\
\hline & & & & & & Gearbox Losses & 0.65 & 0.65 \\
\hline
\end{tabular}

- Bearings

The use of ball bearings accounts for about $0.7 \%$ in frictional 10ss. However, the significance of the kind of bearings extends far beyond their energy consumption for they determine the levels of allowable temperatures in the power plant. Under the condition of the high speeds and high temperatures, gas bearings are an ideal candidate to replace oil-1ubricated bearings. One such candidate, the Hydresil bearing, is shown in Figure 3.22. The advantages of such a bearing are:

- compatibility with high temperatures

- reduced power losses

- no oil supply requirements

- elimination of oil seal, and oil coking at turbine end 

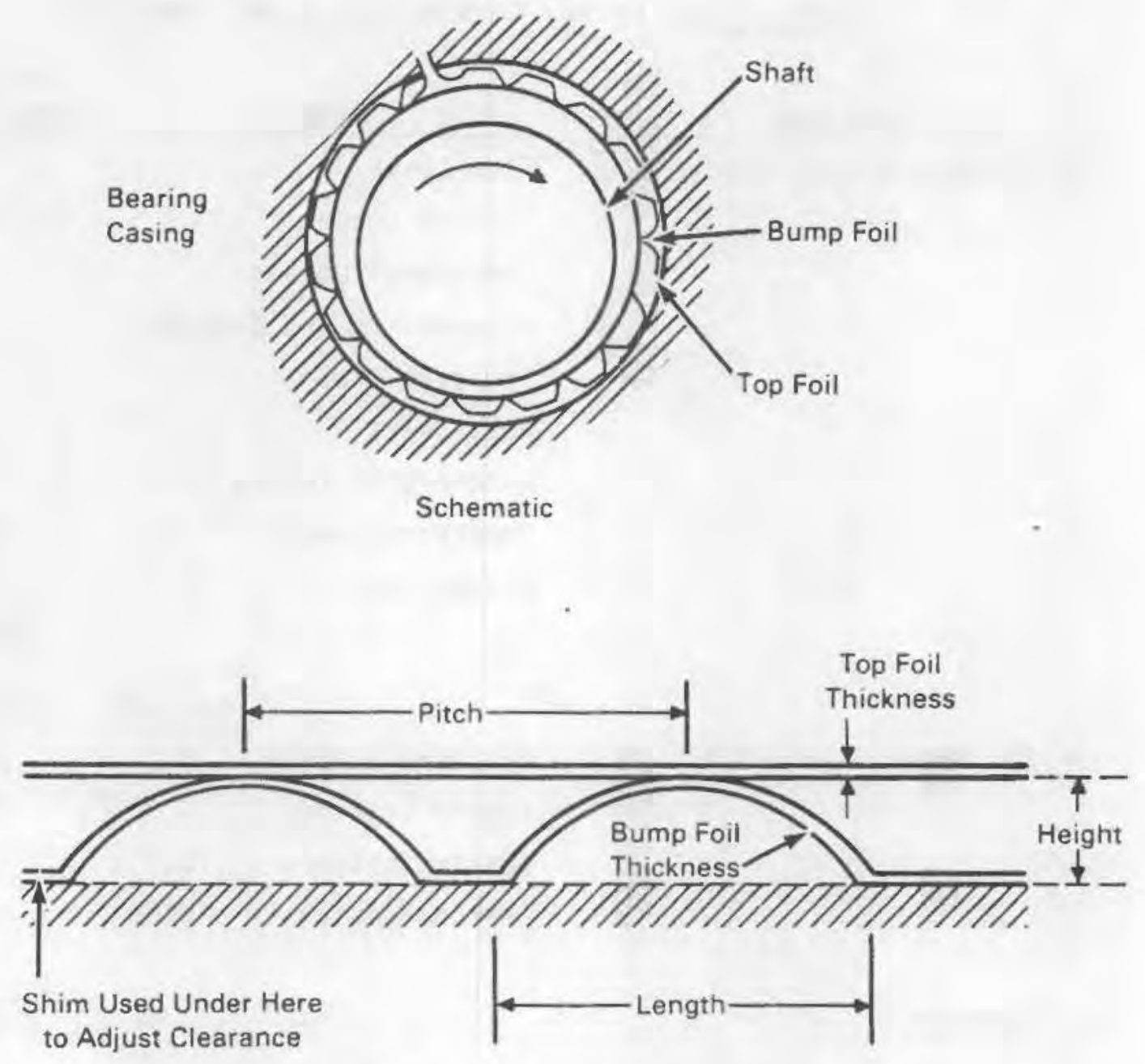

Details of Bearing

FIGURE 3.22. Hydresil Journal Bearing(24)

- accommodation of rotor misalignment, thermal distortion and dirt ingestion

- longer life relative to other bearing systems

- potential for development to higher speeds and turbine inlet temperatures.

For an elevated temperature environment, such as a gas turbine, the air bearing foils are made from Inconel $X-750$ and a dry film coating is bonded to the surface of the top foil to handle the sliding contacts during starting and 
stopping. A commercially available, bondable $\mathrm{MoS}_{2}$ foil coating and a flamesprayed and ground chrome-carbide journal are possible candidates.

The detailed savings due to the use of air bearings are given in Table 3.9 which gives the results of a study which showed that $4 \mathrm{hp}$ would be saved in the gas generator by the complete elimination of oil bearings, oil seals and oil pumping losses, and the substitution of an all air bearing system. There would be some increase in cooling air requirements, but it is believed that this need can be minimized. Results of development work ${ }^{(24)}$ performed to demonstrate the viability of a compliant foil air bearings for the gas generator of an automotive gas turbine when operating at $58,500 \mathrm{rpm}, 500^{\circ} \mathrm{F}\left(260^{\circ} \mathrm{C}\right)$ and $23.3 \mathrm{psi}$ $\left(16.1 \times 10^{4} \mathrm{~N} / \mathrm{m}^{2}\right)$ loading has yielded a saving of $1 \mathrm{hp}$, about $1 \%$ of the energy input.

\subsubsection{Reduction Gears}

Due to the high-speed reduction requirements there is a need for at least two stages of reduction gearing. In the AGT-102, there is a front-wheel drive arrangement with the engine mounted transversely above the transaxle. A 20 to 1 , two-stage reduction gear couples the two components together. A response

TABLE 3.9. Friction Hp Power Savings with an All Air Foil Bearing System (24)

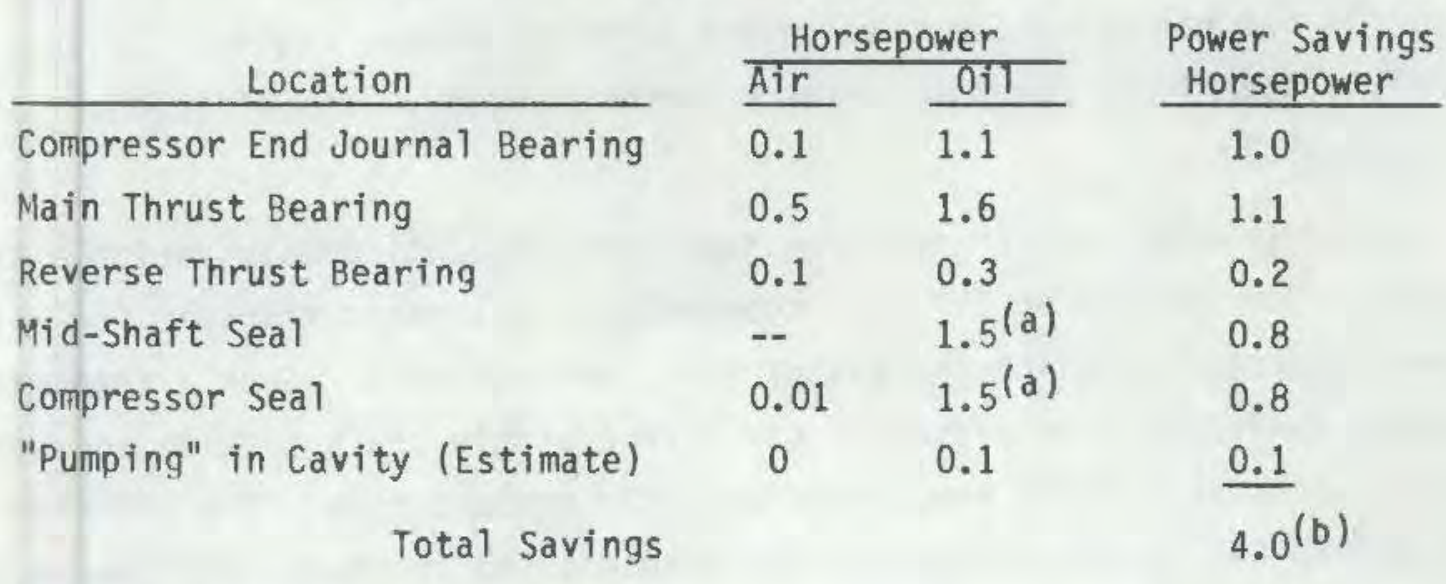

(a) Based on complete oil film.

(b) Additional to $\mathrm{hp}(0.74 \mathrm{~kW})$ saved using air bearing at turbine. 
assist flywheel is attached to the drivetrain at the first stage reduction gear where it rotates counter to the turbomachinery shaft. Accessories and auxiliaries are driven from an idler gear in the second reduction stage. Weight is minimized through the use of cast aluminum for the reduction gear and transaxle housings.

In the AGT-101, speed is reduced in the first planetary gear set with a portion of the engine power provided directly to the output shaft through the rotating planet carrier. Part of the power is "split" and carried via the first ring gear through a reversing gearset to the variable stator torque converter (VSTC). VSTC output power is routed through a clutch and returned, via a ring gear, to the compound planet supported on the carrier. About $35 \%$ of engine power is routed through the VSTC under normal operation thereby minimizing losses. The gearbox allows the gas turbine to operate at any desired speed while the gearbox output is varied to match input speed requirements. The estimated energy consumed by the gearbox is about $1 \%$ of the full energy, or about $3 \%$ of the output.

\subsubsection{Transmission}

The various transmissions proposed for the GT vehicle are all fairly complex arrangements. These can in general be subdivided into conventional and CVT systems. Of the first category, the orshansky hydromechanical transmission, (16) has had extensive development with the piston engine. It should be readily adaptable to the single-rotor turbine engine. Its efficiency is shown in Figure 3.23.

A single-shaft engine requires some form of continuously variable transmission. One concept of CVT is a conventional automatic transmission with torque converter in which the stator vanes are variable. Such a transmission has been evaluated in a passenger car with a single-shaft turbine and was found to have acceptable shift smoothness and idle creep torque. The efficiency of a belt-driven CVT versus a conventional transmission is shown in Figure 3.24. The lower CVT efficiency is more than made up by the raised engine efficiency due to its running at optimum speed load ratio. 


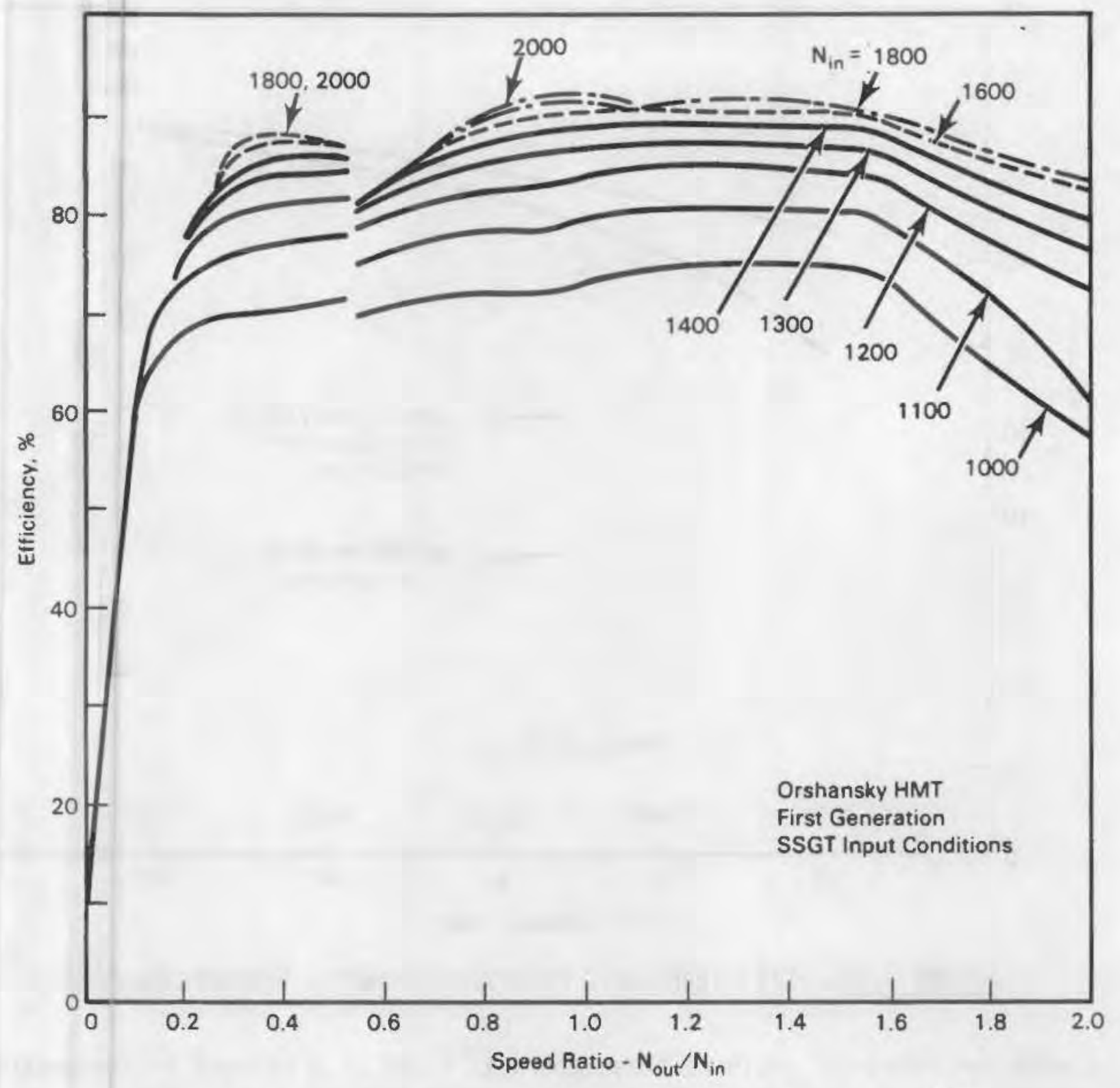

FIGURE 3.23. Hydromechanical Transmission Efficiency (16)

Two other transmission concepts have been studied in addition to conventional four-speed variable stator torque converter (VSTC) automatic transmissions: a split power differential reduction gear with VSTC in which $50 \%$ of the power passes through the torque converter, and a split power differential reduction gear with a traction drive. The latter concept requires a slip 


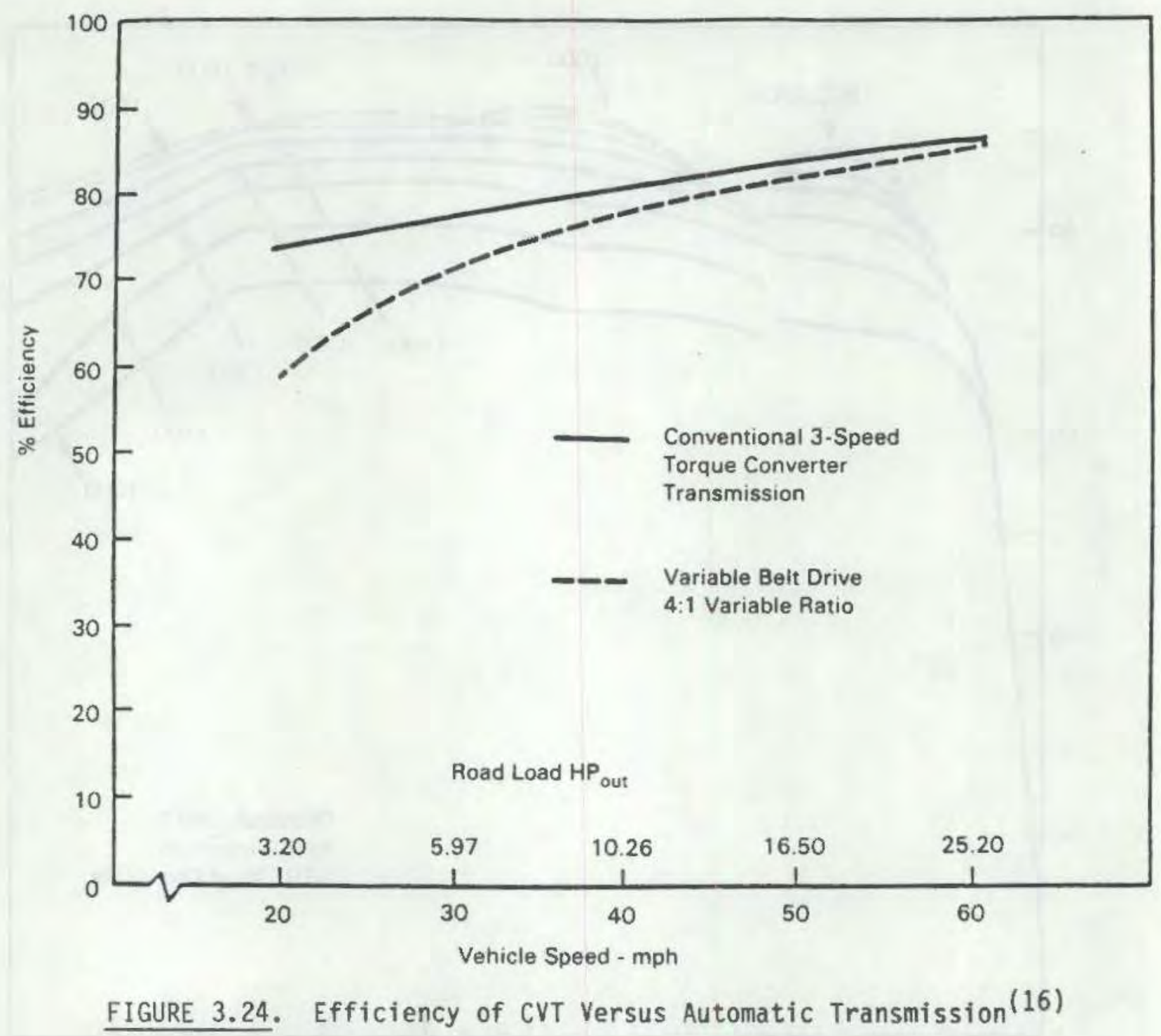

clutch for start-up. Both of these concepts could also be used in conjunction with a conventional four-speed automatic gearbox. The potential fuel economy improvement is as follows:

\begin{tabular}{ll}
\multicolumn{2}{c}{ Fuel Economy Improvement (32) } \\
\hline Split Power VSTC & $13 \%$ \\
Split Power Traction Drive & $24 \%$
\end{tabular}

The variable belt transmission was found to be the most efficient of the CVT types. At high vehicle speeds, it also compares favorably with a conventional 
automatic transmission which is the logical candidate for a two-shaft engine. However, at low speed and power levels, the conventional automatic transmission is more efficient by a significant amount, Figure 3.25. This difference is caused by the variable belt CVT charging pump, whose power requirement la loss to the system) is relatively constant and, therefore causes a larger percentage loss at reduced levels of transmitted power. The power loss in the transmission can be estimated from Figure 3.25 . At $40 \mathrm{mpg}$, this amounts to a loss of $14 \%$ of output power. In terms of input energy, this is close to $5 \%$.

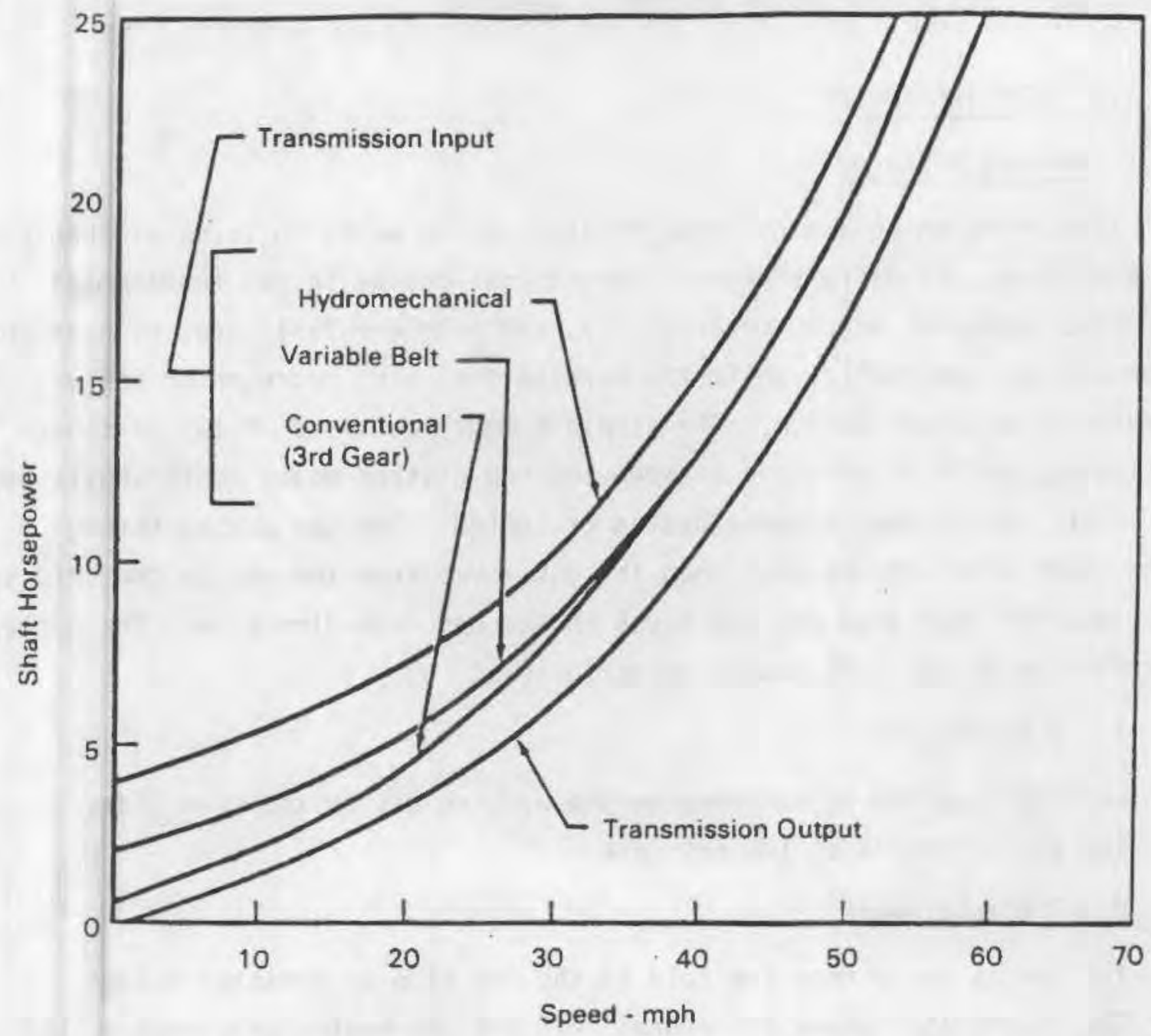

FIGURE 3.25. Input Power at Road-Load for Various Transmissions (16) 


\subsubsection{Ceramics}

As pointed out several times, the development of proper ceramics for high temperature applications is the key to success in the GT engine because of the increase in Carnot efficiency they make possible. The critical parts requiring such high temperature materials are given in Table 3.10 along with the test history of some of these ceramics. The relative advantages and disadvantages of these various materials are shown in Figure 3.26. The success in developing, producing, and integrating these materials in the gas turbine engine will pretty much decide the future of the GT vehicle.

\subsection{THE STIRLING ENGINE}

\subsubsection{General Features}

Similar to an IC engine, the Stirling engine works in terms of compression and expansion. It differs from a conventional engine in two fundamental respects. A heater which, conceptually, can burn any fuel supplies heat continuously and externally, while the working gas (air, hydrogen or helium) operates in a closed system. The simplest model consists of two pistons. The working gas which is enclosed between the two pistons moves continuously back and forth, and is continuously heated or cooled. The gas passes through a regenerator which stores heat when the gas moves from the hot to the cold side, and gives off heat when the gas moves in the opposite direction. The cycle, referring to Figure 3.27 , would be as follows:

1 - 2 Compression

Work is supplied by compressing the working gas on the cold side. The gas is cooled at low pressure.

2 - 3 Displacement

The gas is moved from the cold to the hot side at constant volume. The regenerator gives off stored heat and the heater adds heat to the gas. Pressure increases. 
TABLE 3.10. $2070^{\circ} \mathrm{F}$ Engine Configuration Ceramic Part Development Test Results $1900^{\circ} \mathrm{F}$ Operating Conditions

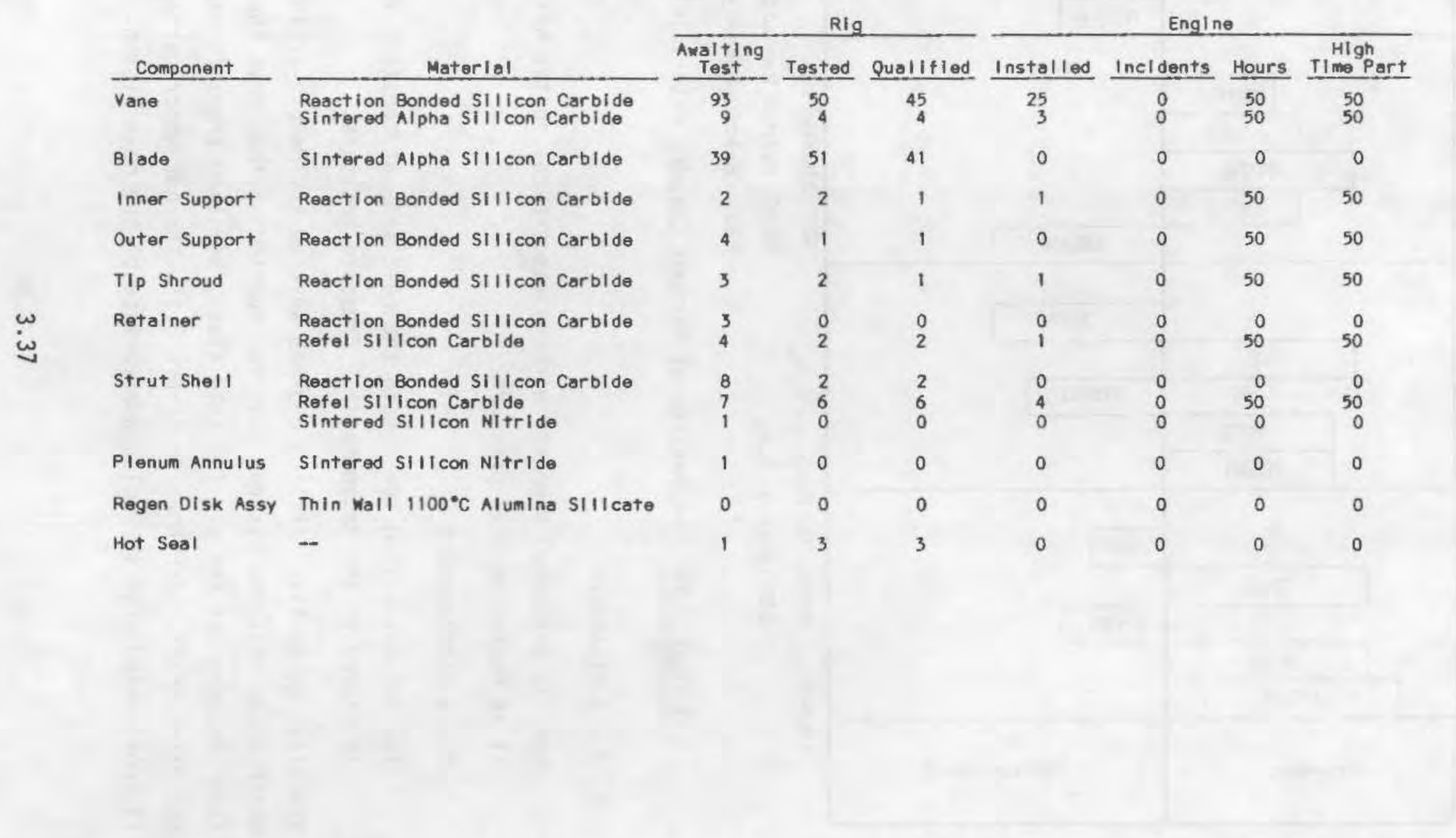




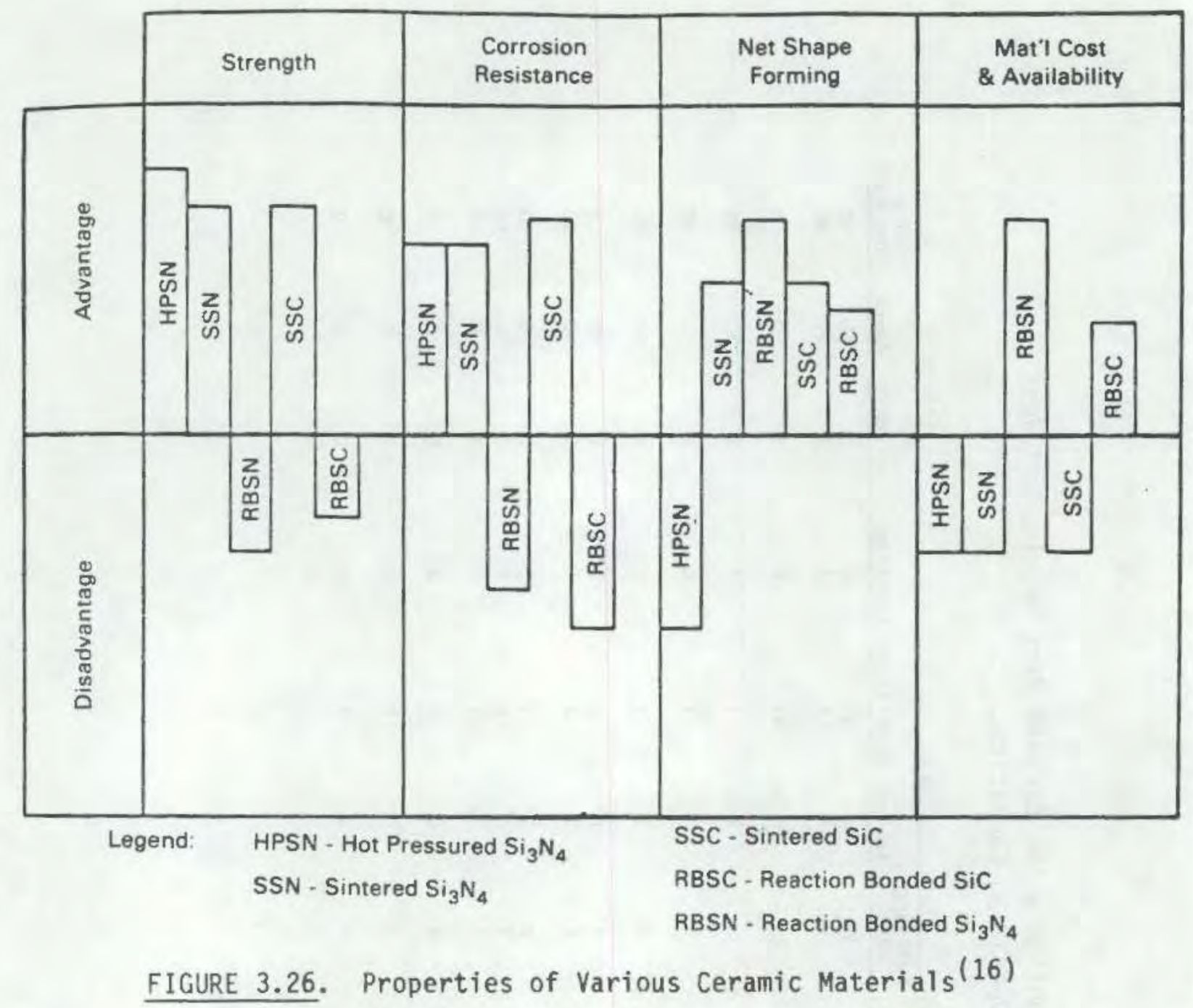

$3-4$ Expansion

Work is performed when the working gas expands on the hot side while it is heated at high pressure.

4 - 1 Displacement

The gas moves from the hot to the cold side at constant volume. Heat is stored in the regenerator. Pressure declines.

Practical automotive Stirling engines work on the double-acting principle, which means that the pistons have two functions; they move the gas back and forth between the hot and the cold sides, and they transmit mechanical work to the drive shaft. As shown in Figure 3.28 , the hot upper surface on one piston is coordinated with the cold undersurface of the next piston. The actual 


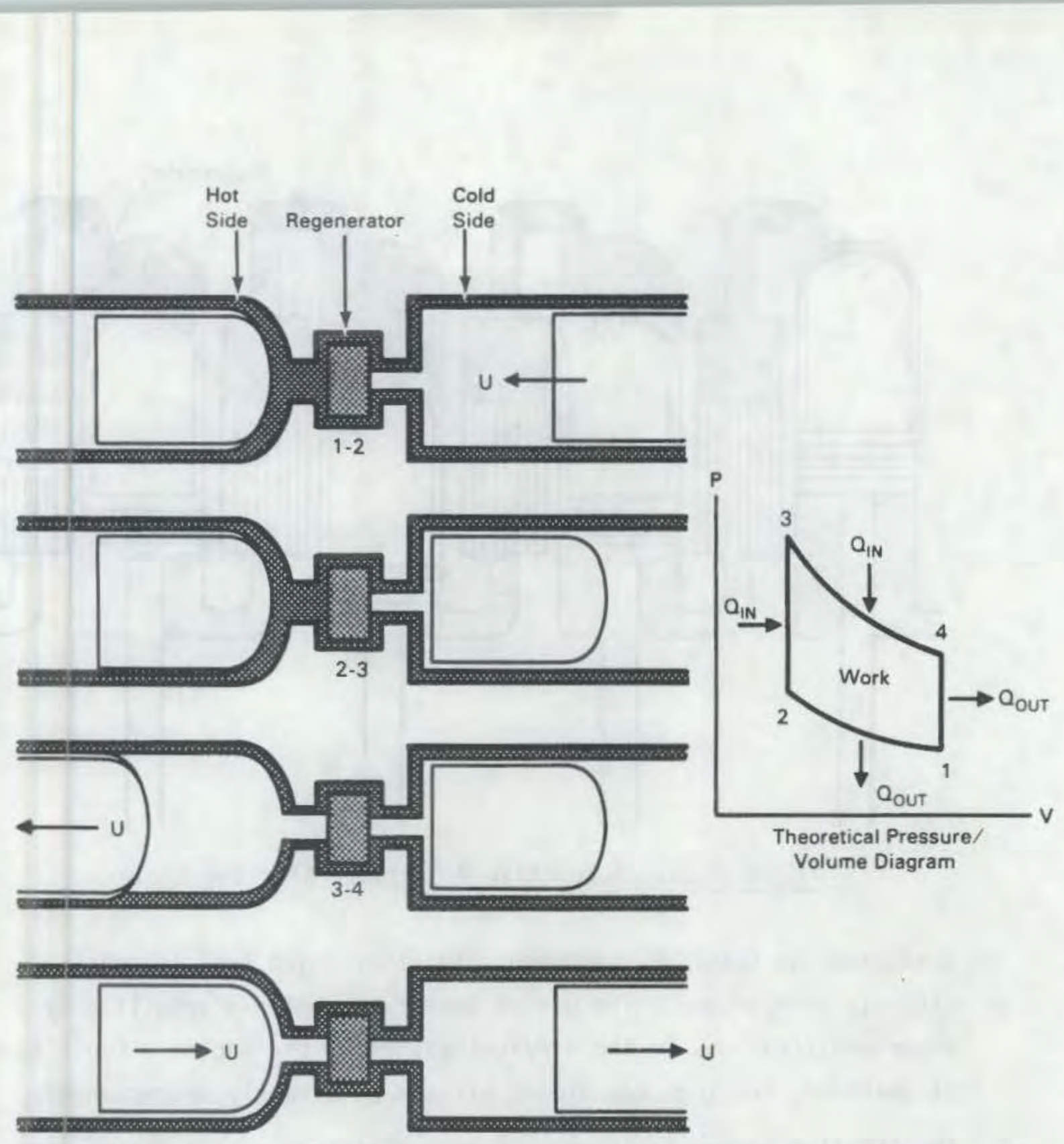

FIGURE 3.27. Basic Model of Stirling Cycle

arrangement in an automotive Stirling engine is shown in Figure 3.29. Both efficiency and output depend on the difference between the high and low temperatures of the working area. This dependence is shown in the diagrams of Figure 3.30 .

Some of the advantages and disadvantages of the Stirling automotive engine vis-a-vis the internal combustion engine are as follows:

1. The Stirling Engine can be easily adapted to alternative fuels. Almost any liquid or gaseous fuel that is reasonably clean can be 


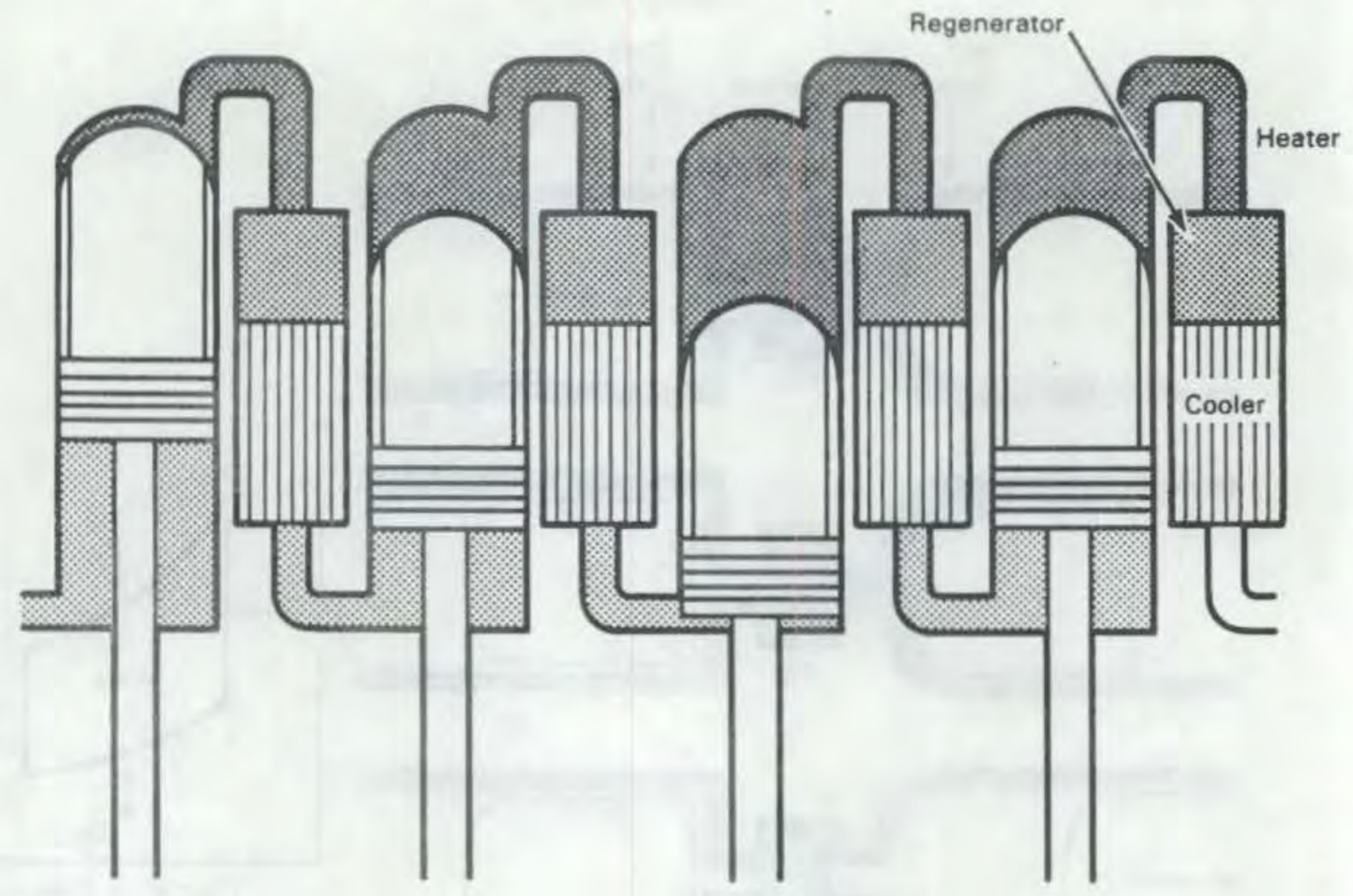

FIGURE 3.28. Automotive 4-Cylinder Stirling Cycle

used, such as gasoline, kerosene, diesel oil, jet fuel, alcohol, city-gas or hydrogen. The use of any of these fuels entails only minor modifications in the air/fuel system of the engine. Fuels such as gasoline, kerosene and diesel oil can be directly interchanged.

2. The Stirling Engine is inherently more efficient. At a maximum temperature of $700^{\circ} \mathrm{C}$ and a minimum of about $70^{\circ} \mathrm{C}$ and hydrogen as a working gas, an efficiency of $37 \%$ has been achieved. By replacing the present metallic heating element materials with other materials that have higher heat resistance, such as ceramics, the temperature on the hot side can be raised $1000^{\circ} \mathrm{C}$ which would correspond to an efficiency of 40 to $45 \%$.

3. The Stirling Engine has severe problems in containing the working fluid, and preventing its contamination with oil. Also, hydrogen tends to diffuse through the surrounding structures. 


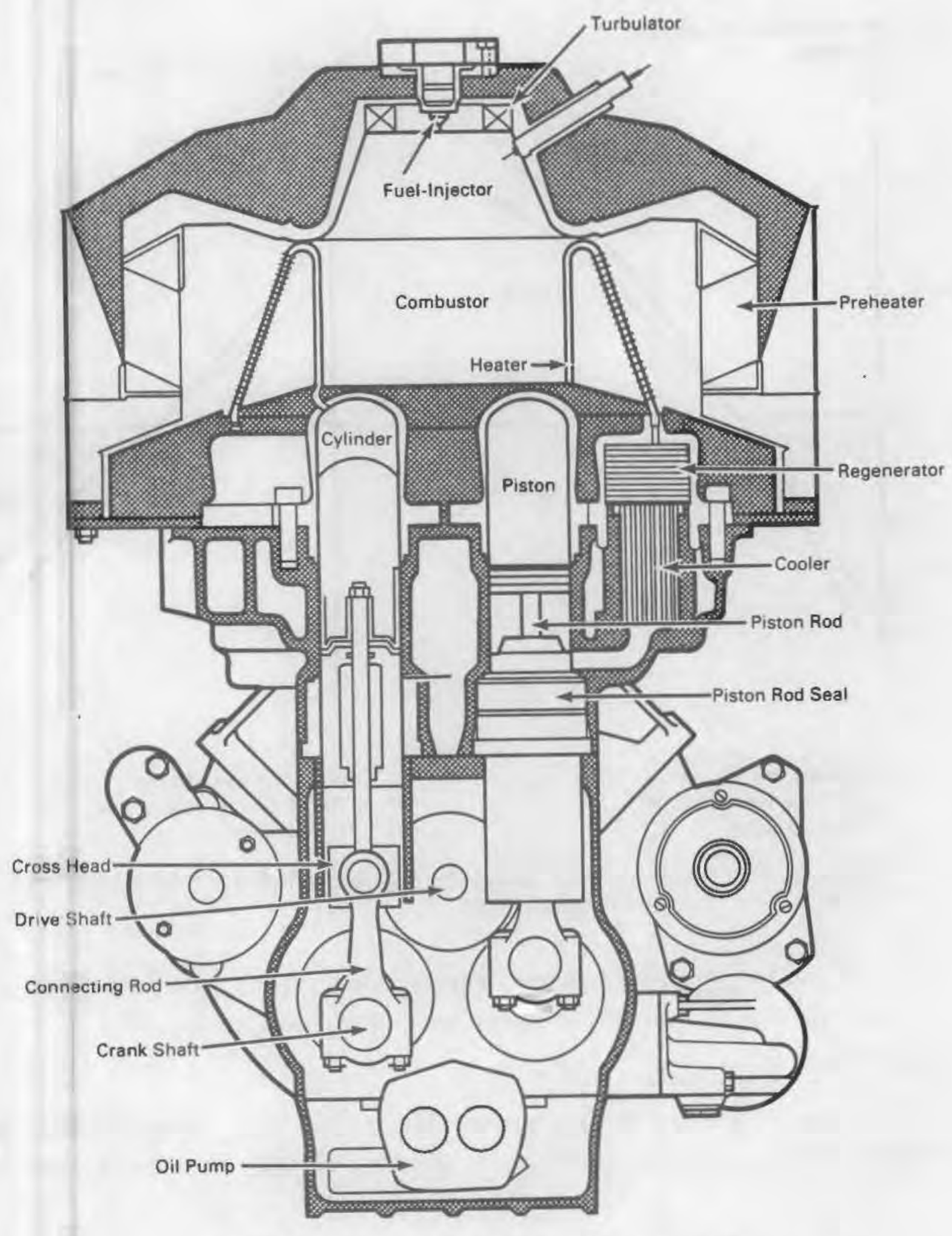

FIGURE 3.29. Automotive Stirling Engine 

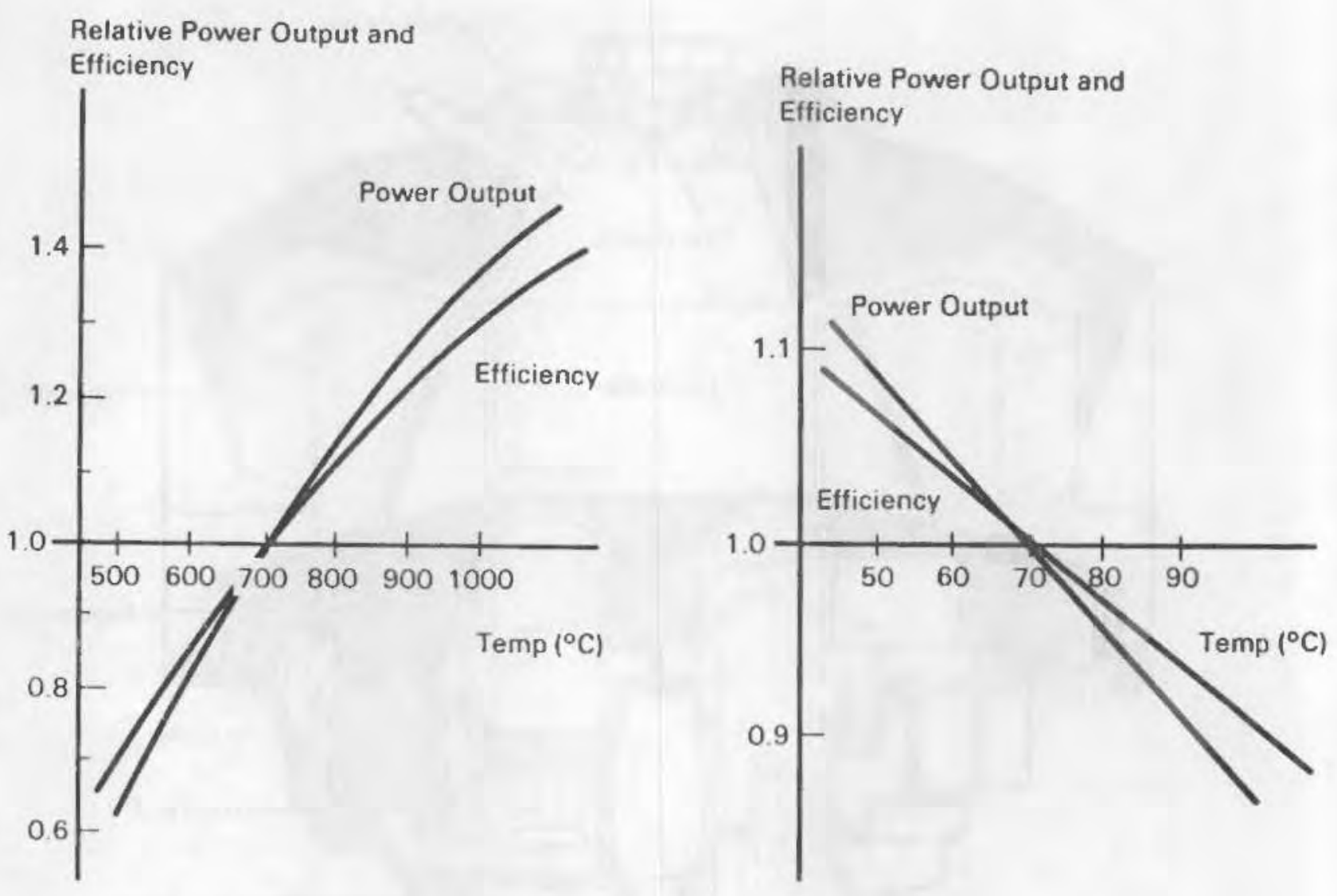
a) Output and Efficiency as Function of Source
Temperature
b) Output and Efficiency as Function of Ambient Temperature

FIGURE 3.30. Dependence of Stirling Engine Performance on Source and Ambient Temperatures

4. The Stirling Engine is bigger, heavier, more costly than IC engines and the use of hydrogen presents some safety problems.

\subsubsection{Development Data}

Similar to the gas turbine automobile, the DOE/NASA requirement for the Stirling engine is a $30 \%$ advantage in fuel consumption over a gasoline-driven 


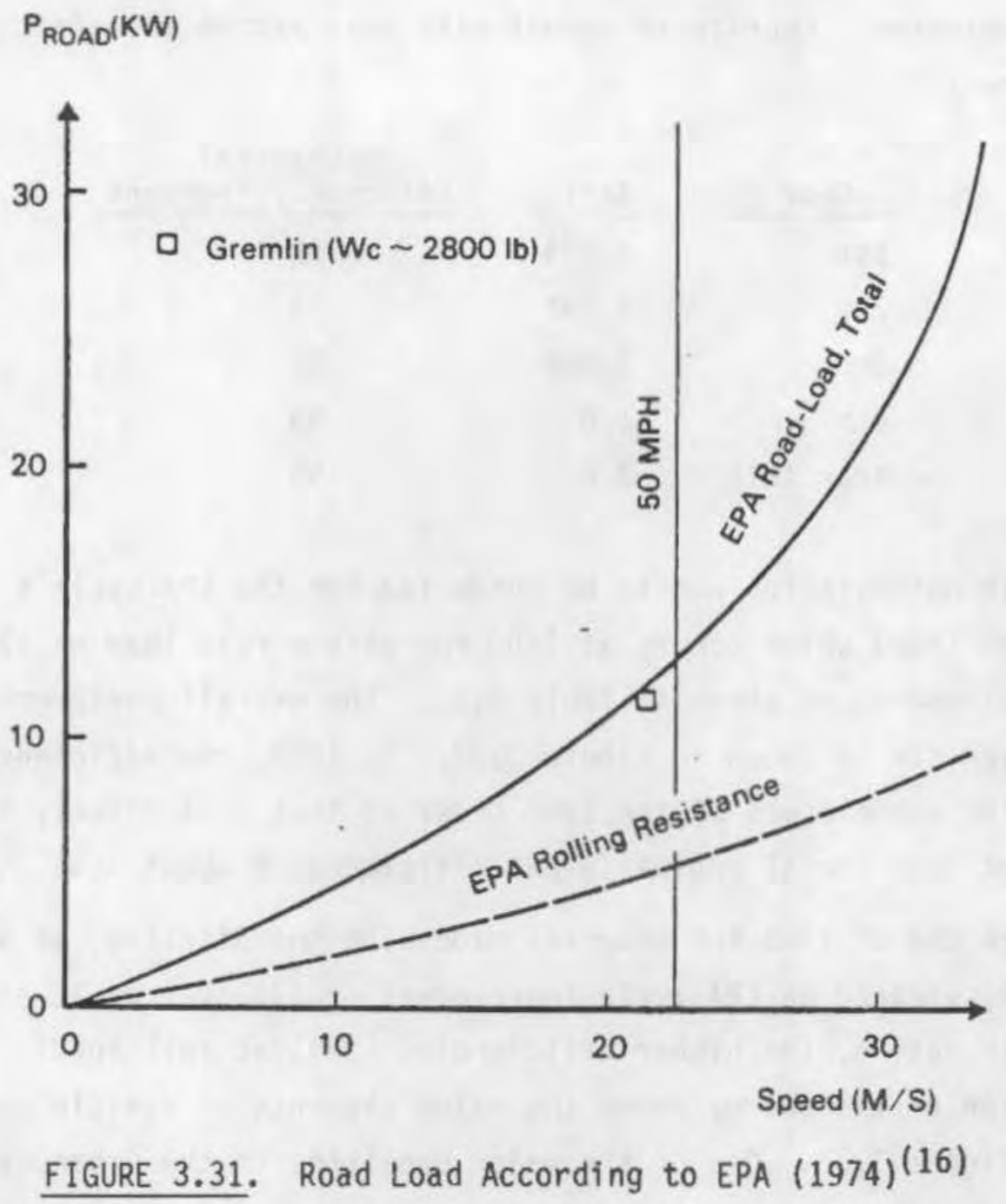

engine. The development work conducted during the last five years by the MTIUnited Stirling team was done on a basic vehicle having the following specifications:

- Curb weight 2900 1b (2725 with SI engine)

- Test weight 3200 1b (3025 with SI engine)

- Road load curve according to EPA as shown in Figure 3.31 
- Transmission: Four-speed manual with gear ratios and efficiencies as follows:

\begin{tabular}{llll}
\multicolumn{1}{c}{ Gear } & & Ratio & \multicolumn{2}{c}{$\begin{array}{c}\text { Mechanical } \\
\text { Efficiency, Percent }\end{array}$} \\
\cline { 1 - 1 } 1st & & 3.444 & 92 \\
2nd & & 2.082 & 94 \\
3rd & & 1.388 & 96 \\
4th & & 1.0 & 99 \\
Rear Axle & 3.0 & 96
\end{tabular}

The vehicle optimization was to be conducted for the EPA cycle's average operating point (AOP) which occurs at $1600 \mathrm{rpm}$ with a road load of $12 \mathrm{~kW}$, and the other requirements as shown in Table 3.11. The overall performance map for the Stirling vehicle is shown in Figure 3.32. By 1978, the efficiency achieved by the Stirling vehicle was of the same order as that of a diesel, i.e., a $10 \%$ improvement over the SI engine (a BHP efficiency of about $36 \%$ ).

By the end of 1983 the progress made with the Stirling, as shown in Table 3.12, yielded an EPA cycle improvement of $17 \%$ over an IC engine. Again it is worth noting, the higher efficiencies (27\%) at full load. The particular distribution of the energy among the major elements of vehicle operation is shown in Figure 3.33. One of the major penalties in the urban cycle is seen to be the cold start expenditure of fuel.

\subsubsection{Tribological Losses}

In support of the Stirling Program, General Electric originally designed a special Stirling General Purpose Test Engine, (26) to test the performance of

TABLE 3.11. DOE/NASA Specifications for Stirling Vehicles

\begin{tabular}{|c|c|c|c|c|}
\hline Point/Parameter & $\begin{array}{l}\text { Power } \\
(\mathrm{kW})\end{array}$ & $\begin{array}{l}\text { Efficiency } \\
\text { Percent }\end{array}$ & $\begin{array}{l}\text { Pressure } \\
\text { (MPa) }\end{array}$ & $\begin{array}{l}\text { Speed } \\
\text { (rpm) }\end{array}$ \\
\hline Maximum Power & 67 & 33 & 15 & 4000 \\
\hline Maximum Efficiency & 29 & 42 & 15 & 1250 \\
\hline AOP and Optimization Point & 12 & 34.4 & 5.3 & 1600 \\
\hline
\end{tabular}




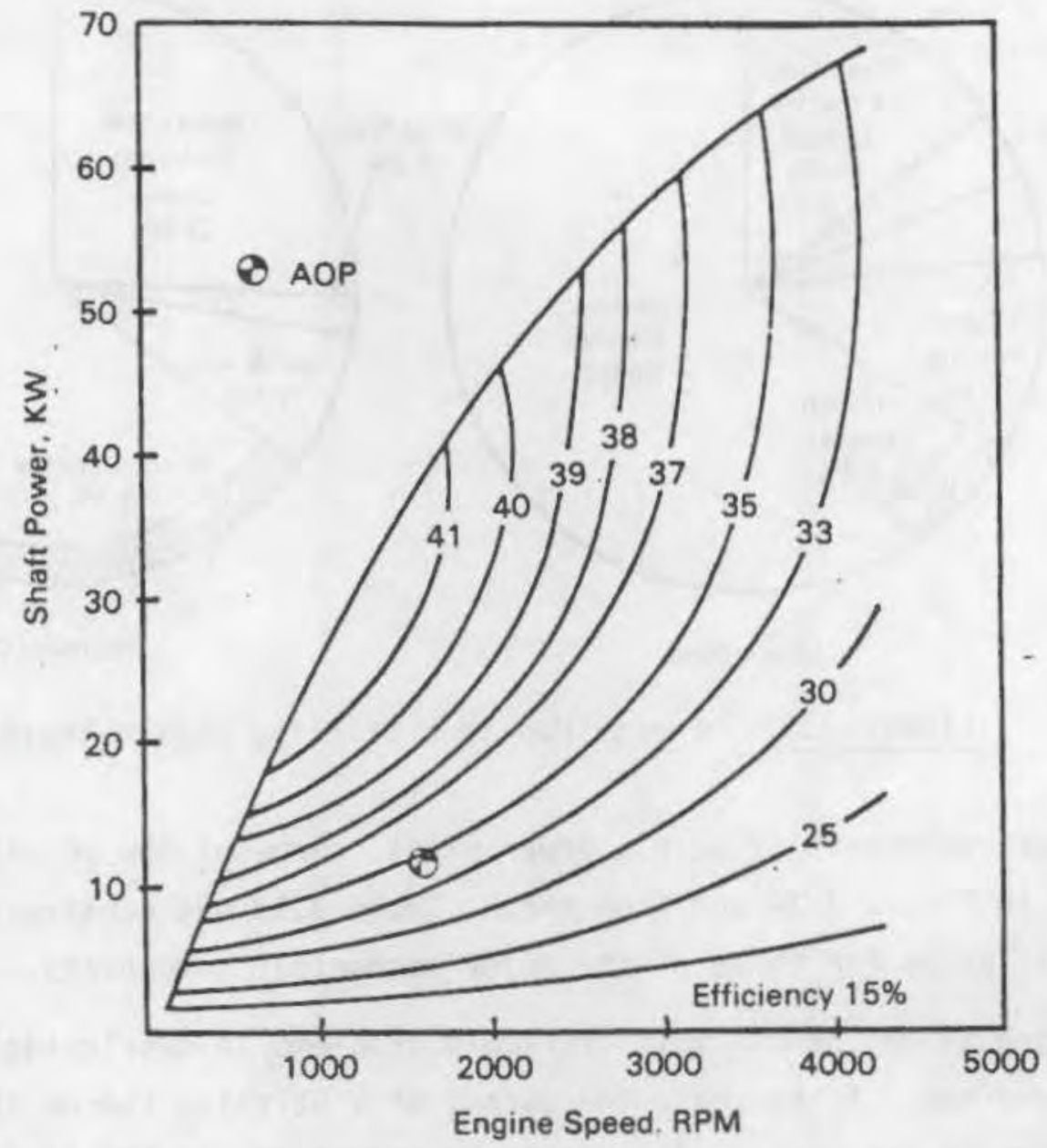

FIGURE 3.32. Scheduled Performance Map for Stirling Vehicle ${ }^{(16)}$

TABLE 3.12. Performance of Stirling Engine Vehicle Engine Mod IA

\begin{tabular}{|c|c|c|c|}
\hline & \multicolumn{3}{|c|}{ Fuel Economy } \\
\hline & Stirling & IC & Gain \% \\
\hline $\operatorname{Urban}(a)$ & 21.5 & 19.4 & 10 \\
\hline Highway & 34.8 & 27.3 & 27 \\
\hline Combined & 26.0 & 22.3 & 17 \\
\hline
\end{tabular}

(a) Cold Start included. 


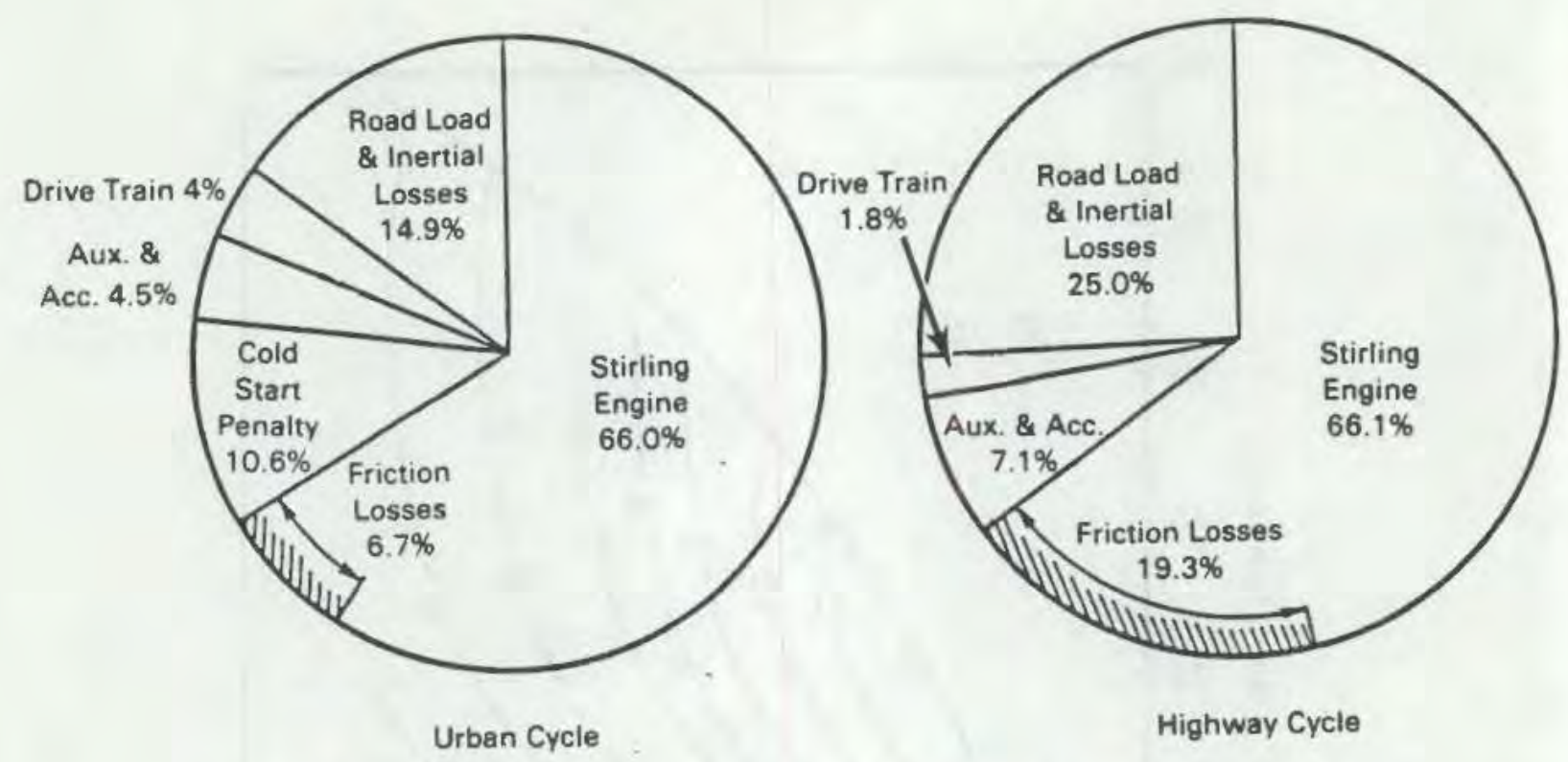

FIGURE 3.33. Energy Map in a Stirling Engine Vehicle

the various components of such a power plant. Some of the results of the tests are shown in Figure 3.34 and from these, Table 3.13 was constructed giving the individual losses for three of the major mechanical components.

Sealing is one of the most difficult problems in developing practical Stirling engines. To increase the output of a Stirling engine of given size, the pressure of the working fluid must be increased and the seals are to contain these high pressures in the working space and prevent leakage to the crankcase. Small engines may be designed so that the crankcase is pressurized to the minimum cycle pressure. In that case, the piston seal is required to seal only the pressure difference between the working space and the crankcase pressures. Engines with pressurized crankcases must also have a dynamic rotary seal, where the crankshaft leaves the crankcase, to contain the crankcase pressure.

As engines become larger, use of the pressurized crankcase becomes less attractive because of the size and weight of the structure necessary to contain the pressure. In these cases, the piston seal must contain the full cyclic pressure difference. Since as shown in Figure 3.35 , the temperature of the piston rod is rather high, the seal must also be able to operate in a hot environment for prolonged periods. 


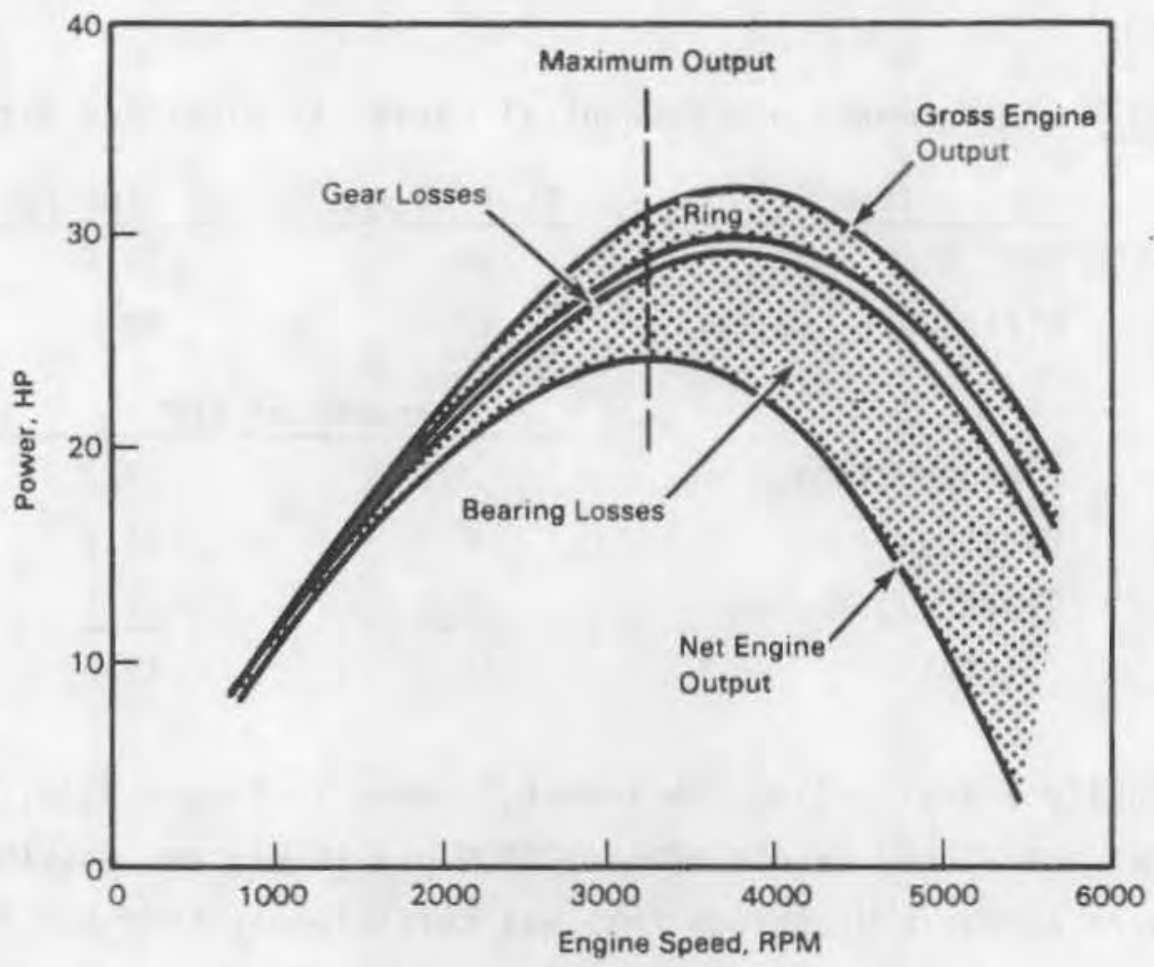

a) Total Engine Output

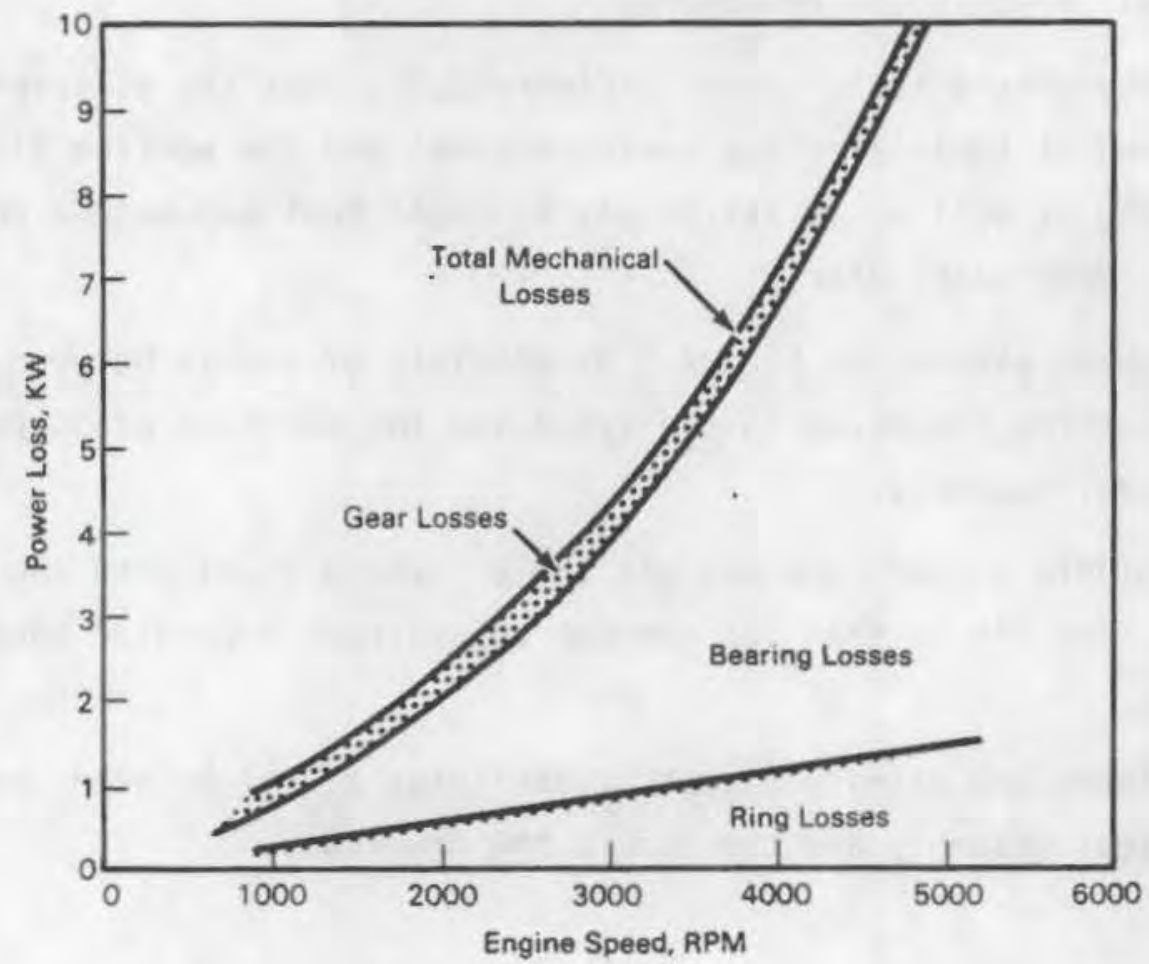

b) Mechanical Losses

FIGURE 3.34. Mechanical Losses in Simulated Stirling Engine(16) 
TABLE 3.13. Performance and Mechanical Losses in Simulated Stirling Engine

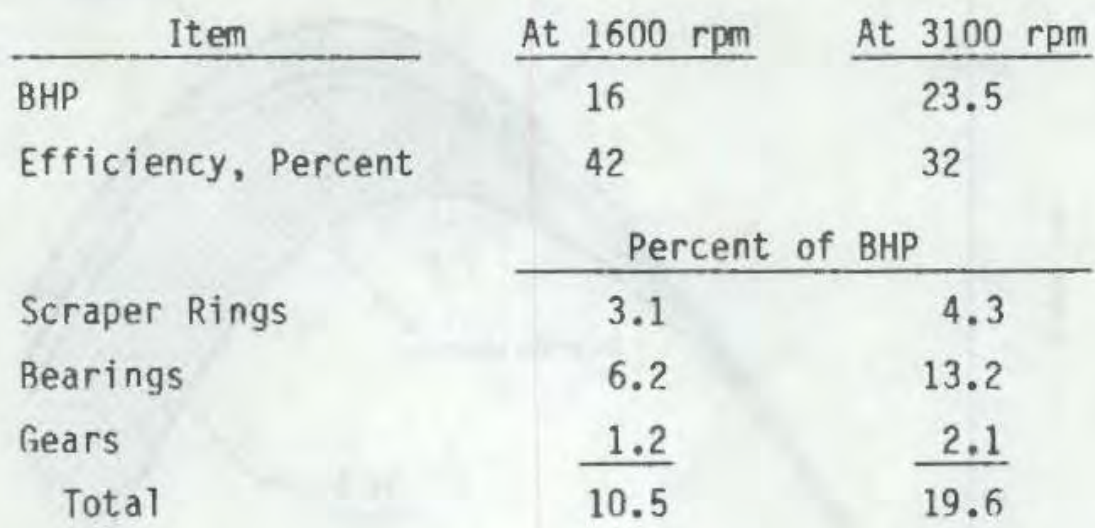

Originally a seal called "roll-sock," shown in Figure 3.36, was used, but as pressures approached levels of over 2000 psi it was not possible to contain this pressure across a diaphragm that was sufficiently thin and flexible to act as a rolling seal. An additional problem was the question of compatibility of the lubricant with the roll-sock seal. The introduction of a more conventional sliding seal then became necessary.

A contemporary seal, shown in figure 3.37 , consists of several sealing stages aimed at separating the pressure zones and the working fluid from the environment, as well as to filter any hydrogen that may become contaminated with oil. More particularly,

- The upper element in Figure 3.37 consists of a seal between the varying working pressures in the cycle and the constant pressure within the seal assembly.

- The middle element scrapes off the oil which moves with the pistonrod. The oil is then led through an oil/cage separator back to the sump.

- The lower and primary element constitutes a seal between the gas in the seal assembly and the air in the crankcase. 

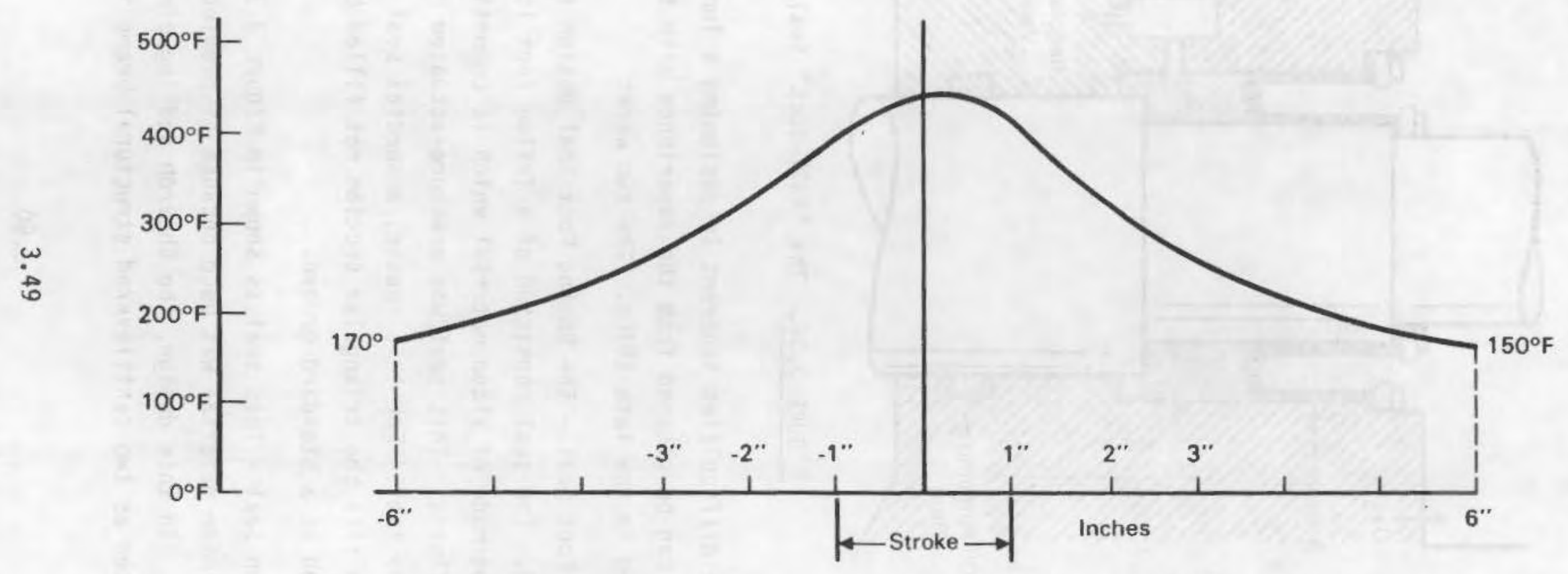

FIGURE 3.35. Typical Rod Surface Temperature Profile 


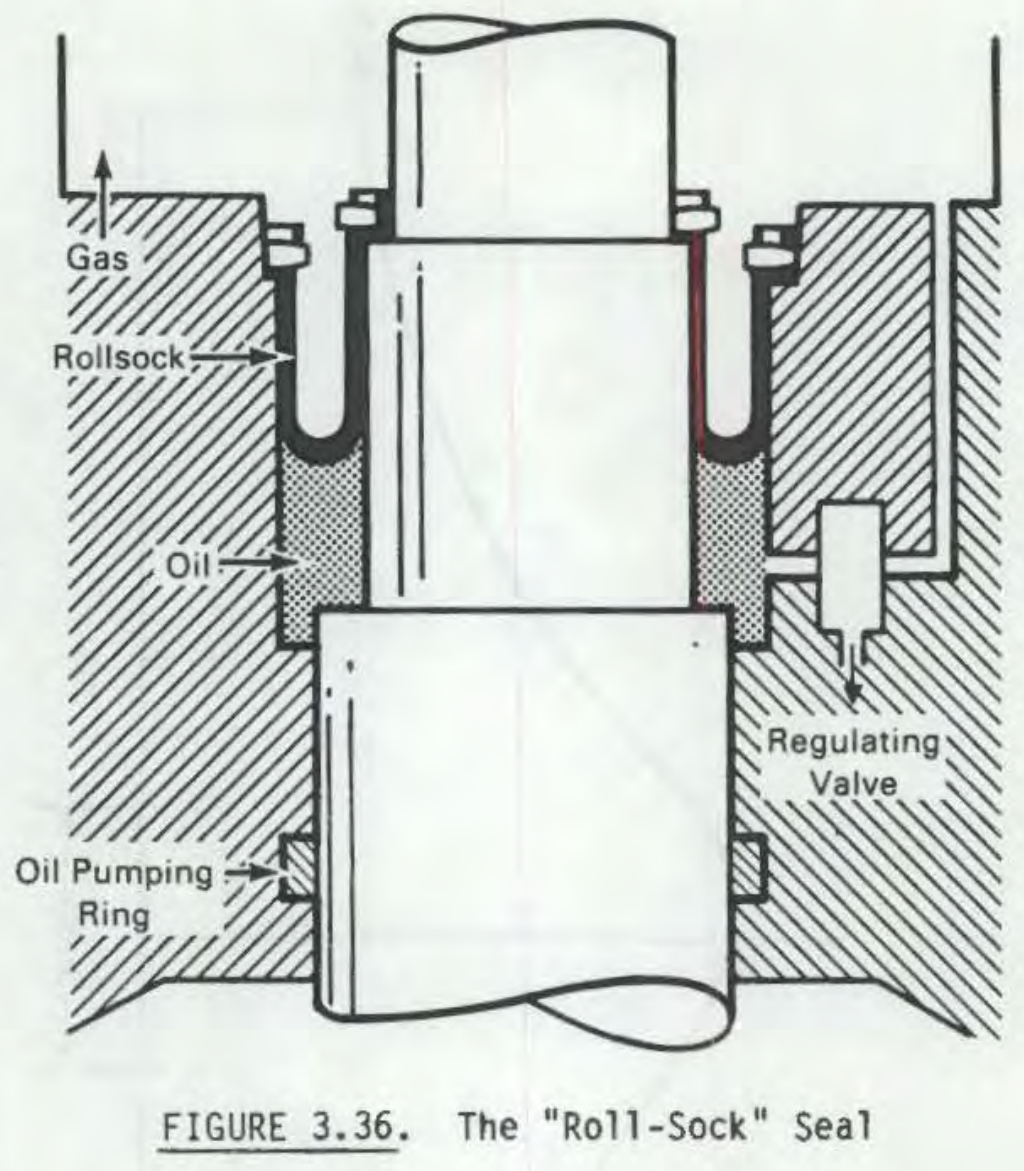

Some of the difficulties inherent in designing a long-lasting seal for the stirling engine can be gleaned from the experience with the following two seal candidates tested in the late 1970s. The two were:

- The Boeing Foot Seal - The Boeing Foot Seal design is shown in Figure 3.38. The seal consisted of a Teflon foot loaded by an elastomer 0-ring made of Viton material which is compatible with petroleum base fluids. This seal was pressure-actuated by the upstream angle of the foot. For this reason, a special seal retainer was required to fill the triangular section not filled by the seal at the upstream end of a standard groove.

- NASA Chevron Seal - This seal is shown in Figure 3.39. A DuPont SP-21 polyimide material was used because of previous successful experience. In this design, the Chevron sealing elements's crosssection acted as two cantilevered structural beams in flexure about 


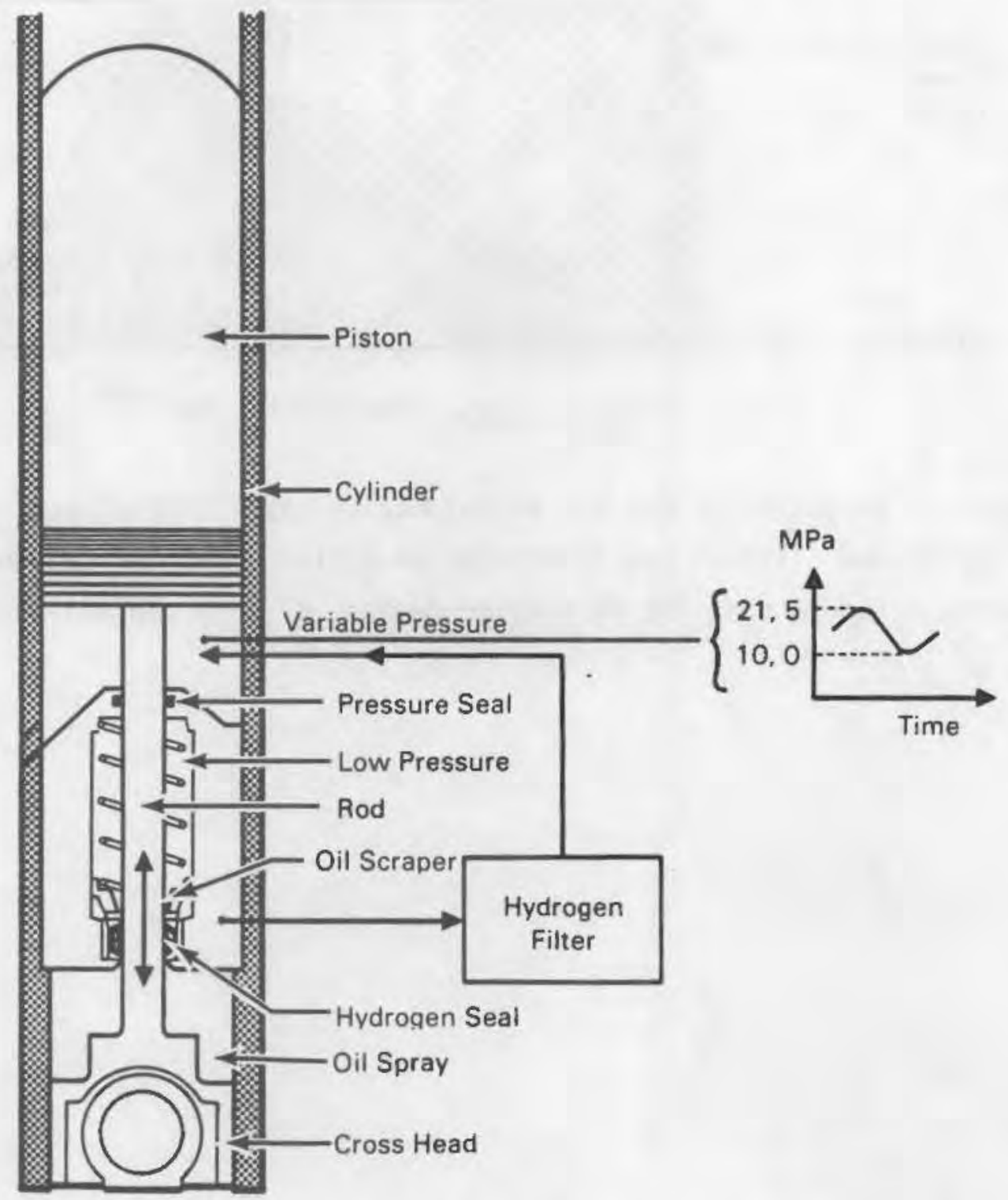

FIGURE 3.37. Stirling Engine Sealing Arrangement

the apex of the geometric shape. Two such elements provided redundant sealing capability. This configuration was designed to maintain sealing pressure with the rod surface over a temperature range from $-20^{\circ} \mathrm{F}$ to $300^{\circ} \mathrm{F}$ in both the pressurized and unpressurized conditions. As shown in Table 3.14 , both seals failed prematurely during cyclic endurance testing. In addition, the excessive friction of the NASA Chevron Seal 


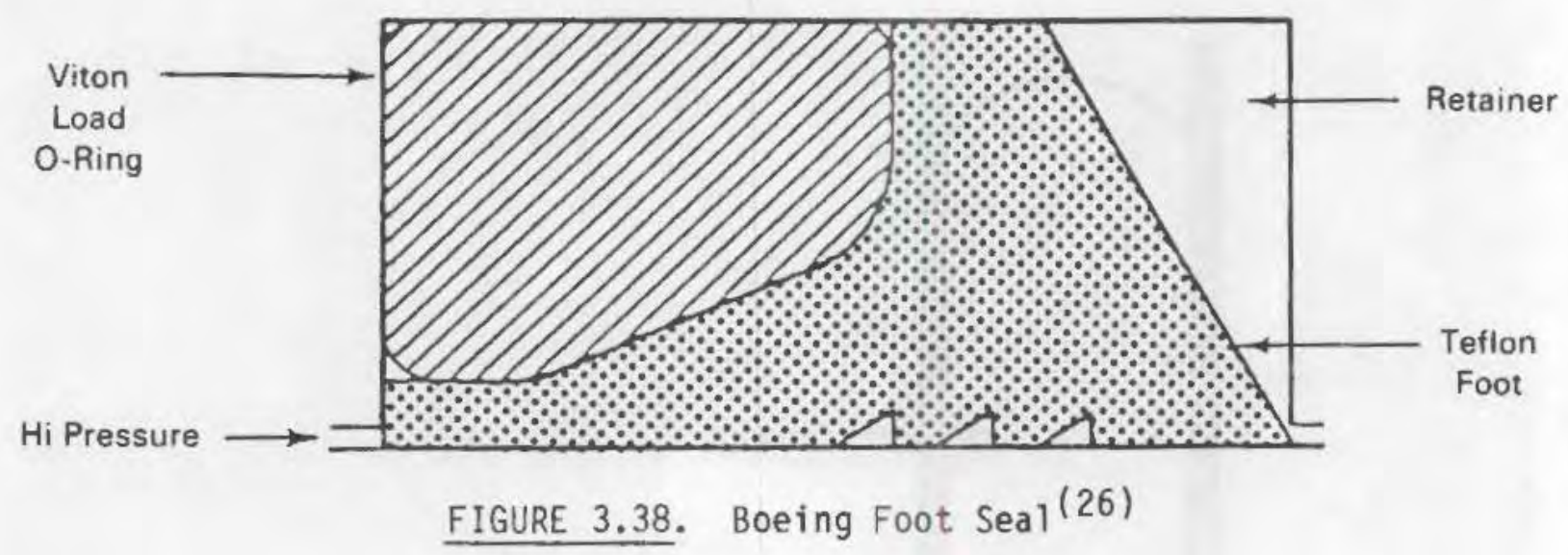

made it unacceptable for use in automotive size Stirling engines. Thus, sealing for the Stirling engine remains an active problem with many new approaches being tried to suit the particular demands of this application. 


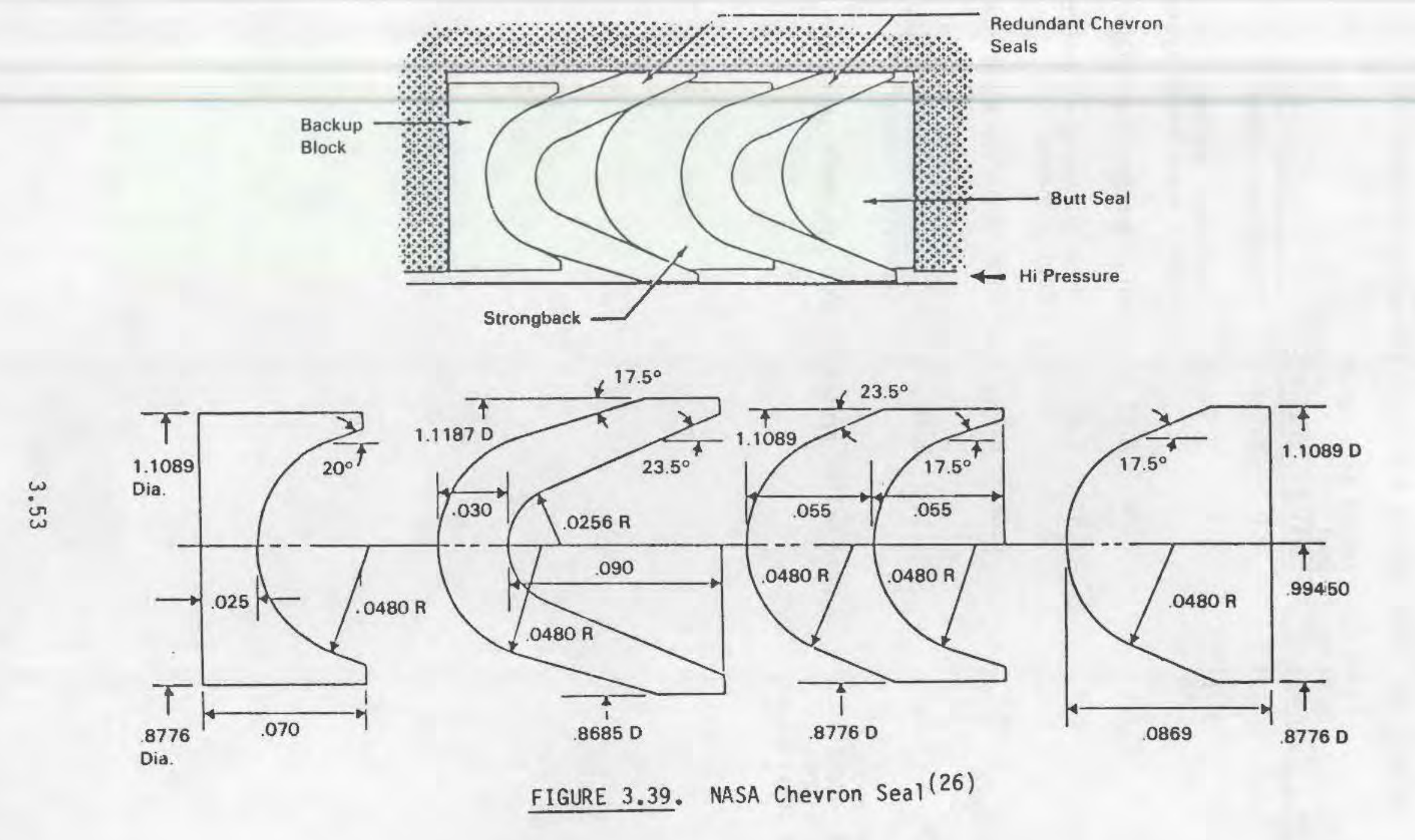


TABLE 3.14. Test Results for Two Stirling Engine Seals(26)

\begin{tabular}{|c|c|c|c|c|c|}
\hline $\begin{array}{l}\text { Foot } \\
\text { Seal } \\
\text { Set } \\
\end{array}$ & $\begin{array}{l}\text { O-Ring } \\
\text { Type }\end{array}$ & $\begin{array}{c}\text { Test } \\
\text { Duratipn } \\
\text { (Hours) } \\
\end{array}$ & $\begin{array}{l}\text { Leakage } \\
\text { Goal }= \\
\text { Seal } 1\end{array}$ & $\begin{array}{l}\text { Rate }(\mathrm{cc} / \mathrm{min}) \\
\frac{0.12 \mathrm{cc} / \mathrm{min}}{\text { Sea } / 2}\end{array}$ & Failure Mode \\
\hline 1 & Viton & Static & 30.0 & 30.0 est. & Excessive leakage \\
\hline 2 & Nitrile & $\begin{array}{l}3.75^{(b)} \\
4.00\end{array}$ & 3.5 & 3.5 est. & $\begin{array}{l}\text { Excessive leakage } \\
\text { Modify measurement system }\end{array}$ \\
\hline 3 & Viton & 1.5 & 0.04 & 0.21 & High temperature failure \\
\hline 4 & Viton & 2.8 & 1.9 & 1.83 & $\begin{array}{l}\text { High temperature failure } \\
\text { Foot deformed }\end{array}$ \\
\hline 5 & $\begin{array}{l}\text { High } \\
\text { Temperature }\end{array}$ & 2.9 & 0.68 & 0.64 & High temperature failure \\
\hline 6 & Nitrile & 1.7 & 3.35 & 1.44 & $\begin{array}{l}\text { High temperature failure } \\
\text { Excessive leakage }\end{array}$ \\
\hline
\end{tabular}

(a) At test conditions: $1750 \mathrm{psig}$ helium pressure, $3000 \mathrm{rpm}$ shaft speed and $275^{\circ} \mathrm{F}$ except as noted.

(b) $450 \mathrm{rpm}$ shaft speed. 


\subsection{ANALYSIS OF TRIBOLOGICAL ENERGY LOSSES}

In the previous sections a general energy flow map was constructed for the automotive vehicle with particular emphasis on the tribological energy sinks. In the present section a closer look will be taken at the individual tribological components or processes with a view to determining the origin of the energy losses, and the extent to which these losses are amenable to reduction or, possibly, elimination. While the primary emphasis will be on the technical aspects of such innovations or modifications, attention will also be paid to the economic cost and benefits attendant on such changes. The latter will receive less detailed attention because such data are scarce and hecause a complete economic evaluation, including the impact of individual component modification on the performance of the vehicle as a whole, would require a complex and elaborate engineering and economic study, beyond the scope of the present project.

Following is a list of tribological elements in a car's engine and drive train more or less in order of their prominence from the standpoint of energy consumption:

- piston assembly (rings, skirts, blowby)

- transmission

- valve train

- 0 il pump

- braking

- bearings

- minor components

- seals

- air, water and fuel pumps

- power assistance: steering, windows and seats, windshield wipers

- couplings

- air conditioning compressor (if present)

- tires. 
While the above lists specific mechanical components, there are two additional major areas which can best be listed generically under the following two headinos:

- Tubricants (viscometrics and additives)

- materials and coatings.

These various components and processes are taken up and discussed individually in the sections that follow.

\subsection{PISTON ASSEMBLY}

The literature on frictional and other energy losses between the sliding piston and cylinder walls is quite voluminous. McGeehan in a 1979 review article, ${ }^{(28)}$ contains a bibliography of 65 articles. But despite the proliferation of technical papers, it remains the opinion of those in industry that little is known of the reality of what transpires at the interface between piston and cylinder wall. This is not surprising given, on the one hand, the complex nature of the process and on the other hand, the difficulties involved in "live" experimental measurements, i.e., the collection of data during the actual firing of the engine. Two things will be attempted here: one a breakdown of the total phenomenon into its component elements and thereby an identification of the sources of energy losses; and two, the definition of means whereby the operation of the piston-cylinder interface can be better quantified and ways for improvement charted.

\subsubsection{Piston Cylinder Interaction}

The nomenclature to be used here is shown in Figure 4.1. The elements that contribute to energy losses at the ring-cylinder interface are:

- number of rings

- compression rings friction; the frictional losses here are a function of the rings' static tension and the variable combustion gas pressure

- oil control ring friction

- piston skirt friction

- blowby leakage losses 


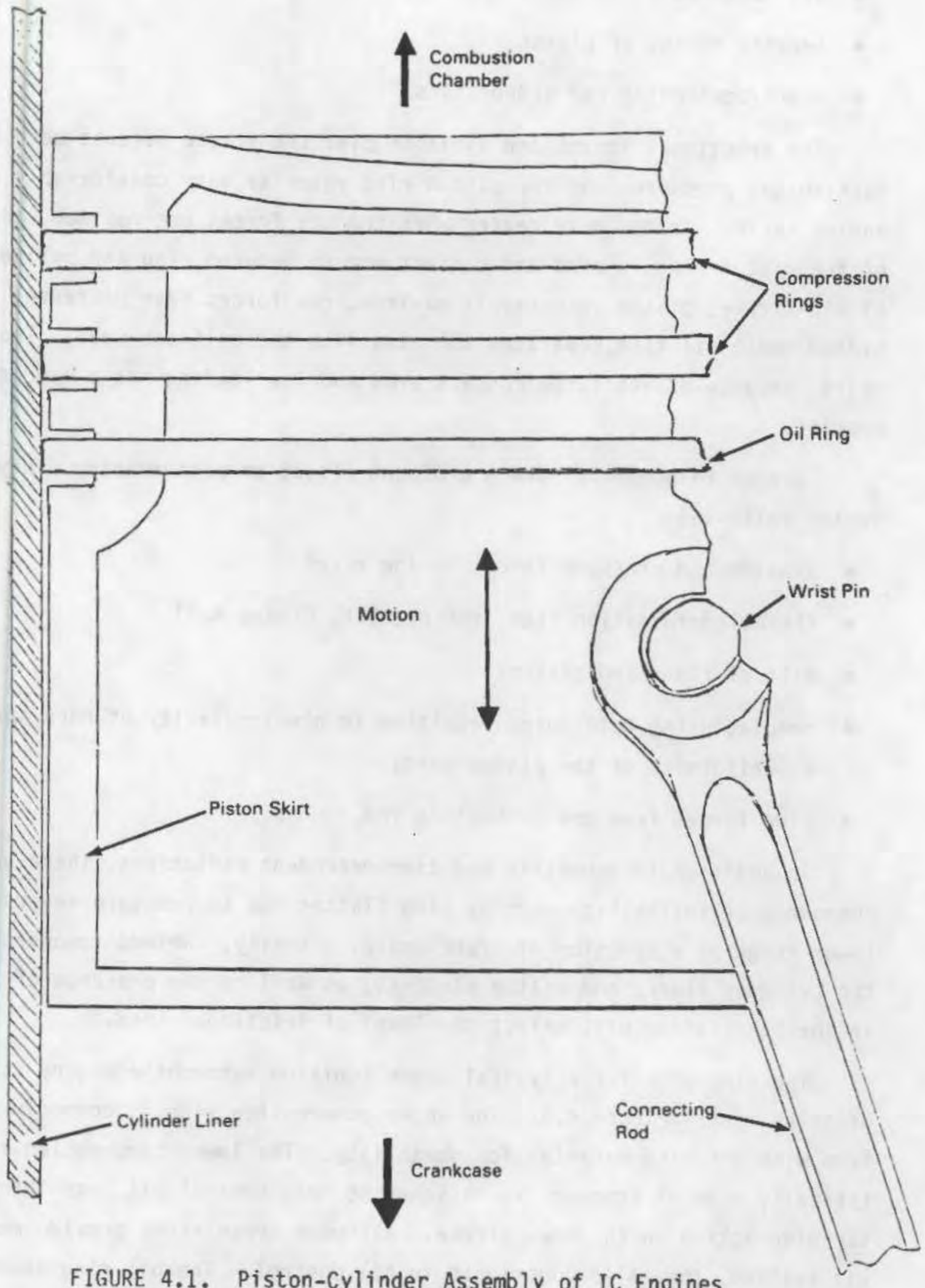

FIGURE 4.1. Piston-Cylinder Assembly of IC Engines 
- 0 il consumption losses

- inertia forces of piston

- crank/connecting rod proportions.

The frictional losses are variable over the stroke because both the combustion gas pressures and the piston ring velocity vary considerably over the engine cycle. At top dead center when the gas forces are maximum, the velocity of the piston ring is zero and contact occurs between ring and cylinder wall. At mid-stroke, piston velocity is maximum, gas forces have decreased and a hydrodynamic oil film separates the ring from the cylinder wall. The piston skirt, because of its large contact area and low loading has a hydrodynamic contact.

Changes in geometry have a profound effect on performance. They are due to the following:

- tension and pressure forces on the rings

- thermal deformation (see, for example, Figure 4.2)

- tilt of rings and pistons

- manufacturing tolerances resulting in noncircularity of bore and nonuniformity of the piston parts

- side forces from the connecting rod.

In addition to aeometric and time-dependent variations, there are also phenomena of instability such as ring flutter due to pressure reversal in the lower rings as a function of crank angle. Finally, surface topography on both the cylinder liners and piston elements, as well as the presence of additives in the lubricating oil, affect the level of frictional loss.

The ring pack for a typical spark ignition automobile engine is composed of three rings, Figure 4.3. The upper compression ring is commonly made of iron with a facing material for durability. The lower compression ring is typically made of iron and is designed to help control oil loss through a scraping action on the down stroke. Although these rings provide most of the gas sealing, they also contribute to oil control. The oil ring assembly is 


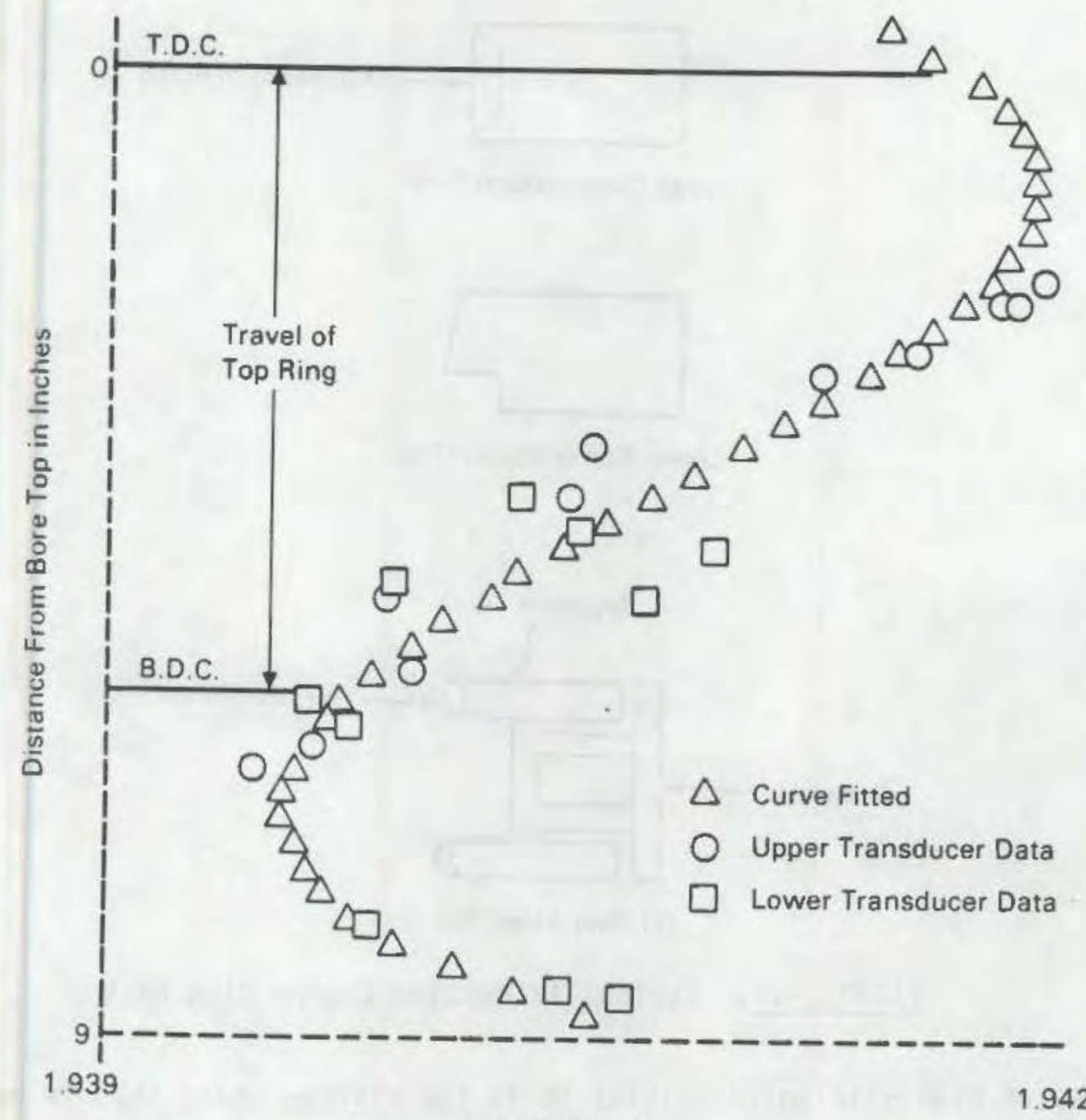

Bore Radius, in

FIGURE 4.2. Cylinder Bore Shape for Perkins AT6-354 Engine During Exhaust Stroke (27)

composed of two relatively thin steel, chrome-faced rings separated by a spring/expander. Pressure due to installation tension is higher for the oil ring assembly than for the individual compression rings by a factor of five or six. Diesel-ring friction tests have shown that the oil ring experiences larger frictional forces than do the compression rings, and it has been estimated that $60 \%$ of the ring friction is due to the oil ring. (1n)

The individual friction components of the total piston assembly friction are portrayed in Figures 4.4 and 4.5 where it can be seen that at low velocities, the nonviscous losses (tension and gas pressure forces) predominate, 


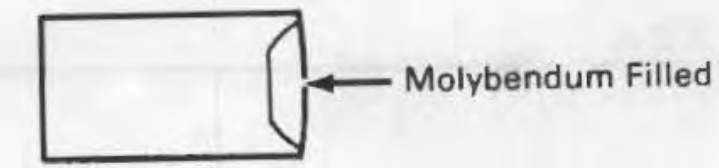

Upper Compression Ring

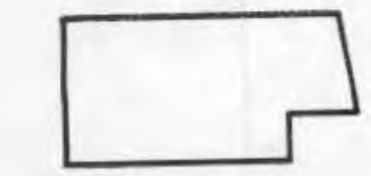

Lower Compression Ring

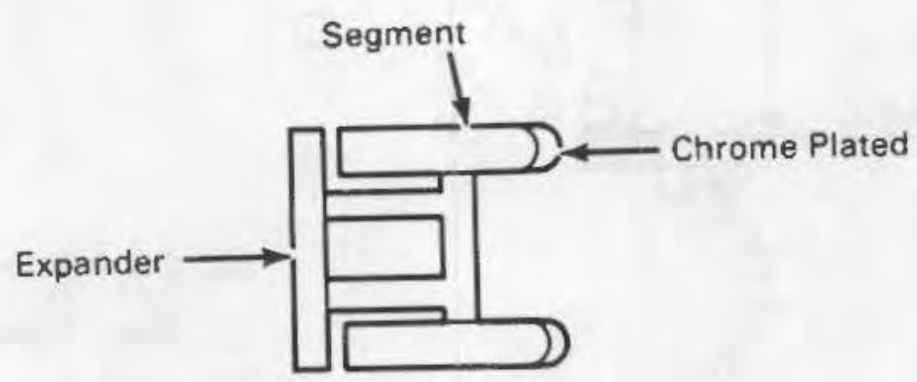

Oil Ring Assembly

FIGURE 4.3. Typical Automotive Engine Ring Pack

whereas, at high sliding velocities it is the viscous shear that is responsible for the major part of friction. Figure 4.6 provides the blowby losses. From this data, one can construct the following distribution of the three major components of energy loss in the piston assembly.

\begin{tabular}{lcc} 
& \multicolumn{2}{c}{ Percent of Total Friction } \\
\cline { 2 - 3 } & $\frac{3000 \mathrm{rpm}}{1500}$ & $\frac{3000 \mathrm{rpm}}{11.5}$ \\
\cline { 2 - 3 } Nonviscous & 15.5 & 22.5 \\
Viscous & 15.5 & $\underline{5.0}$ \\
Blowby & $\underline{10.0}$ & 39.0 \\
Total & 41.0 &
\end{tabular}

Averaging out the $1500 \mathrm{rpm}$ and $3000 \mathrm{rpm}$ data given above and using the 2.8\% given in Figure 2.14 for the losses in the piston assembly, Table 4.1 was 


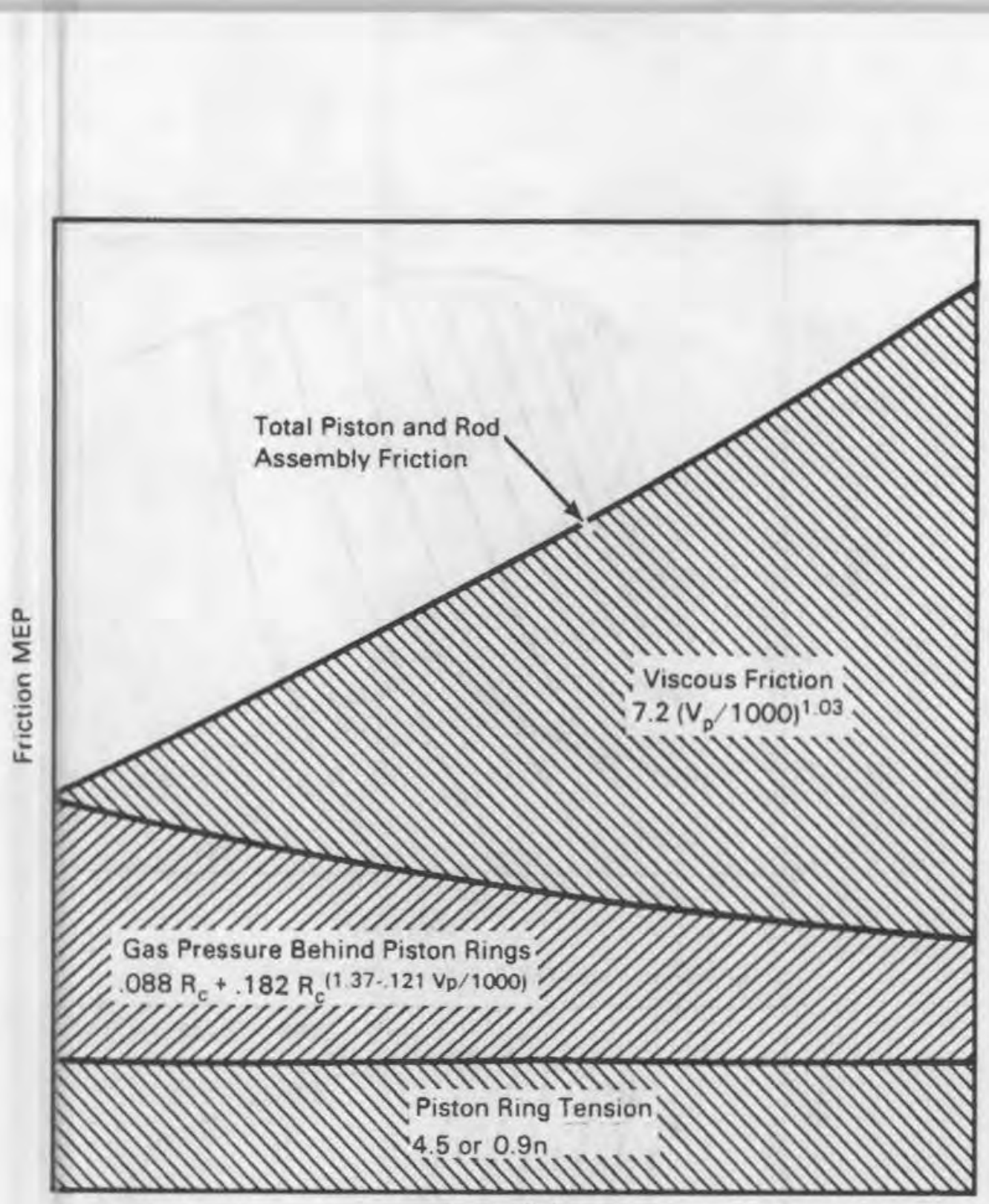

Piston Velocity

FIGURE 4.4. Friction in the Individual Components of Piston Assembly $(9)$

constructed itemizing the individual losses for the viscous, nonviscous and blowby components of the piston assembly. These have been introduced into the mapping of Figure 2.14 on the basis of Table 4.1 .

In discussing possible future modifications of the piston assembly with a view to friction reduction, the hydrodynamics of the ring pack are an item of major interest. Figures 4.7 and 4.8 show two performance items as functions of crank angle (i.e., their variation with time). As seen, the operating pressure level decreases with distance from the top ring. The fluid film thickness is largest at mid-stroke when the velocity is maximum, about 10 to $20 \mathrm{~m} / \mathrm{sec}$, and 


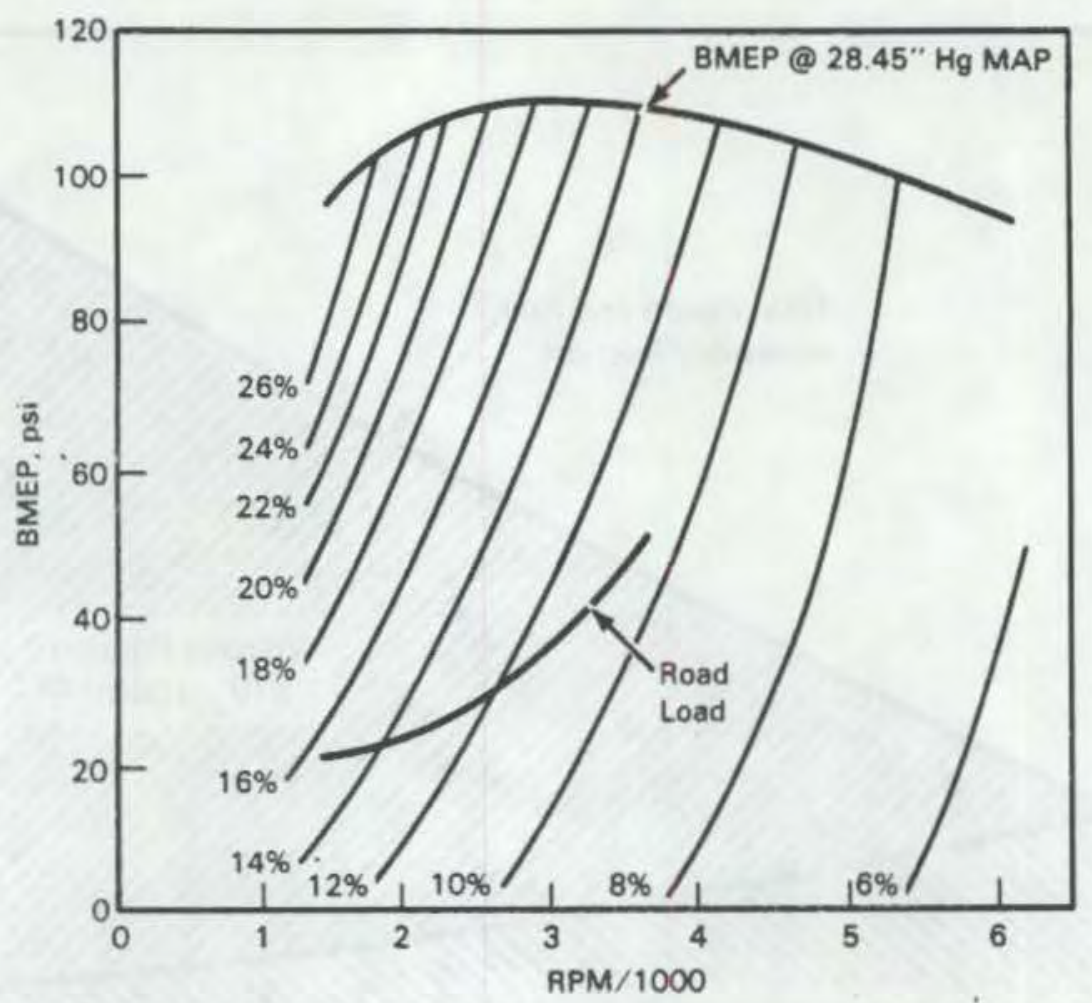

a) Non-viscous Piston FMEP, percent of Total FMEP

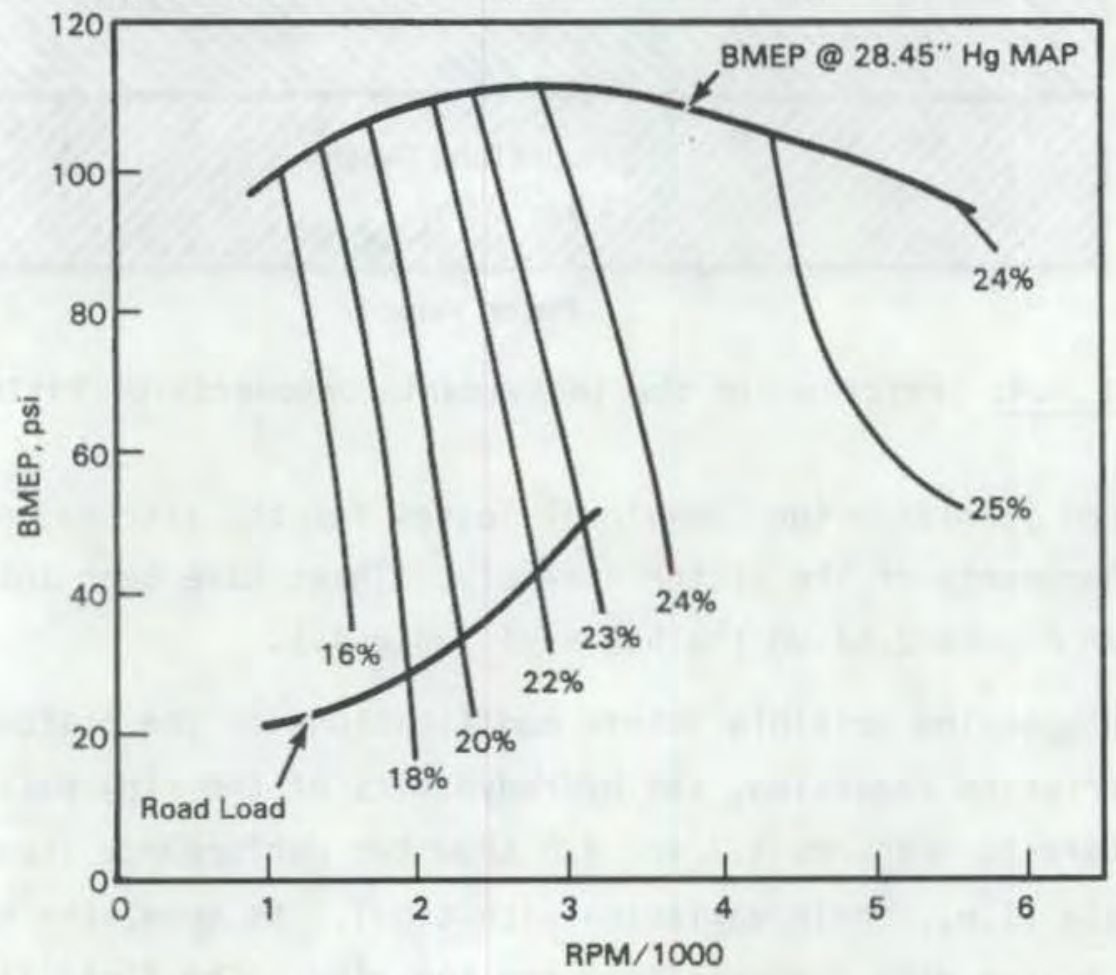

b) Viscous Piston FMEP, percent of Total FMEP

FIGURE 4.5. Viscous and Nonviscous Frictional Losses in Piston Assembly(9) 


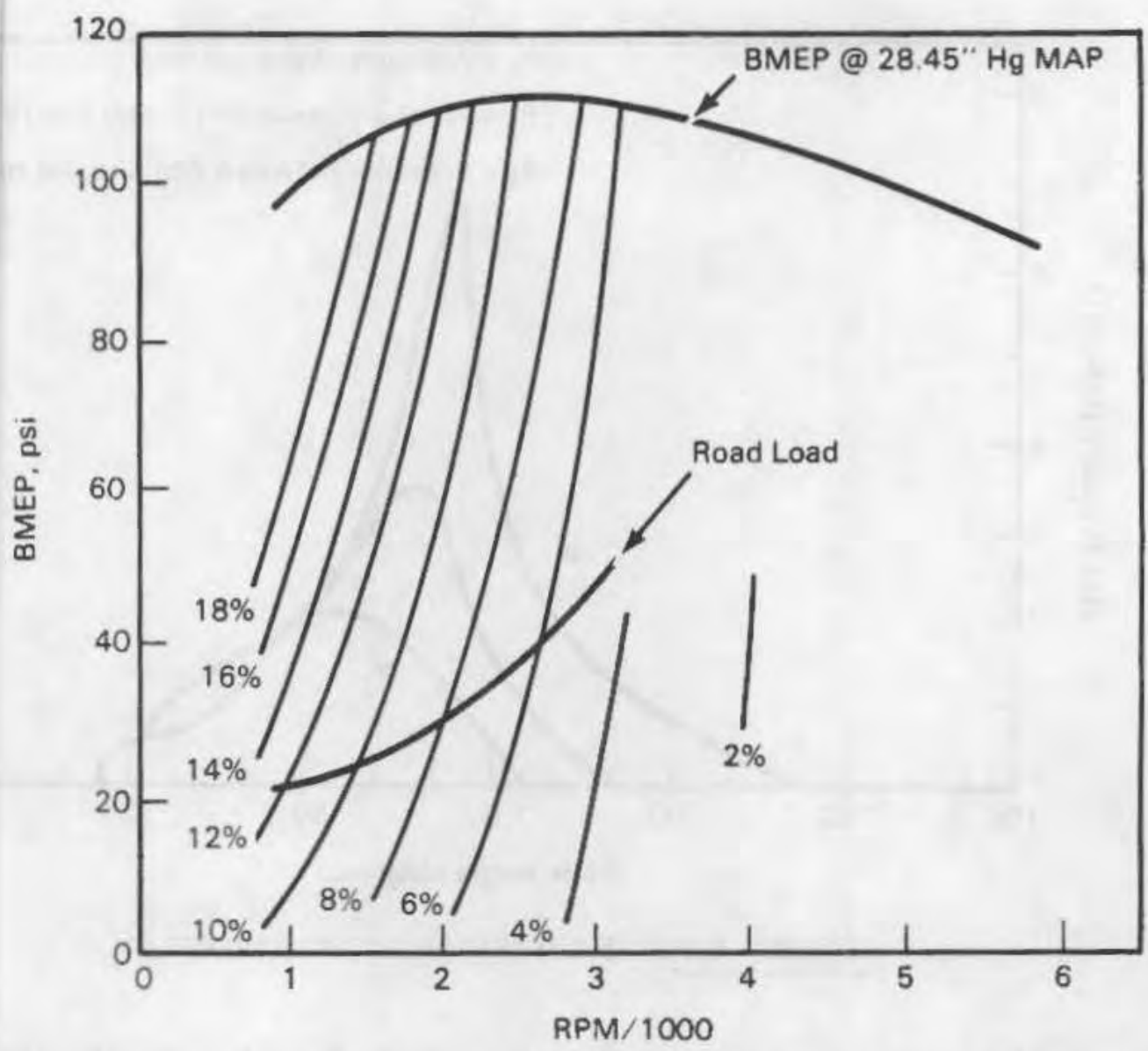

FIGIIRE 4.6. Blowby FMEP, Percent of Total FMEP(9)

TABLF 4.1. Energy Losses in Piston Assembly

\begin{tabular}{|c|c|c|c|}
\hline & $\begin{array}{r}\text { Piston } \\
\text { Assembly (a) } \\
\end{array}$ & $\begin{array}{l}\text { Automotive } \\
\text { Fuel } \\
\text { Consumption } \\
\end{array}$ & $\begin{array}{c}\text { Total } \\
\text { U.S. } \\
\text { Energy } \\
\end{array}$ \\
\hline Nonviscous Losses & 34 & 0.95 & 0.19 \\
\hline Viscous Losses & 48 & 1.35 & 0.27 \\
\hline (Total Friction) & $(82)$ & $(2.30)$ & $(0.46)$ \\
\hline Blowby Losses & 18 & 0.50 & 0.1 \\
\hline $\begin{array}{l}\text { Total Piston } \\
\text { Assembly Losses }\end{array}$ & 100 & 2.8 & 0.56 \\
\hline
\end{tabular}

(a) Averages of Table 4.1 . 


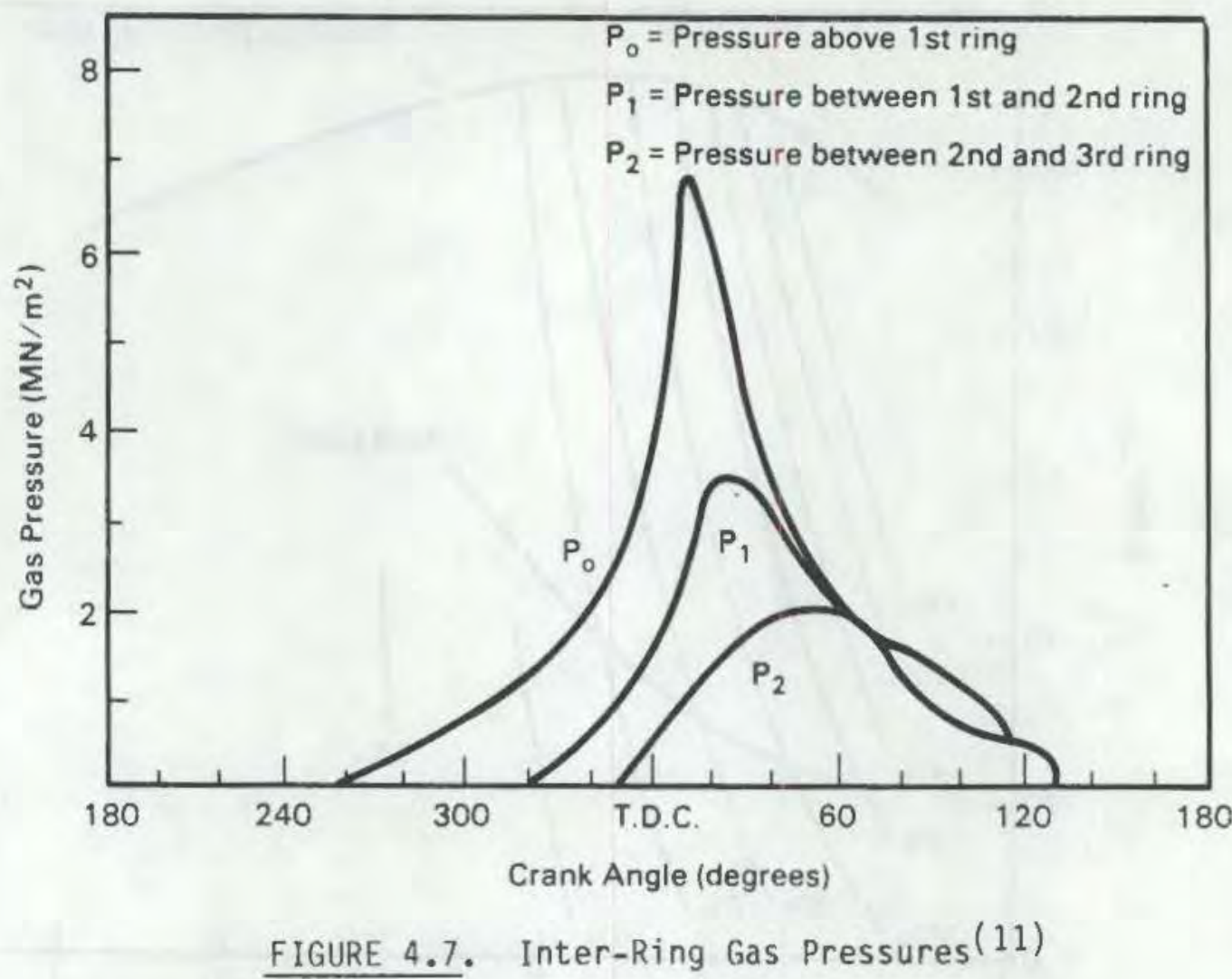

the overall variation in $h_{\min }$ is of the order of $1: 15$. As reported in Reference 11, most of the oil that is lost passes between the ring and bore and not through the ring gap or behind the ring. Tables 4.2 and 4.3 show the temperatures prevailing at the interface. In a 4-cylinder engine the peak oil film temperature was $186^{\circ} \mathrm{C}\left(367^{\circ} \mathrm{F}\right)$ and the average temperature at $50 \mathrm{mph}$ was $144^{\circ} \mathrm{C}$ $\left(292^{\circ} \mathrm{F}\right)$. The oil film temperature did not rise very far above the liner temperature of $320^{\circ} \mathrm{F}$ because it is extremely thin.

Another important item is the incompleteness of the oil film under the rings. This is due both to the cavitation in the diverging portions of the fluid film; and also to oil starvation. Starvation in the compression ring at mid-stroke can be explained by reference to the film thickness distribution in Figure 4.9. $0 i 1$ is supplied to the cylinder wall from the sump as splash lubrication from the bearings. This means that only when the piston is descending, that is from 0 to $180^{\circ}$, does it encounter a new supply of oil. The maximum theoretical film thickness that the ring can achieve with the inlet 


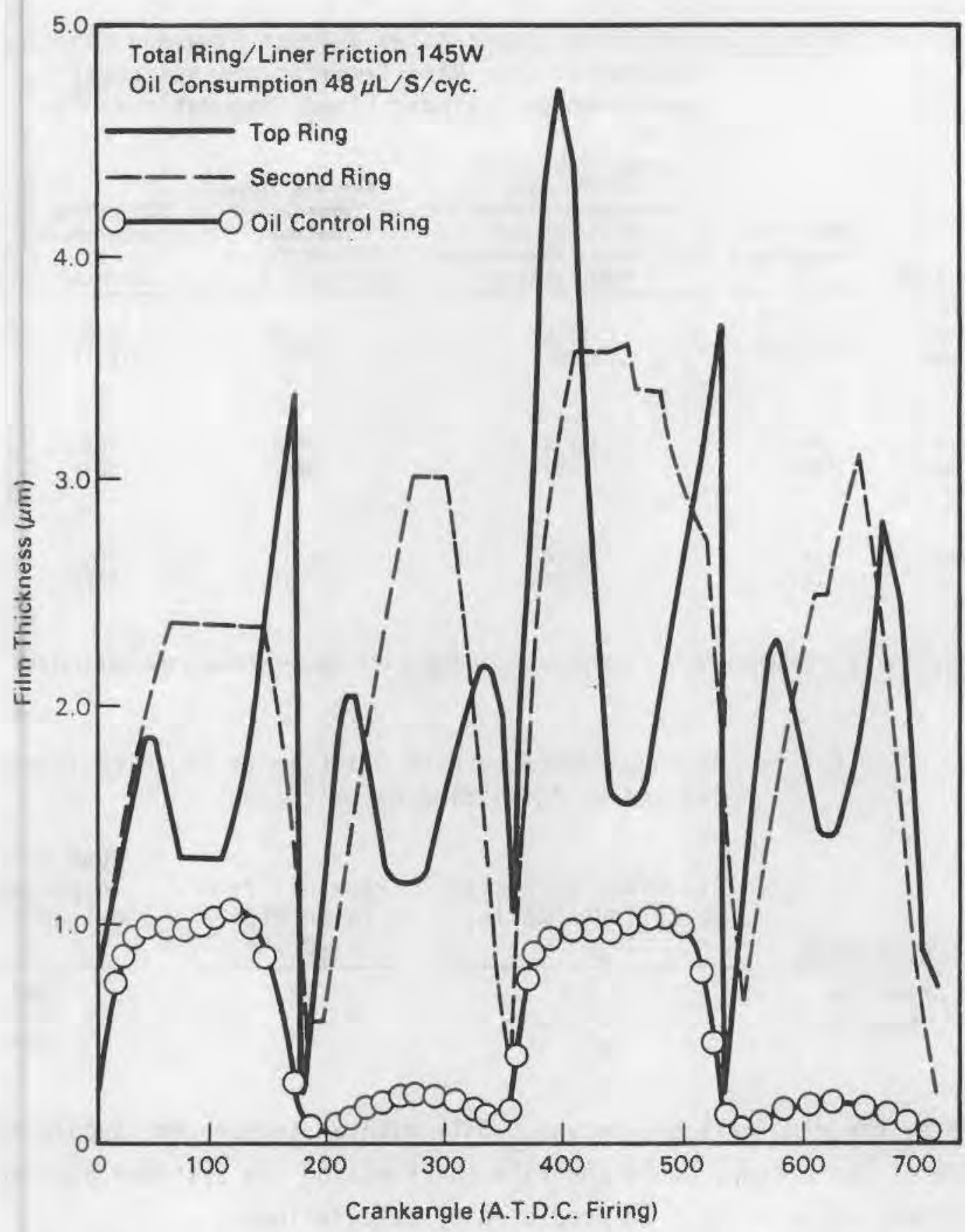

FIGURE 4.8. Calculated Ring-Liner 0il Film thickness of
Turbocharged Diesel Engine at $2600 \mathrm{rev} / \mathrm{min}$

full is $3.8 \mu \mathrm{m}$ at $80^{\circ}$ from TDC. From $180^{\circ}$ to $360^{\circ}$, the piston is moving upwards and the ring has no new supply of oil. The maximum film thickness that the ring attains will, therefore, be similar in value to that which it reached on the preceding down stroke. If a larger film thickness is formed on an 
TABLE 4.2. Oil Film Temperatures Between Ring and Liner Estimated from Ring Temperatures and Loçal and Average Cylinder Liner Temperatures(28)

\begin{tabular}{|c|c|c|c|c|c|}
\hline Enal ne Load & $\begin{array}{l}\text { Mean RInq } \\
\text { Temperature } \\
{ }_{\mathrm{O}} \mathrm{C}\end{array}$ & $\begin{array}{c}\text { Liner Temperature } \\
\text { at TDC Only } \\
\text { Average of Thrust } \\
\text { Wrist PIn end } \\
\text { Ant Ithrust Temperature } \\
\text { Measurements }\end{array}$ & $\begin{array}{l}\text { Average Liner } \\
\text { Temperature } \\
\text { Between } \\
\text { TOC and BDC of } \\
\text { TOP Ring's Travel }\end{array}$ & $\begin{array}{l}\text { OIl FIIm } \\
\text { Temperature } \\
\text { at } \\
\text { TDC Only }\end{array}$ & $\begin{array}{l}\text { Average } \\
\text { OII FIIm } \\
\text { Temperature } \\
\text { Between TDC } \\
\text { and BDC of } \\
\text { RIng's Travel }\end{array}$ \\
\hline $\begin{array}{l}20 \mathrm{bhp} \\
1500 \mathrm{rpm} \\
\text { Road load } \\
25 \mathrm{mph}\end{array}$ & ${ }_{(257)(a)}^{125}$ & $\begin{array}{r}96.6 \\
(206)\end{array}$ & $\begin{array}{r}91.8 \\
(197)\end{array}$ & $\begin{array}{c}110 \\
(231)\end{array}$ & $\begin{array}{c}108 \\
(226)\end{array}$ \\
\hline $\begin{array}{l}50 \mathrm{bhp} \\
3000 \mathrm{rpm} \\
\text { Road load } \\
50 \mathrm{mph}\end{array}$ & $\begin{array}{c}170 \\
(338)\end{array}$ & $\begin{array}{l}136.6 \\
(278)\end{array}$ & $\begin{array}{l}118.8 \\
(246)\end{array}$ & $\begin{array}{c}153 \\
(307)\end{array}$ & $\begin{array}{c}144 \\
(292)\end{array}$ \\
\hline $\begin{array}{l}70 \mathrm{bph} \\
5000 \mathrm{rpm} \\
\text { Road load } \\
80 \mathrm{mph}\end{array}$ & $\begin{array}{c}215 \\
(419)\end{array}$ & $\begin{array}{l}157.6 \\
(316)\end{array}$ & $\begin{array}{l}137 \\
(279)\end{array}$ & $\begin{array}{c}186 \\
(367)\end{array}$ & $\begin{array}{c}176 \\
(348)\end{array}$ \\
\hline
\end{tabular}

(a) Numbers 18 brackets are ${ }^{\circ} \mathrm{F}$. Water and crankcase oll temperatures were maintained at

TABLE 4.3. Maximum Temperature of 0il Film at Top Ring Travel Exposed to Combustion Gases $(28)$

\begin{tabular}{|c|c|c|c|}
\hline Engine Type & $\begin{array}{c}\text { 0il Film Thickness } \\
\text { on Cylinder Walls, } \\
\text { um }\end{array}$ & $\begin{array}{c}\text { Peak } 0 i 1 \text { from } \\
\text { Temperature } \\
\text { Rise, }{ }^{\circ} \mathrm{F} \\
\end{array}$ & $\begin{array}{l}\text { Peak 0il Film } \\
\text { Temperature on } \\
\text { Cylinder Wall, } \\
{ }^{\circ} \mathrm{F} \\
\end{array}$ \\
\hline Gasoline & 0.5 & 32 & 352 \\
\hline Engine & 1.0 & 64 & 384 \\
\hline
\end{tabular}

upstroke, the ring will be starved. Only with an independent supply of oil to the top of the piston, could the film thickness on the upstroke approach the theoretical value of $11.4 \mu \mathrm{m}$ predicted by calculation.

A more general picture of cavitation and starvation is provided in Figure 4.10. Beyond $20^{\circ}$, the cavitation in the outlet became general and the positive pressures drop back to their values on the upstroke. The largest negative pressure observed was $-0.78 \mathrm{MN} / \mathrm{m}^{2}(-113.1 \mathrm{psi})$ at $20^{\circ}$ after TDC, Figure $4.10(H)$. 


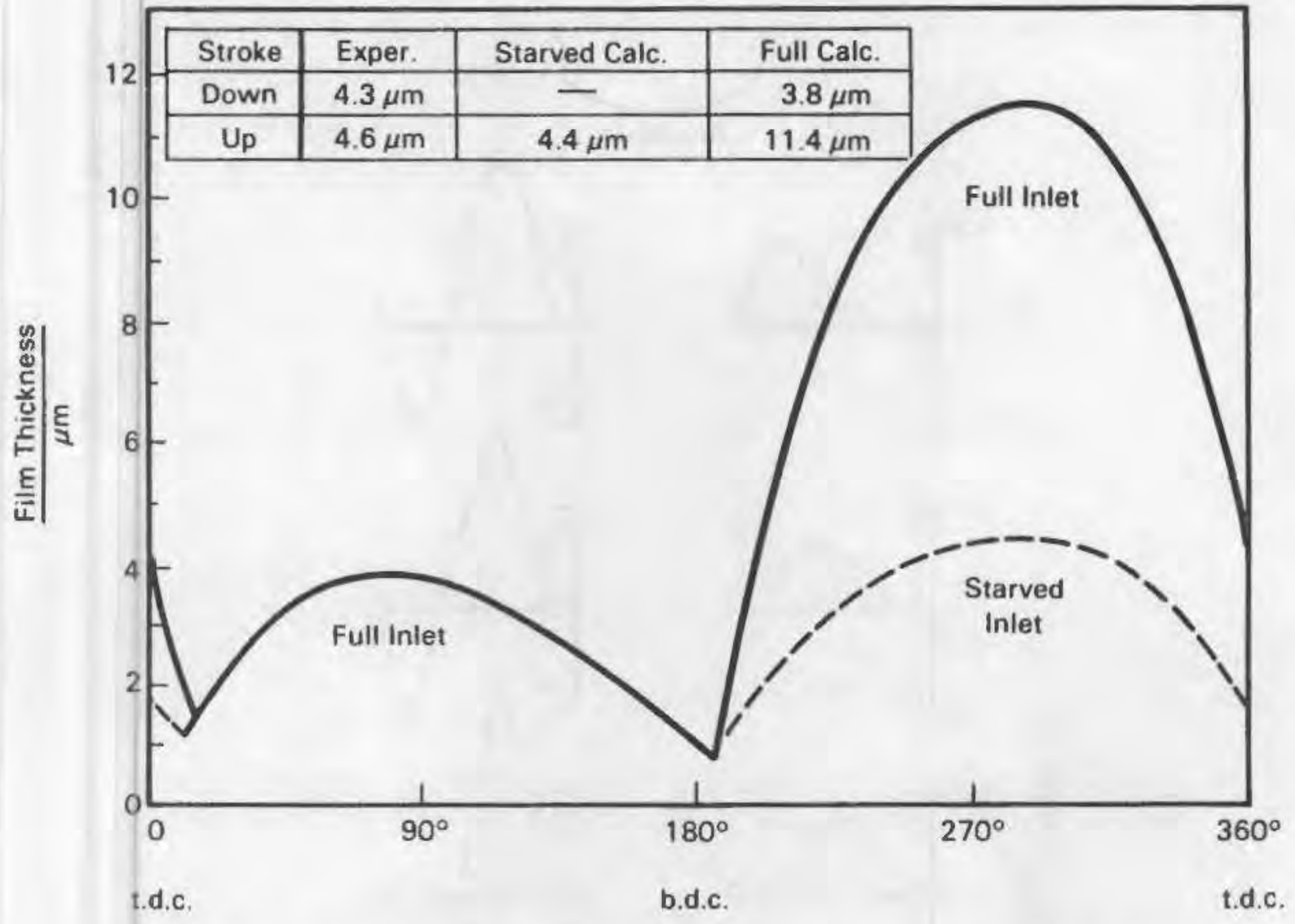

FIGURE 4.9. Calculated 0il Ring Film Thickness Distributions With and Without 0il Starvation(29)

Normally, the cavitating region is maintained at a constant level equal to either the saturation vapor pressure if the region is closed, or atmospheric pressure if aspirating. At room temperature, the vapor pressure of a mineral oil is generally close to vacuum, while the saturation pressure is only a small fraction below atmospheric. However, studies of the tensile strengths of liquids have shown that for short periods of time, such as shown in Figure 4.10 , pressures far below the gas saturation/vapor pressures can be sustained before cavitation occurs.

\subsubsection{Effect of Parameters on Performance}

In order to estimate what a particular technological innovation may accomplish in the way of reduction of parasitic losses, one must have an idea of what effect a given parametric variation has on the level of energy losses. 


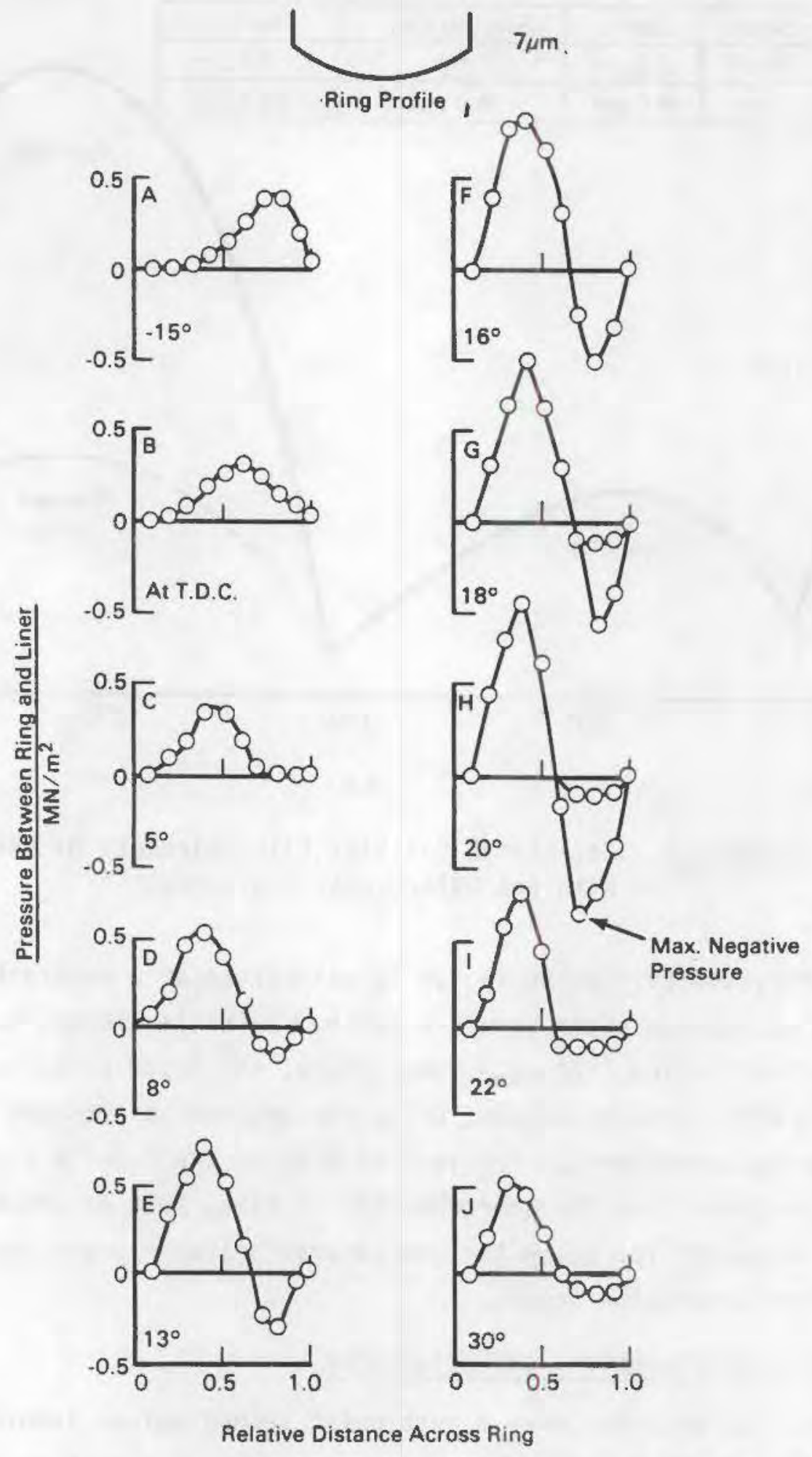

FIGURE 4.10. Pressure Distributions in a Piston Ring with a Shallow Profile. Largest negative pressure was $-0.78 \mathrm{NM} / \mathrm{m}^{2(30)}$. 
Table 4.4 gives a listing of the major items that are likely to affect the frictional losses in a piston assembly and an attempt will be made here to quantify their impact on the performance of the piston assembly. But, as pointed out earlier, it must be kept in mind that any given change will have an effect not only on friction, but on other aspects of performance as well. While it is clear that ring friction could be reduced by decreasing scraper ring pressure, oil viscosity, the number of compression rings and their axial width, decreasing scraper ring pressure will increase oil consumption; decreasing oil viscosity below a critical level will significantly increase wear; decreasing the number of compression rings will increase blowby; and reducing the axial width will impair strength and present manufacturing difficulties.

It should also be recalled that most of the recorded data was obtained from motoring tests or mathematical models. Real behavior of ring packs may conceivably be different and, thus, one of the important recommendations later on will be precisely the development of test techniques that would enable one to obtain measurements under firing conditions.

TABLE 4.4. Parameters Affecting Piston Assembly Friction

\begin{tabular}{ll}
\multicolumn{1}{c}{ Component } & \multicolumn{1}{c}{ Parameter } \\
\cline { 2 - 2 } Rings & Face shape \\
& Face width \\
& Thickness \\
& Number \\
& Loading \\
& Oil viscosity \\
& Materials \\
Skirt & Area \\
& Length \\
Piston and Connecting Rod & Ineartia \\
& Offset wrist pin \\
& Kinematics \\
& Stroke length
\end{tabular}


Based on motoring tests, the following interrelationships were found between piston parameters and performance.

- Ring Width and Tension. In the work of Rosenberg of Ford Motor Company, (11) the engine was a single-cylinder containing four piston rings. Specifications for the test rings are shown in Figure 4.11. Design $\mathrm{N}$ contains rings that have $50 \%$ narrower face width than the standard design. Design $\mathrm{N}-\mathrm{L}$ has in addition to a narrow face width reduced ring tension. The rings were first run individually, one at a time, and then the entire ring pack was run. It was found that for designs $S$ and $N$, the summation of the individual frictions was considerably less than the friction for the assembled pack. Evidently the lower rings in the ring pack influence the behavior of the rings above by reducing the amount of oil available to them. However, for the narrow ring width and low pressure design, $N-L$, the friction was equal to the sum of the individual rings, indicating that starvation of the upper rings was not occurring. In general, reduction of the face width and of the ring tension by one-half, each produced a reduction by one-half of the frictional losses.

In the work of Reference 10, a decrease in ring face width of $25 \%$ produced a $15 \%$ reduction in frictional losses whereas a $50 \%$ reduction in ring pressure reduced the friction by only $10 \%$.

A comparison of three-ring pack designs that were evaluated through engine motor friction tests are shown in Figure 4.12. Design $A$ has the same ring width as the base rings but reduced tension in both the compression rings and the oil ring assembly. In design $B$, both ring widths and tensions were reduced relative to the base design and the lower compression ring profile was modified. Both designs, $A$ and $B$, exhibited lower motoring friction than the base design, with $B$ showing the more significant improvement. These results show that one-third reduction in either width or tension produces respectively, savings of only $6 \%$ and $3 \%$. 


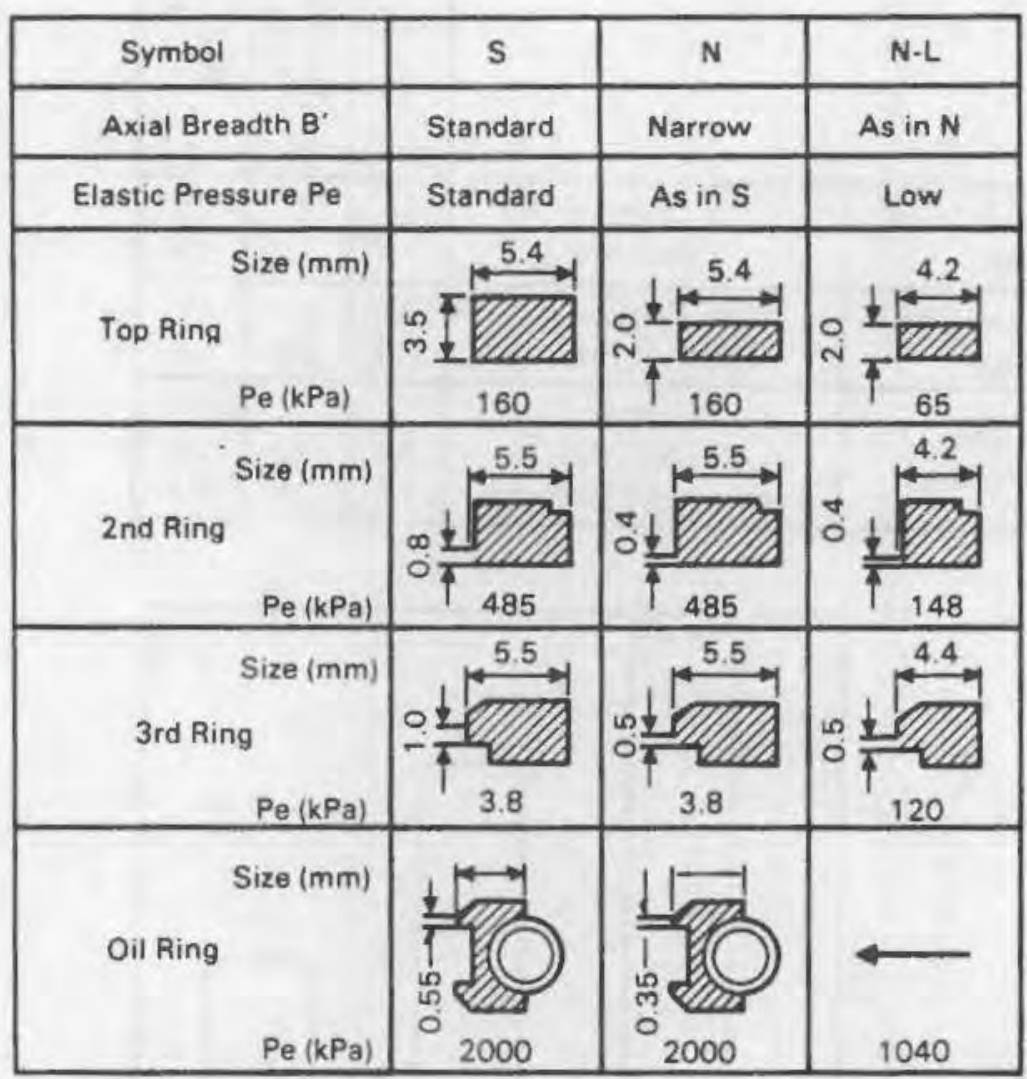

a) Geometry of Rings Tested

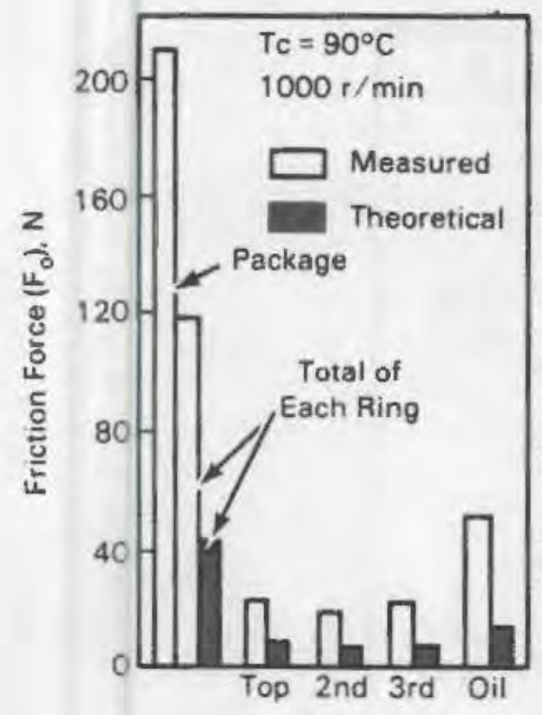

Each Ring

Standard Rings, S

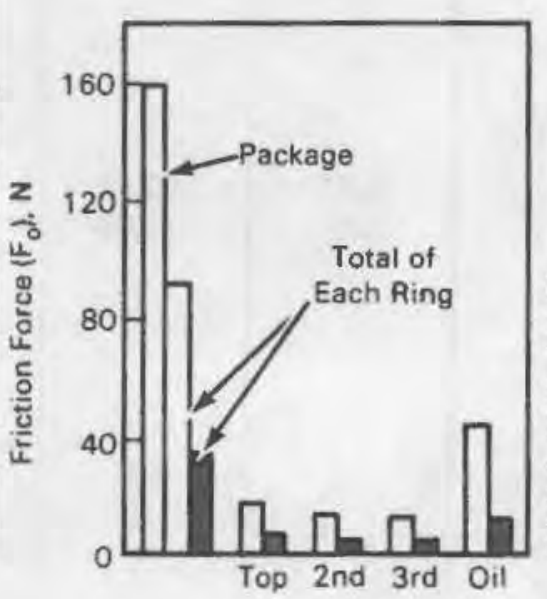

Each Ring

Narrow Rings, $\mathbf{N}$

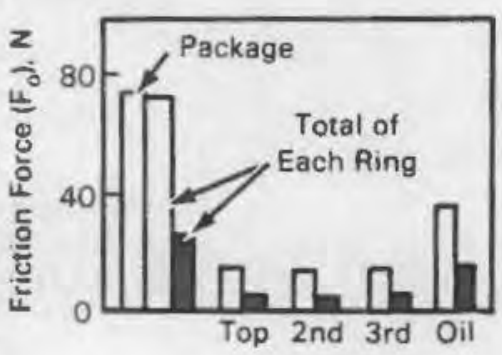

Each Ping Narrow and Low Tension Rings

b) Friction Results

FIGURE 4.11. Effects of Narrow Face and Reduced Tension in Piston Rings(11) 


\begin{tabular}{|c|c|c|c|c|}
\hline & & \multirow[b]{3}{*}{ Base } & \multirow{3}{*}{ 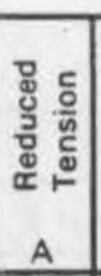 } & \multirow{3}{*}{ 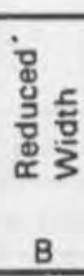 } \\
\hline & & & & \\
\hline & & & & \\
\hline $\begin{array}{l}\text { Upper Comp. } \\
\text { Ring }\end{array}$ & $\begin{array}{l}\text { Dia. Tension (M) } \\
\text { Width }(\mathrm{mm})\end{array}$ & $\begin{array}{l}24 \\
1.6\end{array}$ & $\begin{array}{l}12 \\
1.6\end{array}$ & $\begin{array}{l}26 \\
1.5\end{array}$ \\
\hline $\begin{array}{l}\text { Lower Comp. } \\
\text { Ring }\end{array}$ & $\begin{array}{l}\text { Dia. Tension (M) } \\
\text { Width }(\mathrm{mm})\end{array}$ & $\begin{array}{l}70 \\
2.0 \\
\end{array}$ & $\begin{array}{l}14 \\
2.0 \\
\end{array}$ & $\begin{array}{l}19 \\
1.5 \\
\end{array}$ \\
\hline $\begin{array}{l}\text { Oil Ring } \\
\text { Assembly }\end{array}$ & $\begin{array}{c}\text { Tangential } \\
\text { Tension (M) } \\
\text { Segmental Width (mm) }\end{array}$ & $\begin{array}{l}49 \\
0.6\end{array}$ & $\begin{array}{l}33 \\
0.6\end{array}$ & $\begin{array}{l}25 \\
0.4\end{array}$ \\
\hline
\end{tabular}
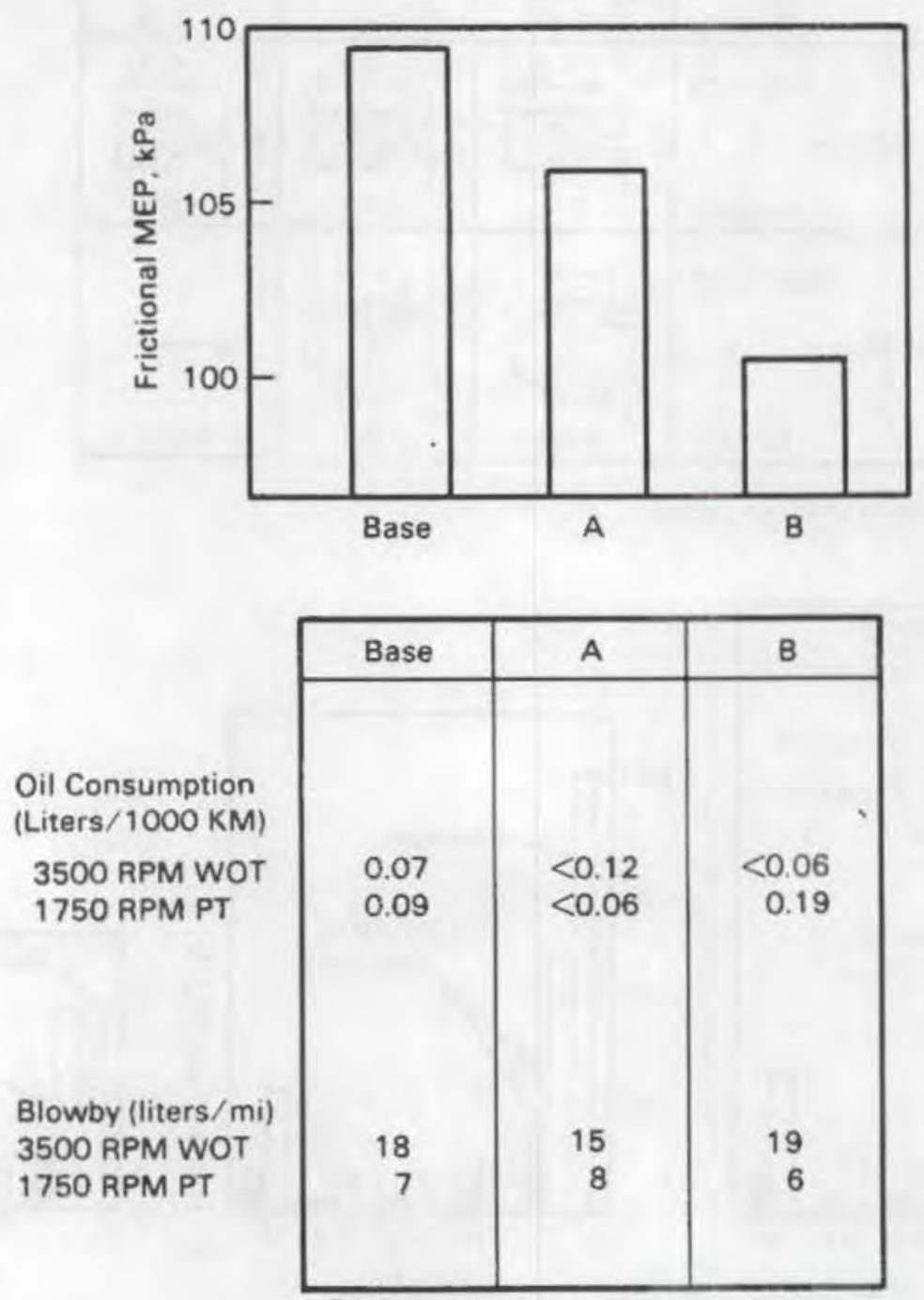

Oil Consumption and Blowby Results

FIGURE 4.12. Effect of Reduced Face Width and Ring Tension in Piston Rings (1500 rpm) (10) 
- Number of Rings. According to Reference 10, reducing the number of rings from 3 to 1 decreased friction by $33 \%$ while increasing blowby by $50 \%$. However, according to Reference 19 , the same reduction in number of rings reduced friction by only $6 \%$.

- Oil Viscosity. Doubling the viscosity of the lubricant increased friction by $50 \%$ and 0 il consumption by $20 \%$. (10)

- Ring Shape. While a highly curved face profile can result in a larger film thickness during the high speed portions of the cycle, the highly curved ring will have a smaller film thickness near TDC and RDC, Figure 4.13 . These results at $T D C$ and $B D C$ are reasonable when considering the squeeze film effect since intuitively the oil will more easily escape from between the highly curved ring profile and the cylinder wall. However, a crowned profile seems, on the
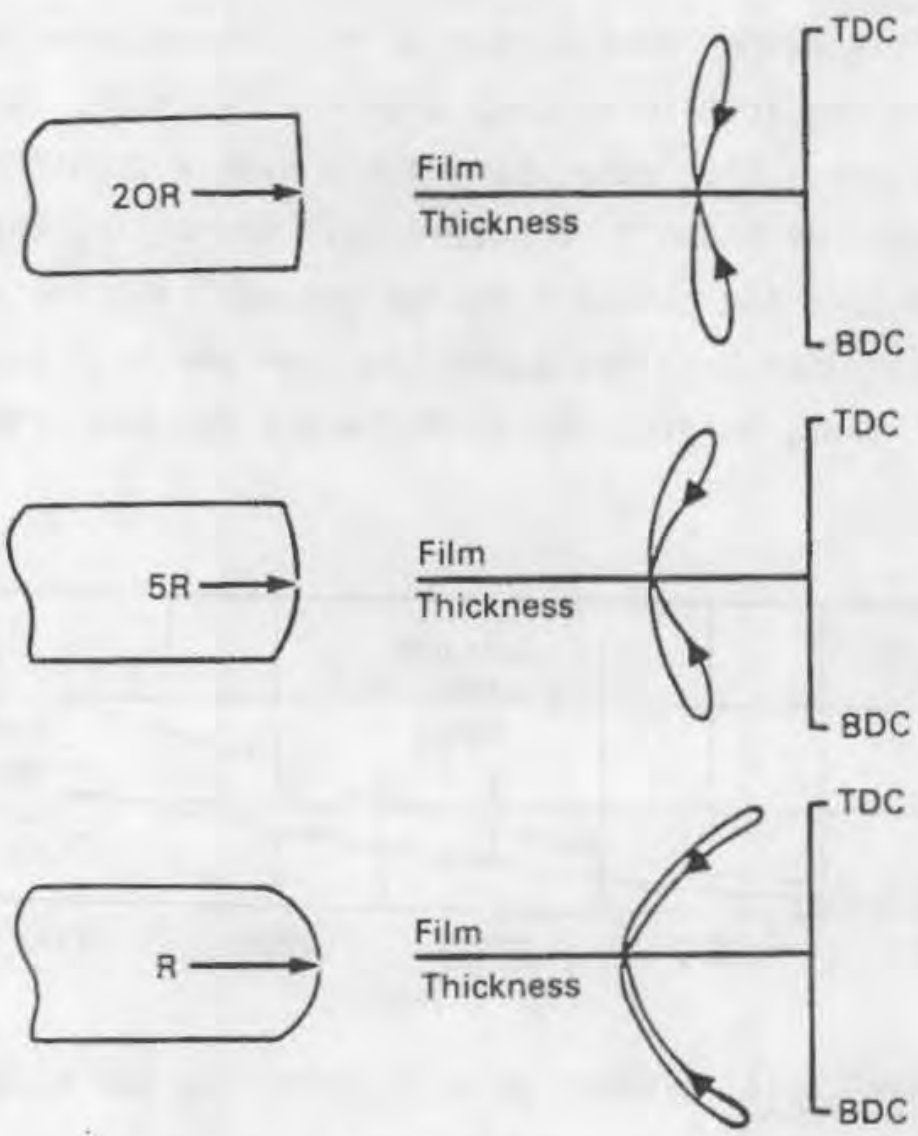

FIriURE 4.13. The Effect of Ring Face Profile on Film Thickness(10) 
whole, to improve film thickness, particularly at the point of maximum energy dissipation (midstroke). This is also corroborated by the results of Reference 78 , shown in Figure 4.14 where the introduction of the barrel-faced piston ring which maximizes hydrodynamic lubrication on both the upstroke and the downstroke also contributed to friction reduction.

- Ring Material. Top compression ring faces are generally coated with a material which is able to resist wear and scuffing. Since such a ring can operate in either the mixed or boundary lubrication mode, the properties of this face material are of particular importance. Limited engine motoring friction results indicated that special topring facing materials such as chromium, (10) result in lower friction than a molybdenum-faced ring (see Figure 4.14).

- Piston Skirts. To reduce skirt frictional losses, skirt area can be reduced. This can be done either by reducing piston length or by undercutting the area in contact with the cylinder. Both options are shown in Figure 4.15. Skirt length can have a significant impact on friction level as shown in Figure 4.16. Decreasing the skirt effective length from the original design reduces friction and improves engine economy for both low speed-low load and high speed-high load operation. Thus, halving the skirt length reduced friction by about $10 \%$.

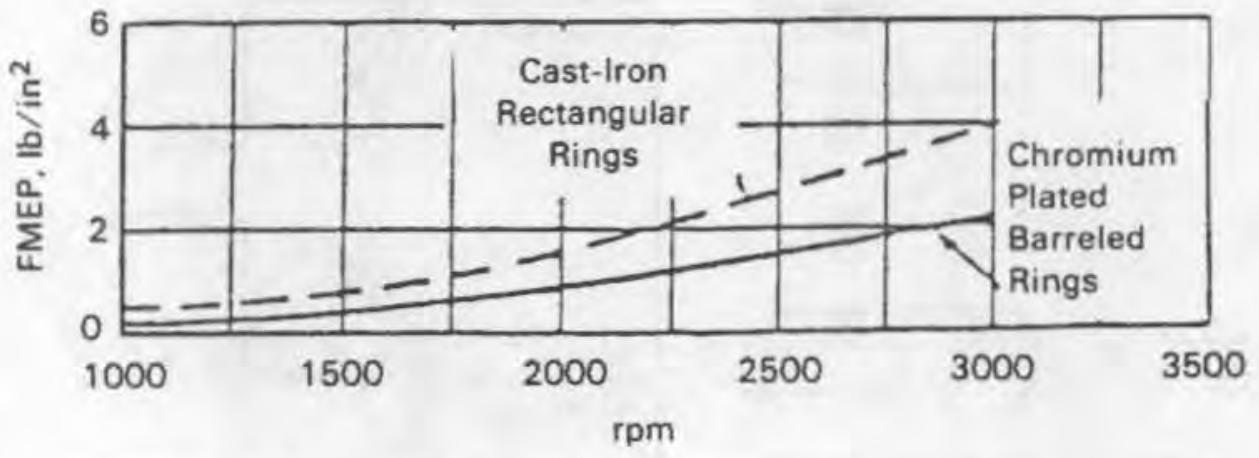

FIGURE 4.14. Effect of Ring Barreling and Plating(28) 

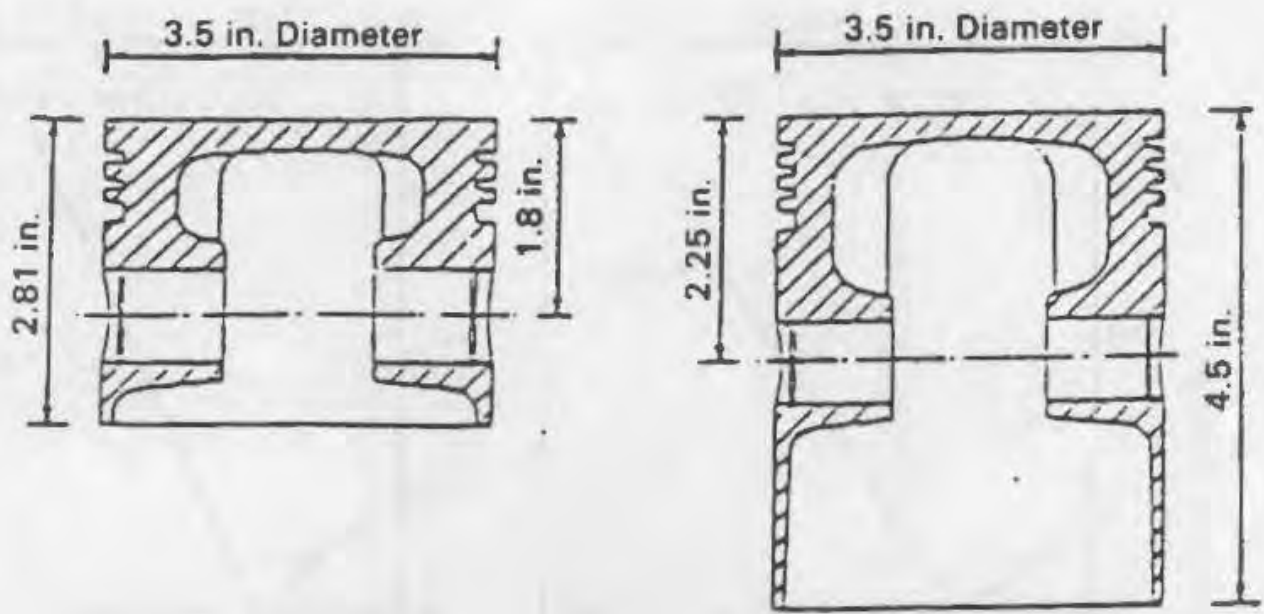

Modern Pattern

Earlier Pattern

a) Change in Piston Skirt Length Over the Decade 1960-1970

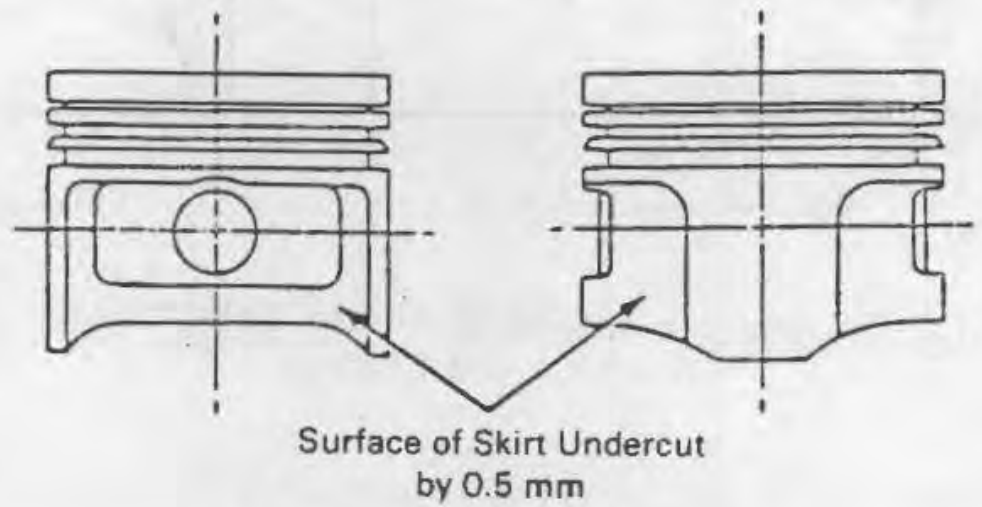

b) Undercut Surface in Piston Skirt

FIGURE 4.15. Means of Reducing Friction in Piston Skirts (10)

In Reference 10, a piston design with reduced skirt area and increased piston-to-bore clearance $(0.04 \mathrm{~mm}$ to $0.06 \mathrm{~mm})$ was evaluated to determine the effect of reducing the area of oil being sheared around the periphery of the skirt. This modification had no detectable effect in reducing engine motor friction at $1500 \mathrm{rpm}$ although the total skirt area was nearly halved. These results suggest that only the shear at the loaded thrust face contributes significantly to piston friction. It is also conceivable that the reduction in area results in a thinner film thickness. This reduction in film thickness may offset the beneficial effects of reduced shear area. 

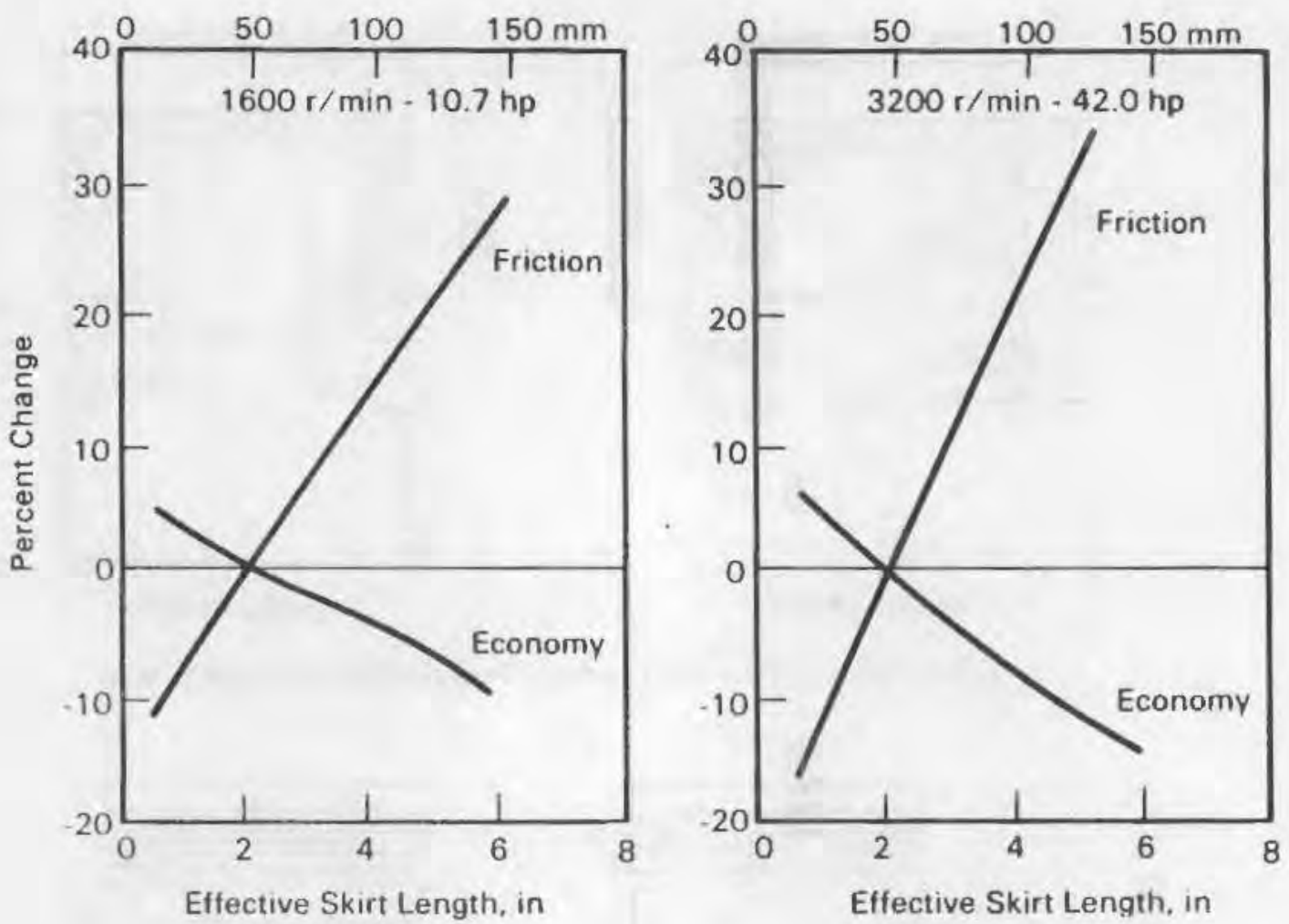

FIGURE 4.16. Influence of Piston $\{k j\}^{t}$ Length on Engine
Friction and Economy

Reducing the reciprocating mass of piston, pin, and rod end should reduce piston-to-bore loading and, therefore, the friction. Analytical results, which consider the effect of inertia and gas pressure on piston/bore loading, indicated that a $25 \%$ reduction in the mass of a typical four-cylinder engine piston lowered friction by less than $0.1 \mathrm{psi}(0.7 \mathrm{kPa})$ MEP at $1500 \mathrm{rpm}$, which is about $0.1 \%$ of the IHP.

- others. Reduced side thrust has reduced viscous friction associated with the piston body in modern engines. The piston's side thrust forces have been lowered with the introduction of the $1 / 16 \mathrm{in}$. offset wrist pin for noise control. Friction-reducing design changes in the piston and ring have been augmented by reductions in their linear speed. With the introduction of short stroke engines, in which the stroke-to-bore ratio has been lowered from 1.3 to 0.8 , piston linear speed and, consequently, friction as shown in Figure 4.17 have been 


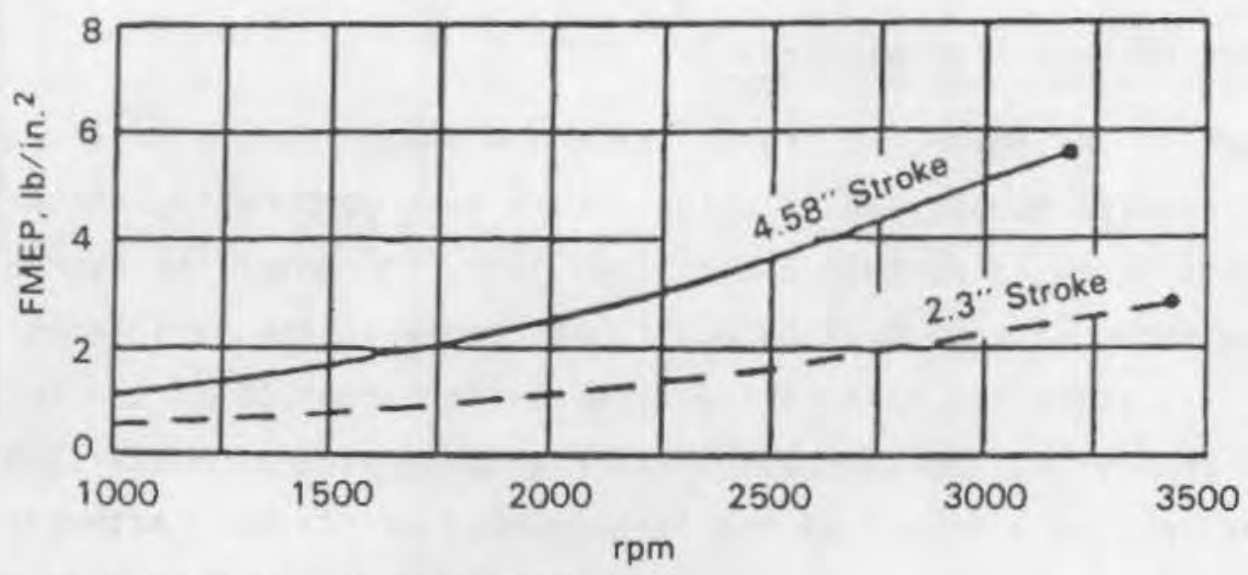

a) Results on Rotational Speed Basis

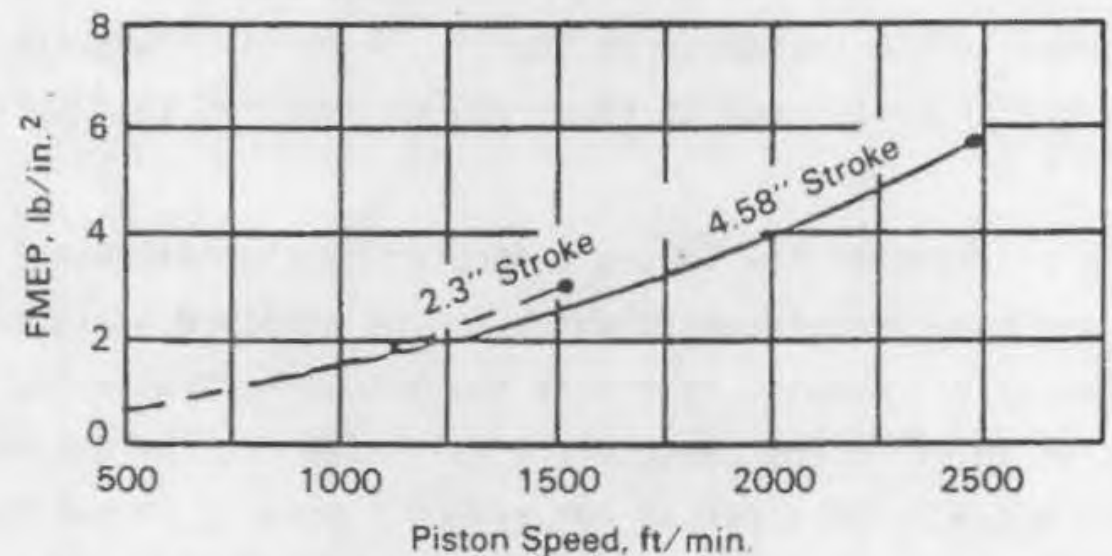

b) Results on Piston Speed Basis

FIGURE 4.17. Effect of Stroke Length on Piston Friction(28)

reduced at a given engine rpm. Bench tests demonstrate ${ }^{(28)}$ that piston and ring friction is a function of mean linear speed rather than of rotational speed.

\subsection{TRANSMISSIONS}

In discussing automotive transmissions, two aspects emerge in connection with potential energy conservation. These are:

- potential improvements in conventional systems

- continuously variable transmissions (CVT) versus conventional transmissions. 


\subsubsection{Conventional Transmissions}

Losses in the automatic transmission are due primarily to the torque converter, hydraulic pumps, and friction. Like most components, automatic transmission efficiency is poorest under light load. Moreover the hydraulic power for transmission control must be available even when the vehicle is standing still. It is estimated that idling accounts for some $75 \%$ of the 1osses. On the urban EPA cycle, the torque converter which serves as a starting device has poor efficiency as a result of the large number of starts. Attempts to improve the efficiency of automatic transmissions include both torque converter lockup schemes to avoid slip once the vehicle is moving, and general reduction of parasitic losses in the transmission itself. A manual transmission in this same service has an efficiency of about $93 \%$ as compared to $73 \%$ for the automatic. (7)

Analysis of transmission losses indicates substantial benefit in decreasing oil pumping power requirements which can be achieved by incorporating a variable capacity oil pumping system in the automatic transaxle. Also, the introduction of an efficient planetary final drive for the automatic transaxle and a helical drive for the manual can reduce losses in comparison with the conventional hypoid final drive required in longitudinally mounted drive trains.

Potential transmission and axle gearing was analyzed in Reference 31 for various engine displacements and several ranges of overall ratio, as shown in Figure 4.18. This graph indicates that greater transmission ratio spread, within the limits of physical design feasibility, is highly desirable. Selection of "wide ratio" gearing for both manual and automatic transmissions enabled the reduction of engine displacement to achieve a further economy gain.

\subsubsection{The THM 125 Transmission}

An example of an improved transmission incorporating most of the above elements, labeled the THM125, is described in Reference 32. It has flexibility to cover a wide range of vehicle applications, because both the chain drive and the final drive ratios can be varied to provide the desired overall ratio. The THM is a three-speed automatic transmission which also includes a planetary 


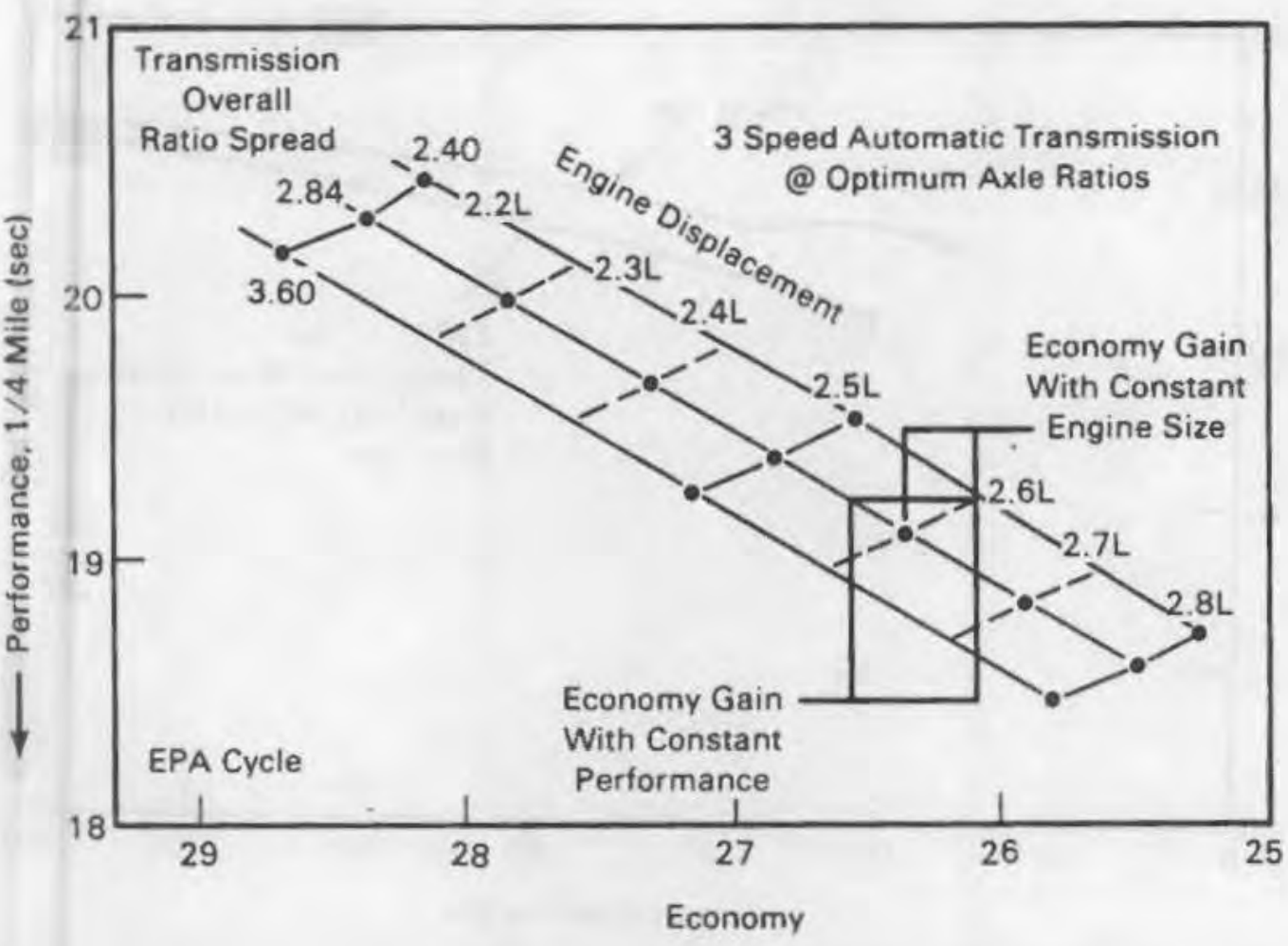

FIGURE 4.18. Effect of Transmission Qverall Ratio Spread on
Performance and Economy (31)

gear final drive and a differential. It yielded high efficiencies, as shown in Figure 4.19 , which is attributed to the following component improvements:

1. an optimized design torque converter

2. efficient, quiet and lightweight inverted tooth chain drive

3. wide ratio transmission gearing

4. planetary gear final drive with integral differential

5. thermally-controlled oil level system

6. lubricating system, which is common to the gearbox, final drive, and differential.

This unique two-axis arrangement has the torque converter and oil pump/valve body on the engine axis and the gearbox, final drive, and differential on the axle axis. The drive from the converter axis to the gearbox axis is through an inverted tooth chain. 


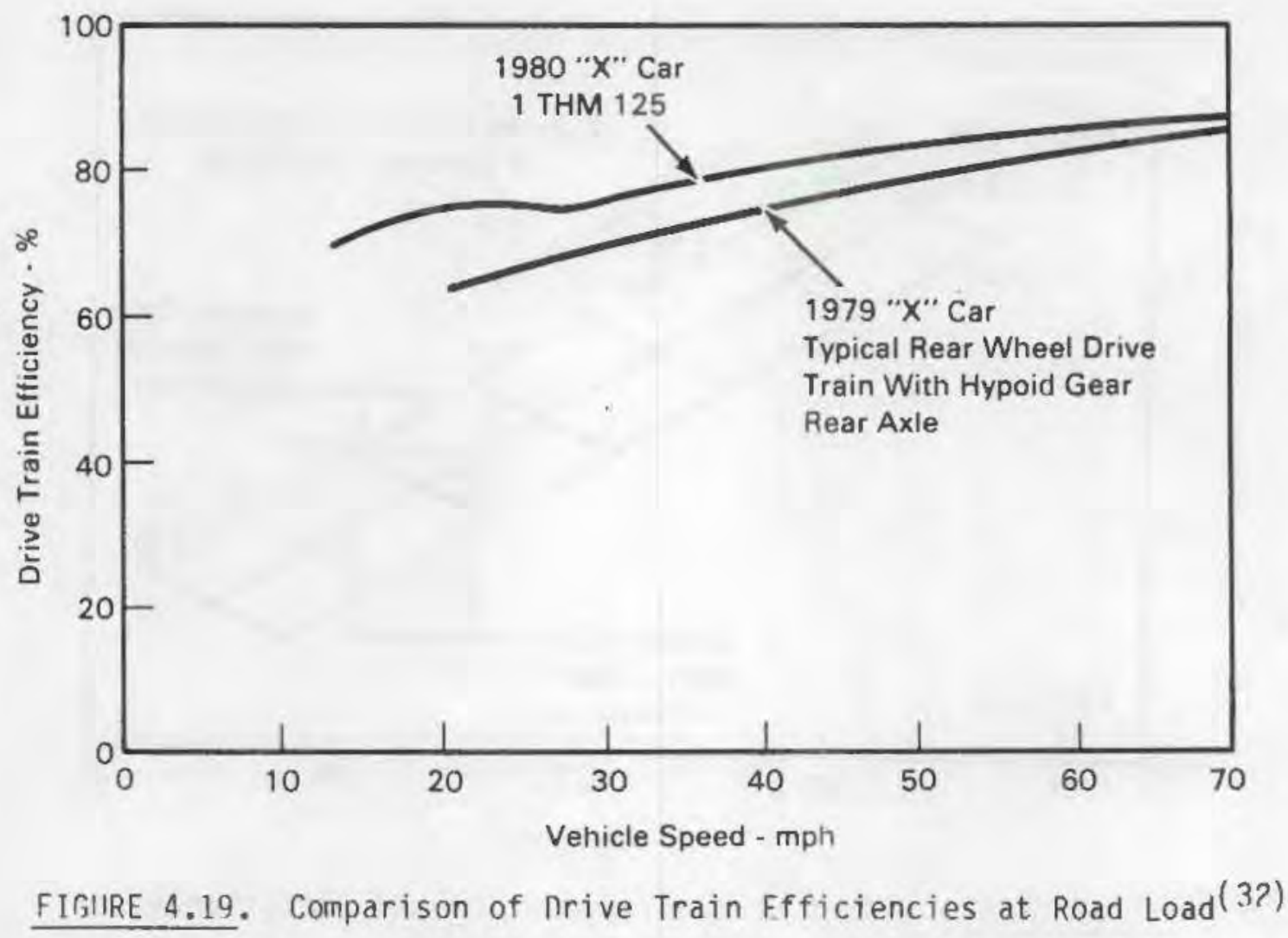

The ratios, which were optimized for vehicle performance and economy through computer modeling, are:

First Gear $=2.84$
Second Gear $=1.60$
Third Gear $=1.00$
Reverse Gear $=2.07$

With these changes, ideal torque was reduced $30 \%$, fuel economy increased, and performance was better than with other previously tested torque converters.

A fixed capacity pump, common in current automatic transmissions, wastes energy in many operating conditions by pumping more oil than is needed. This can he avoided with a variable capacity pump, such as the one used in the THM 125, where the output flow is controlled to match the need. Figure 4.20(a) shows a section of a variable capacity vane pump in which eccentricity is reduced as exit pressure increases. Figure 4.20 (b) shows a comparison of 


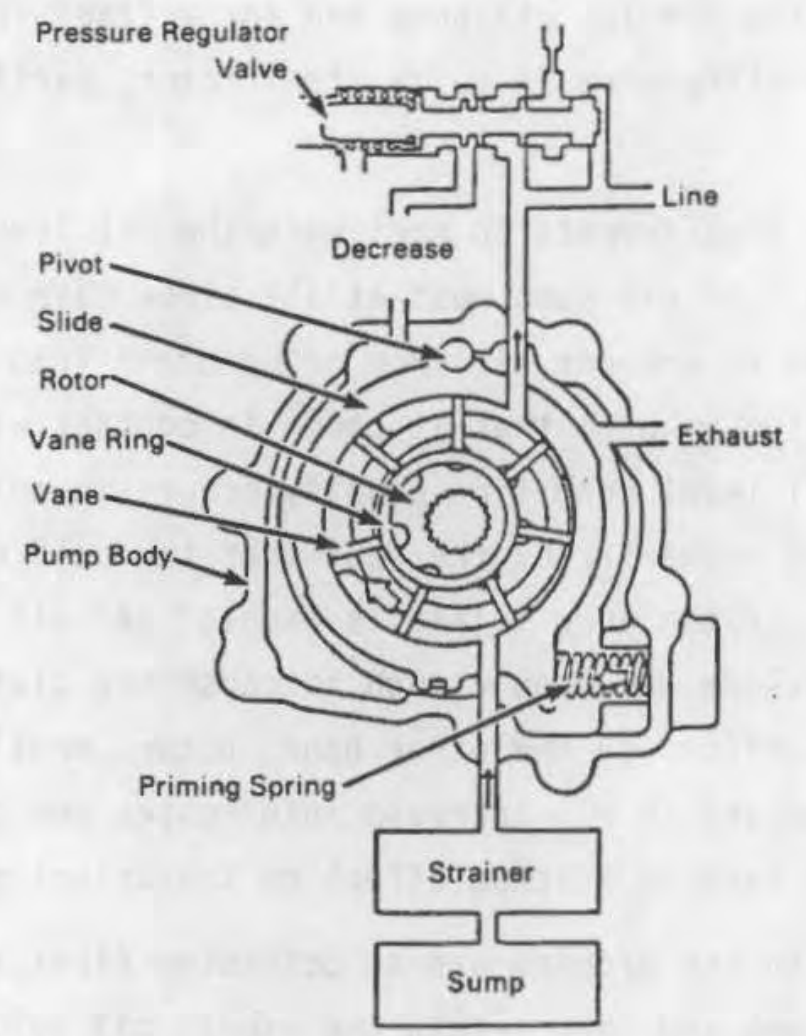

a) Variable Capacity Oil Pump

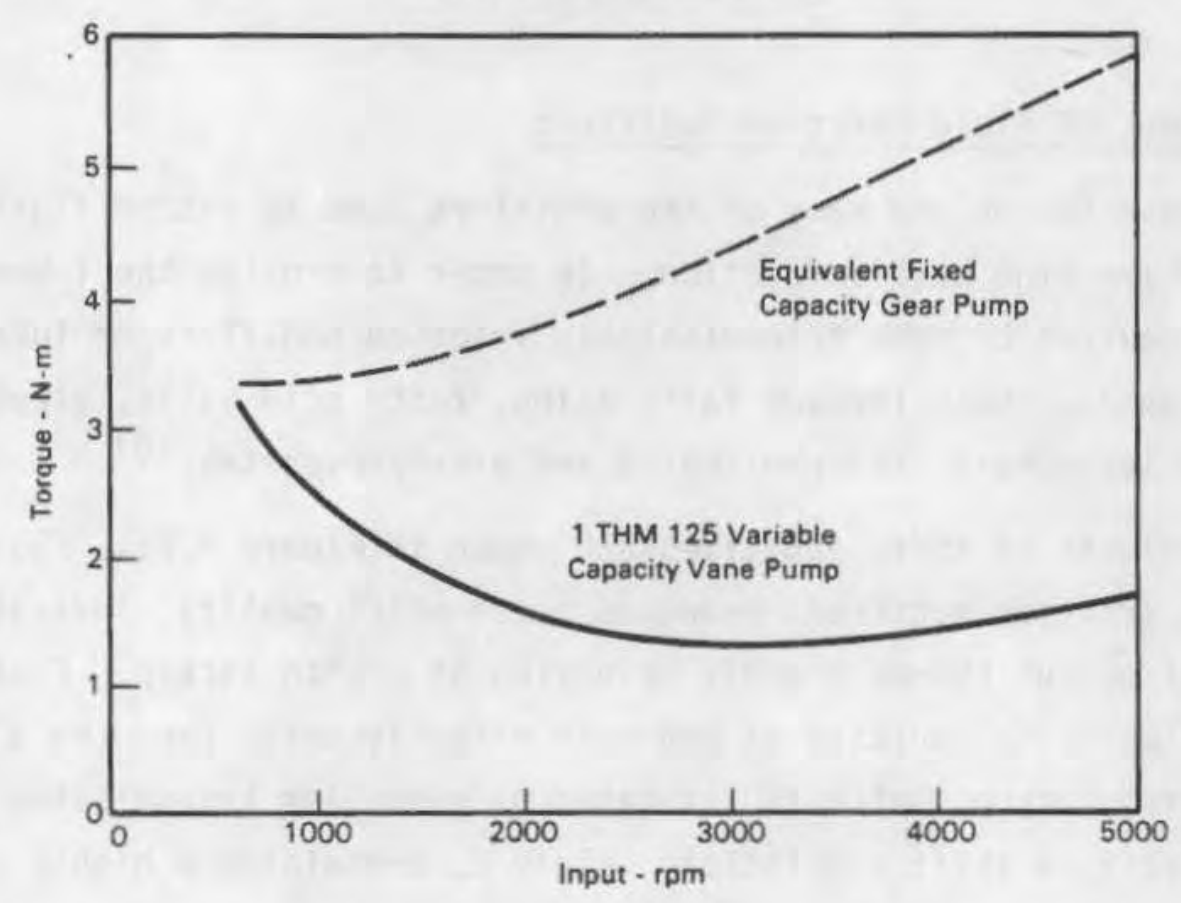

b) Performance of Fixed and Variable Capacity Rings

FIGURE 4.20. Variable Capacity 0il Pump(17) 
torque losses for the THM 125 oil pump and for a fixed capacity pump of equivalent output. The difference is quite significant, particularly at high engine speeds.

There are two requirements to meet when the oil level is set in an automatic transmission. An oil sump must at all times have enough oil to keep the pump intake covered to prevent air from being drawn into the pump; yet the oil level should not rise so high that it comes in contact with the rotating parts. The low oil level condition usually occurs in cold operation. This condition is caused primarily by the fact that the cold oil is slow in draining back to the sump. If the pump intake is exposed and air is permitted to enter the pump, line pressure may drop enough to cause the clutches to slip. The high oil level condition, on the other hand, occurs mostly in hot operation. Rotating parts immersed in oil increase spin losses and cause foaming, which, if excessive, will have an adverse effect on transmission operation.

The solution to the problem was to determine first the lowest acceptable oil level in the sump and then retain the excess oil volume, which increases with the rising temperature in a separate thermostatically controlled reservoir.

\subsubsection{Effect of Fluid Friction Modifiers}

The base fluids and many of the additives used to extend fluid life, generally have high static friction. In order to provide the lower static friction required by some transmissions, friction modifiers or lubricity additives are used. These include fatty acids, fatty acid salts, alkyl esters of fatty acid long-chain alkylphosphates and alkylphosphites. ${ }^{(8)}$

The effects of these additives are shown in Figure 4.21. Fluid A, containing no friction modifier, produces harsh shift quality, indicated by the substantial output torque dropoff occurring at clutch lockup. Fluid B, containing a lubricity additive of moderate effectiveness, produces a moderately sinooth clutch lockup, which is indicated by a smaller transmission output torque dropoff on shift completion. Fluid $C$, containing a highly effective friction modifier system, produces a smooth clutch lockup, a result of the decrease in friction coefficient as the clutch slip velocity decreases. 

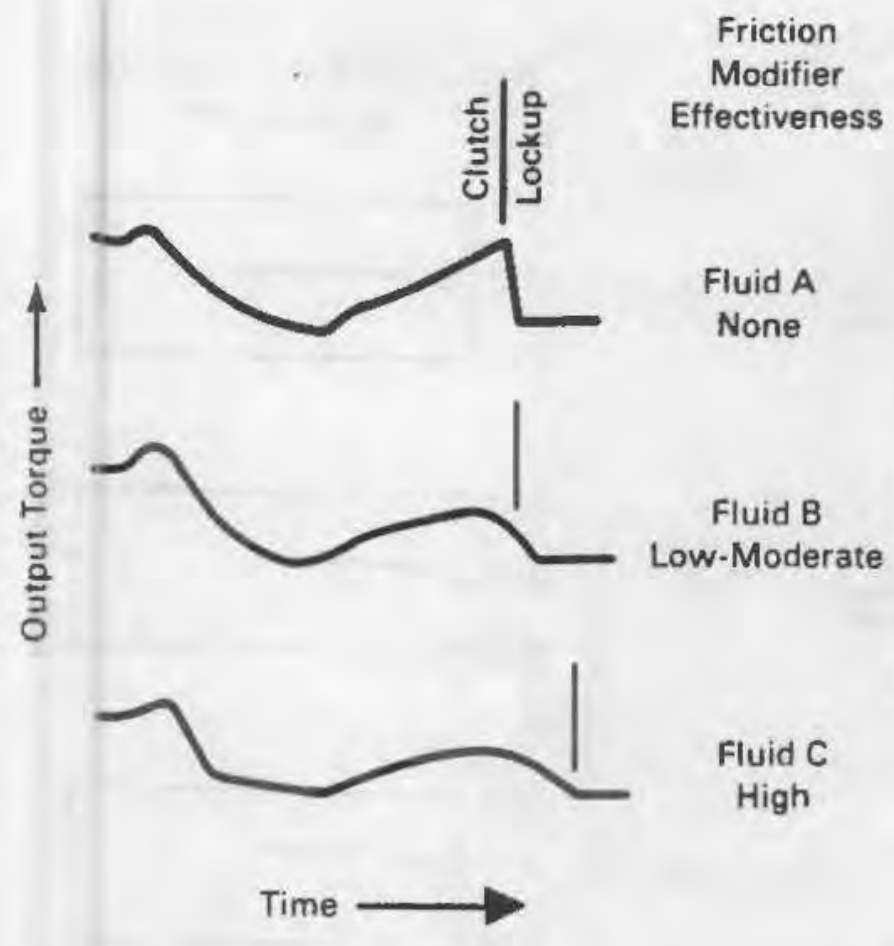

Friction Coefficient (Calculated From Transmission Shifting Data)
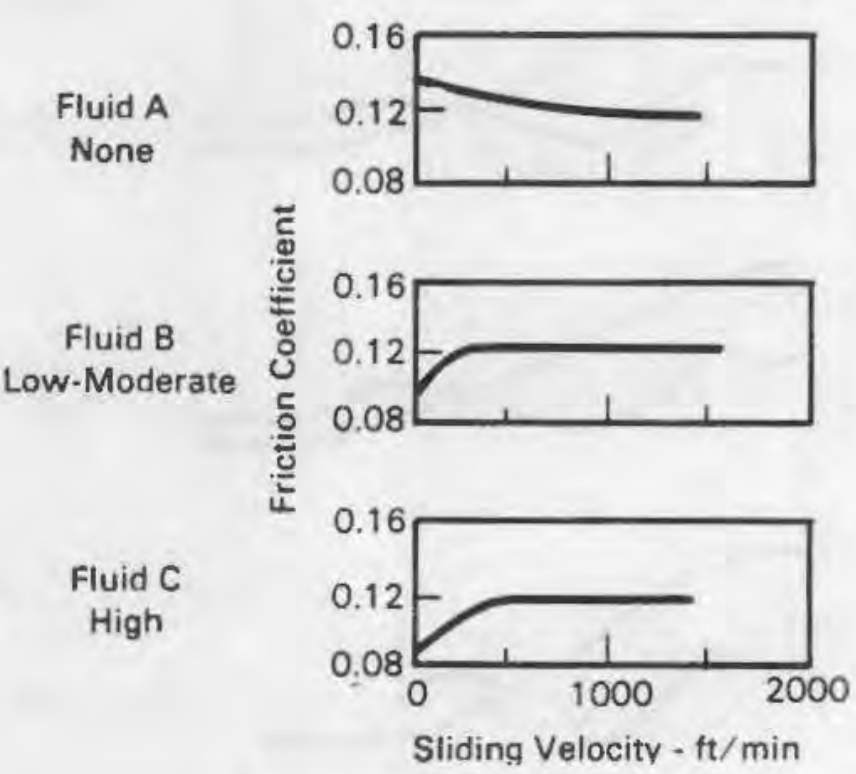

FIGIIRE 4.21. The Effect of Friction Modifiers on Three-Speed Transmission Shift Ouality

Fluid degradation resulting from severe service exposure may produce substantial changes in the frictional properties of the fluid. As a result, the initial good shift quality achieved by the proper balance of frictional and transmission factors may be lost as degradation progresses, and in some cases, the friction element itself may be endangered.

The effect of this friction degradation pattern on transmission shift quality is illustrated in Figure 4.22 , which shows the changes in output torque curves resulting from service degradation in a three-speed transmission test. An investigation $(8)$ was made to determine the ability of fresh fluid to restore satisfactory shifting characteristics to a transmission in which fluid degradation had resulted in excessive clutch slippage. This work was carried out with transmissions in which slippage had increased sufficiently so as to be noticeable to the average driver.

From this work, it appears that when excessive clutch slippage due to fluid frictional changes is discernible by the average driver, irreversible 
Friction Coefficient

(Calculated From Transmission Shifting Data)

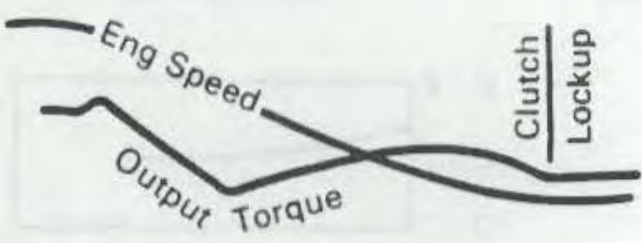

Test

Hours

0

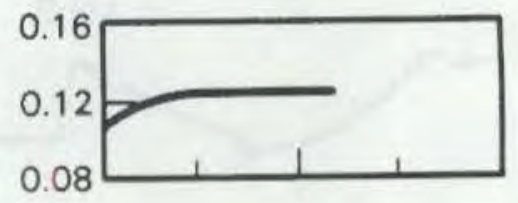

50

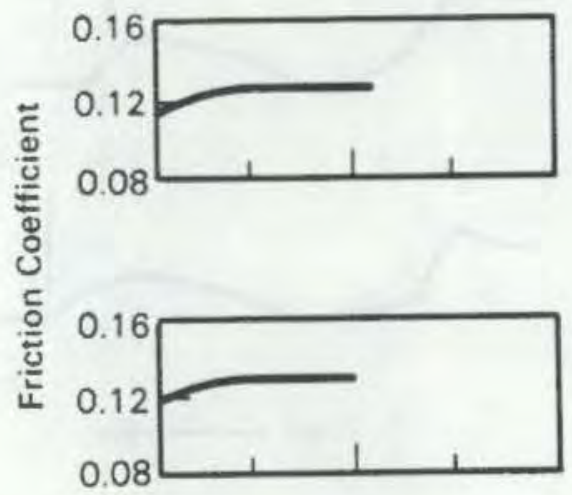

100

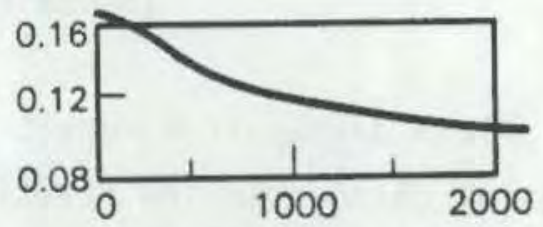

Sliding Velocity - $\mathrm{ft} / \mathrm{min}$

FIGURE 4.22. The Effect of Fluid Degradation on Shifting Quality in Three-Speed Transmission at $275^{\circ} \mathrm{F}$ Bulk Fluid Temperature

clutch plate changes have already occurred. New fluid will at best only partially restore the transmission shifting to original performance levels.

\subsubsection{Continuously Variable Transmissions (CVTs)}

The transmission affects system fuel economy by the way it matches the engine speed and load to vehicle requirements. A perfectly continuous variable transmission could improve fuel economy by causing the engine to produce power near its most efficient operating speed. Figure 2.2 helps illustrate this principle. At any required power level, the speed ratio could be adjusted to move the engine operating point vertically to a speed which yields the best 
thermal efficiency. The benefits are potentially areatest at light loads in high power/mass cars. For a net gain, however, the efficiency improvement must be greater than the added transmission losses.

Mechanical, hydraulic, and electrical continuously variable transmissions have been developed, but the anticipated fuel economy gains have not been realized. This has been due primarily to transmission losses in the light load range almost equal to the gains achieved. (7) Also, substantial gains in the efficiency of conventional transmissions have reduced considerably the attractiveness of using CVT systems. Yet, CVT remains a strong candidate for improving transmission efficiency, particularly the belt driven, van Doorn type, in place of the previously contemplated traction type drives. This is due to the frequent malfunctioning of traction CVTs and the requirement for initial loading to get these drives working. To best utilize traction drives, CVT materials and lubricants with higher values of friction coefficient would have to be developed. Solid lubricants are no solution here because fluid lubricants are required for cooling purposes.

Figure 4.23 shows the ideal line expressed as a power/speed relationship. It demands a unique engine speed for each power output. To take advantage of this concept, a car will need a transmission capable of transmitting power from the prime mover, run at a wide range of speeds, to the driving wheels whose speed will also vary between slow astern through zero to full speed ahead.

Figure 4.23 also shows that the ratio of the transmission will need to be considerably wider than at present. The abscissa of Figure 4.23 shows the relationship between level road speed and engine power. At $80 \mathrm{~km} / \mathrm{hr}$ for instance, the power required is $12 \mathrm{~kW}$ which should be generated at only $1200 \mathrm{rpm}$ for the best economy.

\subsection{VALVE TRAINS}

\subsubsection{General Features}

Valve trains carry high loads over the entire speed range. At low speeds these are due primarily to the spring forces, while at higher speeds inertia 


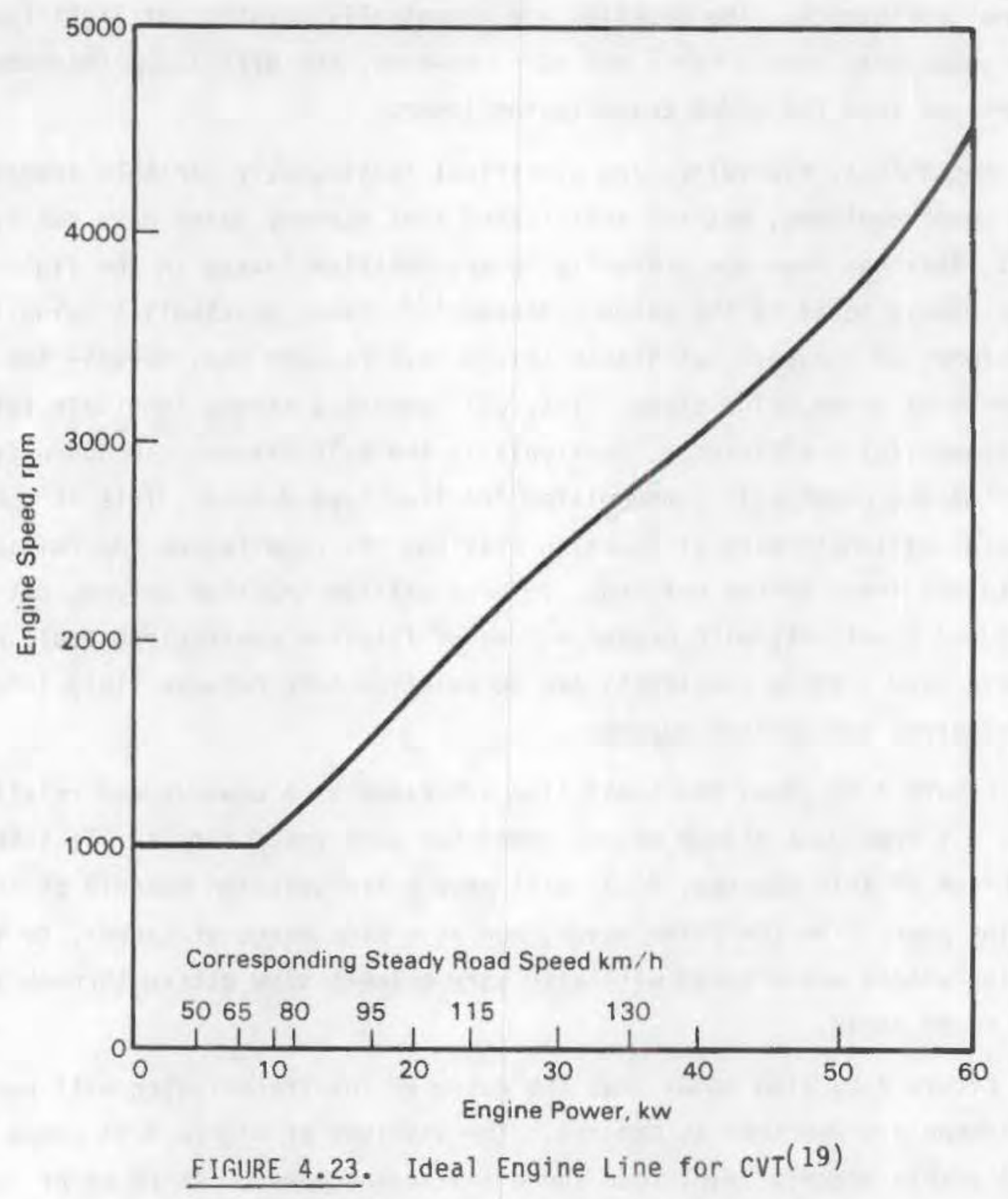

forces predominate. The configuration of typical automotive valve trains is given in Figure 4.24 . These variations include the pushrod, the direct-acting overhead cam, the end-pivot overhead cam, and the center-pivot overhead cam. The predominant regime of lubrication in the valve train is boundary lubrication and the major energy losses occur in the cam lifter interface and in the rocker arm pivot. As shown in Figure 4.24 , the torque required to drive the valve train is lowest for the direct-acting design. This is because there is 


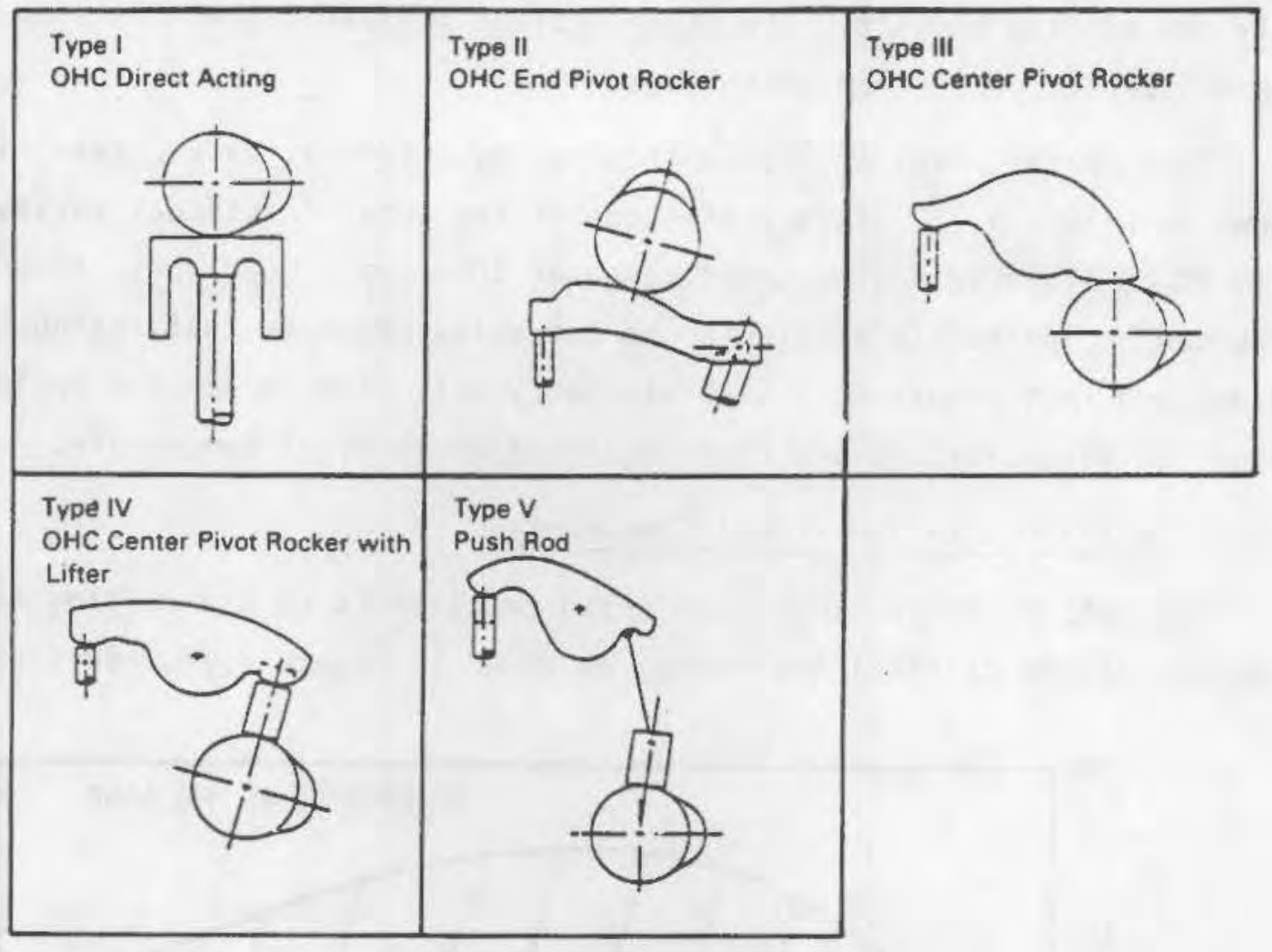

a) Typical Valve Train Configuration

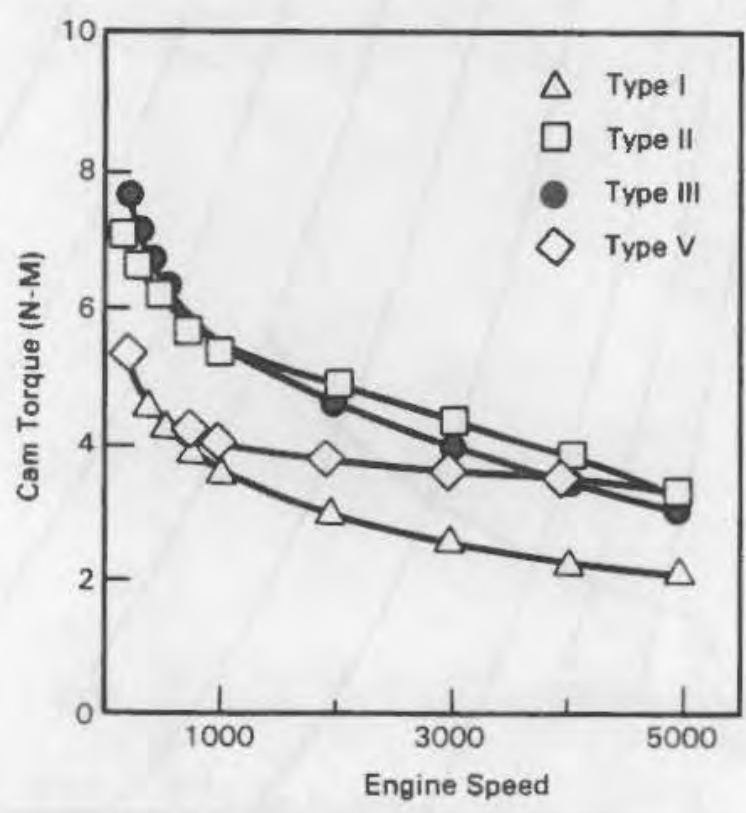

b) Energy Losses in Various Valve Train Designs

FIfURE 4.24. Design Characteristics of Valve Trains(11) 
only one sliding contact. The other designs exhibit higher friction because of the additional rocker-arm pivot loss.

The general level of losses incurred by a typical valve train is also shown in Figure 4.25. As a percentage of the total frictional losses they are from $4 \%$ to $12 \%$ over engine speed range of $1000 \mathrm{rpm}-3000 \mathrm{rpm}$. Another loss that can be indirectly attributed to the valve train is that, being highly loaded and thus requiring a high viscosity oil, they reduce the options of using low viscosity oil and reducing friction in other components.

\subsubsection{Losses Due to Individual Components}

One method of reducing valve train friction is to use rolling element bearings at the critical locations, as shown in Figure 4.26. Rolling element

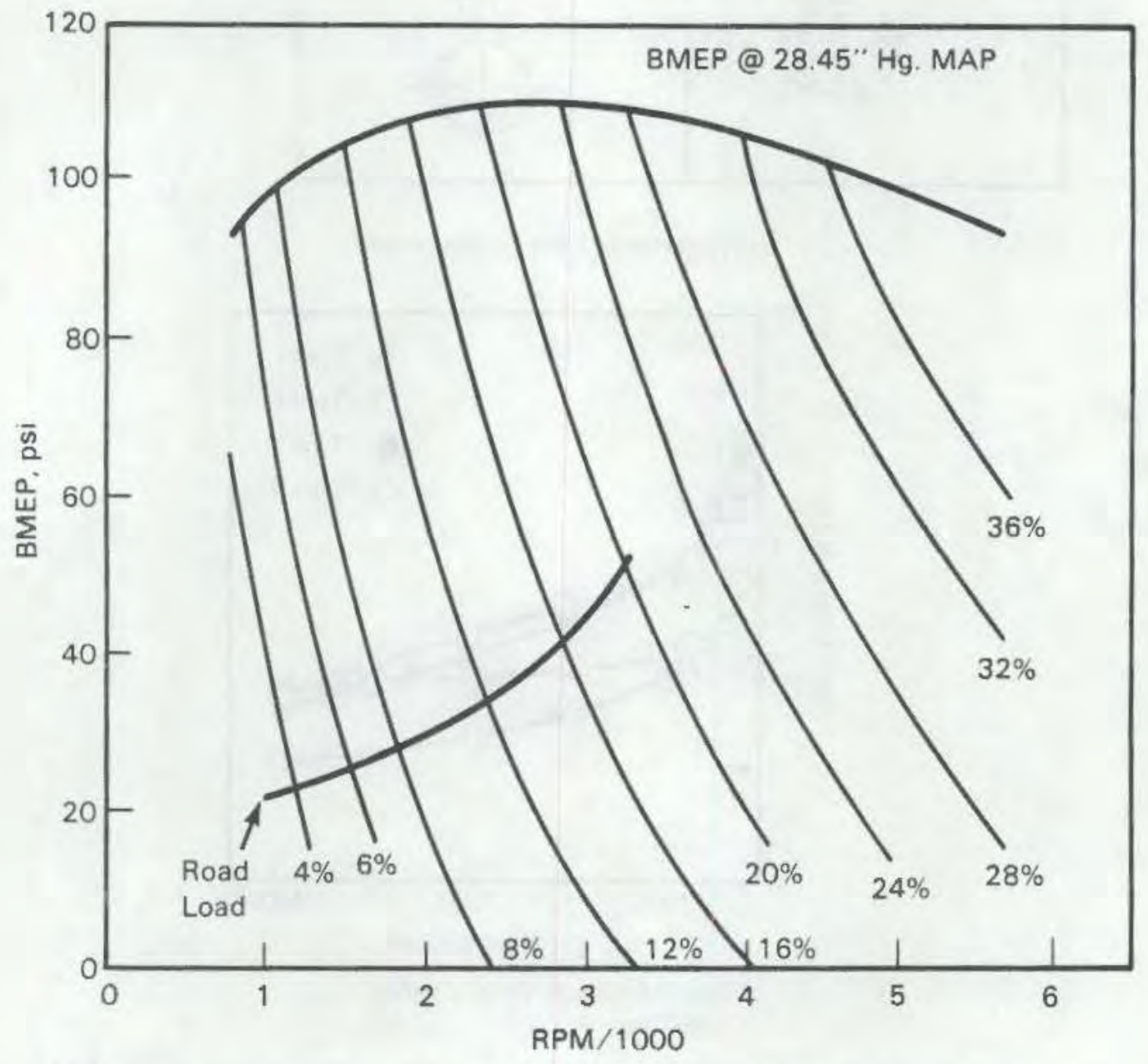

FIGURE 4.25. Valve Pumping FMEP, Percent of Total FMEP(9) 
bearings can be used at the cam lifter interface, the rocker-arm pivot, and the interface between the rocker nose and the valve stem. The disadvantages are bearing susceptibility to contact fatigue and the increased complexity and cost of the design. Figure 4.27 shows typical results obtained from a Type IV valve train via design changes such as reducing the friction at the cam-tappet interface, reducing spring loads and reducing rocker arm fulcrum friction. The largest reduction was obtained by replacing the conventional flat face tappet with a roller follower tappet. The effect is greater at lower speeds where lubrication in the boundary or mixed mode is replaced by rolling action. At $1500 \mathrm{rpm}$, the valve train torque is reduced $51 \%$ by the roller follower and the projected vehicle fuel economy improvement is $2.9 \%$.

As shown in Figure 4.28, instead of roller bearings, some improvement can be obtained by having oil directly sprayed onto the cam-tappet interface. The data of Figure 4.28 indicates that splash lubrication is not supplying the oil to the surface effectively. This approach would also improve cam-tappet life.

Lower spring loads decrease valve train friction significantly. The fuel economy effect projected in this case is about $0.5 \%$ improvement. The decrease in maximum allowable engine speed experienced with lower spring loads can be regained by reducing component inertia and increasing the stiffness of the valve train. All of these improvements combined (except oil-spray) have

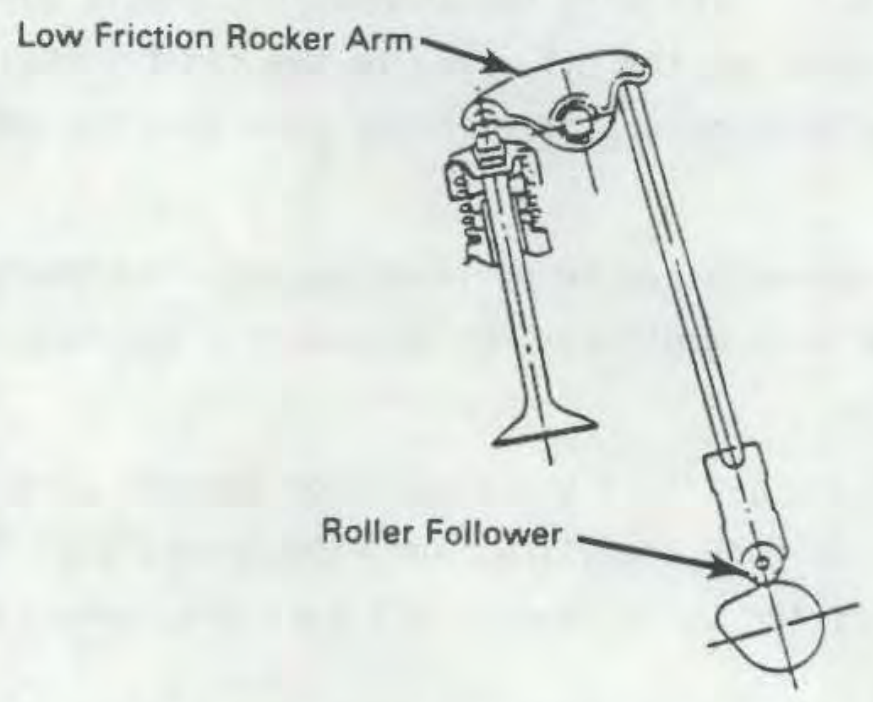

FIGURE 4.26. Rolling Element Bearing Application to Valve Train(11) 


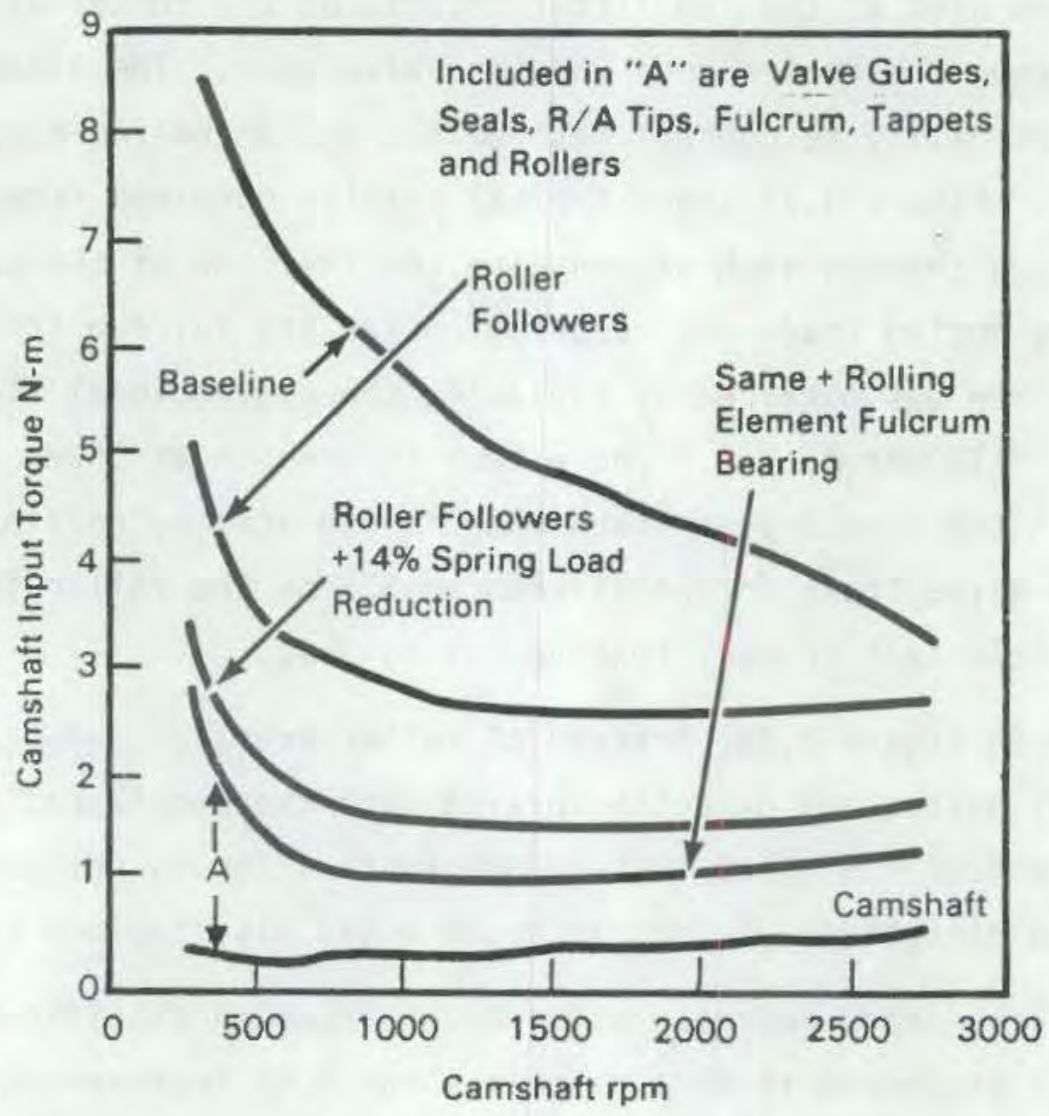

FIGURE 4.27. Type IV Valve Train Friction Reduction with Various Improvements

reduced the valve train torque $82 \%$ at $1500 \mathrm{rpm}$ and the projected vehicle economy improvement is $4.4 \%$. The only two changes not compatible with each other are the roller followers and the oil spray to the cam-tappet interface. When the oil spray is used with others, the torque reduction is $39 \%$ for an economy improvement of $2.7 \%$.

Additional improvements can be achieved by reducing bearing and rod sizes. The effect of such modifications at both low and high engine speeds are shown in Figure 4.29 .

Staron and Willermet, ${ }^{(33)}$ of the Ford Motor Company conducted a fairly detailed investigation, both analytical and experimental, on the losses in the individual elements of the valve train. All data and comments below refer to their work. 


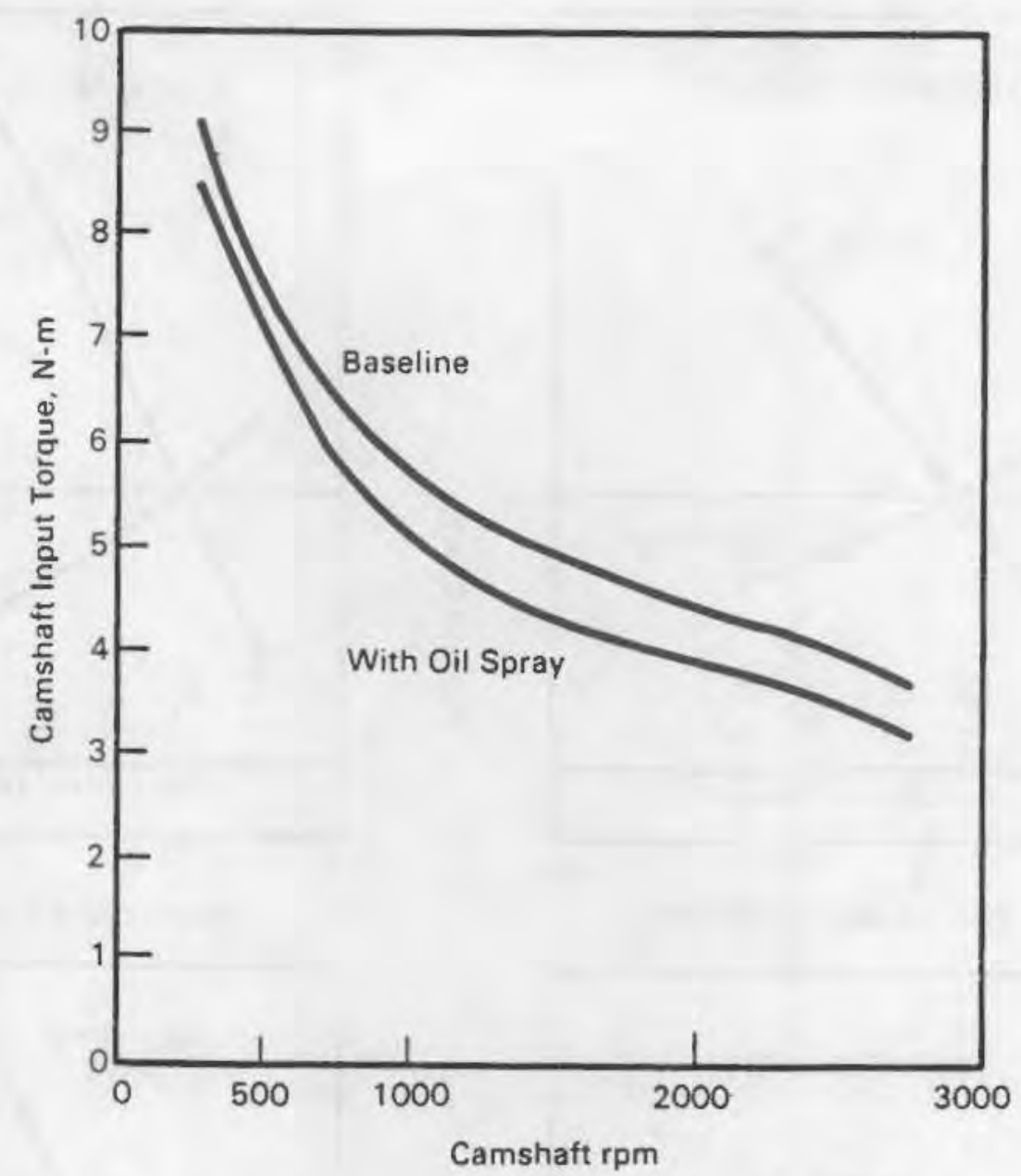

FIGURE 4.28. Effect of Improved Cam-Tappet Interface Lubrication on Type IV Valve Train Friction (see Figure 4.24 ) (10)

- Cam-Tappet. Values for cam-tappet friction calculated in terms of torque loss for the SAE $5 \mathrm{~W}, 10 \mathrm{~W}, 30$ and 50 Newtonian oils having a boundary friction coefficient of 0.1 are presented in Table 4.5 . Friction decreases with increasing speed and $0 i 1$ viscosity, as expected, since these factors lead to increased oil film thickness.

- Cam Journal Bearing. Values for the cam journal bearing friction calculated in terms of torque loss are also presented in Table 4.5. Viscous friction losses were insensitive to viscosity and speed because the bearings are highly loaded. Boundary friction losses become important at low speeds. This effect is most pronounced with lower viscosity lubricants and accounts for the increase in valve 

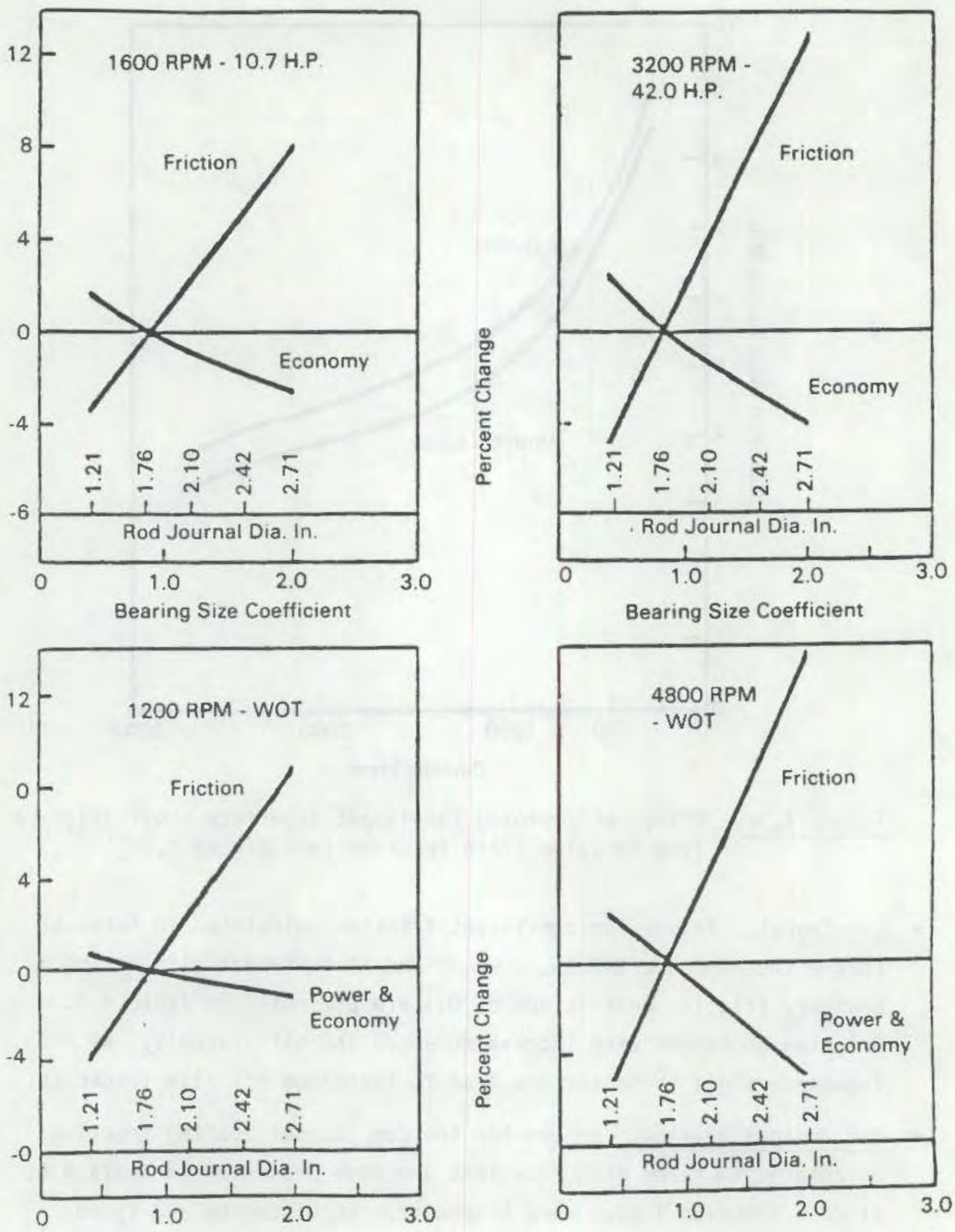

FIGURE 4.29. Effect of Valve Size on Friction, Economy, and Power ${ }^{(9)}$ 
TABLE 4.5. Effects of $0 i 1$ Viscosity and Speed on Friction Loss (33) (Friction Coefficient $=0.1$ )

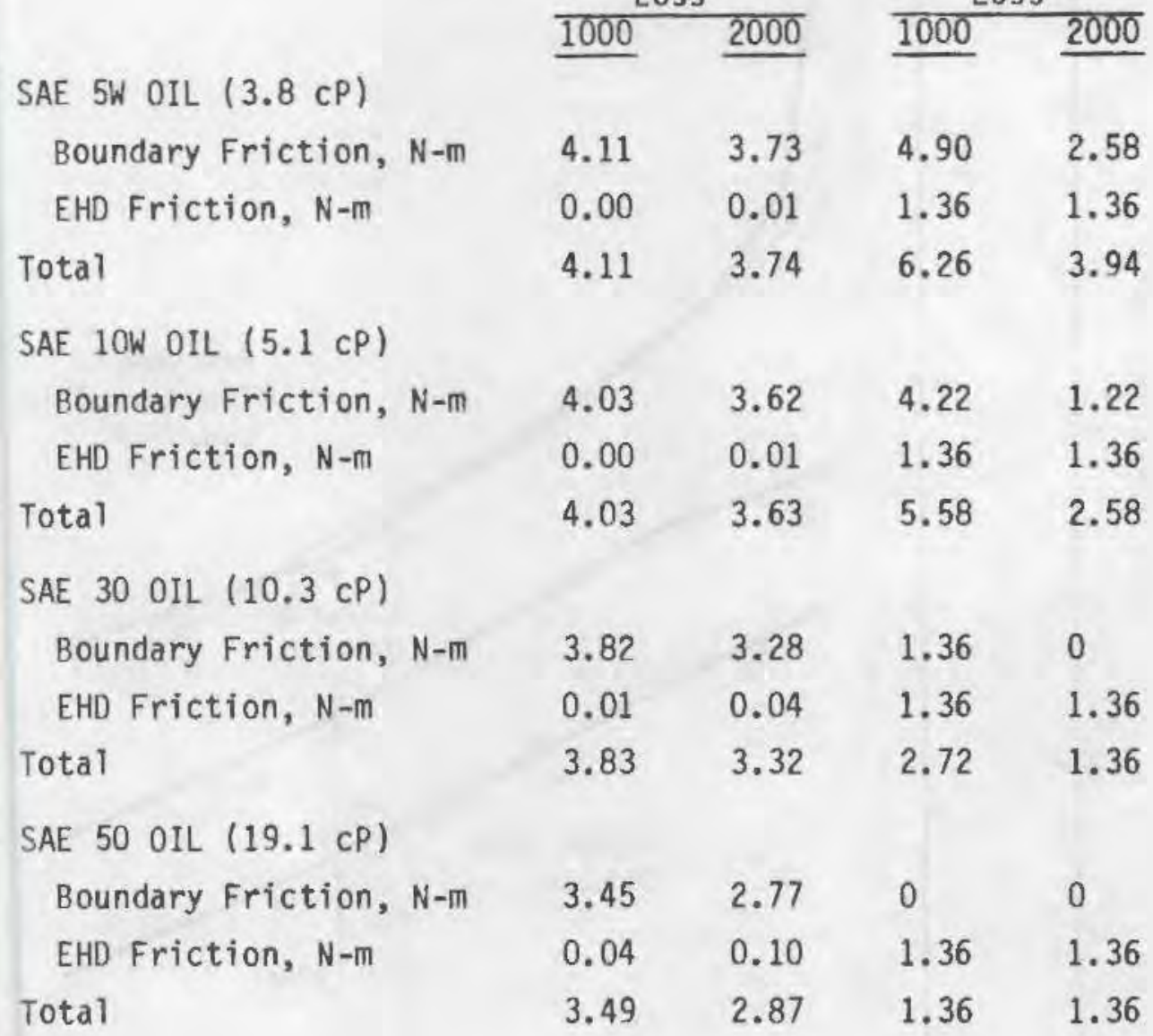

\begin{tabular}{|c|c|}
\hline \multicolumn{2}{|c|}{ Engine RPM } \\
\hline Cam/Tappet & Cam Journal \\
\hline Loss & Loss \\
\hline 1000 & 1000 \\
\hline
\end{tabular}




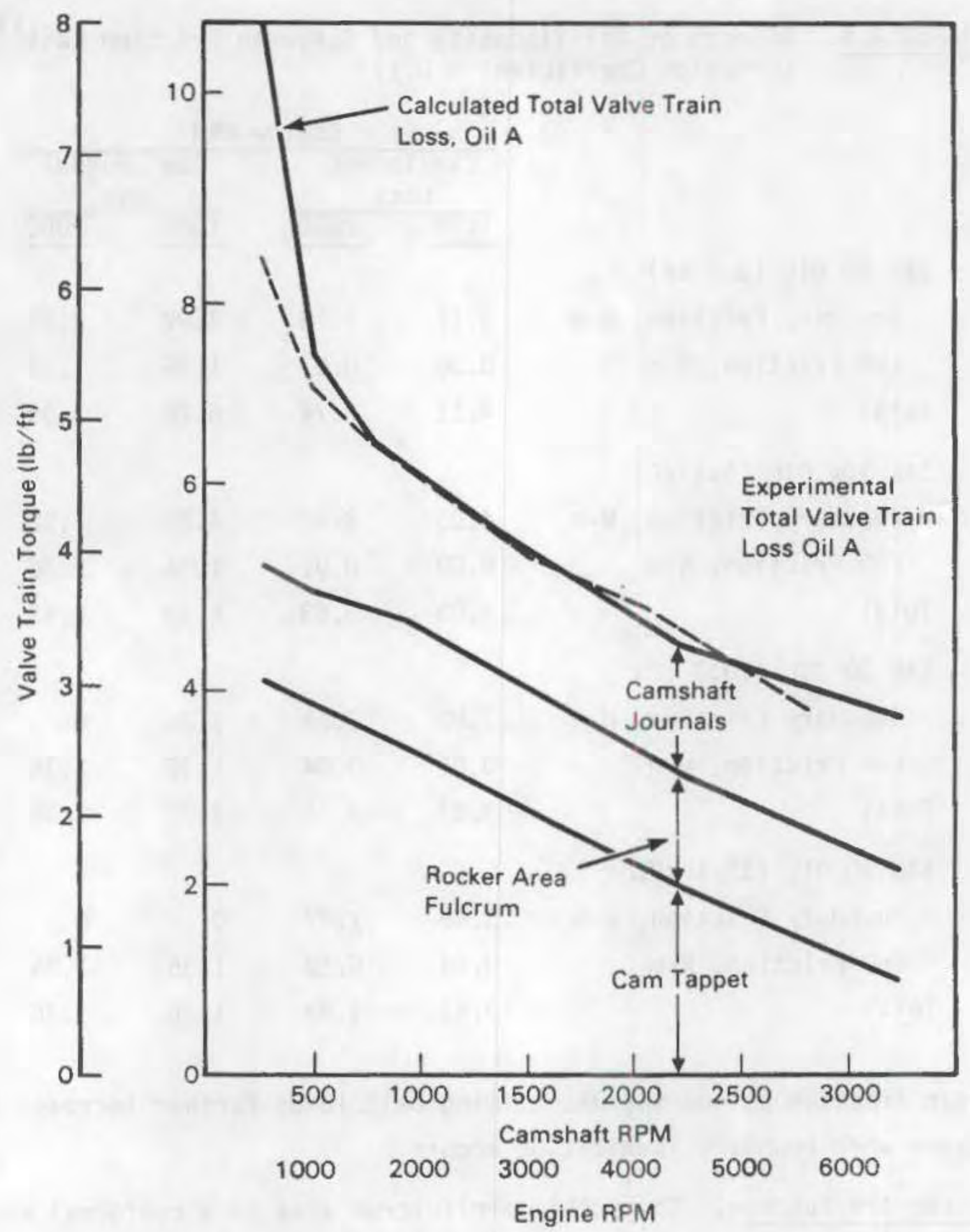

FIGURE 4.30. Torques for Valve Train Contacts, Using a Modified SAE 30011 at $100^{\circ} \mathrm{C}(33)$ 


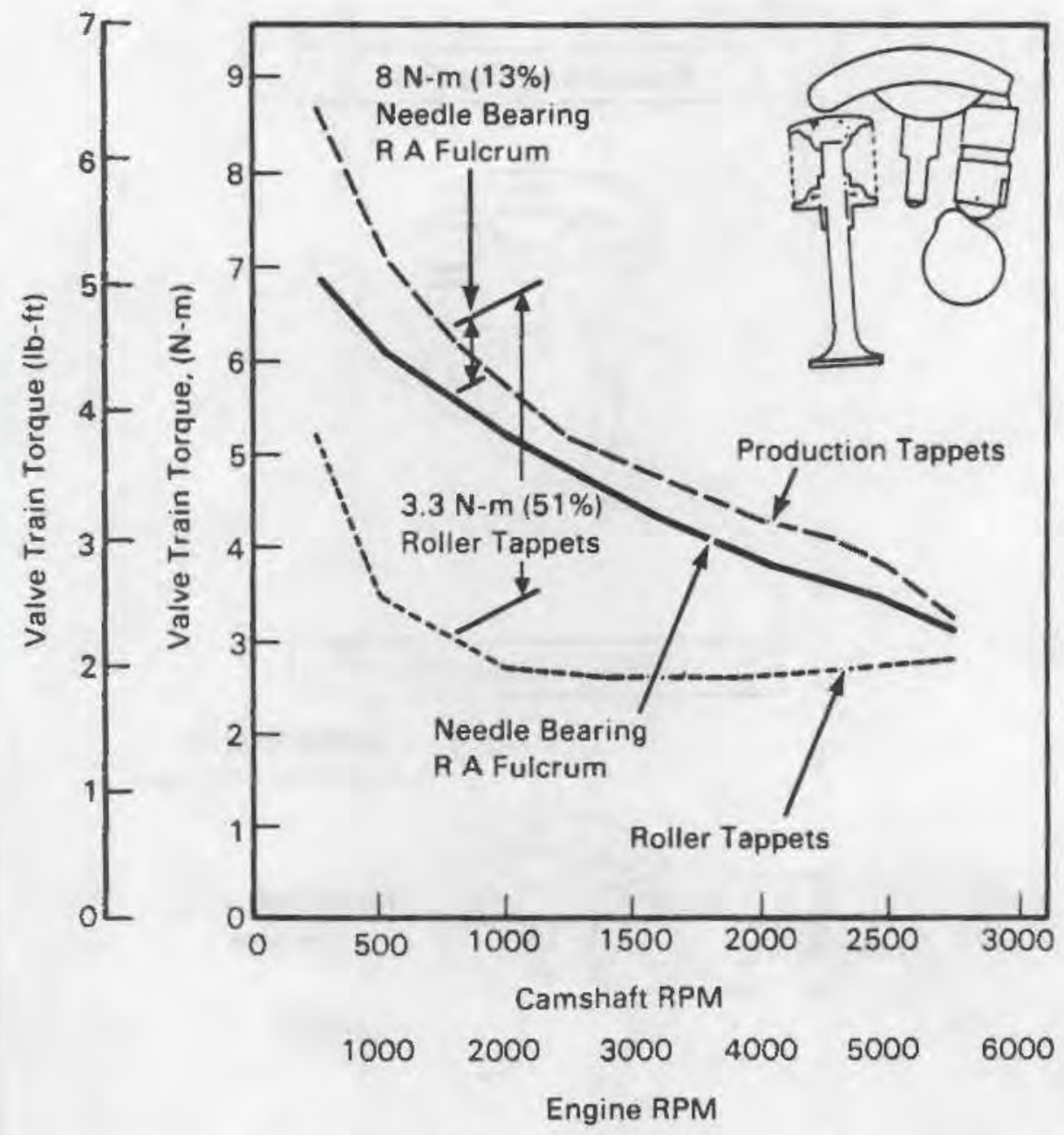

FIGURE 4.31. The Effect of Roller Tappets and Rocker Arm/Fulcrum Needle Bearings on Friction (33)

- Roller Tappets. The use of rolling elements in this part of the valve train is shown in Figure 4.32. The data in Figure 4.30 showed this interface to be the major contributor to valve train friction in agreement with the analytical calculations. The friction model indicated that the cam-tappet interface accounts for approximately 51\% of the total valve train friction at $1500 \mathrm{rpm}$. Table 4.6 makes similar comparisons at other speeds. This suggests that the roller followers eliminate most of the friction losses.

- Cam Journal Bearings. The calculations of Reference 33 showed that the steep increase in valve train friction at lower speeds was due to a transition from hydrodynamic to boundary lubrication in the cam 


\section{Production Valve Train}

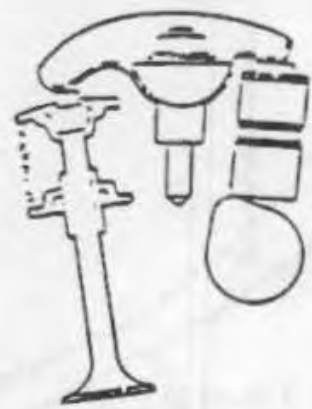

Low Friction Valve Train

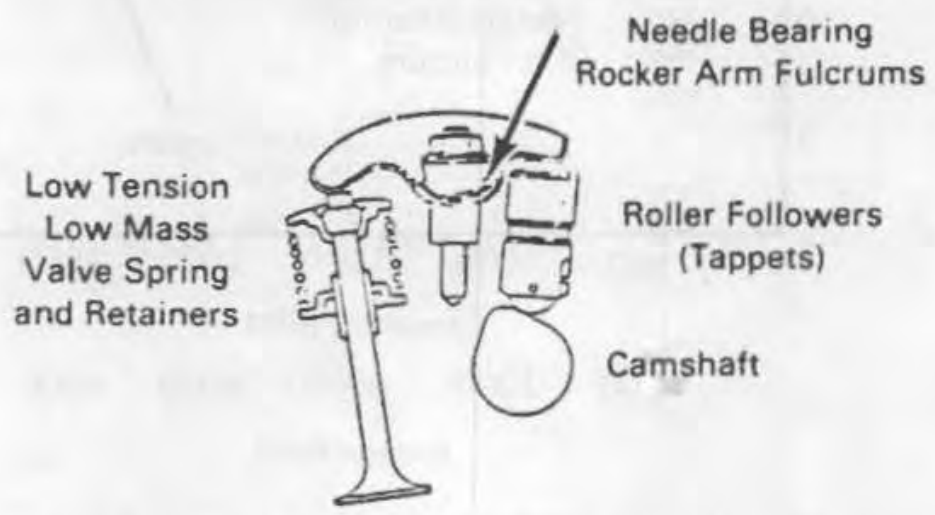

FIGURE 4.32. Design Features of Conventional and Low Friction Valve Trains $(33)$

TABLE 4.6. Effect of Substituting Rolling for sliding Contacts (33)

\begin{tabular}{|c|c|c|c|c|}
\hline \multirow[b]{2}{*}{$\begin{array}{l}\text { Engine } \\
\text { Speed } \\
\text { (RPM) } \\
\end{array}$} & \multicolumn{2}{|c|}{$\begin{array}{l}\begin{array}{c}\text { Experimental Results } \\
\text { Percent Friction Reduction }\end{array} \\
\frac{\text { Rocker Arm/ }}{\text { Reckent }}\end{array}$} & \multicolumn{2}{|c|}{$\begin{array}{l}\text { Calculated Results } \\
\text { Boundary Lubrication } \\
\text { Component of Total } \\
\text { Valve Train Friction }\end{array}$} \\
\hline & $\begin{array}{l}\text { Roller } \\
\text { Followers }\end{array}$ & $\begin{array}{l}\text { Rocker Arm/ } \\
\text { Fulcrum } \\
\text { Roller Bearing } \\
\end{array}$ & $\begin{array}{c}\text { Cam/ } \\
\text { Tappet }\end{array}$ & $\begin{array}{l}\text { Rocker Arm/ } \\
\text { Fulcrum }\end{array}$ \\
\hline 500 & $37 \%$ & $18 \%$ & $38 \%$ & $11 \%$ \\
\hline 1000 & $47 \%$ & $21 \%$ & $51 \%$ & $19 \%$ \\
\hline 2000 & $48 \%$ & $13 \%$ & $53 \%$ & $19 \%$ \\
\hline 4400 & $32 \%$ & $14 \%$ & $42 \%$ & $24 \%$ \\
\hline
\end{tabular}


2.3L Production

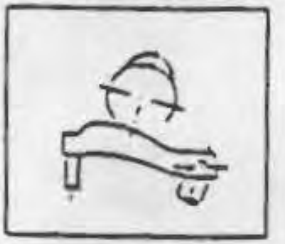

2.3L Roller Follower
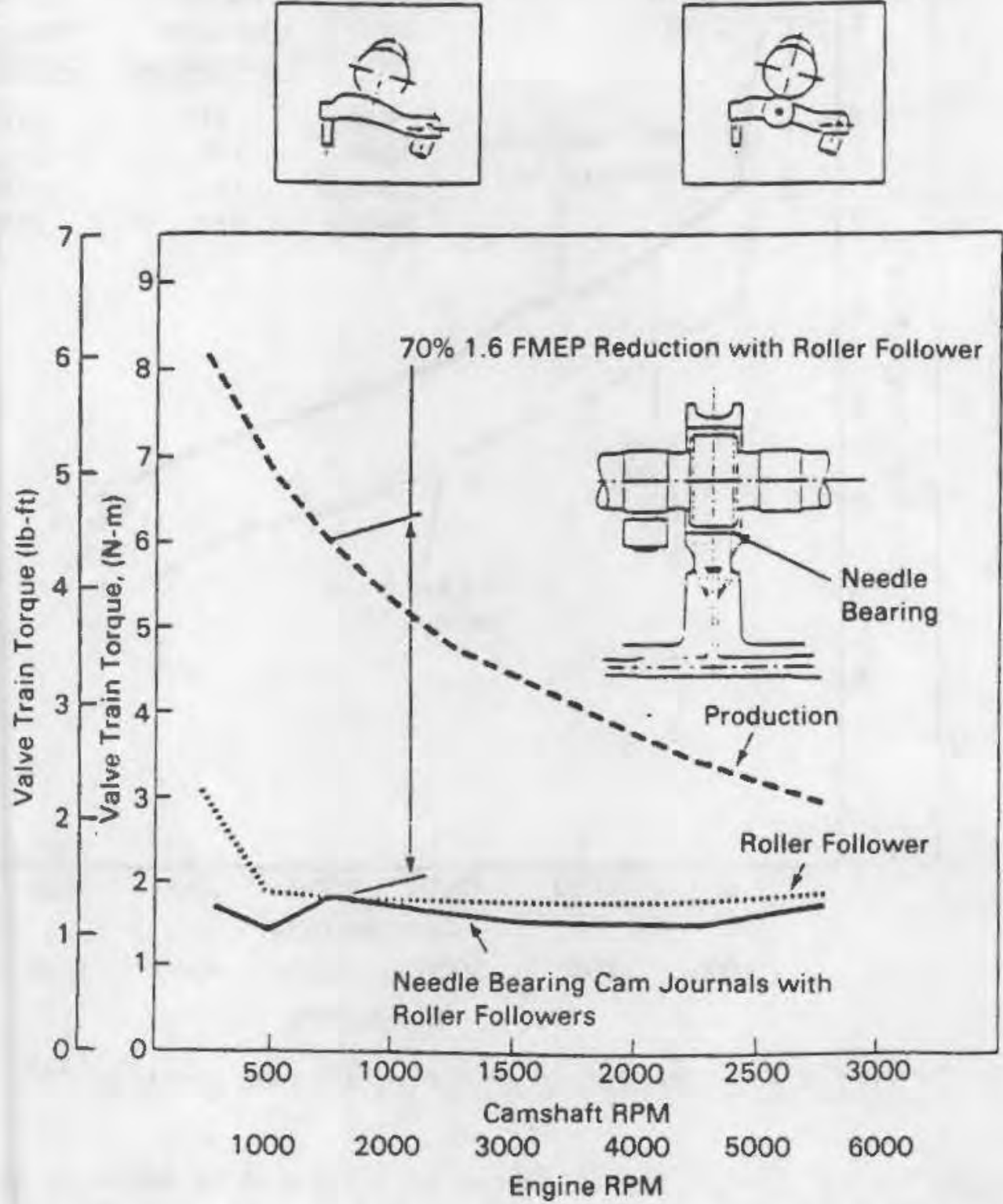

FIGURE 4.33. The Effect of Needle Bearing Cam Journals and Roller Followers on Friction in the Ford 2.3L Engine ${ }^{(33)}$

journals. This effect was seen both for a $1.6 \mathrm{~L}$ valve train (Figure 4.32), and for a 2.3L valve train (Figure 4.33). Incorporation of needle bearings did not reduce friction at higher speeds. However, it did eliminate the steep increase in friction at low speeds. 


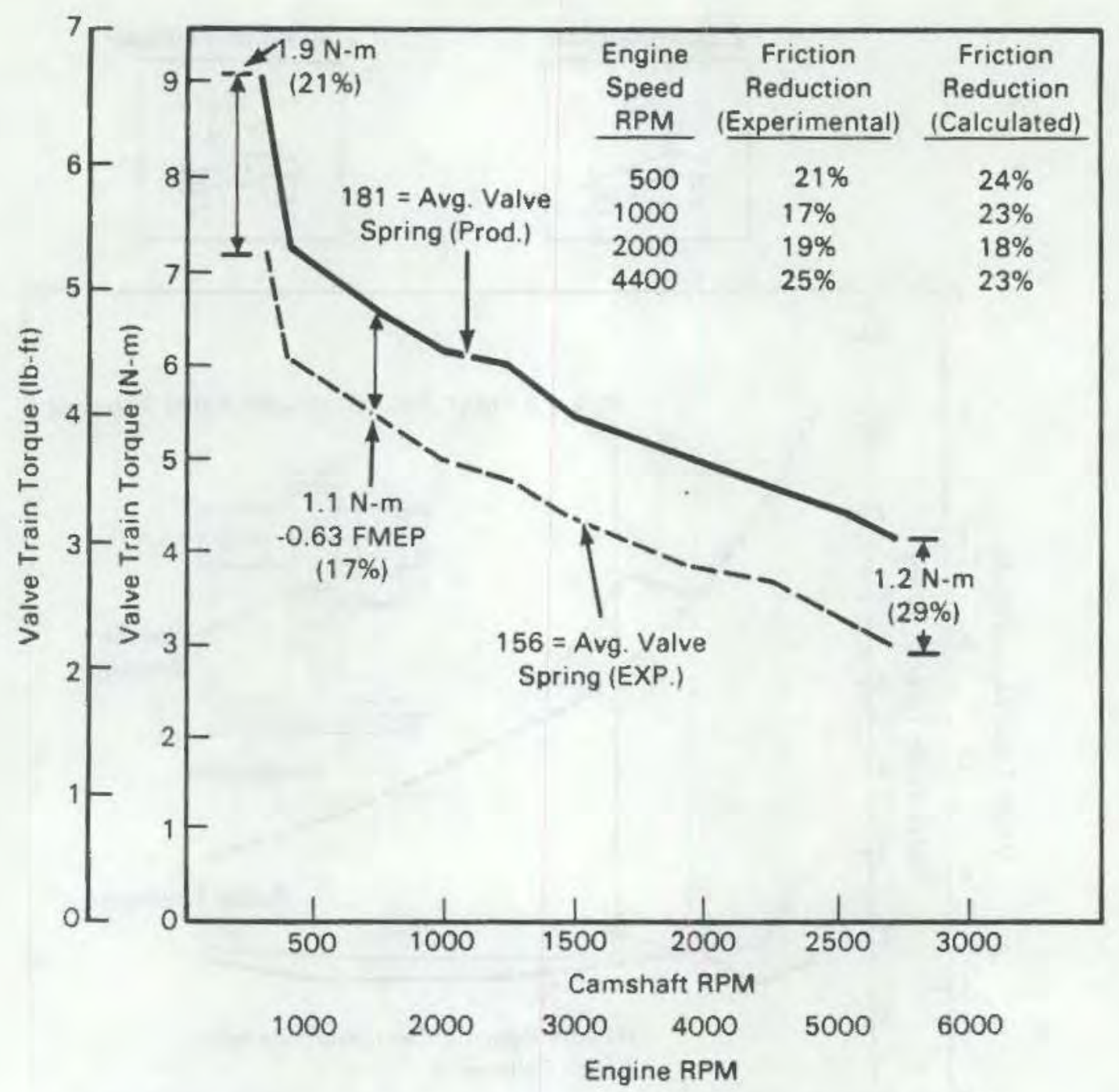

FIGURE 4.34. The Effect of Spring Load on Friction (33)

- Reduced Spring Loads. Normal forces were reduced by reducing spring loads. Reducing the spring load by $11.4 \mathrm{~kg}(25 \mathrm{lb})$ reduced friction by 17 to $25 \%$ (Figure 4.34 ).

- Calibration 0il Experiments. Three calibration oils were used to assess the relative importance of lubricant viscosity and friction reducing additives in determining the level of valve train friction. nil A was a nonfriction modified Newtonian SAE 20W30 lubricant. Oil B was a nonfriction modified Newtonian SAE 50 lubricant. $0 i 1$ C combined the base stock of 0il $A$ with a friction-modified additive package (Table 4.7). Viscosity had a relatively small effect on 
TABLE 4.7. Test $0 i 1$ Description

\begin{tabular}{|c|c|c|c|c|c|c|c|c|}
\hline \multirow[b]{2}{*}{$0+1$} & \multicolumn{2}{|c|}{$\begin{array}{c}\text { Viscosity, } \\
\text { CST }\end{array}$} & \multicolumn{4}{|c|}{$\begin{array}{l}\text { Elemental Composition } \\
\text { (PPM) }\end{array}$} & & \multirow{2}{*}{$\begin{array}{l}\text { Measured } \\
\text { Friction } \\
\text { Coefficient }\end{array}$} \\
\hline & $40^{\circ} \mathrm{C}$ & $100^{\circ}$ & $2 n$ & $p$ & Mo & $\mathrm{Mg}$ & B & \\
\hline A & 76.3 & 9.2 & 1308 & 1185 & -- & 1190 & 141 & 0.1 \\
\hline B & 289.5 & 20.5 & 1767 & 1612 & -- & 1496 & 169 & 0.1 \\
\hline C & 77.6 & 9.3 & 1243 & 1099 & 1998 & 998 & 125 & 0.05 \\
\hline
\end{tabular}

the overall friction loss, but a marked reduction in friction was obtained with the friction modified $0 i 1$ C (Figure 4.35). It suggests that selection of a proper lubricant may give levels of friction reduction comparable to those obtainable by component redesign.

In summary, the model calculations and experiments of Reference 33 show that friction losses in a valve train can be reduced by roller tappets, by needle bearing inserts placed in the rocker arm/fulcrum contact and in the cam journals, and by reducing spring tension. Friction reducing engine oil additives reduce valve train friction substantially, but oil viscosity has only a limited effect. Both the model and the experimental results are consistent with the idea that the friction losses in the valve train are mainly due to boundary and mixed lubrication.

\subsection{OIL PUMPS}

The oil pump types generally used in engines are the spur gear, internalexternal gear, and tip sealing gear types shown in Figure 4.36 which are driven either at engine speed or half speed. Engines with the camshaft in the block typically have a common drive shared by the distributor and oil pump. They generally use spur gear or tip sealing type pumps. Theses have relatively small diameters which minimize friction losses between the gear 0.D. and housing. 


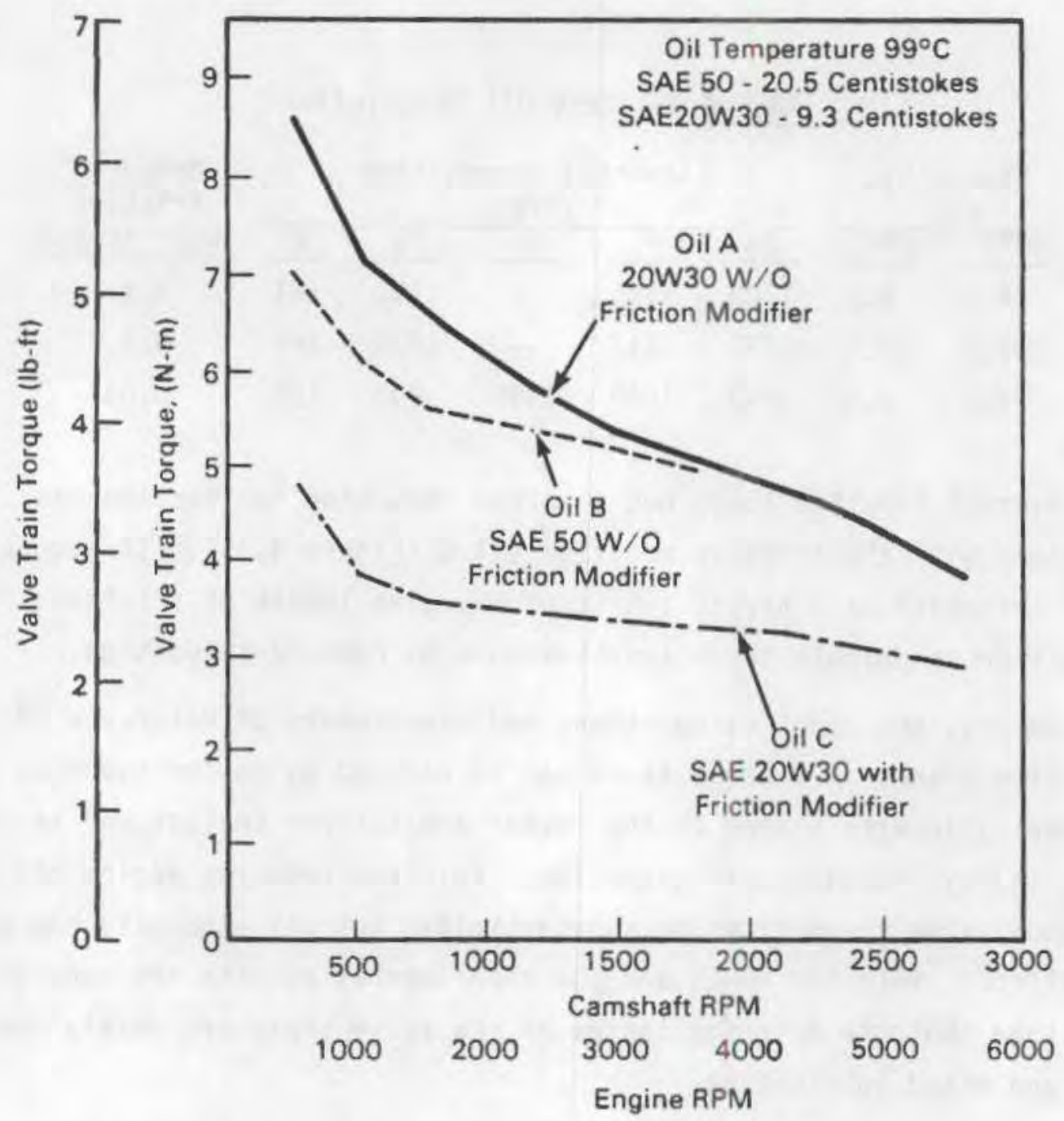
FIGURE 4.35. The Effect of 011 Viscosity and ${ }^{\text {f }}$ a
Friction Modifier on Friction $(33)$

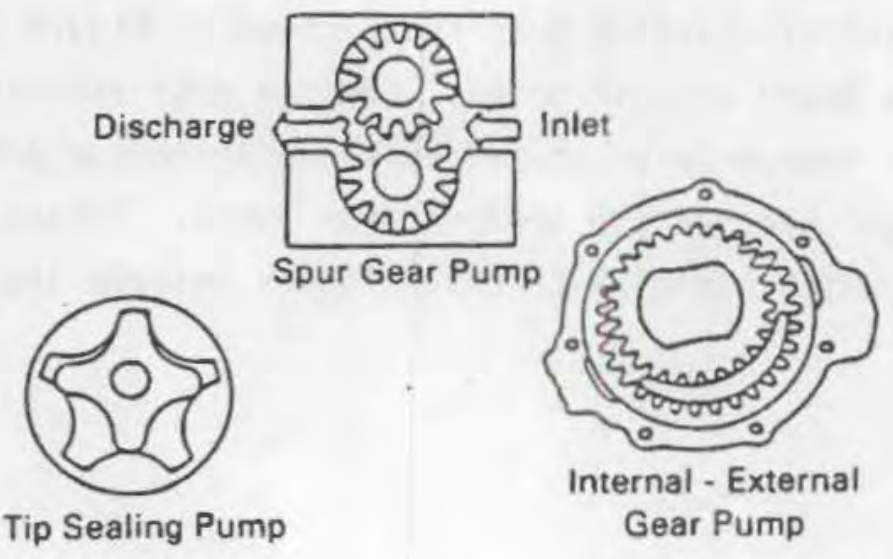

FIGURE 4.36. Types of Engine $0 i 1$ Pumps (10) 
The characteristics of a typical oil pump are as follows:

- torque $0.7-0.9 \mathrm{ft} / 1 \mathrm{~b}$

- exit pressure 35-80 psi

- capacity $4 \mathrm{gpm}$ at $3000 \mathrm{rpm}$.

The oil delivered by the pump is used for both lubrication and cooling. However, it is not clear how much of it is used or, indeed, needed for each of these two functions.

Figure 4.37 compares the input requirements measured for these pumps. The data show that the half speed pumps generally have lower input torque requirements except at very low speeds. The internal-external gear pump, which turns at engine speed and has a much larger diameter than the other two (100 mm versus $67 \mathrm{~mm}$ and $41 \mathrm{~mm}$ ), has a rising motoring torque requirement. However, even for this pump, the power requirements can be considerably reduced by a redesign which includes:

- reduced diameter of gears

- decreased internal flow restriction (without affecting capacity).

Such changes, as shown in Figure 4.38 , yield a $26 \%$ torque reduction requirement at $1500 \mathrm{rpm}$ yielding a $\cap .6 \%$ improvement in mph.

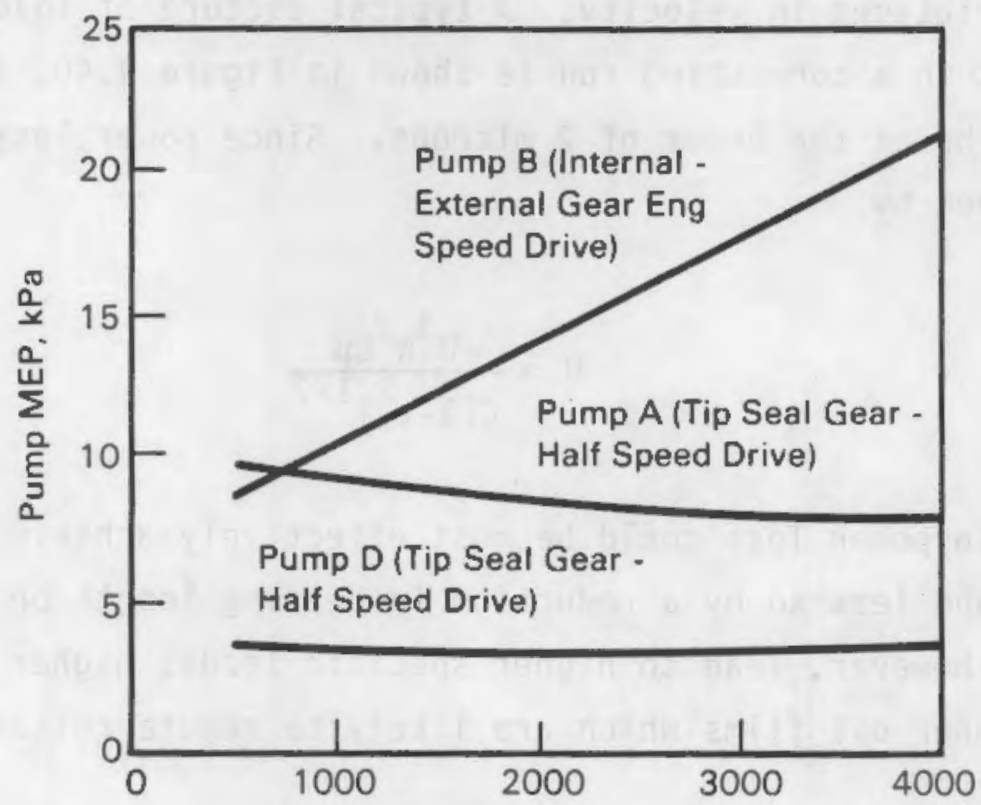

FIGURE 4.37. 0il Pump Drive Requirements at $310 \mathrm{~Pa}$ (45 psi) Pressure, $99^{\circ} \mathrm{C}$ 


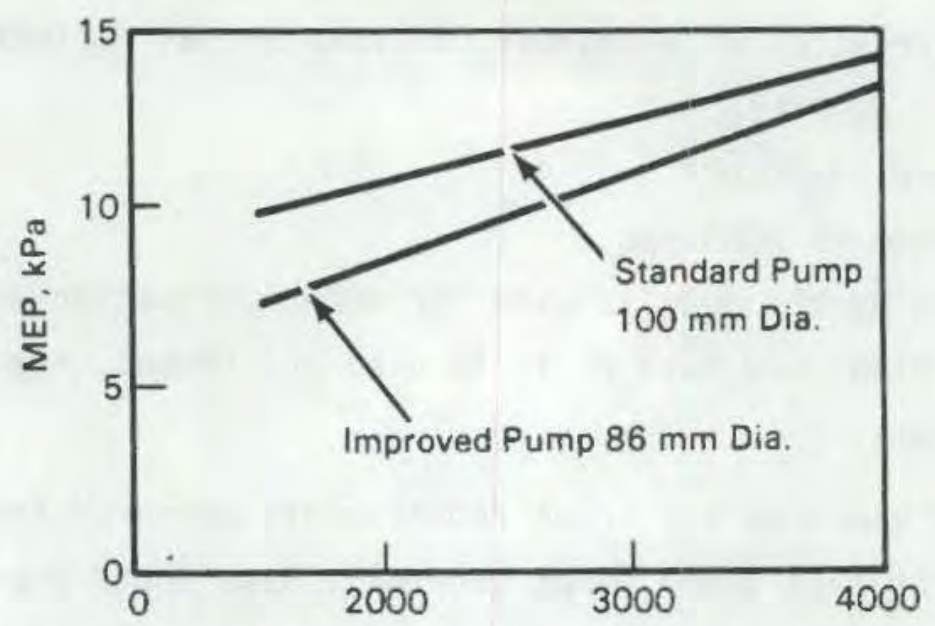

FIGURE 4.38. तil Pump Torque Reduction with Redesign (10)

\subsection{BEARINGS}

An automotive engine has a fairly large number of bearings. A schematic picture of bearing locations in a 6-cylinder engine is shown in Figure 4.39. In addition, there are bearings in the valve train, transmission, wheels, and in the numerous accessories. The engine bearings are subject to variable loads in both magnitude and direction during any given cycle due to the varying inertia forces and variable combustion gas pressures. All of these bearings also experience variations in velocity. A typical picture of loading and resulting film thickness in a connecting rod is shown in Figure 4.40, in which the value of $h_{\min }$ would be of the order of 2 microns. Since power loss in a journal bearing is given by

$$
H \simeq \frac{D^{3} N^{2} L \mu}{C\left(1-\varepsilon^{2}\right)^{1 / 2}}
$$

a reduction in power loss could be most effectively achieved by reducing bearing diameter and less so by a reduction in bearing length or oil viscosity. Such changes, however, lead to higher specific loads, higher bearing temperatures and thinner oil films which are likely to reduce reliability and increase 


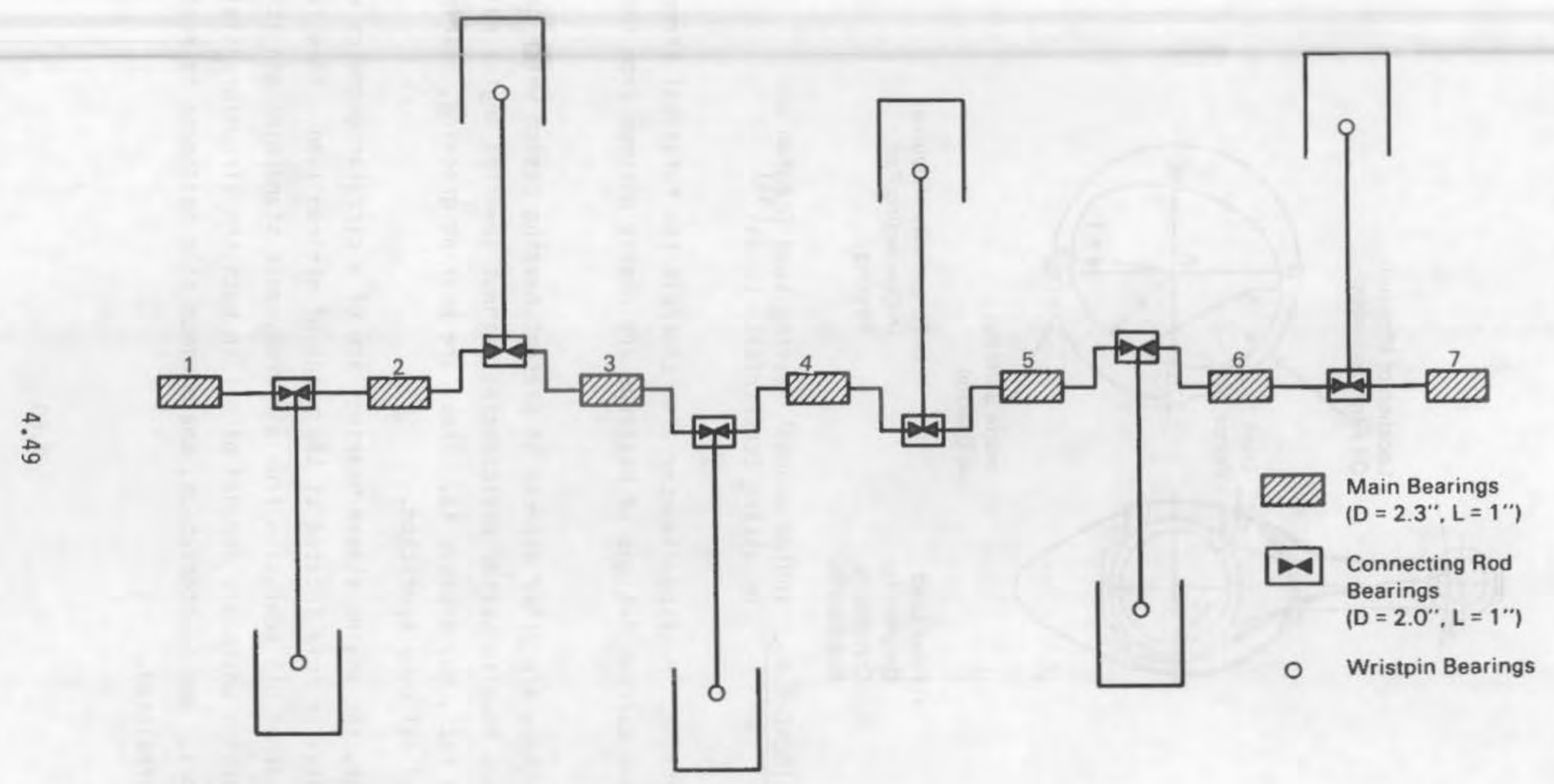

FIGURE 4.39. Bearings in a 6-Cylinder IC Engine 


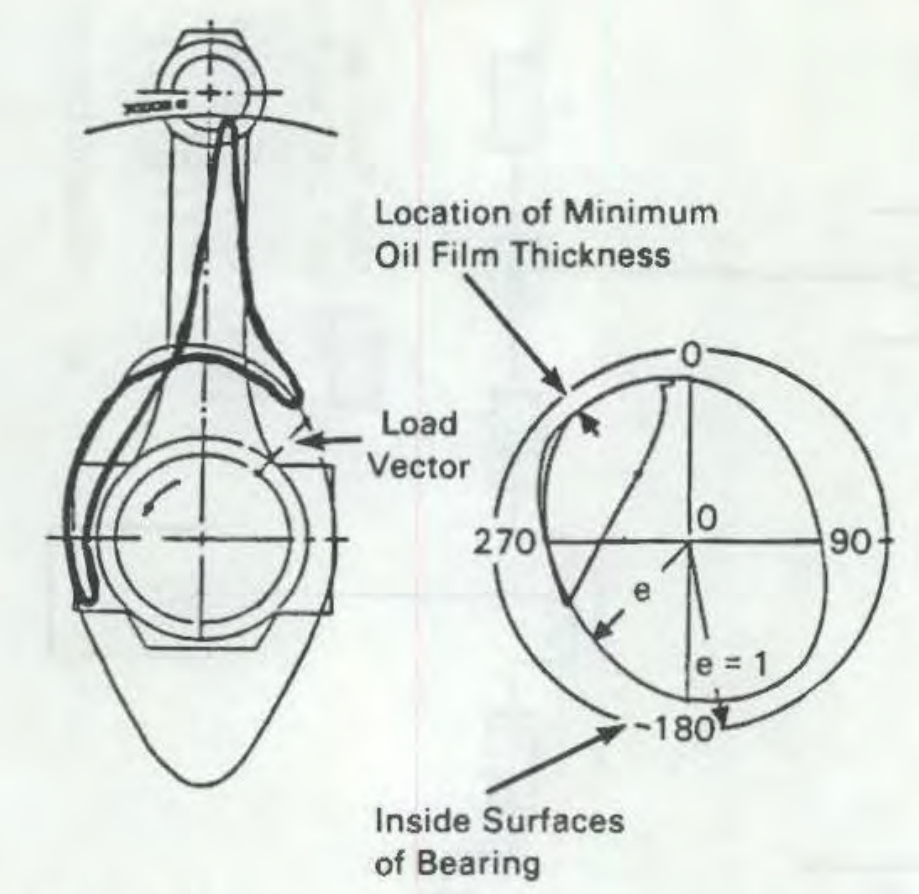
a) Polar Load Diagram for Connecting Rod Bearing
b) Eccentricity of Journal in Connecting Rod Bearing

\section{FIGURE 4.40. Engine Journal Bearing Load Diagram and Resulting Eccentricity Locus (34)}

wear and/or fatigue. Bearing diameter also controls the torsional strength of a crankshaft and current designs of bearings are nearly optimum from these aspects.

However, there are other aspects of present bearing design which call for scrutiny and may lead to better efficiencies without lowering engine reliability and, in fact, may improve it. These are bearing grooving, bearing housing design, and oil pump operation.

At present, the engine sleeve bearings are of a circular geometry with a single oil admission hole located at the point of minimum load. This is not the optimum mode of oil admission from a hydrodynamic standpoint and it results in starved bearings which are denuded of oil in both the circumferential and axial directions. Due to starvation, the minimum film thickness is much smaller than predicted. 
The other even more serious problem, as documented in Reference 34 , is housing distortion due to flexibility of the surrounding structure and shaft. Worse, it may vitiate any design modification aimed at improving bearing performance. Observed journal center orbits are often substantially greater in excursion than the bearing clearance. Figure 4.41, which shows the clearance circle along with the journal center locus, gives a measure of the deformation taking place. This is the deformation of the clearance boundary and is
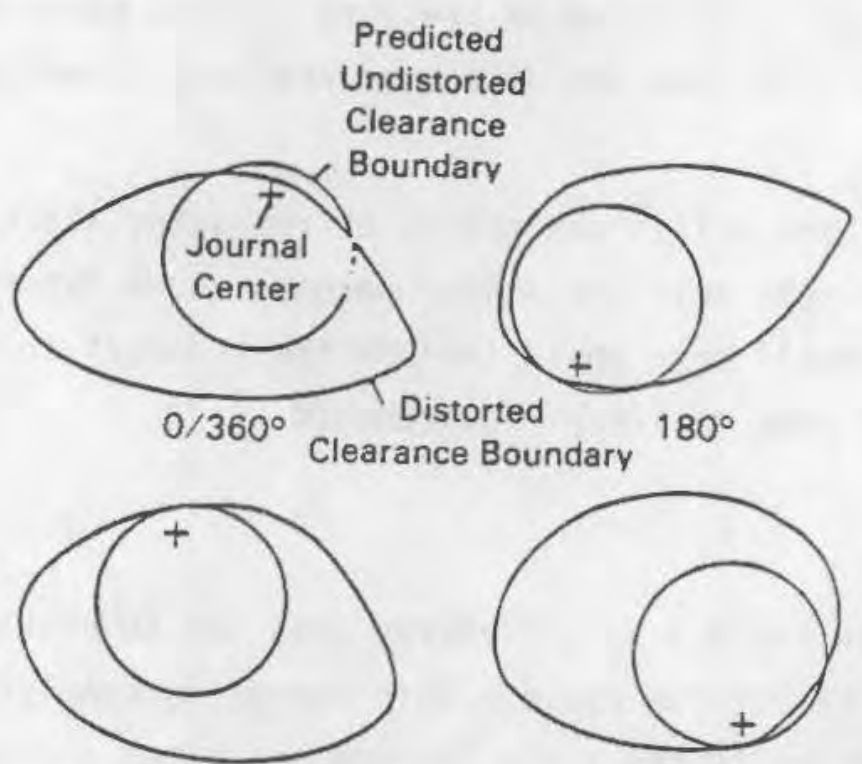

$45^{\circ}$
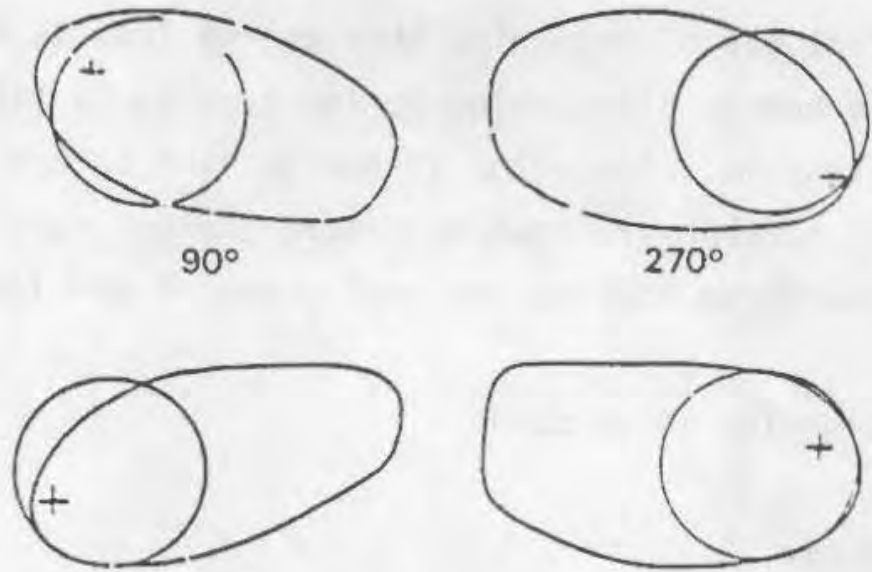

FIGURE 4.41. Distored Bearing Clearance Boundaries at $3000 \mathrm{rpm}(34)$ 
separate from the bodily translation of bearing shell and housing within its supporting structure which almost certainly also occurs.

Two energy-related problems arise with the oil supply to automotive bearings. One has to do with oil viscosity, which is actually a part of the larger problem of viscometrics discussed in Section 4.7. The other item connected with the oil supply is the oil pump, as discussed previously. This enginedriven pump supplies amounts of oil in excess of what the bearings require; also the 50 psi pressure head maintained at bearing inlet is excessive. An appreciable reduction in oil pump power requirements can be achieved by reducing both flow rate and discharge pressure. Since power in the oil pump is proportional to both flow and discharge pressure, considerable savings can be achieved.

Fina11y, there exists the option of replacing all hydrodynamic bearings with rolling element bearings--these perhaps to be lubricated with solid lubricants. The tradeoff here would include the tradeoff in bearing friction as well as the oil pump delivery requirements.

\subsection{BRAKING}

As shown in Table 4.8 , the energy loss due to braking is $2 \%$ of the energy input over an EPA driving cycle. This energy is completely wasted in the form of heat dissipation to the brake linings and often also to the cylinders and the tires.

The only real way of salvaging this energy loss is via regenerative braking, whereby the energy dissipation during braking is stored and then utilized in driving the vehicle. Since the $2 \%$ energy lost in braking represents some $10 \%$ of the brake horsepower, that much more energy could be added to the output. Such regenerative braking can employ any of the following energy storage systems :

- flywheel (running in vacuum)

- battery

- compressed air

- pneumatic-hydraulic system. 
TABLE 4.8. Energy Consumed by Braking

\begin{tabular}{|c|c|c|c|}
\hline Cycle & $\begin{aligned} & \text { Fuel } \text { Input } \\
& \text { Eneray }(\mathrm{MJ} / \mathrm{km}) \\
&\end{aligned}$ & $\begin{array}{l}\text { Energy } \\
M J / \mathrm{km}\end{array}$ & $\begin{array}{c}\text { Consumed by Brakes } \\
\text { Percent of Total }\end{array}$ \\
\hline $\begin{array}{l}\text { Urban } \\
55 \%\end{array}$ & 5.70 & 0.172 & 3.0 \\
\hline $\begin{array}{l}\text { Highway } \\
45 \%\end{array}$ & 4.67 & 0.016 & 0.34 \\
\hline $\begin{array}{l}\text { Combined } \\
\text { EPA }\end{array}$ & 5.24 & 0.102 & 2.0 \\
\hline
\end{tabular}

Not all of the $10 \%$ gain in BHP would, of course, be salvaged since added weight and parasitic losses in regenerative system components would exact their own toll in energy consumption.

\subsection{LUBRICANT FORMULATION}

The type and properties of the lubricant to be used in an automotive crankcase are both of great importance and considerable complexity. A really adequate study must involve the entire engine, its design, economics, cost, and life, as well as the impact on wear and materials. The literature on the subject is therefore quite voluminous.

Even when the area is narrowed to the effects of lubricant properties on engine friction, the field is large. This is so for the following reasons:

- Regimes of lubrication in an engine span all possible modes from full hydrodynamic lubrication to EHD and boundary lubrication. Some elements such as piston rings go through all three modes during each cycle. Thus, while bearings may benefit from low viscosity oil, the valve train would be harmed by it.

- Starts and full speed operation and hot and cold climates have conflicting requirements with regard to oil properties. 
- Additives may be beneficial to some components and harmful to others. This is so because they most often convert the oil to a nonNewtonian fluid whose viscosity deteriorates with the rate of shear. Often there is oil degradation with time which is irreversible.

- One of the major problems in reducing boundary friction is the number of additives present in automotive crankcase oils for other reasons. A typical crankcase oil may contain surface active additives to:

1) depress the pour point, 2) reduce foaming, 3) control rust and corrosion, 4) reduce oxidation by metal deactivation, 5) suspend dirt particles (detergent), and 6) disperse "blowby" products (polymeric dispersants). In addition to the additives used, the conventional mineral oil base fluid contains a significant quantity of polar compounds sometimes called "natural inhibitors." The friction modifier must be compatible with all of the existing additive package and also must provide the friction reduction without interference from these other additives.

- It is not always clear what viscosity value is to be used as a basis of comparison. While the sump viscosity may be the same for various vehicles and road conditions, the actual viscosities in the various parts of the engine during operation will differ widely as a function of both temperature and shear rate.

In the past, low viscosity oils were frequently associated with high oil consumption, poor blowby control, lubricant volatility, and wear. A11 of these undesirable features can be associated with volatility of the lubricant. The principal problem in the formulation of conventional crankcase lubricants is that viscosity and volatility are closely interrelated (see Figure 4.42). In addition, most of the current multigraded crankcase oils contain polymeric VI improvers. There is the further complication that the VI improver also increases the viscosity, so that a given viscosity grade with a VI has a greater volatility than one without. 


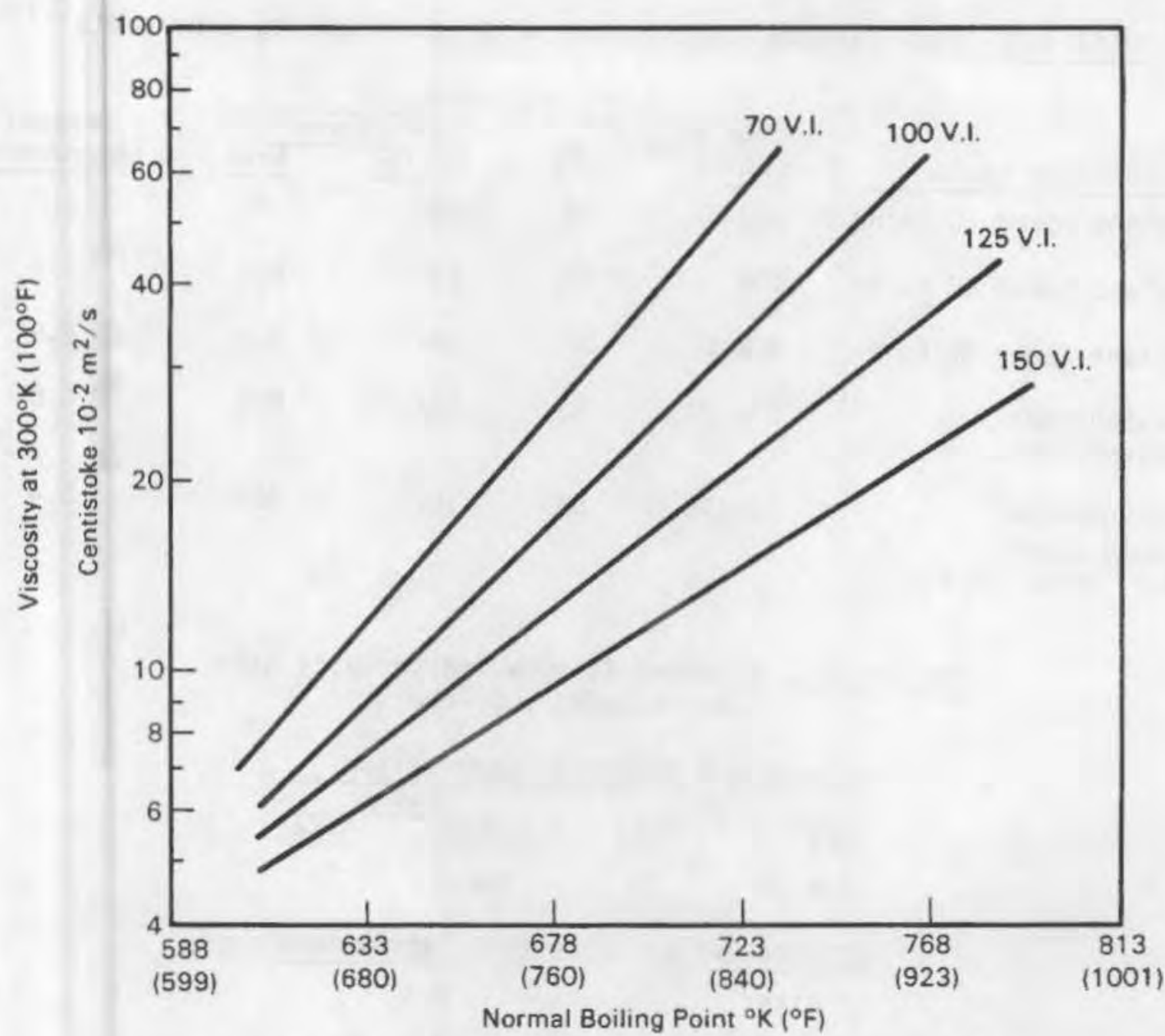

FIGURE 4.42. Viscosity-Volatility Relationship (36)

\subsubsection{Results of ASME/DOE Study (2)}

Some data from the above study on the savings achieved with reduction in oil viscosity alone are given in Tables 4.9 and 4.10 and Figure 4.43. Based on these results and the data given by $\mathrm{Klaus,}(36)$ reduced engine function may yield a national fuel savings of the order of $1 \%$. The companion development of improved friction with additives may produce savings in fuel energy of another $1 \%$ of the national energy consumption. It should be emphasized that the two areas (viscometrics and boundary friction) are independent of each other, that 
TABLE 4.9. Fuel Economy Improvements with Low Viscosity Lubricants (2)

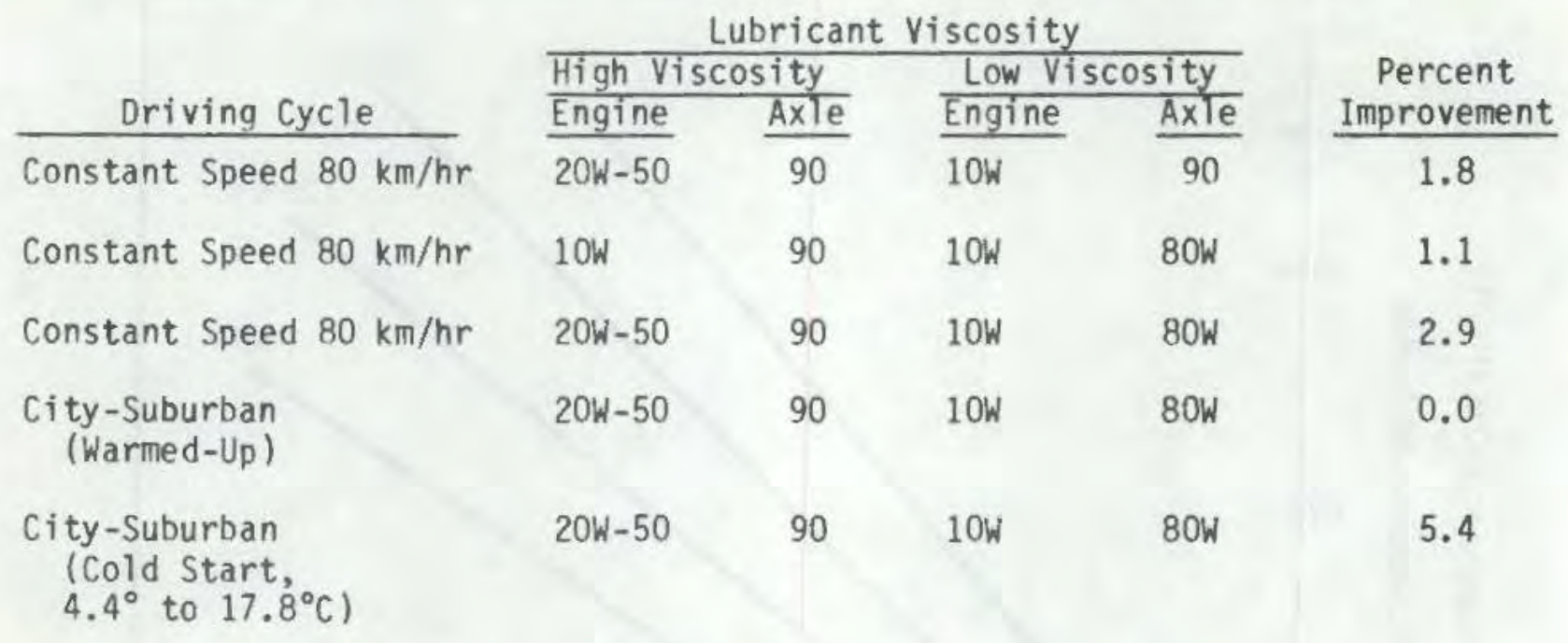

TABLE 4.10. EPA Fuel Economy Improvements with Low Viscosity Lubricants $(2)$

\begin{tabular}{|c|c|c|c|}
\hline \multicolumn{2}{|c|}{ High } & \multicolumn{2}{|r|}{ Low } \\
\hline Engine & AxTe & Engine & Axle \\
\hline $10 W-30$ & 90 & $10 \mathrm{~W}$ & $75 \mathrm{~W}$ \\
\hline \multicolumn{2}{|c|}{ Driving Cycle } & \multicolumn{2}{|c|}{ Percent Improvement } \\
\hline \multicolumn{2}{|l|}{ City } & \multicolumn{2}{|r|}{1.4} \\
\hline \multicolumn{2}{|c|}{ Highway } & \multicolumn{2}{|r|}{3.0} \\
\hline \multicolumn{2}{|l|}{ FPA } & \multicolumn{2}{|c|}{2.3} \\
\hline
\end{tabular}

is the savings from the two approaches should be additive, of the order of $2 \%$. Of the total saving of $2 \%$, two-thirds would be achieved in the engine and one-third in the axle. (36)

\subsubsection{Results of European Study (37)}

Some rather extensive data on vehicle fuel efficiency boosts are given in the above work which was conducted mostly on the European Standard ECE Cycle, but some also on the EPA Cycle. The ECE test consists of runs at 90 and $120 \mathrm{~km} / \mathrm{hr}$ with a 15-cycle duration. Table 4.11 gives results for four different oil compositions along with detailed data for one particular oil, specifying performance separately for the city and highway portions of the EPA cycles 


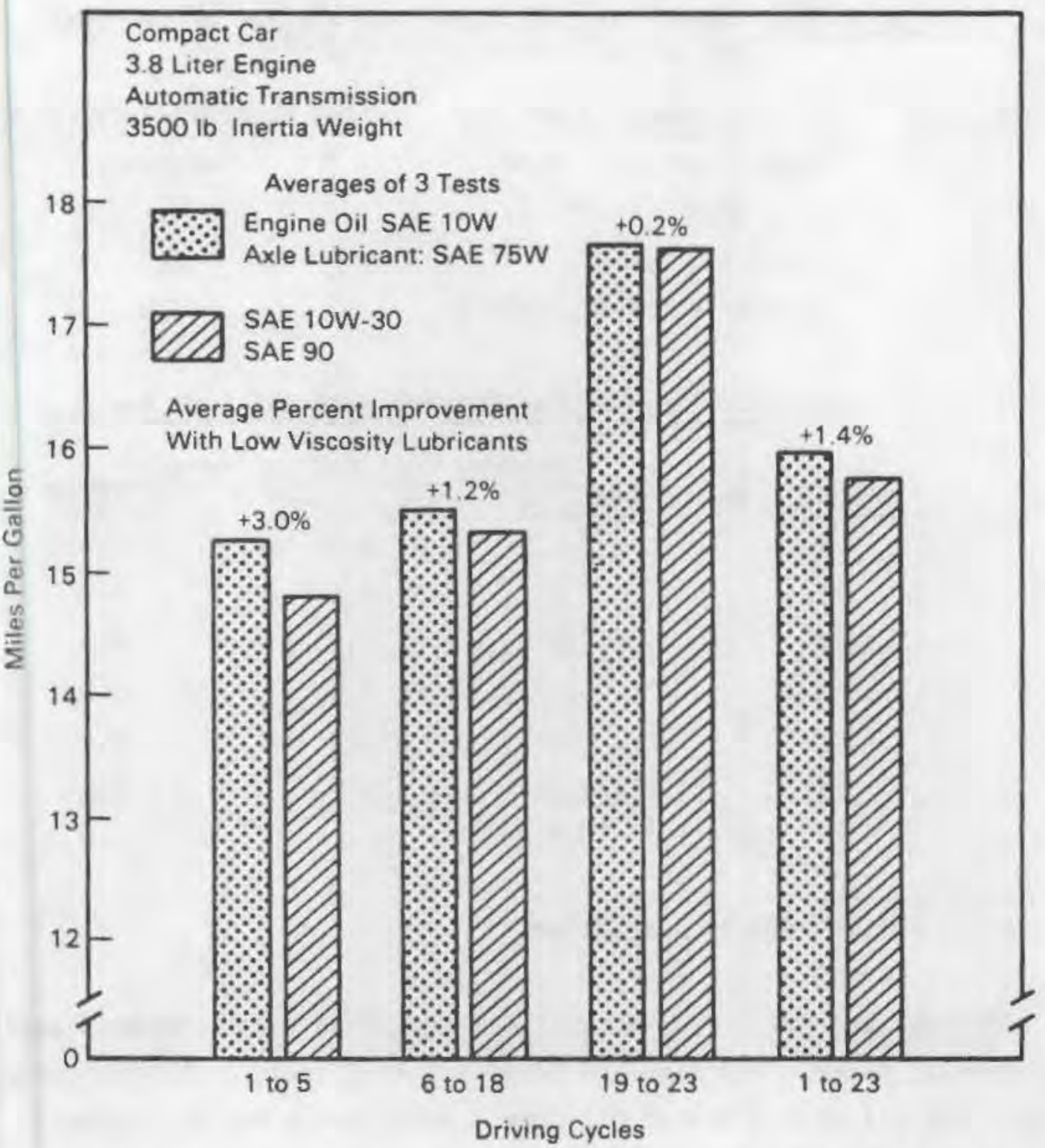

FIGURE 4.43. Average Fuel Economies During EPA City Tests with High and Low Viscosity Engine 0ils and Rear Axle Lubricants (2)

as well as for each individual vehicle. The latter is of interest in that it shows the difficulties in obtaining uniform data from different vehicles and also that the benefits of the low viscosity and additives are much higher at the higher engine speeds. 
TABLE 4.11. Automotive Efficiency as Function of Lubricant Properties for an EPA Cycle $e^{(37)}$

\begin{tabular}{|c|c|c|}
\hline 0il Code & 0il Composition & Rise in Efficiency, Percent \\
\hline 1 & Premium API SAE 10 W40 & Reference \\
\hline 2 & 1 ex $Z D D P+F R A(a) 1 / 2$ & 3.1 \\
\hline 3 & $1+F R A 3$ & 5.5 \\
\hline 4 & 1 with less ZDDP + FRA 2 & 7.0 \\
\hline
\end{tabular}

Sample Results for Six Vehicles with 0 il Code No. 3

\begin{tabular}{|c|c|c|c|c|}
\hline Vehicle & Code & $\begin{aligned} \text { Perc } \\
\text { EPA City }\end{aligned}$ & $\begin{array}{l}\text { Fuel Economy } \\
\text { EPA Highway }\end{array}$ & $\begin{array}{l}\text { Benefit } \\
\text { EPA } 55 / 45\end{array}$ \\
\hline K & & 10.2 & 14.9 & 12.D \\
\hline L & & 4.9 & 10.8 & 6.8 \\
\hline M & & 3.8 & 10.1 & 6.2 \\
\hline N & & 0.1 & 4.3 & 1.5 \\
\hline 0 & & 3.6 & 12.1 & 6.2 \\
\hline P & & 1.3 & 1.9 & 1.5 \\
\hline & Average & 3.9 & 9.0 & 5.5 \\
\hline
\end{tabular}

(a) Friction reduction additive.

The fuel economy performance of $0 i 1$ Code 3 was also compared against a conventional nonfriction modified 10 W40 oil in 6 vehicle chassis dynamo-meter tests. The oil code 3 versus $0 i 1$ code 6 performance was as follows:

\begin{tabular}{cc}
6 Car Fuel Economy Benefit, & Percent \\
\hline $90 \mathrm{KPH}$ & 2.3 \\
EPA Highway & 3.0 \\
ECE & 4.3
\end{tabular}

The effects of VI improvers over straight oils for SAE 20 to 50 grades were obtained using three typical European vehicles ( $A, B$, and $C$ ) of different make and capacity. Figure 4.44, shows the relative fuel consumption data in the ECE test mode for all the test oils in vehicle A. Similar curves were 


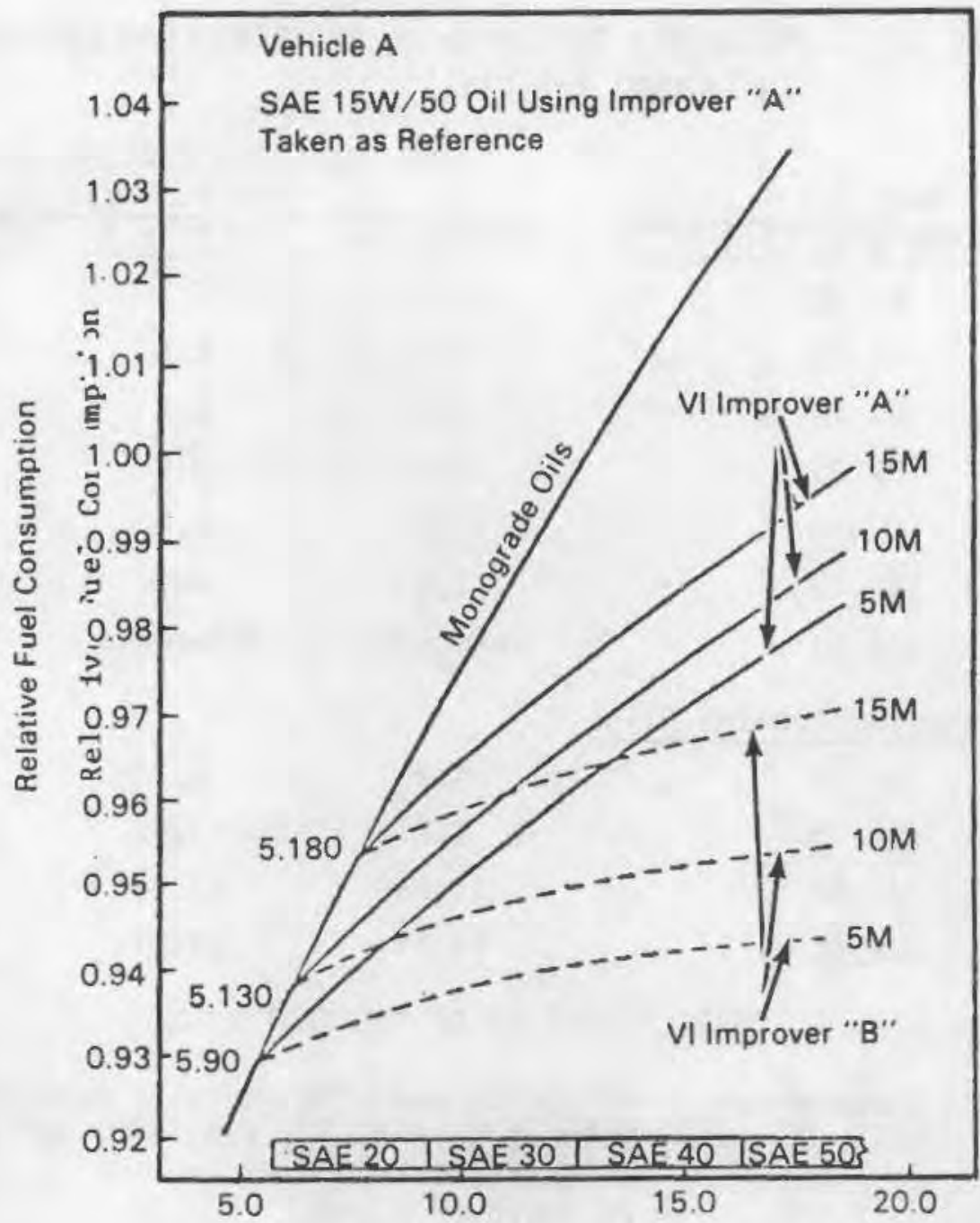

Fresh Oil Viscosity E.V. at $100^{\circ} \mathrm{C}$ (CST)

FIGURE 4.44. Effects of Different VI Improvers and Viscosity Grades on Fuel Consumption for an ECE Cycle ${ }^{(37)}$

obtained in the $90 \mathrm{KPH}$ test mode and for vehicles B and C in both test modes. After approximately 1000 miles of conditioning, the friction-modified $0 i 1$ Code 3 showed a $4.6 \%$ fleet average road fuel economy advantage.

Table 4.1? shows the fuel economy benefit (or debit) compared to a $15 \mathrm{~W}-30$ reference oil in the ECE test mode for a selection of some of the test oils in all three vehicles. Tables 4.13 and 4.14 show the three vehicle fleet average fuel economy benefit (or debit) for a selection of the test oils, with data for two VI improvers. 
TABLE 4.12. Viscosity Influence, on Relative Fuel EconomyIndividual Vehicles $(37)$

Test 0 il

Multigrade 0ils (VII AT

5 W 20

5 W 30

$5 \mathrm{~W} 40$

10w 30

10W 40

$15 \mathrm{~W} 40$

$15 \mathrm{~W} 50$
Percent Fuel Economy Benefit (or Debit) - ECE 15 Vehicle A Vehicle B Vehicle C

6.0

3.2

2.7

4.6

3.0

3.8

2.5

1.5

Reference

2.6

2.0

1.9

1.3

2.0

1.7

1.4

1.0

0.7

0.7

Reference

Reference

Monograde (Newtonian) Dils

SAE 20

SAE 30

SAE 40

SAE 50
4.9

1.2

(1.8)

$(4.8)$
2.2

(0.4)

(4.6)
2.2

0.5

CHARACTERISTICS OF THE TEST OILS:

Test 0il Components: API SE/CC and CCMC Additive Package

Solvent Neutral $90 ; 130 ; 150 ; 180$ and 600 Brightstock 2500

VI Improver A and B

Viscosity Grades: $\quad$ Monograde: SAE $5 \mathrm{~W} ; 7.5 \mathrm{~W} ; 10 \mathrm{~W} ; 15 \mathrm{~W} ; 20$; $30 ; 40 ; 50$

Multigrade: $5 \mathrm{~W} \mathrm{20;5W} \mathrm{30;5W} \mathrm{40;10W} \mathrm{30;}$ 10W $40 ; 10$ W 50 ; 15 W 30 ; $15 \mathrm{~W} 40 ; 15 \mathrm{~W} 50$

A 19-vehicle fleet test was carried out to compare the fuel economy performance of a premium API SAE quality $10 \mathrm{~W}-40$ oil with and without friction modification. The two oils were 0 il code 3 , with friction modification, and $0 i 1$ code 1 referred to in Table 4.11. The tests yielded an overall average fuel economy boost of $4.6 \%$. 
TABLE 4.13. Viscosity Influence on Relative Fuel Economy - 3 Vehicle Average

\begin{tabular}{|c|c|c|c|c|}
\hline \multirow[b]{2}{*}{ Multigrade 0ils } & \multicolumn{4}{|c|}{ Percent Fuel Economy Benefit (or Debit) } \\
\hline & VII ' $A$ ' & $\frac{15}{\text { VII 'B' }}$ & VII ' $\frac{90}{A^{\prime}}$ & VII 'B' \\
\hline SW 20 & 4.0 & 4.6 & 2.6 & 3.2 \\
\hline SW 30 & 3.1 & 4.5 & 2.0 & 3.2 \\
\hline $10 \mathrm{~W} 30$ & 2.5 & 3.7 & 1.6 & 2.5 \\
\hline 10W 40 & 1.6 & 3.6 & 1.1 & 2.4 \\
\hline $15 \mathrm{~W} 40$ & 1.0 & 2.4 & 0.6 & 1.7 \\
\hline $15 W 50$ & Reference & 2.3 & Reference & 1.7 \\
\hline
\end{tabular}

Monograde (Newtonian) 0ils
SAE 30
0.4
0.2
SAE 40
(1.6)
SAE 50 TABLE 4.14. Viscosity Influence on Relative Fuel Economy -
Identical Vehicles 37 )

Percent Fuel Economy Benefit

Vehicle

A1

$A 1^{(a)}$

A2

A3

A4 (or Debit) - ECE 15 T5W 40 VII 'B' Versus $15 \mathrm{~W} 50$ VII 'A'T

5.4

2.7

2.3

2.4

3.0

(a) After engine strip and rebuild with same parts.

Finally, to emphasize the particular importance of oil during cold starts, the fuel economy performance of the two conventional $10 \mathrm{~W}-50$ multigrade oils $\mathrm{A}$ and B were compared against Newtonian SAE 30 and 50 oils in a cold-start chassis dynamometer test. The results are illustrated in Figure 4.45 where fuel consumption is plotted on an ongoing instantaneous basis against distance traveled. The data showed that at start-up, both multigrade oils $A$ and $B$ gave lower fuel consumption than the SAE 30 and 50 oils, and that $B$ always held an 


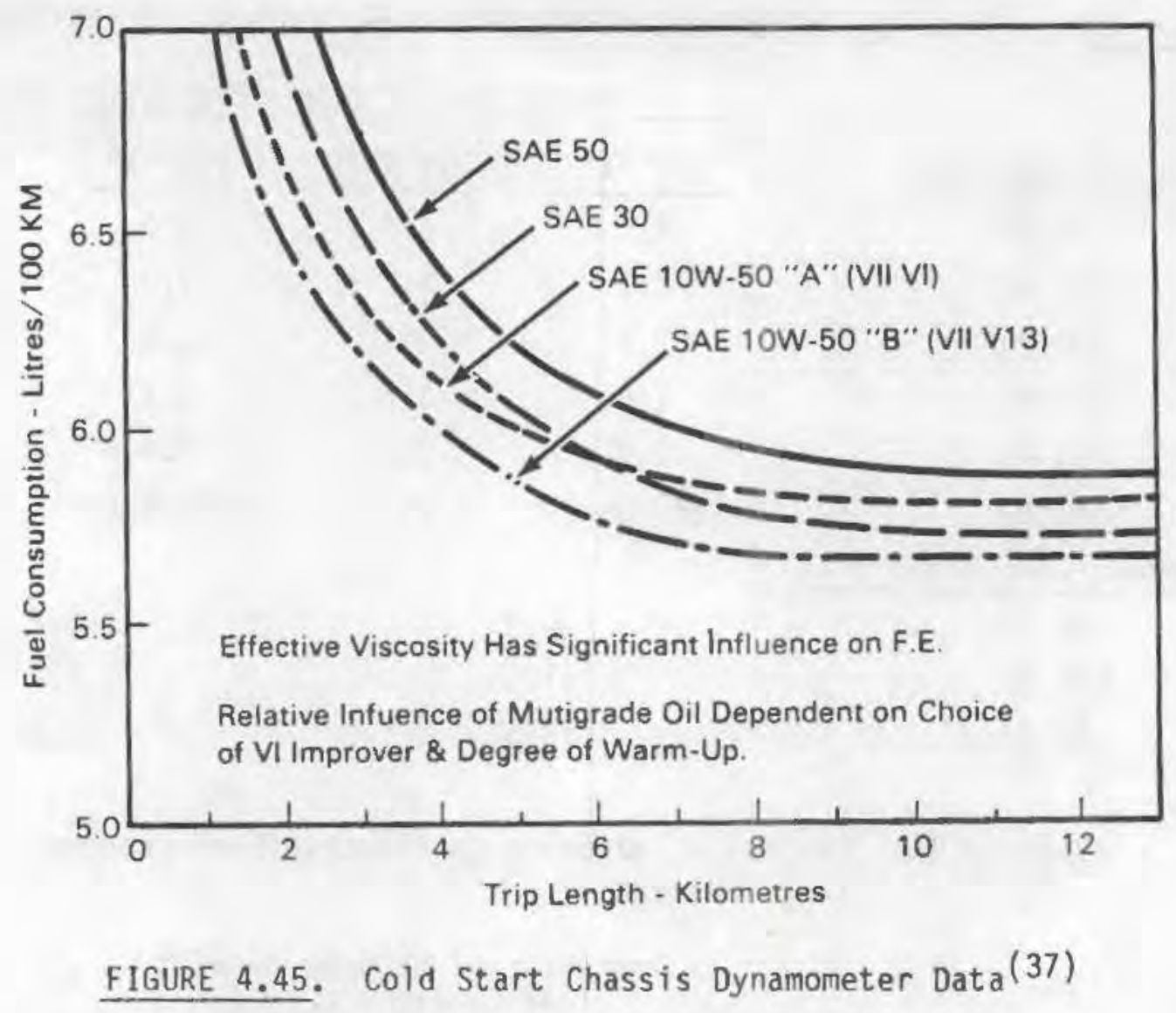

advantage over $A$, the more shear stable product. After 6 kilometers, with the engine and oil warming up, oil A overtook the consumption rate of the SAE 30 oil but never reached that of the SAE 50 oil.

4.7.3 Survey of 80 Papers (1913-1975) ${ }^{\text {(38) }}$

An extensive survey on various aspects of engine performance as related to oil viscosity and oil additives is given by Stewart and Selby in Reference 38. The dependence of fuel economy on viscosity with full or partial engine loading is given in Figure 4.46. An overall relationship developed on the basis of this chart is given in Table 4.15. Two other sets of comparisons with SAE 30 as a base are given in Figures 4.47 and 4.48 . This data plus other fuel efficiency test results are summarized in Table 4.16 , where the gains in fuel consumption are seen to reach levels of $5 \%$. 


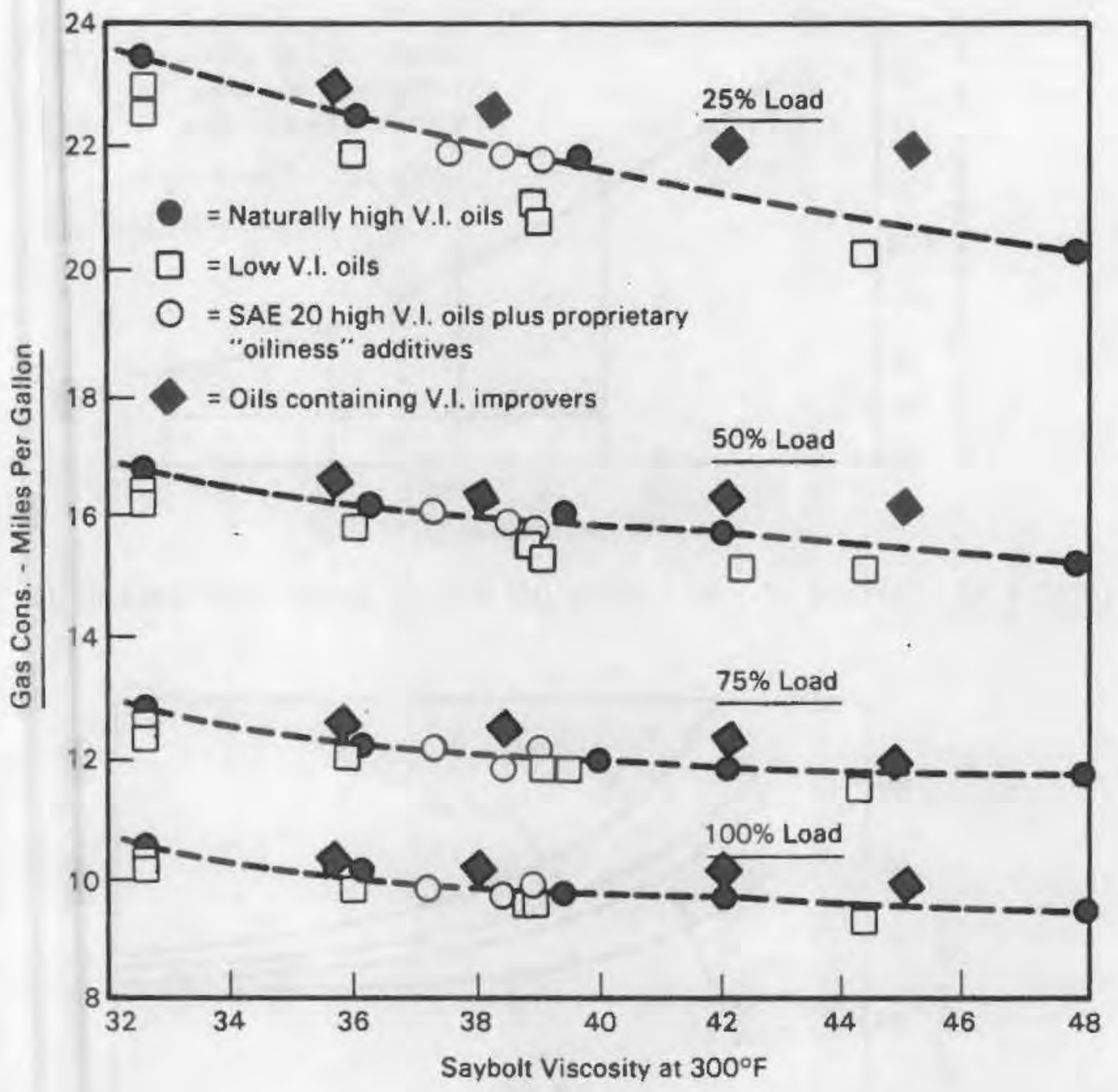

FIGURE 4.46. Average Fuel Consumption Versus $0 i 1$ Viscosity at $300^{\circ} \mathrm{F}(38)$

TARLE 4.15. Typical Fuel-Consumption Ratios as Related to 0 il Viscosity Grade

\begin{tabular}{|c|c|}
\hline $\begin{array}{c}\text { SAE } \\
\text { Viscosity } \\
\text { Grade } \\
\end{array}$ & $\begin{array}{c}\text { Gasoline } \\
\text { Consumption } \\
\text { Ratio } \\
\end{array}$ \\
\hline SAE $5 W$ & 1.03 to 1.06 \\
\hline SAE 10W & 1.01 to 1.03 \\
\hline SAE 20-20W & 1.00 \\
\hline SAE 30 & 0.96 to 0.98 \\
\hline SAE 50 & 0.93 to 0.95 \\
\hline
\end{tabular}




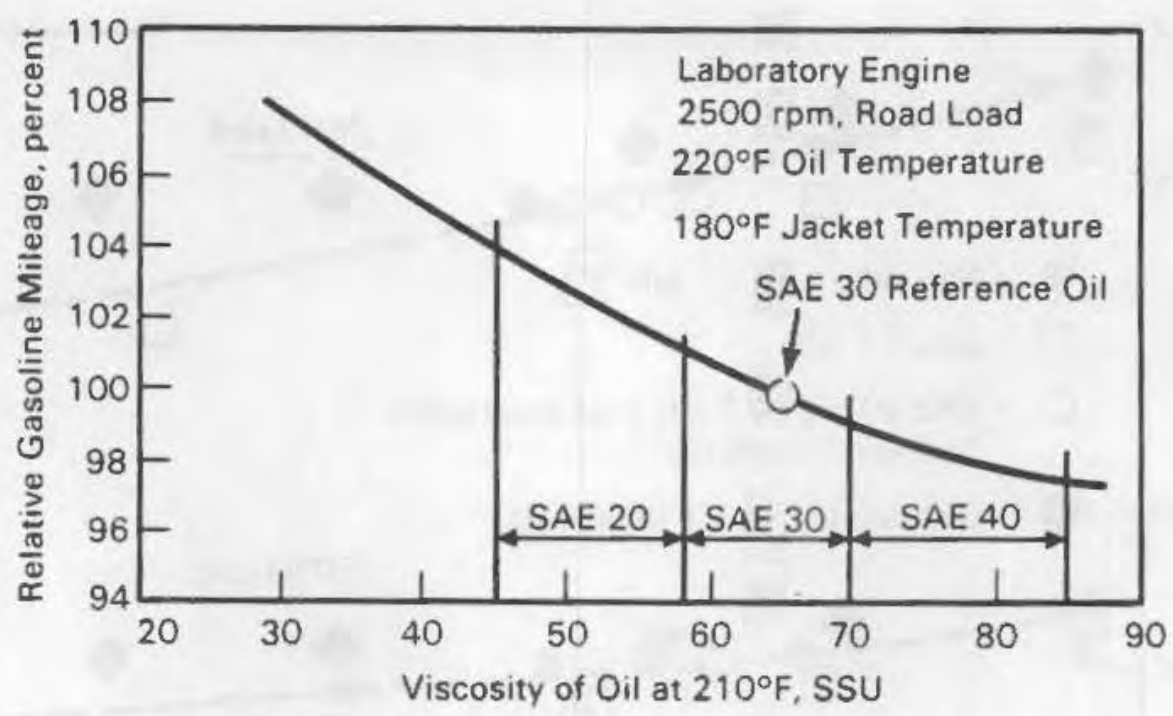

FIGURE 4.47. Effect of Lubricating $0 i 1$ Viscosity on Gasoline Engines (38)

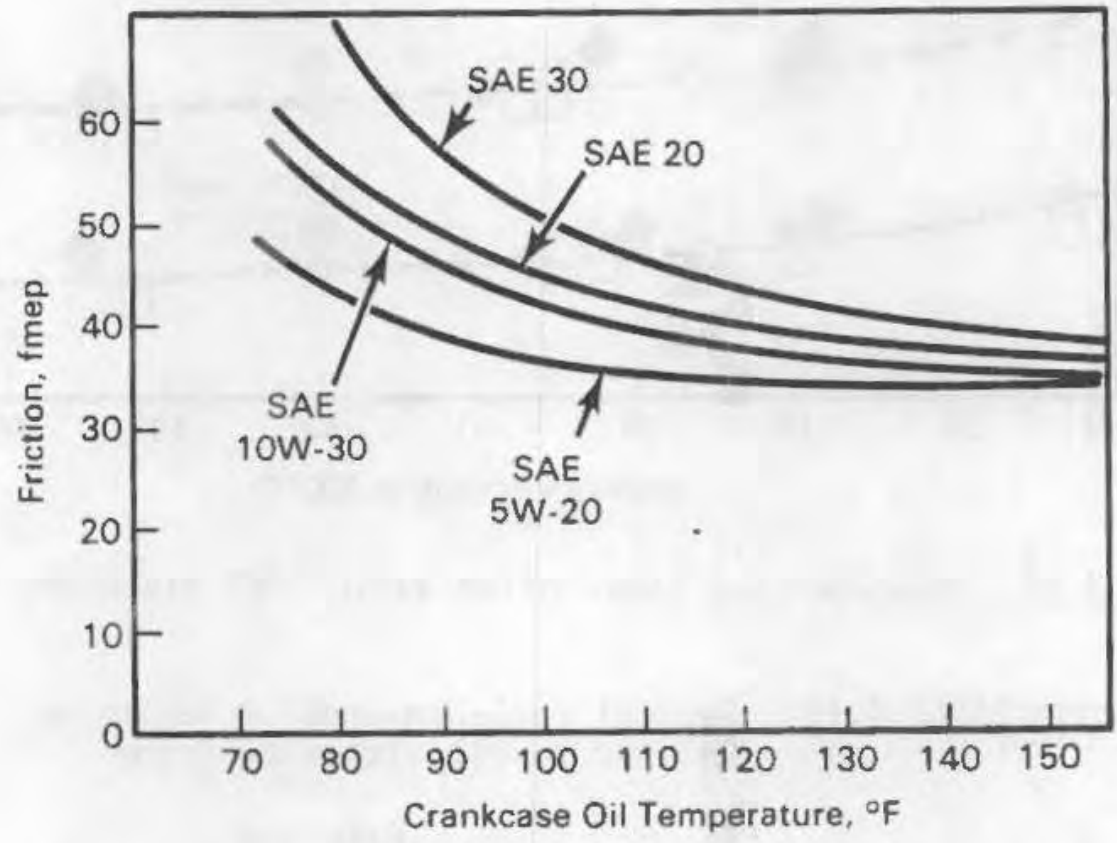

FIGURE 4.48. Friction Versus $0 i 1$ Temperature During Warm-Up CFR-F4 Engine(38) 
TABLE 4.16. Efficiency Gains as Function of $0 i 1$ Properties

\begin{tabular}{|c|c|c|}
\hline Reference $^{(a)}$ & Gain (Loss) & Lubricant \\
\hline 31 & $\begin{array}{c}4 \% \\
(6 \%)\end{array}$ & $\begin{array}{l}\text { SAE } 5 W \text { versus SAE } 20 W / 20 \\
\text { SAE } 50 \text { versus SAE } 20 W / 20\end{array}$ \\
\hline 32 & $2 \%$ & For each $10 \mathrm{SSU}$ of a $210^{\circ} \mathrm{F}$ oil \\
\hline 34 & $5 \%$ & Cold start driving cycle \\
\hline 35 & $3 \%$ & Cold start driving cycle \\
\hline 30 & $5 \%$ & $\begin{array}{l}\text { Properly synthesized } 5 \mathrm{~W} / 20 \text { oil } \\
\text { versus conventional SAE } 10 \mathrm{~W} / 40\end{array}$ \\
\hline
\end{tabular}

(a) These numbers are references in Stewart and Selby. (38)

4.7.4 EPA and FTP(a) Standards Tests ${ }^{\text {(39) }}$

In these tests a sedan with "full power" equipment was tested with a number of oils of varying viscosity with and without anti-friction additives. The kinds of vehicle and oils used are given in Table 4.17. Three conventional long-drain multigraded oils, differing as much as $50 \%$ in kinematic viscosity over the range of engine operating temperatures, demonstrated no consistent differences in vehicle fuel economy (see Figure 4.49 and Table 4.18 ). This is explained in Reference 39 by the argument that since the major friction occurs in the piston oil rings and there the friction is related to only a fractional power of the viscosity, a mere reduction in viscosity has little effect. Next under similar test conditions, the inclusion of a colloid friction modifier in these conventional multigraded oils demonstrated consistent improvement in fuel economy, generally in the 5 to $10 \%$ range. Also, low viscosity multigrade oils containing colloid friction modifiers were shown to provide between $4 \%$ and $7 \%$ fuel economy improvements over commercial type SAE 10 W40 service station oil. Some of the more detailed results for the above tests are shown in Figure 4.49 and Table 4.18.

(a) Federal Test Procedures. 
TABLE 4.17. Vehicles and 0ils Used in EPA-FTP Tests (39)

Test Vehicle Specifications

\begin{tabular}{|c|c|}
\hline Model & 1977 2-door sedan \\
\hline Engine & 5.0 Liter (305 CID) V-8 \\
\hline Equipment & $\begin{array}{l}\text { Automatic Transmission } \\
\text { Power Steering } \\
\text { Power Brakes } \\
\text { Air Conditioning } \\
\text { Radio }\end{array}$ \\
\hline Curb Weight (a) & $4300 \pm 101 b$ \\
\hline
\end{tabular}

(a) Including fuel, all instruments, driver, and observer.

Test 0 i1 Properties

\begin{tabular}{|c|c|c|c|c|c|c|c|}
\hline \multirow[b]{2}{*}{ Viscosity Grade (SAE) } & \multicolumn{4}{|c|}{ Conventional OIIs (NFE) } & \multicolumn{3}{|c|}{ Fuel Efficlent olls (FEO) } \\
\hline & $10 w-40^{(a)}$ & $5 w-30^{(a)}$ & $5 W-20^{(a)}$ & $30^{(b)}$ & $5 w-30^{(a)}$ & $5 w-20^{(a)}$ & $30^{(b)}$ \\
\hline viscosity at $10^{\circ} \mathrm{C}$, cSt & 482.8 & 213.3 & 151.2 & 888.3 & 229.7 & 158.0 & 670.7 \\
\hline viscosity at $40^{\circ} \mathrm{C}$, eSt & 97.20 & 51.37 & 34.73 & 112.5 & 53.96 & 35.33 & 97.77 \\
\hline VIscosity at $100^{\circ} \mathrm{C}$, cSt & 15.91 & 10.22 & 6.68 & 11.55 & 10.47 & 6.68 & 11.38 \\
\hline viscosity at $149^{\circ} \mathrm{C}$, cSt & 6.96 & 4.89 & 3.18 & 4.31 & 4.94 & 3.12 & 4.54 \\
\hline viscosity at $-18^{\circ} \mathrm{C}, \mathrm{CP}$ & 2480 & 1090 & 1040 & - & 1230 & 1150 & - \\
\hline Gravity, API & 29.4 & 29.9 & 30.7 & - & 28.7 & 29.1 & - \\
\hline Flash Point, $\mathrm{COC}$, of & 405 & 405 & 405 & 440 & 415 & 425 & 440 \\
\hline Pour Point, of & -35 & -40 & -45 & - & -40 & -40 & - \\
\hline Sulfated Ash, \$ & 1.04 & 0.97 & 1.10 & 1.00 & 1.03 & 1.00 & 1.00 \\
\hline Chemical Analysis & & & & & & & \\
\hline Zinc, $w T q$ & 0.16 & 0.16 & 0.16 & 0.16 & 0.16 & 0.17 & 0.16 \\
\hline Phosphorous, WT\% & 0.14 & 0.14 & 0.13 & 0.14 & 0.13 & 0.14 & 0.14 \\
\hline
\end{tabular}

(a) API Proposal $5-1$.

(b) API SE Classification.

\subsubsection{Cold Start Fuel Efficiency}

Two kinds of vehicles with an in-line 4-cylinder and a V-8 engine were tested under cold starting conditions according to the cycle shown in Figure 4.50. The results are given in Figure 4.51 and Table 4.19 where it is seen that, as expected, the gains with lower viscosity oils are larger the colder 

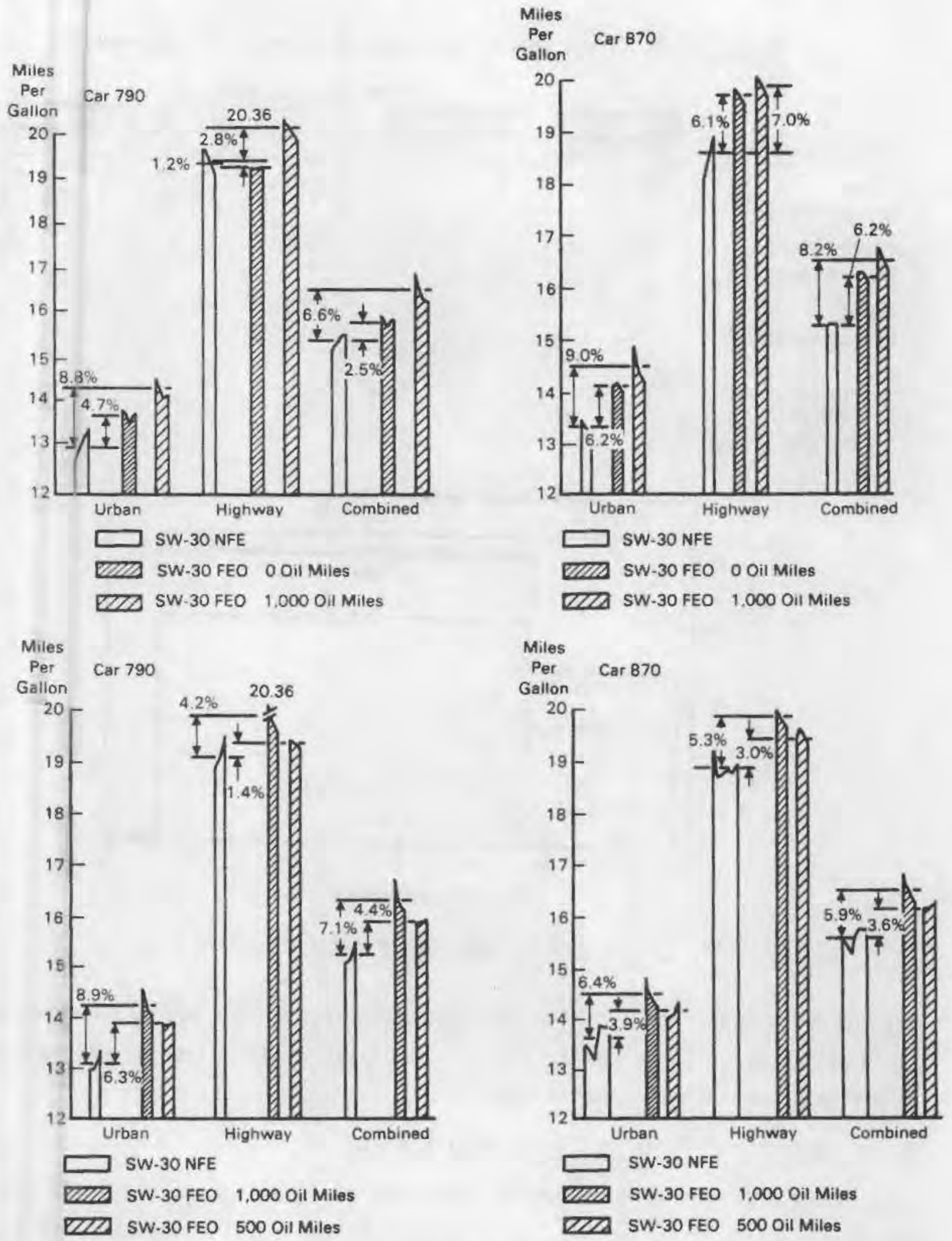

FIGURE 4.49. Fuel Efficiency Details for EPA-FTP Tests (39) 
TABLE 4.18. Improvement in Constant Speed Fuel Economy

\begin{tabular}{|c|c|c|c|c|c|}
\hline \multirow[b]{2}{*}{ Oil Miles } & \multicolumn{5}{|c|}{ Miles per Gallon } \\
\hline & $1000-2500$ & 1000 & 0 & 500 & 1000 \\
\hline $\begin{array}{l}\text { Car } 790 \\
\% \text { improvement (a) }\end{array}$ & 19.97 & -- & $\begin{array}{c}20.11 \\
0.7\end{array}$ & $\begin{array}{c}20.99 \\
5.1\end{array}$ & $\begin{array}{c}21.04 \\
5.4\end{array}$ \\
\hline $\begin{array}{l}\text { Car } 870 \\
\% \text { improvement (a) }\end{array}$ & 19.71 & $\begin{array}{c}20.72 \\
5.1\end{array}$ & $\begin{array}{c}20.55 \\
4.3\end{array}$ & $\begin{array}{c}21.30 \\
8.1\end{array}$ & $\begin{array}{c}21.07 \\
6.9\end{array}$ \\
\hline $\begin{array}{l}\text { Car } 984 \\
\% \text { improvement (a) }\end{array}$ & 19.87 & $\begin{array}{c}20.42 \\
2.8\end{array}$ & $\begin{array}{l}20.10^{(b)} \\
1.2\end{array}$ & $\begin{array}{l}20.84^{(b)} \\
4.9\end{array}$ & -- \\
\hline
\end{tabular}

(a) Compared to SAE 30 NFE oil.

(b) mpg on SAE 30 FEO.

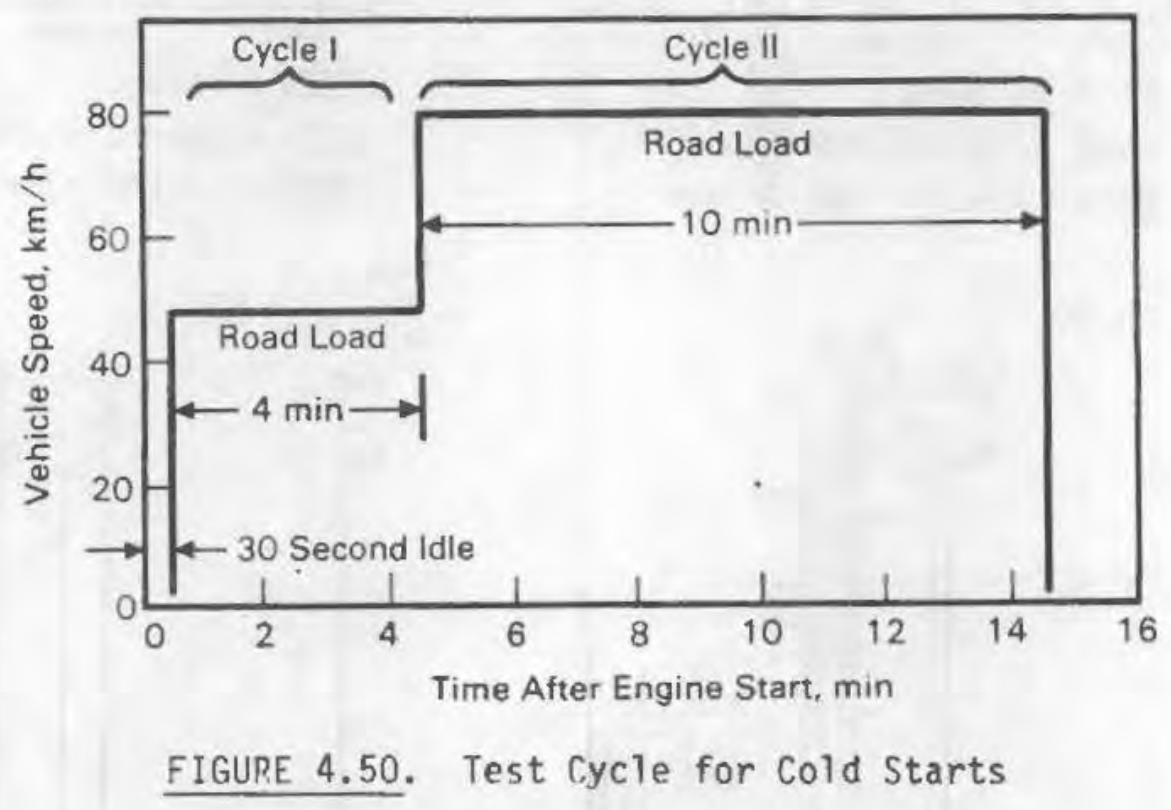

the starting temperature. Also the gains were larger for the $\mathrm{V}-8$ engine than the L-4 engine which is consistent with the higher percentage of mechanical friction present in the larger engine.

4.7.6 Negative Effects of Low Viscosity 0ils

There are several undesirable side effects of using low viscosity oil. One is the consumption of oil in the piston assembly which, as shown in Figure 4.52 , goes up with a decrease in viscosity. Others are higher temperatures 

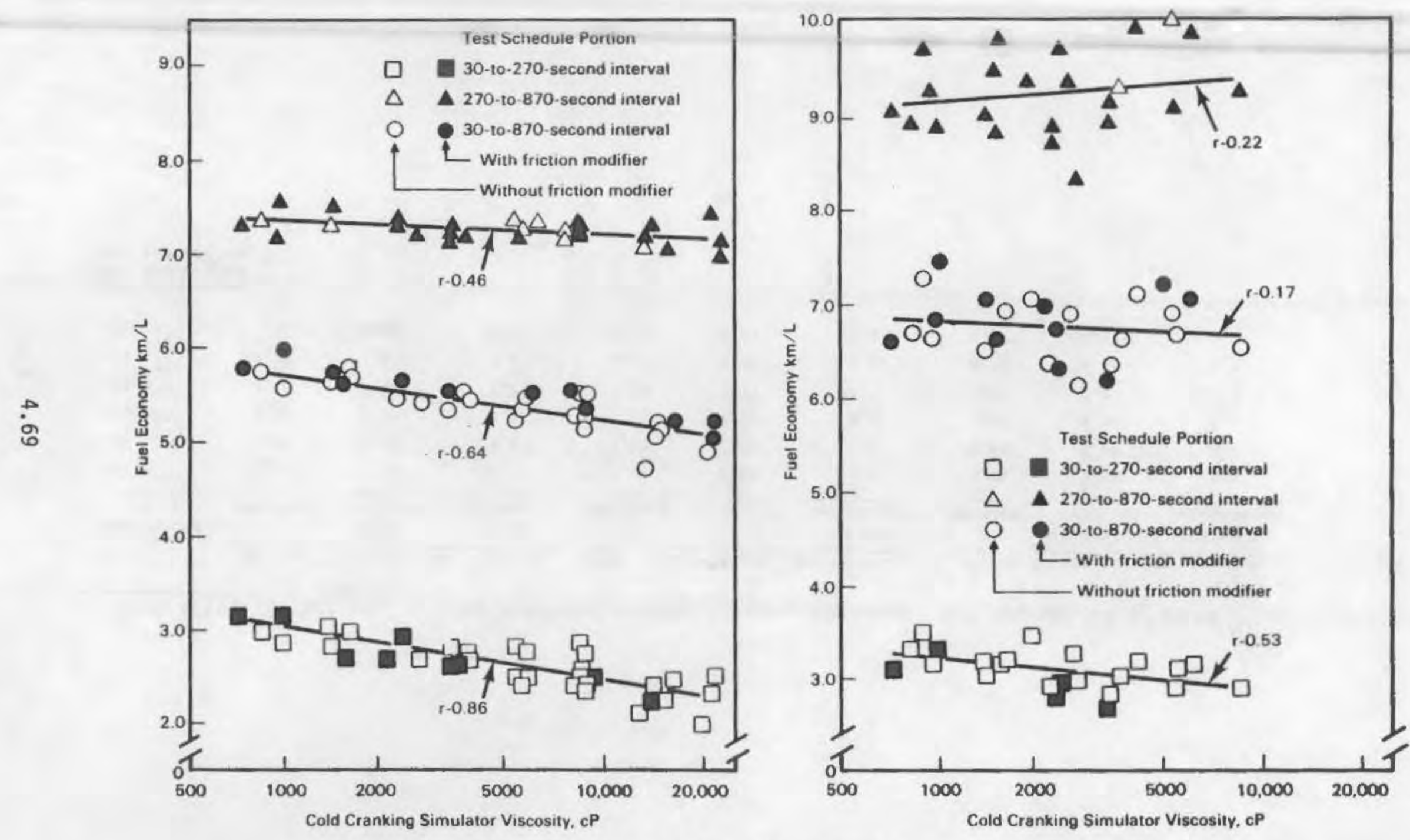

FIGURE 4.51. Effect of Engine 0il Viscosity on Fuel Economy 
TABLE 4.19. Effect of Friction Modifier on Fuel Economy Obtained with Two SAE 5W-10 0ils (40)

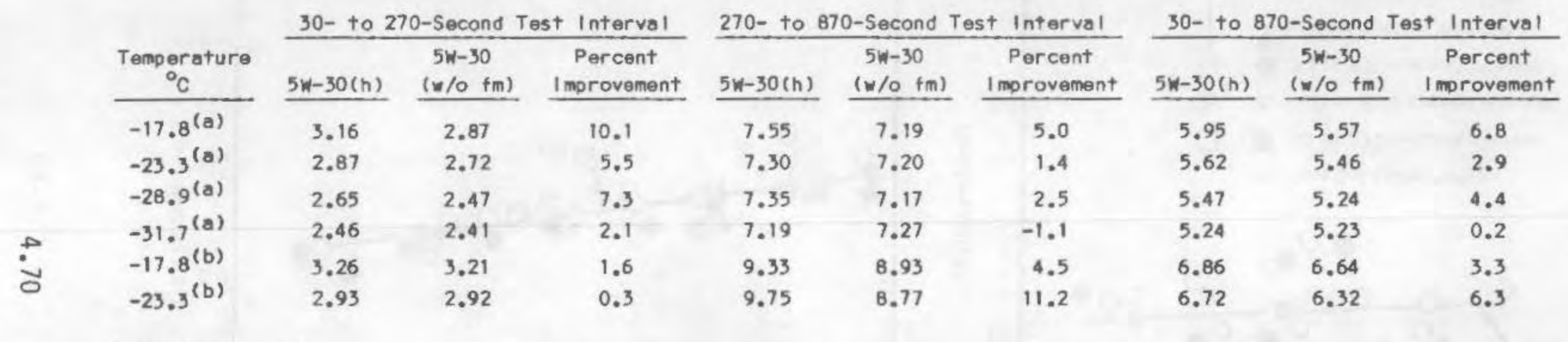

(a) $v-8$ engine.

(b) $L-4$ engine. 


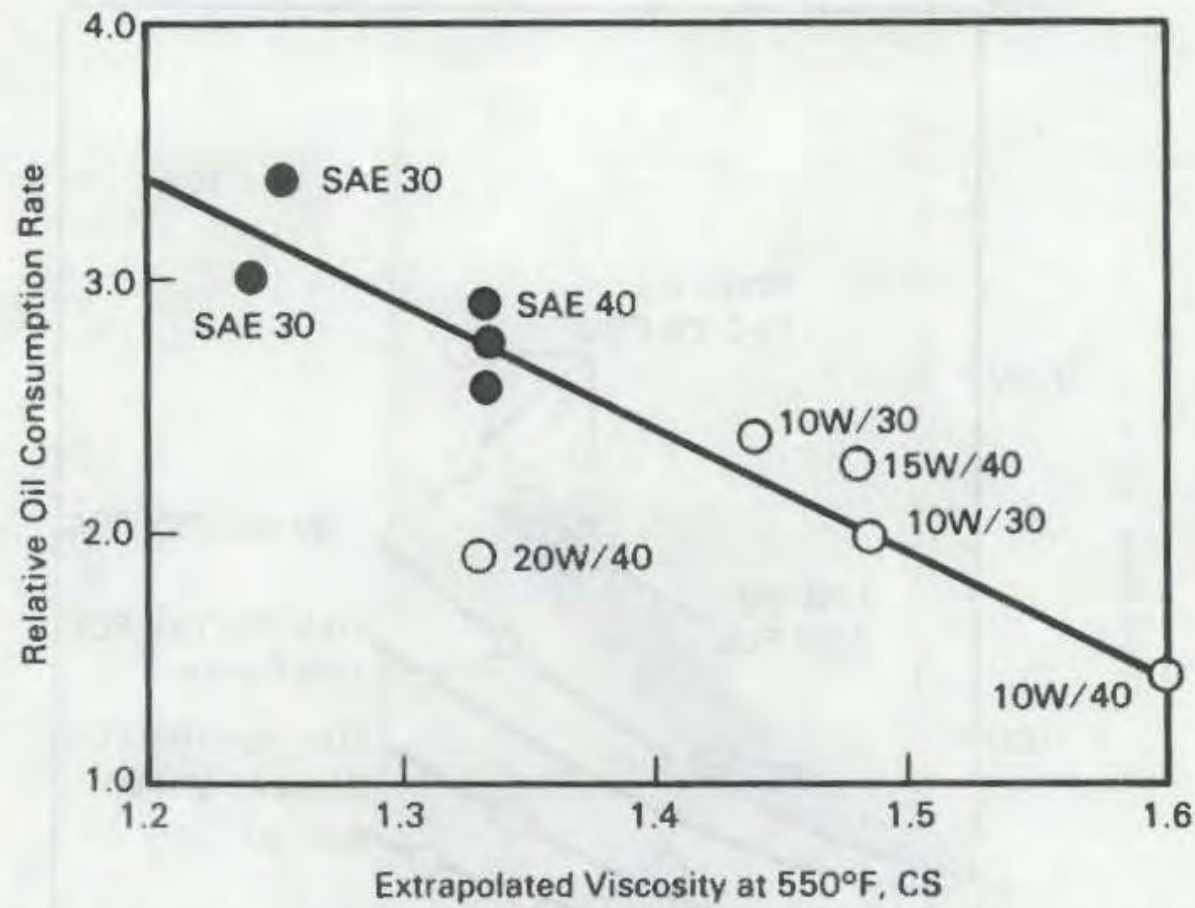

FIGURE 4.52. Relationship of Viscosity to 0 il Consumption Rate

due to lowered film thickness in bearings and sliding contacts. But the biggest concern is the impact of low viscosity oils on the rate of wear of engine parts, a sample of which is shown in Figure 4.53. The problem of wear is one of major significance, because even while fuel economy is improved, the increased wear, which would make itself felt only over a long period (exceeding the duration of most tests), may eventually increase friction. Even more important, wear may cause failures and in the end shorten the life of the engine. Aside from the economic cost of such failures, the need for new parts and engines itself involves the expenditure of energy thus impinging directly on the conservation effort.

\subsection{MATERIALS AND COATINGS}

There is obviously a wide field open for the introduction of new materials into automotive engines, which may have an impact on fuel consumption. However, except for unconventional engines, particularly the adiabatic diesel, new materials and coatings would not have too much impact in conventional otto 


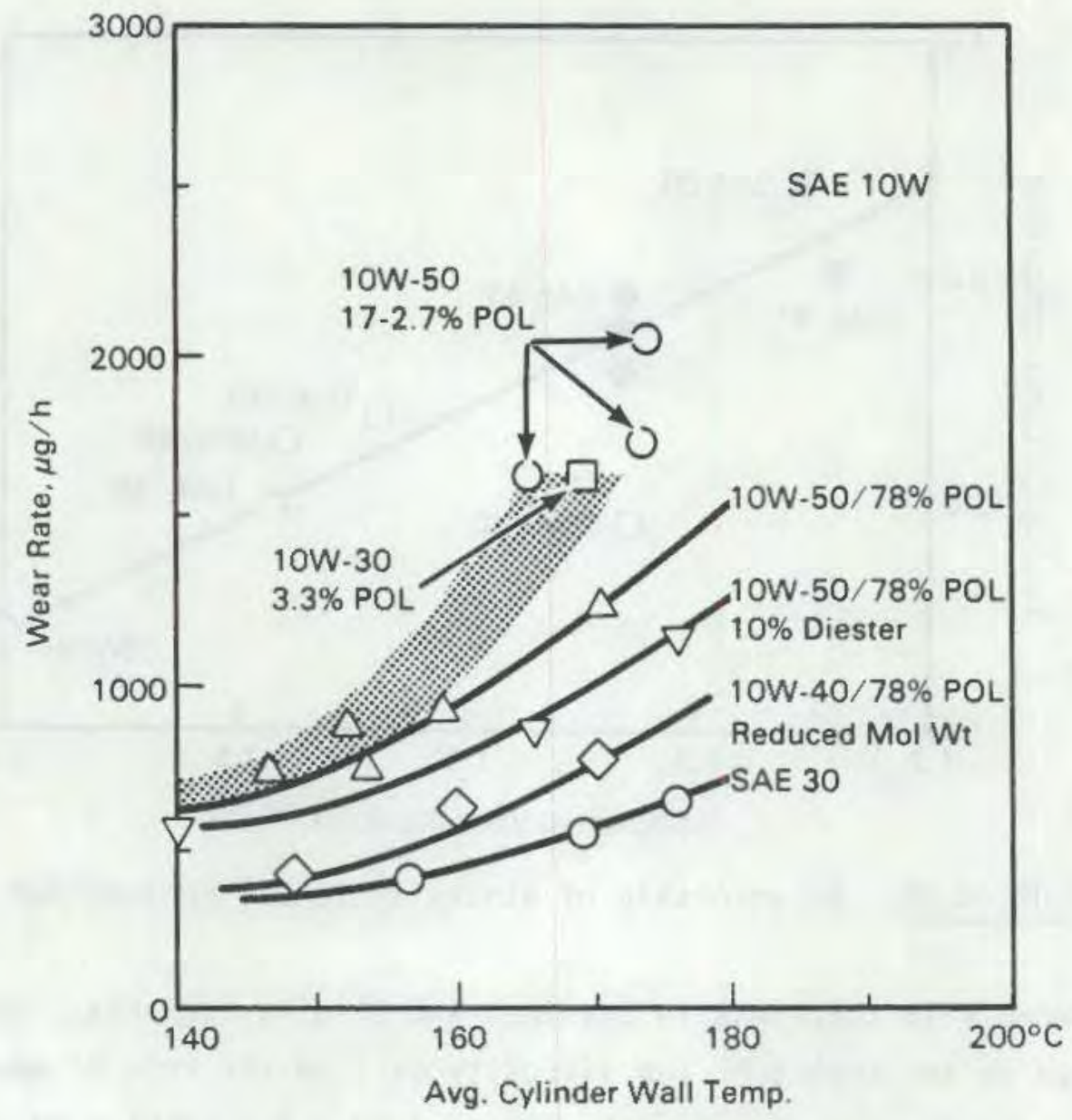

FIGURE 4.53. Daimler Benz OM 616 Cylinder Wear as Detected by Ratiotracer Method

cycle engines. The main reason is that while new materials and coatings may raise the permissible temperature levels in the thermodynamic cycle, one would have to resort to an extremely large compression ratio to take advantage of it and this in turn would call for large engine sizes. Since weight and engine size are crucial parameters, such a rise in upper cycle temperatures would not benefit the conventional automotive vehicle. The only possible benefit would be the development of specific coatings such as the chrome plated rings mentioned in Section 4.1 that would reduce friction and wear in specific components. Such detailed studies have not yet been carried to a point where the benefits in terms of energy conservation could be quantified. 


\subsection{OTHERS}

Under "others" are grouped all those components which absorb a relatively small portion of the input energy, or for which tribological improvements would produce negligible savings. Some of these elements are the following:

- The Axle. The losses due to the axles are made up of friction in the gears and bearings, plus a tire creep loss which occurs when traction forces are transmitted through tire/road contact (in addition to the free rolling loss). However, since axle efficiency is relatively high, $87 \%$, potential improvement is limited. This is particularly true with increasing use of front wheel drives.

- Tires. The sliding losses in the tire-road interface are given in Table 4.20. While these are appreciable, and a large portion of it can be considered to be tribological in nature, not much reduction may be possible or even desirable since this frictional force is a necessary part of vehicle propulsion. Still the parasitic component in it could profitably be minimized.

- Power Assisted Processes. This area involves power steering, power brakes, the operation of seats, windows, doors, wipers, radio antennas and other similar arrangements. In most cases, the pumps supplying the $0 i 1$ for these operations work even where these functions are not required, and disengagement during idle periods would produce some savings.

TABLE 4.20. Energy Consumed by Tires for an EPA Cycle $e^{(7)}$

\begin{tabular}{|c|c|c|c|}
\hline & Input Energy & \multicolumn{2}{|c|}{ Energy Consumed by Tires } \\
\hline Cycle & $(\mathrm{MJ} / \mathrm{km})$ & $\mathrm{MJ} / \mathrm{km}$ & $\%$ of Total \\
\hline $\begin{array}{l}\text { Urban } \\
55 \%\end{array}$ & 5.70 & 0.251 & 4.5 \\
\hline
\end{tabular}

$\begin{array}{llll}\text { Highway } & 4.67 & 0.306 & 6.5 \\ 45 \% & & \end{array}$

$\begin{array}{llll}\text { Combined } & 5.24 & 0.275 & 5.25 \\ \text { EPA } & & 0.27\end{array}$


- Accessories. The various accessories and the power required to operate them have been itemized in Section 2.0. They consume something on the order of $1 \%$ of energy input ( $6 \%$ of BHP). A11 these accessories have bearings, seals and possibly also gearing. They probably constitute a small part of the power consumed by the operation of these accessories and so here, too, more efficient bearings and seals would bring only small benefits. The only exception here perhaps would be the area of the air-conditioning compressor.

- Pumps. In addition to the oil pump, pumps are also used for supplying fuel, air and cooling water. They all require only minimal energy inputs for the tribologically related components.

Except for the effect of viscometrics and anti-friction oil additives, most of the individual savings consist of relatively small percentages of the total fuel energy demanded by an automobile. Yet this should not, by any means, lead to the conclusion that they can be dismissed or that they do not offer a path for effective improvement in car fuel performance and energy conservation. The consensus of both Ford Motor Company and General Motors personnel who were interviewed was that efficiency improvement of the tribological components remains an active concern and that it is one of the practical ways of raising car performance. In fact, Ford and GM personnel were convinced that the success Japan has had with its automotive industry came to a large extent from its concern and investment in a number of seemingly small improvements which, in their cumulative impact, gave Japanese cars an edge in performance. Some of this is reflected in the following section (see Table 5.5) where, aside from viscometrics, the combined saving potential of the various components adds up to some $5 \%$ of the automotive fuel consumption. 


\subsection{POTENTIAL ENERGY SAYINGS}

In Section 4 our concentration was on a quantitative examination of the losses in specific tribological areas and the variation of these losses with parametric changes. Here, the potential energy savings to be achieved by instituting certain design or system modifications will be examined. Since for most areas the needed data are not complete, and often lacking altogether, much extrapolation and engineering judgment will have to be resorted to in order to arrive at specific numbers. Moreover, care will have to be exercised that while ascribing gains to a particular modification, losses incurred elsewhere by such changes are taken account of, at least to the degree that the available data permit such an evaluation. Since ultimately the savings are to be translated into terms of national energy consumption and dollars, Table 5.1 given an overview of the key statistical data pertinent for such quantification.

\section{TABLE 5.1. Statistical Overview (1976)}

$\begin{array}{ll}\text { Total U.S. Eneray Consumption } & 74 \times 10^{15} \mathrm{Btu} \\ \text { - Transportation } & 26.1 \% \\ \text { - Highway Fleet } & 20.1 \% \\ \text { Total U.S. Petroleum Consumption } & 35 \times 10^{15} \mathrm{Btu} \\ \text { - All Transportation } & 53.6 \% \\ \text { - Highway Fleet } & 41.3 \% \\ \text { Barrel of Petroleum 0il } & 5.8 \times 10^{6} \mathrm{Btu} \\ \text { Gallon of Gasoline } & 125 \times 10^{3} \mathrm{Btu} \\ \text { Number of Vehicles } & 142 \mathrm{million} \\ \text { Average Mileage per Car } & 10,000 \mathrm{miles} / \text { year } \\ \text { Gasoline Cost/Total Operating Cost } & 23 \% \\ \text { Cost of Barrel of Crude 0il } & \$ 30 \\ \text { One Percent U.S. Energy } & 128 \mathrm{million} \text { barrels of oil } \\ \end{array}$


The basis for the quantification of the potential tribological losses will be the energy flow map of Figure 2.14. This map gives a simple accounting of the total combustion energy in the fuel put into the automotive fuel tank. Thus, in this accounting, the valve train consumes $1.3 \%$ of the energy content of the fuel and the transmission 2.0\%. However, these percentages are not the correct basis for evaluating the impact of the potential gain. Reduction of the level of loss, for example, of the valve train would not only reduce the required IHP but also the levels of exhaust and cooling which are a necessary part of generating the IHP. Thus, if the valve train expenditure of energy is reduced by a half the gain is not $0.5 \times 1.3 \%=0.65 \%$ but

$$
0.5 \times 1.3 \% \times\left(\frac{100}{35}\right)=2.85 \%
$$

Where the 35 represents the percentage IHP resulting from an input of $100 \%$ of energy. With this in mind Figure 5.1 shows a diagram with IHP representing $100 \%$ of energy, in which the various components are allocated portions of energy (including the necessary exhaust and cooling) required to run them.

A similar argument holds for the components that take their energy from BHP. Thus if, for example, the transmission losses are reduced by a half, the gain is not $0.5 \times 2.0 \%=1 \%$ but

$$
0.5 \times 2.0 \% \times\left(\frac{100}{23}\right)=4.35 \%
$$

where the 23 represents the percentage BHP resulting from a $100 \%$ input of fuel energy. The gain ratio here is higher because in addition to lowering the exhaust and cooling losses, there would also be a reduction in such things as air pumping, size of valve train, number of cylinders, etc., namely, of all the components used to produce a given BHP. Consequently Figure 5.2 shows a mapping of the energy allocation to the various components which take their energy from BHP, with the latter representing $100 \%$ of power. Any percentage reduction in the components taking their energy from BHP would have to be evaluated on the basis of the numbers given in Figure 5.2 . 


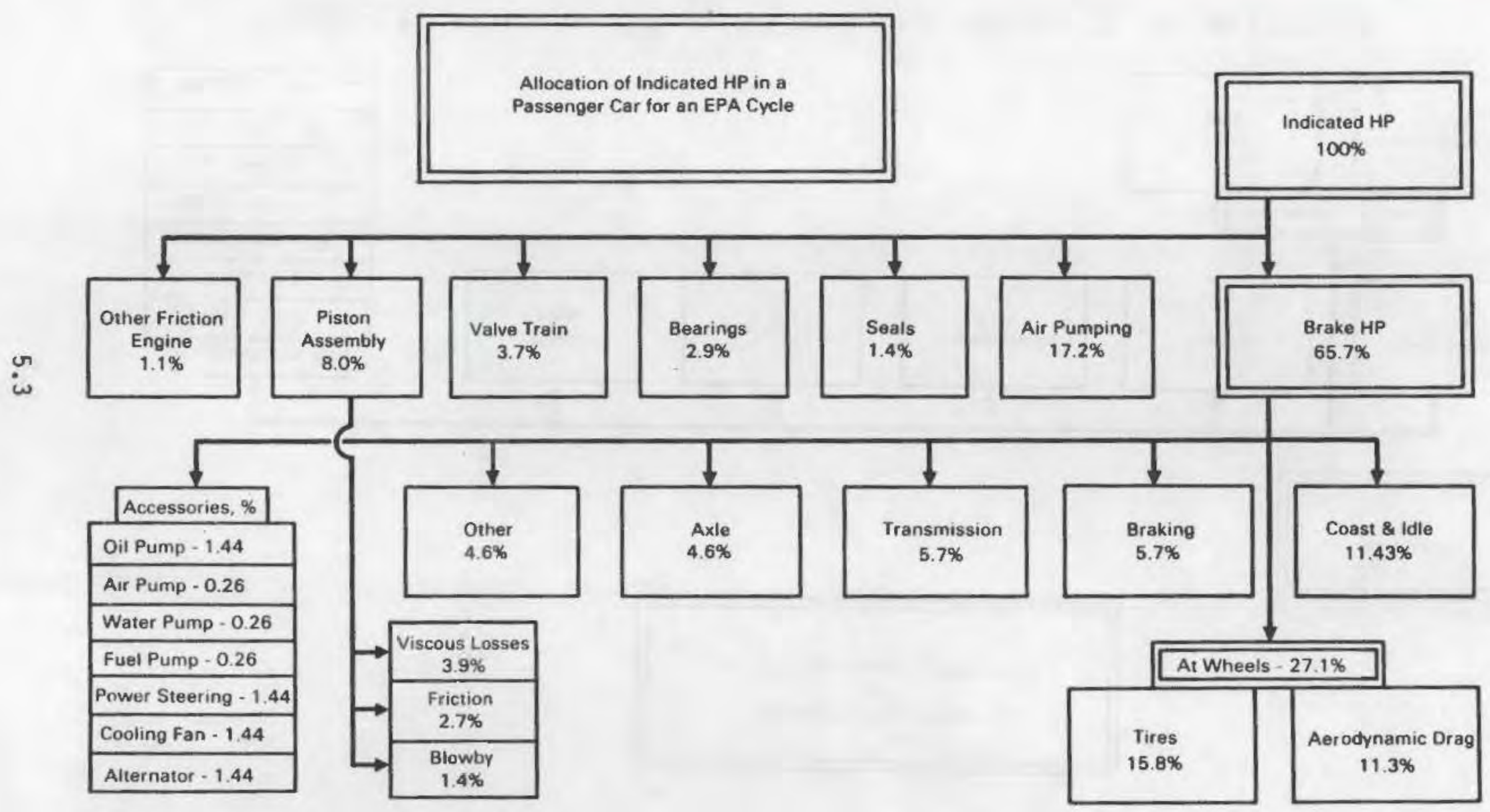

FIGURE 5.1. Energy Required by Passenger Car Components in EPA Cycle 


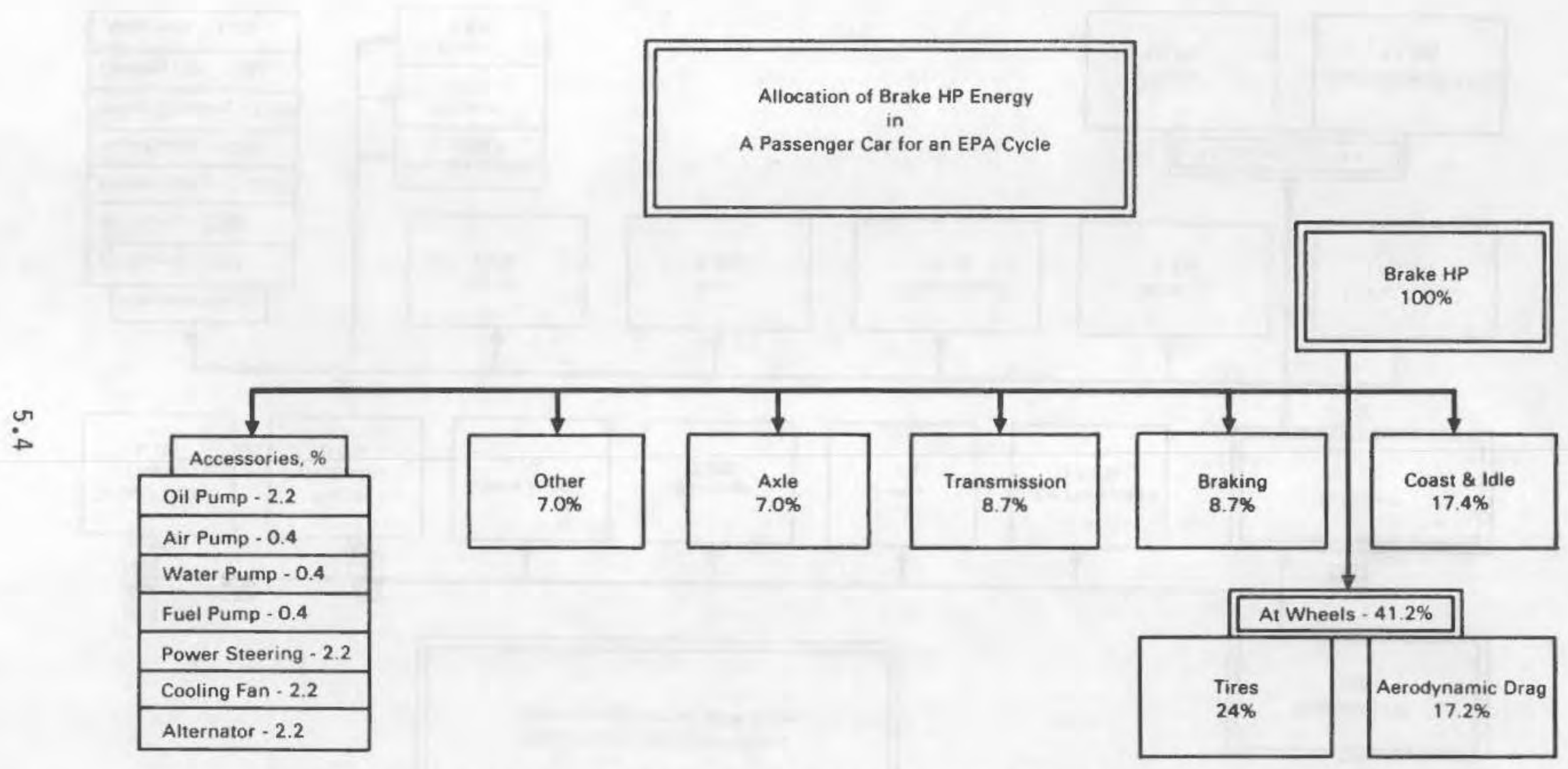

FIGURE 5.2. Allocation of Brake HP Energy in a Passenger Car for an EPA Cycle 
In surmary, starting with the basic map of Figure 2.14, any saving in IHP fed component will have its level raised by $(100 / 35)=2.85 \%$; and any component taking its energy from BHP will have $f$ ts saving level rafsed by $(100 / 23)=$ 4. 35:

\subsection{PISTON ASSEMBLY}

The potential gains to be achieved by varying certain design and opera"ional parameters in the piston assembly are given in Table 5.2. The worksheet is based on the data gathered in Section 4.1 and the results have been calculated as follows:

- In reducing parametric changes to a common base of either $-25 \%$ or $-50 \%$, the corresponding losses were varied on a linear basis.

- The average losses are based on an average of all the friction data available. Thus, for example, the $15 \%$ reduction in friction for a 25\% reduction in ring width was obtained as follows:

\begin{tabular}{|c|c|c|c|c|}
\hline Ref & $\begin{array}{c}\text { Parametric } \\
\text { Change } \\
\text { in Ref } \\
\end{array}$ & $\begin{array}{l}\text { Friction } \\
\text { Reduction } \\
\text { s }\end{array}$ & $\begin{array}{c}\text { Assumed } \\
\text { Parametric } \\
\text { Change, } \\
\end{array}$ & $\begin{array}{c}\text { Friction } \\
\text { Reduction } \\
x \\
\quad 0 \\
\end{array}$ \\
\hline 28 & -25 & 15 & -25 & 15 \\
\hline 10 & -33 & 6 & -25 & 5 \\
\hline 11 & -50 & 50 & -25 & 25 \\
\hline \multicolumn{2}{|c|}{ Total } & & & 45 \\
\hline
\end{tabular}

The average friction reduction is thus $(45 / 3)=15 \%$.

- The "Cumulative Friction Reduction" column represents the combined effects of a number of parametric changes. Thus the combination of reducing face width and ring tension by $25 \%$ yielded a gain of $24.5 \%$ and was calculated as follows: 
TABIE 5.2. Reduction of Tribological Losses in fiston Assembly

\begin{tabular}{|c|c|c|c|c|c|c|c|c|c|c|}
\hline \multirow[b]{2}{*}{$1 \tan$} & \multirow[b]{2}{*}{ Paramefor } & \multirow{3}{*}{$\frac{\mathrm{RA}_{*}}{2 \mathrm{R}}$} & \multicolumn{2}{|c|}{ As givan In Raf. } & \multicolumn{3}{|c|}{$\begin{array}{l}\text { For an Astumed } \\
\text { Paramater change of - }-258\end{array}$} & \multicolumn{3}{|c|}{$\begin{array}{l}\text { For an Asstumed } \\
\text { Parameter Chandye of -50s }\end{array}$} \\
\hline & & & $\begin{array}{c}\text { Parametar } \\
\text { Crange } \\
\quad\end{array}$ & $\begin{array}{c}\text { Friction } \\
\text { taductlon } \\
4\end{array}$ & 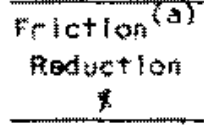 & 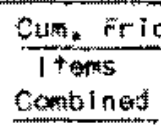 & $\begin{array}{c}\text { Ten Redict } \\
\text { Reduetion } \\
\quad\end{array}$ & $\begin{array}{c}\text { Friction } \\
\text { Roduction } \\
\quad\end{array}$ & $\begin{array}{l}\text { Cun Fris } \\
\text { frens } \\
\text { Combined }\end{array}$ & $\begin{array}{c}\text { ton foduct } \\
\text { Reduct } \\
x\end{array}$ \\
\hline$T$ & Ring Face width & & $\begin{array}{l}-25 \\
-33 \\
-50\end{array}$ & $\begin{array}{r}15 \\
6 \\
50\end{array}$ & 15 & 1 & 15 & 30 & 1 & 30 \\
\hline 2 & Rting Tassion & $\begin{array}{l}28 \\
10 \\
11\end{array}$ & $\begin{array}{l}-50 \\
-35 \\
-50\end{array}$ & $\begin{array}{r}10 \\
3 \\
50\end{array}$ & 11 & $1+2$ & 24,5 & 27 & $1+2$ & 45.5 \\
\hline 3 & sklot length & $\begin{array}{l}20 \\
11\end{array}$ & -50 & 10 & 6.5 & $1 \neq 0$ & 29.5 & 13 & 1 to 3 & 52.5 \\
\hline 4 & Stroke Length & 28 & -50 & 55 & 27, & 1 to $A$ & 49 & 55 & 1 to 4 & 權.5 \\
\hline 5 & Crowing and chrom Plating & 26 & $-\infty$ & 50 & 50 & 1 to 5 & 74 & 50 & 45 & 69.0 \\
\hline 6 & No. of Rla & 10 & 3 to ? & 33 & & $-m$ & $\cdots$ & & -..- & - \\
\hline 7 & $\forall$ scosity of ofl & 10 & -50 & 33 & 16.5 & $+\cdots$ & $-\infty$ & 33 & $-m$ & $\cdots$ \\
\hline
\end{tabular}

fat Ayaroged values, 


\begin{tabular}{|c|c|c|c|}
\hline Item & $\begin{array}{l}\text { Gain per } \\
\text { Iten, } \% \\
\end{array}$ & $\begin{array}{c}\text { Cumulative } \\
\text { Gain, } 9 \\
\end{array}$ & $\begin{array}{c}\text { Pematinifo } \\
\text { Los\$, } \\
\end{array}$ \\
\hline 1 & 15 & 15 & 85 \\
\hline 2 & 11 & - & -- \\
\hline $11 \%$ of 85 & 9.5 & $\rightarrow$ & - \\
\hline $1+2$ & $15+9.5$ & 24.5 & 75.5 \\
\hline
\end{tabular}

In calculating the cumulative effects of rable 5.2 no account was taken of reducing the number of rings since this may bring about a severe increase in blowby losses and oil consumption which may affect the gains. In this connection it should be pointed out that the changes in face width and ring tension will likewise increase the rate of blowby, though not to the same degree as reducing the number of rings. Properly speaking, account should be taken of these negative features but, unfortunately, no quantitative data exists on the effect of blowby when face width or tension in the ring is reduced. Account of these can only be taken in reducing the expected gains from the numbers given in Table 5,2. Likewise oil viscosity is not consideren here because viscosity effects are accounted for in the section on lubricant formulation.

Finally, the crowning and chrome plating effects will also not be considered here since these have already been introduced in many production morels. We thus have from Table 5.2

\begin{tabular}{lll} 
Anount of Decrease & \multicolumn{2}{c}{ Savings, } \\
\cline { 2 - 3 } Ring width and Tension & $\frac{-25 \%}{18.4}$ & $\frac{-50 \%}{25.7}$ \\
Above Plus Skirt Changes & 36.75 & 37.2
\end{tabular}

With thuse qualifications in mind, then, Table 5.3 gives the potential gains to be expected from a redesign of the piston assembly in terms of both tha highway fleet and U.S. total energy consumption. 
TABLE 5.3. Potential Savings in Autonotive piston Assembly

\begin{tabular}{|c|c|c|c|c|c|c|c|}
\hline \multirow[b]{2}{*}{ Modification } & \multirow{2}{*}{ Amount } & \multicolumn{3}{|c|}{ Sarings in ${ }^{2}$ of } & \multicolumn{3}{|c|}{ Savings in } \\
\hline & & $\begin{array}{l}\text { piston } \\
\text { Assembly }\end{array}$ & $\begin{array}{l}\text { Highway } \\
\text { Fleet }\end{array}$ & $\begin{array}{l}\text { U.S. } \\
\text { Total } \\
\text { Energy }\end{array}$ & Btu $* 10^{-12}$ & $\begin{array}{c}\text { Barrels of } \\
\text { Petrolestm } \\
10^{-6} \\
\end{array}$ & $\begin{array}{c}\text { Milions } \\
(1984) \\
\end{array}$ \\
\hline Ring Redesign(a) & $-25(b)$ & 18.4 & 1.47 & 0.29 & 215 & 37.4 & 1.12 \\
\hline Ring and Skirt & -25 & 36.7 & 2.94 & 0.58 & 433 & 74.1 & 2.22 \\
\hline Ring Redestign & $-50(b)$ & 25.7 & 2.06 & 0.52 & 301 & 52.1 & 1.56 \\
\hline Ring and Skirt & -50 & 39.2 & 3.14 & 0.61 & 466 & 80.5 & 2.41 \\
\hline
\end{tabular}




\subsection{TRANSMISSIONS}

Since the THM-125 vehicle ${ }^{(32)}$ provides the most detailed data on the component, gains achievable in an autonatic transmission, these will be taken here to provide a model for the possible gains to be achieved in this ared. The scheme essentially entails the incorporation of the following elements:

- a drive that can be varied to provide optimum transmission-speed ratio.

- a planetary or helical gear drive

- a variable output oll pump

- adjustable oil level system.

With these changes, an improvement in efficiency as shown in Figure 4.19 can be achiever. This figure gives for an EPA cycle the following gains over a conventionel automatic transmission

$10 \%$ at $20 \mathrm{mph}$

4 at 55 moh.

Using the $55 \%$ - 45 EPA driving pattern, the average efficiency gain then arounts to $7.3 \%$. Since from figure 5.2 the drive train transmission plus axle) raquires some $15.7 \%$ of the total automotive energy consumption, we have for the potential gains the following numbers:

$\begin{array}{ll}\text { Refuction in Drive Train Energy Loss } & 7.32 \\ \text { Rejuction in Automotive Energy Use } & 1.13(0.073 \times 15.7) \\ \text { Conservation of U.S. Energy } & 0.22 \\ \text { Conservation of Btu's } & 161 \times 10^{12} \\ \text { Conservation of Barrels of Crude ail } & 27.8 \text { million } \\ \text { Savings in U.S. Dollars }(1984) & 833 \text { million. }\end{array}$




\subsection{VALYE TRALNS}

From the data of Section 4.3 we learn that the oreatest gains can be achleved by replacing sliting wh rolling element contacts. The gains brought ahout by such changes and others would be an gla total savings made up of the following components:

$\begin{array}{ll}\text { Roller Tappets } & 51 \text { savings } \\ \text { Other Rolling Elements } & 10 \% \\ \text { Reduction of Spring Loads } & \frac{20 \%}{81^{*}} \\ \text { Total } & \end{array}$

An additional 10 saving can be achieved by reducing rod and bearing sizes (F)gure 4.29$)$. These cumblative savings reduce the $3.7 \%$ loss of the value train valve to an 0.22 share of the automotive energy. The yearly savings achievable are therefore as follows:

\begin{tabular}{|c|c|}
\hline Reduction in Valve Train Energy Loss & 83 \\
\hline Reduction in Highway Fleet Energy Loss & $3.08 \%$ \\
\hline Conservation of U.S. Energy & 0.638 \\
\hline Conservation of Btus & $465 \times 10^{12}$ \\
\hline Conservation of Barrels of Crude oil & $80 \mathrm{mi} 111 \mathrm{on}$ \\
\hline avings in 1.s. Dollars 1984 j & 2.42 billion \\
\hline
\end{tabular}

\subsection{LUBRICANT FORNULATION}

Table 5.4 summartzes the numbers quoted by various investigators on the potential savings due to a lowering of oil viscosity and the adding of antifriction components. While the tests were conducted on the basis of different variations in viscosity level and quantity of polymer addition in the oll, it: seems that a comon low viscosity oil of $5 \mathrm{k} 20$ or $10 \mathrm{~W}-20$ oil was the new lubricant uted by most. It was not always possible to separate the effects of this change to low viscosity from that of the influence of the anti-friction additives; in Reference 39 it was even concluded that low viscosity per se produces no benefits, which contradicts the results of References 37 and 2 . The average improvenent anounts to a fuel saving of $5.6 \%$ of autonotive energy consumption. Subject thus to the qualification that there are serious implications to 
TABLE 5.4. Potential Savings from Lowering 011 Viscosity and Adding Anti-Friction Components

\begin{tabular}{|c|c|c|}
\hline Reference & Total Savings & Remarks \\
\hline 2 & 10,0 & $5 A E$ 10N ys $20 \mathrm{~W}-50$ \\
\hline \multirow[t]{2}{*}{37} & 3.0 & EPA cycle \\
\hline & 4.3 & cote cycle \\
\hline \multicolumn{3}{|l|}{38} \\
\hline$(31)^{(a)}$ & 4.0 & SAE $5 W \times S 20 W-20$ \\
\hline$(30)^{(a)}$ & 5.0 & SAE $5 W-20$ v $10 \mathrm{~W}-40$ \\
\hline$(34 \& 35)^{(a)}$ & 4.5 & Cold start cycle \\
\hline 39 & $5-10$ & $S A E-20$ VS SAE 30 \\
\hline Average & 5.6 & \\
\hline
\end{tabular}

(a) Numbers in parentheses refer to references auoted in peference 38 .

the use of low viscosity oils, particularly with regard to long-term wear of engine parts, we have the following savings:

$\begin{array}{ll}\text { Reduction in automotive energy consumption } & 5.60 \\ \text { conservation of U.S. energy } & 1.12 \% \\ \text { Conservation of } 8 \text { tu } & 830 \times 10^{12} \\ \text { Conservation of barrels of crude oll } & 142 \text { million } \\ \text { Savings in U.S. dollars (1984) } & 4.321 \text { billion }\end{array} \mid$ per year

\subsection{OTEERS}

The potential savings in the other tribological areas can be briefly summarized nere.

- 011 Pump - Aside from the posstble use of reduced speed pumps, the shaft mounted pump losses can be reduced by decreasing gear diameter and reducing internal pump friction. This, according to flgure 4.36 , would reduce friction by over 20k yielding for the vehicle a gain of $0.1 \%$. 
- Sraking - The solution here is to use regenerative braking to retrieve the 8.70 eneroy loss dissipated in an EPA cycle. However, a regenerative braking system requires equipment and would involve its own frictional losses. Assuming conservatively that half of the braking energy can be retrieved, the gain would stll1 be $4.35 \%$ of the total automotive energy used.

- Bearings - As described in Section 4.5, this is a complicated area and modifications are difficult to specify, in view of the severe distortions of bearing housing. Eut with a successful investigation of this area, it should be possible to reduce the losses in the bear. ings by a third, gaining 0.85 of the automotive energy.

\subsection{SUMMARY}

Table 5.5 sumarizes the potential gains to be achieved in the tribological areas of a conventional autonotive vehicle. Due to lack of quantiative data in some of the areas, some of the gains hawa been pared down to a fraction of their potential ivalve train, bearingsl. According to this sumary, then, the impact of the various modifications from the standpoint of energy conserytion, would be in the following order.

- lubricant formulation

- regenerative braking

- valve traín

- piston assembly

- bearings and oil puimp

- transmission

The total impact is some $17-1 / 2$ saving in automotive fuel consumption, or a 3-1/2x saving in the national energy consumption. In terms of the critical fuel, oil, the saving would anount to some 7.4 of the petroleum consumption per year.

If one assumes a realization of the adiabatic engine for trucks and buses which constitute 23 of the highwy fleet, one obtains, as shown in Table 3.3 , savings of the order of $1.7 \%$ in 1.5 . energy consumption. If one next assumes that the projected goals of a $30^{\mathrm{w}}$ improvement in fuel consumption for the gas 
TABLE 5.5. Sumary of Fotentlial Savings in Autumotye Tribological Losses (a)

\begin{tabular}{|c|c|c|c|c|c|c|c|c|c|}
\hline \multirow[b]{2}{*}{ ID } & \multirow[b]{2}{*}{ Component } & \multirow{2}{*}{$\begin{array}{l}\text { Eergy Con: } \\
\text { sumed: of of } \\
\text { lotal fleet } \\
\text { tonsumption }\end{array}$} & \multicolumn{3}{|c|}{ Patential saving: in erecent } & \multicolumn{3}{|c|}{ 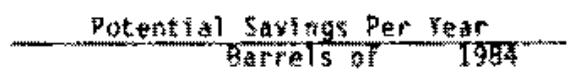 } & \multirow[b]{2}{*}{ Remarks } \\
\hline & & & Component. & $\begin{array}{l}\text { Hi ghway } \\
\text { fleet }\end{array}$ & $\begin{array}{l}\text { 1).5. Total } \\
\text { Entergy Uemand }\end{array}$ & $8 \%, 4 \times 10^{-12}$ & $\begin{array}{l}\text { Crude bil. } \\
\text { milizions }\end{array}$ & $\begin{array}{c}13.5 \\
\text { B.1110?5 }\end{array}$ & \\
\hline 1 & Piston Assenbly & 8.6 & 39.2 & 3.1 & 0.51 & 镂 & 0.5 & 2.41 & 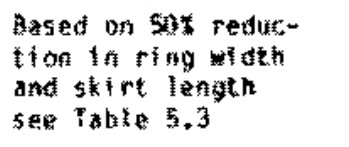 \\
\hline 2 & Ttansmitsition & 8.7 & 2.3 & 1.1 & n.22 & 植 & 27.8 & 0.83 & $\begin{array}{l}\text { Refers to convent bnal } \\
\text { system }\end{array}$ \\
\hline 3 & Vaive Iration & $3 * \frac{7}{7}$ & $B 3$ & 3.1 & 0.52 & 6 & 810 & 2.4 & \\
\hline 4 & $011 P_{\text {Uam }}$ & 2.2 & 20 & 0.44 & 0.09 & 66 & 1.0 & t. 35 & Shaft axunted pum \\
\hline 5 & Brates & 9.7 & 50 & 4.35 & 0.87 & 652 & 109.0 & 3.35 & $\begin{array}{l}\text { Use of regenerative } \\
\text { brakthg }\end{array}$ \\
\hline 5 & Reartngs & 2.9 & 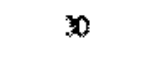 & 0.85 & 0.17 & 228 & 21.4 & ). 66 & \\
\hline 7 & Lubricant & $\cdots$ & -. & 5.6 & 1.12 & 93 & 142.0 & 4.30 & $\begin{array}{l}\text { Includes ant t-frietion } \\
\text { additilues }\end{array}$ \\
\hline & $1 \mathrm{gtan}$ & & -. & 17.5 & 3.5 & 2760 & 474 & 14.3 & \\
\hline
\end{tabular}

Sarings based on highway fleat size in 1976 , (3) and on energy cast of 330 per barrel of crude oil. 
turbine or Stirling engine on passenger cars whll become a reality, one obtains a saving of 4.4 in total U.S. Consumption, or $8.8 \%$ savings in oll demand. These and other detailed quantitative data are sumarized in Table 5.6 which shows a saving for the total highway fleet of 11-12\% in J.5. oll demand, and $5 \%$ to 6 in U.S. energy consumption.

TABLE 5.6. Sumary of Potential Savings with Non-Conventional Engines

\begin{tabular}{|c|c|c|c|c|c|c|}
\hline \multirow[b]{2}{*}{ 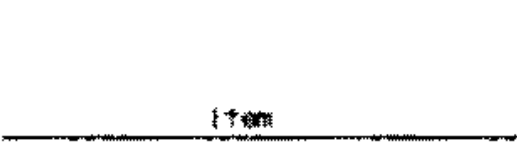 } & \multicolumn{3}{|c|}{ Sarings, 1 of } & \multicolumn{3}{|c|}{ Yearly Suvings in } \\
\hline & $\begin{array}{l}\text { HIghway } \\
\text { Floot }\end{array}$ & Tata & $\frac{\text { Demand }}{\text { Energy }}$ & 8 年彺 $10^{-12}$ & $\begin{array}{l}\text { Iy Suvings } \\
\text { crude oll } \\
\text { Mllil lons }\end{array}$ & 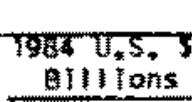 \\
\hline 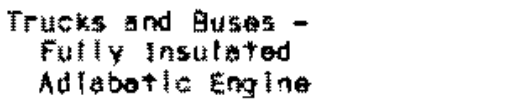 & a.s & 3.4 & 1.7 & 1,412 & 216 & 6.6 \\
\hline 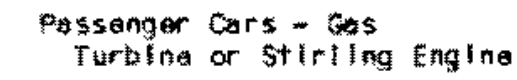 & $2 z+1$ & 8. & 4.4 & 3,65 & 350 & 17.0 \\
\hline Tota: & 30.6 & 12.3 & 6. & 5,071 & 774 & 23.6 \\
\hline
\end{tabular}




\subsection{RECOMMENDED RED PROGRAMS}

In the preceding sections, a number of areas have been noted in wich the prospects for significant energy savings in the field of automotive transportation warrant the expenditure of R\&o funds to stimulate nigher efficiency vehiches. The total potential that is envisaged is set forth in the preceding Table 5.5.

In this section, a number of projects are drafted, each of which has a direct bearing on the improved technology necessary to stimulate the desian of nigher efficiency automotive engines. While the passenger car is the dominant aser of energy in transportation, many, if not most, of the suggested prograns will also benefit the next largest transportation group, the truck fleet. where it seens appropriate, programs which may be better done within the industry because of close coupling to specific designs are narked for industry or for pooled industrial support. Still others are indicated as candidates for joint industrial-government funding.

The programs are grouped into five categories as follows:

- general autonotive data

- engines

- lubricants

- drive systems

- nonconventional engines

One nuch needed progran has been strongly suggested in the meatings neld with tha automotive industry. Because it is much more general in nature than the 5 pewific programs relating to tribology, it is discussed at this point. The EPA driving cycles, city, Country and combined, are representative of driving conditions in warmer areas of the United States such as Southern California and florida. Thus they do not take into account the inefficiencies arising frot cold starts which reduce city driving efficiency over roughly half the year in most parts of the country where many short trips are involved. Since the EPA cycle performance numbers are used as guide in the development of more efficient engine designs, it is important that the EPA cycle be broadly representative of U.S. driving conditions in order for the resultant designs to 
have a maximum impact on total U.S, energy consumption. While a program to make the EPA driving cycle broadly representative of U. S. conditions is obviously not within the scope of the Tribology Transportation R\&D Program, it may be highly desirable to recommend its need to the appropriate group in the Department of Energy.

The tribologymrelated programs recomended herein are sumarized in Table 6.1. This table provides a number of factors related to each program which will need to be considered in selecting those for inclusion in future buogeted work. These factors are:

- the type of support suggested for the program

- the potential savings, in billions of dollars per year, that would be achieved by successful completion of the program group, as estimated in Table 5.5

- the estimated RoD cost, in millions of dollars (total)

- the estimated benefit to cost ratio, including completion of the required devejopment work (see below)

- the probable number of years to market injection, and

- the overall suggested priority rating for the progran, taking account of benefits, cost and probable success, with $A$ the highest.

The benefit to cost ratio is calculated by dividing the estimated annual benefits (in dollars) by ten times the estimated total dollar cost of the research. This roughly represents the fact that developnent usually costs ten tines the research to prove feasibllity. However, it should be noted that only the annual benefits have been used. Since benefits over some peryod of years, perhaps five or ten at least, should accrue from a given efficiency development, the cited benefit-to-cost ratio is conservative by this factor.

A word needs to be said about the suggested source of sponsorship, govermment or industry. The role of government, in this case DoE ECUT, is envisaged as supporting advanced R80 work which will point the way for improvement in industrial products and thence toward nore efficient use of our 
TABLE 6.1. Summary of Recomended Research and Development

\section{prograns - Transportation Sector}

\begin{tabular}{|c|c|c|c|c|c|c|c|c|c|}
\hline itatap & 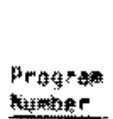 & Erous tyle & Progtat Title & Sugoested Suproer: & 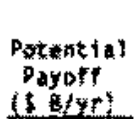 & $\begin{array}{l}\text { Est imated } \\
\text { Rug Cost } \\
\text { (\$ M) }\end{array}$ & 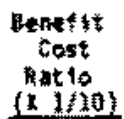 & $\begin{array}{l}\text { raboble } \\
\text { Years to } \\
\text { Markest } \\
\text { Integtion }\end{array}$ & $\begin{array}{l}\text { Prtomtity } \\
\text { class }\end{array}$ \\
\hline
\end{tabular}

$+$

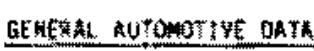

\begin{tabular}{|c|c|c|c|c|c|c|}
\hline $1+1$ & 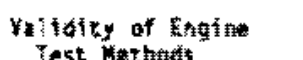 & Pooled Industrial & (n) & 15 & (a) & $\{t$ \\
\hline$\frac{5}{3-4}$ & 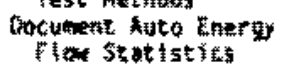 & fayernamst & $\{t$ & 0. & & \\
\hline $1+3$ & 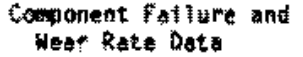 & Goverment & (a) & 0.1 & & \\
\hline
\end{tabular}

3

EMASIAES - PISTOH LSSEMAL:

$\underset{2+2}{2+2}$

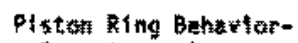 Experimental
*nalytleal model
Piston Ring Quresentic

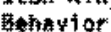
Latit Industatat-
Govergaent:
Gotermont.

corernont

2,4

1.5

$\underset{3.8}{3.8}$

95

$\star$

QNGINES - GEFRINGS

:

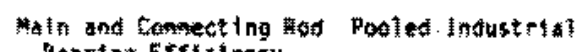

Q.66

1.5

4

$s$

草

3

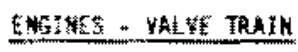

$2-5$

$$
\text { Hes of R.E. In vaive }
$$

Interstata

a

2.0

240

5

A

20

ENEINES - OLL PUAP DESIG

2-6

0.35

0.3

117

3

3

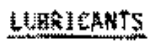

$3-1$
$3-3$

4
Finteton Reduetion रेditititio
Wear life with low Wy seosity thas
(b) Cont Hetnation ofte

Covernamentit

pooled Indutriat

Pooled Industerts

4,3

0.9

4,6

1.5

ty Coestadstinan

TRIVE 575 TEM

$4-1$
$4-2$

Franswassion
fequeneration arsing

Industridal
Joint Inatustalal-

Governomit.

$\begin{array}{ll}0.8 & 5,0 \\ 3.3 & 5,0\end{array}$

5,0
5,0

66

66

5

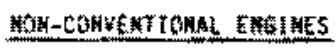

\begin{tabular}{|c|c|c|}
\hline $5+1$ & 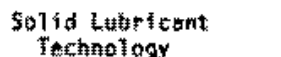 & Gevartament \\
\hline$b_{i=2}$ & 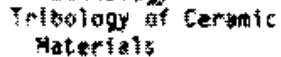 & bovernuent \\
\hline $5+3$ & 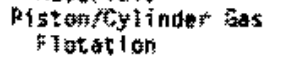 & 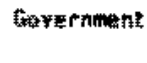 \\
\hline
\end{tabular}

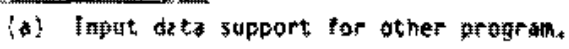


national energy resources. Many of the programs outlined in this section are of this advanced $R B D$ nature. However, others cover changes in the design of specific engine components, such as valve trains and oll pumps. In these cases, the direction of improvement toward greater energy efficiency is rather clear, and in some cases some work in the indicated direction has been published or discussed. These items also tend to be design-specific in many detaits so that they may best be carried out under industrial sponsorship by individual companies or groups of companies. Research organizations, both comnercial and academic offer a ready means to combine the resources of the companies of an industry to carry out generic development work. Finally, DoE is able to participate in such areas by the use of extensuve cost sharing under jts contracts.

On the following pages, each program is briefly described. The objective provides a brief statement of the need for the program and its specific role. The work Statement sets forth briefly the principal elements of research or development needed to achieve the objective. The Technical background refers the reader to appropriate sections of the report. 
R8O TRIBOLOGY PROGRAM--ENERGY CONSERVATION

GROup: 1--General Automotive Data

PROGRAM NUMBER: $\quad 1-1$

TITLE: Validity of Engine Test Methods

POTENTIAL PAYOFF: Input data other programs

PRIORITY CLASS: A

ESTIMATEO RESEARCH COST: 3 Years, at $\$ 5.0 \mathrm{M} / \mathrm{Yr}$

TOTAL:

$\$ 15 \mathrm{M}$

SUGGESTED SUPPORT: Pooled Industrial

\section{OSIECTIVE}

Most data on the performance and power consumption of individual components in an automotive engine is sought via tests in an engine that is "motored," i.e., driven by an external source while measurements of power input and friction forces are mate. The next stage of verification is "firing" type tests in an engine test cell under controlled conditions. The objective of this program is to extend the evaluation of changes in selected engine component designs to measurements of engine energy consumption when operated in a car under actual road conditions. From this data would be extracted a reliable frame of reference that can be used to improve the prediction of onthe-road performance from laboratory and test-cell data.

\section{WORK STATEMENT}

The program will obtain and compare experimental data from component function tests, motored tests in engines, tests in engine test cel1s, and vehicle road performance tests for a selected series of typical power consuming engine components. The progran will contain at least the following tasks:

1. Selection of a representative group of at least four engine components, such as piston rings, crankcase bearings, oit pumps, etc.

2. Component energy loss testing.

3. Motored tests, with at least two conditions of component design with significant difference in loss characteristics.

4. Engine test cell evaluations. 
5. Road performance tests under a variety of load and temperature conditions.

6. Preparation of a full tectinical report.

7. Preparation and presentation of at least one technical paper on the results to a recognized Technical society meeting.

TECHHICAL DACKGROUHD

See Section 1.0 of this report. 
RED TRIBOLOGY PROARAM-WENERGY CONSERVATION

GROUP: 1--heneral Autonotive Data

PROGRAM NIIHER: $1-2$

TITL: Bocument Auto Energy Flow Statistics

POTENTIAL PAYOFF: input data other programs

PRIORITY CLASS: A

ESTIMATED RESEARCH COST: 1 Year, at 30.1 M/YT TOTAL:

SIGGESTEn SUPPORT: Government

DOSECTIVE

In arder to provide a sound basts for measuring the energy savings potential for specific improvements that would result from tribological advances, it is desirahle that more detalled information on individual components of the englne, transmission and chassis he deternined and be avallabla. The objective of this progran is to deternine the fine structure of the energy flow tree for automotive vehicles.

WORK STATEMENT

The program shall comprise a thorough andysis of all avallable sources of energy loss data. Visits to key sources for additional information, and publication in a "source book" zype of report. The following tasks shall be carried out:

1. A thorough search of the world literature relative to energy losses in automotive components, specifically engine, chassis, and transmisston components, shall be conducted covering the most recent tenyear period. Searchbacks to earlier infornation shall be conducted *henever appropriate from the more recent references.

2. Wherever possible, losses shall he classified according to the car size class to which they apply, for example, sub-compact, compact. mit-size; and front wheel versus rear wheel drive.

3. The data for indluidual components and groups of components shall be collated together with a sumary of the probable value of the loss, 
the range reported in the literature, and the probable error in the single most likely value.

4. An AUTOMOTIVE ENERGY LOS5 SOURCE BOOK shall be prepared which shall contain the interpreted dat, the references used, and a narrative discusston of the information and ts interpretation.

TECHNICAL BACKGROUND

See Section 1.0 of this report. 
RAD TREBOLOCY PROGRAM- ENERGY CONSERVATION

Goutp: 1-meneral Autonotive nata

PROGRAH NUHEER: $\quad 1-3$

TITLE: Component Failure and hear Rate Data for the Automotive Vehicle

POTENTIAL PAYOFF: Input tata other prograns PRIOETTY CLASS: R

ESTIMATEN RESFARCH COST: 1 Year, at SO.1 M/Yr TOTAL:

SHGGESTEN SIPPORT: Tovernment

OSUECTIVE

The scrapping of worn out or obsolete vehicles and the replacement of inividual parts in vehicle maintenance represents a direct eneryy loss in terms of the energy required to manufacture the replacement parts or vehicles. The ohjective of this program is to conduct a statistical study of the rates of wear and fallure of various automotive components and of vehicles themselves in order to provide a sound basis for assessing the energy-saving benefits of increasiog life through tetter tribological engineering.

WORK STATEMENT

The program shall obtain failure rate data on the key atomotive engine, transmission and thassis components in order to prepare a statistical evaluation of the replacement costs of wear and fallure. The specific tasks are as follows:

1. Secth the literature and other direct and indirect sources for data on auto parts replacement, and new vehicle production.

2. Analyze the data in terms of the manufacturing year of the vehicle, the number of each replacenent component used, and the projected wear history per million cars manufactured.

3. Fs"imate the sensitivity of each component to the level of tribological engineering applied, and to the opportunity for imanowement. 
4. Prepare a detalled report sumarizing the data and its sources, its interpretation in terms of opportunity for improvement, the potential energy-saving value of the improvenent, and the resulting change in the repair energy cost per million vehicles produced.

TECHNICAL BACKGROUND

See Section 1.0 of this report. 
REO TRIBOLOGY PROGRAM--ENERGY CONSERVATION

RRAuP: 2A-mugines-mpiston Assembly

PROGRAM NUMBER: $2-1$

TITLE: 2fston Ring Behavior-mexperimental

DITEN?A. PAYOFF: Part of $\$ 2.4 \mathrm{~B} / 4 \mathrm{r}$

PRIORITY CLASS: A

ESTIMATEJ RESEARCH COST: 3 Years, at $\$ 0.5 \mathrm{M} / \mathrm{Yr}$

TOTAL:

$\$ 1.5 \mathrm{~N}$

SUGGESTED SUPPORT: Joint Industrial Government

QBJECTIVE

Friction in the piston ring/cylinder interfaces is perhaps the predominant energy loss factor in an engine. Experimental techniques for measuring the detalled behavior of a ring during actual operation can provide key information for improving the design while simplifying and reducing the number of rings. The objective of this program is to develop techniques for accurate measurement of local ring filn thicknesses, pressures, temperatures, gas leakage (blowby), deflections and starvation; and to use this information for studies of rings in their operational mode.

WORK STATEMENT

This progran shall develop advanced techniques for the measurement of piston ring operating parameters whlle in use in fired engines, and shall use these techniques for a broad initial exploration of the details of ring operatixn. The following tasks are to be carried out:

1. Conduct a IIterature study to establish the experimental technigues already developed, and to determine their strong and weak points.

2. Develop advanced techniques for the measurement of 1 ) film thickness and fill shape under a ring; 2$)$ filln pressures; 3$)$ temperatures; 4) circumferential ring deflection; 5) starvation and gas blowby. Th's shall include design and fabrication of a feasibllity test rig and feasibillty tests. 
3. Design and build a one-cylinder (or more) test device which can be used for both motored and fired testing of rings over the entire length of stroke.

4. Use the ring test device to conduct a study of typical ring performance over a range of speeds and cylinder pressures. The testing shall include evaluations of compression rings, ail rings and scrapers.

5. Prepare annual reports providing full details on the measurement technioues, designs, and ring tests. Prepare appropriate technica? papers covering the key advances and results.

TECHNICAL BACKGROUND

See Sections $2.2,4.1,5.1$ of this report. 
RRO TRIBOLOGY PROGRAM--ENERGY CONSERYATION

GRoup: $2 A--$ Engines--Piston ssembly

PROGRAM MLMBER: $2-2$

TITLE: Analytical Model of Piston Ring/Cylinder Contacts

POEENTIAL PAYOFF: Part of $\$ 2.40 / 4 r$

PRIORITY CLASS: B

ESTIMATEE RESEARCH COST: 3 Years, at $\$ 0.3 \mathrm{M} / \mathrm{Yr}$ TOTAL: $\$ 0.9 \mathrm{M}$

SHGGESTEO SUPPORT: Government

\section{OBOECTUE}

Friction losses in the piston ring/cylinder interfaces represent the major source of mechanical losses in the engine. If ring behavior can be better understood, these losses may be reduced significantly through better design for lower ring friction or through reducing the number of rings. The objective of this program is to prepare as complete a mechanical/hydrodynamic model of ring behavior as possible, and to make posstble reliable analysis of groups of rings.

WORK STATEMENT

This program shall develop a complete ring package analytical model and compare it with avallable experimental data, e.g., from program $z-1$. The principal program tasks are as follows:

1. Determine the current state-of the-art on analytical plston ring models both in the USA and abroad. Based on this, lay out a detailed plan for further analytical development, taking advantage of modern computer capability.

2. Collect and collate the best avallable experimental information on ring behavior, and use as a guide to the verification of the analytical assumptions and results.

3. Construct the analytical model, and prepare one or more computer proarans to make them vable. 
4. Test the computer models against available experimental information, and revise as necessary.

5. Prepare a complete report. covering the mathematical analysis and recording the computer cotes developed. Prepare technical papers presenting the work and the findings.

TECHHICAL PACKGROLNO

See Sections $2.2,4.1,5.1$ of this report. 
GROUP: 2A--Engines--Piston Assembiy

PROGRAM NUMBER: $2-3$

--ITLE: Piston Ring Parametric Behavior

POTENTIAL PAYOFF: Part of $\$ 2.4 \mathrm{~B} / \mathrm{Yr}$

PRIORITY CLASS: A

ESTIMATED RESEARCH COST: 2 Years, at $\$ 0.4 \mathrm{M} / \mathrm{Yr}$

TOTAL:

$\$ 0.8 \mathrm{M}$

SUGGESTED SUPPORT: Government

$\underline{\text { OBJECT IVE }}$

There is extensive evidence that the details of the design of a piston ring have a dominant influence on its performance as evidenced by overall engine performance measurements. The objective of this program is to use the experimental capability developed under program 2-1 to measure the effect of ring des an parameters on ring performance. In addition to such performance parameters as drag force, film thickness and oil flow past the ring, it is desired to determine the influence of design on gas blowby.

\section{WORK STA EMENT}

Work: under this program shall be conducted via the following tasks:

1. Prepare a detailed test program that will evaluate the performance inf uence of ring width, ring tension, ring cylindrical conformity, shape of crown profile, ring surface material and cylinder material on ring friction, oil flow and blowby.

2. Carry out the test program over a range of speeds and cylinder pressures typical of automotive engine operation.

3. Analyze the results, and conduct further tests that may be indicated.

4. Prepare a detailed report and technical papers describing the results and their potential application.

\section{TECHNICAL. BACKGROUND}

See Sections $2.2,4.1,5.1$ of this report. 
R\&D TRIBOLOGY PROGRAM--ENERGY CONSERVATION

GROUP: $\quad 2 B--$ Engines--Bearings

PROGRAM NUMBER: $2-4$

TITLE: Main and Connecting Rod Bearing Efficiency

POTENTIAL PAYOFF: $\$ D .66 \mathrm{~B} / \mathrm{Yr}$

PRIORITY CLASS: $\quad \mathrm{C}$

ESTIMATED RESEARCH COST: 3 Years, at $\$ 0.5 \mathrm{M} / \mathrm{Yr}$

TOTAL:

$\$ 1.5 \mathrm{M}$

SUGGESTED SUPPORT: POoled Industrial

OBJECTIVE

The main and connecting rod bearings in an engine represent a highly developed component. Nevertheless, the energy consumed in the bearings is substantial and an appreciable reduction in bearing losses seems possible. A better understanding of the influence of housing distortion, cavitation and oil feed design could make possible reductions in viscous losses while carrying the heavy time-varying loads. The objective of this program is to study this area both experimentally and analytically with an eye to the possibilities for more efficient designs.

\section{WORK STATEMENT}

Work under this program shall be conducted via the following tasks:

1. Prepare a computer code capable of accounting for the influence of housing distortion under heavy load on operating bearing film thickness. The code shall also handle cavitation conditions and predict the film boundaries resulting from any specified inlet oil configuration.

2. Design and build a test rig capable of testing an engine bearing under simulated load and speed conditions, and capable of measuring film thicknesses, temperatures and bearing torque, and with the capability of direct visual observation of unfilled zones.

3. Prepare and conduct a test program to explore the key design variables and their influence on bearing power loss and minimum operating film thickness. 
4. Analyze the data and compare it with the analytical predictions.

5. Prepare complete report including recomendations for design direction leading to lower loss bearings.

IECHWICAL BACKGROUND

See sections $2.2,4.5$ of this report. 
RED TRIBOLOGY PROGRAM--ENERGY CONSERVATION

GROUP: 2C--Engines-valve Train

PROGRAM NUMBER: $2-5$

TITLE: Use of Rolling Elements in Valve Trains

POTENTIAL PAYOFF: $\$ 2.4 \mathrm{~B} / \mathrm{Yr}$

PRIORITY CLASS: A

ESTIMATED RESEARCH COST: 2 Years, at $\$ 0.5 \mathrm{M} / \mathrm{Yr}$ TOTAL: $\$ 1.0 \mathrm{H}$

SUGGESTED SUPPORT: Industrial

OBUECTIVE

Some development work has already shown the feastbility of using rolling elenent bearings in cam followers and fulcrums of valve trains as a means of reducing the friction energy losses in them. This design approach will also remove the problem in these contact areas with the use of the low viscosity engine oils. The objective of this program is to carry out development work on this section of the engine and to life test engines modified in this way to encourage the use of rolling element valve trains in production engines.

WOPK STATEMENT

This program shall develop a valve train design using rolling element support at key points such as the can follower, the fulcrum and the lifter/rocker arm contacts, in order to reduce the frictional energy losses in the valve traln. The following tasks shall be carried out:

1. Select typical nid-size or compact size auto engine using an Lmead design; and another using an overhead cam design.

2. Design a rolling element version for each.

3. Fabricate and install in a test rig for friction measurements.

4. Install in the engine and measure before and after efficiency on a test bed.

5. Prepare a full report, plus aporopriate technical papers afmed at engine designers. 
TECHNICAL. BACKGROUND

See Sections $2.2,4.3,5.3$ of this report. 
R\&D TRIBOLOGY PROGRAM--ENERGY CONSERVATION

GROUP: 2D--Engine--0il Pump Design

PROGRAM NUMBER: $2-6$

TITLE: Variable Delivery oil Pump

POTENTIAL PAYOFF: $\$ 0.35 \mathrm{~B} / \mathrm{Yr}$

PRIORITY CLASS: B

ESTIMATED RESEARCH COST: 1 Year, at $\$ 0.3 \mathrm{M} / \mathrm{Yr}$

TOTAL :

$\$ 0.3 M$

SUGGESTED SUPPORT: Industrial

OBJECTIVE

The standard oil pump normally used in automotive engines delivers oil at a flow rate proportional to engine speed. As a result, when sized to deliver an adequate amount at idle, it delivers too much at higher speeds. The excess is dumped back to the crankcase by a pressure control valve, and the pumping energy is wasted. The objective of this program is to develop a variable delivery rate pump and control which will adjust the delivery rate to the ençine requirements.

WORK STATEMENT

Work under this program shall be conducted via the following tasks:

1. Prepare two or more conceptual approaches to oil pump flow control.

2. Select the best two and prepare designs for pump and control.

3. Construct and test the selected designs.

4. Prepare a report with recommendations for efficient manufacture while retaining reliability.

TECHNICAL BACKGROUND

See Sections $2.2,4.4,5.5$ of this report. 
R\&D TRIPOLOGY PROGRAM-ENERGY CONSERVATION

GROUP: 3-Lubricants

PROGRAM NUMBER: $3-1$

TITLE: Friction Reduction Additives

POTENT:AL PAYOFI: Part of $\$ 4.3 \mathrm{~B} / \mathrm{Yr}$

PRIORITY CLASS: A

ESTMATED RESEARCH COST: 3 YearS, at \$0.3 $\mathrm{M} / \mathrm{Yr}$ TOTAL: $\$ 0.9 \mathrm{M}$

SUGGESTED SUPPORT: Government

DQUESTIVE

The emphasis in the long history of the development of boundary lubricant additues for hydrocarbon, ester and other oils has been placed on the creation of sulid surface layers which will mitigate surface damage of the contacting surfaces. The current interest in increasing the efficiency of automotive vehicles has brought out the energy-saving value that will attach to the use of lubricant additives wich wil reduce the friction coefficient in the contact zone. The objective of this program is to find or synthesize additive compounds which will reduce the friction coefficient fo normal temperature heavily loaded contacts.

WORK STATEMENT

This program shall be directed toward the search for ininimum friction additives for hydrocarbon and related olls that may be used in low viscosity crankcase service, and to characterization of their friction properties as a function of surface composition, texture, and roughness, and of sliding speed, load and contact geometry. The following tasks shall be accomplished:

1. From a literature search, identify compounds reported to have exceptional friction reduction capability. Correlate by cherpical structure or active group. Determine nost promising active groups to be nuestigated.

2. obtin candidate compounds. If not available, obtain by synthesis or by extraction from cride sources. 
3. Measure friction coefficient as a function of percent additive, load, sliding speed and surface composition for each selected compound.

4. Analyze and correlate the data.

5. Prepare detailed reports and technical papers presenting the information for wse by lubricant formulators.

TECHNTCAL BACKGROUND

See Sections $2.2,4.7,5.4$ of this report. 


\section{RRO TRIBOLOGY PROGRAM--ENERGY CONSERVATION}

GROUP: 3-Lubricants

PROGRAM NUMBER: $3-2$

TITLE: Wear Life With Low-Viscosity dils

POTENTIAL PAYOFF: Part of $\$ 4.3 \mathrm{~B} / \mathrm{Yr}$

PRIORITY CLASS: A

ESTIMATED RESEARCH COST: 2 Years, at $\$ 2.0 \mathrm{M} / \mathrm{Yr}$ TOTAL: $\$ 4.0 \mathrm{M}$

SUGGESTED SUPPORT; POOled Industrial

QBJECTIVE

Low viscosity engine oils, of the $5 \mathrm{~W}-\mathrm{X}$ type, have been shown to contribute significantly to increased gasoline mileage, particularly during warm-up and the city cycle type of drivina. Because wear-out is an indirect but important energy expenditure, there is a need to determine the extent of any increased wear resulting from the use of such oils over a long term, such as 50,000 to 100,000 miles, in key areas such as pistontcylinder, valve train, and crankcase and piston-pin bearings. The objective of this program is to conduct long-tenm fleet tests to determine the long-term wear behavior of the low-viscosity ails.

\section{WORK STATEMENT}

This program shall be directed toward the determination, in long-term fleet driving tests, of the wear performance of one or more typical lowviscosity engine oils compared to that of "nomal" $10 \mathrm{~W} 40$ engine oils. The following tasks shall be carried out:

1. Dewermine the fleet size necessary to achleve statistically significant results. Select the engines and vehicles to be studied and establish the performance profiles to be used.

2. Conduct the fleet tests. Measure and record oll consumption and other maintenance required. Determine wear products in drained oil at each oil change.

3. Tear down the engines and measure the wear of engine bearings, niston/cylinder surfaces, oil rings, and valve train components. 
4. Prepare a complete analysis of the results including the statistical significance and prepare a complete report and technical papers for presentation.

TECHNICAL BACKGROUND

See Sections $2.2,4.7,4.7 .5,4.7 .6,5.4$ of this report. 
RRD TRIBOLOGY PROGRAM--ENERGY CONSERVATION

GROUP: 3-Lubricants

TITLE: Dil Contamination and Degradation
PROGRAM NUMBER: $3-3$

PRIORITY CLASS: $\quad$ C

TOTAL: $\$ 1.5 \mathrm{M}$

SUGGESTED SUPPORT: Pooled Industrial

\section{OBJECTIVE}

Low-viscosity oil formulations using polymers to maintain high tenperature viscosity and additional additives to assist in boundary lubrication, coupled with the desire to reduce the number of rings to reduce friction loss, are increasing the probability of increased blowby into the crankcase and increased contamination of the crankcase oil. Deterioration of the oil and depletion of its additive package from this process before the normal change period can impact regatively on the total wear life of the engine. The objective of this program is to adjust oil formulations to minimize these effects.

\section{WORK STHTEMENT}

This program shall be directed toward the determination of oil formulation practices and additive packages which will extend oll life to greater than 10,000 miles in normal service in low friction-designed engines. The following tasks shall be carried out:

1. In cooperation with an automobile manufacturer, select a test engine model which employs or is modified to employ a low-friction piston ring package.

2. Plat a test procedure, including the number of engines to be tested, which will subject the engine to typical vehicle life usage and which wil provide statistically significant results.

3. Contuct engine tests, as per Task 2, on one or more current oil formulations. 
4. Prepare revised oil formulations that may exhibit longer crackcase life and conduct engine tests per Task 2 .

5. Andyze the engine life data with respect to the oil formulations, and determine the formulation principles conducive to extended bil life in low-friction engines.

6. Prepare a full report, and write technical paper(s) outlining the results.

TEOHWICAL BACKGROUND

See Sections $2.2,4.7,5.4$ of this report. 


\section{R\&D TRIBOLOGY PROGRAM- -ENERGY CONSERVATION}

GROLP: 4-Drive Systern

TITLE: Transmission

POTENTIAL PAYOFF; $\quad \$ 0.9 \mathrm{~B} / \mathrm{Yr}$

ESTIMATED RFSEARCH COST: 3 Years, at $\$ 1.0 \mathrm{M} / \mathrm{Yr}$

SUGESTHD SUPPORT: IndUStrial
PROGRAM NUMBER: $\quad 4-1$

PRIORITY CLASS: B

TOTAL: $\quad \$ 3.0 \mathrm{M}$

OEDECTIV

As the automatic transmission has reached acceptance worldwide as the preferred method of speed control, much attention has been given to means for increasing its efficlency. Even more, the matching of the transmission ratio to the bptimum engine speed over the speed and power range has been recognized as a means of gaining effictency beyond the improvements possible by optimizing the transmission efficiency alone. The objective of this progran area is to encouracte the continuation of work on the automatic transmission efficiency, e. 9., a fourth speed, and torque converter lockout; and on CVT embodiments as a means of better matching of engine to wheel load.

\section{TECHNICAL BACKGROUND}

See Sections $4.2,5.2$ of this report. 
RED TRIBDLOGY PROGRAM--ENERGY CONSERVAYION

Geve: 4--orive systenm-Braking

PROGRAN NUWBER: $4-2$

TITLE: Regenerative Braking

POTENTLAL PAYOFF: $\$ 3.3 \mathrm{~B} / \mathrm{Yr}$

PRIORITY CLASS: A

ESTIMATED RESEARCH COST: 7 Years, at * M/Yr

TOTAL:

$\$ 5.0 \mathrm{M}$

* First year $0.15 \mathrm{M}$

SUGCESEO SUPPORT: woint Industrial-Government

OBSECTIUE

one of the major untapped sources of energy loss in autombiles is the energy transfer to heat in the braking process. The greatest portion of this loss occurs during the city driving phase which in turn represents nearly half of the total driving mileage. The elinination of a major portion of this frictional energy process through the use of regenerative braking is the abjectuve of this program.

WORK STATEHENT

This programi is concerned with an examination of various techniques for converting venicle translational energy into a form of stored potential energy and of using the stored energy to supplement the prime motive power. As a thiti-year program, the principal tasks are as follows:

1. Review the literature on regenerative braking, conceive additional possible systems, and rate the systens as to the amount of additional equipment required and its cost and weight, and as to the losses in the regenerative system itself. Prepare a recommendation on the system or systems showing the gratest promise for ultimate application in terms of benefits and cost.

2. For the one or two most promising systems, carry out a canceptual destan study; and evaluate the system in terms of its cost in large audity manufacture, its probable reliabilicy, and its benefits in terms of energy savings via increased fuel mi leage. 
3. For the most promising system, design, build and test a model of the system. Install the mode in a compact and/or mid-size car and evaluate its road performance.

4. Install and test the system in a fleet of cars $(20)$, and evaluate the regenerative braking system performance over a car life of 50,000 niles as to benefits and maintenance history.

\section{TECHNICAL BACKRROUND}

See section 4.6 of this report. 


\section{RBD TRIBOLOGY PROGRAM-DNERGY CONSERVATION}

GROUP: 5 -Nonconventional Engines

PROGRAM NUMBER: $5-1$

T1TE: Solid Lubricant Technology

POTENTIAL PAYOFF: Part of $\$ 23 \mathrm{~B} / \mathrm{Yr}$

PRIORITY CLASS: A

ESTIMATED RESEAPCH COST: 5 Years, at $\$ 0.4 \mathrm{M} / \mathrm{Yr}$ TOTAL: $\$ 2.0 \mathrm{M}$

SUGGESTEP SUPpoRT: Government

OBUECTIE

Advances in the efficiency of automotive engines, particularly in the case of nonconventional engines, depends on operating components at much higher temperatures. This is required to raise the basic cycle carnot efficiency as in the case of the gas turbine and the stirling engine, or to reduce hightemperature heat flow to colling systems with concomitant higher local tenperatures as in the case of the adiabatic diesel. The objective of this program is to extend the technology of solid lubrication and solid lubricant replenishment so that it can be applied successfully in long life, hightemperature engines.

\section{WOUK STATEMENT}

The program shall extend the technology of solid lubrication in the fundanental areas of adhesion, friction, wear rate, replenishent, material composition, and surface texture effects. Individual programs shall address one or more of the following tasks:

1. Deternine the friction and wear rate behavior of a series of comon and new solid lubricants as a function of temperature $1100^{\circ} \mathrm{F}$ to $\left.1500^{\circ} \mathrm{F}\right)$, load, sliding velocity, and continuous or reciprocating stiding.

2. Develop the techniaues of lubricant replenishment including powder delivery, "stick" lubrication, and vapor delivery. 
3. Develop solid lubricant compositions which will adhere to metal and/or ceramic surfaces, but which will not build up layers of excessive thickness on the component surface.

4. With selected solid luturant compositions, determine the role of the strface material to which it is applied and the role of surface roughess and texture to long-term servicability.

5. Prepare detailed reports and technical papers making the results avallable to component and engine developers.

ECHNICAL BACKGROUND

See Sections $3,4.1,4.3,5.5$ of this report. 
GROUP: 5--konconventional Engines

PROGRAM NUMBER: $5-3$

TITLE: Piston/cylinder Gas Flotation

POTENTIAL PAVOFF: Part of $\$ 2.3$ BIPr

PRTORITY CLASS: 8

ESTIMATEO RESEARCH COST: 3 Years, at $\$ 0.3 \mathrm{M} / \mathrm{YP}$ TOTAL: $\$ 0.9 \mathrm{M}$

SUGGESTEO SUPPORT: GOVEmment

QP.]EGTIVE

The adsabatic cylinder concept, in its highly insulated embodiment, must operate at high temperatures in the absence of conventional liquid lubrication. Because of the high side loads in conventional crank-type englne, even the successful use of low wear rate ceramic or solid-lubricated surfaces will negate much of the increased efficiency gain because of firictional work losses. One approach is to design for a gas film to be formed between the piston skirt and the cylinder. A complex split-ring seal is culrently under contract research. The objective of this program is to concelve and test simple designs which may be more practical to introduce into production engaties.

WORK STATEMENT

The work under this program shall be condicted via the following tasks:

1. Prepare two or more conceptual approaches employing either squeeze film hydrodynanics or hydrostatic principles with an external air supply for the flotation of pistons in cylinders.

2. Evaluate these concepts against practical engine considerations of production capability and economics.

3. Prepare a test rig or test engine for evaluating the two best concepts, including the capability of direct measurement of piston/cylinder frictional work. 
4. Conduct tests on the performance of the selected concepts, including evaluation of the extent and location of contact between the two bodies, and of frictional work.

5. Prepare a detajled report, and a technical paper describing the concepts and the test results.

PECHNICAL BACKGROUND

Sete Sections $3,4,1,4,3,5.5$ of this report. 

PART II

ELECTRIC UTILITIES 


\subsection{POHER PLANT STATISTICS}

in parallel with the data complled for the automotive field, some basic statistics for the electric utilities will prepare the ground for an evaluation of the possible improvements to be expected from tribological progress. The data will be confined primarily to the utilities ${ }^{1}$ power plants and wili concern itself with the following: the kind of equipment and fuels employed; the effim ciency and reliability of the facilities which bear directly or indirectly on the letels of energy consumed by this economic sector; and fanally with the major sinks and problems areas that account for the bulk of discarded energy and plant downtime.

\subsection{THE ELEGTRIC UTMLITIES AND ENERGY}

The total generating capacity of the electric utilities in the USA is given in figure 7.1. Table 7.1 shows the levels of energy demanded and the share of the total 4.5 . energy consumption that these levels represent. classified by the kind of fuel the uttlities use for the production of electristy, we have the data given in Table 7.2. Thus the slice of energy resources taken by the electric utilities is on the rise and is soon to amount to half of the total energy consumption. Half of that energy will be in the form of coal. Thus, the utilities equipment of the future will have to be such as to be able to handle and convert large quantities of coal and coal products.

\subsection{EOLIPMENT USEO BY UTILUTIES}

The equipment used by the utilities in terms of both kind and size is given in Tables 7.3 and 7.4 . As seen, Targe strean turbines constitute the main prine movers. This trend, i.e., the predominance of steam turbines, often in sizes abova the 1000 lut range, has conthued into the 80 . During 1981, of 2,2000 utility systems only 514 operated diesel units and a mere 77 employed zas turbines for a combined capacity of 8,000 Wh, and these operated at a reduced load factor due to high fuet cost and low avaliability. This represents less than 1.5 of the installed capacity of the utilities power plants. 


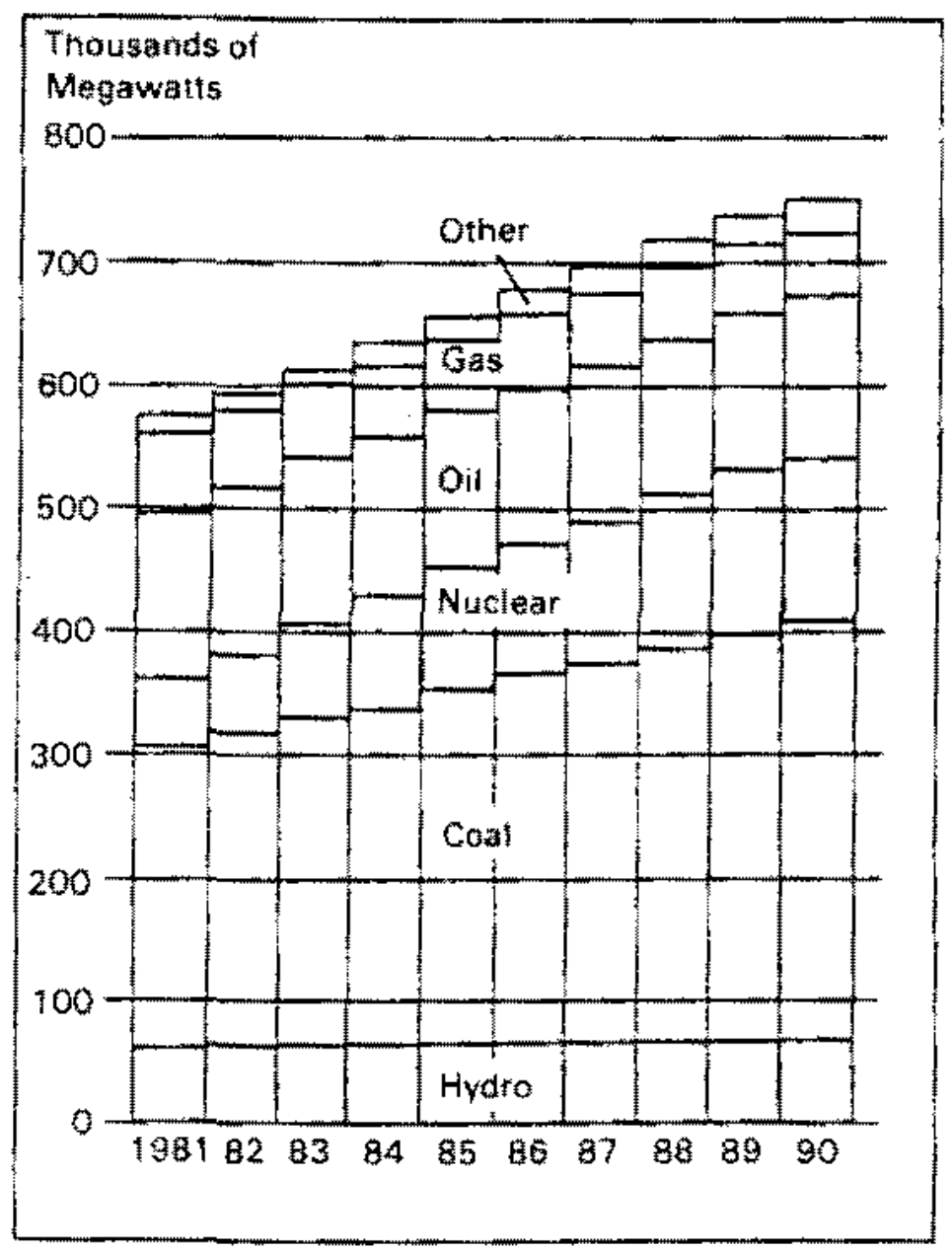

EIGURE 7.1. Installed USA Generating Capability by principal Fuel Types (4L)

TABLE 7.1. Energy Consumed by Electric Utilities, $10^{15}$ Btul(2)

\begin{tabular}{lccc} 
Year & Total U.5. & Utitities & $\frac{\text { of Total }}{1970}$ \\
\cline { 2 - 3 } & 68.3 & 15.1 & 22 \\
1975 & 71.1 & 20.0 & 28 \\
$1990(a)$ & 133.4 & 49.6 & 37
\end{tabular}

(a) Prajected.

The range of auxiliary equipment in a modern large size power plant is enomious. These auxiliaries can be broken down into three subgroups as shown in Figure 7.2 , whlle a more detailed listing of the equipment required in an 900 Wh facility is given in Table 7.5 by way of illustration. As seen, that 
TABLE7.2. Kind of Fuel Used by the Utilities, of Total ${ }^{(42)}$

\begin{tabular}{|c|c|c|c|c|c|}
\hline & $\operatorname{coa} 1$ & $0 i\}$ & $\begin{array}{c}\text { Hatural } \\
\text { Gas }\end{array}$ & Nuclear & Hydro \\
\hline 1963 & 54 & $6 \%$ & $22 \%$ & 0 篓 & $18 \%$ \\
\hline 1969 & 52 & 8 & 23 & 1 & 17 \\
\hline 1973 & 46 & 17 & 18 & 4 & 15 \\
\hline 1978 & 44 & 17 & 14 & 13 & 13 \\
\hline $1983^{(a)}$ & 55 & 6 & 12 & 13 & 14 \\
\hline $1985^{\{b}$ & 54 & 11 & 8 & 15 & 12 \\
\hline $1990^{(\mathrm{b})}$ & 53 & 9 & 8 & 19 & 11 \\
\hline
\end{tabular}

(a) Estinate.

(b) Projections as of April 1983.

TABLE 7.3. Equipment Used by U.5. Utilities $(2)$

\begin{tabular}{|c|c|c|}
\hline Kind of Prime Mover & $\begin{array}{c}\text { of } \\
\text { Capacity } \\
1973\end{array}$ & $\begin{array}{c}\text { Power } \\
\text { Generation } \\
1976\end{array}$ \\
\hline Stean Turbines & 77.5 & 83.0 \\
\hline Gas Turbines & 7.5 & 1.2 \\
\hline Hydro Power & 14.7 & 15.5 \\
\hline Diesel Units & 0.3 & 0.3 \\
\hline Total & 100.0 & 100.0 \\
\hline
\end{tabular}

TABLE 7.4. Size of New Units Installed in 1973(2)

\begin{tabular}{|c|c|c|}
\hline ize, Megawates & Capacity, Gigawatts & Total \\
\hline Below 100 & 0.13 & 0.2 \\
\hline $100=200$ & 0.42 & 0.8 \\
\hline $200-500$ & 5.19 & 14.0 \\
\hline Above 500 & 31.27 & 85.0 \\
\hline Total & 37.0 & 100.0 \\
\hline
\end{tabular}




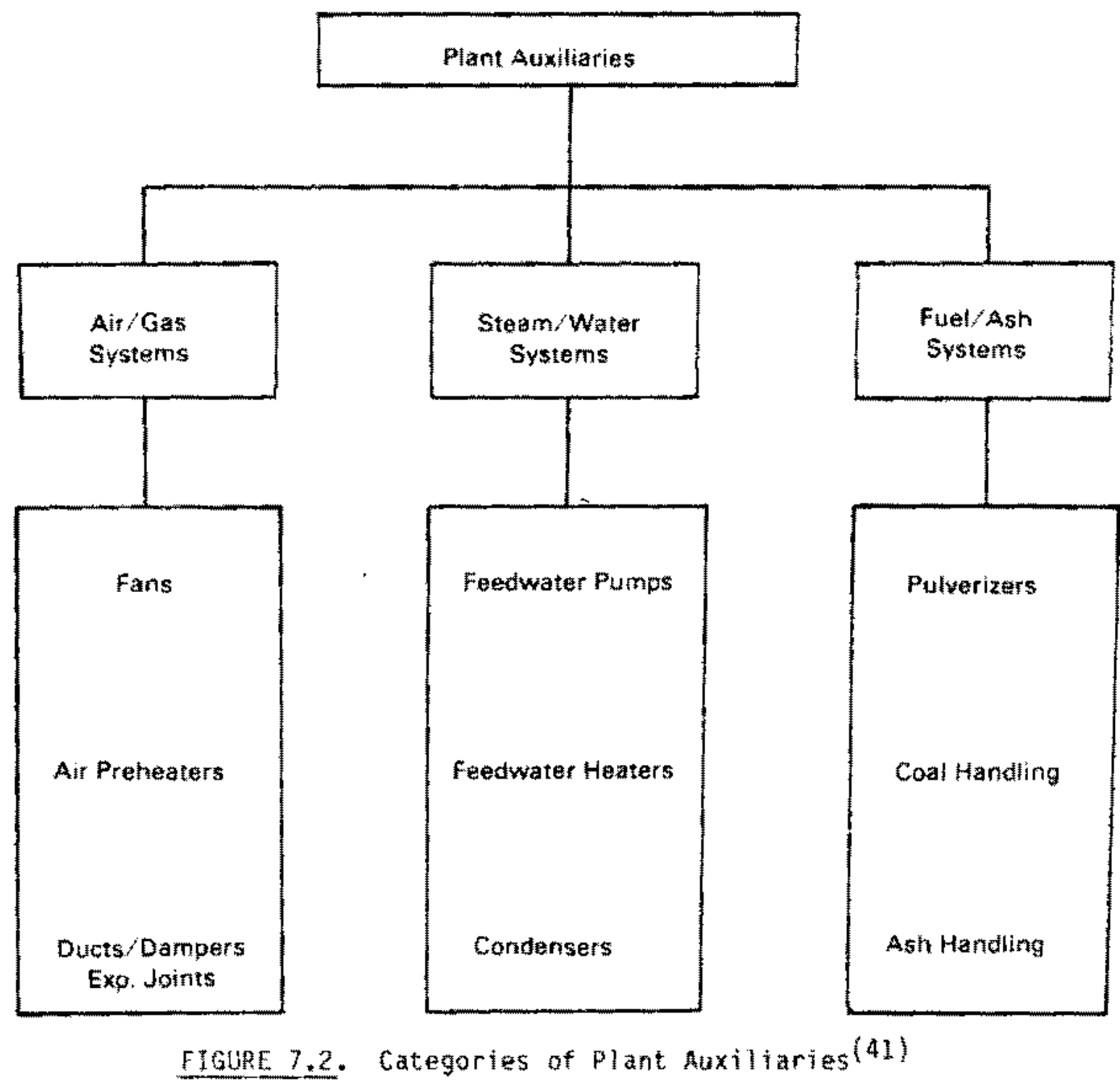

equipment uses over 7 of the power generated by the facllity; worse, by having reliability problems, the equipment often causes vutages of power whose cost and losses exceed by far the drect expendicures of operating this equipment, a subject discussed more fully in the next section.

\subsection{EFFICIENCY AND REL IABLLIVY}

When discussing atumotive vehicles, it was sufficlent to discuss component performance to obtain a picture of energy lost in various forms of mechanical inefficiefcy or other parasitic energy sinks. However, while efficiency 
IABLE 7.5. Typical Auxiliary Equiment in a 800 MW Coal-Fired Electric Utility

Equipment

Circulating water Pumps

Cooling Tower Fans

Induced Oraft fans

Forced Draft Fans

Primary Air Fans

Dulverizars

Cooling Tower Make-up Pumps

Condensate Pumps

foiler Mise. Pumps

Cooling kater Pump

Service and Instrument Air Compressor

soot Rlower Air Compressor

Coal Feeders

Air Condtitining system

Exhaust Fans

Srecipitator systerl

oal Handing System

Sottom Ash Handling System

it Scrubber \$ystem

I vel 0 il Supply Pump

Fuel 0il Transfer Punp

racuum Pump
No. 1

No. 2

No. 1 to

No. 30

No. 1

No. 2

No. 3

No. 4

No. 1

No. 2

No. 1

Ho. 2

No. 1 to

No. 8

No. 1

No. 2

No. 1

No. 2

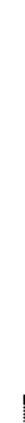

No. 1 to

No. 20
Percent

of Unit.

$\frac{\text { Input Power }}{2,700 \mathrm{kw}}$

Load

$0.78 \%$

$0.78 \%$

$0.009 \%$

$0.17 \%$

$0.22 \%$

$0.22 \%$

$0.22 \%$

$0.22 \%$

$1,750 \mathrm{kr}$

$0.26 \%$

$0.26 \%$

$2,000 \mathrm{~kW}$

$0.13 \%$

$0.13 \%$

$1,000 \mathrm{~kW}$

$0.058 \%$

$0.45 \%$

$3,600 \mathrm{~kW}($ total)

0.18

$0.1 \%$

$800 \mathrm{~kW}$

0.898

$700 \mathrm{~kW}$

$700 \mathrm{~kW}$

$0.088 \%$

$200 \mathrm{~kW}$

$0.025 \%$

$400 \mathrm{~kW}$

$0.05 \%$

$400 \mathrm{~kW}$

$0.05 \%$

4,000 k k

$0.5 \%$

$50 \mathrm{kw}$

$0.006 \%$

$100 \mathrm{kN}$

$0.013 \%$

$5 \mathrm{~kW}$ (each)

$100 \mathrm{~kW}($ total)

0.013

$7,000 \mathrm{~kW}$

$0.88 \%$

$550 \mathrm{~kW}$

$0.059 \%$

$650 \mathrm{~kW}$

$0.059 \%$

$16,000 \mathrm{~kW}$

2.0

$50 \mathrm{kH}$

$0.008 \%$

$25 \mathrm{kH}$

$0.003 \%$

$150 \mathrm{~kW}$

$0.019 \%$ 
TABLE 7.5. Contd

\begin{tabular}{|c|c|c|c|}
\hline Equipment & & Input Power & $\begin{array}{c}\text { Percent } \\
\text { of unit } \\
\text { Load }\end{array}$ \\
\hline Cooling Tower Blowdown Transfer Pump & & $200 \mathrm{kH}$ & $0.025 \%$ \\
\hline Auxiliary Boiler Fans & $\begin{array}{l}\text { No. } 1 \\
\text { No. } 2\end{array}$ & $\begin{array}{l}150 \mathrm{~kW} \\
150 \mathrm{kw}\end{array}$ & $\begin{array}{l}0.019 \% \\
0.019 \%\end{array}$ \\
\hline Auxiliary Boiler Feed Punps & $\begin{array}{l}\text { No. } 1 \\
\text { No. } 2\end{array}$ & $\begin{array}{l}100 \mathrm{kH} \\
100 \mathrm{kH}\end{array}$ & $\begin{array}{l}0.013 \% \\
0.013 \%\end{array}$ \\
\hline Service Water Putop & & $150 \mathrm{kw}$ & 0.0194 \\
\hline Sump pumps & $\begin{array}{l}\text { No. } \frac{1}{1} \text { to } \\
\text { No. } 8\end{array}$ & $\begin{array}{c}20 \mathrm{kw}(\text { each }) \\
150 \mathrm{kw}(\text { total })\end{array}$ & $0.02 \%$ \\
\hline Screen wash Pump & No. 1 & $75 \mathrm{kw}$ & 0.0090 \\
\hline Fire Protection Water Pumps & $\begin{array}{l}\text { No: } 1 \\
\text { No. } 2\end{array}$ & $\begin{array}{l}75 \mathrm{kw} \\
75 \mathrm{kw}\end{array}$ & $\begin{array}{l}0.009 \% \\
0.009 \%\end{array}$ \\
\hline \multirow[t]{2}{*}{ Fire protection Water pooster Pumps } & $\begin{array}{l}\mathrm{No} \cdot 1 \\
\mathrm{No} \cdot 2\end{array}$ & $\begin{array}{l}20 \mathrm{~kW} \\
20 \mathrm{~kW}\end{array}$ & $\begin{array}{l}0.0025 \% \\
0.0025 \% \\
\end{array}$ \\
\hline & & TOTAL & 7.3 \\
\hline
\end{tabular}

remains a vital concept here too, so that an improvement of $0.5 \%$ in efficiency has been and remains a vital goal of turbine designers-yet another concept looms here as perhaps the more important aspect of efficient utility operation. That concept is reliability which pertains to avoidance of all those forms of equipment malfunction which very often cause the shutdown of turbo-generator sets and the cessation of operation of the power plant. The losses and penalties associated with such outages are usually many times the cost of the various inefficiencies inherent in the equipment.

Utilities have always used heat rates to discuss power plant performance. Heat rates denote the input energy required per unit output, which is merely the inverse of efficiency. As seen from Figure 7.3, there has been a deterioration in plant efficiency starting with the 1970s, due to ecological requirements and frequent cycling. The present overall heat rates of about 10,500 Btu/kwh correspond to an efficlency of some 32\%. This holds for the average power plant. The efficiency improves sonewhat with the size of the unit, as can be seen from Table 7.6, with some units reaching as high as over $40 \%$. Table 7.6 is of interest also on two other counts. It shows that the various 
TABLE 7.6. Coal-Burning Steam Power Plants for 1973-1978

\begin{tabular}{|c|c|c|c|c|c|c|c|c|c|c|c|c|c|c|c|c|}
\hline \multirow[b]{4}{*}{$\begin{array}{l}\text { I.D. } \\
\text { No. }\end{array}$} & \multirow{4}{*}{$\frac{\text { size }}{10^{3}}$} & \multirow{4}{*}{ Pressure } & \multirow{4}{*}{ Temp. } & \multicolumn{2}{|c|}{ Forced } & \multicolumn{2}{|c|}{ Induced } & \multirow{2}{*}{\multicolumn{2}{|c|}{$\begin{array}{l}\text { Feedwater } \\
\text { Pumps }\end{array}$}} & \multicolumn{5}{|c|}{ Efticlencies } & \multirow{4}{*}{ Ratio $\frac{(5)}{(4)}$} & \multirow{4}{*}{$\begin{array}{l}\text { Total } \\
\text { Aux. }\end{array}$} \\
\hline & & & & Dratt & Fans & Draft & Fans & & & \multirow{3}{*}{$\begin{array}{l}\text { (1) } \\
\text { Heat } \\
\text { Rate } \\
\text { Btu/klwh }\end{array}$} & \multirow{3}{*}{$\begin{array}{l}\frac{(2)}{\text { Actual }} \\
\text { EffIC. } \\
8\end{array}$} & \multirow{3}{*}{$\begin{array}{l}\frac{(3)}{\text { Ideal }} \\
\text { Ef fic. } \\
\end{array}$} & \multirow{3}{*}{ 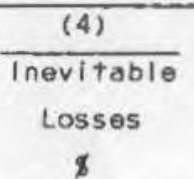 } & \multirow{3}{*}{$\begin{array}{l}\frac{(5)}{\text { Mechan. }} \\
\text { Losses } \\
8\end{array}$} & & \\
\hline & & & & & & & & & & & & & & & & \\
\hline & & & & $\begin{array}{l}10^{-} \\
\mathrm{K} \text { m }\end{array}$ & $\begin{array}{c}8 \\
\text { Power }\end{array}$ & $\begin{array}{l}10^{\circ} \\
\text { kws }\end{array}$ & Power & $\begin{array}{l}10 \\
k w s\end{array}$ & 8 & & & & & & & \\
\hline 2 & $\overline{880}$ & 3,025 & 1,000 & $\overline{14.9}$ & 1.7 & 15.8 & 1.8 & 36.8 & $\overline{4.2}$ & 9,208 & 37 & 60 & 40 & 23 & 57.5 & 7.7 \\
\hline 12 & 750 & 3,850 & 1,010 & 3.0 & 0.4 & - & - & 29.2 & 3.9 & 9,830 & 35 & 61 & 39 & 26 & 67 & $\cdots$ \\
\hline 21 & 550 & 2,620 & 1,005 & 3.0 & 0.55 & 9.0 & 1.65 & 13.1 & 2.4 & 9,337 & 36.5 & 63 & 37 & 26.5 & 72 & 4.6 \\
\hline 26 & 511 & 2,620 & 1,005 & 4.48 & 0.87 & 8.22 & 1.60 & 15.0 & 2.9 & 7,946 & 43 & 60.5 & 39.5 & 17.5 & 44 & 5.4 \\
\hline 31 & 460 & 1,800 & 1,000 & - & - & -- & - & 9.0 & 1.95 & 9,565 & 35.5 & 60.5 & 39.5 & 25 & 63 & - \\
\hline 36 & 350 & 2,500 & 1,005 & 3.46 & 1.0 & 4.48 & 1.28 & 10.5 & 3.0 & 8,250 & 41.5 & 60.5 & 39.5 & 19 & 48 & 5.3 \\
\hline 41 & 250 & 2,520 & 1,000 & 1.05 & 0.42 & 3.37 & 1.35 & 7.50 & 3.0 & 9,880 & 34.5 & 62 & 38 & 22.5 & 73 & 4.8 \\
\hline 43 & 141 & 1,955 & 1,005 & 2.62 & 1.78 & None & - & 3.00 & 2.1 & 8,910 & 38 & 61.5 & 38.5 & 23.5 & 60 & $\cdots$ \\
\hline 54 & 38 & 1,375 & 955 & - & - & None & - & 1.05 & 2.76 & 12,855 & 26.5 & 60 & 40 & 23.5 & 56 & -- \\
\hline
\end{tabular}




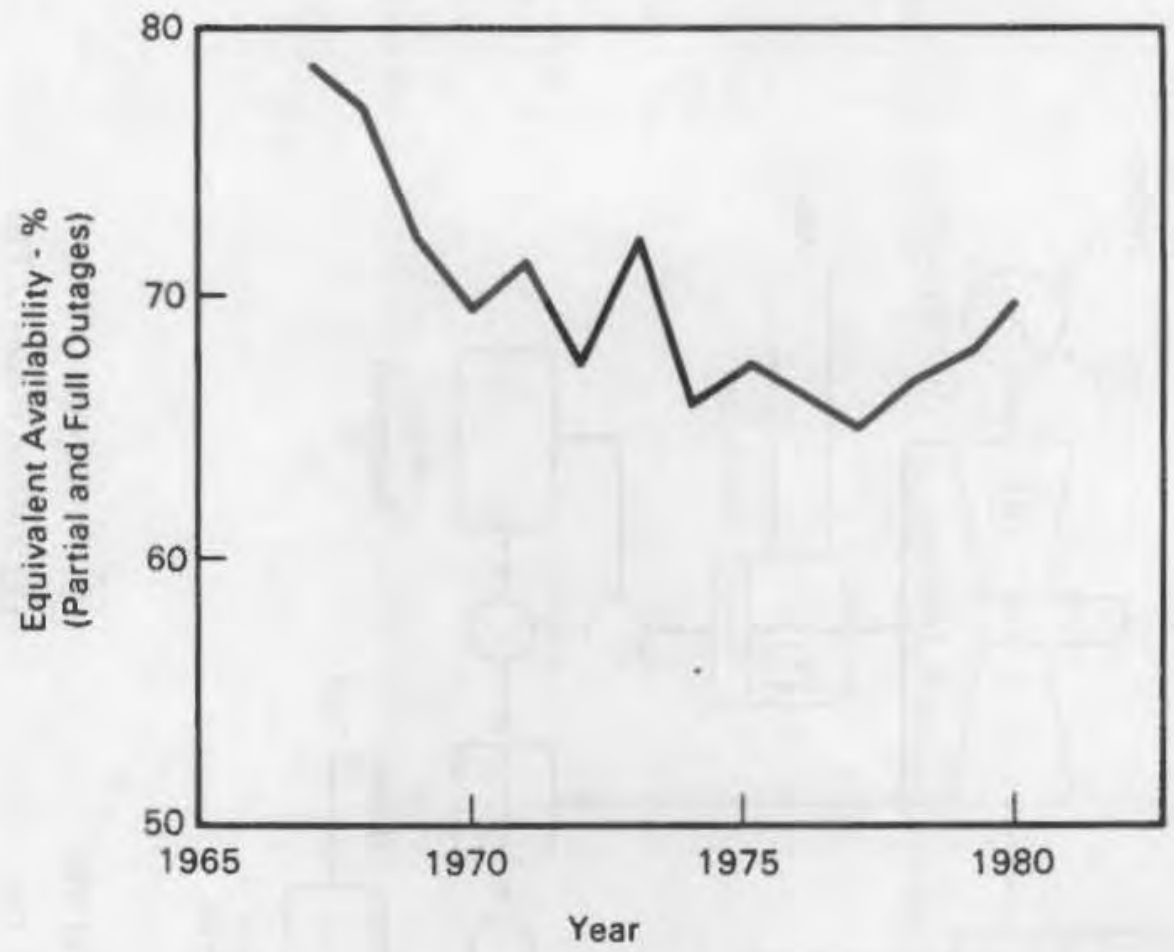

FIGURE 7.4. Equivalent Availability of Fossil Units Over $400 \mathrm{MW}(43,41)$

In terms of cost, a 1\% loss of availability for a unit of $600 \mathrm{MW}$ and higher is about $\$ 125$ million per year, only a little less than the loss of $\$ 160$ million per year for a loss of $1 \%$ in efficiency. (41)

\subsection{PROBLEM AREAS}

Figure 7.5 shows the major elements responsible for the roughly $30 \%$ plant outages. Put in order of the given percentages we have the following:

\begin{tabular}{ll} 
Boiler & $4.2 \%$ \\
Condenser & $3.8 \%$ \\
Generator & $3.8 \%$ \\
Fouling/Slagging & $2.8 \%$ \\
Turbine Blades & $2.7 \%$ \\
Bearings & $2.0 \%$ \\
Pumps & $1.7 \%$ \\
Pulverizer & $0.6 \%$ \\
Fans & $0.6 \%$ \\
\hline & $22.2 \%$
\end{tabular}




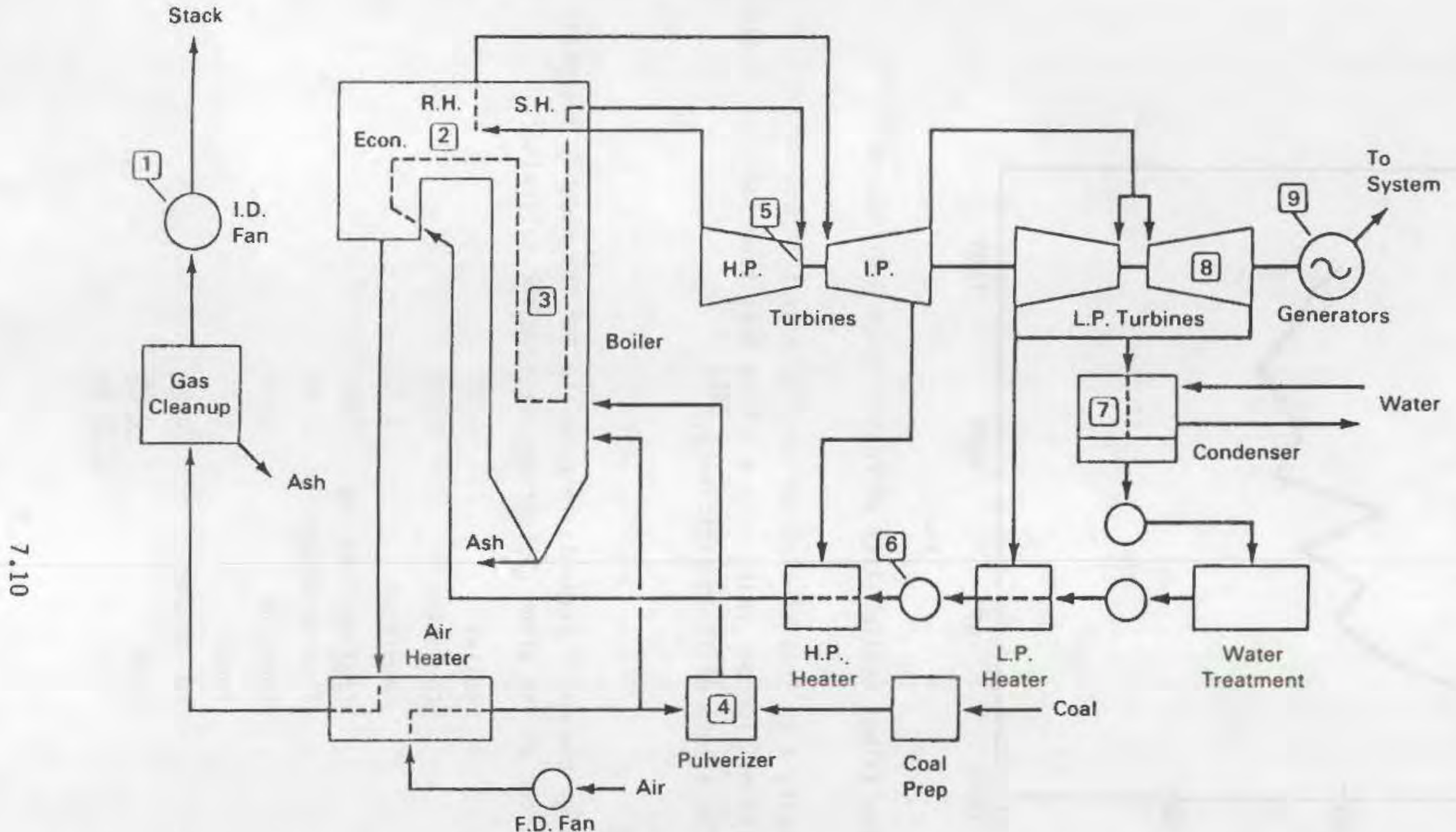
[1] Fans (0.6\%)
[3] Fouling/Slagging (2.8\%)
5 Bearings (2.0\%)
7 Condensers (3.8\%)
[2] Boiler Tubes (4.2\%)
44) Pulverizer (0.6\%)
[6] Pumps $(1.7 \%)$
[8] Turbine Blades (2.7\%)

9] Generators (3.8\%)

FIGURE 7.5. Problem Areas in Fossil Unit (41) 
When one includes the entire spectrum of outages caused directly and indirectly by the bearings, such as bearing-induced vibrations, the lube system, and problems with oil pumps, then the distribution of these causes is as shown in Figure 7.6. Two things stand out in this diagram. One is the steady increase in outages due to tribological causes with increase in unit size; and second, that while with the smaller units vibration was the largest contributor to outages, in the rank of $800 \mathrm{MW}$ and higher it was directly the bearings and the lube system that caused the most outages.

Finally, Table 7.7 shows the direct losses (about 1.5\%) in generating power caused by the various tribological subgroups, again with the lube system being the largest culprit. According to Reference 45 a $0.5 \%$ outage on $257,000-M W$ generating capacity incurs a penalty of $\$ 340$ million. Thus for the 1984 generating capacity of some $730,000 \mathrm{MW}$, outages on the order of $1.5 \%$ would incur losses of $\$ 2.9$ billion for the industry. A good portion of this loss is due to the use of stand-by equipment of a lower efficiency than that of the main power plant, i.e., a loss which can be directly translated into terms of an unnecessary expenditure of energy. A reduction in such outages would thus directly contribute to energy conservation. 


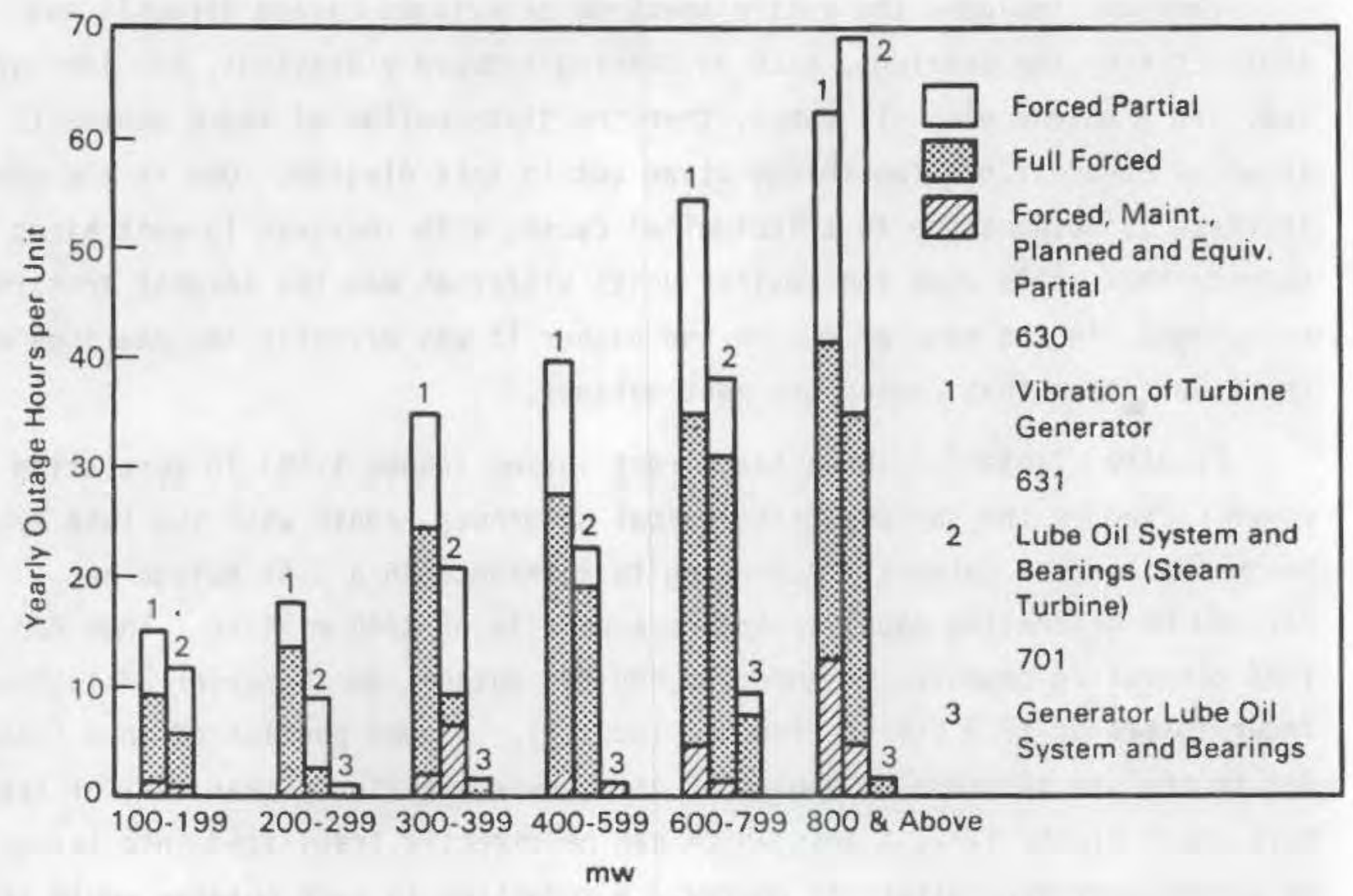

Unit Size, MW

FIGURE 7.6. Yearly Outage Hours in Fossil Units $(44)$ 
TABLE 7.7. Tribologically Related Causes of Outages (45)

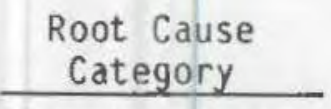

Lube-0il System

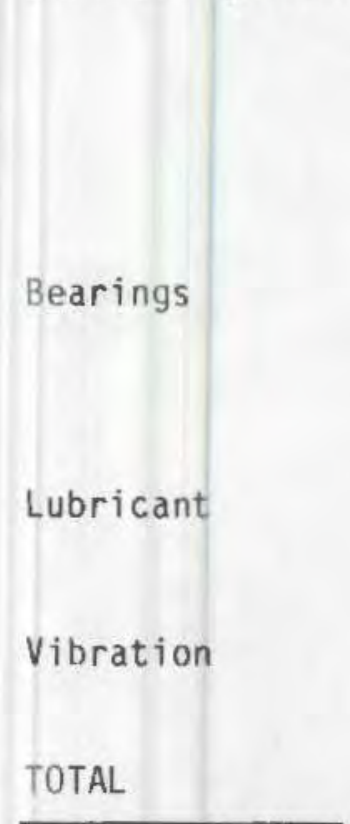

$\%$ of

Theoretical Generation

0.521

\author{
Principal Root Causes
}

Electrical power for back-up pumps not available

Heat exchanger failures

Vapor extractor failures

Return oil blockages

Mechanical errors

Misalignment Lead to Vibration

High metal temperature

High particle content

Excessive moisture

For which underlying causes were not cited

(a) Significant portions of this attributable to bearings 


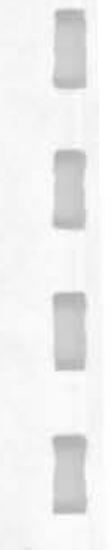

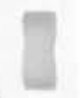

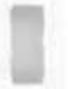

17

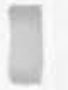

(1)

?

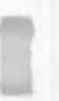

D.

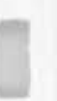

7

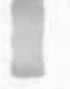

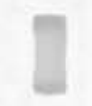

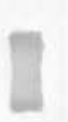

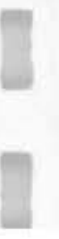




\subsection{ENERGY FLOW MAP}

The history of a given quantity of energy delivered to an electric facility in the form of either coal, oil, or some other fuel until it reaches the user in form of available electrical power is portrayed in Figure 8.1. These are generic figures typical for a large coal-fired facility but though the individual members may shift by several percentage points, the numbers given are quite typical of the industry. The biggest single loss of energy, which is on the order of more than $50 \%$ is due to the thermodynamic nature of the steam cycle. Of the other energy sinks, using a straight accounting system we have the following hierarchy of energy expenditure, in terms of the fuel energy delivered to the system:

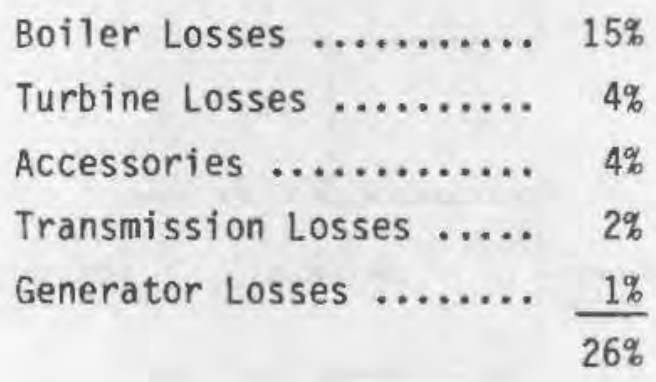

In terms of the energy delivered to the turbo-generator set, Figure 8.2 gives a detailed mapping of the individual energy sinks throughout the installation, including the power required by the accessories. The losses due to blade friction, gaspath leakage, and windage end up mostly as part of the thermal energy discarded and can be lumped with the thermodynamic losses to give a total thermal loss of some $62.5 \%$. Table 8.1 gives a detailed accounting of the energy losses in the various groupings of accessories, compiled on the basis of the data given in Table 7.5. The accessories are driven either by steam extracted from certain turbine stages or directly by the turbine shaft as well as electrically. Exhaust losses refer to the losses in the condenser, in large part due to the wasted kinetic energy discharging from the last stage of the turbine. Modern plants tend to drive their auxiliaries mostly via electric 


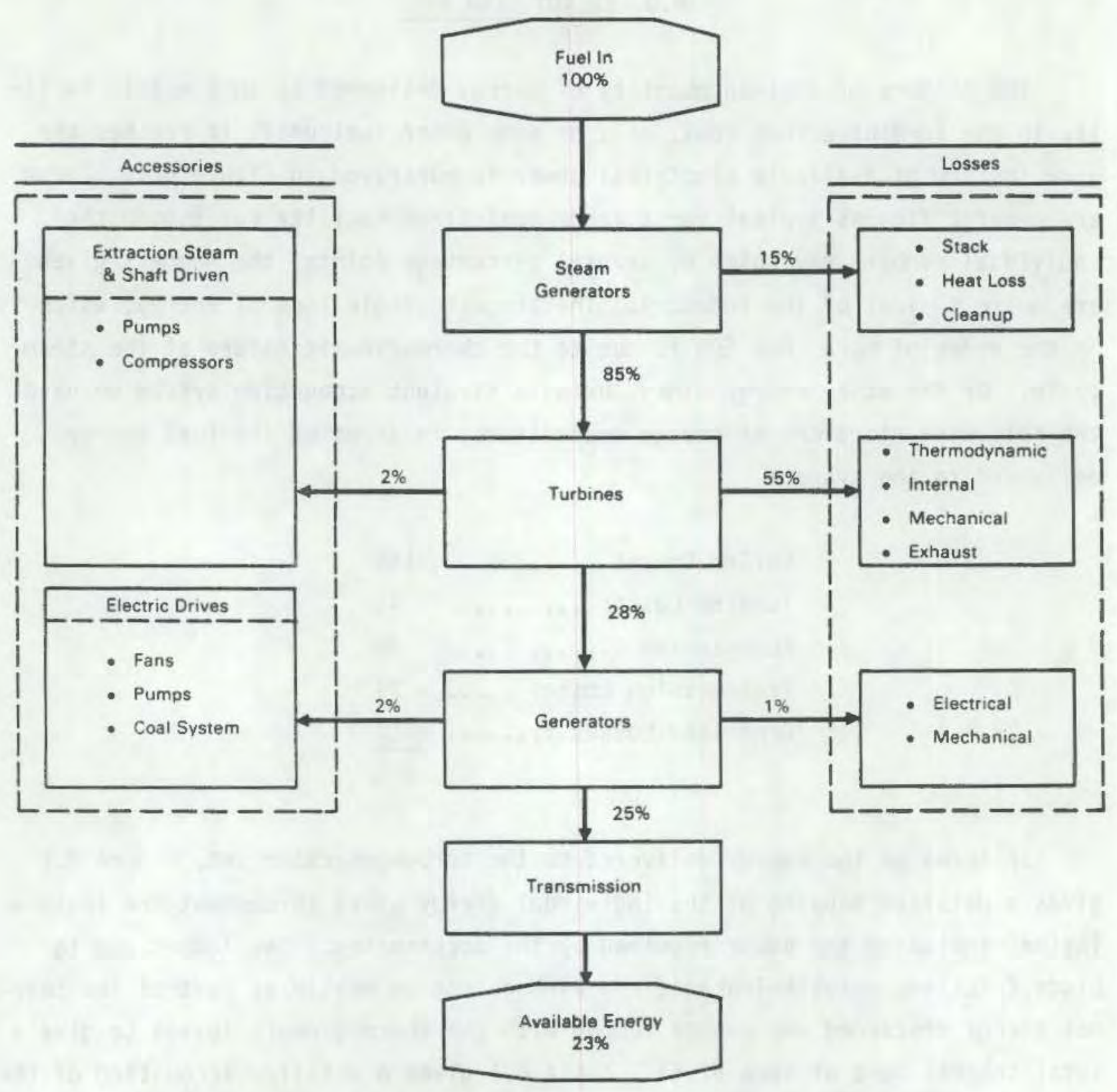

FIGURE 8.1. Energy Flow in Large Electric Utility

motors which is both simpler and less costly, and this includes the operation of the coal crushers and pulverizers. However, large facilities in excess of 500 MW use mostly special turbines to drive their feed water pumps, draft fans and other large pieces of equipment. 


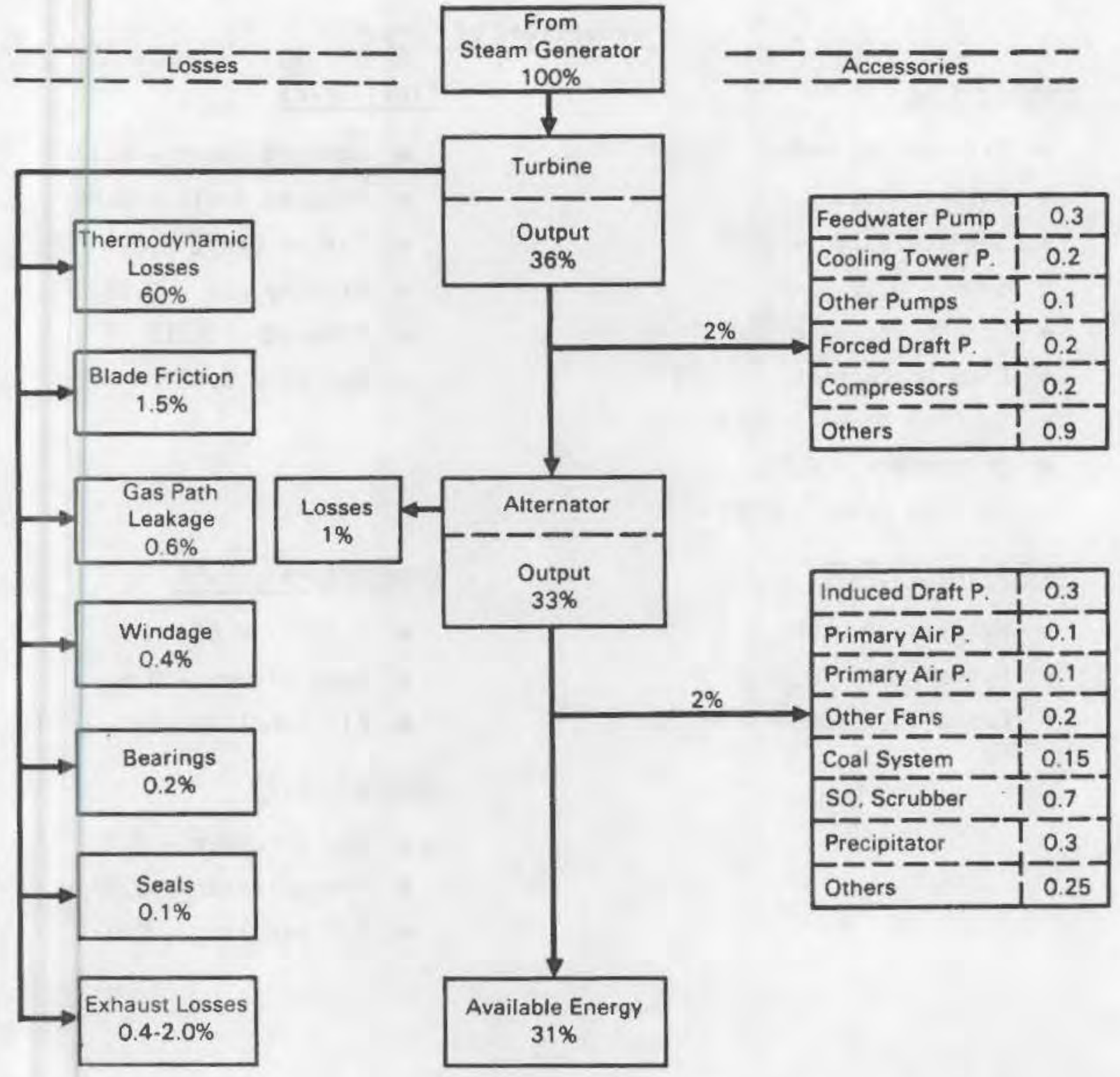

FIGURE 8.2. Energy Flow in Large Power Plant Excluding the Steam Generator 
TABLE 8.1. Power Required by Accessories in an 800-MW Coal-Fired Utility Plant Percentages of Output

Pumps: 1.67

- Circulating Water - 0.28

- Boiler - 0.5

- Service Water - 0.02

- Sump - 0.02

- Screen Work - 0.008

- Fire Protection - 0.023

- Cooling Tower - 0.57

- Condensate - 0.18

- Cooling Water - 0.05

Coal System: 0.52
- Handling - 0.06
- Pulverizer -0.45
- Feeders - 0.006

Fans: 2.21

- Cooling Tower - 0.17

- Induced Oraft - 0.88

- Forced Draft - 0.5

- Primary Air - 0.26

- Exhaust - 0.013

- Boiler - 0.38
- S Air - 0.05

- Soot Blower - 0.5

- Air Conditioning - 0.013

Others: 2.95

- $\mathrm{SO}_{2}$ Scrubber - 2.0

- Precipitator - 0.88

- Ash Handling - 0.07 


\subsection{TRIBOLOGICAL ELEMENTS}

As explained in the opening section, the role played by tribological components and processes in the field of electric utilities comprises not only the area of efficiency, but also the reliability of the equipment. This comes from the simple fact that outages caused by breakdown, or suspected imminence of breakdown, of the equipment are perhaps more costly in terms of dollars and wasted energy resources than the direct inefficiencies associated with particular tribological components of the plant. Thus, the discussion here will embrace systems and processes in which perhaps no improvement in performance is expected, but whose enhanced reliability would be the primary goal. Together with the reduction of energy wastage they would converge toward the common goal of energy conservation in the electric utilities sector.

Figure 9.1 gives a diagrammatic representation of the technical areas of a turbor-generator plant where reliability problems exist and where improvement can be expected via advances in tribological technology. While these areas

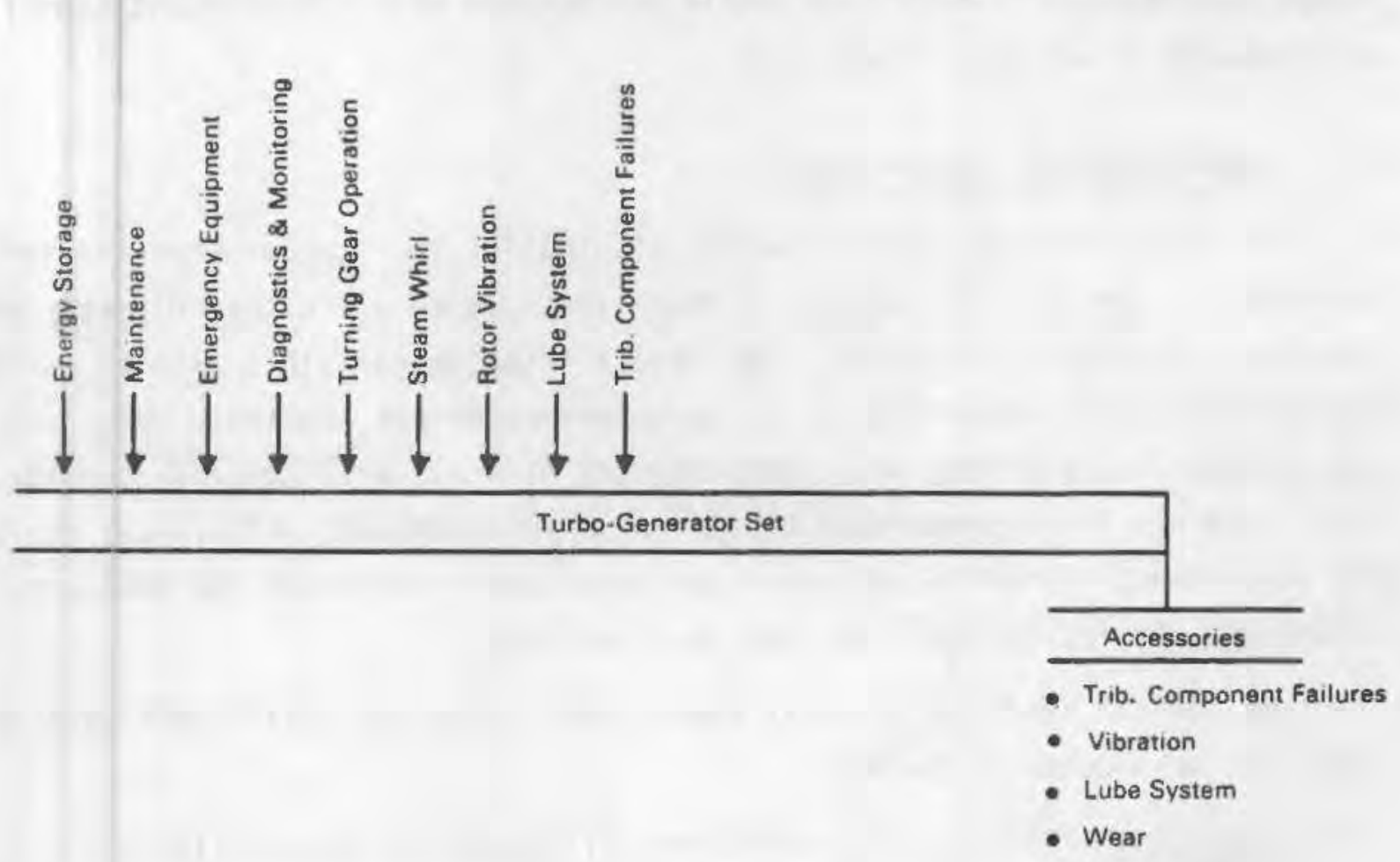

FIGURE 9.1. Tribologically Related Areas Affecting Plant Reliability 
will be discussed in detail in the individual sections that follow, a few general remarks at this point will set the diagram in its proper perspective. While it is clear that vibration and outright failures should be minimized, the purpose of the monitoring and maintenance efforts would be to alert the personnel ahead of such possible failures so that preventive measures can be taken without plant shutdown. Also, standards are needed to guide personnel when a shutdown is required and when not. Thus diagnostics are a very important feature of reliability improvement.

Figure 9.2 gives a listing of the tribological sinks in a turbo-generator set. The energy sinks due to windage, gaspath leakage and blade aerodynamic losses all fall within the tribological spectrum because they all occur in narrow spaces of the order of lubrication theory. Perhaps the only item that may seem to be alien to tribology is the inclusion of thermodynamic or cycle losses in this listing. The connection here is via the materials used in turbines and steam generators. Should tribology be able to supply materials and coatings which can withstand higher pressures and temperatures than those used today, then the cycle efficiency could be improved with a consequent significant salvage of wasted exhaust beat.

\subsection{TURBO-GENERATOR ENERGY SINKS}

Out of the various form of energy dissipation in a turbo-generator set, our interest here is exclusively in those areas which are either directly or indirectly linked to tribology. The direct tribological sinks will be subdivided between those occurring in the turbo-generator set and those occurring in the numerous accessories; while the indirect elements will comprise, on the one hand, coatings and materials which may raise thermodynamic efficiency, and on the other hand, overall plant practices which may help reduce the frequency of tribologically related failures and plant outages.

The several forms of internal energy loss occurring inside each turbine stage can be grouped as follows:

- Stage Loss - This is the incomplete utilization of the available steam energy caused by various cycle deficiencies; the non-ideal 


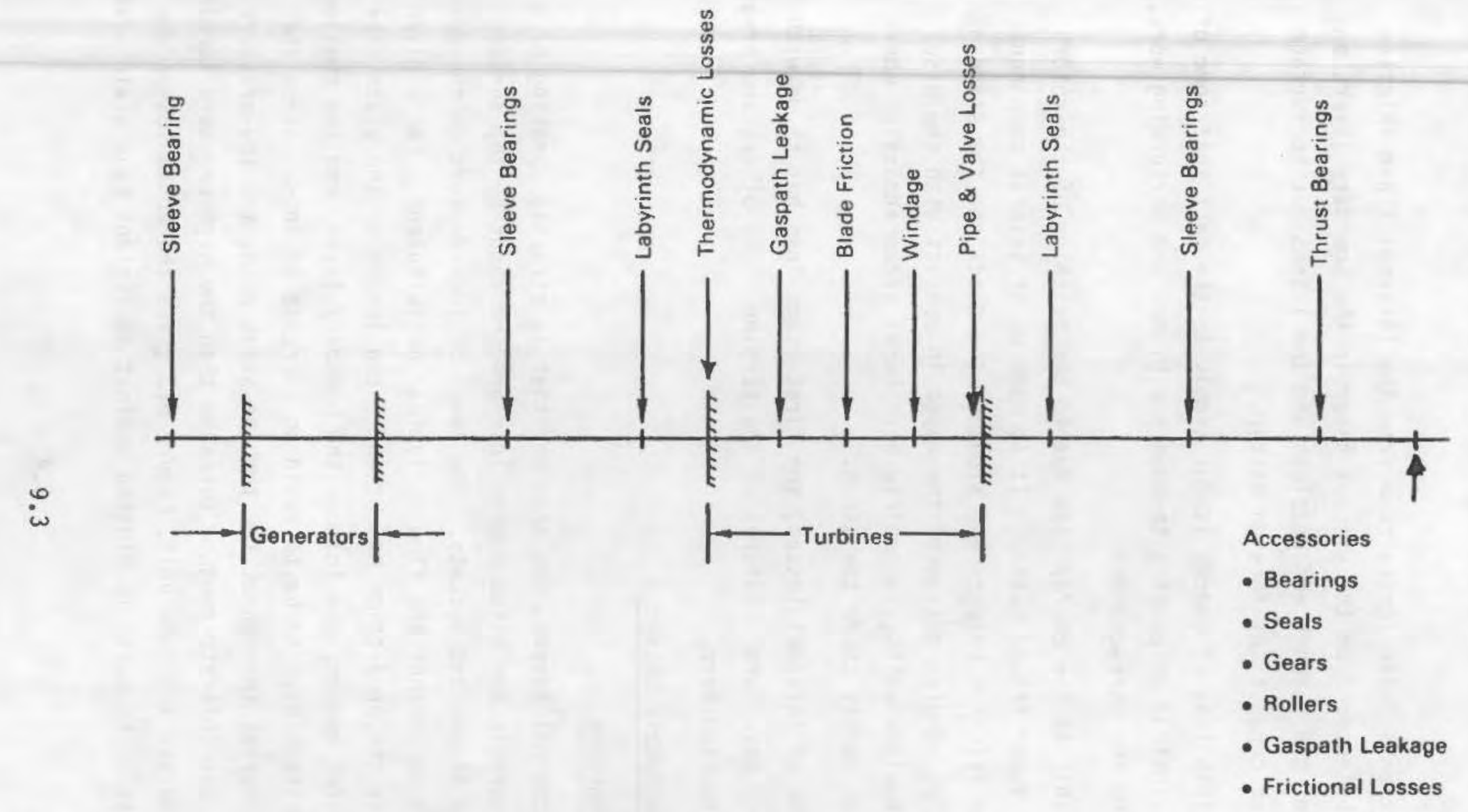

FIGURE 9.2. Tribological Energy Sinks in Turbo-Generator Sets 
velocity diagram; the non-isentropic expansion of the steam; and the excessive exhaust velocity, though this is later utilized in the next stage.

- Blade Friction - These losses come from the internal fluid friction due to turbulence; from the viscous shear in the boundary layers on the walls of the buckets and nozzles; and the losses due to surface roughness or deposits of foreign matter.

- Leakage - This loss of energy is due simply to the fact that some of the steam, instead of passing through the blades and performing work, leaks around the work-channel.

- Windage - This is the energy loss due to the spinning of the rotor inside the vapor filled casing. It is made up of several components: the surface friction between the sides of the discs and the stagnant vapor; radial pumping action of the vapor in contact with the disc; and, with smaller units, incomplete peripheral steam admission where some nozzles merely churn the steam.

Of the four forms of internal losses, the first-stage loss has to do with thermodynamic and structural features of the turbine. The others are areas that will be discussed here.

\subsubsection{Blade and Nozzle Losses}

Surface Roughness

of the frictional losses, the only one that is strictly speaking of a tribological nature is the extra energy loss brought about by the surface roughness of the blades and buckets. The level of loss depends on the degree of roughness and on whether the flow is laminar or turbulent. For a given $\mathrm{K} / \mathrm{L}$ ratio, where $K$ is the projection height and $L$ the length of the plate, the larger the Reynolds number, the thinner the boundary layer, and the smaller the roughness projections have to be to avoid an increase in loss. Since the Reynolds number varies throughout the turbine steam path, the low-pressure turbine steam path can tolerate rougher surfaces than the high-pressure turbines. For both a 200-MW and a 500-MW unit, Figure 9.3 gives the added losses due to surface roughness. The curve is plotted against equivalent sand grain size, as 


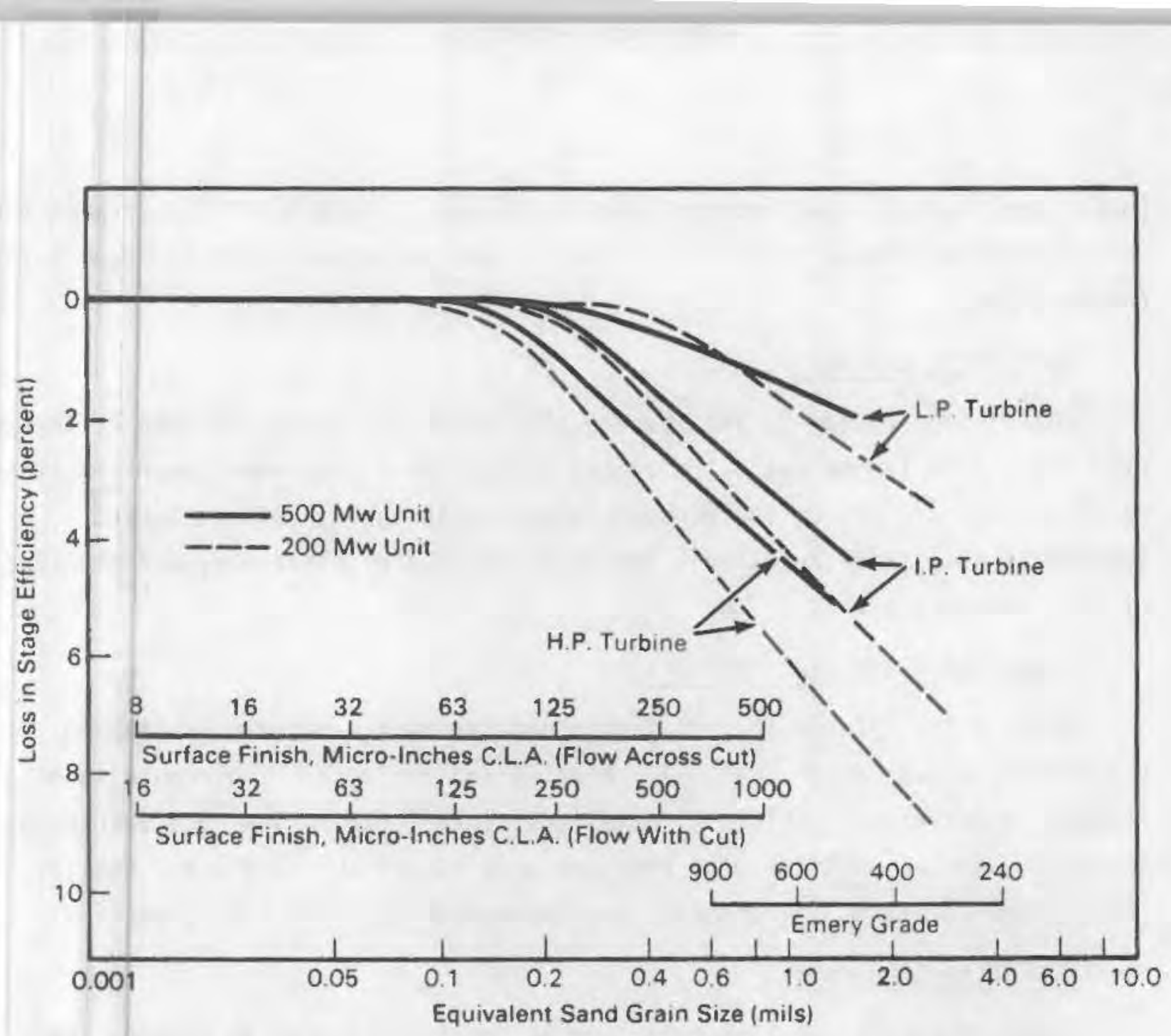

FIGURE 9.3. Approximate Loss in $\left\{\begin{array}{l}\text { Agge Efficiency as a Function } \\ \text { of Surface Roughness }\end{array} 43\right)$

well as against typical machined surface finishes and emery grade finishes. In test data obtained in the General Electric Turbine-Generator Development Laboratory, ${ }^{(43)}$ a decrease in turbine efficiency of $3 \%$ to $4 \%$ was measured for a deposit thickness of about $0.003 \mathrm{in}$. This result emphasizes the fact that the surface roughness in high-pressure sections need not be very thick to have a substantial effect on turbine efficiency.

\section{$\underline{\text { Leakage Losses }}$}

Steam which bypasses either the bucket or nozzle does not produce work and, in fact, disturbs the flow that goes through so as to further decrease the output. Leakage occurs as diaphragm packing leakage, bucket tip leakage, 
bucket root leakage, and internal packing leakage. Figure 9.4 illustrates the several leakages for a typical wheel and diaphragm construction and drum rotor construction.

Bucket Tip Leakage

Bucket tip leakage is the leakage that skips the bucket passage by leaking over the tip of the bucket. The amount of leakage is dependent upon the steam conditions of the stage, the pressure drop across the tip of the bucket (dependent upon stage reaction), the axial and radial clearance, and the type of tip leakage control.

\section{Diaphragm Shaft Packing Leakage}

This is the leakage flow that bypasses the nozzle passage by leaking between the diaphragm of stationary nozzles and the rotor. To reduce this leakage, a labyrinth packing is installed. This leakage flow is dependent upon the stage steam conditions, the pressure drop across the stationary nozzles, the radial clearance, the diameter and the number of teeth in the packing.

\section{Bucket Root Leakage}

Wheel or bucket dovetail holes are an important factor in keeping the bucket root leakage loss to a minimum. Without the wheel or dovetail holes, the diaphragm packing leakage would flow out into the steam path disturbing the main steam flow. Bucket root leakage flow entering the steam path results in stage efficiency loss of $1 \%$ for a leakage flow equivalent to $1 \%$ of the main steam flow. (43) This loss can be considerably reduced with a wheel and diaphragm construction (Figure 9.4a) which provides for wheel or bucket dovetail holes. These wheel or bucket dovetail holes are sized to accommodate the normally expected diaphragm-packing leakage flow so that under normal operating conditions, little if any flow enters or leaves the steam path at the root of the bucket. If, however, the diaphragm packings have a greater-than-normal clearance, then the wheel or bucket dovetail holes cannot pass the increased leakage flow. The excess flow will enter the main steam path at the bucket root, resulting in additional 1oss. 


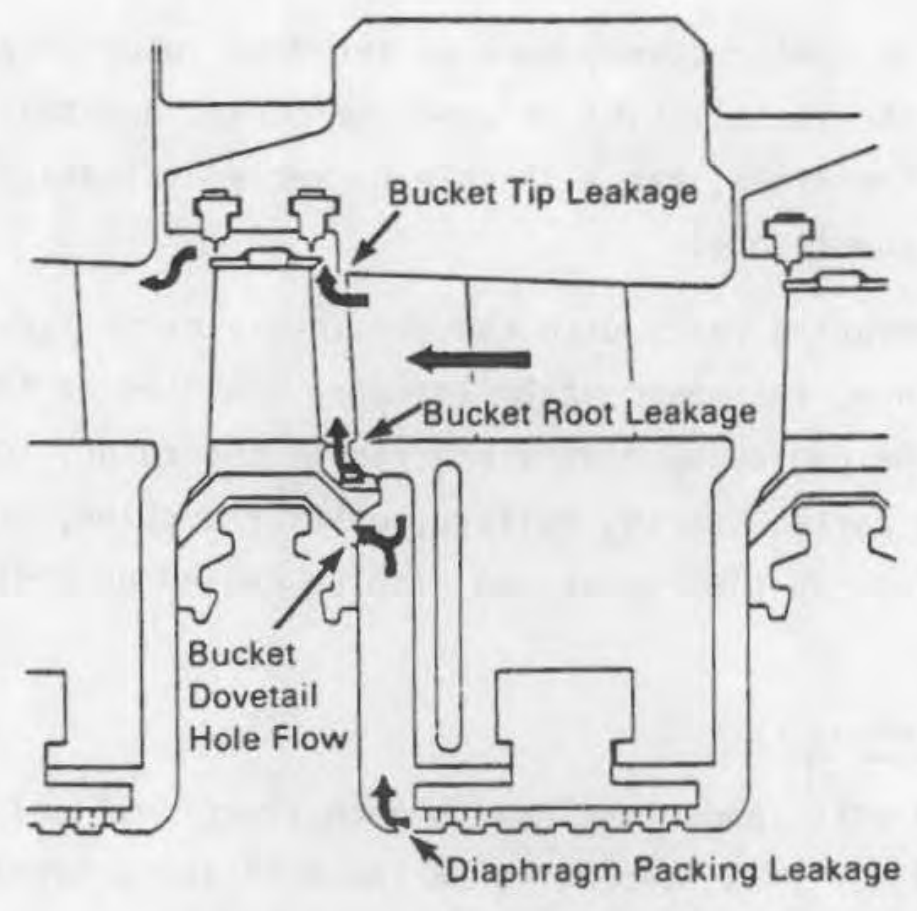

a) Impulse Wheel and Diaphragm Construction

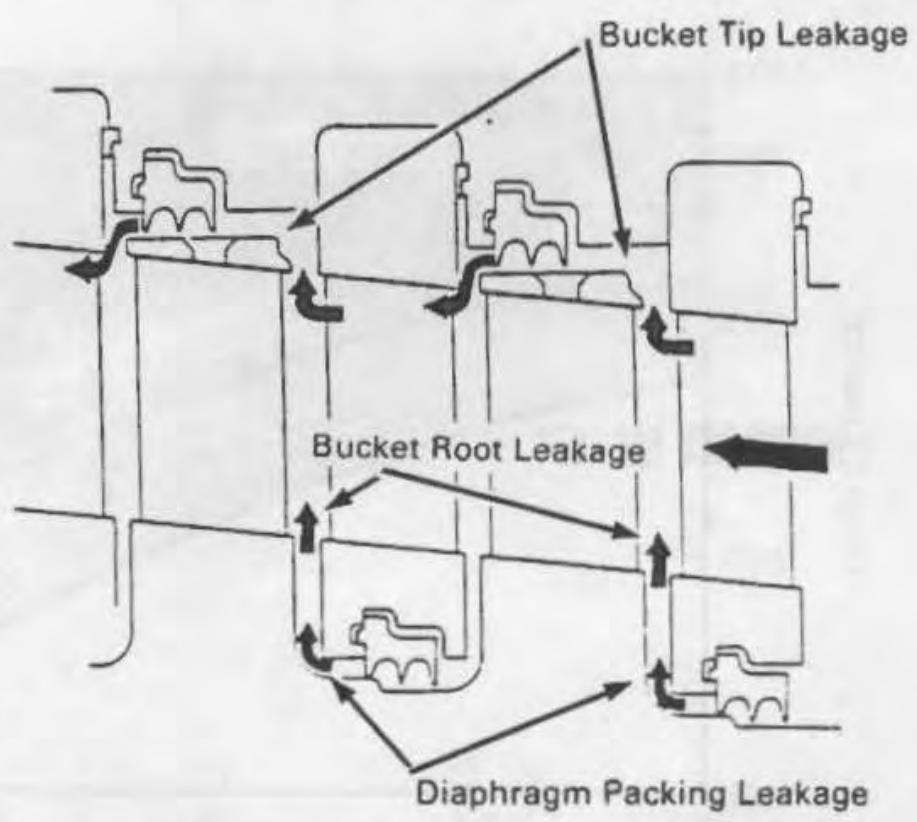

b) Reaction Drum Rotor Construction

FIGURE 9.4. Gaspath Leakage in a Turbine Stage ${ }^{(43)}$ 
Other types of construction, such as the drum rotor shown in Figure $9.4 \mathrm{~b}$ do not allow for the installation of wheel or bucket dovetail holes. This type of construction, therefore, has a sizable bucket-root leakage penalty even at normal operating conditions.

Rubbing of rotating parts with the stationary parts results in increased clearance and, hence, increased steam leakage. Rubbing of the packings and spill strips can be caused by high vibration of the rotor, thermal distortion of the stationary parts, bearing failure, water induction, etc. Increased packing and spill-strip clearances can also be caused by erosion from solid particles.

\section{Combined Internal Losses}

The combined efficiency loss due to both frictional and leakage losses is given in Figure 9.5. Thus, depending on the efficiency level, the total loss due to friction is some $4-5 \%$, while that due to leakage is some $2-3 \%$. (43) The frictional losses can be reduced by making more slender blades but for this to be practical, stronger materials are required both from the standpoint of strength and resistance to erosion and vibration.

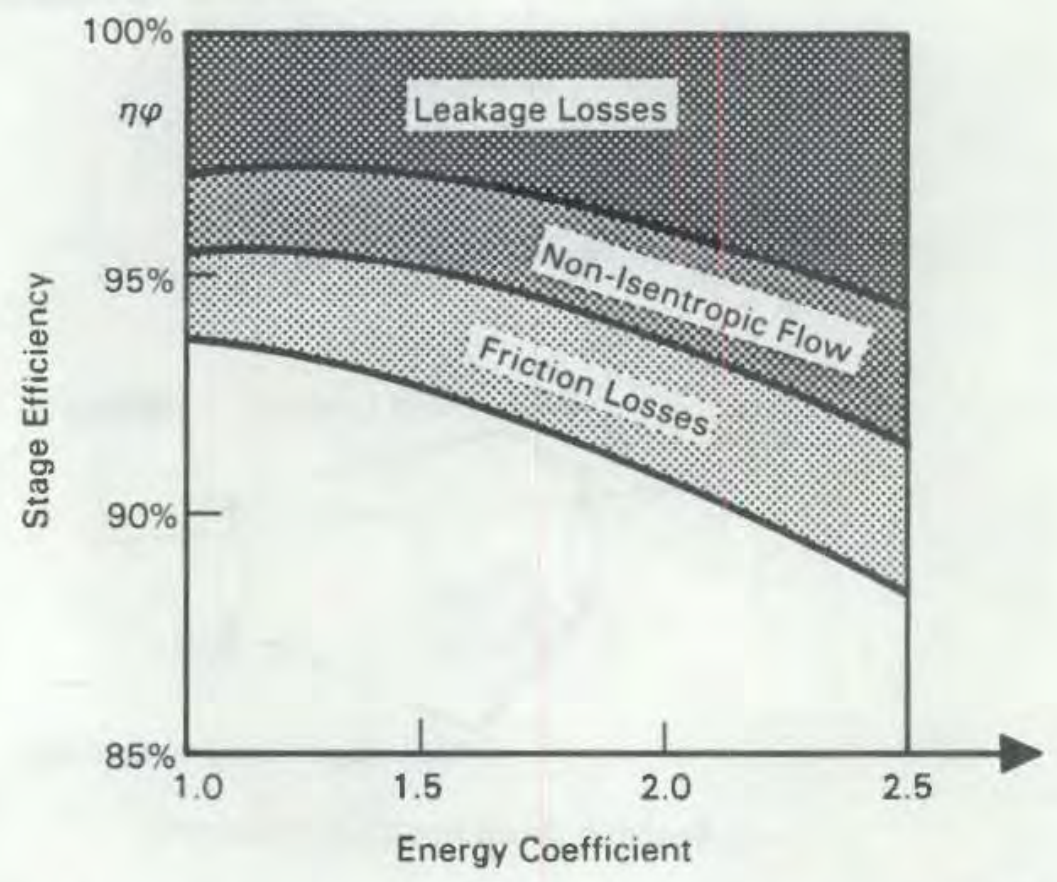

FIGURE 9.5. Internal Losses in Turbine Stage ${ }^{(43)}$ 
A most comprehensive diagrammatic representation of the component losses internal to the turbine including, for comparison, exhaust and other miscellaneous losses are given in Figure 9.6 for a facility with a theoretical capacity of some $900 \mathrm{MW}$. Since the abscissa represents the total output of the power plant and the ordinate the percentage loss in efficiency, the product of

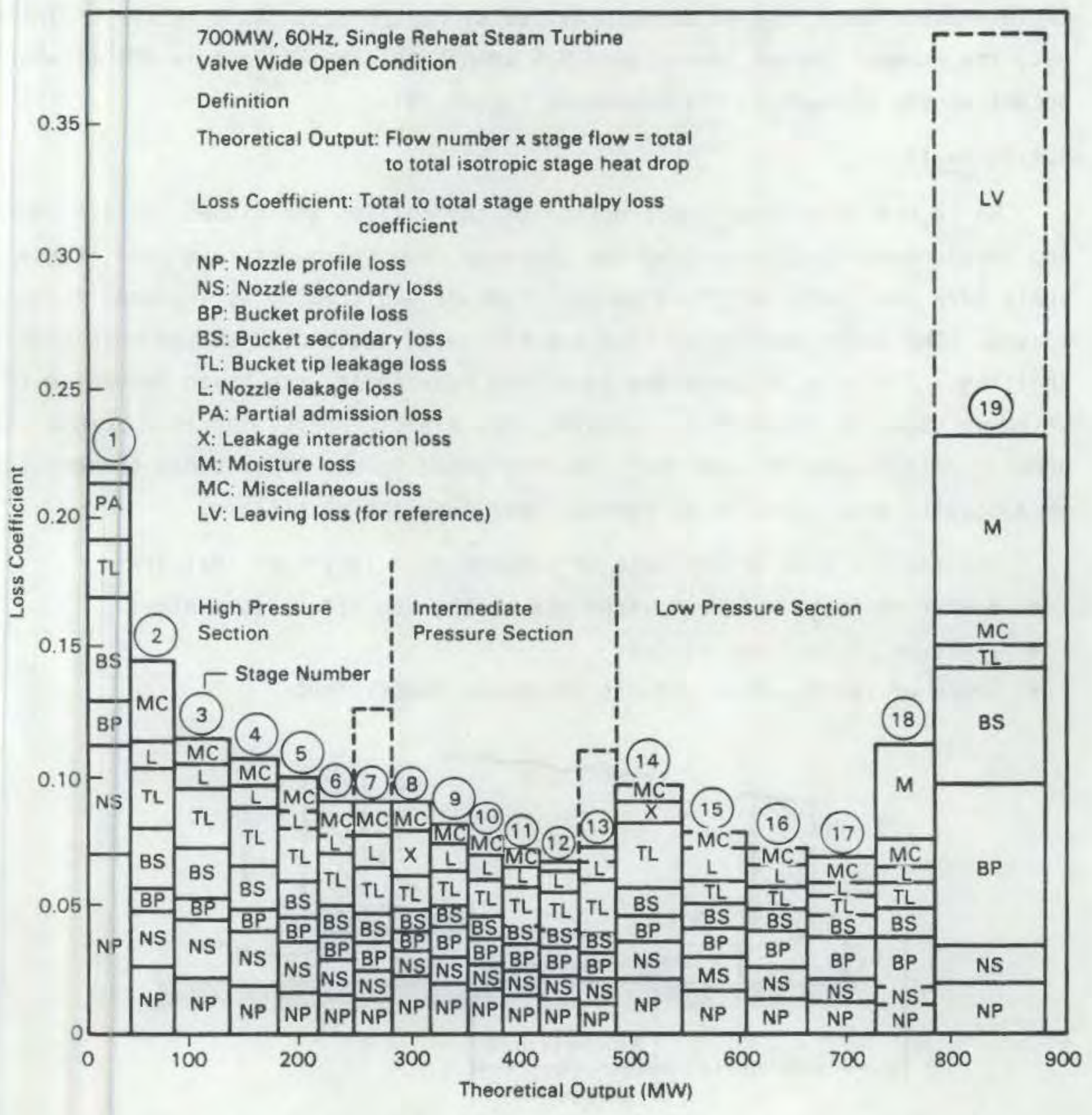

FIGURE 9.6. Internal Stage Losses in Large Turbogenerator Set (43) 
the abscissa as a fraction of the $900 \mathrm{MW}$ and of the ordinate yields the losses of each of the elements listed. By a rough evaluation we obtain from Figure 9.6 , the following levels of losses:

$$
\begin{array}{ll}
\text { frictional losses } & -3 \% \\
\text { leakage } & -2 \%
\end{array}
$$

These numbers are close to those provided by Figure 9.5. As a matter of interest, the exhaust losses from Figure 9.6 amount to some $2 \%$, nearly $90 \%$ of which occurs at the exhaust to the condenser (stage 19).

\section{1 .2 Seals}

While the interstage construction of the nozzles and blades contain sealing arrangements for separating the upstream from the downstream side, these seals have been referred to as gaspath leakage and treated as internal turbine losses. The seals considered here are the large seals used on the main turbine shafting. The bulk of these are labyrinth type seals, the basic mechanism of which is shown in Figure 9.7. Ideally, the kinetic energy increase across each annular orifice should completely be dissipated in the inter-tooth chamber but in actuality some velocity is carried over into the next shape.

The factors that affect rate of leakage in a labyrinth seal are:

- number of teeth - though after six teeth, the effect is minimal

- pressure ratio cross stages

- shape of teeth, which affects discharge coefficient

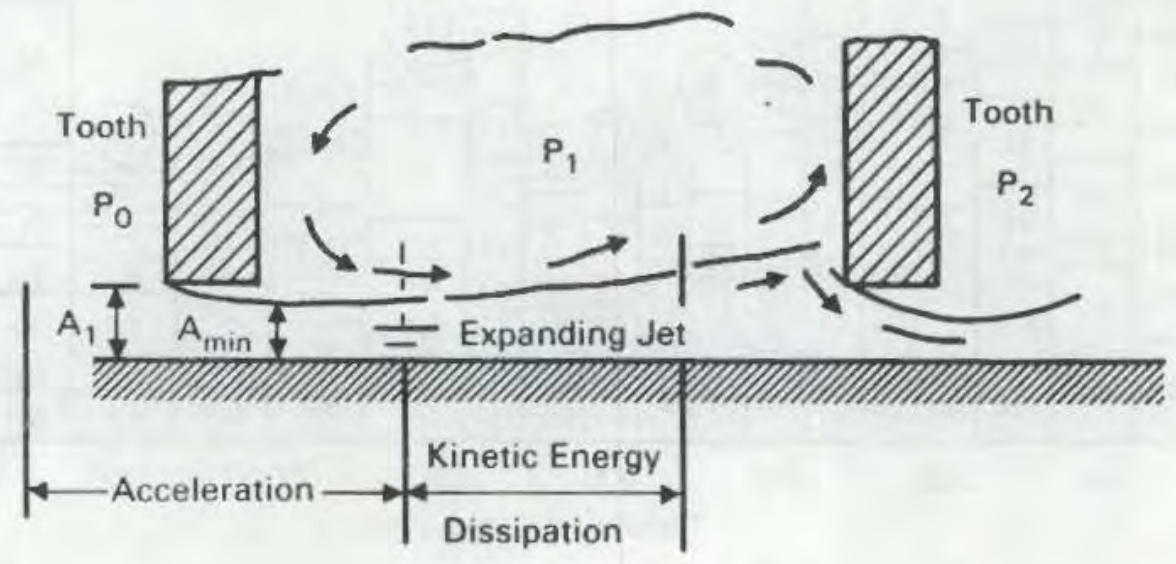

FIGURE 9.7. Model of Labyrinth Seal 
- clearance between teeth and shaft

- concentricity and potential rubbing.

The energy considerations in labyrinth seals involve frictional losses, rate of leakage, and seal life and reliability. Additional elements are the pressure and temperature characteristics of the seal which may enable the running of more efficient thermodynamic cycle. Of the above factors, the main loss in labyrinth seals is due to leakage.

\section{$9,1.3$ Bearings}

Figure 9.8 illustrates a typical arrangement of large-size steam turbine bearings, and other component parts. The generator unit, not shown, is directconnected to the output shaft of the LP cylinder and its rotating member is similarly supported. Total length of the shafting may be in excess of $100 \mathrm{ft}$, and the individual cylinder shafting is usually supported at each end by journal bearings. The shafting is axially supported and located by a thrust bearing usually placed between the HP and IP cylinders. The thrust bearing is double-faced, with one side active, the other inactive. The bearing housings are supported on pedestals and concrete foundations. The thrust bearing housing is either securely anchored to its foundation or to other connecting cylinders which are axially anchored; the axial location of the rotor with respect to the stators is defined by the thrust bearing.

In a typical installation the lubrication system is physically located some $30-40 \mathrm{ft}$ below the elevation of the rotor. Also indicated is the shaft driven main pump supplying oil to all the bearings.

Together with the generator there are about a dozen journal bearings and two thrust faces. These bearings can be up to two feet in diameter and they consume about one half a percent of the turbine output. The particular losses in some other than fossil plants are given in Table 9.1. These relatively high losses are due to the large $(L / D)$ ratios at the journal bearings and the turbulent conditions under which most of these bearings tend to operate. The penalty for turbulence in bearings can be seen from Figure 9.9, where at a $\operatorname{Re}=$ 3,000 the power loss is double that prevailing at laminar conditions. 


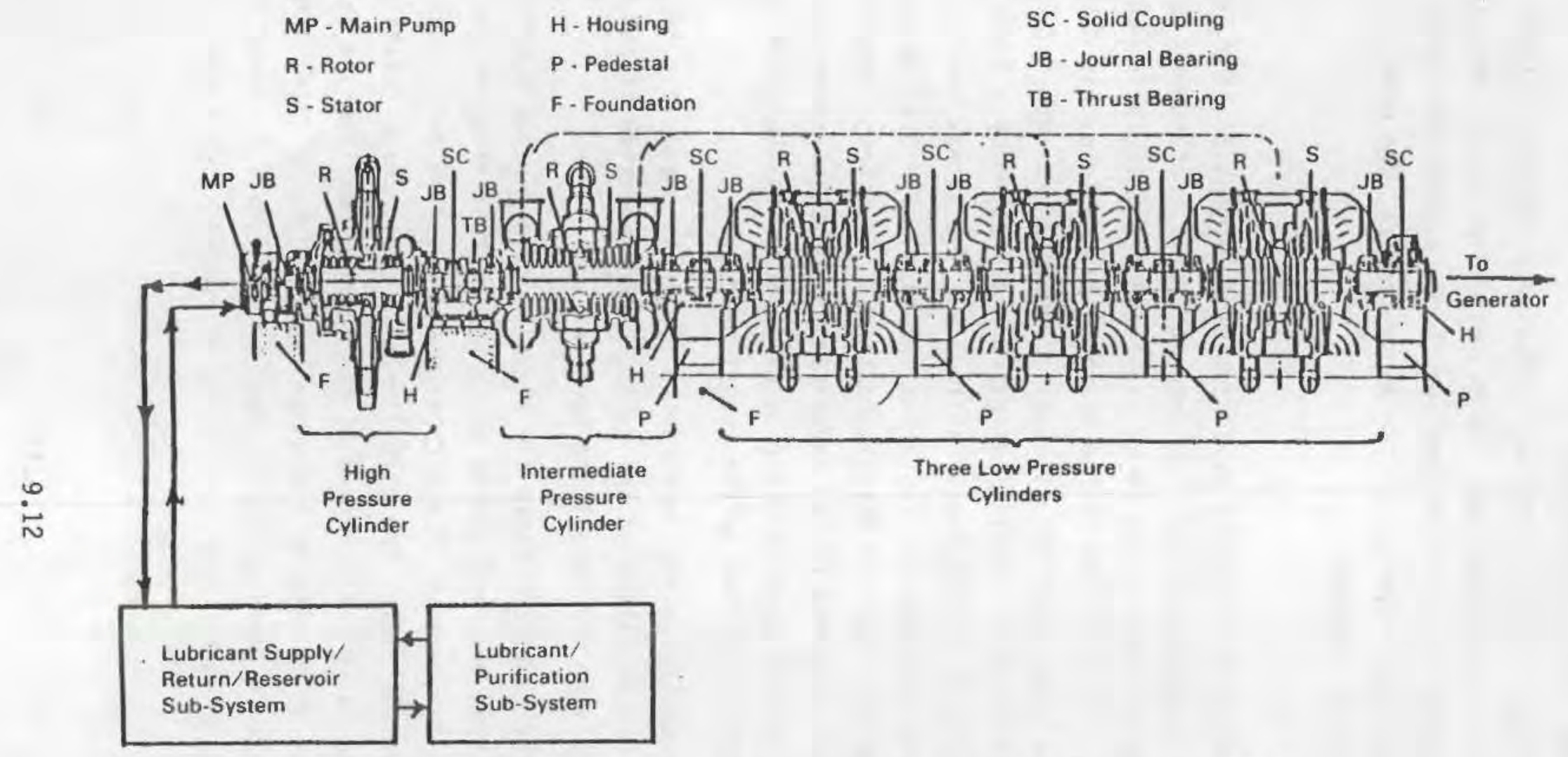

FIGURE 9.8. Bearing Arrangement on a Large-Size Turbine(45) 
TABLE 9.1. Fluid Film Bearing Losses in Utilities

\begin{tabular}{|c|c|c|c|}
\hline Type of Utility & $\begin{array}{l}\% \text { of Power } \\
\text { Output }\end{array}$ & $\begin{array}{l}\text { Million } \\
\mathrm{kWh} / \text { year }\end{array}$ & $\begin{array}{c}10^{12} \text { Btu/Year } \\
\text { Energy Out }\end{array}$ \\
\hline \multicolumn{4}{|l|}{ Steam Turbines } \\
\hline Fossil & 0.45 & 6600 & 23 \\
\hline Nuclear & 0.22 & 460 & 1.6 \\
\hline Hydroelectric & 0.3 & 900 & 3.1 \\
\hline Gas Turbines & 0.7 & 170 & 0.6 \\
\hline Total & -- & 8130 & 28.3 \\
\hline Total Electric Energy Production & & $2,030,000$ & 7770.0 \\
\hline
\end{tabular}

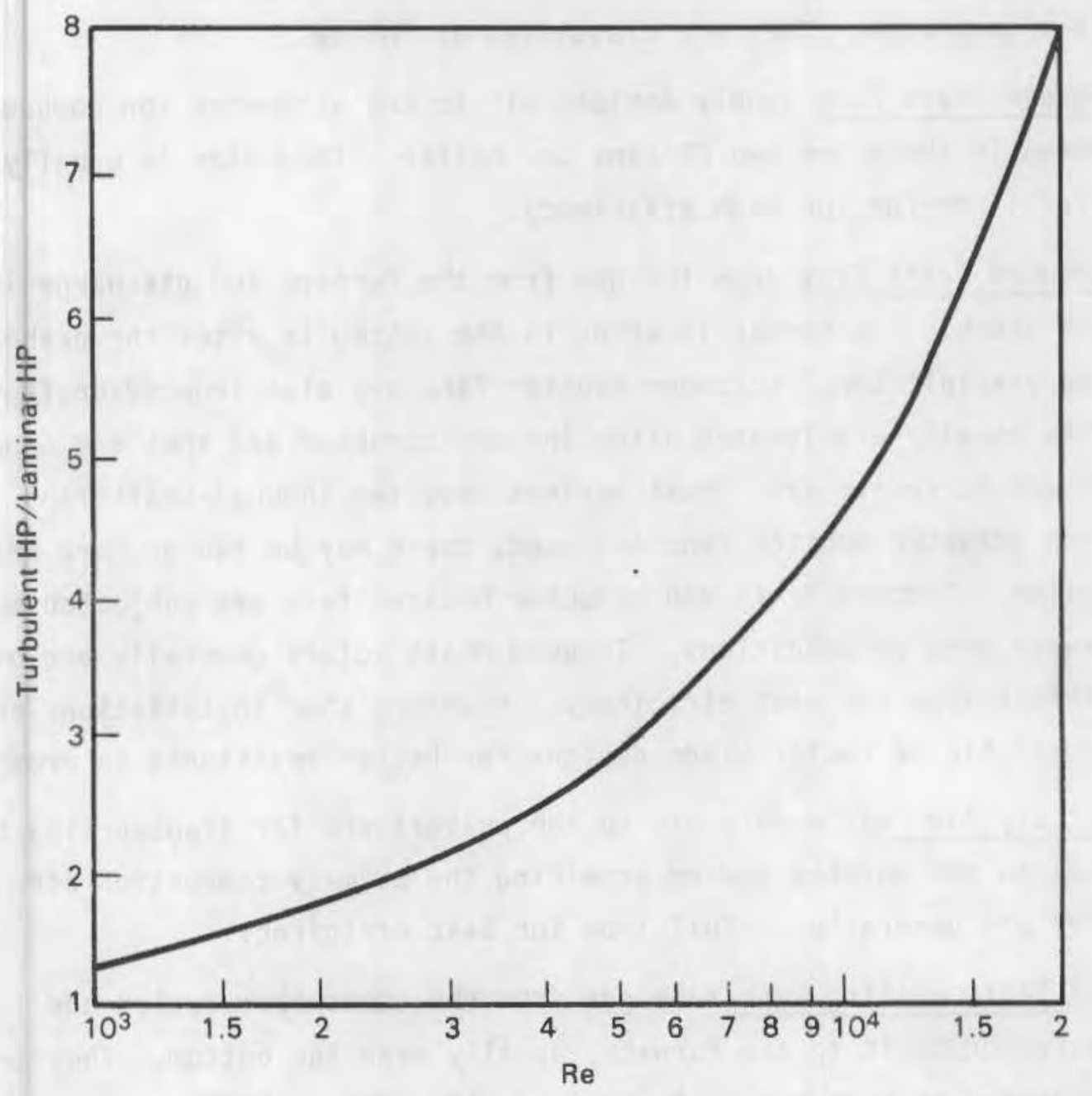

FIGURE 9.9. Power Loss in Turbulent Bearings 


\subsection{ACCESSORIES}

The accessories, as we have seen, consume about $10 \%$ to $15 \%$ of the power output of a utility to support the power plant and its services. As an estimate, one-tenth of that power may be dissipated in tribological components such as bearings, seals, gears, roller and other frictional elements. Thus, the total level of energy consumed or tribological elements would be on the order of $1 \%$ to $2 \%$ spread among a wide array of machine components. For this reason, the scrutiny here will be brief when efficiency is considered; more attention will be given to those factors that may affect plant reliability.

\subsubsection{Fans}

Fans are primarily used in connection with the operation of the furnace and steam generator. They are classified as follows:

- Forced Draft Fans supply ambient air to the windowbox for combustion. Normally there are two FD fans per boiler. The rotor is usually airfoil design for high efficiency.

- Induced Draft Fans draw the gas from the furnace and discharge it to the stack. The normal location in the system is after the preheater and precipitator. Scrubber booster fans are also induced-draft type. They usually are located after the wet scrubber and thus are exposed to wet corrosive gas. Most boilers have two induced-draft fans. When scrubber booster fans are used, there may be two or more per boiler. Induced-draft and scrubber booster fans are subjected to severe erosion conditions. Induced-draft rotors generally are of the airfoil type for best efficiency. However, some installations are of radial tip or radial blade designs for better resistance to erosion.

- Primary Air Fans supply air to the pulverizers for transporting the coal to the burners and/or providing the primary combustion air. They are generally airfoil type for best efficiency.

- Gas Recirculating Fans take gas from the economizer outlet and re-introduce it to the furnace, usually near the bottom. They are subjected to high temperatures (normally $700^{\circ}$ to $800^{\circ} \mathrm{F}$ ) and to severe erosion conditions. For these reasons, the rotor design is usually radial tip or radial blade with blade liners. 
The location of these fans in the furnace-boiler system is shown in Figure 9.10.

The failures of fans attributable to various specific causes are given in Table 9.2. As seen, in all cases of fans, bearings constituted the largest cause of failure, except in the induced fan category where bearings occupied second place. In all classes combined, bearings account for one-quarter of all

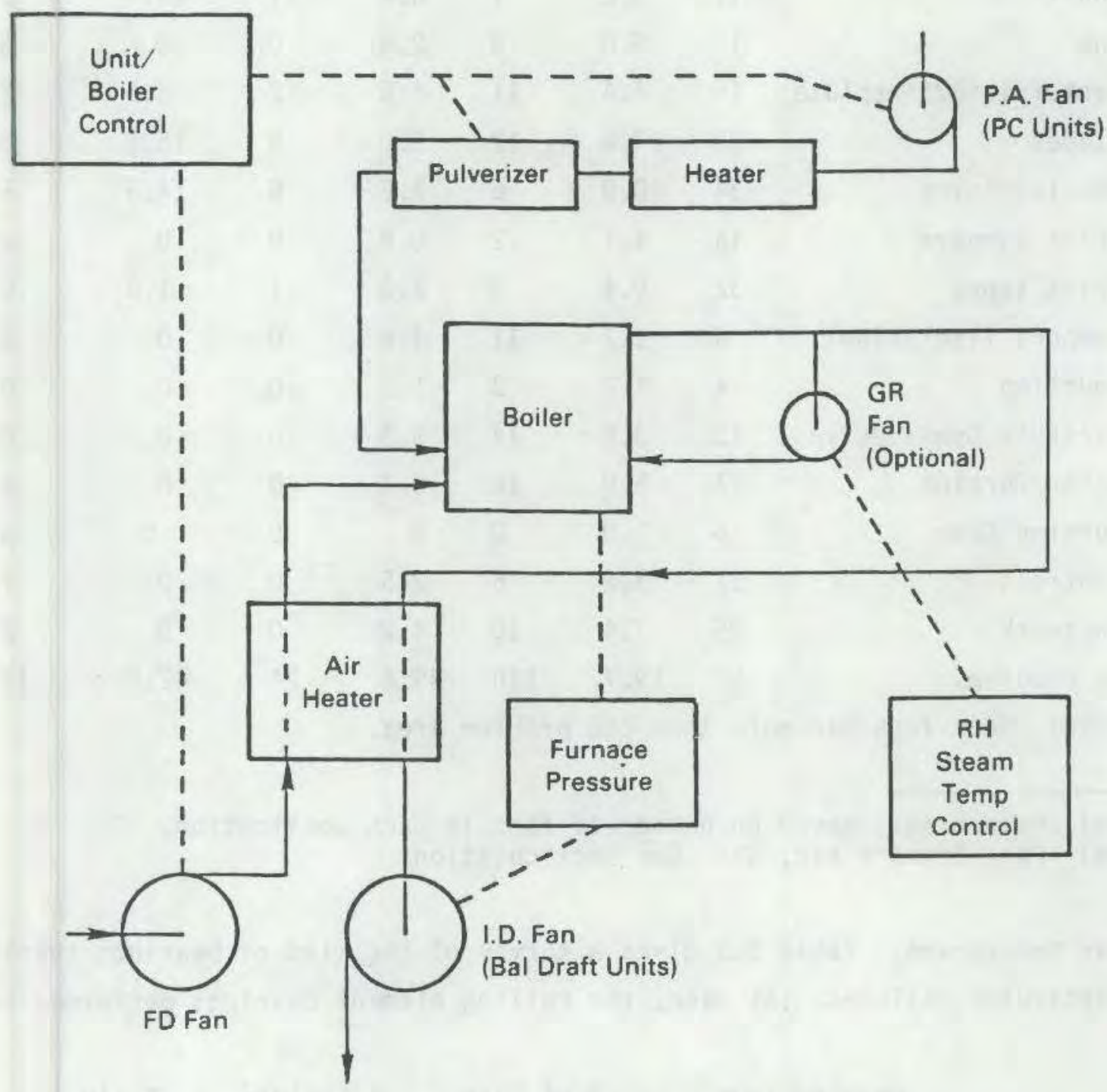

FIGURE 9.10. Furnace Boiler Draft System (46) 
TABLE 9.2. Summary of Centrifugal Fan Problem Areas According
to Applications $(47)$.

\begin{tabular}{|c|c|c|c|c|c|c|c|c|}
\hline & ID & $g(a)$ & $F D$ & $\%$ & $P A(b)$ & $q$ & $G R(b)$ & $q$ \\
\hline NUMBER OF FANS & 30 & 100.0 & 239 & 100.0 & 56 & 100.0 & 66 & 100.0 \\
\hline Foundation & 65 & 19.1 & 1 & 0.4 & 11 & 19.6 & 5 & 7.6 \\
\hline Pedestals & 12 & 3.5 & 4 & 1.7 & 0 & 0 & 0 & 0 \\
\hline Bearings & 66 & 19.4 & 79 & 33.1 & 22 & 39.3 & 11 & 16.7 \\
\hline Shaft & 11 & 3.2 & 1 & 0.4 & 11 & 19.6 & 3 & 4.5 \\
\hline Hub & 17 & 5.0 & 6 & 2.5 & 0 & 0 & 5 & 7.6 \\
\hline Centerplate/Sideplate & 15 & 4.4 & 11 & 4.6 & 2 & 3.6 & 2 & 3.0 \\
\hline Blades & 93 & 27.4 & 12 & 5.0 & 9 & 16.1 & 5 & 7.6 \\
\hline Housing/Boxes & 34 & 10.0 & 6 & 2.5 & 8 & 14.3 & 5 & 7.6 \\
\hline Inlet Dampers & 14 & 4.1 & 2 & 0.8 & 0 & 0 & 2 & 3.0 \\
\hline Inlet Vanes & 32 & 9.4 & 3 & 1.3 & 1 & 1.8 & 0 & 0 \\
\hline Dampers (Isolation) & 4 & 1.2 & 11 & 4.6 & 0 & 0 & 1 & 1.5 \\
\hline Coupling & 4 & 1.2 & 3 & 1.3 & 0 & 0 & 6 & 9.1 \\
\hline Variable Speed Drive & 13 & 3.8 & 14 & 5.9 & 0 & 0 & 0 & 0 \\
\hline Motor/Turbine & 17 & 5.0 & 16 & 6.7 & 0 & 0 & 1 & 1.5 \\
\hline Turning Gear & 6 & 1.8 & 0 & 0 & 0 & 0 & 4 & 6.1 \\
\hline Controls & 11 & 3.2 & 6 & 2.5 & 0 & 0 & 7 & 10.6 \\
\hline Ductwork & 25 & 7.4 & 10 & 4.2 & 0 & 0 & 2 & 3.0 \\
\hline No Problems & 67 & 19.7 & 118 & 49.4 & 24 & 42.9 & 17 & 25.8 \\
\hline
\end{tabular}

(a) Percentages based on number of fans in each application.

(b) PA: Primary Air, GR: Gas Recirculation.

fan breakdowns. Table 9.3 gives a survey of the kind of bearings involved in particular failures. As seen, the rolling element bearings performed poorly.

\begin{tabular}{|c|c|c|c|}
\hline Bearing Type & $\%$ of Fans & \& Failure & Ratio \\
\hline Sleeve & 88.9 & 87.2 & $\sim 1.0$ \\
\hline Rolling Element & 6.1 & 9.4 & 1.54 \\
\hline
\end{tabular}


TABLE 9.3. Lost Generation in Fans Due to Different Bearing and Lubrication Systems $(46)$

\begin{tabular}{|c|c|c|c|c|}
\hline Bearing Type & $\begin{array}{c}\text { Lubrication } \\
\text { System }\end{array}$ & $\begin{array}{c}\text { Percentage } \\
\text { of Total Fans } \\
\text { in Survey } \\
\end{array}$ & $\begin{array}{c}\text { Percentage } \\
\text { of } 299 \\
\text { Events Caused } \\
\text { by Bearings } \\
\text { and Lubrication }\end{array}$ & $\begin{array}{c}\text { Percentage } \\
\text { of Total of } \\
2,723,170 \mathrm{MWH} \\
\text { Lost } \\
\end{array}$ \\
\hline Sleeve & $\begin{array}{l}\text { Oil Ring } \\
\text { Circulating } \\
\text { Total }\end{array}$ & $\begin{array}{l}73.7 \\
15.2 \\
88.9\end{array}$ & $\begin{array}{l}68.8 \\
18.4 \\
87.2\end{array}$ & $\begin{array}{r}72.3 \\
8.7 \\
80.9\end{array}$ \\
\hline Rolling Element & $\begin{array}{l}\text { 0il Ring } \\
\text { Circulating } \\
\text { Total }\end{array}$ & $\begin{array}{l}0 \\
6.1 \\
6.1\end{array}$ & $\begin{array}{l}0 \\
9.4 \\
9.4\end{array}$ & $\begin{array}{l}0 \\
16.1 \\
16.1\end{array}$ \\
\hline $\begin{array}{l}\text { Hybrid (sleeve } \\
\text { combined with } \\
\text { rolling element) }\end{array}$ & $\begin{array}{l}0 i 1 \text { Ring } \\
\text { Circulating } \\
\text { Total }\end{array}$ & $\begin{array}{l}3.6 \\
1.4 \\
5.0\end{array}$ & $\begin{array}{l}1.7 \\
1.7 \\
3.4\end{array}$ & $\begin{array}{l}0.1 \\
2.8 \\
2.9\end{array}$ \\
\hline & Total All Fans & 100 & 100 & 100 \\
\hline
\end{tabular}

Finally, Table 9.4 gives the type of breakdown involved that caused the outage of the fan. Of the bearing failures, the major categories are:

- overheating - $27 \%$ of total

- vibration - $20 \%$ of total

- Tube system - $14 \%$ of total.

\subsubsection{Feedwater Pumps}

Feedwater pumps are the largest pieces of equipment in a utility after the turbo-generator set. The size and operating parameters of feedwater pumps are given in Table 9.5. They are the third largest cause of plant shutdowns. In 1981 , the cost to utilities of shutdowns due to feedwater pump failures amounted to $\$ 400$ million. (41)

A more detailed accounting of the cost due to feedwater pump breakdowns is given in Table 9.6. The main causes of these breakdowns are given in Table 9.7. As seen, the direct tribological elements are responsible for the following percentages:

- seals - $27.8 \%$

- wear rings - $10.7 \%$

- bearings - 3\% 
TABLE 9.4. Lost Generation Attribyted to Bearings and Lubrication System for All Fans in Survey ${ }^{46}$ )

Cause

Bearing Failures

Vibration Related

No cause given

Pedestal/support failure

Debris buildup

Direct vibration

Subtotal, vibration related

overheated (no cause given)

Involving motor/driver failure

Lubrication system failure

Lubricant leak

Lubricant contamination

Insufficient cooling

Design

Subtotal, bearing failures
Lost

Generation

MWH
Percentage

of

Total
549,278

100,025

6,903

2,065

658,271

741,746

488,367

188,777

166,661

24,866

5,107

333

$2,272,128$

132,450

78,846

41,702

21,064

13,881

6,444

2,000

481

296,868
20

2.7

0.25

0.08

24

27

18

6.9

6.1

0.91

0.19

0.01

83

Lubrication System (without a bearing failure)

Lubrication system failure (undefined)

Seals

Vibration related

Contamination

0il pressure

Wrong viscosity

Insufficient cooling

Subtotal, lubrication system

Bearing Overheated (without a bearing failure)

A1 ignment

Unknown

Design

Inadequate cooling

Subtotal, bearing overheated

Total Bearing and Lubrication System

\begin{tabular}{rr}
61,480 & 2.3 \\
40,893 & 1.5 \\
32,482 & 1.2 \\
19,319 & $\frac{0.71}{6}$ \\
\hline 154,174 & $\frac{1}{100}$
\end{tabular}


TABLE 9.5. Functional and Design Parameters of Main Boiler Feed Pumps (Fossil Units $600 \mathrm{MW}$ or Larger)

Parameter

Design

Total Oynamic Head

(TDH) - $\mathrm{ft}$

Design Flow (gpm)

Design Suction

Pressure

(psi)

Design Discharge

Pressure

(psi)

Design Suction

Temperature

$\left({ }^{\circ} \mathrm{F}\right)$

Design Speed

(rpm)

Size

(hp)

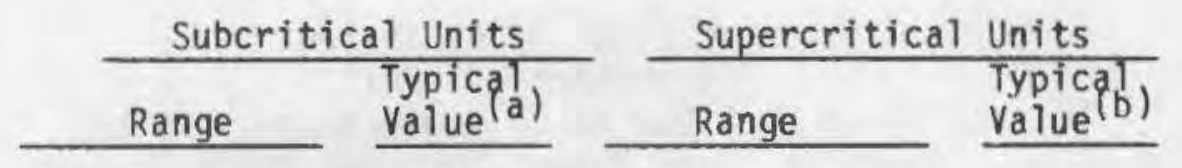

$$
6,500-7,700
$$

7,700

$10,800-12,500$

10,950

$5,500-16,000$

11,500

$5,000-22,000$

6,940

$120-220$

211

$160-450$

320

$2,700-3,260$

3,164

$4,200-4,760$

4,500

$300-360$

360

$340-414$

363

$3,600-6,000$

5,200

$3,600-6,000$

5,500

$9,000-28,500$

24,000

$13,000-66000$

22,500

(a) Typical values for subcritical boiler feed pumps based on modern 800 -MW plant with two $50 \%$ pumps.

(b) Typical values for supercritical boiler feed pumps based on modern $750-$ MW plant with two $50 \%$ pumps.

The total is $41.5 \%$. When one considers that vibration and shaft damage often occur due to bearing and stability problems, it is safe to say that tribological inadequacies are responsible for at least one half of all feedwater pump problems of which the seals are the most critical item.

\subsubsection{Coal Handling Equipment}

The function of a pulverized-coal system is to pulverize the coal, deliver it to the fuel-burning equipment, and accomplish complete combustion in the 
TABLE 9.6. Cost of Lost Generation Due to Feedwater Pump Problems at Nuclear and Fossil Generating Stations (41)

\begin{tabular}{|c|c|c|c|c|c|c|}
\hline Unit Type & $\begin{array}{l}\text { Unit } \\
\text { Calendar } \\
\text { Years } \\
\end{array}$ & $\begin{array}{l}\text { Lost } \\
\text { Generation } \\
\text { Due to } \\
\text { Feed Pumps } \\
\text { (MW - HRS) }\end{array}$ & $\begin{array}{c}\text { Equivalent } \\
\text { Full } \\
\text { Power Hours } \\
\text { Lost Due to } \\
\text { Feed Pumps } \\
\end{array}$ & $\begin{array}{l}\text { MW-HRS } \\
\text { Lost Per } \\
\text { Unit Year } \\
\end{array}$ & $\begin{array}{c}\text { Equivalent } \\
\text { Full Power } \\
\text { Hours } \\
\text { Lost Per } \\
\text { Unit-Year } \\
\end{array}$ & $\begin{array}{l}\text { Cost of } \\
\text { Lost } \\
\text { Genera- } \\
\text { tion Per } \\
\text { Unit-Year }\end{array}$ \\
\hline Nuclear & 227.4 & $4,134,893$ & 5691 & 18,200 & 25 & $\$ 440,000$ \\
\hline Fossil & 107 & $5,639,000$ & 7147 & 52,700 & 67 & $\$ 1,000,000$ \\
\hline
\end{tabular}

Note:

(1) Figures represent replacement power costs of $\$ 24$ and $\$ 19$ per MW-HR, respectively, for nuclear and fossil generation as reported in "1978 Economic Survey Results: Nuclear Power Generation Costs Stable, Reliability Improved," Atomic Industrial Forum Inc., May 14, 1979. These figures represent the total cost differential of producing power at the bus bar, assuming that the replacement power is generated by oil-fired units.

TABLE 9.7. Pump Failure Rankings (41)

\begin{tabular}{|c|c|c|c|c|c|}
\hline Pump Failures & $\begin{array}{r}\text { Feedpump } \\
\text { Outages } \\
\end{array}$ & $\begin{array}{c}\text { Average } \\
\text { Hours } \\
\text { Outage } \\
\end{array}$ & Hours & $\begin{array}{c}\% \text { of Grand } \\
\text { Total } \\
\end{array}$ & $\begin{array}{l}\text { Relative } \\
\text { Ranking } \\
\end{array}$ \\
\hline $\begin{array}{l}\text { Cavitation, unstable } \\
\text { head curve, impeller } \\
\text { breakage, vibration }\end{array}$ & 650 & 48 & 31,200 & 45 & 1 \\
\hline Seals & 602 & 32 & 19,264 & 27.8 & 2 \\
\hline Wear rings & 155 & 48 & 7,440 & 10.7 & 3 \\
\hline Axial balancing device & 337 & 16 & 5,392 & 7.8 & 4 \\
\hline Shaft broken/damaged & 77 & 48 & 3,696 & 5.3 & 5 \\
\hline Journal bearing & 209 & 8 & 1,672 & 2.4 & 6 \\
\hline \multirow[t]{2}{*}{ Thrust bearing } & 58 & 8 & 464 & 0.57 & 7 \\
\hline & & & 69,128 & & \\
\hline
\end{tabular}

furnace with a minimum of excess air. The basic equipment components of a pulverized-coal system, shown in Figure 9.11, are:

- raw-coal feeder

- pulverizer fan, also known as the primary-air fan, arranged as a blower (or exhauster) 


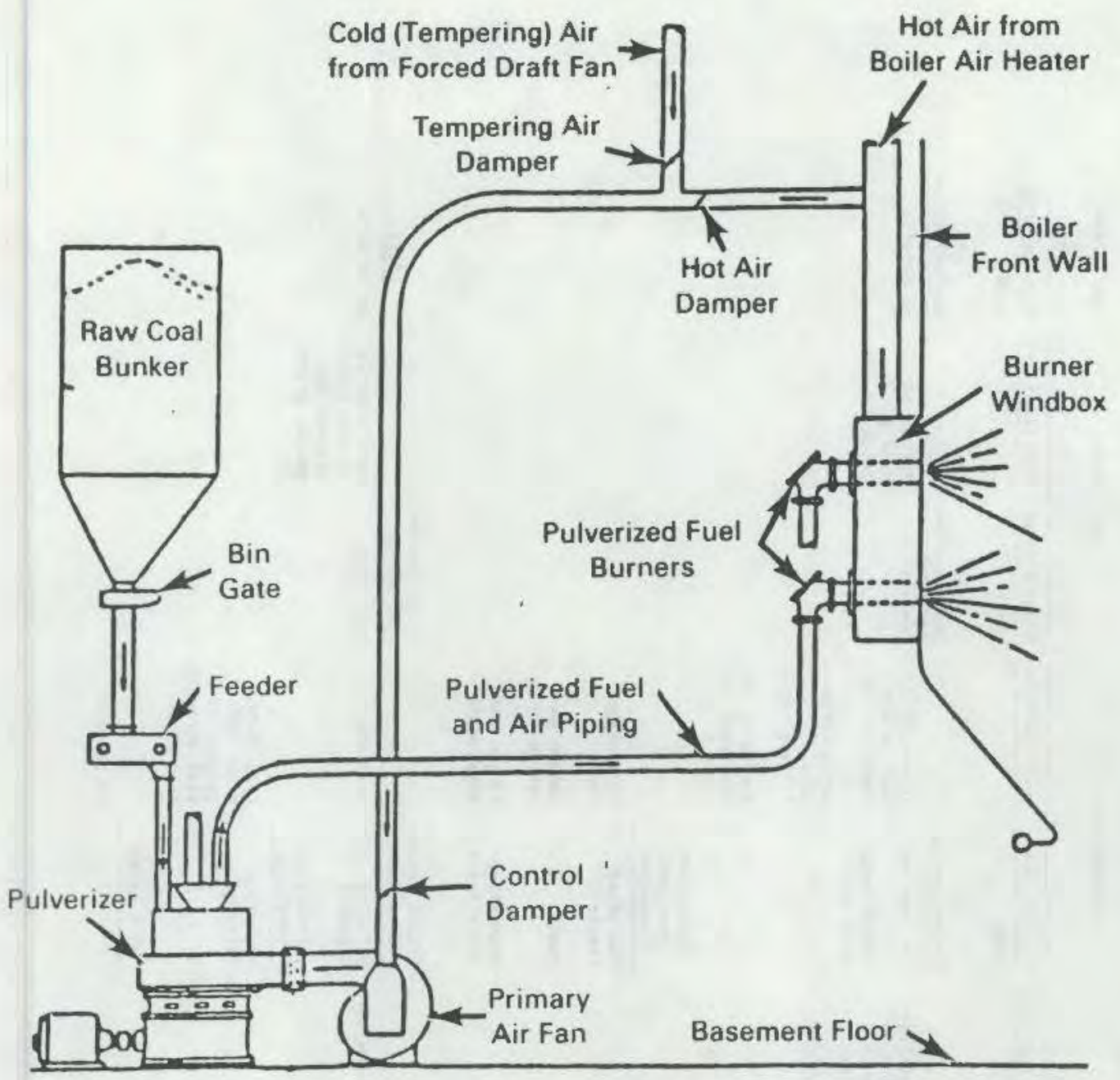

FIGURE 9.11. Direct-Firing System for Pulverized Coal

- pulverizer arranged to operate under pressure (or suction).

Tables 9.8 and 9.9 give summaries of the problem areas generic to the pulverizing units. As seen, the major causes of difficulties are:

- wear of grinding elements

- oil contamination

- gearboxes

- seals

- bearings.

Some of these, such as wear or seal problems, were reported as problem areas by nearly all surveyed plants. Thus, tribological difficulties are the key causes of outages caused by the coal handling system. 
TABLE 9.8. Causes of Pulverizer System Breakdowns (48)

\begin{tabular}{|c|c|c|c|c|c|c|c|c|c|}
\hline \multirow[t]{2}{*}{$\begin{array}{l}\text { Units } \\
\text { MIIIs }\end{array}$} & \multicolumn{2}{|c|}{$\begin{array}{c}\text { Bow } 1 \text { MIIIs } \\
40 \\
276\end{array}$} & \multicolumn{2}{|c|}{$\begin{array}{c}\text { Rol I-Race } \\
? \\
59\end{array}$} & \multicolumn{2}{|c|}{$\begin{array}{c}\text { Planetizing RotI } \\
52 \\
52\end{array}$} & \multicolumn{2}{|c|}{$\begin{array}{c}\text { Bolf-Rece } \\
7 \\
36\end{array}$} & \multirow{3}{*}{$\begin{array}{c}\text { Ball/Tube } \\
6 \\
18 \\
\text { Problen Aroo }\end{array}$} \\
\hline & Problom Areo & Modificotions & Problem Aros. & Modifications & Problem Aroo & Moditications & Problem Aroo & Mod If I cations & \\
\hline \multirow{8}{*}{$\begin{array}{l}\text { Drive } \\
\text { Train }\end{array}$} & $(545)(8)$ & & $(145)$ & & $\overline{(675)}$ & & $\overline{(575)}$ & & \\
\hline & $\begin{array}{c}\text { ol1 } \\
\text { Contominatlon }\end{array}$ & & Gearbox & & $\begin{array}{c}\text { oll } \\
\text { Contamination }\end{array}$ & & $\begin{array}{c}\text { Ofl } \\
\text { Contanlnation }\end{array}$ & . & $\begin{array}{c}\text { Oll } \\
\text { Contoalnation }\end{array}$ \\
\hline & low seal alr & $\begin{array}{l}\text { soal alr } \\
\text { cappefity } \\
\text { Wu }\end{array}$ & $\begin{array}{l}\text { O-ring } \\
\text { probitons }\end{array}$ & $\begin{array}{l}\text { No detalis-- } \\
\text { gearbol no } \\
\text { longer a" } \\
\text { problom }\end{array}$ & $\begin{array}{l}\text { low soal alr } \\
\text { cooter supply } \\
\text { vater wall }\end{array}$ & $\begin{array}{l}\text { Incroasod } \\
\text { seal in air } \\
\text { capacity (U) }\end{array}$ & low seat air & $\begin{array}{l}\text { Incroased } \\
\text { soal air } \\
\text { capecity (U) }\end{array}$ & no detalls \\
\hline & burned seals & $\begin{array}{l}\text { trequent oll } \\
\text { analysis } \\
\text { (overy two } \\
\text { months) }\end{array}$ & $\begin{array}{l}\text { thrust beor- } \\
\text { Ings lost }\end{array}$ & & & $\begin{array}{l}\text { extro large } \\
\text { lubo oll } \\
\text { fliters (U) } \\
\text { synthetlic oll } \\
\text { lubrleant (U) }\end{array}$ & & & \\
\hline & $\begin{array}{l}\text { Excessive } \\
\text { Shatt } \\
\text { Breakoge }\end{array}$ & & . & & $\begin{array}{l}\text { Excesss lve } \\
\text { Woar and } \\
\text { Breakege }\end{array}$ & & & & \\
\hline & $\begin{array}{l}\text { Improper roll } \\
\text { adjustment }\end{array}$ & $\begin{array}{l}\text { spring com- } \\
\text { comprosslom } \\
\text { reduced (M) }\end{array}$ & & & $\begin{array}{l}\text { low speed } \\
\text { shafts }\end{array}$ & $\begin{array}{l}\text { new design } \\
(M / U)\end{array}$ & & & \\
\hline & bear Ings & resset rolls & & & gears & $\begin{array}{l}\text { larger goer } \\
\text { system (M/U) }\end{array}$ & & & \\
\hline & & $\begin{array}{l}\text { lerger beor- } \\
\text { lngs (U) }\end{array}$ & & & $\begin{array}{l}\text { underslzed } \\
\text { drive troln }\end{array}$ & $\begin{array}{l}\text { larger beor- } \\
\text { lngs (W/U) }\end{array}$ & & & \\
\hline \multirow[t]{6}{*}{$\begin{array}{l}\text { Grinding } \\
\text { Areo }\end{array}$} & $\begin{array}{l}\text { (358) Exces- } \\
\text { sive Hoor }\end{array}$ & & $\begin{array}{l}\text { (298) Rolls } \\
\text { Crecking }\end{array}$ & & $\begin{array}{l}(100 \$) \text { Excos- } \\
\text { sive Noor } \\
\end{array}$ & & $\begin{array}{l}\text { (15s) Exces- } \\
\text { sive }\end{array}$ & & (333) \\
\hline & rolls/rings & $\begin{array}{l}\text { Hard faced } \\
\text { rolis (M/U) }\end{array}$ & & New materlal & $\begin{array}{l}\text { grinding } \\
\text { olements }\end{array}$ & no detalls & ball/ring & $\begin{array}{l}\text { wear mater lol } \\
\text { on balls In- } \\
\text { creased for }\end{array}$ & no detalls \\
\hline & IIners & NIHerd & & & $\begin{array}{l}\text { Excessive } \\
\text { Brooksoge. }\end{array}$ & & & $\begin{array}{l}\text { better grind } \\
\text { (U) }\end{array}$ & \\
\hline & & $\begin{array}{l}201 \text { ehrom } \\
\text { surface }\end{array}$ & & & $\begin{array}{l}\text { thrusting } \\
\text { fallure }\end{array}$ & $\begin{array}{l}\text { hlgh carbon } \\
\text { steel (U) } \\
\text { (higher ton- }\end{array}$ & & & \\
\hline & & $\begin{array}{l}\text { Iorger } \\
\text { I1nors (M) }\end{array}$ & & & & $\begin{array}{l}\text { sIle strength } \\
\text { then MI hard) }\end{array}$ & & & \\
\hline & & & & & IIII Sklds & & & & \\
\hline
\end{tabular}


TABLE 9.8. (contd)

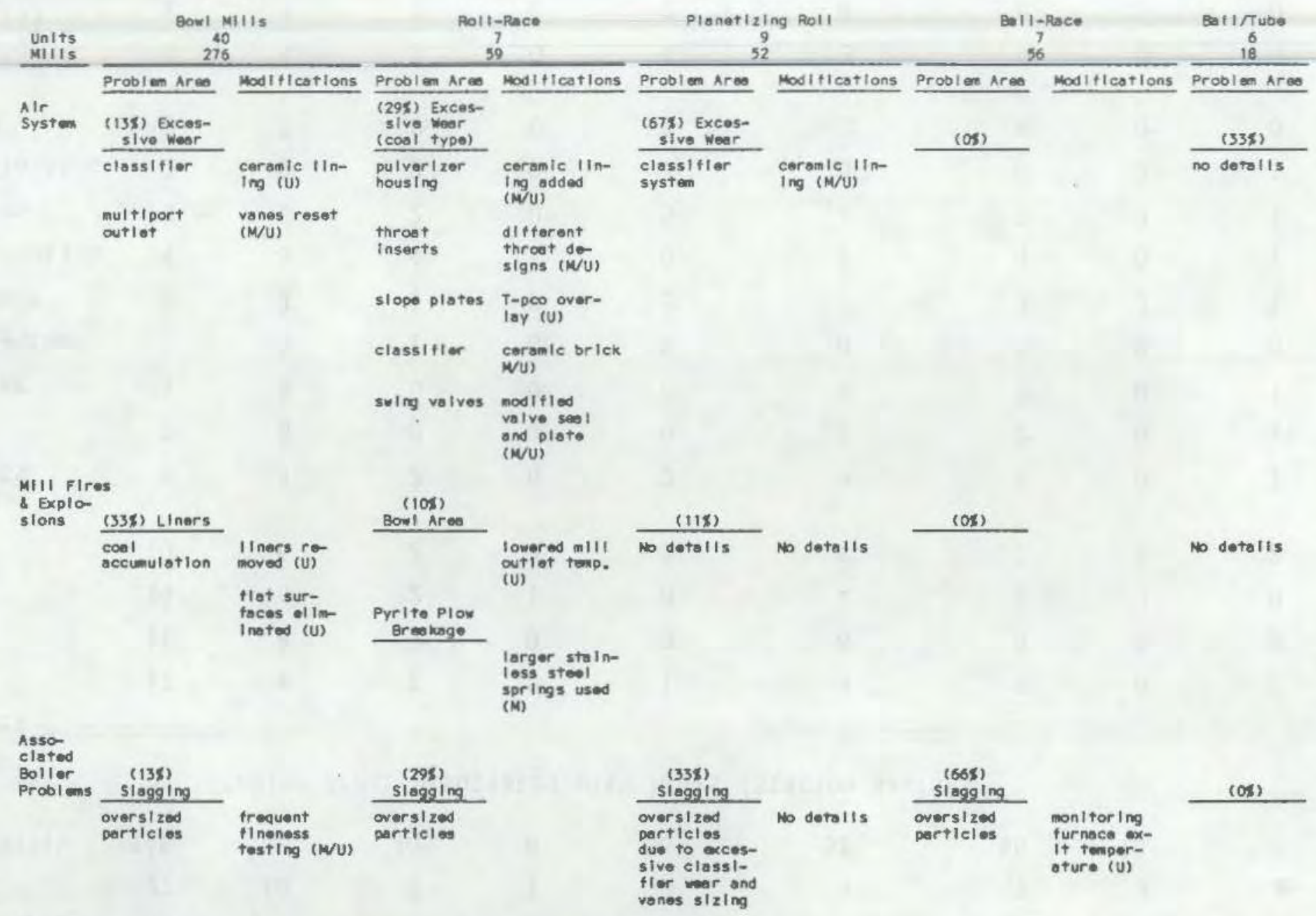

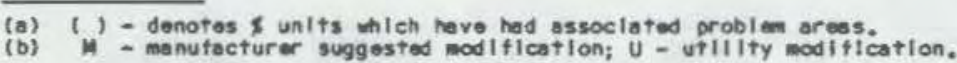


TABLE 9.9. Pulverizer Problem Areas on a Station Basis

\begin{tabular}{|c|c|c|c|c|c|c|c|c|c|}
\hline & $\begin{array}{c}\text { Press. } \\
\text { Bowl }\end{array}$ & $\begin{array}{l}\text { Press } \\
\text { Suction } \\
\text { Bowl } \\
\end{array}$ & $\begin{array}{l}\text { Suction } \\
\text { Bowl } \\
\end{array}$ & $\begin{array}{l}\text { Deep } \\
\text { BowI }\end{array}$ & Roll-Race & $\begin{array}{l}\text { Planetizing } \\
\text { Roll } \\
\end{array}$ & Ball-Race & Ball & Ball/Tube \\
\hline \multicolumn{10}{|l|}{$\begin{array}{l}\text { Number of } \\
\text { Stations }\end{array}$} \\
\hline Number of Mills & 146 & 82 & 40 & 8 & 58 & 52 & 56 & 18 & 9 \\
\hline & & Problem A & treas Asso & ciated & with Mills & (Station Bas & is) & & \\
\hline \multicolumn{10}{|l|}{ Problem Area } \\
\hline Gearbox & 12 & 8 & 2 & 0 & 1 & 8 & 6 & 0 & 2 \\
\hline Bearings & 11 & 8 & 3 & 0 & 0 & 6 & 6 & 3 & 2 \\
\hline Shafts & 14 & 6 & 2 & 1 & 0 & 4 & 0 & 3 & 0 \\
\hline Seals & 10 & 6 & 2 & 0 & 3 & 4 & 7 & 3 & 2 \\
\hline $\begin{array}{l}\text { Grinding } \\
\text { Elements }\end{array}$ & 8 & 4 & 2 & 0 & 2 & 9 & 1 & 0 & 1 \\
\hline Motor & 2 & 0 & 0 & 0 & 0 & 1 & 2 & 0 & 1 \\
\hline Classifier & 1 & 0 & 0 & 0 & 0 & 6 & 0 & 0 & 1 \\
\hline Pyrite System & 3 & 0 & 1 & 0 & 2 & 0 & 0 & 0 & 0 \\
\hline Excess Wear & 8 & 3 & 1 & 0 & 2 & 7 & 3 & 3 & 1 \\
\hline Excess Breakage & 4 & 3 & 4 & 1 & 0 & 7 & 0 & 0 & 1 \\
\hline Mill Fires & 6 & 5 & 2 & 0 & 5 & 1 & 0 & 3 & 1 \\
\hline Mill Explosions & 0 & 0 & 2 & 0 & 3 & 0 & 0 & 3 & 1 \\
\hline Slagging & 3 & 2 & 0 & 0 & 2 & 3 & 6 & 0 & 0 \\
\hline $\begin{array}{l}\text { Trash (a) } \\
\text { Separators }\end{array}$ & 4 & 4 & 2 & 0 & 4 & 3 & 0 & 0 & 0 \\
\hline Crushers (a) & 4 & 2 & 1 & 0 & 2 & 0 & 0 & 0 & 0 \\
\hline
\end{tabular}

(a) Ancillary equipment associated with the mill. 


\subsubsection{Lube 0il System}

The lube oil system in modern power plants utilizes three independent methods for pumping oil to the bearings and other parts, as shown in Figure 9.12. The primary pumping system consists of the main shaft and booster pumps. The hydraulic turbine-driven booster pump, mounted in the main oil tank, provides the required suction pressure for the main shaft pump. The latter is mounted at the turbine end and is driven by the turbine shaft. This primary pumping system is self-sustaining at speeds about $80 \%$ rated speed. During startup and shutdown operations, the motor driven suction pump develops the necessary suction pressure for the main shaft pump.

A separate $A C$-motor-driven turning gear oil pump serves as backup for the primary pumping system, as does the $D C$-motor-driven emergency oil pump, which comes into action when $A C$ power is not available. All pumps are of the centrifugal type and, except for the primed main shaft pump, take suction directly from the main oil tank.

In many plants, hydrostatic lift pockets are provided in the bearings for supporting the shaft when it is running at turning gear conditions, i.e., somewhere from 5 to $20 \mathrm{rpm}$. A pumping system for this operation is shown in Figure 9.13. The oil tank is designed to adequately remove air entrained in the lube oil and to permit the settling of particulates. Two full-size coolers, arranged in parallel, control oil temperature.

The two major causes of lube system inadequacy, leading to plant outages are contamination of the oil with particulates and water, and pump failures due either to improper power switching or crew negligence. Free water in oil (emulsions) may impair oil circulation, remote rust and corrosion, and interfere with iubrication. Particulates may cause abrasive wear of bearings and seals, plug oil lines, and result in faulty control functioning of those units where the control and lubricating oil systems are common. The outages caused by oil contamination are shown in Figure 9.14. In addition, there were bearing outages which were not forced, i.e., preventive outages. 


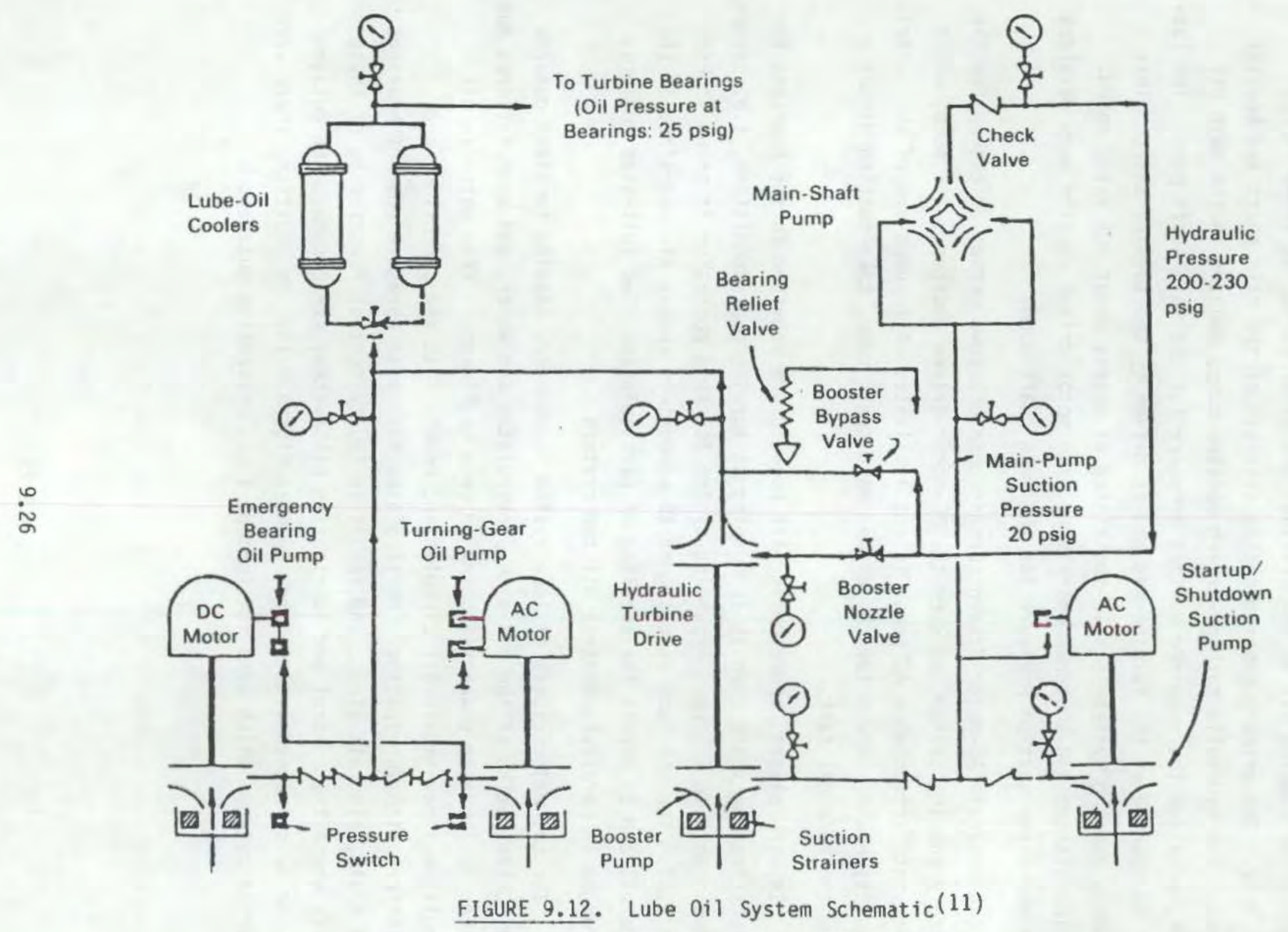

FIGURE 9.12. Lube 0il System Schematic(11) 

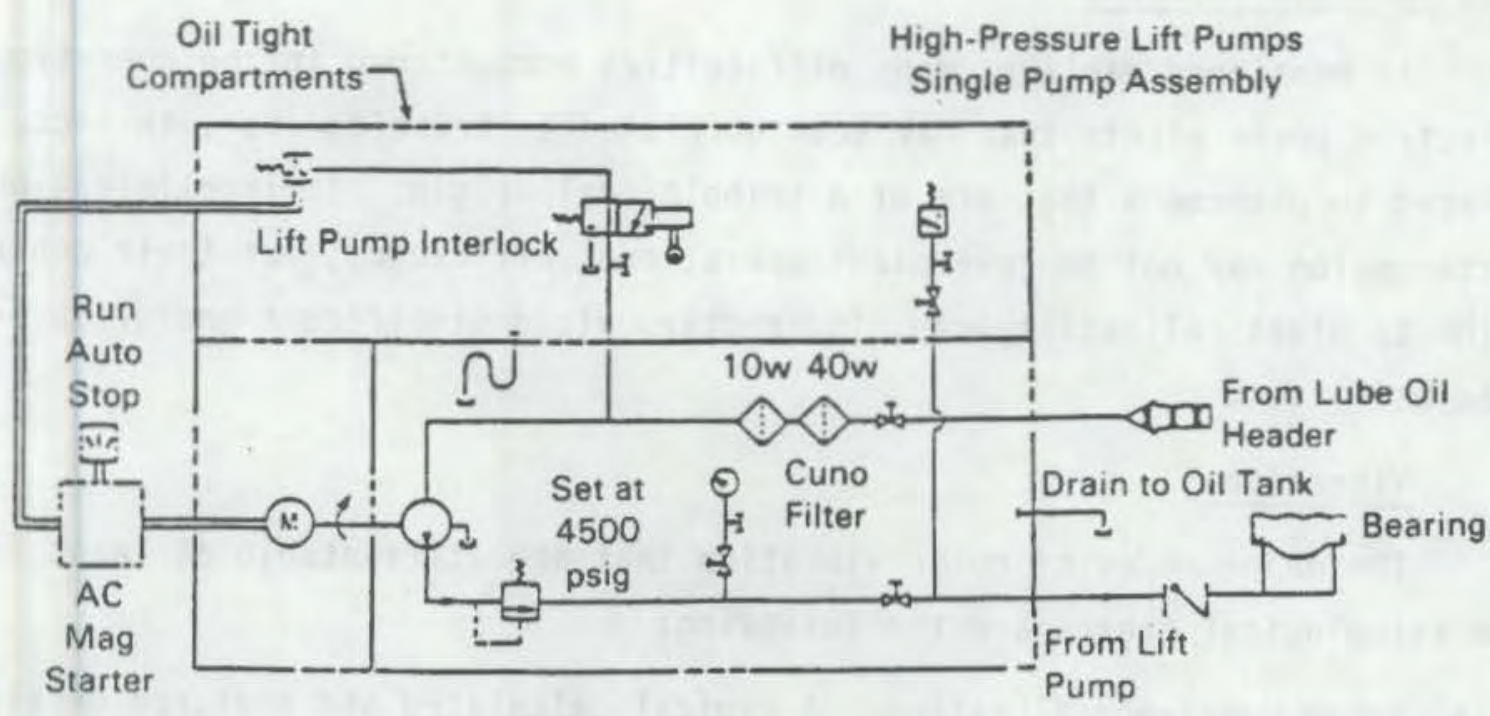

FIGURE 9.13. Lift Pump System Schematic

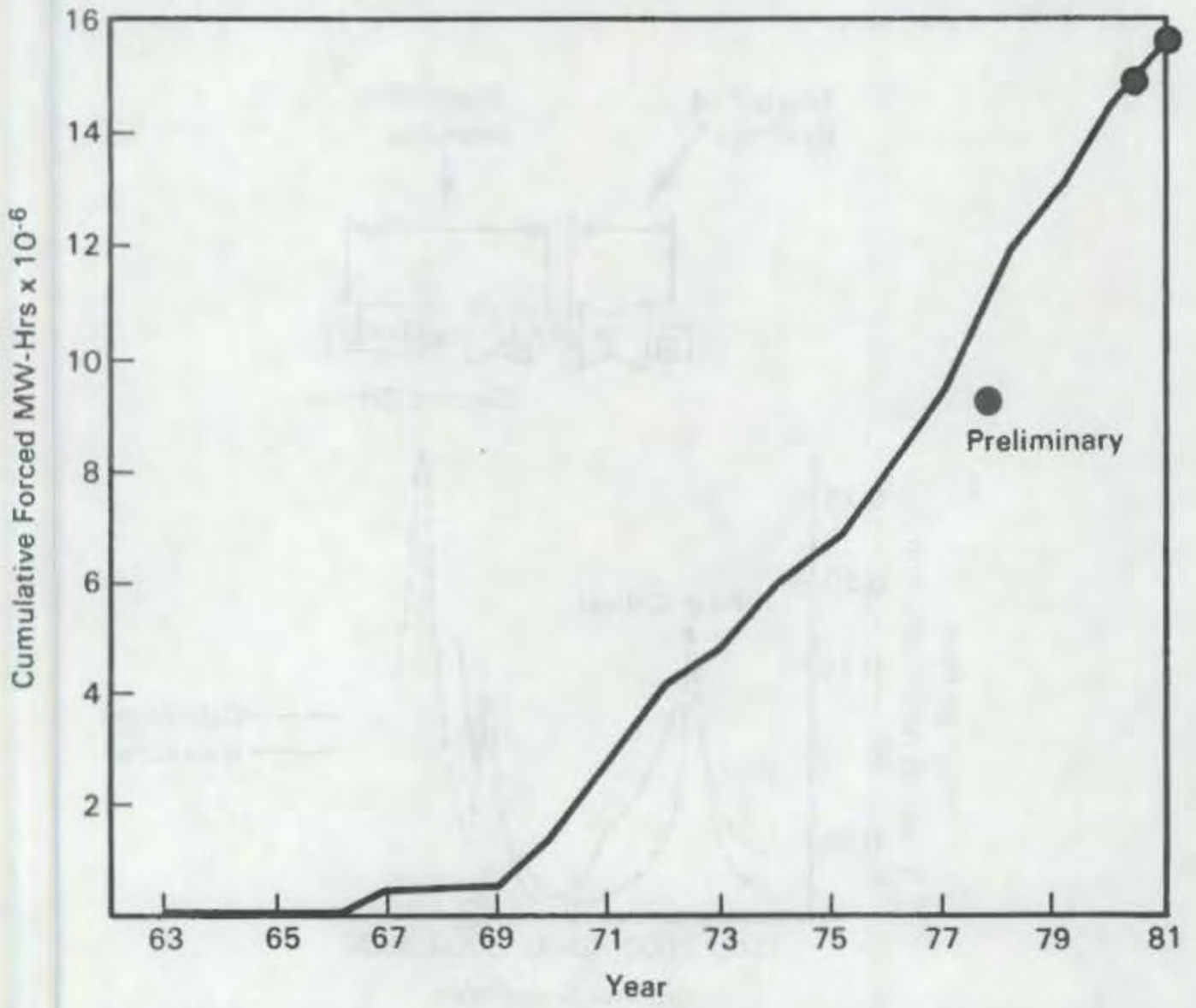

FIGURE 9.14 Cumulative Forced Outage Megawatt-Hours due to Contaminated 0il 


\subsection{GENERIC PROBLEMS}

As mentioned earlier, many difficulties encountered in the operation of electric power plants that may seem unrelated to tribology can, in fact, be traced to phenomena that are of a tribological origin. Their elimination or attenuation may not improve plant operational efficiency, but their contribution to plant reliability can, indirectly, yield significant energy savings for the utilities.

\section{Vibrations}

The major modes of rotor vibration that are attributable at least in part to tribological causes are the following:

- Rotor Unbalance Vibration. A typical calculated and measured unbalance vibration on a 350-MW unit is shown in Figure 9.15. While the origin of this vibration is mechanical in nature, the intensity of
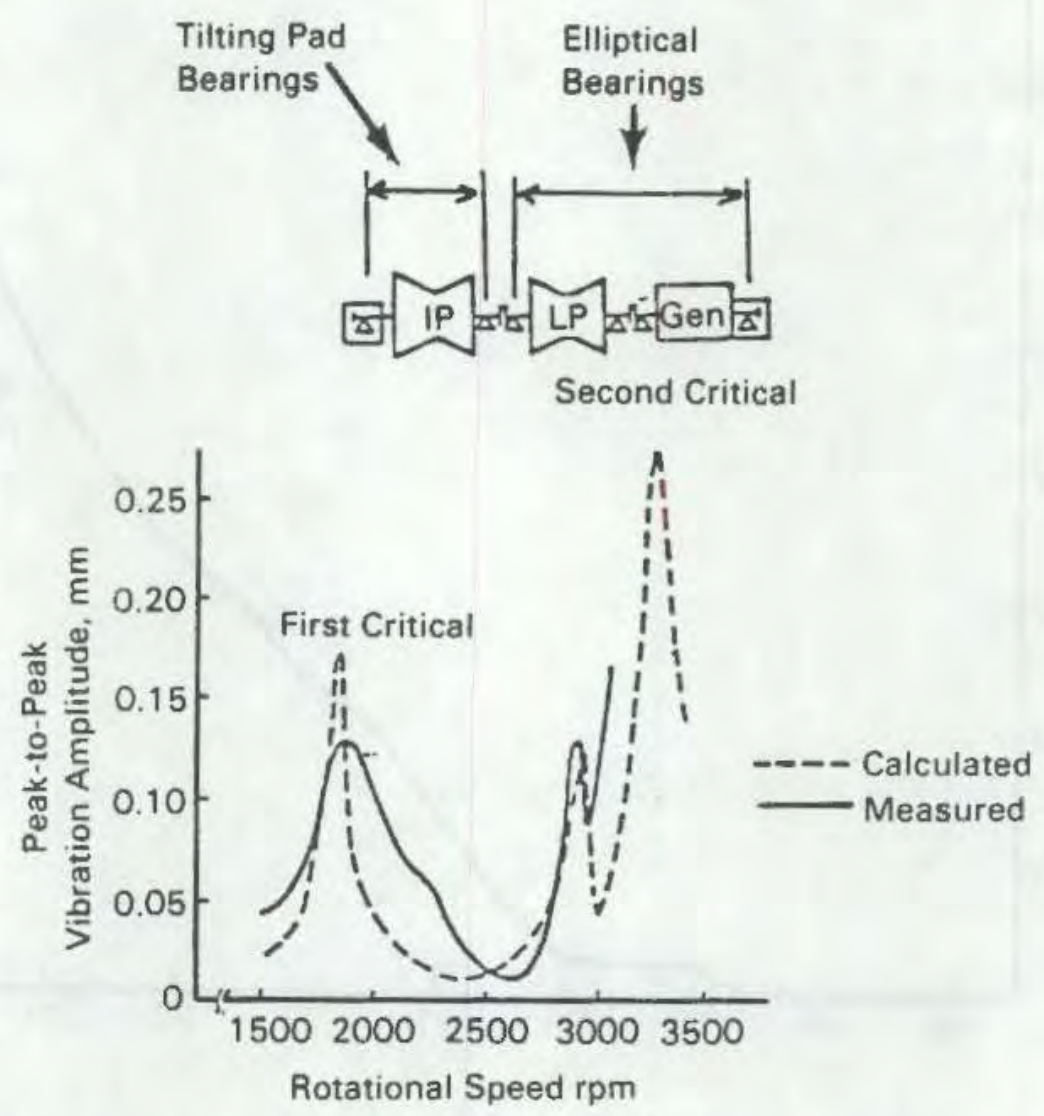
FIGURE 9.15. Unbalance Respgnse of a 350-MW Steam-Turbine and
Generator Unit 
vibration once it occurs depends very much on the damping characteristics of the numerous bearings supporting the rotor. Both the kind of bearings used, their loading, operational conditions, position, degree of misalignment, and others, all have an effect on the amount of damping and thus, on the amplitudes of vibration. The bearings also affect the rotor's natural frequencies. An example of the pronounced difference in response produced by different bearing designs is shown in Table 9.10 where a vibration caused by loss of part of a bucket produced peak to peak amplitudes of $87 \mathrm{mils}$ using a conventional sleeve bearing, but only 38 mils using a tilting pad design. While the amplitude was reduced below one half, the level of transmitted force decreased to about one quarter.

- 0il Whirl. Unlike the unbalance vibration, oil whirl is a self excited vibration originating in the bearings. While the unbalance vibration frequency is synchronous, oil whirl frequency runs from about 0.47 to 0.5 of the running frequency. An example of the different stability characteristics of various bearings is shown in

\footnotetext{
TABLE 9.10. Oynamics of Low-Pressure Steam Turbine with Loss of a
Last-Stage Blade $(\mathrm{N}=3600 \mathrm{rpm})$

TABLE 9.10. Oynamics of Low-Pressure Steam Turbine with Loss of a
Last-Stage Blade $(\mathrm{N}=3600 \mathrm{rpm})$
}

Case 1:

Rotor Supported

Peak-To-Peak Journal

Vibration

Peak Dynamic Bearing Force (1bs) Transmissibility

Bearing Min(mils) on Fixed-Arc

Journal

Bearings

87

184,000

3.68

0.1

(Indicates severe babbit wiping)

Case 2:

Rotor Supported on Pivoted-Pad 38

46,700

0.93

2.0

(Indicates Journal

Bearings maintenance of noncontracting full-film lubrication) 
Figure 9.16. The upper parts of these curves represent unstable zones and the lower part represents stable zones. Taking the example of a rotor-bearing system whose operating point is " 0 ", this point will move in the direction " $0 \rightarrow A$ " as the rotational speed of the rotor increases and will eventually cross the stability limit curve. The
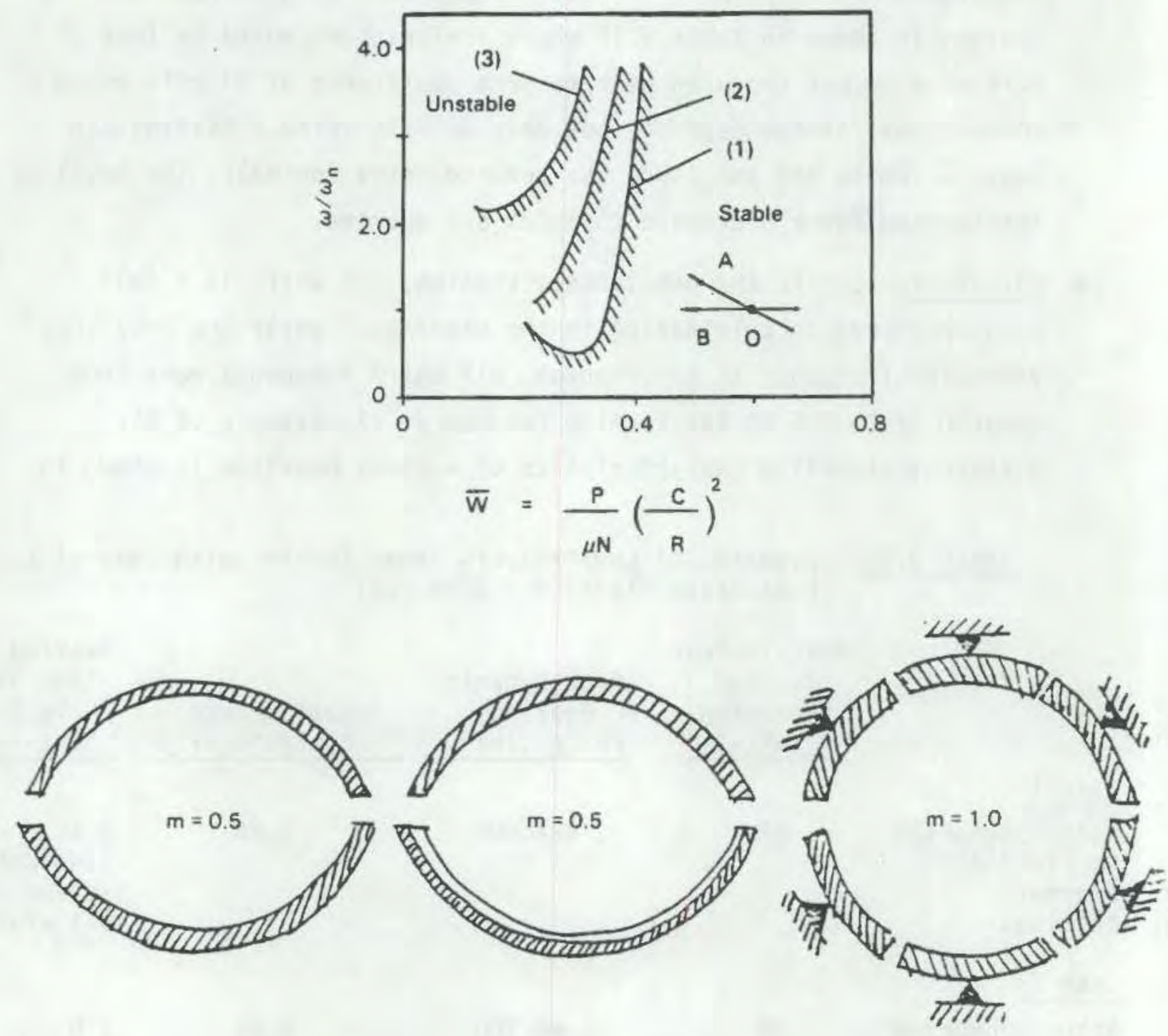

(1) Elliptical

(2) Elliptical with Circumferential

(3) Tilting Pad Groove $D=20^{\circ},(L / D)=0.6,(C / R)=1.3 \times 10^{-3}$

FIGURE 9.16. 0il Whirl Stability Characteristics of Three Bearing Designs 
crossover point represents the limiting stable speed of this rotorbearing system. The point also moves in the direction of " $0 \rightarrow B$ " by changing other bearing parameters such as load, oil temperature and clearance ratio. Low unit loadings on the bearings are usually the most common cause for oil whirl (low loads move the line along " $0 \rightarrow B$ " in Figure 9.16) and most turbo-generator bearings are overdesigned in that respect, usually for reasons of high bearing damping. But other elements of the rotor design and operation can cause oil whirl such as the unloading of one or more bearings due to rotor-bearing misalignment. This misalignment can, as shown in Figure 9.17, be of two sorts. Part (a) in this figure shows the shape of a typical rotor as it deflects due to its normal bending mode. Due to this misalignment, some of the bearings will be underloaded. The other form of unloading journal bearing and one which is more serious and very often causes severe problems, is the mode portrayed in part (b). Here, even assuming a parallel rotor, a shift in foundation and pedestals causes some of the bearings to be partly or completely unloaded, and in some cases to be loaded sideways or even on top, with serious consequences to the dynamic characteristics of the system. Additional change in bearing loading can result from bearing wear incurred during prolonged turning gear operation.

- Steam Whirl. Steam whirl is an instability caused by steam forced generated in the small clearances between stationary and rotating components of the machine. The destabilizing forces might lie in the dynamic behavior of the labyrinth seals or in the unbalanced torque force of the turbine blades. These forces can be generated when a rotor is displaced by a distance " $e$ " from the equilibrium point by a lateral force $W_{X}$ perpendicular to the displacement and a radial force $W_{y}$ parallel to the displacement. The dynamics of such a system can be represented $(50)$ by:

$$
\left[\begin{array}{l}
\Delta F_{x} \\
\Delta F_{y}
\end{array}\right]=\left[\begin{array}{c}
-W_{y} / e, W_{x} / e \\
-W_{x} / e,-W_{y / e}
\end{array}\right]\left[\begin{array}{l}
x \\
y
\end{array}\right]=\left[\begin{array}{cc}
-k_{y} & k_{x} \\
-k_{x} & k_{y}
\end{array}\right]\left[\begin{array}{l}
x \\
y
\end{array}\right]
$$

where $k_{y}$ and $k_{x}$ represent flow induced spring constant. 


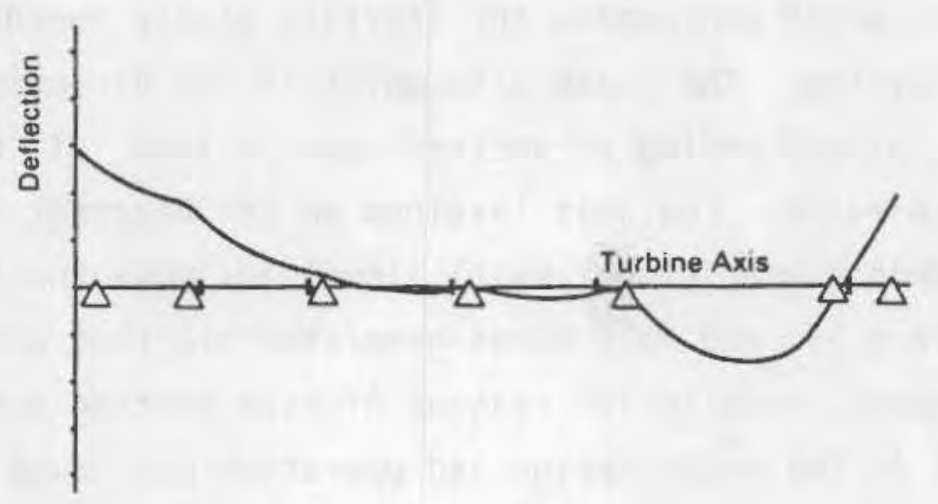

a) Bending Line of a Typical $500 \mathrm{MW}$ Turbine Generator

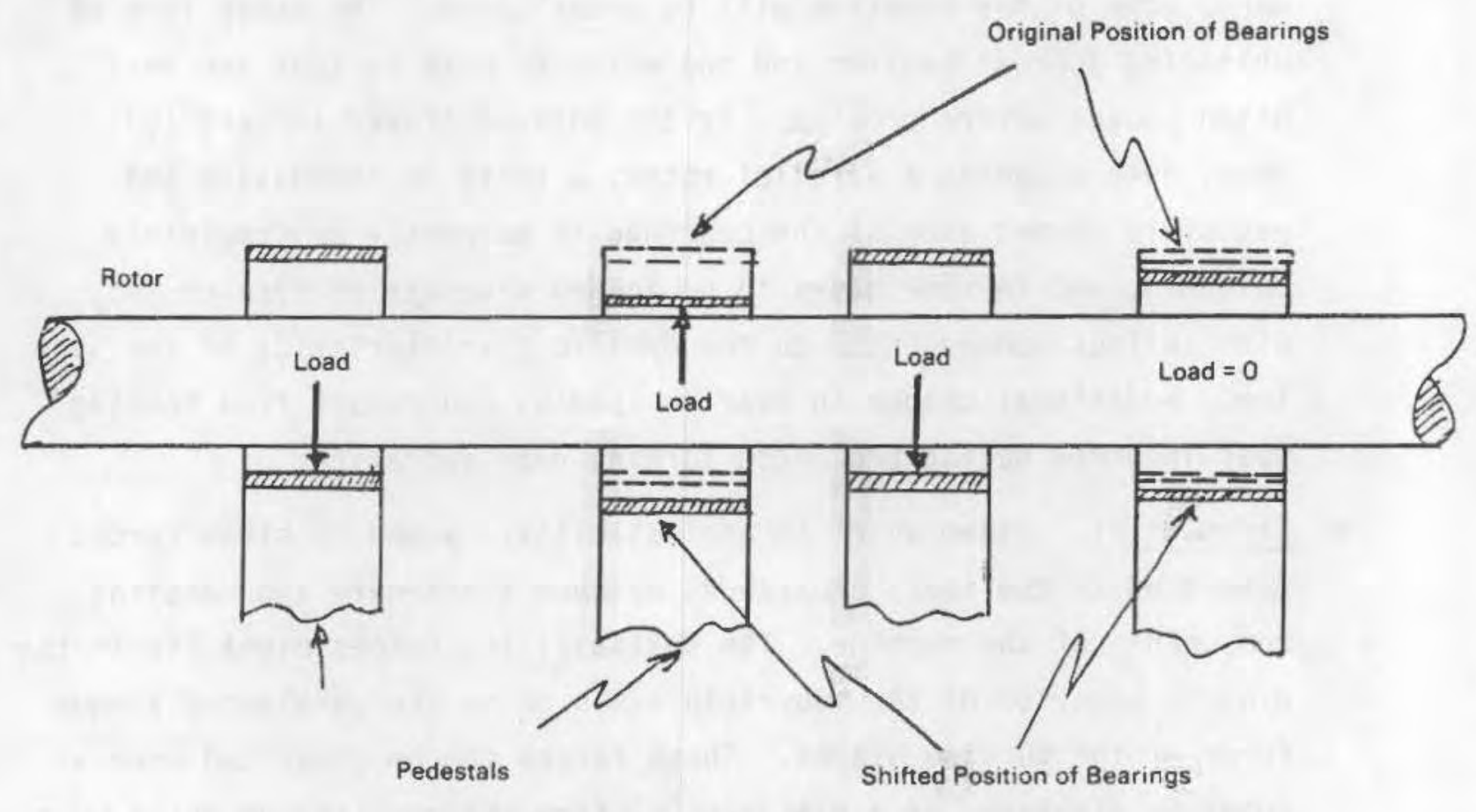

b) Mismatch Due to Shift of Pedestals

FIGURE 9.17. Causes of Journal Bearing Unloading(52) 
The results for tilting pad and elliptical bearings are shown in Figure 9.18. The results show that the laterally induced forces, $W_{x}$, have a significant effect on steam whirl stability, whereas the force in the direction of the rotor displacement has only a minor effect. Again, the tilting pad bearing is superior to the conventional design.

- Others. Several other tribologically induced vibrations can come from the stick-slip bearing behavior during turning gear operation; from the improper switching of $0 i 1$ pumps; and from rubbing of rotor against seals, or of turbine blades against the shroud.

\subsubsection{Coatings}

There are several areas where special coatings may protect turbine parts from inherent operational hazards and thus boost the reliability of the power plant. One of these is the use of abradable blade tips to avoid the damaging effects of contact between the blades and the shroud. This is detrimental on at least two accounts: it increases interstage leakage and it may lead to steam whirl. Presently used abradable materials on shrouds are not fully successful due to wear and erosion. Moreover, present polymer materials are good only to $500^{\circ} \mathrm{F}$. For temperatures up to $1400^{\circ} \mathrm{F}$, felt metal and honeycomb structures are often used but then distortion becomes a problem. Thus, new materials are needed. Also, new systems for controlling the clearance need to be developed, systems which keep the clearances moderately large during nonvital operation of the turbine and conserve the tight clearance requirements for vital phases of operation.

The other area for use of coatings is in the reduction of erosion in turbine nozzles. This form of hard particle erosion is due to the loss of iron oxide particles from the interior of boiler tubing and high temperature pipe systems into the steam turbine blade path. These oxides enter the steam turbine nozzle and blade passages at high velocity and abrade the finely machined surfaces. The changes in flow passage dimensions affect the heat rate, and degrade component reliability. The situation can be improved by the use of a metallurgically bonded coating. ${ }^{(53)}$ No change in dimensions or surface finish need occur after process application, somethina which constitutes a serious problem with conventional plasma spraying. 

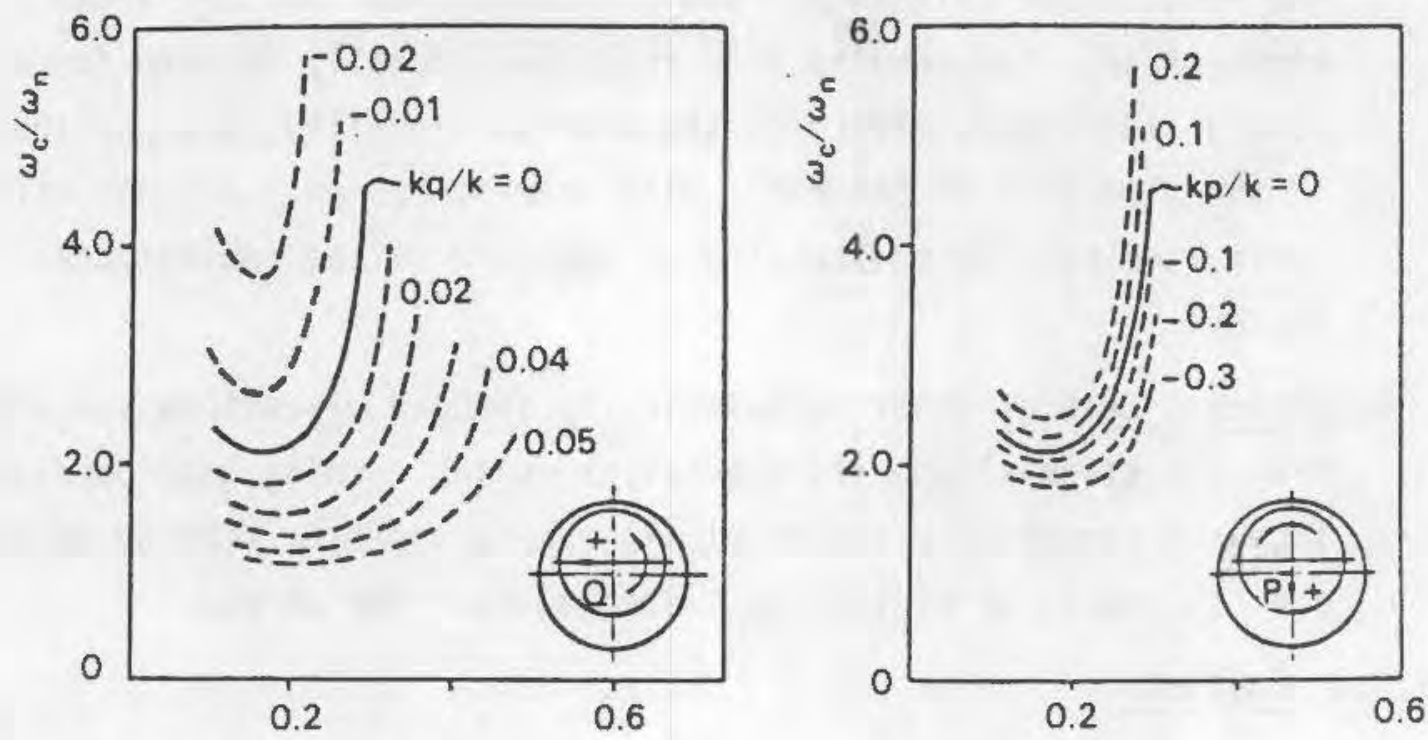

$\bar{w}$

$\bar{w}$

a) The Tilting Pad Bearing

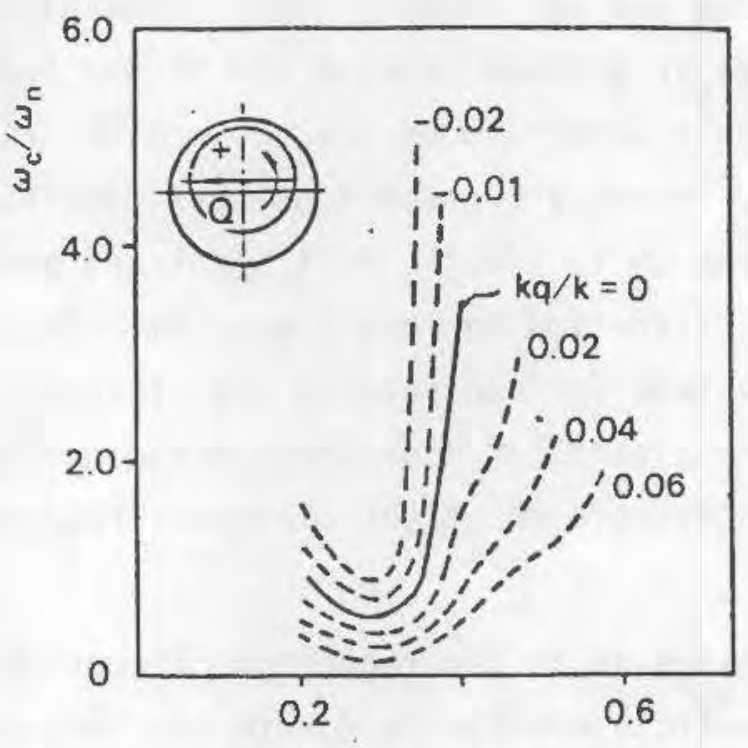

$\bar{W}$

b) The Elliptical Bearing

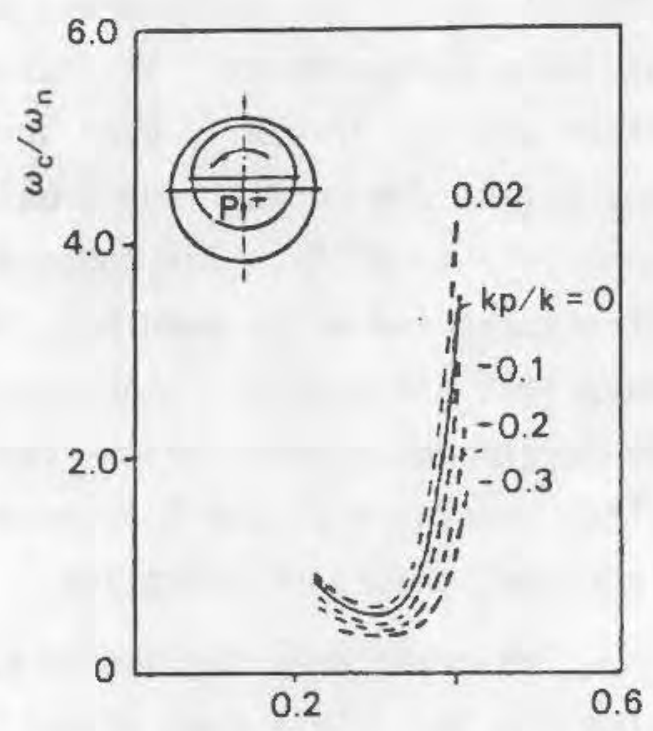

$\bar{w}$

FIGURE 9.18. Effect of Steam Exciting Forces on Rotor Stability 


\subsubsection{Monitoring and Diagnostics}

The aim of diagnostics, i.e. of utilizing a system which would anticipate and give warning of impending difficulties in the operation of the power plant involves essentially three areas, namely:

- Criteria - This relates to a set of standards with regard to plant operation which specify, in a quantitative way, when and when not a given component is on the verge of failure or exceeds permissible operational limits.

- Monitoring - This deals with the installation of a set of instruments that would record, on a continuous or periodic basis, the vital signs of the various components involved.

- Diagnostics - This deals with the proper evaluation and diagnosis of the received data leading up to the crucial decision of whether or not to order a plant shutdown.

While computerized on-line monitoring is useful, periodic monitoring has the advantage in that it can be run on a small budget. Even with periodic monitoring, the volume of data generated is large and the ability of operators and engineers to make meaningful evaluations is strained.

In a given power plant, the turbine-generator is the most critical piece of machinery and the one to which innovative, advanced monitoring and diagnostics tools should be applied. For example, automated monitoring of bearing oil film pressures, temperature, shaft orbit and shape, acoustic signals for rubs, torsional vibration, and blade vibration all could be accomplished by a suitably configured minicomputer system. The reduced output of all these sensors could be integrated with the output of standard, installed sensors to yield an overall picture of the state of health of the turboset.

As an example of some of the modern techniques available for bearing diagnostics one may mention the work of Reference 54. Figure 9.19 shows a diagram of the method of acoustic emission analysis used to obtain a bearing damage diagnostic. The one-channel AE system consists of an AE sensor, an amplifier, an envelope detector, a ringdown counter, an event counter, an energy counter and a R.M.S. meter. Acoustic emission signals are monitored and recorded with a data recorder. 


\subsection{POTENTIAL ENERGY SAVINGS}

Figure 8.2 provides an energy flow map for the turboset, including its accessories. This flow chart is a simple energy accounting, similar to that provided in Figure 2.14 for the automobile. However, as explained in detail in Section 6.0, any savings in a particular component would save also an equivalent portion of the thermodynamic losses, since less power would have to be generated initially. Since the thermodynamic losses amount to $60 \%$, the useful turbine energy amounts to $40 \%$, and thus any saving in a portion of the $40 \%$ would be supplemented by an even bigger saving in the thermodynamic losses. Thus if gaspath leakage (shown in Figure 8.2 ), which amounts to $0.5 \%$, were to be cut in half, the saving would amount not to $0.5 \times 0.6 \%=0.3 \%$ but to an additional $(60 / 40) \times 0.3 \%=0.45 \%$, yielding a total saving of $0.75 \%$. Thus, in general, the energies required by the various components (including the wasted thermodynamic losses) are the values given in Figure 8.2 multiplied by a factor of $1+60 / 40=2.5$. With this as a background, Figure 10.1 was constructed which gives the actual energy requirements by the various components and auxiliaries of a turboset system.

The tribological areas in which direct energy savings can be achieved by reducing losses embrace gaspath leakage, seals, and bearings on the main turbogenerator; and the same areas on the various accessories. The losses in these areas in terms to input to the turbine are $1.5 \%$ for gaspath leakage, $0.25 \%$ for shaft sealing and $0.5 \%$ for the bearings.

We sha11 next assume that about $10 \%$ of the power required for the accessories is spent on tribological components, so that the energy spent here is $1 \%$ of the input. The improvements possible in the various areas are as follows:

- Gaspath Leakage and Seals

As discussed in Section 9.1, the use of abradable blade tips and new coatings may make it possible to tighten the leakage paths to reduce the leakage losses to half their present level. Thus, the savings in the internal and external leakage would amount to $0.75 \%$ of input energy. 


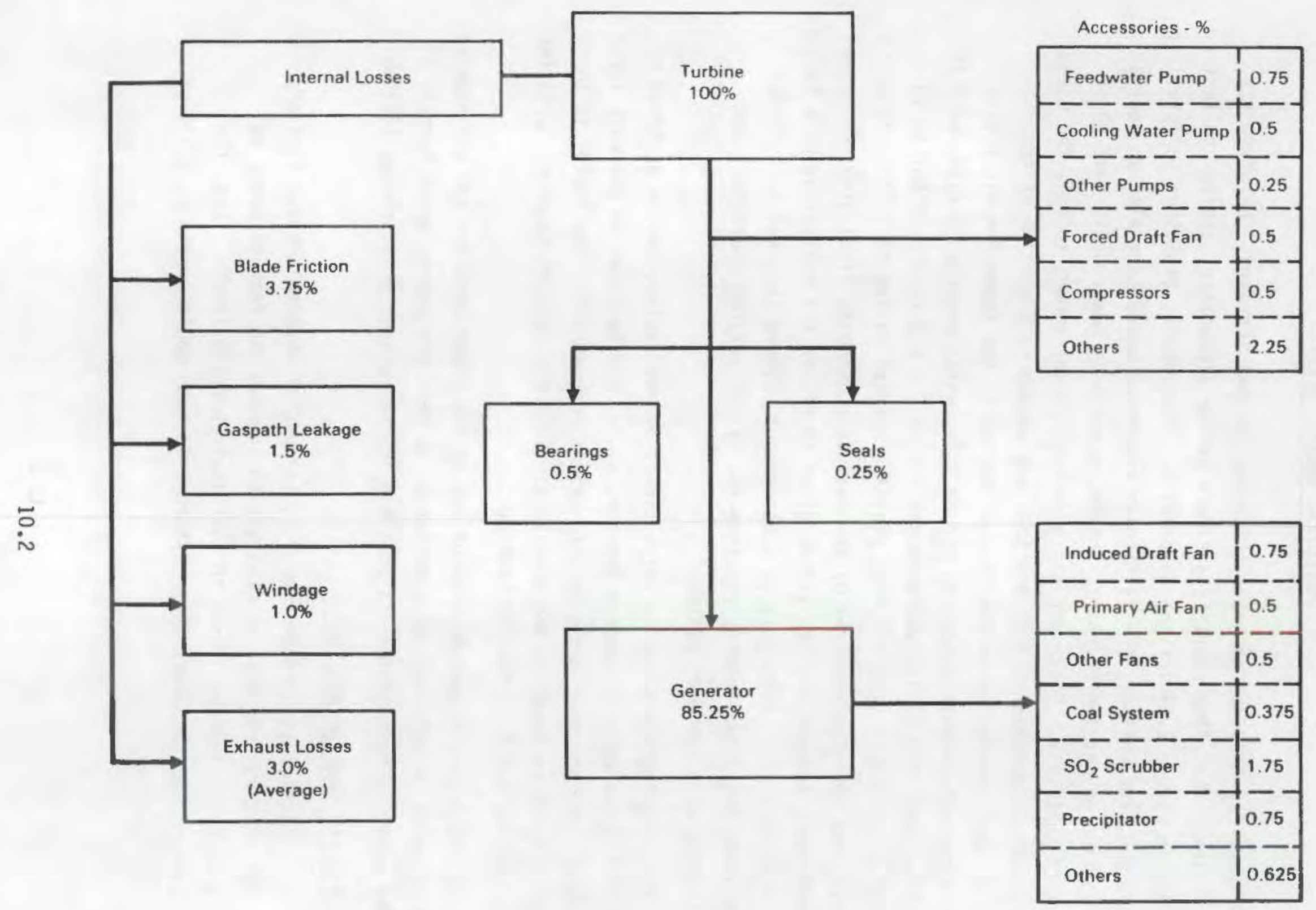

FIGURE 10.1. Energy Required by Turboset Components and Auxiliaries 
- Bearings

This area is open to considerable improvements in both efficiency and reliability. A special study of this area is contained in Reference 55. After considering a number of options for low power loss journal bearings, the designs chosen were those shown in Figure 10.2. Both the 3-pad and the basket designs were evaluated against a prototype used in present-day installations. All the calculations were made for the standard conditions of loading, speed, and oil viscosity, with the proviso that the minimum film thickness remains the same. The power loss savings achieved by those designs are given in Table 10.1.

For the thrust bearings, the new design, schematically portrayed in Figure 10.3, consists of a free-floating disc inserted between the runner and stationary element. The disc rotates at half runner speed and forms two hydrodynamic films. By making each film half the thickness of an equivalent single film, the ratio of $(\mathrm{hp} / \mathrm{load})$ is reduced by $50 \%$ to $65 \%$. To assure that such a bearing will not adhere to either the moving or the stationary surface, particularly at start-up, the configuration provides a self-generated lift-off force at the sticking interface.

The reduction of power loss achieved with the optimized floating disc configurations for both large and small thrust bearings is shown in Table 10.2. The savings achieved in the thrust bearings result, to a large degree, from a reduction of the number of pads. In this respect, there is some parallel between the approaches taken for the thrust and journal bearings, namely that in both cases, the large savings in power loss come from a reduction in bearing area.

- Accessories

Assuming that levels of savings similar to those on the main turbogenerator can be achieved on the seals and bearings of the accessories, an additional saving of $0.5 \%$ of energy input can be achieved. 

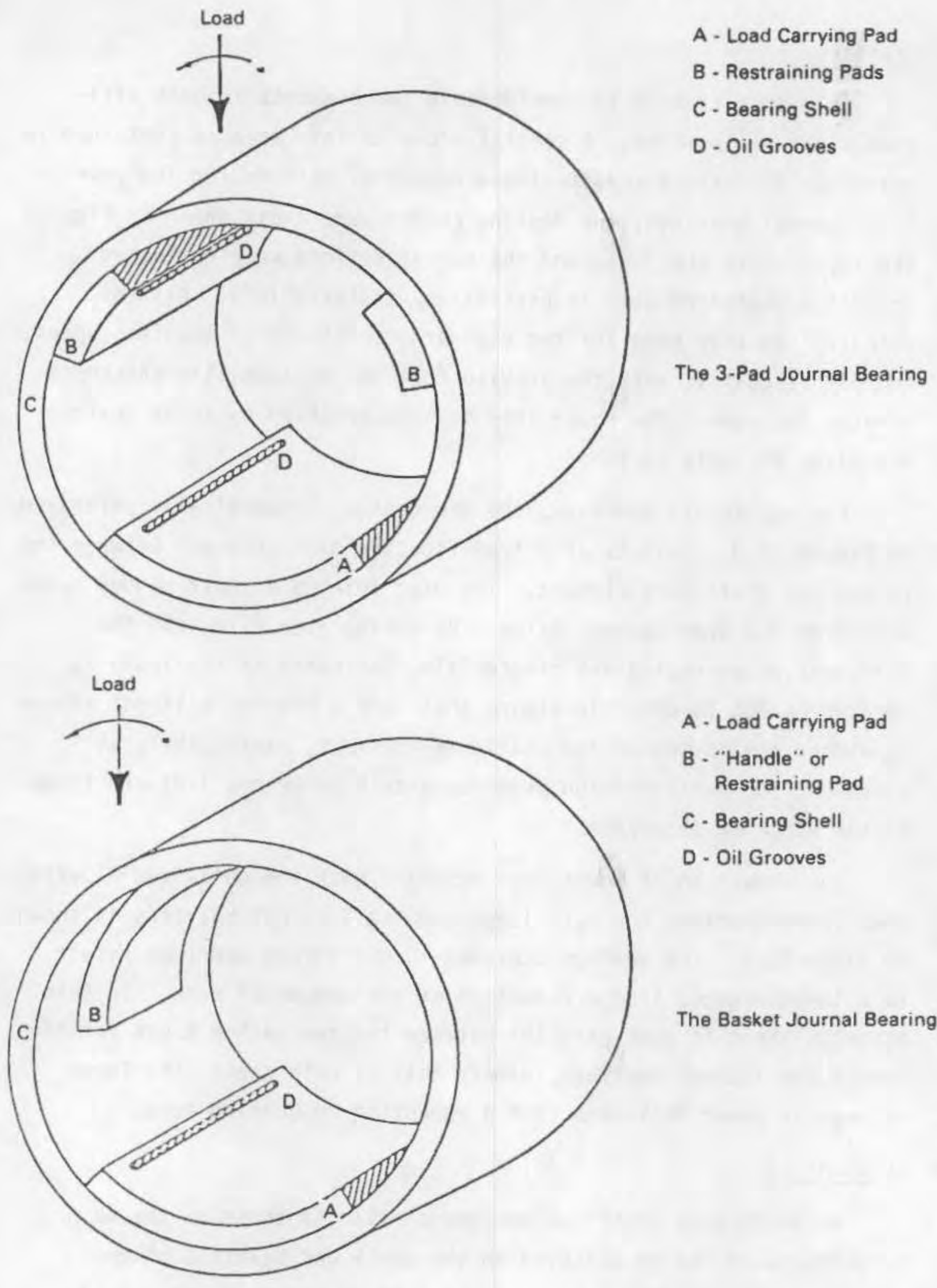
A - Load Carrying Pad
B - "Handle" or Restraining Pad
C - Bearing Shell
D. Oil Grooves

The Basket Journal Bearing

FIGURE 10.2. Low Power Loss Journal Bearings (55) 
TABLE 10.1. Savings with the New Journal Bearings (55)

\begin{tabular}{|c|c|c|c|}
\hline Bearing & 100015 & Savings, $\%$ & $\mathrm{~T}_{\max },{ }^{\circ} \mathrm{F}$ \\
\hline Reference & 15.4 & Ref. & 177 \\
\hline 3-pad design & 7.2 & 53 & 222 \\
\hline Basket design & 7.0 & 55 & 222 \\
\hline
\end{tabular}

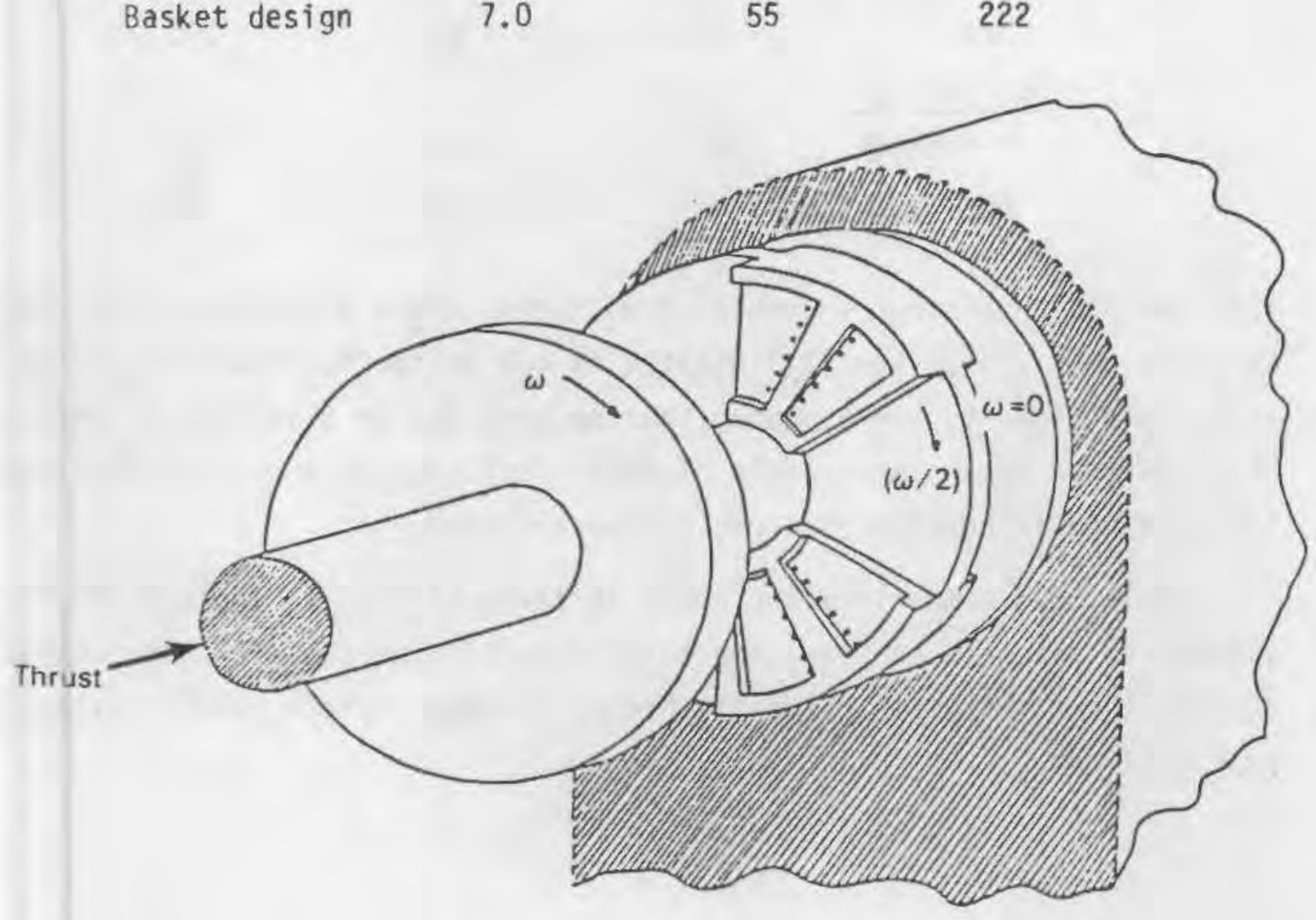

FIGURE 10.3. Floating DisC Thrust Bearing(55)

The next area of savings is that due to increased plant reliability. In Section 7.4 we have seen that the penalties due to tribologically induced loss of generating power is $\$ 2.9$ billion. There is no breakdown available on the particulars of this cost, but a large portion of it is due to the use of standby equipment which is much less energy efficient than the main power plant. 
TABLE 10.2. Savings with the New Thrust Bearings (55)

\begin{tabular}{|c|c|c|c|}
\hline Bearing & $1000 \mathrm{~Tb}$ & Savings, \% & $\mathrm{T}_{\max },{ }^{\circ} \mathrm{F}$ \\
\hline \multicolumn{4}{|l|}{$O D=32 \mathrm{in}}$. \\
\hline Reference & 8.6 & Ref. & 150 \\
\hline New & 3.0 & 65 & 171 \\
\hline \multicolumn{4}{|l|}{$O D=48 \mathrm{in}}$. \\
\hline Reference & 14.2 & Pef. & 178 \\
\hline New & 5.1 & 65 & 196 \\
\hline
\end{tabular}

This use of inefficient equipment translates into a direct waste of energy. Assuming that $25 \%$ of the $\$ 2.9$ billion is due to the lower efficiency of the stand-by equipment, and assuming that outages due to tribological elements can be eliminated by an improvement of their performance, then a yearly saving of $\$ 725$ million in energy resources can be achieved.

Table 10.3 summarizes the above in terms similar to those given for the automotive sector. As seen, the total possible savings via tribology is about 2. 3\% in the utilities' fuel bill which translates into a yearly saving of about $\$ 2.4$ billion. 
TABLE 10.3. Summary of Potential Savings in the Electric Utilities (a)

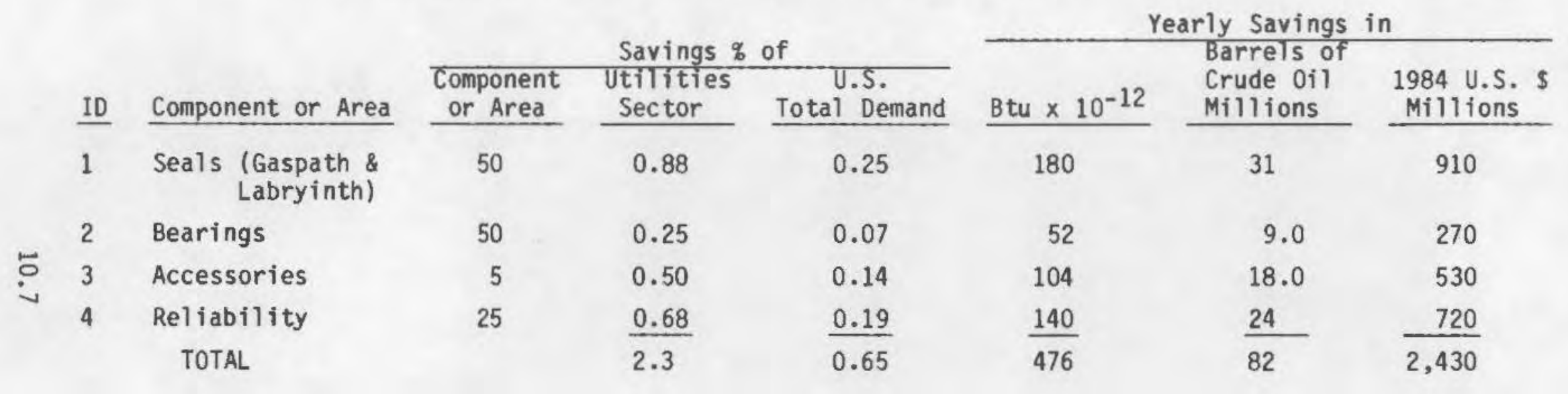

(a) Savings based on estimate of installed capacity in $1983,{ }^{(41)}$ and on energy cost of $\$ 30$ per barrel of crude oil. 


\subsection{RECOMMENDEO R\&D PROGRAMS--UTILITY SECTOR}

In the preceding sections discussing the Utility, or power Generator sector, of the economy, several areas have been pointed out and described in which the prospects for significant energy savings would warrant the expendi * ture of folu funds as a means of stimulating improvements in power generation nachinery. The nature of this industry is such that improvenents leading towaro reliability (reduced downtime) are at least as important as improvements wat may lead toward greater thermodynamic efficiency. The total potential What may be achievable is set forth in Table 10.3 in the preceding section, and is about 32.4 billion per year.

In this section, a number of projects are suggested, each of which has the sotential either to increase efficiency or to increase reliabllity, or both. As was tre case with the Transportation Sector, sone of the suggested work may best be done within the industry because of close coupling with specific designs, while other Ro work is more generic in nature and will be better accepted and more effectively accomplished if done under government sponsorship. The programs are grouped into five categories as follows:

- 5eals

- bearings for turbine-generator

- accessories

- relability

All of the tribology-related programs are sumarized in Table 11.L. Here, the overall factors related to each program are sumarized, and all programs related to each of the groups listed above are collected together. Table 11.1 presents those factors bearing on the inclusion of each program in future budgeted work. These factors are:

- the type of support suggested for the progran

- the potential savings, in billjons of dollars per year, that would be achieved by successful completion of the program group, as estimated in Table 10,3

- the estimated Rod cost, in millions of dollars (total) 
TABLE 11.1. Sumary of Recomended Ro Programs-Utillty Sector

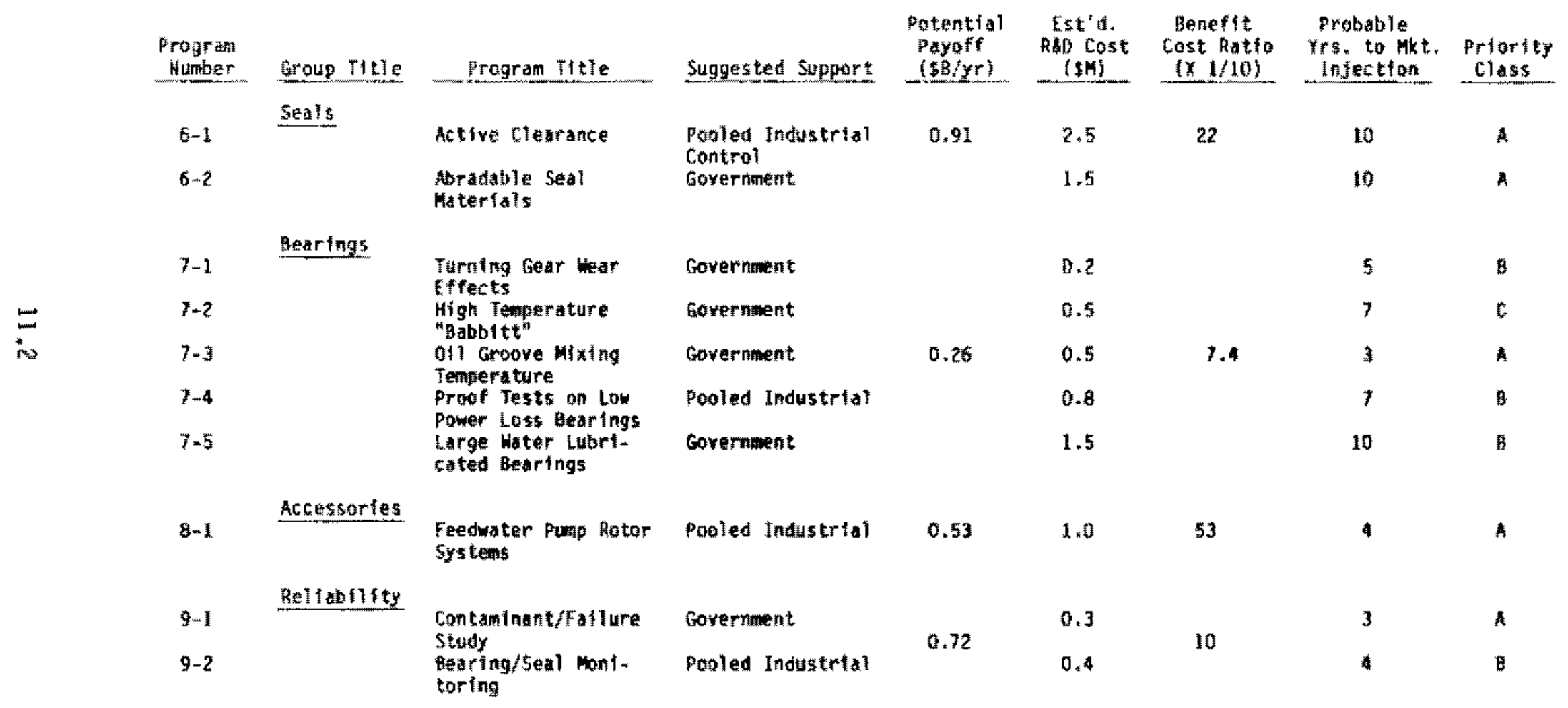


- the estimated benefit to cost ratio to completion of the development (see below)

- the probable number of years to market injection

- the overall suggested priority rating for the program, taking into account the levels of benefits, cost, and probability of success, with $A$ the highest priarity rating.

The benefit-to-cost ratio is calculated by dividing the estimated annual benefits (in dollars) by ten times the estimated total dollar cost of the research. This roughly represents the fact that development usually costs ten times the research to prove feasibility. However, it should be noted that only the annual benefits have been used. Since benefits over some period of years, perhaps five or ten at least, should accrue from a given efficiency development, the cited benefit-to-cost ratio is more conservative by this factor.

On the following pages, each program is briefly described. The objective provides a brief statement of the need for the program and its specific role. The Work Statement briefly sets forth the principal elenents of research or developnent needed to achieve the objective. The Technical Background refers the reader to appropriate sections of the report. 
RUD TRIBOLOGY PROGRAM--ENERGY CONSERVATION

GROIP: 6--Seats

PROGRAM NUHUER: 6-1

TILE: Active clearance Control

POTENTIAL PAYOFF: Part of $\$ 0.91$ P/Yr

PRIORITY CLASS: A

ESTMATED RESEARCH COST: 2 Years, at $\$ 0.5 \mathrm{M} / \mathrm{Yr}$ TOTAL: $\quad \$ 2.5 \mathrm{M}$

SUGGESTED SUPPORT: Pooled Industrial

\section{OBJEC.UIE}

Leakage through the clearances between blade tips and shroud in the steam turbine, and between rotor and stator elements in labyrinth steam seals, is a significant cause of loss of energy because the clearances must be large enough to handle a variety of operating conditions under which the rotor changes its position in the bearings. The objective of this program is to develop reliable means to "servo" the stationary member so as to reduce the running clearances significantly.

\section{WORK STATEMENT}

This program shall develop and evaluate a prototype of active control of clearance in steam turbine blade tip seals and labyrinth interstage seals. The following tasks shall be accomplished:

1. Develop a number of concepts for adjusting the position of the stationary seal member based on measurenent of the position of the rotor at the seal location and use of this information to move the stationary member inward or outward to hold a predetermined value of clearm ance.

2. Develon a number of concepts for measuring the position of the rotor at each seal location, appropriately averaging these values, and moving the rotor in the support fluid film bearings so as to maintain the rotor centered in the seal clearance spaces. 
3. Analyze the concepts developed in Tasks 1 and 2 as to their merit based on reliablity, probability of success, ease of implementation, and dificulty of development.

4. Select the two most promising concepts for demonstration.

5. hesign, construct and test reduced scale models of each of the two selfcted systems.

6. Prefare a detajled report andyzing the designs and their performanck and recommending the course of further work. Prepare technical papars describing the results.

TECHNTCAI. RACKGROUNO

See sections $7.4,9.1 .2$, and 10.0 of this report. 
RED TRIBOLOGY PROCRAM--ENERGY CONSERVATION

QRoup: $6--5$ eals

PROGRAM HUMBER: $6-2$

TITLE: Abradable Seal Materials

POTENTIAL PAYOFF: Part of \$0.91 B/Yr PRIORITY CLASS: A

ESTIMATED RESEAPCH COST: 5 Years, at $\$ 0.3 \mathrm{M} / \mathrm{Yr}$ TOTAL: $\$ 1.5 \mathrm{M}$

SUGGESTED SLPPORT: Govermment

\section{OBJECTIVE}

Leakage of steam through the clearances of blade tip seals and labyrinth seals represents a significant source of energy loss in large steam turbines. Variaus approaches to reducing the clearances to reduce these losses incur the possibility of rubbing between the stationary and rotating members. Present materials usable in the high temperature steam atnosphere do not cut away smoothly with the result that larger gaps may be torn open or catastrophic failures may require expense teardowns for repair. The ohjective of this program is to develop materials which will exhibit good rub-away properties in order to make posstble effective closer clearance seals.

WORK STATEMFNT

This program shall develop and evaluate a series of thaterials in order to obtain compositions which can rub in a steam atmosphere against typical blade and rotor materials without tearing or sejzing to create the need for teardown of the steam turbine. The following tasks shall be carried out:

1. Through literature research and contacts with turbine and seal experts, select a number of materials which may be anticipated to perform well in stean atmosphere rubbing at high velacity.

2. Build or make avaliable a high speed rub test rig capable of reproducing the rub speeds, temperatures and steam atmosphere of typical large steam turbines.

3. Evaluate the performance of the selected materials. 
4. Based on Task 3, evaluate the relation between composition and performance and develop concepts for better performing naterials. Prom curte test samples of these compostions.

5. Evaluate the new compositions in the test rig.

6. Prepare a detailed report including an andysis of the data, the ind"cations of materials which may be successful, and recomending further work which may lead to successful compositions,

7. prepare technical papers presenting the results.

TECHWYCA-BACWRROINO

See Sections $7,4,9.1 .2$, and 10,0 of this report. 
R\&D TRIBOLOGY PROGRAM--ENERGY CONSERVATION

GROLP: 7-Bearings

PRDGRAM NUMBER: $7-1$

TITE: Turning Gear Wear Effects

POTENTIA: PAYOFF: Part of $\$ 0.26 \mathrm{~B} / \mathrm{Yr}$

PRIORITY CLASS: $B$

ESTMATED RESEARCH COST: 1 Year, at $\$ 0.2 \mathrm{M} / \mathrm{Yr}$

TOTAL:

$50.2 \mathrm{H}$

SUGGESTED SUPPORT: Government

OBJECTIVE

During the very low speed turning gear pperation when a steam turbine is on standby or cooling down. wear of the babbitt bearings may occur at the bottom of the bearings. There has been some evidence also of displacement of the babbitt so that the revised shape is not a simple "fitted bearing" worn area in the loat carrying portion of the bearing. The implications of such wear patterns to the dynamic behavior of the rotor may be critical to successfut performance, as may the capability of the bearing to carry heavy loads under extrene conditions. The objective of this program is to examine babbitt bearings to determine typical wear patterns, and to determine the influence on full speed bearing perfornance.

\section{WORK STATEMENT}

This proaram shall investigate the nature of wear and displacement pat* terns in very low speed operation of babbitt bearings, and the influence of these patterns on full speed bearing dynamic and overload capabilities. The following tasks shall be carried out:

1. Make avallable a test rig capable of testing a model babbitt bearing of about 6-in. diameter, with loads and surface speeds typical of large turbine-generator bearings.

2. Measure the Dearing proflle accurately before and after operation for extended periods at typical turning gear surface speeds. Repeat to determine repeatability. Also repeat under a variety of low speeds and typical loads. 
3* Revise a computer code capable of analyzing full scale turbinegenerator type bearings wh provision for adiabatic and turbulent operation so that typical worn or displaced profiles may be introduckd.

4. Lsing the computer code of Task 3, determine the Influence of turning cear profile operation on the dynamic stiffness and damping propertes of the bearings, and on its abllity to carry overload safely.

5. Prenare a detalled report describing the work and its implications to turbine generator reliablity. Prepare and present appropriate papiss.

\section{TECHNICA. BACKGROUND}

See Sections $7.4,9.1 .3,9.2$, and 10.0 of this report. 
R\&D TR IBDLOGY PROGRAM--ENERGY CONSERVATIDN

GROUP: T-Bearing̣s

PROCRAM NIMAER: $\quad 7-2$

TITLE: High Temperature "Babbitt"

POTENTIAL PAYOFF: Part of $\$ 0.26$ P/Yr

PRIORITY CLASS: C

ESTIMATED RESEARCH COST: 5 Years, at $\$ 0.1 \mathrm{M} / \mathrm{Yr}$ TOTAL: $\$ 0.5 \mathrm{M}$

SUGGESTED SUPPORT: Government.

OE) JECTIVE

For a century, babiltt lead-tin alloys have been ideal materals for bearings based on their compatabllity with shaft steels and their abllity to embed dirt and prevent it from creating major bearing damage. Its major limitation is the low $275-300^{\circ} \mathrm{F}$ temperature which has been found to be the safe upper linit for bearing naximum filn temperature. In large steam turbine bearings this factor limits the unit loading that can be used so that wider bearings are used with corresponding higher power losses. The objective of this program is to search for bearing material compositions with comparable compatability and dirt tolerance, and with temperature capability of $400^{\circ} \mathrm{F}$ or higher.

HORK STATEMENT

This program seeks to develop new bearing material compositions having the desirable properties of babbitt and also having an operating temperature capability over $400^{\circ} \mathrm{F}$. The following tasks shall be carried out:

1. Review the literature for results of work on "soft" bearing materials, and correlate observed behavior with composition.

2. Based on the review of Task 1 and on avallable netallurgical information, conceive of compostions which may have the desired properm ties. Mixtures of organic polymers with metallic or ceramic materials may be included.

3. Obtain sarples of the new compositions. 
4. Ising a test rig capable of rubbing the new "baboitts against steel at appropriate loads and speeds in the presence of turbine oil, test the perforlance of each over a range of temperature from $100^{\circ} \mathrm{F}$ to $500^{\circ} \mathrm{F}$ with and whout the addition of hard dirt particles to the oil feer.

5. Prevare a detaled report including the rationale for the tes: alloys, the results of the tests, and recommendations for the potentia application of one or more of the compositions. Prepare appropriate technical papers for presentation and publication.

\section{TECHNICA BACKGROUND}

See Sections $7.4,9.1 .3,9.2$, and 10.0 of this report. 
RED TR:BOLOGY PROGRAM-ENERGY CONSERVATION

GROLP: 7--gearings

PROGRAM NIMMER: $7-3$

TITLE: 0ii Groove Mixing Temperature

POTENTIAL PAYOFF: Part of $\$ 0.26 \mathrm{~s} / \mathrm{pr}$

PRIORITY CLASS: A

ESTIMATEO RESEARCH COST: 2 Years, at $\$ 0.25 \mathrm{M} / \mathrm{Yr}$ TOTAL: $\$ 0.5 \mathrm{M}$

SUFGESTED SUPPORT: Government.

QBJECTIVE

The dynamic stiffness and dampino coefficients of fluid film bearings supporting large steall turbine rotors are directly proportional to the inlet viscosity to the film and hence to the inlet oil temperature. Many large turbine bearings are sensitive to these coefficients and their effect on the dynamic stability of the heavy rotors. The correct inlet oil film temperature for a given ofl feed condition and bearing design is not predictable based on current knowledge except for information on very similar situations. The objective of this program is to determine the correct techniques for deternining the mixing effect of the oil feed groove where fresh oil and hot carryover oil mix in order to improve predictability of the dynamic behavior of bearing designs.

WORK STATEMENT

This program shall include the following tasks:

1. Using the most capable avallable bearing computer codes, analyze the thermal and fluid conditions in the inlet oil feed groove of typical large bearings.

2. Make available or modify a test rig capable of testing nodel size $(1 / 3$ to $1 / 5$ size) bearings under speed and load conditions correctly simulating full scale bearings. The rig and test bearing shall be capable of measuring temperatures both in the bearing groove and in the both halves of the bearing during operation, and of measuring flow velocities over the cross section of the inlet feed groove. 
3. Carry out a series of tests varying the size bearing simulated, the typical load ranges, and the temperature and pressure of the oll fed to the oll inlet groove.

4. Analyze and correlate the experinental and analytical results, and rod fy the computer code to inprove its predicting capability.

5. Pretare a detalled report including the analyses and the results of *itying the andysts to the experimental behavior. prepare technical papar(s) covering the findings.

IECHNICA BACKGROUINI

See Sections $7.4,9.1 .3,9.2$, and 10.0 of this report. 
REO TRIBOLOGY PROGRAM--ENERGY CONSERVATION

GROUP: 7-mearings

PROTRAM NUMBER: $7-4$

TITLE: Proof Tests on Low Power Loss Bearinos

POTENTIAL PAYOFF: Part of $\$ 0.26 \mathrm{~B} / \mathrm{Yr}$

PRIORITY CLASS: $\quad$ B

ESTMATEO RESEAROH COST: 2 Years, at $\$ 0.4 \mathrm{M} / \mathrm{Yr}$ TOTAL: $\$ 0.8 \mathrm{M}$

SUGGESTED SUPPORT: POOTed Industrial

OBJECTIVE

The fluid film bearings used in large turbine-generators usually operate in the turbulent regine and so have power losses that are a significant power drain on the equipment. Under work sponsored by the Electric Power Research Institute, analyses of turbulent bearings have been carried out leading to design proposals for bearings having roughly half the power consumption of the conventional journal and thrust bearings of large turbine-generators. The objective of this program is to verify the predicted performance and to solve the problem of scavenging oil from interpad spaces as called for by some of the proposed designs.

WORK STATEMENT

This experimental program shall accomplish the following tasks:

1. Supply or adapt a test rig capable of testing models of large fluid film bearings under conditions simulating full scale turbine operation. Similarity in Somerfeld Number and Reynolds Number, as well as clearance ratio and length/dianeter ratio is required.

2. Prepare design drawings for and fabricate test bearings as follows: a reduced area journal bearing; a low power loss type tilting pad bearing; and a floating disc thrust bearing.

3. Conduct performance tests at speeds, loads and inlet oil temperatures simulating full scale turbine-generator bearings. Test over a range of loads and at three or hore inlet oil temperatures, measuring power consunption, bearing temperatures, and oil outlet temperature. 
4. Andyze the test results and compare with the predicted results.

5. Prepare a detajled report including recommendations; and prepare technical paperts) presenting the findings.

TECANICAL BACKGROUND

See Sectons $7.4,9.1 .3,9.2$, and 10.0 of this report. 


\section{RED TRIBOLOGY PROGRAM-ENERGY CONSERVATION}

CROUP: 7 -Bearings

PROGRAM NIMBER: $7-5$

TITLE: Large Hater Lubricated Bearings-measibility Study

POTENTIAL PAYOFF: Part of $\$ 0.26 \mathrm{~B} / \mathrm{Pr}$

PRIORITY CLASS: B

ESTIMATED RESEARCH COST: 1 Years, at $\$ 0.1 \mathrm{M} / \mathrm{Yr}$ TOTAL: $\$ 0.1 \mathrm{M}$

SUGGESTED SUPPORT: Government

\section{ODETCTIV}

The oil system of large turbine-generators is a major cost and naintenance item, and oil contamination by dirt and water is responsible for a significant fraction of system outage. Water lubricated bearings could make possible a much simpler supply system and provide a clean filtered luoricant supply. Bearing system seals would become simple water-steam separators. On the other hand, a water system would require changes in both shaft and bearing materials with unknown problems, and the bearing design would require adjustment to the lower viscosity lubricant. The objective of this prograls is to study the feasibility of such a system and to recomend whether further experimental work would be justified.

\section{WORK STATEMENT}

The feastility of using water lubrication for large turbine-generator bearings shall be examined with respect to the follawing tasks:

1. Determine the changes in bearing design required to accomodate the lower viscosity of water and its different lubrictly characteristics. Typical large turbine bearings shall be used for this study which shall include both journal and thrust bearings.

2. Examine the corrosion aspects of the change to water lubrication, and determine the types of material which would be expected to be successful for both shaft, bearing and housing applications.

3. Examine the system aspects, and the means for assuring reliability of the water supply, as well as means for recirculating if desirable. 
4. Prepare a report presenting the results of the feasibility study together with recomendations on the desirability of developing the water bearing for turbine application.

TECHNICAL BACKGROINO

See Sections $7.4,9.1 .3,9.2$, and 10.0 of this report. 
RED TRIBOLOGY PFOGRAM-MNERGY CONSERYATION

GROUP: 8--Accessories

PROGRAM NUMBER: $8-1$

TITLE: Feedwater punp potor systems

POTENTIAL PAYOFF: $\$ 0.53$ B/Yr PRIORITY CLASS: A

ESTIMATED RESEARCH COST: 2 Vears, at $\$ 0.5 \mathrm{M} / \mathrm{Yr}$ TOTAL: $\$ 1.0 \mathrm{M}$

SUGGESTED SUPPAR: Pooled Industrial

OBUECTIVE

Outages on boiler feedwater pumps are a frequent cause of plant shutdowns. Seals and hearings have been a consfistent trouble spot for this all. impartant accessory. Also important are the shutdowns due to serfous vibration which can be traced to the influence of both bearings and seals on rotor dynamics. The objective of this program is to conduct a detalled review of feetwater pump designs with a view to redesign of the rotor/bearing/seal system.

\section{WORK STATEMENT}

The following tasks shall be accomplished:

1. Determine the principal feedwater pump suppliers, and work with them to determine the designs and design features that are relevant to the rotor/bearing/seal system design.

2. Analyze the systems and their components with respect to individual perfornance, potential reliability, and tendency to encounter rotor dynamic problems.

3. Gevelop improved design approaches for components and/or rotor systems, and work with one or more of the manufacturers toward adopting and testing out the revised designs.

4. Prepare a report covering the details of the work and its results. 
TECHNICAL BACKGROUND

See Section 9.2 of this report.

11.19 
RBO TRIBOLOGY PROSRAM--ENERGY CONSERVATION

GROUP: 9--Reliabijity

PROGRAM NJMMEER: $9-1$

TITLE: ContaminantFailure Study

POTEETIAL PAYOF: Part of $\$ 0.7$ ? B/Yr

PRPORITY CLASS: A

ESTIMATEO RESEARCH COST: I Year, at $\$ 0.3 \mathrm{M} / \mathrm{Yr}$ TUTAL: $\$ 0.3 \mathrm{M}$

SUEGESTEO SUPFERT: Government

\section{OBUECTIVE}

Dirt and water contamination in the lubricating oll of large turbinegenerator systems is responsible for numerous plant shutdowns, particularly from bearing wear and shaft scoring. Knowing this, plant engineers montor oil quality frequently and spend much plant shutdown time in the flushing of ofl systems following any operation in which the systen is exposed to external contamination. The objective of this program is to determine experinentally the specific effects of dirt, its particle size, hardness and quantity, on babyitt bearing wear and on shaft scoring.

\section{WORK STATEMENT}

The following tasks shall be accomplished:

i. Supply or modify a test rig capable of passing lubricant through a babbitt bearing or section of a bearing under controlled load and speed conditions. An bil supply system shall be used which can inject controlled quantities of dirt of specified composition and particle size distribution.

2. Prepare a number of babbitt bearing specimens and shaft section specimens for test.

3. Conduct a planned series of tests to determine quantitively the effect of ofrt content in the oll on surface damage in terms of wear rate and surface morphology. 
4, Prepare a detailed report on the findings, together wh recomendation on limits of dirt contamination below which long life bearing and shaft surfaces should be found.

TECHN ICAL BACKGROUND

see section 7.3 of this report. 
GRoup: 9-meliabllity

PROGRAM NUMEER: $9-2$

TITLE: Bearing/Seal Monitoring

POTENTIAL PAYOFF: Part of $\$ 0.72 \mathrm{~B} / \mathrm{Yr}$

PRIORITY CLASS: B

ESTIMAYED RESEARCH COST: 2 Years, at $\$ 0.2 \mathrm{M} / \mathrm{Yr}$ TOTAL: $\$ 0.4 \mathrm{M}$

SUGOESTEO SUPPORT: Pooled Industrial

OBDECTIYE

Large turbine-generator sets are usually continuously monitored by accelerometers located at strategic locations on the machine. Shutdowns are triggered, often automatically, when vibration levels become too large. The search for the cause would be helped by infornation on the dynamic behavior at each of the many bearings in the set. The purpose of this program is to establish criteria for determining specific bearing dynamic problems and to develop simple reliable means for determining the magnitude and direction of the load on a fluid film journal bearing.

\section{WORK STATEMENY}

This program shalt accomplish the following tasks:

1. Determine the magnitude of the orbit of the journal center which is acceptable from the standpoint of safe bearing operation.

2. Conceive and develop means for determining the magnitude of the load on a fluid film, and its direction, based on simple and reliable measurements. (one method that has been suggested is to use measurements of two or more pressures in the bearing film.)

3. Demonstrate the method of Task 2 on a model bearing.

4. Prepare a report detalling reliable means for instrumenting a turbine-generator flutd film bearing so that its dynamic behavior, and the share of the load it is carrying, can be determined continuously as one means of anticipating dynamic problems. 
TECHNICAL BACKGROUNO

See Section 7.3 of this report. 

PART III

BRIEF EUROPEAN STUDY 


\subsection{ENERGY CONSERVATION AND UTILIZATION TECHNOLOGY IN EUROPE}

As an extension of the work under this program in the economic sectors of transportation and power generation a task was added to make a brief assessment of energy conservation and utilization technology in Europe. Because of the relatively limited resources which the United States government can apply to the tribological aspects of ECUT when compared to the large levels of needs and opportunities, it was desirable to become familiar with European efforts in order to avoid duplication.

Based on our knowledge of the literature, meeting attendance, etc., France, West Germany and Great Britain were selected as the most likely sources of F.CUT activity in Europe. In each country a key organization and a key individual were identified as having a broad knowledge of the domestic activities and plans in the field of tribology. The following persons were interviewed:

Country

France

Germany

Great

Britain Prof. D. Dowson

$\frac{\text { Person }}{\text { Prof. M. Godet }}$

$$
\text { Dr. H. Czichos }
$$

\author{
Organization \\ Mechanical Contacts Laboratory, INSA, Lyons \\ Bundenstalt fur Material-prufung (BAM), Berlin \\ Institute of Tribology, University of Leeds, \\ Leeds
}

As might be expected, there were major differences among the three countries in their approaches to the activity and planning for work in tribology with the objectives of energy conservation and utilization. Each is discussed in turn in the following sections.

\subsection{FRANCE--PROF. M. GODET \\ Information on the level of activity in France relating to energy con- servation through tribological research was obtained during an interview with Professor Maurice Godet of INSA, Villeurbanne, Lyon, France.}


France has two central agencles which could eventually become involved in tribological research aimed at energy conservation. One of these agencies is the Agencie Francais for Master of Energy (AFME). This agency was started in the $1981-\mathrm{g}_{2}$ fiscal year under the Mitterand government. It is part of the Ministry of Industry and Research and has an engineering orientation.

Its function is to sponsor research or other appropriate activity aimed at saving energy.

The AFME, to Godet's knowledge, has not yet identified the important fields in which energy saving research should be conducted. There has not yet been any specific identification of tribology as a significant field for research. The AFIE functions by recelving and evaluating proposals for the funding of research.

The second organization is the the centre Nationale de la Recherche Scientifique (CNRS) The CNRS has initiated some action in tribology, but there has beer little actual funding of work in the field. It could recommend approprlate action to the Ministry of Industry and Research which could then be passed on to the AFHE.

The conclusion is that planning activity directed toward tribological research for energy conservation in france has not yet reached the desired levei.

\subsubsection{Professor Godet's Personal Thoughts and Recomendations}

Professor Godet believes that high temperature operation and high temperature bearings are the key to improving nachine efficiency. This seens clear in engines for transportation, and in other forms of power equipment. He had no particular coments regarding improving efficiency in electric utifities, commenting that almost all of the work in this area is carried on within the Electricite" de France (EDF) organization.

On a more fundamental note, he feels that bastc work on the detailed mechanishs of friction and wear should be valuable in the development of improved tribulogical high temperature materials. However, he does not see a reasonable relationship between tribological research on ceramics conducted at modest (near rom temperatures and the requirements for high temperature oputation in 
heat engines such as diesel engines, gasoline engines and turbines. An example of this is the operation of pin-on-disc research often conducted at roon temperature on ceranics.

He feels that work directed toward reducing the friction coefficient and the wear rate between ceranis pars at high temperatures is useful, because there orobably will always be some rubbing interaction between noving parts. However, he feels that in the development of high temperature machinery, where temperatures are too high for the use of liquid lubricants, there should be a basic principle of designing for surface separation even at high loads. For example, this might be done using hydrodynamic or hydrostatic air films through appropriate machine design, thus reducing the level of contact loading drastically. The use of solid lubricants would then pernit the carrying of any tetworary contact loads without excessive friction or energy loss.

\subsection{GEMANY (FEOERAL PEPLPLIC OF) -PROF. H. CZICHOS}

The BAM organization is roughly the equivalent of the U.S. Bureau of Stancards. The department of BAM managed by Dr. Czichos, Special Fields of Materials Testing, has been active since the 1950 s in areas such as the fundamentals of lubricant properties, mixed lubrication, friction and wear, and surface coatings. In addition BAM has monitored (through contracts) work at universities and selected compantes.

Fron 1961 to 1969, funding in the area of tribology was from the DFG (Deutsche Forschungs Gemeinschaft), the equivalent of the U.S. National Science Foundaticn. Work was carried out in the fields of wear, friction, and lubricaton, ane run by BAM and universities.

In 1976, the German Tribology society asked the BMFT (Bundesnisteruun fur Forschung und Technologiel to involve government, universities and industry in a study of tribology and the work required to advance further this field. BMFT then funded a study to report on the following:

- the importance of the subfields

- their relevance to Industry and the Economy

- those fields where research is needed

- spectific proposals. 
The objective was a report somewhat similar to the ASME/DOE report on "Strategy for Energy Conservation Through Tribology."

In 1978 BMFT made the decision to establish a Tribology Program, and funded BAM's participation in the program. There have been some 170 projects over the past six years. A total of 46 million DM has been expended. A majority of the projects have been with industry, with industry sharing the cost of the work on a $50 / 50$ basis. The objectives have been as follows:

- to increase product reliability and safety

- to foster programs where the results can readily be transferred to industry

- to reduce production costs

- to generate or promote new designs

- to improve performance in terms of speed, accuracy, etc.

- to conduct failure analyses

- to improve material selection.

Collective books are issued containing the project reports at the rate of one or two per year. Some six have been published up to this time. In addition, BASE TRIBO, a tribology index comprising a bibliographic data base of titles covering the worldwide literature on Tribology, i.e. Friction, Lubrication and Wear, in all aspects.

Areas of concentration of the programs are given in Tables 12.1 and 12.2. Table 12.2 also gives the percentage of papers that have been published worldwide in each of these subfields in the years 1977 and 1978, based on a total sample of 9000 papers.

Some sixty percent of the BMFT industry-shared projects have been concerned with resolving some immediate problem in the industry or in the particular company. Thus the expenditure rate on what might be termed advanced R\&D in tribology has averaged about three million dollars per year. This appears to have been spread rather broadly over a wide range of tribological problems. 
TABLE 12.1. Tribology Programs Pursued by BAM in west Germany Research Areas

Percentage

of Projects

Surface Treatment

20.9

Manufacturing

13.8

Ab astive Wear

10.1

Me isuring and Testing Techniques

8.4

EH)

8.4

Design

7.8

Sliding Bearings

7.8

Performance of Tribological systems

7.2

Mixed Lubrication

5.4

Sliding Bearing Materials

4.8

Lubricants for combustion Engines

3.0

diesel Engines Lifetime Improvement)

2.4

Most of this work is only indirectly linked to advances needed to make more efficiert engines and manufacturing processes. Thus, there appears to be no duplication of DDE ECUT plans now being formulated in the U.S.A. 
TABLE 12.2. Percentages of Papers Published in Yarious Tribological Areas During 1977/78; Worldwide Sample of 9000 Papers

Area of Application

Machine elements lbearings, transtistions, clutches, brakes, seals)

Machinery lengines, pumps, hydraulic systems, textile machinery, printing machineryl

Specific industries imining, agriculture, forestry, power plants

Manufacturing processes, tools

vehites, traffic

Precision engineering

Electrical engineering

\begin{tabular}{c}
\multicolumn{2}{c}{ Percentage } \\
RaD International \\
program Literature \\
\hline
\end{tabular}

28.2

23.8

23.3

16.0

19.1

6.5

12.0

25.7

11.8

$25+2$

4.0

1.3

1.5

1.5

Machine Elements
Sliding bearings
Toothed gears
Ball and roller bearings
Friction drives
Crank and can drives
Clutches and brakes
Seals
other

\begin{tabular}{|c|c|}
\hline \multicolumn{2}{|c|}{ Percentage } \\
\hline $\begin{array}{l}\text { PagD } \\
\text { Program }\end{array}$ & $\begin{array}{l}\text { International } \\
\text { Literature }\end{array}$ \\
\hline 34.2 & 41.1 \\
\hline 19.0 & 13.5 \\
\hline 12.6 & 23.2 \\
\hline 10.1 & 0.4 \\
\hline 8.9 & 0.4 \\
\hline 5.3 & 7.3 \\
\hline 6.3 & 12.3 \\
\hline 2.6 & 1.8 \\
\hline
\end{tabular}

\subsection{GREAT BRITAIN-MPOF. D. DOWSON}

Some sixteen years ago, the Eritish Goverment funded the foundation of three tribolooy centers. One was located at the Universty of leeds, one at the Atomic Energy Research Centre at Risley, and one at University College, Swangea, in hales. As government support was reduced over the years, the Institute of Tribology at leeds has been by far the most successful in terms of 
recoanition and accomplished work. Both Prof, Dowson and his associate Dr. chris Taylor are in close couch with the British technical comunity in tribology. For this reason they were contacted for information on the approach in Great Britain to energy conservation and utilization through advanced tribology, and on the level of planning on this subject.

In the meeting Prof. Dowson pointed out that even though there is no organizet government-led leadership in steering tribology Rad in Great Britain toward energy conservation, apart from certain aspects of Research Council initiations, much work is going on in the field having bearing on energy conservacion or machine efficiency. Most of the work is judged by its direct benefit :o industry. Some of the specifics mentioned are:

- A gowing emphasis an materials, and particularly on the reclamation of materials for remuse

- Wors on net-shape forming as a means to conserve materials and the energy cost of wasted materials

- A rapidly growing interest in ceramics (discussed further below)

- Industrial work on CVT transmissions, flywheel storage for buses, use of gear boxes to better match load requirements to the optimun engine speed, with some emphasis on propeller drives for aircratt.

There is a strong interest in the tribologlcal properties of ceramics and there is a Department of Ceramics at Leeds. An ECt 3-year program on high temperature toughened ceramics is underway in which there is some effort on tribology. Some work is also underway in the U.K. on the high temperature lubrication of ceramics in the temperature range of $500^{\circ}$ to $800^{\circ} \mathrm{C}$. The emphasis is on fluorides. Industrial work is underway on ceramic cam and camfollower designs. At leeds, wear evaluations of Zro toughened ceramics are being conducted.

The Sclence and Engineering Research council is supporting research work related to Combustion Engines via grants-in-aid. The following is a quote from an SERC Communication to Dr. Taylor: 
"... Applications for grants from academic institutions are unsolicited but the Engineering Board of the council has selective approach and a proportion of its funds are tevoted to toplcs deened to require special promotion.

"Such a topic is combustion engine research wich lies within the ambit of the Board's Machines and power Commtetee. A spectally Promoted Programme was launched in the autumn of 1980 covering all aspects of reciprocating engine research but identifying the following as requiring particular consideration:

(a) small high speed drect injection biesel engines,

(b) lean burn, high compression ratio, high turbulence spark ignition petrol engines,

(c) direct injection stratified charge spark ignition engines,

(d) combustion studies, particularly alternative fuels,

(e) basic studies in automatic control, including improved sensor and actuator technolagy,

(f) turbochargers and engine/turbomachinery interaction,

(a) design and structural analysis,

(h) tribologica! aspects.

"The programe is axpected to last for flve years and a mid-tem review is it hand which may lead to a modification of the priorities listed above. The current level of support is about lin pounds per annum. Close cooperation between academic institutions and with industry and government departments is encouraged...."

The current fesearch areas at Leeds institute of Tribology, reflecting a broad interest in the field, are as follows:

- Ent (a) - contact along the long axis of the contact ellipse

- entrainment at an arbitrary angle (non-aligned discs)

- simultaneous solution for rolling, sliding and squeeze film effects in EHL.

- oil flow through a single feed hole--defining the cavitation boundaries

- cam and tappet lubrication

- ofl ping bearings (a new area)

- taylor vortex flow

(a) Elastohydrodynamic lubrication. 
- piston ring analysis and design

- human joints-use of ceramics and ceramic coatings

- flash temperatures.

\subsection{1 tiveneral Comments}

We were referred to the excellent paper by $H$. Peter Jost and J. Schofield entitled Energy Saving Through Tribology: A Techno-Economic Study presented as a Memorial Lecture to mark the twenty-fif th anniversary of the formation of the Iribology Group of Institute of Mechanical Engineers on February 4, 1981, and sublishes in Volume 195 No. 16 of the Proceedings. The key conclusion is that "....by the application of mainiy known tribological knowledge together with some Rin effort, energy and energy associated savings in the UK on the order of 468-700 million pounds sterling per annum are possible and that the centre of gravity for such savings lies in the areas of transportation, other areas of savings being the metallurgical, manufacturing and power generation industries. Added to these (direct sayings) must be consequential savings in materials, maintenance, labor and especially avoidable outage of machinery twhether power plant, rolling mills, motor cars or washing machines)." (Underlining added for emphasis).

The general approach in the Uk seems to be consistent with this general thesis, namely that we are far from applying our present knowledge of tribology in an er ergy-effective manner and that progress in advancing the general understanding of tribological processes will be fruitful. Absent at the moment is evidence of a planned centralized effort to encourage and support a concerted attack on a few perceived roatblock problem areas in tribology which, if resolved would clear the way for major advances in the efficiency of energy usage in transportation and industry.

\subsection{SUMAARY}

Judging from the glimpse that has been possible into the activity in three of these three European countries, France, Germany (FRG), and Great Britain, it appears that centralized planning efforts focused on "cutting edge" R8D 
activity in tribology that can catalyze breakthroughs in basic machine efficiency are still in their infancy. There is, however, a sizeable body of work going on in the traditional areas of tribology. This may be the reflection of a broadly sensed feeling that significant improvements in energy utilization efficiency can be made by better application of present knowledge in the field, and by the results of RoD in the usual areas of interest. In these latter areas, industry appears to be assisted by substantial government participation, particularly in Germany and Great Britain.

In 1981 France established an Agency for Mastery of Energy under the Ministry of Industry and Research. However, there has been as yet no specific identification of tribology as a significant field for energy research. The French National center for Scientific Research has initiated some action in tribology, but there has been little actual funding.

In Germany, there has been a highly focused effort for almost ten years. Funding at the level of several million dollars per year has been devoted to development in tribology. This has largely been in conventional areas, however. Much of the effort has been used to support the solution of specific industrial problems, and to collect, codify and analyze the worldwide results of tribological work.

In Great Britain, the Institute of Tribology at Leeds has emerged as the dominant center for tribology both in research and in the training of new professionals. By whatever means, the British are continuing to contribute significantly in many of the traditional areas of tribological research. However, their planning of breakthrough work in the key areas significant to energy conservation is only at a moderate level, falling between the activity in France and Germany.

To conclude, focused efforts towards energy conservation via tribology are only now beginning to take root in Europe. Continued progress in the field in this country, with continued attention to catalytic support in key breakthrough areas, may give the 1.5 . a technological lead in the intensely competitive areas of the automotive and power plant industries. 
1. The New York Tines. September 30, 1983.

2. Pinkus, O. and D. F. Wilcock. September 1977. Strategy for Energy Conservation Through Tribology. ASME Publication Ho0109, American society of lechanical Engineers, New York.

3. Shonka, 0. B. et a1. October 1977. Transportation Energy Conservation Datil Book. Znd ed. ORNL -5320 , Nationat fechnical Information Service, springfield, Virginia.

4. Proceedings of Highway Vehtcle Systems Contractor's Coordinating Meeting, J5E 1 Summary Report. March 1979. J.S. Department of Energy, washington, 1). C.

5. Jentings, B. H. and C. F. Obert. 1944. Internal Combustion Engines Analysis and Practice. Int. Textbook Company, Scranton, Pennsylvania.

6. Hard's Engine Update. Decenber 1982 and May 1983.

7. Bidwell, J. B. October 1976. Conserving Vehicle Energy. Acs Paper 24, General Motors corp., Warren, Michigan.

8. Lubrication. 1966. Vol. 52, No. 7, Texaco 011 Company, P.0. Box 509, Beacon, il 12508.

9. Bishop, 1. N. January 1984. Effect of Design Variables on Friction and Eccnomy. SAE Paper 812A, Society of Automotive Engineers, Warrendale, Pernisyvania.

10. Kouach, J. T, et al. February 1982. Engine Friction Reduction for Im: roved Fuel Economy: SAE Paper 820085, Society of Automotive Enţineers, Warrendale, Pennsylvania.

11. Rocenterg, R. C. 1981. General Friction Considerations for Engine Design. SAE Paper 821576. Soclety of Automotive Engineers, Warrendale, Pennsylvania.

12. Cole, R. M. and A. C. Alkidas. September 1982. Inventory of Heat Losses for a Divided Chanber Diesel Engine. SAE Paper 821050, Society of Automotive Engineers, Warrendale, Pennsylvania.

13. Parker, D. A. and D. R. Adams. 1982. "Friction Losses in the Reciprocating Internal Combustion Engine." Paper No. C51/82 of Tribology - Key to the Efficient Engine. Institution of Mechanical Engineers, Eondon.

14. Gaker, R. E., Ford Motor Company. November 2, 1983, Letter to authors (s:a Appendix $B$ of this report). 
15. Plerce, J. R. January 1975. "The Fuel Consumption of Automobiles." Scientific American.

16. Proceedings of Highway Vehicle Systems Contractors' Coordinating Heeting. Aprit 1979. CoNf 790415, 1.S. Department of Energy, Washington, 1.t.

17. Proceedings of Highway Vehicle Systems Contractors Coordinating Heet Ing. Detober 1979. CONF 791082, 0.S. Department of Energy, Nasningtor, $0, \mathrm{C}$.

18. Toyama, $x$, et al. 1983. Heat Insulated Turbocompound Engine. SAE 831345, Society of Automotive Engineers, Warrendale, Pennsylvania.

19. Advanced Gas Turbine Powertrain System, Development for Automotive

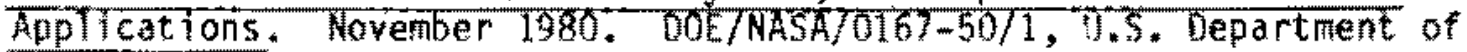
Energy, Washington, $0 . \mathrm{C}$.

20. Advanced cas Turbine Powert rain System, nevelopment for Automotive Applications. March 1980. nOE7NASA/0167-50/1, 1.5. Tepartiment of Energy, Washington, 0.e.

21. Carriere, D. L. October 1980. "Differential Split Power Transmission for a single Shatt Passenger Car Gas Turbine." J. of Engineering for Power, Trans. ASHE, vol. 102.

22. Chapman, W. I. 1980. "Advanced Gas Turbine Powertrain system Development Project: The Chrysler Williams AfT 102, 19th Sumary Report of Highway Vehicle systems contractors Coordination Meeting. presented at Automotive Technology Development Contractors Coordinating Meeting, Dearborn, Michigarl. 1.5. Department of Energy, ffflce of Transportation Programs, Washington, D.C.

23. AGT 101: Carrett/Ford Advanced Gas Turbine Program Summary, october 1981. MS635T, Garrett Tursine Engine Co., Phoentx, Arizona, and Ford Motor Co., Dearborn, Michigan.

24. Gray, S. February 1979. Foil Type Bearings for the Chrysler Automotive Gas Turbine Engine Program - Development and Operational Experience. SAE 790109, society of Autonot lve Engineers, Warrendale, Pennsylvania.

25. Ceramic Application in Turbine Engines. November 1980* EDR 10436 , Detroft Diesel ATlison, Indianapolis, Indiana.

26. 15th Surmary Report of Highwy Vehicle Systems Contractors' Coordinating Heetfig. October 1978. Conf 781050, 11.S. Department of Energy, Office of Transportation programs. Washington, D.c. 
2.7. Allen, 0. G. et a1. May 1975. Prediction of Piston Ring-Cylinder Bore Dit Film Thickness in Two Particular Engines and Correlation with Experinental Evidence. Paper C73/5, Institution of Mechanical Engineers. Eonton, NY.

28. McGeehan, 1. A. 1979. "A Literature Review of the Effects of Piston and Ring Friction and Lubricating 011 Yjocosity on Fuel Economy. Energy Conservation Through Fluid Film Lubrication Technology Frontier in Research and Design. ASHE PubTication No. Go0160, American Society of Mechanical Engineers, New York.

29. Moore, S. L. and G. M. Hamilton. 1978. "The Starved Lubrication of piston pings in a Diesel Engine." J. of Mech. Engineering Science.

30. Brown, $S . R$ and $\mathrm{G}$. M. Hamilton. 1978. "Negative Pressures Under a lubricating Piston fing." J. of Mech. Engineering Science.

31. Porter, F. C. June 1979. Design for Improved Fuel Economy - The New front Drive Car. SAE 790721 , Society of Automotive Engineers, warrendale, Pennsylvaniz.

32. Koivunen, E. A. and P. A. LeBar. 1980. A Hew Automatic Transmission for Improved Fuel Econony - General Motors THM 125. SAE 790725, Soctety of Automotive Engineers, Warrendate, Pennsylvania.

33. Staron, 1. T. and P. A. Willemet. 1983. An Analysis of Valve Train Friction in Terms of Lubrication Principles. SAE 830165, Society of Automotive Engineers, Warrendale, Pennsylvania.

34. Goodwin, G, and R. Holmes. 1982, "On learing Deformation and Temperature Distribution in Dynamically Loaded Engine Bearings: Paper C2/ac of Tribology - Key to the Efficient Engine. Institution of Mechanical Engineers, London.

35. Spikes, A. H. and S. H. Robinson. 1982. "Engine Bearing Design up-toDate." Paper C1/82 of Tribology - Key to the Efficient Engine.

Instutution of Mechanical Engineers, London.

36. KTaUs, E. E. November 1978. "Energy Conservation in Road Transportation Through Lubricant Technology." Lubrication Engineering $34(11)$.

37. Roterts, D. C. et al. 1982. "The Influence of Motor 0il viscosity and Friction Modifications on Automotive Fuel Economy. " Paper C6/82 of Tr'bology - Key to the Efficient Engine. Institution of Mechanical Entineers, London.

38. Stwart, R. M, and T, W. Selby, 1977. "The Relationship Between oil Viscosity and Engine Performance - A Literature Search." In: The Relationship Between 0il Viscosity and Engine Performance. Society of Automotive Engineers, Varrendale, Pennsylvania. 
39. Ghirla, $P . J$. and $R, K$. Snith. 1978, "Autonotive Engine Friction and Fuel Efficiency - Viscous Versus Non-Viscous Effects." In: The Relationship Between oil Viscosity and Engine Performance, Part IV. society of Automotive Engineers, Warrendale, Pennsylvante.

40. Caracciolo, F, and M, L. Macmillan. 1980, "Effect of Engine oil Viscosity on Low Temperature Cranking Starting and Fuel Econony " In: The Relationship Between Engine oil yiscosity and Engine Performance, Part. V. Soclety of Automotive Engineers, Warrendale, Pennsylvania.

41. Symposiun Proceedings: Power Plant Feed Pump - The State of the Art. JuTy 1983. EPRI CS-3158, Electric Power Research Institute, Research Report Center, P.0. Box 50490, Palo Alto, CA 94303.

42. Mechanical Engineering. January 1982.

43. Fossil Plant Heat Rate Improvement 1981 Conference and Workshop. December 1981. EPRI CS-2180, Electric Power Research Institute, Research Report Center, P.0. Box 50490, Palo Alto, CA 94303.

44. Assessment of Rotor-Bearing Dynanics: A Planning Study for the Utility Industry. August 1981. EPRI CS-1990, Electric Power Research Institute, Research Report Center, P.0. Box 50490, Palo Alto, California 94303.

45. Rippe1, H. C. and R. Colsher. September 1982. Failure Cause Analysis: Turbine Bearing systems. EPRI Turbine Bearing and Rotor Dynamics Workshop, Detroit, Michigan. EPRI CS-1801-SY, Electric Power Research Institute, Palo Alto, GA 94303.

46. Root Cause Fallure Analysis: Fossil Fired Power Plant Draft Forms, July 1983. EPRI CS-3199, Electric Power Research Institute, Research Report Center, P.0. Box 50490, Palo Alto, CA 94303.

47. Fallure Cause Analysis - Fons, February 1981. EPRI CS-1693, Electric Power Research Institute, Research Report Center, P.0. Box 50490, Palo Alto, California 94303 .

48. Pulverizer Fallure Cause Analysis. December 1979. EPRI CS-1226, Electric Power Research Institute, Research Report Center, P.0. Box 50490, Palo Alto, CA 94303.

49. Missana, A. et al. September 1982. Lube 0il Cleanliness for Large Stean Turbines. EPRI Turbine cearings and kotor Dynamics Workshop, Detroit, Michigan. EPRI CS-4024, Electric Power Research Instituta, Palo Alto, CA 94303 .

50. Hisa, 5. et al. September 1982. Stability of Journal Bearings in Large Steam Turbines. EPRI Turbine Bearings and Rotor Dynamics Workshop, Detroit, Michigan. EPRI CS-4024, Electric Power Research Institute, Palo Alto, CA 94303. 
51. Adams, M. L. September 1982. Turbine Generator Catastrophic Failure Caused by large Rotor Unbalance. EPR! Turbine Bearings and Rotor Dynanics Workshop, Detroit, Michigan. EPRI CS-4024, Electric Power Research Institute, $\mathrm{Pa}$ lo Alto, CA 94303.

52. Wohrab, R. and J. E. Bertilsson. September 1982. Procedure for the Dynamic Layout of Rotor Bearing Foundation Systems For Large Turbine Cenerators: September 1982. EPRI CS-4024, EPRI Turbine bearings and Rotor Dyramics Workshop, Detroit, Michigan. Electric Power Research Institute, Palo Alto, CA 94303.

53. Kraner, L. et al. 1984. Improvement of Steall Turbine Hard Particle Eroded Nozzles Using MetalTurgical Coatings. ASME Paper 83-JPGC-PWR-29, American Society of Hechanical Engineers, New York, Ny.

54. Sato, I. Feasible Acoustic Emission Techniques for lournal Bearing Diagnosis. EPRT CS-4024, ETectric Power Research Institute, Palo hl to, CA 94303.

55. Pinkus, 0. and 0. F. Wilcokk. Septemer 1981. Low Power Loss Bearings for Electric Utilities - Volume I. EPRI CS-4048, Electric Power Research Institute, Palo Atto, CA 94303. 



\section{ACKNOWLEDGMENTS}

Acknowledgatert is due the following organizations that prouided informat"on for the present study: Curmins Motor Company, Ford Motor Company, Ganeral Motors Research Lab. Detroit Edison, Westinghouse Electric Corporation, Genural Electric Company, and the Electric Power Research Institute. The particular individuals whose time and effort have helped make this study nore complete are named in Appendix $C$. 

APPENDIX A

STATEMENT OF WORK 
APPENDIX A

STATEMENT OF WORK

\section{Identification of Research and Development Needs in Tribological Aspects of Energy Conservation in Transportation and Utilities}

The seller shall perform the following tasks.

Task 1. Identify Long-Tern Tribological Research and Development Needs in the Transportation sector.

Finy and all information on long-term tribological research and developnent. needs if the transportation sector shall be identified. Only autonotive (including trucks and buses) applications shatl be considered. Tribological aspects of the engines, drive trains, and the remainder of the vehicle structure shill be addressed. Specific tribological conditions, present or expected, in the major tribologically important components of the three subsystens shall be identifled. Whenever appropriate, it should be pointed out where tribolocical advances are needed or desirable to achieve the designated condititans.

In'ormation shall be supplied on the following engine types:

- current and advanced otto-cycles

- cument diesel cycle

- gas turbines

- aziabatic diesel

- minimum friction engine

- stirling engine. Any or all of the following tribological conditions shall be identified:

- speed

- load

- materials

- temperatures 
- environment

- lubricants

- lifecycle.

Task 2. Identify Long-Term Tribological Research and Development Needs in the utilities sector

Any and all information on long-term tribological research and development needs in the utilities sactor shali be identified, High-speed turbines shall be given special emphasis, and other systems may be considered as well. Specific tribological conditions in major tribologically important components of present and advanced systems shalt be identified. The same conditions listed in Task 1 shall be listed. Whenever possible, it should be pointed out where tribological advances are needed or desirable to achieve the destgnated conditions.

Task 3. Reports and Deliverables

\subsection{QUARTERLY PROGRESS REPORT}

A brief report, simply indicating the status of the work and not results, shall be submitted by close of business on the fifteenth, or the first working day thereafter, of the fourth month after the initiation of the subcontract.

\subsection{SUMMARY REPORT}

A final oraft of a summary report shall be submitted by close of business on the last day of the sixth month after subcontract inithation. An initial draft shall be submitted by close of business on the last day of the fourth month after intiation. The orkt technical manager shall respond by close of business on the last day of the fifth month with changes andor conments to be incopporated in the final draft.

The above reports should be delivered to the onkL technical manager of the ECUT Tribology project at the address below. 
Dr. Joseph A. Carpenter, Jr.

fanager, Tribology Project

DoE Energy Conversion and Utilization

Technologles (Ecur) Program

Buil ding 4508, Room 109

Dak lage National Laboratory

Pust office Box $x$

Oak Ridge, Tennessee 37830 

APPENDIX $\mathrm{B}$

LISTING OF CONDUCTED INTERVIEHS 
APPENOIX B

\section{LISTING OF CONDUCTED INTERVIEWS}

Interviews in the Area of Transportation

1. Cumbins Engineering Company, Columbus, Indiana. Interview conducted on September 23, 1983, Present were:

1. 1. Kubo

2. J. G. Crofts - Engineering Account: Executive

3. J. W. Patten - Dipector, Materials Engineering

4. G. L. Stan - Manager, Metallicle teramics Materials Development

5. P, A. Bennet - Director, Fuels and Lubricants

2. For 1 Motor Company, Dearborn, Michigan. Interview condusted on September 28, 1983. Present were:

1. S. Gratch - Director, Chemical Science Laboratory

2. E. Korcek - Research Laboratory

3. A. jainiee - Research Laboratory

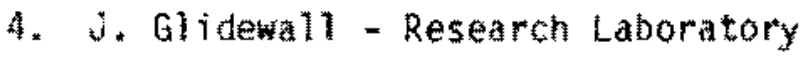

5. P. Willermet - Research Laboratory

6. 1. L. Tiny - Research Laboratory

7. R. Baker - Fuels and Lubricants

B. G. Chui - Fuels and Lubricant.

Attached is a letter from $R$. Baker on frictional losses in an automotive engine which is cited as Reference [9] in the report.

3. General Motors, Warren, Michigan. Interview conducted on September 29 , 1983. Present were General Motors Research Laboratory the following dersonnel:

1. Earl Heffner - Engine Research

2. Don Siegla - Engine Research 
3. John bierlein - Fluid Mechanics

4. Butch Dehart - Fluid Mechanics

5. Jin Mattavi Fluda Mechanics

6. Dick Rosenberg - Fluid Mechanics

7. Fred Rounds - Fuels and Lubricants

8. Jin Spearot - Fuels and Lubricants

9. Ed Mllyer - Metallurgy

10. M. Rashid - Metallurgy

11. Lou Hewko - Power systems Research

Interviews conducted in the area of Electric Utilities:

4. Detroit Edison, Detroit, Michigan. Interview conducted on September 28 , $19 e^{3}$ with $\mathrm{Dr}$. M. Moaveni,

5. Westinghouse Electric Corporation, Orlando, Florida. Interview conducted an 0ctober 14, 1983. present were:

1. P. W. Viscovich - Manager, Turbine Programs

2. L. F. Hackstie - Service Engineer

3. J. Qureshi - Materials Engineering

4. L. 0. Kramer - Manager, Materials Energy

5. R. E. Warner - Developmental Engineering

6. A. F. LeBreton - Developmental Engineering

6. EPRi, Palo Alto, California Interview conducted on October 27,1983 with T. H. McCloskey, Manager, Stear Turbines Coal Conbustion Systems Division.

7. General Electric Company, Schenectady, New York. Interview conducted on February 3, 1984 with J. Mangan, Manager, Steam Turbines, and A, Missana. 


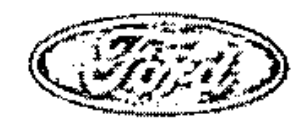

Ford Mato tompary

20000 Roturda Otive

RESEAREH

Oearbom. Michiçẩ 4812 :

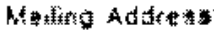

F.0 632053

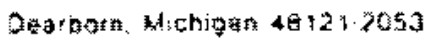

Novenber 2, 1983

$\because$ Dondat. Wilcock

- sology Technology Managenent

"ijolock, lnt.

ingnectidy, Hew lork 12309

ar ar. wllosek:

loloced are two papers that fay be of some help to quatify mechanical

iction distribution. SAt gaogs describes typical tear-dowt studtes

rd SAE, S3U165 expands on falvetrath friction.

can offer you the following breaktown integrated over the Ept perro cycle

it a srall, frontwheel drive valucle:

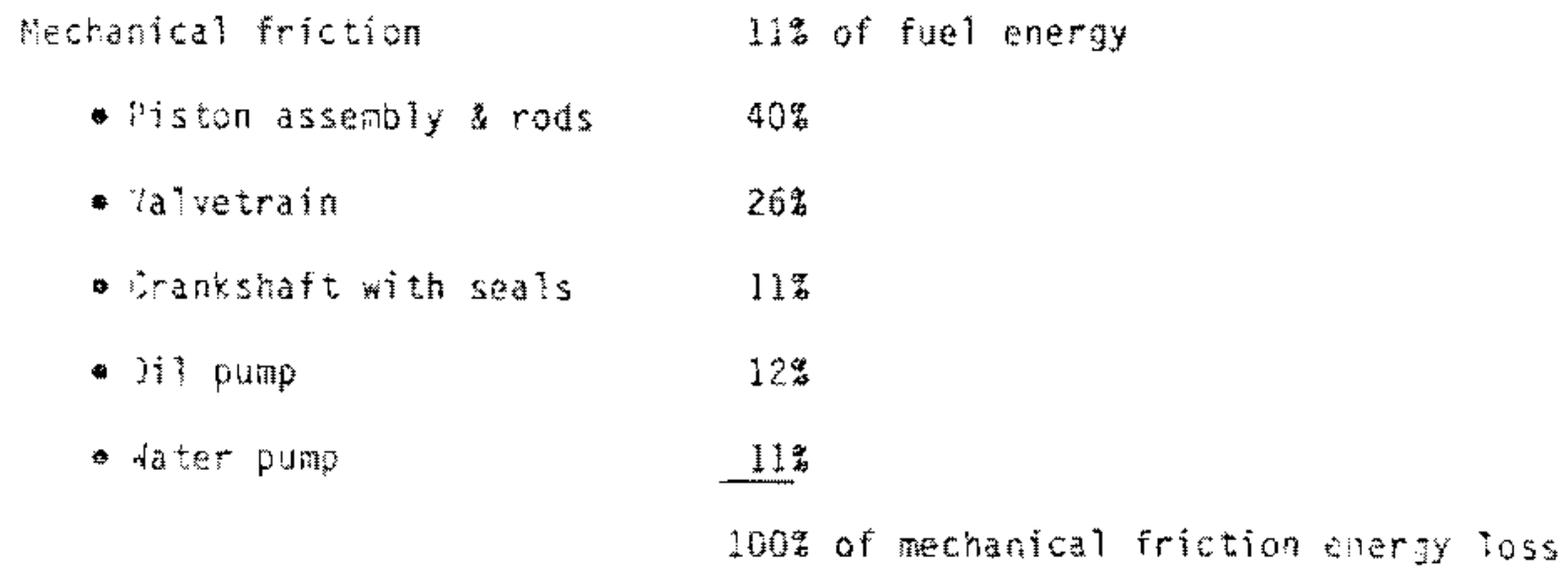

1 hope this will be useful in your study.

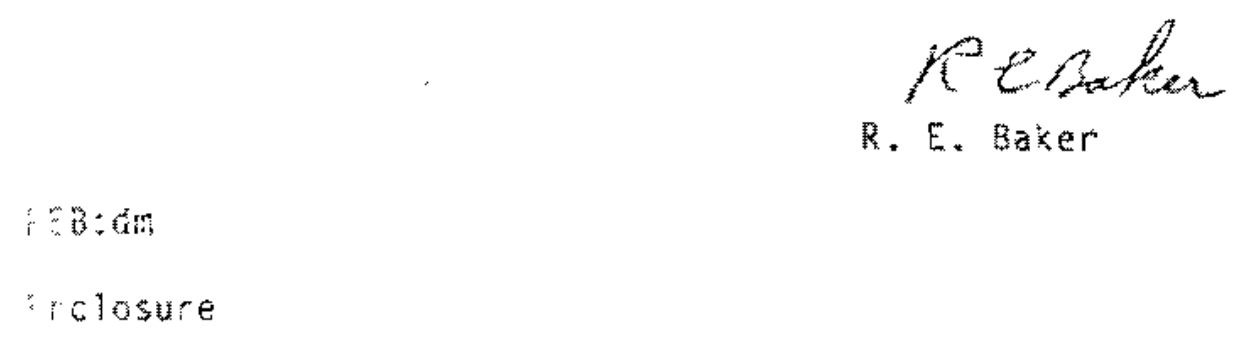

R. E. Baker

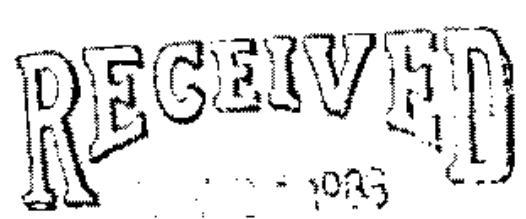


APPENOIX

CONYERSION TABLES 


\section{LIST OF SPECLAL CONVERSIONS}

1 barrel of petroleum oil $\left(5.6 \mathrm{ft}^{3}\right)=5.8 \times 10^{6}$ Etu $=42$ gallons $10^{6}$ barrels of oil $=5.8 \times 10^{1 \%} \mathrm{Btu}$ $10^{15}$ Pu $-172 \times 10^{6}$ barrels of ol1

$1 \mathrm{t}^{3}$ of natural gas $=10^{3} \mathrm{ntu}$

1 gallo: of gasoline $=125 \times 10^{3} \mathrm{Btu}$

1 th of $\operatorname{col}=10$ to $13 \times 10^{3} \mathrm{But}$

$1 \mathrm{hp}=42.5 \mathrm{Btu} / \mathrm{min}=0.7457 \mathrm{~kW}$

$1 \mathrm{in.}=2.54 \mathrm{~cm}$

$1 \mathrm{kh}=10^{3}$ atts $=1.341 \mathrm{hp}=56.9 \mathrm{Atu} / \mathrm{min}$

$1 \mathrm{~km}=0.621 \mathrm{mite}$

$1 \mathrm{mfl} / \mathrm{e}=1.6093 \mathrm{~km}$

$1 \mathrm{~kW}-\mathrm{hr}=3413 \mathrm{Btu}$

1 F tu $=252$ calories

$10^{5}$ pascals $=1$ atn. $=44.7$ pst

1 meganat. $=10^{6}$ watts $=10^{3}$ kilowatts

1 gigawatt $=10^{9}$ watts $=10^{6}$ kilowats

1 U. 5 . gallon $=0.134 \mathrm{ft}^{3}=0.0044 \mathrm{~m}^{3}=3.81$ iters

$10^{5}=$ million mega

$10^{\circ}=$ hlllion

$10^{12}=$ trillion

$10^{15}=$ quadrillion 


\section{Conversion Chart to SI Units}

\begin{tabular}{|c|c|c|c|}
\hline & $\begin{array}{l}\text { Owantity in } \\
\text { Old Units }\end{array}$ & Mulzigyy by & $\begin{array}{l}\text { duantity in } \\
\text { 51 Units }\end{array}$ \\
\hline \multirow[t]{2}{*}{ Aeceleration } & $\mathrm{ft} / \mathrm{sec} \mathrm{t}^{2}$ & 0.305 & $\mathrm{~m} / \mathrm{sec}^{2}$ \\
\hline & $\ln \sec 2$ & 0.0254 & $\operatorname{tsec}^{2}$ \\
\hline \multirow[t]{2}{*}{ Area } & $\mathrm{tt}^{2}$ & 0.0929 & $m^{2}$ \\
\hline & $i n x^{2}$ & 0.000645 & $\mathrm{~m}^{2}$ \\
\hline \multirow[t]{2}{*}{ Density } & $10 \pi / t^{3}$ & 16.02 & $\mathrm{kgm} / \mathrm{m}^{2}$ \\
\hline & $1 b^{2}=t^{3}$ & 535.38 & $\mathrm{~kg} / \mathrm{m} \mathrm{n}^{3}$ \\
\hline \multirow[t]{4}{*}{ Energy-both } & ctu & 1058.7 & joula, (n-m) \\
\hline & Calorte & 4.19 & toule \\
\hline & $f t+1 b f$ & 1.356 & joule \\
\hline & watt-her & $3,600.0$ & joule \\
\hline \multirow[t]{6}{*}{ Force } & dine & $10^{-5}$ & hementon $(\mathrm{kg} \cdot \mathrm{g})$ \\
\hline & $\log$ & $4.80 t$ & Newton \\
\hline & $10 \div$ & 4.448 & Newton \\
\hline & 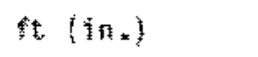 & 0.305 & Metwr \\
\hline & & $(0.0254)$ & \\
\hline & $16 \mathrm{~m}$ & 0.4536 & 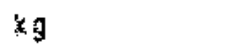 \\
\hline \multirow[t]{2}{*}{ Power } & ft-lociset & 1.356 & wate \\
\hline & h & 745.7 & watt \\
\hline \multirow[t]{6}{*}{ Pressure } & atn & $1.023 \times 10^{5}$ & Pascol $\left(n / m^{2}\right)$ \\
\hline & $\mathrm{in}=\mathrm{Nz}=60^{\circ} \mathrm{F}$ & $3,376.8$ & pascal \\
\hline & fn. $\mathrm{H}_{\mathrm{z}} \mathrm{O}\left(60^{\circ} \mathrm{F}\right)$ & 246.8 & Pascal \\
\hline & $\operatorname{lof} / f+2$ & 47.65 & Pascal \\
\hline & $10 \operatorname{lin}^{2}$ (psi) & 6.494 .76 & Pastal \\
\hline & $\operatorname{mz}$ & 133.3 & Pascal \\
\hline \multirow[t]{4}{*}{ Velocity } & mites/hr & 0.447 & $\mathrm{~m} / \mathrm{s} \neq \mathrm{c}$ \\
\hline & 0.0050 & $m / s e c$ & \\
\hline & in.tsec & 0.0254 & $m / s t e t$ \\
\hline & a & ${ }^{\circ} \mathrm{C}=5 / 8\left({ }^{\circ} \mathrm{F}-32\right)$ & ${ }^{\circ} \mathrm{C}$ \\
\hline \multirow[t]{2}{*}{ Viscosity } & centipoise & $10^{-3}$ & Pascal-sec. \\
\hline & $1 \mathrm{~b}-\mathrm{sec} / \mathrm{in} x^{2}$ & 6.894 .7 & fascal msec \\
\hline \multirow[t]{4}{*}{ Vol unie } & $\mathrm{tt}^{3}$ & 0.0283 & $\mathrm{~m}^{3}$ \\
\hline & $U_{*}^{*}=$ gallot & 0.0044 & $m^{3}$ \\
\hline & in..$^{3}$ & $1.639 \times 10^{-5}$ & $\mathrm{n}^{3}$ \\
\hline & litser & $10^{-3}$ & $m^{3}$ \\
\hline
\end{tabular}

C. 2 
Ho. of

copies

OFFSITE

12 T. Levinson

11.5. Department of Energy

forrestal Building CE-142

Washington, D.C. 20585

30 DDE Technical Information

Cenoter

A. Anderson

Mult t-Arc vacuum 5ystems inc.

26. East 5th Avenue

St. Paul, MN 55101

C. Albertson

Borg-warmer Corporation

I200 South wolf Road

Des Plaines, IL 60018

A. Becker

Alumina, Chem. Ceramics Civision

Alcoa Research Laboratories

Alcoa center, PA 15069

P. N. Blumberg

integral Technologies, Inc. 415 East Plaza 0rive

Hestmont; IL 60559

1. J. Brombolich

Compu-Tec Engr. Inc.

30 Chesterfield Center, 205

chasterfield, M0 63017

W. Bryzik

U.S. ArTy TACOM

AMSTA-RGR

Warren, MI 49090

0. H. Buckley

NASA/Letis Research Center

23-2

chaveland, OH 44135
No of

Copies

R. F. Bunshah

Department of Materials Sclence

University of Californat

Los Angeles

6532 Boelter Hall

Los Angeles, CA 90024

3. A. Carpenter, Ir.

Oak Ridge National Laboratory

po Box ${ }^{x}$, 8uilding 4508

Dak Ridge, TN 37831

D. C. Classen

Cateroillar Tractor co.

Mfg. Engr. Building $W$

600 West Washingt on street

East Peorta, IL 61630

F. J. Carignan

Advanced Mechanical

Technology Inc.

141 California street

Newton, Ma 02158

D. L. Cocke

Texas AkM Iniversity

Department of Chemistry

College Station, Tx 77843-3255

H. S. Cheng

Dept. of Mechanical Engineering

Center for Engineering Tribology

Northwestern University

Evanston, 11 60201

G. W. Clark

Oak Ridge National Laboratory

PO Box $x_{\text {, Building } 4508}$

oak Ridge, TN 37031

6. Chang

29615 Lincoin Road

Bay village, oly 44140 
No of

Copies

M. J. Cronín

Mechanical Technology, Inc. 968 Albany-Shaker Road

Latharf, Wy 12110

1. L. Duda

Pennsylvania 5tate University

133 Fenske Laboratory

Universtity Park, PA 16802

S. K. Das

Materials Laboratory

Allied Corporation

P.0. Box 102L R

Morristown, NJ 07960

J. F. Dill

Mechanical Technology Inc.

968 Albany-Shaker Road

Latham, Ny 12110

R. L. Dastlveira

Eutectic Corp.

404017 ind Street

Fiushing, Ny 11358

d. d. Eberhard:

U.5. Department of Energy

Forrestal Bullding

Mail Stop 6BO25

Washington, 0.C. 20585

C. $A$, Ebel

High Performance Ceramics

Norton Conpany

1 New Bond Street

Worcester. MA 01606

R. Erickson

Battel le-Columbus Laboratory

$505 \mathrm{king}$ Avenue

Columbus, $\mathrm{DH}$ 43201-2693

1.. L. Fehrenbacher

$200 z$ Huntwood Drive

Hunt ington Woods

Cambrilis, MD 21054
No of

Copies

D. G. Flom

General Electric Company

Corporate RED, 4B4, $\mathrm{X}-1$

P.0. Box 8

Schenectady, NY 12301

T. Fischer

Exxon Research

Glinton Township Route 22 East

Annandale, NJ 08801

P. Grayson

Eagle Picher Industries, Inc.

P.0. Box 1090

Müani, $0 \mathrm{~K} \quad 74354$

3. Grahatu

Deere and Company

Technical center

3300 River Drive

Moline, Il 61265

5. coguen

U.\$. Department of Energy, CE 131

Mailstop 5E 043

Forrestal Butlding

1000 Independence Ave., $5 \mathrm{~W}$

Washington, D.C. 20585

R. H. Greshan

E) Lubricants, Inc.

P.0. Box 2200, Highway 52 N.W.

West Lafayette, IN 47906

d. Horwath

Borg-Warner Corporation

ingersoli Research Center

$1200 \mathrm{~S}$. Wolf Road

Les Plaines, IL 60018

5. M. Hsu

Rooth A257, Building 223

Inorganic Materials Diviston

National Bureau of standards

Gathersburg, M0 2089 ? 
No of

Copies

N. S. Hakim (RO3B)

Detroit Diesel Allison Division 36830 Ecorse Road

Romulus, MI 48174

c. 2. Houska

Dept. of Materials Engineering

Virginia Polytechnic Institute

placksburg, 24061

R. A, Harmon

25 Schalren Drive

Latham, NY 12110

]. K. Hi rvonen

Spire Corporation

Patriots Park

Bedford, MA 07130

10 M. Kaminsky

Arconne Nationat Laboratory

9700 South Cass

Argonne, It. 60439

E. F. Klaus

Deft, of Chemical Engineering

Perinsyluania State University

University Park, PA 16802

R. Krutenat, $102 / 0217$

Exxon Research and

lingineering $\mathrm{Co}$.

Florham Park, NJ 07932

5. Khanna

So:ld State Sclence Research iroup

Je- Propulsion Laboratory

48 in Dak Grove Drive

MS 122-123

Paradena, CA 91109

K. Ludema

University of Michigan

Dest. of Mechanical Engineering

2024 G. G. Brown

Anr Arbor; MI $48109-2125$
No of

Copies

\author{
Lubrartan \\ Deere and Company \\ Technical Center \\ 3300 River orive \\ Moline, IL 61265-1792 \\ F. F. Ling \\ Mechanical Englneering \\ Jonsson Engineering Center \\ Rensselaer polytechnic \\ Institute \\ Troy, NY 12181 \\ H. Lexhac \\ oute Inc. \\ 6849 0ld Domint on Drive \\ Mclean, wa 22101 \\ H. E. MCCormick \\ Director of Engineering \\ Ransey oiston Ring Division \\ TRW Automotive Products, inc. \\ 1233 Manchester Road \\ Manchester, M0 63011 \\ C. Mecklenburg \\ AFWAL/MLET \\ Wright patterson $A F B$ \\ Dayton, oH 45433-6533 \\ 3. Mceool \\ SkF Industries \\ 1100 first Avenue \\ King of Prussia, PA 19406 \\ R. W. Meyerhof \\ Union Carbide Corporation \\ coat ings service \\ 1500 polco street \\ Indianapolis, IN 46224 \\ a. R. Mullaly \\ Pratt \& Whitney Aircraft \\ P.o. Box 2691 \\ US $70 \%-28$ \\ West Paln Beach, FL 33402
}


No of

Copies

P. Madden

SKF Industies

1:00 First Avenue

king of Prussia, PA 19506

V. B. Peterson

Wear Sciences, inc.

$925 \mathrm{Mallard}$ Circle

Arnold, MD 21012

120 p pinkus

Mechancal Tectinology Inc.

968 Albany-Shaker Road

Latham, NY 12110

T. J. J. กữnn

Tribology and Rheology

Laboratory

School of Mechanical

Engineering

Georgia Institute of Technology

Atianta, Ga 3033

R. C. Rosenberg

General Motors Research

luboratory

Fluid Mechanics Department.

Warren, H 48090

0. A. Rigney

The ohio State Untyersity

lept, of Metallurgical

Engineering

141A Fontana Laboratories

116 West 19 th Avenue

Columbus, oH $43210-1179$

A. H. Ruff

Nationa? Bureau of Standards

Netallurgy Division

Roon B266-Materials Building

Gaithersburg, Mn 20899

W. D. Sorou?

Borg-harner Corporation

1200 South wolf Road

Des Platues, IL 60019
No of

Coples

P. Sutor

Midwest Research institute

425 Volker Boulevard

kansas City, Mo 64110

L. B. Sibley

Tribology Consultants, Inc. 504 Foxwood Lane

paoli, PA 19301

A. C. Schathauser

Dak Ridge National Laboratory

P.0. Box $x^{\prime}$

Dak fidge, TN 37831

1. L. Singer

Naval Research Laboratory

Code 6170

kashington, D.C. 20375

G. L. Starr, Manager

Metallurglcal Engineering

Cummins Engine Technical Center

Box 3005

Columbus, IN 47202-3005

R. Slone 50165

Cumins Engine Technical Center

Box 3305

Columbus, IN 47202-3005

T. C. Spatvins

HASA/Lew Is Research Center

MS 23-2

Cleveland, oH 44135

M. Shaw

Arizona State University

ECG 247, Mechanical Engineering

Tempe, AZ 85287

P. Swanson

John Deere Company

Technical Center

3300 River Drive

Moline, IL 61265 
to of

Copies

L. D. Wedeven

SKF Industries, Inc.

1100 First Avenue

King of Prussia, PA 19406

R. Ted wimber

Deere and Company

Technica I Center

330) River Drive

Moline, IL 61265-2792

0. F, Wilcock, President

Trijolock, Inc.

1949 Hexham Road

Schenectady, NY 12309

W. O. Winer

Tribology and Rheology

Laboratory

School of Mechanical

Engi neering

Georgia Institute of Technology

Atlunta, GA 30332

0. Kuhlman-Wilsdort

University of Virginia

Physics Department

McCormich Road

Charlottesville, V 22901

h. Il. Winnard

Battelle Memorial Institute

2030 M. Street Nk

Washington, D. C. 20036

C. S. Yust

Metals and Ceramics Division

Oax Ridge National Laboratory

P.0. $80 \times x$

oak Ridge, TN 37831

T. M. Yonushonis

Cummins Engune

Mall Code 50183, Box 3005

Columbus, IN 47202-3005
No of

Copies

M. Zlotnick

141 East B8th Street

New York, NY 10028

C. A. Zanis

Department of the Navy

Naval Sea Systems Command

Research and Development office

Washington, $0 . \mathrm{C}, 20362$

FOREIGN COUNTRIES

Dr. Jochen P. Biersack

Hahn-Meitner-Institut

Glientcker Strabe 100

1000 Bertin 39

West Gemany

Dr. Erich Bergmann

Balzers Akt iengesell schaft

FL-9496 Balzers

Furstentum, Liechtenstein

Professor Dr. H. Czichos

Federal Institute for Materials

Research and Testing

Unter den Eichen 87

D-1000 Berlin 45

West Gernany

Dr. Geoff Dearnaley

Nuclear Physics Division

Building 48

AERE Harwell

Didcot, Oxfordshire

United Kingdom 0 11 DRA

Dr. Hans E. Hintermann

Laboratolre Suisse de

Recherches Hor logeves.

$\mathrm{CH}-2000$ Neuchatel

Switzerland 
No of

Copies

Dr. Richard Horton, Manager Energy Conservation Technology Centre

Engineering Sciences Division

B151 Harwell Laboratory

Dxfordshire 0X 11 ORA

England

Dr. Boris Navinsek

Jozef Stefan Institute

61001 Ljubljana

Jamova 39

Yugoslavia

Prof. Dr. ir. J. Roos

Katholieke Universiteit Leuven

Department Metaalkunde

de Croylaan 2

B-3030 Leuven (Heverlee)

Belgium

Dr. S. Veprek

Anorganisch-Chemisches

Institut der Universitat Zurich

Winterthurerstrasse 190

8057 Zurich

Switzerland
No. of

Copies

DNSITE

DOE Richland Operations Office

H. E. Ransom

12 Pacific Northwest Laboratory

D. L. Brenchley

C. H. Imhoff

D. C. Kuick

J. A. Russell

M. T. Thomas

Publishing Coordination $\mathrm{MH}$ (2)

Technical Information (5) 